
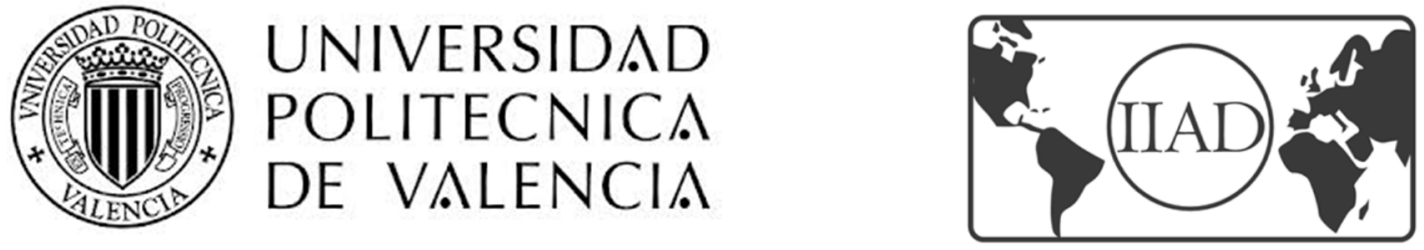

INSTITUTO DE INGENIERÍA DE ALIMENTOS PARA EL DESARROLLO

\title{
DESARROLLO TECNOLÓGICO Y VALORACIÓN FUNCIONAL DE APERITIVOS DE MANZANA Y ZUMO DE MANDARINA. EFECTO ANTIOXIDANTE EN NIÑOS OBESOS Y EFECTO PROBIÓTICO CONTRA LA INFECCIÓN POR HELICOBACTER PYLORI EN NIÑOS.
}

INSTITUTO UNIVERSITARIO DE INGENIERÍA DE ALIMENTOS PARA EL DESARROLLO

UNIVERSIDAD POLITÉCNICA DE VALENCIA

TESIS DOCTORAL

Realizada por: $\quad$ María Ester Betoret Valls

Dirigida por: Dra. Noelia Betoret Valls

Dr. Pedro Fito Maupoey

Valencia, Diciembre 2012 

EL Dr. PEDRO FITO MAUPOEY, PROFESOR EMÉRITO Y LA Dra. NOELIA BETORET VALLS TITULAR DE UNIVERSIDAD DEL DEPARTAMENTO DE TECNOLOGÍA DE ALIMENTOS Y MIEMBROS DEL INSTITUTO UNIVERSITARIO DE INGENIERÍA DE ALIMENTOS PARA EL DESARROLLO DE LA UNIVERSIDAD POLITÉCNICA DE VALENCIA,

CONSIDERAN, que la memoria titulada DESARROLLO TECNOLÓGICO Y VALORACIÓN FUNCIONAL DE APERITIVOS DE MANZANA Y ZUMO DE MANDARINA. EFECTO ANTIOXIDANTE EN NIÑOS OBESOS Y EFECTO PROBIÓTICO CONTRA LA INFECCIÓN POR HELICOBACTER PYLORI EN NIÑOS, que presenta, MARÍA ESTER BETORET VALLS, para aspirar al grado de Doctora por la Universidad Politécnica de Valencia, y que ha sido realizada bajo su dirección en el Instituto Universitario de Ingeniería de Alimentos para el Desarrollo de la Universidad Politécnica de Valencia, reúne las condiciones adecuadas para constituir su tesis doctoral, por lo que AUTORIZAN a la interesada para su presentación.

Valencia, Diciembre 2012

Fdo. Dr. Pedro Fito Maupoey

Director de la tesis
Fdo. Dra. Noelia Betoret Valls

Directora de la tesis 

Arribat este moment vull agrair-vos tot el que heu fet per mí:

A Pere gràcies per donar-me l'oportunitat i el suport necessari per començar i acabar esta tesis.

A Noe gràcies per tot. Pel suport incondicional, les paraules d ànim i l'esforç compartit. Perquè hem sigut un gran equip i ho hem fet juntes. Als meus pares gràcies perquè sense el seu esperit d'esforç i sacrifici jo no haguera pogut arribar fins ací i perquè m éensenyaren des de ben menuda que les coses costen i és necessari treballar dur per aconseguir-les. A Rosario gràcies per ser molt més que una companya de doctorat i perquè sempre trobà el moment per escoltar-me. I com no, a Marek, per aguantar-me molt i estimar-me més i perquè sense dubte el millor de tot açò ha sigut trobar-lo. 



\section{RESUMEN}

En la presente tesis doctoral se ha llevado a cabo el desarrollo tecnológico y la valoración funcional, mediante estudios in vivo, de aperitivos de manzana y zumo de mandarina desarrollados utilizando la técnica de impregnación a vacío. Concretamente, se han desarrollado dos alimentos, uno con efecto sobre el riesgo cardiovascular en niños obesos de edad escolar y otro con efecto contra la infección por Helicobacter pylori también en niños de edad escolar. La investigación, de marcado carácter interdisciplinar, se ha llevado a cabo en colaboración con el Departamento de Ciencia de los Alimentos del Instituto de Agroquímica y Tecnología de Alimentos (IATA, CSIC), con el Departamento de Ginecología y Obstetricia de la Universidad de Valencia y con el Servicio de Pediatría del Hospital Universitario Dr. Peset de Valencia.

En primer lugar, se llevó a cabo una revisión bibliográfica que permitió analizar la situación actual y la evolución en los últimos años de las tecnologías utilizadas en el desarrollo de alimentos funcionales. Las tecnologías implicadas en el desarrollo de alimentos funcionales han cambiado, aumentando considerablemente aquellas tecnologías que forman una estructura capaz de prevenir el deterioro de los componentes fisiológicamente activos. La revisión bibliográfica ha dado lugar a la publicación del artículo "Functional foods development: Trends and technologies", que se incluye en el apartado de resultados, publicado en la revista "Trends in Food Science \& Technology" de Elsevier con un índice de impacto 3.672 y se encuentra dentro de los 5 artículos más descargados desde septiembre de 2011.

En segundo lugar, se diseñó una planta piloto que permitió fabricar el alimento funcional en cantidades suficientes para poder llevar a cabo los estudios in vivo realizados en esta tesis. Si bien no se ha llevado a cabo el escalado a nivel industrial, supone un primer paso para ello y además, se ha desarrollado un modelo matemático en el que se establecen las relaciones entre todas las variables implicadas.

En el desarrollo del alimento funcional de baja humedad a partir de manzana y zumo de mandarina, con efecto sobre el riesgo cardiovascular en niños obesos de edad escolar, se tuvieron en cuenta aspectos tecnológicos, económicos y medioambientales asociados al proceso de fabricación. La valoración funcional del alimento se llevó a cabo mediante estudios in vivo.

- Se estudió el efecto de la presión de homogeneización sobre las propiedades funcionales y fisicoquímicas del zumo de mandarina. Se estudió la idoneidad del zumo para su uso en la operación de impregnación a vacío. Para ello, el zumo de mandarina se homogeneizó a las presiones de 0, 5, 10, 15, 20, 25 y 30 MPa y se determinó el tamaño de partícula, la pulpa suspendida, la turbidez, el contenido en flavonoides, el color y la capacidad antirradical del zumo a cada presión de homogeneización así como el volumen de zumo incorporado en la manzana mediante la operación de 
impregnación a vacío. Los resultados obtenidos en este estudio permitieron concluir que la aplicación de una presión de homogeneización al proceso de obtención del zumo de mandarina resulta favorable para una posterior operación de impregnación a vacío debido a que el uso de presiones de homogeneización permite una mayor incorporación de zumo en la estructura matricial de la manzana, disminuye el tamaño de partícula y aumenta la estabilidad de la pulpa sin afectar negativamente al color, al contenido en flavonoides y a la actividad antirradical del zumo. Este estudio ha dado lugar a la publicación de dos artículos, uno titulado "Effects of pressure homogenization on particle size and the functional properties of citrus juices" y otro titulado "Homogenization pressures applied to citrus juices manufacturing. Functional properties and application", publicados ambos en la revista "Journal of Food Engineering" de Elsevier con un índice de impacto de 2.414 .

- Se llevó a cabo el desarrollo tecnológico del alimento funcional. Se analizó la operación de impregnación a vacío, determinándose la uniformidad de la operación en función de la utilización de los zumos de mandarina homogeneizados a las distintas presiones y se estimó, en aquellos casos en que la impregnación a vacío resultó uniforme, la cantidad de flavonoides incorporados a la estructura matricial de la manzana. Para estabilizar la manzana impregnada se utilizaron diferentes métodos y condiciones de deshidratación. Concretamente, se utilizaron el secado por aire caliente a $40{ }^{\circ} \mathrm{C}$ durante 24 horas y a $70{ }^{\circ} \mathrm{C}$ hasta alcanzar la misma humedad final y la liofilización durante 12 y 24 horas. Se determinaron las propiedades ópticas y mecánicas de todos los productos obtenidos y además se llevó a cabo un análisis sensorial. Debido a su relación aceptación-coste se utilizó el secado por aire caliente a $40{ }^{\circ} \mathrm{C}$ para el desarrollo del alimento funcional. Se estimó el contenido en flavonoides del mismo y se determinó el efecto del procesado sobre la actividad antirradical del aperitivo de manzana desarrollado así como la composición de la manzana impregnada y deshidratada. La conclusión principal de este estudio fue que los componentes bioactivos del zumo de mandarina se incorporaron satisfactoriamente a la matriz estructural de la manzana mediante la operación de impregnación a vacío, sin afectar negativamente a la actividad antirradical después del secado por aire caliente. De tal manera que, $40 \mathrm{~g}$ de producto seco contienen la misma cantidad de flavonoides que $250 \mathrm{ml}$ de zumo de mandarina fresco. Este estudio ha dado lugar a la publicación de un artículo titulado "Technological development and functional properties of an apple snack rich in flavonoid from mandarin juice" publicado en la revista "Innovative Food Science and Emerging Technologies" de Elsevier con un índice de impacto de 3.030.

- Se estudió el efecto del alimento funcional desarrollado sobre la salud. Para ello, se realizaron dos estudios in vivo, uno con animales de 
experimentación y el otro con niños obesos de edad escolar. En el estudio in vivo con animales de experimentación se evaluó el efecto del alimento funcional desarrollado sobre los biomarcadores de estrés oxidativo en el hígado inducido por la acción del tamoxifeno. Se determinaron las aminotransferasas en plasma como índice de daño hepatocelular y la interleukina-6 como medida de inflamación. Se midieron los grupos carbonilo del plasma y del hígado, como indicativo de la oxidación de proteínas, y $\alpha$-tocoferol como evaluación de la defensa antioxidante y se determinó la base modificada 8-hydroxydexyguanosine como indicativo de daño en el ADN. Los resultados obtenidos en este estudio permitieron concluir que el tamoxifeno indujo un incremento de las aminotranferasas y de los marcadores de estrés oxidativo y daño en el ADN tanto en plasma como en hígado que disminuyeron significativamente después del consumo de aperitivos de manzana; en la mayoría de los casos se alcanzaron los valores normales previos al tratamiento con tamoxifeno. El efecto del zumo de mandarina incorporado a la estructura de manzana principalmente supuso un incremento de los niveles de $\alpha$-tocoferol tanto en plasma como en el hígado. Este estudio ha dado lugar a la elaboración de un artículo titulado "Dried apple enriched with mandarin juice by vacuum impregnation counteracts the liver oxidative effect of tamoxifen in rats" enviado a la revista "Food and Chemical Toxicology" de Elsevier con un índice de impacto de 2.999. En el estudio in vivo con niños obesos de edad escolar se evaluó el efecto de la incorporación de los aperitivos de manzana y zumo de mandarina a una dieta moderadamente baja en energía. En este estudio se trató de obtener información sobre el potencial antioxidante y antiinflamatorio del producto. En este sentido, se llevó a cabo un estudio de intervención para examinar si la ingesta diaria del aperitivo desarrollado se podía asociar a una modificación del estado oxidativo y de los marcadores de la inflamación sistémica como la proteína C-reactiva de alta sensibilidad (CRP), el factor de necrosis tumoral $\alpha$ (TNF- $\alpha)$, la interleukina $1 \alpha(\mathrm{IL}-1 \alpha)$ y la interleukina 6 (IL-6). Los resultados obtenidos en este estudio permitieron concluir que la incorporación a la dieta del alimento funcional mejoró la presión sanguínea sistólica y el perfil lipídico de los niños. Aumentó las defensas antioxidantes y disminuyó los marcadores relacionados con el daño oxidativo al ADN y con la inflamación, todos ellos factores de riesgo cardiovascular. Este estudio ha dado lugar a la elaboración de un artículo titulado "Dried apple snacks enriched with mandarin juice improve antioxidant capacity and decreases inflammation in obese children" enviado a la revista "Plant Foods for Human Nutrition" de Springer con un índice de impacto de 2.505.

En el desarrollo del alimento funcional de baja humedad a partir de manzana y zumo de mandarina, con efecto contra la infección por Helicobacter pylori en niños de edad escolar, se evaluó el crecimiento de dos microorganismos probióticos (Lactobacillus acidophilus y Lactobacillus salivarius 
spp. salivarius), con efecto probado contra Helicobacter pylori, en dos zumos comerciales (zumo de mandarina y zumo de piña/ uva) a 3 pHs diferentes ( 5 , 5.5 y 6) e incubados a dos tiempos diferentes ( 24 y 48 horas). El zumo de mandarina con Lactobacillus salivarius spp. salivarius con un $\mathrm{pH} 6$ e incubado durante 24 horas fue el que obtuvo un mayor crecimiento microbiano. Este zumo se utilizó para la fabricación del alimento funcional. Se determinaron las propiedades fisicoquímicas y el contenido microbiano en cada etapa del proceso de fabricación, se analizó la operación de impregnación a vacío y finalmente se realizó una prueba piloto con 5 niños infectados por Helicobacter pylori. Para completar el estudio del proceso de fabricación, se estabilizó la manzana impregnada mediante diferentes métodos y condiciones de deshidratación. Concretamente, se utilizaron el secado por aire caliente a 30 y $45{ }^{\circ} \mathrm{C}$ durante 24 horas y la liofilización durante 12 y 24 horas. Se determinaron las propiedades ópticas y mecánicas de todos los productos obtenidos así como el contenido microbiano. Los resultados obtenidos en este estudio mostraron que tanto después de la operación de impregnación a vacío como después de los diferentes métodos de deshidratación y las distintas condiciones empleadas se alcanzaron niveles de microorganismos lo suficientemente altos para que el producto pueda tener efecto probiótico. Del mismo modo, los resultados obtenidos en la prueba piloto in vivo confirmaron los efectos potenciales del producto desarrollado en contra de la infección por Helicobacter pylori. Este estudio ha dado lugar a la publicación un artículo titulado "No invasive methodology to produce a probiotic low humid apple snack with potential effect against Helicobacter pylori" publicado en la revista "Journal of Food Engineering" de Elsevier con un índice de impacto de 2.414. 


\section{RESUM}

En la present tesi doctoral s ha dut a terme el desenvolupament tecnològic i la valoració funcional, per mitjà d'estudis in vivo, d'aperitius de poma i suc de mandarina desenvolupats utilitzant la tècnica d ímpregnació a buit. Concretament, s han desenvolupat dos aliments, un amb efecte sobre el risc cardiovascular en xiquets obesos d'edat escolar i un altre amb efecte contra la infecció per Helicobacter pylori també en xiquets d'edat escolar. La investigació, de marcat caràcter interdisciplinari, s ha realitzat en col-laboració amb el Departament de Ciència dels Aliments de l'Institut d'Agroquímica i Tecnologia d'Aliments (CSIC), amb el Departament de Ginecologia i Obstetrícia de la Universitat de València i amb el Servei de Pediatria de l'Hospital Universitari Dr. Peset de València.

En primer lloc, es va dur a terme una revisió bibliogràfica que va permetre analitzar la situació actual i l'evolució en els últims anys de les tecnologies utilitzades en el desenvolupament d'aliments funcionals. Les tecnologies implicades en el desenvolupament d aliments funcionals han canviat, augmentant considerablement aquelles tecnologies que formen una estructura capaç de previndre el deteriorament dels components fisiològicament actius. La revisió bibliogràfica ha donat lloc a la publicació de l'article "Functional foods development: Trends and technologies", que s'inclou en el apartat de resultats, publicat en la revista "Trends in Food Science \& Technology" d'Elsevier amb un índex dimpacte $\underline{3.672} \mathrm{i}$ es troba dins dels 5 articles més descarregats des de setembre de 2011.

En segon lloc, es va dissenyar una planta pilot que va permetre fabricar l'aliment funcional en quantitats suficient per poder dur a terme els estudis in vivo realitzats en aquesta tesi. Si bé no s ha realitzat l'escalat a nivell industrial, suposa un primer pas i a més, s ha desenvolupat un model matemàtic en el qual s'estableixen les relacions entre totes les variables implicades.

En el desenvolupament de l'aliment funcional de baixa humitat a partir de poma i suc de mandarina, amb efecte sobre el risc cardiovascular en xiquets obesos d'edat escolar, es va tindre en compte, aspectes tecnològics, econòmics i mediambientals associats al procés de fabricació. La valoració funcional de l'aliment es va dur a terme per mitjà d'estudis in vivo.

- Es va estudiar l'efecte de la pressió d'homogeneïtzació sobre les propietats funcionals i fisicoquímiques del suc de mandarina. Es va estudiar la idoneïtat del suc per al seu ús en l'operació d împregnació a buit. El suc de mandarina es va homogeneïtzar a les pressions de 0, 5, 10, 15, 20, 25 i 30 MPa i es va determinar el tamany de partícula, la polpa suspesa, la terbolesa, el contingut en flavonoides, el color i la capacitat antirradical del suc a cada pressió d homogeneïtzació així com el volum de suc incorporat en la poma mitjançant l'operació dímpregnació a buit. Els resultats obtinguts en este estudi van permetre concloure que l'aplicació d'una pressió d homogeneïtzació al procés d'obtenció del suc de mandarina resulta favorable per a una posterior operació d împregnació a buit pel fet 
que l'ús de pressions d homogeneïtzació permeten una major incorporació de suc en l'estructura matricial de la poma, disminueixen el tamany de partícula i augmenten l'estabilitat de la polpa sense afectar negativament el color, el contingut en flavonoides i l'activitat antirradical del suc. Este estudi ha donat lloc a la publicació de dos articles, un titulat "Effects of pressure homogenization on particle size and the functional properties of citrus juices" i altre titulat "Homogenization pressures applied to citrus juices manufacturing. Functional properties and application", publicats ambdós en la revista "Journal of Food Engineering" $d$ 'Elsevier amb un índex d impacte de 2.414.

- Es va dur a terme el desenvolupament tecnològic de l'aliment funcional. Es va analitzar l'operació d'impregnació a buit, determinant-se la uniformitat de l'operació en funció de la utilització dels sucs de mandarina homogeneïtzats a les distintes pressions i es va estimar, en aquells casos en què la impregnació va resultar uniforme, la quantitat de flavonoides incorporats a l'estructura matricial de la poma. Per a estabilitzar la poma impregnada es van utilitzar diferents mètodes i condicions de deshidratació. Concretament, es van utilitzar el secat per aire calent a $40 \stackrel{\circ}{\circ}$ durant 24 hores i a $70{ }^{\circ} \mathrm{C}$ fins aconseguir la mateixa humitat final i la liofilització durant 12 i 24 hores. Es van determinar les propietats òptiques i mecàniques de tots els productes obtinguts i a més es va dur a terme una anàlisi sensorial. A causa de la seua relació acceptació-cost es va utilitzar el secat per aire calent a $40{ }^{\circ} \mathrm{C}$ per al desenvolupament de l'aliment funcional. Es va estimar el contingut en flavonoides i es va determinar l'efecte del processat sobre l'activitat antirradical de l'aperitiu de poma desenvolupat així com la composició de la poma impregnada i deshidratada. La conclusió principal d'este estudi va ser que els components bioactius del suc de mandarina sincorporen satisfactòriament a la matriu estructural de la poma mitjançant l'operació dîmpregnació a buit, sense afectar negativament l'activitat antirradical després del secat per aire calent. De tal manera que, 40 grams de producte sec contenen la mateixa quantitat de flavonoides que $250 \mathrm{ml}$ de suc de mandarina fresc. Este estudi ha donat lloc a la publicació d'un article titulat "Technological development and functional properties of an apple snack rich in flavonoid from mandarin juice" publicat en la revista "Innovative Food Science and Emerging Technologies" d'Elsevier amb un índex d'impacte de 3.030.

- Es va estudiar l'efecte de l'aliment funcional desenvolupat sobre la salut. Per a això, es van realitzar dos estudis in vivo, un amb animals d'experimentació i l'altre amb xiquets obesos d'edat escolar. En l'estudi in vivo amb animals d'experimentació es va avaluar l'efecte de l'aliment funcional sobre els biomarcadors d'estrés oxidatiu en el fetge induit per l'acció del tamoxifeno. Es van determinar les aminotransferases en plasma com a índex de dany hepatocel-lular i la interleukina- 6 com a mesura 
d'inflamació. Es van mesurar els grups carbonil al plasma i al fetge, com indicatiu de l'oxidació de proteïnes, $\alpha$-tocoferol com a avaluació de la defensa antioxidant $i$ es va determinar la base modificada 8hydroxydexyguanosine com indicatiu de dany en l'ADN. Els resultats obtinguts en este estudi van permetre concloure que el tamoxifeno va induir un increment de les aminotransferases i dels marcadors d'estrés oxidatiu i dany en l'ADN tant en plasma com en fetge que van disminuir significativament després del consum d'aperitius de poma; en la majoria dels casos es van aconseguir els valors normals previs al tractament amb tamoxifeno. L'efecte del suc de mandarina incorporat a l'estructura de poma principalment va suposar un increment dels nivells de $\alpha$-tocoferol tant en plasma com en fetge. Este estudi ha donat lloc a la elaboració d'un article titulat "Dried apple enriched with mandarin juice by vacuum impregnation counteracts the liver oxidative effect of tamoxifen in rats" enviat a la revista "Food and Chemical Toxicology" d'Elsevier amb un índex d'impacte de 2.999. En l'estudi in vivo amb xiquets obesos d'edat escolar es va avaluar l'efecte de la incorporació dels aperitius de poma i suc de mandarina a una dieta moderadament baixa en energia. En este estudi es va tractar d'obtindre informació sobre el potencial antioxidant i antiinflamatori del producte. En este sentit, es va dur a terme un estudi d intervenció per a examinar si la ingesta diària de l'aperitiu desenvolupat es podia associar amb una modificació de l'estat oxidatiu i dels marcadors de la inflamació sistèmica com la proteïna $\mathrm{C}$-reactiva d'alta sensibilitat (CRP), el factor de necrosi tumoral $\alpha$ (TNF- $\alpha$ ), la interleukina $1 \alpha$ (IL-1 $\alpha$ ) i la interleukina 6 (IL-6). Els resultats obtinguts en este estudi van permetre concloure que la incorporació a la dieta de l'aliment funcional va millorar la pressió sanguínia sistòlica i el perfil lipídic dels xiquets. Va augmentar les defenses antioxidants i va disminuir els marcadors relacionats amb el dany oxidatiu a l'ADN i amb la inflamació, tots ells factors de risc cardiovascular. Este estudi ha donat lloc a la elaboració d'un article titulat "Dried apple snacks enriched with mandarin juice improves antioxidant capacity and decreases inflammation in obese children" enviat a la revista "Plant Foods for Human Nutrition" de Springer amb un índex d impacte de 2.505.

D'altra banda, en el desenvolupament de l'aliment funcional de baixa humitat amb efecte contra la infecció per Helicobacter pylori en xiquets d'edat escolar, es va avaluar el creixement de dos microorganismes probiòtics (Lactobacillus acidophilus i Lactobacillus salivarius spp. salivarius), amb efecte provat contra Helicobacter pylori, en dos sucs comercials (suc de mandarina i suc de pinya/ raïm) a 3 pHs diferents (5, 5.5 i 6) i covats a dos temps diferents (24 i 48 hores). El suc de mandarina amb Lactobacillus salivarius spp. salivarius amb un $\mathrm{pH}$ 6 i covat durant 24 hores va ser el que va obtindre un major creixement de microorganismes. Este suc es va utilitzar per a la fabricació de l'aliment funcional. Es van determinar les propietats fisicoquímiques $i$ el contingut en 
microorganismes a cada etapa del procés de fabricació. Es va analitzar l'operació d'impregnació a buit i finalment es va realitzar una prova pilot amb 5 xiquets infectats per Helicobacter pylori. Per a completar l'estudi del procés de fabricació, es va estabilitzar la poma impregnada mitjançant diferents mètodes i condicions de deshidratació. Concretament, es van utilitzar el secat per aire calent a 30 i $45^{\circ} \mathrm{C}$ durant 24 hores i la liofilització durant 12 i 24 hores. Es van determinar les propietats òptiques i mecàniques de tots els productes obtinguts així com el contingut en microorganismes. Els resultats obtinguts en este estudi van mostrar que tant després de l'operació d'impregnació a buit com després dels diferents mètodes de deshidratació i les distintes condicions empleades s'aconseguixen nivells de microorganismes prou alts perquè el producte puga tindre efecte probiòtic. De la mateixa manera, els resultats obtingut en la prova pilot in vivo confirmen els efectes potencials del producte desenvolupat en contra de la infecció per Helicobacter pylori. Este estudi ha donat lloc a la publicació d'un article titulat "No invasive methodology to produce a probiotic low humid apple snack with potential effect against Helicobacter pylori" publicat en la revista "Journal of Food Engineering" d'Elsevier amb un índex d impacte de 2.414. 


\section{ABSTRACT}

In this thesis the technological development and functional assessment by in vivo studies of snacks from apple and mandarin juice by vacuum impregnation has been carried out. Specifically, two foods were developed, one with effect on cardiovascular risk in obese children of school age and the other one effective against Helicobacter pylori in infected children of school age. The interdisciplinary research has been carried out in collaboration with the Department of Food Science at the Institute of Agrochemistry and Food Technology (CSIC), with the Department of Obstetrics and Gynecology at University of Valencia and with the Paediatric Service of the Hospital Universitario Dr. Peset in Valencia.

Firstly, a literature review was conducted in order to identify the current situation and the evolution of the technologies used in the development of functional foods during last years. The technologies used to develop functional foods have evolved, increasing considerably those technologies that form a structure aimed to prevent deterioration of physiologically active compounds. Literature review resulted in a review article titled "Functional foods development: Trends and technologies", included on results section, and published in a Elsevier journal "Trends in Food Science \& Technology" with impact factor 3.672. The review is included into 5 most downloaded articles list since september 2011.

Secondly, a pilot plant was designed in order to produce the functional food in quantities to carry out the in vivo studies conducted in this thesis. While it has not been carried out at industrial level scaling, is a first step in this direction and a mathematical model has been developed establishing the relationship between all the variables involved.

In the development of low humid functional food from apple and mandarin juice, with effect on cardiovascular risk in obese children of school age, technological, economic and environmental aspects associated with the manufacturing process were taken into account. The functional assessment of the food was carried out by in vivo studies.

- The effect of homogenization pressure on the physicochemical and functional properties of mandarin juice was studied. The suitability of the juice to be used in the vacuum impregnation operation was assessed. Mandarin juice was homogenized at pressures of 0, 5, 10, 15, 20, 25 and 30 $\mathrm{MPa}$ and the particle size, suspended pulp, turbidity, flavonoid content, colour and antiradical capacity were determined in the juice at each homogenization pressure as well as the volume of the juice incorporated in the structural matrix of apple by vacuum impregnation operation was calculated. The results obtained allowed to conclude applying homogenization pressures in obtaining process of mandarin juice is favourable for a subsequent implementation of a vacuum impregnation operation because homogenization pressures led to greater incorporation of juice into the structural matrix of apple, decreased particle size and 
increased the stability of the pulp without adversely affecting the colour, the flavonoid content and the antiradical activity of the juice. This research resulted in two articles, one titled "Effects of pressure homogenization on particle size and the functional properties of citrus juices" and the other one titled "Homogenization pressures applied to citrus juices manufacturing. Functional properties and application", both published in "Journal of Food Engineering" with impact factor of 2.414.

- The technological development of the functional food was carried out. Vacuum impregnation operation was analyzed; the uniformity of the operation was determined in juices homogenized at different pressures and, in those cases in which vacuum impregnation was regular, the amount of flavonoid incorporated into the structural matrix of apple was calculated. To stabilize the impregnated apple different dehydration methods and conditions were used. Specifically, we used hot air drying at $40{ }^{\circ} \mathrm{C}$ for 24 hours and at $70{ }^{\circ} \mathrm{C}$ until the same final moisture content was achieved and freeze-drying for 12 and 24 hours. The optical and mechanical properties of all the products obtained were determined and sensory analysis was also conducted. Due to the relation cost-acceptance, hot air drying at $40{ }^{\circ} \mathrm{C}$ was used to develop the functional food. The flavonoid content was estimated and the effect of processing on the antiradical activity as well as the composition of the impregnated and dried apple was determined. The main conclusion from this study was bioactive components of mandarin juice were successfully incorporated into the structural matrix of apple by vacuum impregnation operation, without adversely affecting the antiradical activity after drying by hot air. So that, $40 \mathrm{~g}$ of dry product contained the same amount of flavonoid as $250 \mathrm{ml}$ fresh mandarin juice. This study resulted in article titled "Technological development and functional properties of an apple snack rich in flavonoid from mandarin juice" published in journal "Innovative Food Science and Emerging Technologies" with impact factor 3.030.

- The effect of the functional food developed on health was studied. Two in vivo studies were conducted, one with experimental animals and the other with obese children of school age. In the in vivo study with experimental animals, the effect of functional food developed on biomarkers of oxidative stress in the liver injury induced by the action of tamoxifen was studied. Plasma aminotransferase levels were determined as an indicator of hepatocellular damage and interleukin- 6 as a measure of inflammation. Carbonyl groups were measured in plasma and liver, as indicative of protein oxidation, $\alpha$-tocopherol as antioxidant defense evaluation and the modified base 8-hydroxydexyguanosine was determined as indicative of DNA damage. The results obtained in this study allowed to conclude tamoxifen induced an increase in aminotranferase, markers of oxidative stress and DNA damage in both plasma and liver that were 
significantly reduced, following consumption of apple snacks; in most of cases they even reach normal values as those achieved previous to induce the injury with tamoxifen. The effect of the mandarin juice incorporated into the structure of apple mainly accounts for increased levels of $\alpha$-tocopherol in both plasma and liver. This research resulted in article titled "Dried apple enriched with mandarin juice by vacuum impregnation counteracts the liver oxidative effect of tamoxifen in rats" submitted to the journal "Food and Chemical Toxicology" with impact factor 2.999.

In the in vivo study with obese school-age children, the effect of incorporating snacks made from apple and mandarin juice in the mild energy-restricted diet was studied. This study attempted to provide useful information about antioxidant and anti-inflammatory potential of the product. In this way, we conducted an intervention study to examine whether the dietary intake of the snacks developed could be associated with a modification in oxidative status and biomarkers of systemic inflammation such as high sensitivity C-reactive protein (CRP), tumour necrosis factor $\alpha$ (TNF- $\alpha$ ), $\alpha$ interleukin 1 (IL-1 $\alpha$ ) and interleukin 6 (IL-6).The results obtained in this study led to conclude that incorporation to the diet of the functional food developed improved systolic blood pressure and lipid profile of children. A significant increase in the antioxidant capacity of serum, a reduction in DNA oxidative damage and in inflammatory markers was found. Overall, short-term intake of the products ameliorates several risk factors for atherosclerosis. This research resulted in article titled "Dried apple snacks enriched with mandarin juice improves antioxidant capacity and decreases inflammation in obese children" submitted to journal "Food Chemistry" with impact factor 3.655.

Moreover, in the development of functional food low humidity from apple and mandarin juice, effective against Helicobacter pylori infection in children of school age, we assessed the growth of two probiotic microorganisms (Lactobacillus acidophilus and Lactobacillus salivarius spp. salivarius), effective against Helicobacter pylori, in two commercial juices (mandarin juice and pineapple/ grape juice) to three different pHs (5, 5.5 and 6) and incubated at two different times ( 24 and 48 hours). Mandarin juice with Lactobacillus salivarius spp. salivarius at $\mathrm{pH} 6$ and incubated for 24 hours resulted in higher growth of microorganisms. This juice was used for the manufacture of functional food. Physicochemical properties and microorganism content were determined at each stage of the process, vacuum impregnation operation was analyzed and finally a preliminary in vivo test with 5 children infected by Helicobacter pylori was carried out. To complete the study of the manufacturing process, the impregnated apple was stabilized by different dehydration methods and conditions. Specifically, hot air drying at 30 and $45^{\circ} \mathrm{C}$ for 24 hours and freeze-drying for 12 to 24 hours were used. The optical and mechanical properties of all the products obtained were determined as well as the microorganism content. The results obtained in this 
study showed that after the vacuum impregnation operation and different dehydration methods and conditions employed the microorganisms levels reached in the product were enough to have probiotic effect. Similarly, the results obtained in the in vivo test confirmed the potential effects of the developed product against Helicobacter pylori infection. This research resulted in article titled "No invasive methodology to produce a probiotic low humid apple snack with potential effect against Helicobacter pylori" published in "Journal of Food Engineering" with impact factor 2.414 . 
*Nota al lector: En esta tesis doctoral, el capítulo 3 de resultados se ha organizado incluyendo los artículos científicos publicados o en vías de publicación en revistas internacionales.

\section{Introducción.}

Pág.

1.1. Importancia de los alimentos funcionales.

1.2. Aspectos relacionados con los alimentos funcionales en los que se ha trabajado en los últimos 10 años y se sigue trabajando en la actualidad.

1.2.1. Identificación de compuestos fisiológicamente activos.

1.2.2. Tecnologías de fabricación de alimentos funcionales. La impregnación a vacío.

1.3. Preocupaciones sociales-políticas-sanitarias que puedan encontrar una solución en los alimentos funcionales.

1.3.1. Estrés oxidativo.

1.3.2. Enfermedades cardiovasculares - colesterolemia.

1.3.3. Obesidad en niños y adolescentes.

1.3.4. Infección por Helicobacter pylori en niños.

1.4. El mercado de los alimentos funcionales en la actualidad. Nichos de oportunidad en el desarrollo de alimentos funcionales.

1.5. Bibliografía citada.

\section{Objetivos y plan de trabajo.}

2.1. Justificación e interés de la investigación.

2.2. Objetivos.

2.3. Plan de trabajo.

\section{Resultados y discusión.}

3.1. Revisión bibliográfica sobre las tecnologías utilizadas en el desarrollo de alimentos funcionales.

3.1.1 E. Betoret, N. Betoret, D. Vidal \& P. Fito. Functional foods development: Trends and technologies. 
Trends in Food Science \& Tecnology, 22 (2011), 498508.

3.2. Valoración de algunos aspectos tecnológicos, económicos y medioambientales para la implantación industrial del proceso de fabricación del alimento funcional.

3.3. Efecto de la presión de homogeneización sobre las propiedades fisicoquímicas y funcionales del zumo de mandarina. Estudio de la idoneidad del zumo para su uso en la operación de impregnación a vacío.

3.3.1. E. Betoret, N. Betoret, J.V. Carbonell \& P. Fito. Effects of pressure homogenization on particle size and the functional properties of citrus juices. Journal of Food Engineering, 92 (2009), 18-23.

3.3.2. E. Betoret, E. Sentandreu, N. Betoret \& P. Fito. Homogenization pressures applied to citrus juices manufacturing. Functional properties and application. Journal of Food Engineering, 111 (2012), 28-33.

3.4. Efecto del proceso de fabricación del alimento funcional a partir de manzana y zumo de mandarina sobre las propiedades fisicoquímicas y funcionales del mismo. Evaluación del grado de aceptación.

3.4.1. E. Betoret, E. Sentandreu, N. Betoret, P. CodoñerFranch, V. Valls-Bellés \& P. Fito. Technological development and functional properties of an apple snack rich in flavonoid from mandarin juice. Innovative Food Science and Emerging Technologies (2012), doi:10.1016/j.ifset.2012.07.003.

3.4.2. Efecto de diferentes técnicas y condiciones de deshidratación sobre las propiedades ópticas y mecánicas de un alimento funcional de manzana de baja humedad enriquecido con zumo de mandarina. Análisis sensorial.

3.5. Estudio in vivo de la capacidad antioxidante del alimento funcional desarrollado y sus efectos sobre la salud.

3.5.1. Dried apple enriched with mandarin juice by vacuum impregnation counteracts the liver oxidative effect of tamoxifen in rats. 
3.5.2. P. Codoñer-Franch, E. Betoret, N. Betoret, A.B. LópezJaén, V. Valls-Bellés \& P. Fito. Dried apple snack enriched with mandarin juice improves antioxidant capacity and decreases inflammation in obese children. Plant Foods for Human Nutrition (2012), (Submitted to the Journal).

3.6. Efecto del proceso de fabricación del alimento funcional a partir de manzana y zumo de mandarina con microorganismos probióticos sobre el contenido en microorganismos, las propiedades fisicoquímicas y funcionales en contra de la infección ocasionada por Helicobacter pylori.

3.6.1. E. Betoret, A. Arilla, N. Betoret, M. Bennár, C. Barrera, P. Codoñer \& P. Fito. No invasive methodology to produce a probiotic low humid apple snack with potential effect against Helicobacter pylori. Journal of Food Engineering, 110 (2012), 289-293.

3.6.2. Aplicación de diferentes técnicas de deshidratación en la estabilización de una alimento funcional a base de fruta con efecto probiótico contra la infección ocasionada por Helicobacter pylori.

\section{Discusión general de los resultados.}

4.1. Desarrollo de un alimento funcional a partir de manzana y zumo de mandarina.

4.2. Desarrollo de un alimento funcional con alto contenido en microorganismos probióticos a partir de manzana y zumo de mandarina con efecto contra la infección por Helicobacter pylori.

4.3. Bibliografía citada 246

5. Conclusiones.

6. Anejos. 

1. INTRODUCCIÓN 



\subsection{Importancia de los alimentos funcionales}

El interés de los responsables de la salud pública y de los consumidores por conocer la relación entre la dieta y la salud ha aumentado considerablemente. Se ha demostrado que muchos alimentos contienen componentes que resultan beneficiosos para nuestro organismo. De esta manera, se ha generado un gran interés por los beneficios de una dieta adecuada para la salud y diferentes estudios ponen énfasis sobre los beneficios de los productos vegetales en la reducción del riesgo de padecer ciertas enfermedades como el cáncer (Hennekens, 1986; Block et al., 1992), enfermedades cardiovasculares, cataratas y otras. Cada vez más, los consumidores muestran una mayor conciencia por su salud a la hora de seleccionar sus alimentos, aumentando el interés por consumir alimentos saludables, bajos en colesterol, bajos en grasas saturadas y sodio, con altos niveles de vitaminas, minerales y fibras; prefiriendo frutas y hortalizas frescas en lugar de procesadas.

Los expertos recomiendan seguir una dieta sana, variada y equilibrada como la mejor manera de prevenir ciertas enfermedades asegurando una buena salud. Sin embargo, los nuevos estilos de vida han provocado que se abandonen determinados hábitos de alimentación saludables que durante años han formado parte de nuestra historia y tradición. En la sociedad actual, los desequilibrios y desajustes alimentarios están relacionados con la aparición de un gran número de enfermedades. La falta de tiempo para cocinar, el ritmo de vida actual y la enorme oferta de alimentos que hace difícil la toma de decisiones adecuadas, conduce a que muchas personas no sigan una alimentación equilibrada y, por tanto, no ingieran todos los nutrientes que necesitan o en las cantidades adecuadas.

Nuestros hábitos dietéticos han variado. Ya no se trata únicamente de que reduzcamos los alimentos cuyo exceso puede ser perjudicial para nuestra salud, sino de buscar aquellos que tengan beneficios saludables y nos ayuden a retrasar la aparición de algunas enfermedades. Como consecuencia de esta situación surgen los alimentos funcionales que pueden compensar los desequilibrios alimentarios y garantizar las ingestas de nutrientes recomendadas por los especialistas en nutrición. Sin embargo, los alimentos con efecto beneficioso para la salud no son nuevos y el ser humano los ha utilizado a lo largo de la historia desde hace más de 2500 años (Shi et al., 2005 a,b). Ya Hipócrates en el siglo V a.C. dijo "que la comida sea tu alimento y el alimento tu medicina".

El término "Alimento Funcional" se introdujo por primera vez en Japón, a mediados de los ochenta en un intento del ministerio japonés de salud y bienestar de mejorar la salud de una población cada vez más envejecida y de reducir los costes sanitarios, y se refería a "aquellos alimentos procesados que contienen compuestos que afectan a funciones específicas del cuerpo" (Arai, 1996). A nivel global, no existe una definición única y legalmente aceptada para los alimentos funcionales. En Japón los alimentos funcionales son conocidos como "Alimentos que tienen un Uso Específico sobre la Salud" (Foods for Specified Health Use 
"FOSHU") y se considera que "afectan a la estructura y/ o las funciones del cuerpo humano" (Ohama et al., 2006). Health Canada define un alimento funcional como "aquél que es similar en apariencia a un alimento convencional y que consumido como parte de la dieta habitual, más allá de las funciones básicas de nutrición, tiene efectos fisiológicos beneficiosos demostrados y/ o reduce el riesgo de padecer enfermedades crónicas" (Health Canada website: http:// hc-sc.gc.ca). En Corea se considera alimentos funcionales a los "suplementos dietéticos que contienen dosis cuantificables de compuestos fisiológicamente activos" (Kim et al., 2006). En los Estados Unidos, los alimentos funcionales no tienen una identidad regulatoria, aunque en 1999, la American Dietetic Association definió a los alimentos funcionales como "aquellos alimentos que están enriquecidos o mejorados y que proporcionan beneficios para la salud que van más allá de la nutrición básica cuando se consumen de forma regular" (American Dietetic Association, 1999). En China, un alimento funcional se define como "un alimento dirigido a grupos especiales de la población que tiene efectos sobre la salud mediante la regulación de las funciones del cuerpo humano pero que no se utiliza con fines terapéuticos (Ministry of Health, 1996). En Europa, no existe una definición legalmente aceptada para los alimentos funcionales y como definición práctica se utiliza aquella que considera al alimento funcional como "un alimento que afecta beneficiosamente a una o más funciones del cuerpo y que además de nutrir adecuadamente contribuye a mejorar la salud y el bienestar, reduce el riesgo de padecer enfermedades y se consume como un alimento (no es una píldora, una cápsula o un suplemento dietético)" (European Commission, 2010).

El desarrollo de un alimento funcional es un proceso multietapa que requiere, desde la idea de producto hasta la comercialización del mismo, de las aportaciones de investigadores, médicos y agentes sociales y sólo a través de la colaboración activa entre estas partes el proceso de desarrollo puede llevarse a cabo con éxito y el sector de los alimentos funcionales puede crecer de manera continua y sostenible. En la actualidad, la concienciación de los consumidores combinada con los avances científicos ofrecen la oportunidad para el desarrollo de un amplia gama de nuevos conceptos de alimentos funcionales (Biström \& Nordström, 2002; Van Kleef et al., 2002). Por el contrario, el desarrollo y la comercialización de este tipo de alimentos resulta bastante compleja, cara y arriesgada ya que es necesario cumplir una gran cantidad de requisitos para que el producto tenga éxito (Van Kleef et al., 2002, 2005).

Para el desarrollo de un alimento funcional hay que tener en cuenta:

a. Necesidades del consumidor, preocupaciones sociales.

Según las últimas encuestas llevadas a cabo las enfermedades que más preocupan a los consumidores son las enfermedades cardiovasculares, las enfermedades del sistema digestivo y la obesidad (Drbohlav et al., 2007; Hilliam, 1998; Keller, 2006; Korzen-Bohr \& O'doherty Jensen, 2006; Van Kleef et al., 2002, 2005).

b. Estudio de mercado que permita detectar nichos de oportunidad. 
Previamente al desarrollo es necesario realizar un estudio que permita identificar los nichos de oportunidad existentes en el mercado.

c. Revisión bibliográfica.

La revisión bibliográfica permite identificar los avances científicos existentes en el área de interés, las tecnologías disponibles para llevarlos a cabo, las áreas sin desarrollar así como la libertad para operar y definir el desarrollo del producto.

d. Identificación de compuestos fisiológicamente activos y desarrollo de una matriz alimentaria.

Es necesario seleccionar o desarrollar una matriz alimentaria adecuada que tanto en su estado fresco como después del procesado proteja a los compuestos fisiológicamente activos y al mismo tiempo permita la liberación de los mismos en el organismo en el lugar y momento adecuados.

e. Análisis de los cambios durante el proceso.

El éxito comercial de los productos funcionales depende en última estancia del sabor, la apariencia, el precio y la alegación saludable dirigida a los consumidores. Para la obtención de un alimento funcional de calidad y efectivo es necesario analizar los cambios que experimentará dicho alimento durante el procesado tanto a nivel microscópico como macroscópico. Los cambios durante el proceso de fabricación sobre los compuestos con actividad funcional o sobre la propia estructura del alimento afectan directamente a la eficacia y a la aceptación del producto funcional desarrollado.

f. Evaluación de la eficacia y la seguridad del alimento funcional completo.

La evaluación de la eficacia y la seguridad es una etapa esencial para demostrar el efecto del alimento funcional y puede llevarse a cabo utilizando estudios in vitro o in vivo. Los sistemas celulares proporcionan información biológica básica sobre las interacciones de los nutrientes en procesos bioquímicos. Sin embargo, para evaluar la actividad biológica sobre una base fisiológica de cuerpo entero es preferible el uso de animales o seres humanos. Los estudios in vivo con animales permiten un alto grado de control de la dieta, el medio ambiente y la genética, si bien, existen casos en donde los modelos animales no imitan adecuadamente las respuestas fisiológicas de los seres humanos. Existen numerosas diferencias en el metabolismo de los lípidos entre las diversas especies que deben ser consideradas cuando se evalúa la relevancia en humanos de los resultados obtenidos en la investigación con modelos animales (Bergen \& Mersmann, 2005). La confirmación de la eficacia del alimento funcional en un sistema humano proporciona una base sólida que permite establecer las alegaciones de propiedades saludables para ese producto específico.

g. Legislación.

Los aspectos legales no pueden dejarse a un lado. Especialmente en Europa, las empresas que tratan de poner en marcha un alimento funcional se han 
enfrentado a una variedad de marcos legislativos que regulan la aprobación de productos, los tipos de información nutricional requerida en las etiquetas y los tipos de alegaciones funcionales y de salud en relación con un producto, normalmente de manera muy inconsistente entre los estados miembros (Bech-Larsen \& Scholderer, 2007). Sin embargo, el "Reglamento (CE) No. 1924/2006 del Parlamento Europeo y del Consejo, de 20 de diciembre de 2006, sobre la nutrición y de las propiedades saludables en los alimentos" ha entrado en vigor (European Comission (CE), 2006) y unifica los criterios legales de todos los estados miembros a tener en cuenta a la hora de comercializar un alimento funcional. Este reglamento fija los procedimientos de autorización necesarios para garantizar que las declaraciones que figuran en el etiquetado, la presentación o la publicidad de alimentos sean claras, precisas y se fundamenten en pruebas aceptadas por toda la comunidad científica. Este reglamento se ha ido modificando con reglamentos posteriores de tal manera que la última modificación corresponde al reglamento (UE) No. 432/ 2012 de la Comisión de 16 de mayo de 2012 por el que se establece una lista de declaraciones autorizadas de propiedades saludables de los alimentos distintas de las relativas a la reducción del riesgo de enfermedad y al desarrollo la salud de los niños.

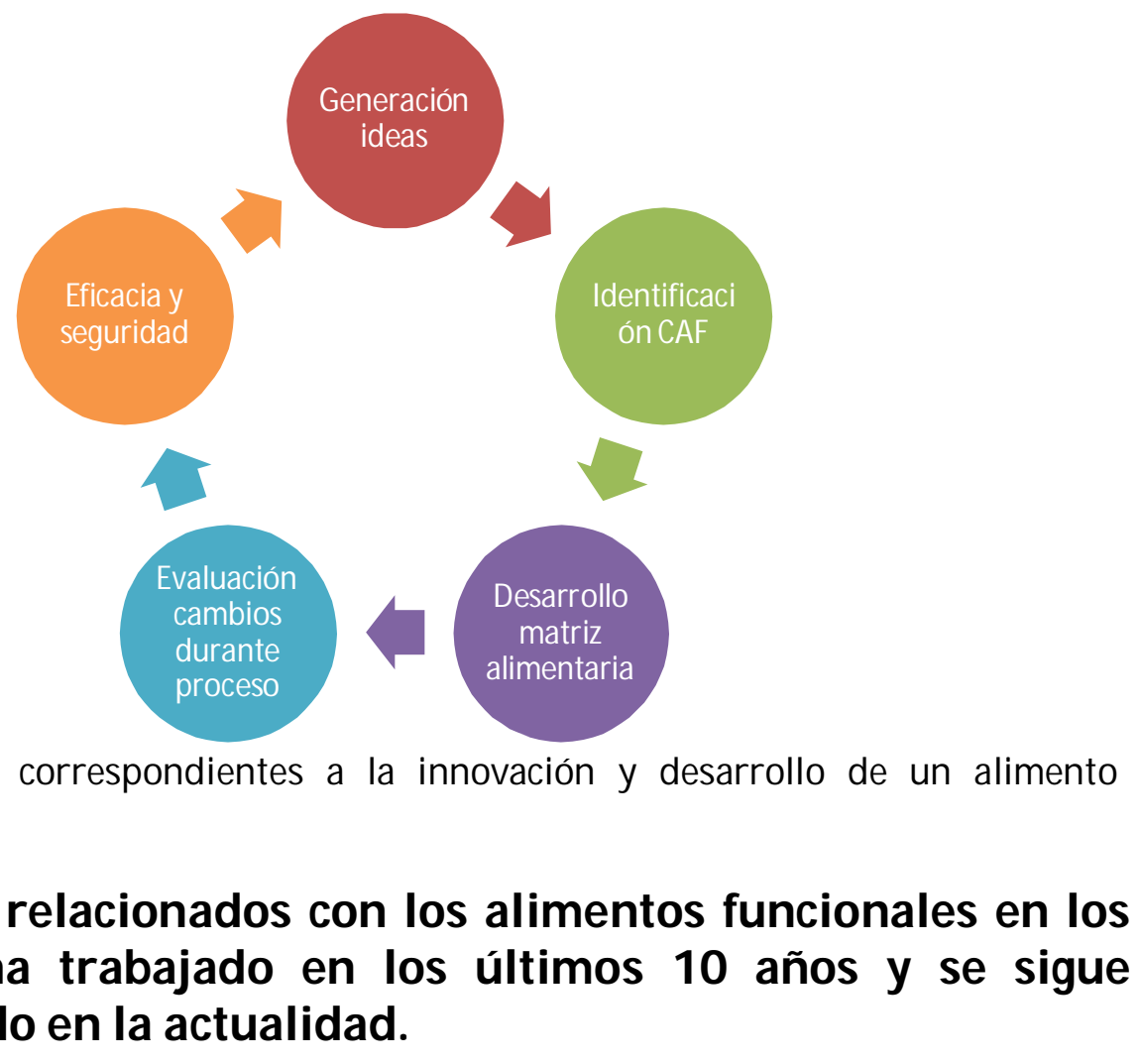

Figura 1.1. Etapas correspondientes a la innovación y desarrollo de un alimento funcional.

\subsection{Aspectos relacionados con los alimentos funcionales en los que se ha trabajado en los últimos 10 años y se sigue trabajando en la actualidad.}

\subsubsection{Identificación de compuestos fisiológicamente activos}

Un aspecto importante relacionado con los alimentos funcionales en el que se ha trabajado en los últimos 10 años, en el que se sigue trabajando en la actualidad 
y que es una pieza clave en el desarrollo de un alimento funcional es la identificación y la purificación de componentes funcionales. La identificación, extracción y purificación de compuestos fisiológicamente activos se tiene en cuenta tanto para el desarrollo de un alimento funcional como para la identificación del mismo.

La lista de compuestos fisiológicamente activos (vitaminas, probióticos, péptidos bioactivos, compuestos antioxidantes...) presentes en los alimentos que forman parte de nuestra dieta no tiene fin y las pruebas que se llevan a cabo para identificar, extraer y purificar este tipo de compuestos en productos naturales se suceden y crecen de manera constante (Wildman, 2006).

El conocimiento de la existencia de este tipo de compuestos ha supuesto una excelente oportunidad para mejorar la salud pública y por esta razón han recibido mucha atención en los últimos años por parte de la comunidad científica, los consumidores y la industria alimentaria. Desde la aparición de la sal yodada en los años 20, la fortificación de la leche con vitamina $\mathrm{D}$ en los 30 o la adición de calcio a una gran variedad de productos en los años 80, las tecnologías utilizadas en la identificación y extracción de compuestos funcionales han evolucionado considerablemente.

Los compuestos fisiológicamente activos están presentes en una gran cantidad de alimentos, pero sin duda, abundan en las frutas y las verduras. Si se considera a los alimentos funcionales como aquellos alimentos que consumidos habitualmente como parte de la dieta contienen componentes fisiológicamente activos que mejoran la salud o reducen el riesgo de padecer una enfermedad, entonces las frutas y las verduras representan la forma más simple de alimento funcional. Las autoridades sanitarias recomiendan un consumo mínimo de cinco frutas y verduras al día (National Academy of Sciences, 1989). Estudios epidemiológicos han demostrado que el consumo de frutas y verduras es beneficioso para la salud ya que reduce el riesgo de padecer enfermedades cardiovasculares y de sufrir un infarto, así como de padecer ciertos tipos de cáncer, diabetes, alzhéimer, cataratas y el deterioro funcional relacionado con la edad (Temple, 2000; Willet, 1994; Willet, 1995).

La tabla 1.1 muestra algunos ejemplos de compuestos fisiológicamente activos presentes en alimentos.

Tabla 1.1. Compuestos fisiológicamente activos presentes en algunos alimentos (Adaptado de Kaur $\&$ Das, 2011).

\begin{tabular}{ccc}
\hline Componente funcional & Fuente/ Alimento & Efectos beneficiosos \\
\hline $\begin{array}{c}\text { Ácido algínico y } \\
\text { xylofucanos }\end{array}$ & $\begin{array}{c}\text { Sargassum vulgare } \\
\text { (alga) }\end{array}$ & Actividad antiviral \\
\hline $\begin{array}{c}\text { Antocianinas, catequinas, } \\
\text { cianidinas, flavonoles, } \\
\text { quercitina, miricetina }\end{array}$ & $\begin{array}{c}\text { Piel de uvas, zumo y } \\
\text { vino (de uva tinta); bayas y } \\
\text { berenjena }\end{array}$ & $\begin{array}{c}\text { Actividad antioxidante, inhibición de la oxidación de } \\
\text { LDL, captador de radicales superóxido }\end{array}$ \\
\hline Calcio & Leche y derivados & $\begin{array}{c}\text { Disminución del cáncer de colon, disminución de los } \\
\text { efectos proliferativos e irritativos del intestino }\end{array}$ \\
\hline Capsaicina & Pimientos rojos y verdes & Captador de aniones superóxido \\
\hline $\begin{array}{c}\text { Carnosol y ácido } \\
\text { carnosoico }\end{array}$ & Extractos de romero & Inhibición de la peroxidación de aceites \\
\hline Carotenoides y licopeno & $\begin{array}{c}\text { Tomates, zanahorias, } \\
\text { pimientos, vegetales de hoja }\end{array}$ & $\begin{array}{c}\text { Actividad antioxidante, antiinflamatoria y anti } \\
\text { carcinogénica, inhibición de la oxidación del LDL, }\end{array}$ \\
\hline
\end{tabular}


Desarrollo tecnológico y valoración funcional de aperitivos de manzana y zumo de mandarina.

\begin{tabular}{|c|c|c|}
\hline & $\begin{array}{l}\text { verde, frutas y aceite de } \\
\text { palma }\end{array}$ & $\begin{array}{l}\text { disminución del riesgo de padecer enfermedades } \\
\text { cardiovasculares }\end{array}$ \\
\hline $\begin{array}{l}\text { Ácidos linoleicos } \\
\text { conjugados (CLA) }\end{array}$ & $\begin{array}{l}\text { Cordero, pavo, carne de } \\
\text { vacuno }\end{array}$ & $\begin{array}{c}\text { Reducción del cáncer de mama, aterosclerosis y } \\
\text { diabetes tipo } 2\end{array}$ \\
\hline Curcuminoides & $\begin{array}{l}\text { Cúrcuma longa } \\
\text { (cúrcuma) }\end{array}$ & $\begin{array}{c}\text { Disminución de la oxidación lipídica, evita la hipoxia } \\
\text { isquémica }\end{array}$ \\
\hline $\begin{array}{l}\text { Daidzeína, genisteína e } \\
\text { isoflavonas }\end{array}$ & Soja y derivados & $\begin{array}{l}\text { Inhibición de la peroxidación lipídica, disminución } \\
\text { del riesgo cardiovascular y de cáncer }\end{array}$ \\
\hline $\begin{array}{l}\text { Fibra (soluble e } \\
\text { insoluble) }\end{array}$ & $\begin{array}{c}\text { Cereales de avena, } \\
\text { Clondrus crispus (alga) }\end{array}$ & Reduce el colesterol total y el LDL \\
\hline $\begin{array}{c}\text { Flavonoides (flavonas, } \\
\text { flavanonas, flavonoles y flavan- } \\
\text { 3-oles) }\end{array}$ & $\begin{array}{l}\text { Apio, perejil, cítricos, } \\
\text { cebolla, té, judías verdes, } \\
\text { tomates, coco, manzanas, } \\
\text { bayas, algunas habas y el } \\
\text { chocolate }\end{array}$ & $\begin{array}{l}\text { Actividad antioxidante, anti-proliferativa, anti- } \\
\text { hipertensiva, anti-carcinogénica, anti-trombótica, } \\
\text { inhibición de la oxidación del LDL, mejora del tono } \\
\text { vascular }\end{array}$ \\
\hline $\begin{array}{l}\text { Ácido gálico, sulfuros y } \\
\text { tioles, quercetina y } \\
\text { compuestos organosulfurados }\end{array}$ & Ajo, cebolla y brócoli & Disminución de la presión sanguínea \\
\hline Lignanos & Semillas de lino & Actividad estrogénica \\
\hline $\begin{array}{l}\text { Ácidos fenólicos y ácidos } \\
\text { grasos monoinsaturados }\end{array}$ & $\begin{array}{l}\text { Café, té verde, té negro, } \\
\text { copos de cereales, frutas, } \\
\text { aceite de oliva virgen extra }\end{array}$ & Actividad anti-inflamatoria \\
\hline Prebioticos & $\begin{array}{l}\text { plátanos, ajo, cebolla, } \\
\text { leche, miel y alcachofas }\end{array}$ & $\begin{array}{l}\text { Estimulación del crecimiento de bacterias } \\
\text { beneficiosas en el intestino }\end{array}$ \\
\hline Probióticos & $\begin{array}{l}\text { Productos lácteos } \\
\text { fermentados }\end{array}$ & $\begin{array}{c}\text { Mejora la salud del tracto intestinal y el sistema } \\
\text { inmunológico }\end{array}$ \\
\hline $\begin{array}{c}\text { Resveratrol, polifenoles, } \\
\text { ginsenósidos y ácido ascórbico }\end{array}$ & $\begin{array}{l}\text { Uvas, vino tinto, ginseng, } \\
\text { cítricos }\end{array}$ & $\begin{array}{l}\text { Disminución de la presión sanguínea, prevención de } \\
\text { procesos malignos avanzados }\end{array}$ \\
\hline Sesaminol & $\begin{array}{l}\text { Arroz y aceite de arroz, } \\
\text { semillas y aceite de sésamo }\end{array}$ & $\begin{array}{l}\text { Inhibición de la oxidación del LDL y disminución del } \\
\text { riesgo de padecer cáncer }\end{array}$ \\
\hline Estilbenos & Uvas, cacahuetes & Actividad antioxidante y cardioprotectiva \\
\hline $\begin{array}{l}\text { Tocoferol, ubiquinol, } \\
\text { tocotrienoles, ácidos grasos w- } \\
\text { 3, fitosteroles y otros }\end{array}$ & $\begin{array}{c}\text { Almendras, nueces, } \\
\text { trigo, aceite de pescado, } \\
\text { aceites de soja, de oliva, de } \\
\text { arroz }\end{array}$ & $\begin{array}{l}\text { Disminución del nivel de colesterol en sangre e } \\
\text { inhibición de la peroxidación lipídica }\end{array}$ \\
\hline
\end{tabular}

Los compuestos fisiológicamente activos también se encuentran en los restos del procesado de determinados alimentos. Debido al aumento en la producción, la eliminación de residuos supone un problema cada vez mayor ya que el material vegetal se deteriora rápidamente y esto limita la explotación. Por otra parte, los costes de secado, almacenamiento y transporte de los subproductos son factores limitantes y el problema aumenta con las restricciones legales, de manera que los desechos agroindustriales normalmente se utilizan como pienso o fertilizante. Sin embargo, la demanda de pienso puede variar y depende de los rendimientos agrícolas.

La obtención de compuestos fisiológicamente activos a partir de residuos vegetales plantea la posibilidad de reutilizar los subproductos vegetales de manera eficiente y ambientalmente responsable obteniendo una rentabilidad elevada. Los compuestos fisiológicamente activos se extraen principalmente de la pulpa, la semilla y la piel resultante de la fabricación de zumos o el procesado de verduras. Las técnicas de extracción mayoritariamente utilizadas son sólido-líquido, líquidolíquido y adsorción aunque está aumentando la popularidad de las técnicas de extracción a presión como la extracción mediante la utilización de fluidos supercríticos y la extracción con ultrasonidos y membranas debido a la mayor especificidad molecular y a la menor cantidad de disolventes residuales generados.

La tabla 1.2 muestra algunos ejemplos de componentes fisiológicamente activos extraídos de subproductos vegetales utilizando diferentes métodos de extracción. 
Tabla 1.2. Componentes fisiológicamente activos extraídos de subproductos vegetales (Adaptado de Wijngaard et al., 2012).

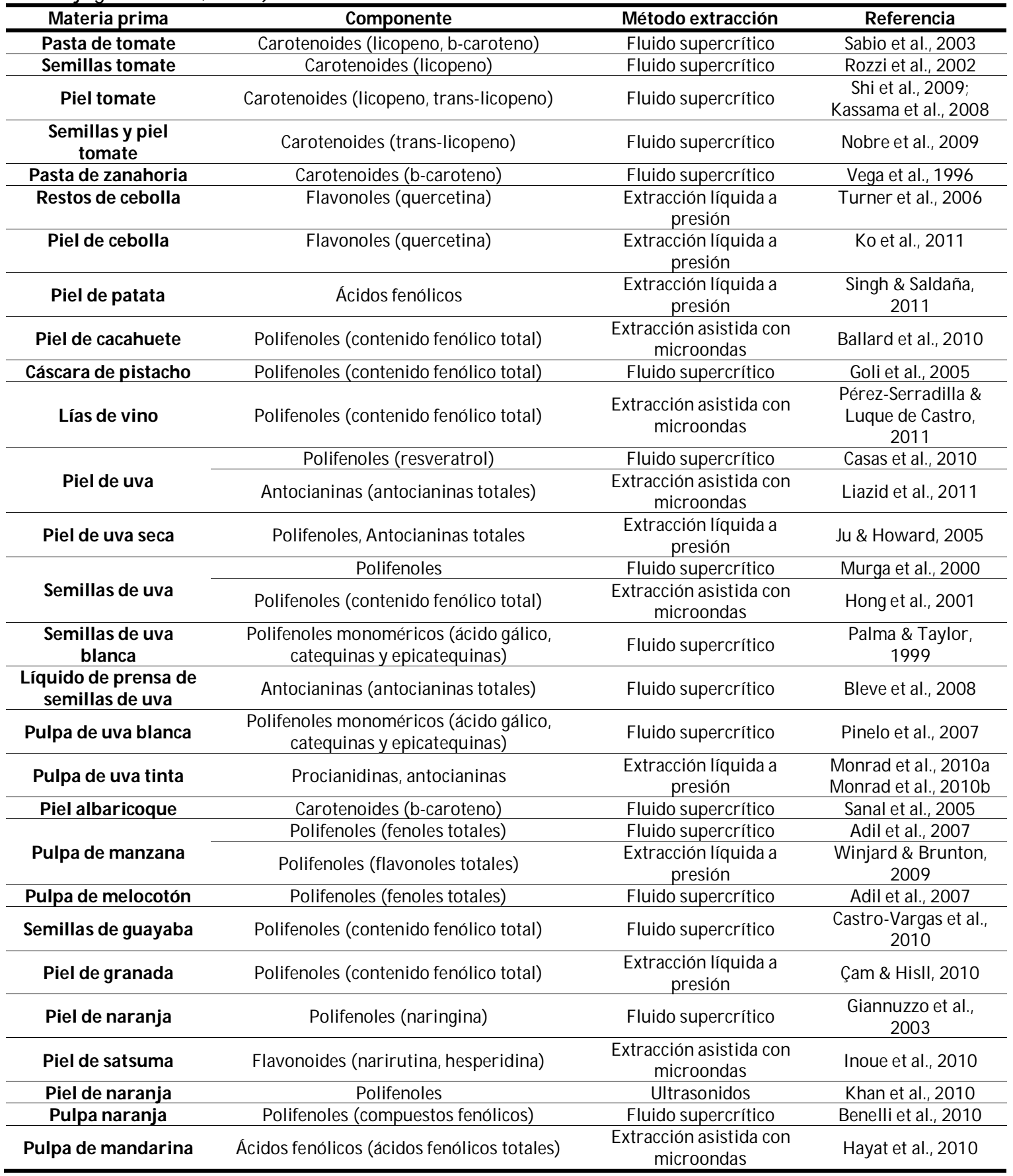

\subsubsection{Tecnologías de fabricación de alimentos funcionales. La impregnación a vacío.}

(Por su relación directa con los objetivos de la tesis se desarrolla con mayor extensión en el apartado de resultados.)

No hay duda de que el desarrollo de alimentos funcionales tiene un gran interés para los consumidores, la industria, los gobiernos y las universidades. Desde el punto de vista de la investigación y el desarrollo, los alimentos funcionales suponen una oportunidad para obtener productos innovadores que satisfagan de 
manera considerable la demanda que existe en la actualidad. Se requiere de una gran variabilidad de técnicas que satisfagan las necesidades y expectativas de los consumidores en materia de alimentos funcionales. Las tecnologías utilizadas en el desarrollo de este tipo de alimentos han cambiado de forma considerable a lo largo de los años. Estas tecnologías pueden clasificarse básicamente en tres grandes grupos:

a. El primer grupo está formado por las tecnologías tradicionalmente utilizadas en el desarrollo de alimentos: la formulación y mezcla y el cultivo y cría. La formulación y mezcla constituye una tecnología sencilla y barata para desarrollar nuevos alimentos funcionales $y$ ha sido ampliamente utilizada en la elaboración de alimentos. Su uso en el desarrollo de alimentos funcionales tiene una larga historia de éxitos en el control de las deficiencias de vitamina A, D, B (tiamina, riboflavina y niacina), yodo y hierro. Desde las clásicas leches enriquecidas con calcio hasta las últimas carnes enriquecidas con componentes bioactivos el número de productos obtenidos mediante formulación y mezcla está en constante aumento.

La agricultura y la ganadería constituyen la principal fuente de los nutrientes necesarios para el ser humano. La biotecnología se ha utilizado en los cultivos y la cría de animales desde el comienzo de la historia humana. Con el uso de herramientas de biología molecular y el desarrollo de semillas genéticamente modificadas, la biotecnología se ha convertido en una técnica moderna que ofrece una alternativa para modificar la composición de los alimentos.

b. El segundo grupo lo constituyen las tecnologías que formando una estructura tratan de prevenir el deterioro de los compuestos fisiológicamente activos: la microencapsulación, los recubrimientos y películas y la impregnación a vacío, forman parte de este grupo. La microencapsulación se basa en el efecto envolvente de una matriz polimérica, que crea un microambiente en la cápsula capaz de controlar las interacciones entre la parte interna y la externa. La microencapsulación permite la protección de una amplia gama de materiales de interés biológico y sus características la hacen adecuada para su aplicación en la industria de alimentos funcionales. La microencapsulación se ha utilizado mayoritariamente para encapsular lípidos, proteínas e hidratos de carbono así como para mejorar la viabilidad de las bacterias probióticas. Actualmente una gran parte de los esfuerzos en esta área se dedican a encapsular componentes sin que esto interfiera en el sabor, la textura o la sensación en boca del producto "original".

Las películas y recubrimientos comestibles se aplican en muchos productos para controlar la transferencia de humedad o el intercambio de gases. Varias investigaciones han incorporado con éxito minerales, vitaminas y ácidos grasos a los recubrimientos aplicados a frutas y verduras para 
mejorar su valor nutricional. La adición de microorganismos probióticos a los recubrimientos está siendo estudiada.

La técnica de impregnación a vacío plantea la posibilidad de incluir un producto líquido en el interior de la matriz estructural de un producto poroso obteniendo un producto nuevo que combine los efectos derivados del consumo de ambos y proporciona una alternativa adicional al desarrollo de alimentos funcionales. Por ser la tecnología utilizada en esta tesis se explica con más detalle posteriormente.

c. Por último, el tercer grupo está formado por aquellas tecnologías recientes destinadas a diseñar alimentos funcionales personalizados: la nutrigenómica. La nutrigenómica considera las interacciones entre los alimentos y el genoma de un individuo y los consiguientes efectos posteriores en su fenotipo. Reconoce que el asesoramiento dietético apropiado para un individuo puede ser inapropiado o perjudicial para otro. El campo tiene el potencial de proporcionar un asesoramiento nutricional personalizado y desarrollar productos alimentarios específicos para una determinada parte de la población. Esta ciencia todavía se considera una ciencia emergente.

Así, mientras que las "técnicas tradicionales" eran las más comúnmente utilizadas para el desarrollo de alimentos funcionales desde el año 2000 hasta el 2005, las tecnologías dirigidas a una nutrición personalizada han aumentado enormemente. De la misma manera, el grupo de tecnologías que forman una estructura para prevenir el deterioro de los componentes fisiológicamente activos han crecido de forma significativa desde el año 2005 al 2010.

En esta tesis doctoral se ha utilizado la tecnología de impregnación a vacío para el desarrollo de alimentos funcionales.

La técnica de Impregnación a Vacío (IV) es una operación de transferencia de materia entre un medio líquido y un sustrato sólido con estructura porosa. La creación de gradientes de presión en el sistema constituido por el sólido sumergido en el seno del líquido junto con la presión capilar que aparece a la entrada de los poros, provocan una importante transferencia de gas y líquido entre el sólido y el medio líquido. Basándose en la estructura porosa de algunos alimentos y en la existencia de gas ocluido en ésta, Fito (1994) y Fito \& Pastor (1994), explicaron lo que llamaron el mecanismo hidrodinámico, principal mecanismo implicado en la operación de impregnación a vacío. Al someter el producto, inmerso en un líquido, a presiones subatmosféricas, este gas sufre en primer lugar una expansión para equilibrarse con la presión impuesta al sistema, lo que implica por una parte, un nivel de desgasificación de la estructura porosa del alimento en función de la presión aplicada, y por otra, una penetración de líquido por capilaridad una vez alcanzado el equilibrio de presiones en el sistema. En segundo lugar, la restauración de la presión atmosférica provoca un nuevo gradiente de presiones que va a actuar como fuerza impulsora y que hará que los espacios intercelulares se llenen parcialmente de líquido. La cantidad de líquido 
que impregne la estructura, dependerá del nivel de desgasificación, y por tanto de la presión de trabajo. Esta penetración de líquido, producida por gradientes de presión, que actúan como fuerzas impulsoras, es reversible y está controlada por la compresión o expansión del gas ocluido en los espacios intercelulares. Diferentes investigaciones sobre la aplicación de la impregnación a vacío en frutas indican que el HDM tiene lugar acoplado con fenómenos de deformación-relajación (DRP) en la matriz sólida, con propiedades viscoelásticas, del alimento poroso. La actuación del HDM y DRP, está muy afectada por la microestructura del alimento y sus propiedades mecánicas, pudiendo, a su vez, ambos fenómenos provocar importantes cambios en las propiedades físicas del producto.

En 1996, Fito et al., propusieron un modelo matemático que contempla el acoplamiento de los dos mecanismos, HDM y DRP. La ecuación general de modelo relaciona, en cada una de las etapas del proceso de impregnación, la fracción volumétrica de líquido incorporado $\left(\mathrm{X}_{1} \mathrm{y} \mathrm{X}\right)$, la deformación volumétrica de la muestra $\left(\gamma_{1}\right.$ y $\gamma$ ) y la porosidad eficaz $\left(\varepsilon_{e}\right)$. Esta ecuación, aplicable a operaciones sólido-líquido a vacío puede utilizarse para calcular los valores de $\varepsilon_{\mathrm{e}}$ a partir de valores experimentales de $\mathrm{X}, \gamma \mathrm{y} \gamma_{1}$.

$$
\varepsilon_{e}=\frac{(X-\gamma) r+\gamma_{1}}{r-1}
$$

donde r es la relación de compresión real definida como:

$$
r=\frac{p_{2}-p_{c}}{p_{1}}
$$

Donde $\mathrm{p}_{\mathrm{c}}$ es la presión capilar $\left(\mathrm{N} / \mathrm{m}^{2}\right)$.

La impregnación a vacío permite la incorporación de forma controlada de solutos en la estructura matricial de un alimento poroso modificando convenientemente su composición original sin prácticamente afectar a su estructura. Como no requiere de la utilización de altas temperaturas se minimiza el daño a los tejidos vegetales y se preserva mejor el color, el sabor y los aromas naturales. Es por esto que esta tecnología ha sido ampliamente utilizada como pretratamiento antes del secado, la congelación y la fritura (Bolin \& Huxsoll, 1993). También se ha observado que la impregnación a vacío es efectiva en la prevención del pardeamiento oxidativo de las frutas debido a la eliminación del oxígeno de los poros (Alzamora et al., 2000; Barbosa-Cánovas \& Vega-Mercado, 1996). Además, la posibilidad de incluir en la estructura matricial de un alimento poroso compuestos fisiológicamente activos ha establecido a la impregnación a vacío como una técnica eficaz en el diseño de nuevos productos. El hecho de que los componentes fisiológicamente activos estén incluidos en la matriz estructural puede suponer una protección de los mismos frente a las reacciones de deterioro, pero al mismo tiempo la nueva estructura desarrollada debe permitir su liberación en el momento y la forma adecuados para que el organismo pueda utilizarlos.

En este sentido es importante hacer hincapié en la importancia de la relación "estructura-propiedad". El efecto funcional de un alimento o compuesto depende de que el componente activo tenga acceso a la "diana" del organismo. Sin embargo, 
los alimentos son mezclas complejas de macro- y micro- componentes que ordenados forman una estructura determinada y que pueden atrapar al componente activo, modular su liberación y potenciar o inhibir su actividad (Chen et al., 2006; Chen \& Subirade, 2007). La matriz alimentaria en su estado inicial, después del almacenamiento o de la preparación culinaria puede tener una gran influencia en la actividad y la liberación de los componentes clave. La selección y el desarrollo de una matriz apropiada que mantenga el compuesto molecular activo hasta el momento del consumo y que libere este compuesto en el lugar apropiado del organismo, es un paso clave en el éxito de un alimento funcional. Aguilera, destacó en 2005 la importancia de la microestructura de los alimentos en los procesos agroalimentarios. Turgeon \& Rioux en 2011 revisaron el efecto de la matriz alimentaria sobre las propiedades nutricionales de carbohidratos, proteínas y lípidos determinando, entre otras cosas, que la viscosidad de la matriz alimentaria es determinante en el proceso de digestión y la organización de los componentes en una estructura afecta a la activación de determinadas enzimas que son clave no sólo en el proceso de digestión sino también en el proceso de absorción. De la misma manera, Ferrua et al. (2011) están llevando a cabo estudios para determinar el efecto de la matriz estructural sobre la liberación de los compuestos fisiológicamente activos en el estómago y la absorción de los mismos por el organismo. Como ejemplo, se ha demostrado que la eficacia de los esteroles vegetales difiere entre matrices siendo la incorporación de los mismos en la leche tres veces más efectiva que su incorporación en pan o cereales (Jones \& Jew, 2007). La pasta de trigo deshidratada a $180{ }^{\circ} \mathrm{C}$ presenta una menor digestibilidad que la deshidratada a $20{ }^{\circ} \mathrm{C}$ (después de un proceso de digestión in vitro con pepsina y pancreatina). Esto puede deberse a la formación de enlaces disulfito y a la agregación de proteínas que tiene lugar a elevadas temperaturas (Turgeon \& Rioux, 2011). Unas condiciones suaves en un proceso de extrusión (elevada humedad, tiempo de residencia bajo y baja temperatura) pueden mejorar la calidad nutricional de los alimentos observándose una mejor retención de aminoácidos y vitaminas así como una mejor digestibilidad de proteína y almidón (Singh et al., 2007).

Aunque durante los últimos años una gran cantidad de estudios han demostrado el efecto beneficioso del consumo de algunos componentes sobre la salud, hay un número creciente de autores que defienden que el consumo de alimentos completos puede suponer un beneficio mayor que el consumo del componente activo sólo en forma de cápsula o pastilla. El efecto de componentes fisiológicamente activos de forma individual difiere del efecto de su mezcla y está demostrado que los diversos nutrientes proporcionados por los productos alimenticios pueden tener un efecto sinérgico relevante. La hesperidina (el principal flavonoide del zumo de mandarina) es más eficaz cuando se administra en combinación con la vitamina C (Garg et al., 2001). La combinación de todos los componentes fisiológicamente activos presentes en las frutas y los vegetales son responsables de su elevada actividad antioxidante. Por ejemplo, la vitamina $\mathrm{C}$ de 
una manzana con piel contribuye con un $0.4 \%$ aproximadamente a la actividad antioxidante total de la misma (Eberhardt et al., 2000). Además, los compuestos presentes en alimentos raramente pueden producir toxicidad aunque se consuman grandes cantidades del alimento en sí, sin embargo en las cápsulas o pastillas que contienen componentes fisiológicamente activos se necesitan excipientes que acompañen al componente y que consumidos en grandes cantidades pueden resultar perjudiciales (Codoñer-Franch et al., 2010).

\subsection{Preocupaciones sociales - políticas - sanitarias que puedan encontrar una solución en los alimentos funcionales.}

Existen numerosas enfermedades que por su prevalencia preocupan a la sociedad y que están claramente relacionadas con la dieta y el modo de vida. Estas enfermedades pueden encontrar solución en los alimentos funcionales que de forma directa pueden contribuir a mejorar la salud pública de la población.

\subsubsection{Estrés oxidativo}

El estrés oxidativo se describe generalmente como un desequilibrio en los niveles netos de las especies reactivas oxigénicas (ROS) en relación con la capacidad antioxidante del organismo, que resulta en la acumulación de productos de oxidación. Este desequilibrio conduce a la desregulación celular, lo que altera la señalización celular y otras funciones celulares (Azzi, 2007). El estrés oxidativo se ha relacionado en diversos procesos patogénicos incluyendo enfermedades degenerativas, aterosclerosis e inflamación (Valko et al., 2007).

En las especies reactivas oxigénicas (ROS) se incluyen radicales libres como los radicales superóxido e hidroxilo, que son los radicales libres más tóxicos en los sistemas biológicos. También existen otras moléculas que no son técnicamente radicales libres pero que, sin embargo, son muy reactivas, como el peróxido de hidrógeno, que se forma cuando el radical superóxido acepta otro electrón y dos iones de hidrógeno. Además, también cabe tener en cuenta a las especies reactivas de nitrógeno (RNS), entre las que se incluye el radical peroxinitrito que se forma al reaccionar el radical superóxido con el óxido nítrico.

Para un estado redox celular normal se necesitan bajas concentraciones de ROS y RNS. Estas especies intervienen en la regulación de diversas actividades y funciones celulares como la señalización intracelular, la diferenciación celular, la activación de vías metabólicas específicas y la inmunidad (Manea, 2010). La fisiología normal requiere de una producción y una disponibilidad de ROS y RNS cuidadosamente regulada (Codoñer-Franch et al., 2011). Si los sistemas antioxidantes no inactivan el exceso de ROS, las especies reactivas oxigénicas pueden interactuar con un gran número de moléculas, causando al final del proceso, un daño celular irreversible. Las especies reactivas oxigénicas pueden reaccionar: con los lípidos poliinsaturados de las membranas celulares provocando 
una pérdida de fluidez y una lisis celular debida a la peroxidación lipídica (Andresen et al., 2008); con la molécula del colesterol produciendo hidroperóxidos de colesterol y óxidos de colesterol que están implicados en la aterosclerosis y en enfermedades cardiovasculares (Valko et al., 2007); con los carbohidratos alterando funciones celulares como las relacionadas con las interleukinas y la formación de prostanglandinas, hormonas y neurotransmisores (Manea, 2010); con las proteínas y aminoácidos causando cambios en las funciones celulares y la fragmentación química, aumentando la susceptibilidad a un ataque proteolítico (Liu et al., 2006); con los ácidos nucleicos produciendo mutagénesis y carcinogénesis (Wang et al., 2010).

Todos los sistemas biológicos han desarrollado mecanismos para contrarrestar las consecuencias potencialmente perjudiciales de los oxidantes (Codoñer-Franch, 2011). La capacidad de la defensa antioxidante de una célula depende, de las enzimas que catalizan las reacciones oxidantes y de las moléculas con actividad antioxidante (Rizzo et al., 2011).

Los antioxidantes enzimáticos (Limón-Pacheco \& Gonsebatt, 2009) incluyen la superóxido dismutasa y los principales antioxidantes no enzimáticos incluyen los siguientes: el tripéptido (Glu-Cys-Gly) glutatión que es el antioxidante primario intracelular soluble en agua (Harvey et al., 2009); un conjunto de vitaminas, como el $\alpha$-tocoferol (Farbstein et al., 2010) y el ácido ascórbico (Valdecantos et al., 2010); otros fitoquímicos como los carotenoides (Demmig-Adams \& Adams, 2010) y los flavonoides (Benavente-García \& Castillo, 2008) proporcionados a través de la dieta y otros antioxidantes endógenos como la albúmina, el ácido úrico y la bilirrubina que poseen una substancial actividad antioxidante in vivo.

No se conoce con exactitud la prevalencia del estrés oxidativo pero sí se sabe con certeza que las enfermedades con las que está relacionado son la primera causa de muerte en los países desarrollados. La inflamación, la infección, la radiación ultravioleta, el humo del tabaco, el estrés y una dieta desequilibrada pueden aumentar la producción de radicales libres y producir finalmente estrés oxidativo. El tratamiento está basado en terapias con antioxidantes. La dieta equilibrada forma parte importante del tratamiento ya que supone el aporte de componentes antioxidantes que pueden ayudar a regular el desequilibrio redox del organismo. Se han realizado numerosos estudios in vitro e in vivo que relacionan el consumo de alimentos o de componentes con actividad fisiológica con los parámetros indicadores del estrés oxidativo. La tabla 1.3 muestra algunos ejemplos de estudios realizados en los últimos años.

Tabla 1.3. Ejemplos de estudios relacionados con el estrés oxidativo en los últimos años.

\begin{tabular}{|c|c|c|c|}
\hline Ingredientes o alimentos & Tipo de estudio & Resultados & Referencia \\
\hline $\begin{array}{l}\text { Chocolate puro con alto } \\
\text { contenido en flavonoides }\end{array}$ & $\begin{array}{l}\text { Estudio in vivo en humanos } \\
\text { sanos. Consumo de } 50 \mathrm{~g} \text { de } \\
\text { chocolate puro al día } \\
\text { durante } 3 \text { semanas. }\end{array}$ & 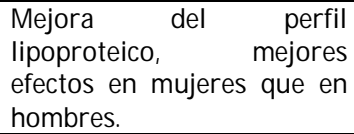 & Nanetti et al., 2012 \\
\hline Extracto de dátil. & $\begin{array}{l}\text { Estudio in vivo con animales } \\
\text { (ratas). Consumo de } 4 \\
\mathrm{ml} / \mathrm{kg} \text { de extracto al día } \\
\text { durante } 2 \text { meses. }\end{array}$ & $\begin{array}{l}\text { Disminución de la } \\
\text { hepatoxicidad y del daño } \\
\text { celular en hígado de rata } \\
\text { después de la exposición al }\end{array}$ & Saafi et al., 2011 \\
\hline
\end{tabular}




\begin{tabular}{|c|c|c|c|}
\hline & & dimetoato. & \\
\hline $\begin{array}{l}\text { Quercetina e isoflavona } \\
\text { biochanina A }\end{array}$ & $\begin{array}{l}\text { Estudio in vitro utilizando } \\
\text { células humanas del epitelio } \\
\text { pigmentario de la retina a } \\
\text { nivel de expresión génica. }\end{array}$ & $\begin{array}{l}\text { Protección de la quercetina } \\
\text { frente a la muerte cellular } \\
\text { debido al estrés oxidative } \\
\text { inducido, la biochanina no } \\
\text { tuvo un efecto protector } \\
\text { estadísticamente } \\
\text { significativo frente a la } \\
\text { degeneración macular. }\end{array}$ & Saviranta et al., 2011 \\
\hline $\begin{array}{l}\text { Lactobacillus casei y } \\
\text { Lactobacillus reuteri }\end{array}$ & $\begin{array}{l}\text { Estudio in vivo con animales } \\
\text { (ratas). Consumo de } \\
10 \mathrm{ml} / \mathrm{kg} \text { de una suspension } \\
\text { de lactobacillus al día } \\
\left(10^{11} \mathrm{CFU} / \mathrm{ml}\right) \text { durante } 4 \\
\text { semanas. }\end{array}$ & $\begin{array}{l}\text { Mejora significativa de } \\
\text { todos los parámetros } \\
\text { bioquímicos y de la } \\
\text { histología del hígado en } \\
\text { frente al estrés oxidativo } \\
\text { inducido con aflatoxinas. }\end{array}$ & Hathout et al., 2011 \\
\hline Hesperidina & $\begin{array}{l}\text { Estudio in vitro con células } \\
\text { hepáticas humanas (cepa } \\
\text { L02). }\end{array}$ & $\begin{array}{l}\text { Prevención del daño celular } \\
\text { aumentando las defensas } \\
\text { antioxidantes. Mejora de los } \\
\text { parámetros indicadores del } \\
\text { estrés oxidativo los ROSy la } \\
\text { peroxidación lipídica. }\end{array}$ & Chen et al., 2010 \\
\hline Licopeno & $\begin{array}{l}\text { Estudio in vivo en humanos. } \\
\text { Consumo de } 0 \text { a } 30 \mathrm{mg} \text { de } \\
\text { licopeno al día durante } 8 \\
\text { semanas. }\end{array}$ & $\begin{array}{l}\text { Las dosis más altas } \\
\text { disminuyeron el daño al } \\
\text { DNA y los marcadores 8- } \\
\text { OHdGen la orina. }\end{array}$ & Devaraj et al., 2008 \\
\hline Aceite de oliva & $\begin{array}{l}\text { Estudio in vivo en humanos. } \\
\text { Consumo de } 25 \mathrm{ml} \text { a } 70 \mathrm{~g} \text { de } \\
\text { aceite de olive desde } 4 \text { días } \\
\text { hasta } 8 \text { semanas. }\end{array}$ & $\begin{array}{l}\text { Reducción del daño } \\
\text { oxidativo a lípidos y a ADN. }\end{array}$ & Fitó et al., 2007 \\
\hline Antocianinas & $\begin{array}{l}\text { Estudio in vitro con células } \\
\text { hepaticas de ratas a las que } \\
\text { se ha inducido un estrés } \\
\text { oxidativo. }\end{array}$ & $\begin{array}{l}\text { Aumento de la capacidad } \\
\text { antioxidante y de las } \\
\text { defensas antioxidantes } \\
\text { frente a la programación de } \\
\text { la muerte celular inducida } \\
\text { mediante } \mathrm{H}_{2} \mathrm{O}_{2} \text {. }\end{array}$ & Shih et al., 2007 \\
\hline Tomate y licopeno & $\begin{array}{l}\text { Estudio in vivo en humanos. } \\
\text { Consumo de } 0 \text { a } 40 \mathrm{mg} \text { de } \\
\text { licopeno al día durante } 1 \text { a } \\
12 \text { semanas. }\end{array}$ & \begin{tabular}{lcr} 
Disminución & de & los \\
marcadores del & estrés \\
oxidativo y y de & de \\
carcinogénesis en humanos \\
sanos, pacientes & con \\
diabetes tipo 2 y pacientes \\
\multicolumn{2}{l}{ con cáncer de próstata. }
\end{tabular} & Basu \& Imrhan, 2007 \\
\hline Tomate y ajo & $\begin{array}{l}\text { Estudio in vivo con animales } \\
\text { (ratones). Consumo de } 500 \\
\mathrm{mg} \text { de tomate/ } \mathrm{kg} \text { y } \\
125 \mathrm{mg} / \mathrm{kg} \text { de ajo durante } 5 \\
\text { días. }\end{array}$ & $\begin{array}{l}\text { Efectos significativos frente } \\
\text { al estrés oxidativo inducido } \\
\text { mediante DMBA. }\end{array}$ & Bhuvaneswari et al., 2004 \\
\hline Quercetina y vitamina C & $\begin{array}{l}\text { Estudio in vitro en células } \\
\text { PC12. }\end{array}$ & $\begin{array}{l}\text { Aumento de la viabilidad } \\
\text { celular y reducción del daño } \\
\text { a la membrana en células } \\
\text { neuronales. }\end{array}$ & $\begin{array}{l}\text { Ho Jin Heo and Chang Yong } \\
\text { Lee. } 2004\end{array}$ \\
\hline
\end{tabular}

En algunos casos, los estudios se realizan en individuos sanos pero en otros, principalmente en los estudios in vitro e in vivo con animales, se utilizan modelos prooxidantes y se observa el efecto del alimento 0 del componente fisiológicamente activo sobre los parámetros indicadores del estrés oxidativo inducido. Estos modelos permiten estudiar toxicidades concretas y graves producidas en el organismo por el tratamiento de una enfermedad grave como el cáncer pero debe tenerse en cuenta que los compuestos oxidantes administrados generan cantidades de radicales libres mucho mayores que las que normalmente pueden producirse en el organismo. Además se ha visto en muchos casos que la capacidad del organismo para captar y utilizar los compuestos antioxidantes difiere según se ha inducido o no el estrés oxidativo. 


\subsubsection{Enfermedades cardiovasculares - colesterolemia}

El colesterol es un regulador esencial de la membrana celular, un precursor necesario para la síntesis de ácidos biliares y un sustrato para la síntesis de hormonas esteroides incluyendo el estrógeno y el andrógeno. La vitamina D se forma a partir de un derivado del colesterol, el 7-dehidrocolesterol. El colesterol no es un elemento esencial de la dieta porque el organismo es capaz de sintetizarlo. Es insoluble en agua y se transporta a los tejidos a través de la sangre mediante cuatro lipoproteínas: los quilomicrones $(\mathrm{CM})$, las lipoproteínas de muy baja densidad (VLDL), las lipoproteínas de baja densidad (LDL) y las proteínas de alta densidad (HDL). Los quilomicrones CM se forman en los vasos linfáticos intestinales y transportan el colesterol dietético y los triglicéridos TG desde el intestino al tejido adiposo y los músculos esqueléticos (Brown et al., 1983). Las lipoproteínas de muy baja densidad VLDL se producen en el hígado y transportan los triglicéridos recién sintetizados desde el hígado al tejido adiposo y a los músculos esqueléticos. Las lipoproteínas de baja densidad LDL, el mayor transportador del colesterol en sangre, se forman en el plasma cuando las lipoproteínas de densidad intermedia adquieren ésteres de colesterol de las lipoproteínas de alta densidad HDL (Walker, 1994). Las LDL proporcionan colesterol a los tejidos que lo necesitan. Las HDL eliminan el colesterol excesivo de los tejidos periféricos al hígado y juega un papel importante en el mantenimiento de la homeostasis del colesterol en el plasma.

La hipercolesterolemia es la presencia de elevadas cantidades de colesterol en sangre. No puede considerarse una patología sino un desajuste metabólico que se debe a las anormalidades en los niveles de lipoproteínas. La hipercolesterolemia es uno de los principales factores de riesgo cardiovascular y tiene un claro papel causal en el inicio y la progresión de la aterosclerosis. Dichas enfermedades son la causa más común de muerte en los países industrializados y en numerosos países en vías de desarrollo (Ministerio de Sanidad y Consumo, 2000).

Las tablas 1.4 y 1.5 muestran los límites establecidos de colesterol en adultos y niños respectivamente.

Tabla 1.4. Valoración de los niveles de colesterol en adultos.

\begin{tabular}{cccc}
\hline Categoría & $\begin{array}{c}\text { Colesterol total } \\
\text { (mg/ dl) }\end{array}$ & $\begin{array}{c}\text { LDL-colesterol } \\
\text { (mg/ dl) }\end{array}$ & $\begin{array}{c}\text { HDL-colesterol } \\
\text { (mg/ dl) }\end{array}$ \\
\hline Aceptable & $<200$ & $>130$ & $>35$ \\
En los límites & $200-239$ & $130-159$ & \\
Elevado & $\geq 240$ & $\geq 160$ & $<35$ \\
\hline
\end{tabular}

Tabla 1.5. Valoración de los niveles de colesterol total y LDL-c en niños y adolescentes

\begin{tabular}{ccc}
\hline Categoría & Colesterol total (mg/ dl) & LDL-colesterol (mg/ dl) \\
\hline Aceptable & $<170$ & $<110$ \\
En los límites & $170-199$ & $110-129$ \\
Elevado & $\geq 200$ & $\geq 130$ \\
\hline
\end{tabular}


La prevalencia de la hipercolesterolemia en la población española es alta. En personas de 35 a 64 años de edad, el 18\% (18.6\% en los varones y el $17.6 \%$ en las mujeres) tiene una colesterolemia igual o superior a $250 \mathrm{mg} / \mathrm{dl}$ y el $57.8 \%$ (56.7\% en los varones y el $58.6 \%$ en las mujeres) igual o superior a $200 \mathrm{mg} / \mathrm{dl}$. En la edad escolar un 22\% presenta valores de colesterol superiores a $200 \mathrm{mg} / \mathrm{dl}$ (Banegas et al., 1993).

En la actualidad existen cuatro clases de fármacos que modifican el metabolismo de las lipoproteínas: las estatinas (lovastatina, pravastatina, simvastatina, fluvastatina, atorvastatina y cerivastatina), los secuestradores de ácidos biliares (colestiramina, colestipol y colesevelam), el ácido nicotínico y los derivados del ácido fíbrico (gemfibrozilo, fenofibrato y clofibrato). Las estatinas son los fármacos de elección en el tratamiento de la hipercolesterolemia. Son los hipolipemiantes con mayor capacidad para descender el LDL. También producen, aunque en menor grado, una elevación del HDL y tienen buena tolerancia. Las resinas de intercambio iónico y los fibratos son fármacos de segunda elección, siendo útiles en las personas con intolerancia o contraindicación a las estatinas aunque pueden elevar los triglicéridos y producen con frecuencia intolerancia digestiva. Los fibratos son los hipolipemiantes que más descienden los triglicéridos y más elevan el $\mathrm{HDL}$, aunque tiene menos efecto descendiendo el LDL, y se toleran bien. La indicación del tratamiento farmacológico y el establecimiento del objetivo terapéutico se lleva a cabo tras la valoración global del paciente, prestando atención a su edad, sexo, riesgo familiar y presencia de otros factores de riesgo cardiovascular. La hipercolesterolemia es uno de los principales factores de riesgo cardiovascular modificables, por lo que unido al tratamiento farmacológico no se deben olvidar las medidas relacionadas con el estilo de vida, fundamentalmente la dieta y la actividad física (Ministerio de Sanidad y Consumo, 2000).

En los niños y adolescentes con colesterolemia elevada que tienen una mayor probabilidad de presentar una hipercolesterolemia en la edad adulta y en aquellos pacientes cuyo nivel de colesterol es alto pero no requiere la prescripción de medicamentos reductores del colesterol resulta interesante la utilización de alimentos funcionales como medida de prevención. En la tabla 1.6 se muestran algunos estudios en los que se muestra el efecto sobre el colesterol que puede provocar el consumo de determinados alimentos o componentes fisiológicamente activos.

Tabla 1.6. Efecto sobre el colesterol del consumo de determinados alimentos o componentes fisiológicamente activos (Adaptado de Chen et al., 2008).

\begin{tabular}{|c|c|c|c|}
\hline Ingredientes & Tipo de estudio & $\begin{array}{c}\text { Resultados } \\
\end{array}$ & Referencia \\
\hline \multirow{4}{*}{ Esteroles vegetales } & $\begin{array}{l}\text { Estudio in vivo con animales } \\
\text { (ratones). }\end{array}$ & $\begin{array}{l}\text { Inhibición de la absorción } \\
\text { de cholesterol en el lumen } \\
\text { intestinal. }\end{array}$ & Plösch et al. 2006 \\
\hline & $\begin{array}{l}\text { Estudio in vivo con animales } \\
\text { (cerdos de guinea). }\end{array}$ & $\begin{array}{l}\text { Inhibición de la absorción } \\
\text { de cholesterol y } \\
\text { disminución de los niveles } \\
\text { en plasma cLDL. }\end{array}$ & Ramjiganesh et al., 2001 \\
\hline & $\begin{array}{l}\text { Estudio in vivo con animales } \\
\text { (hamsters). }\end{array}$ & $\begin{array}{l}\text { Prevención en el desarrollo } \\
\text { de foam cells en la aorta. }\end{array}$ & Ntanios et al., 2003 \\
\hline & Estudio in vivo en humanos & Reducción del contenido en & Becker et al., 1993 \\
\hline
\end{tabular}




\begin{tabular}{|c|c|c|c|}
\hline & $\begin{array}{l}\text { (niños). Consumo } \text { de } \\
\text { sitoesteroles } 6 \mathrm{~g} \text { al día } \\
\text { durante } 3 \text { meses seguido del } \\
\text { consumo de } 1.5 \mathrm{~g} \text { de } \\
\text { sitostanol durante } 7 \text { meses. }\end{array}$ & $\begin{array}{l}\text { cLDL un } 20 \% \text { e inhibición } \\
\text { de la absorción del } \\
\text { colesterol. }\end{array}$ & \\
\hline & $\begin{array}{l}\text { Estudio in vivo en humanos. } \\
\text { Consumo de margarina } \\
\text { enriquecida en esteroles } \\
\text { vegetales. }\end{array}$ & $\begin{array}{l}\text { Reducción del cholesterol } \\
\text { total en sangre, de la cLDL y } \\
\text { de la apoliproteina B un } 7 \text { - } \\
10 \% \text {. }\end{array}$ & Temme et al., 2002 \\
\hline & $\begin{array}{l}\text { Estudio in vivo en humanos. } \\
\text { Consumo de margarina } \\
\text { enriquecida en esteroles } \\
\text { vegetales. }\end{array}$ & $\begin{array}{l}\text { Reducción del cholesterol } \\
\text { total y del cLDL en } \\
\text { voluntarios con niveles de } \\
\text { colesterol normales y } \\
\text { medianamente elevados. }\end{array}$ & $\begin{array}{l}\text { Weststrate,J. A.; Meijer, } \\
1998\end{array}$ \\
\hline & $\begin{array}{l}\text { Estudio in vivo en humanos. } \\
\text { Consumo de } 2 \mathrm{~g} \text { al día. }\end{array}$ & Reducción del cLDL un 10\%. & Kantan et al., 2003 \\
\hline & $\begin{array}{l}\text { Estudio in vivo con animales } \\
\text { (ratones). Consume de } \\
\text { isoflavonas de soja. }\end{array}$ & $\begin{array}{l}\text { Reducción del cholesterol } \\
\text { en plasma y aumento de la } \\
\text { actividad del receptor LDL. }\end{array}$ & Owen et al., 2004 \\
\hline Fitoestrógenos & $\begin{array}{l}\text { Estudio in vivo en humanos. } \\
\text { Consumo de isoflavonas de } \\
\text { soja. }\end{array}$ & $\begin{array}{l}\text { Resultados inconsistentes. } \\
\text { Algunos estudios indican } \\
\text { reducción del colesterol } \\
\text { total en plasma y del cLDLD } \\
\text { en pacientes } \\
\text { hipercolesterolémicos } \\
\text { mientras que otros studios } \\
\text { no muestran diferencias en } \\
\text { los niveles de cholesterol en } \\
\text { sangre. }\end{array}$ & $\begin{array}{l}\text { Lichtenstein et al., 2002; } \\
\text { Steinberg et al., } 2003\end{array}$ \\
\hline \multirow{7}{*}{ Policosanol } & $\begin{array}{l}\text { Estudio in vitro. Incubación } \\
\text { de policosanol con células } \\
\text { de fibroblastos. }\end{array}$ & $\begin{array}{l}\text { Reducción del cholesterol } \\
\text { en plasma. Inhibición de la } \\
\text { HMG-CoA reductasa. } \\
\text { Aumento de la actividad del } \\
\text { receptor LDL e inhibición de } \\
\text { la absorción de ácidos } \\
\text { biliares. }\end{array}$ & Ng et al., 2005 \\
\hline & $\begin{array}{l}\text { Estudio in vivo con animales } \\
\text { (monos). Consumo de } 0.25 \mathrm{a} \\
25 \mathrm{mg} \text { de policosanol/ } \mathrm{kg} \text { al } \\
\text { día durante } 54 \text { semanas. }\end{array}$ & $\begin{array}{l}\text { Reducción de los niveles de } \\
\text { colesterol en sangre. }\end{array}$ & $\begin{array}{l}\text { Rodríguez-Echenique et al., } \\
1994\end{array}$ \\
\hline & $\begin{array}{l}\text { Estudio in vivo con animales } \\
\text { (Conejos). Consumo de } 5 \\
\mathrm{mg} / \mathrm{kg} \text { al día. }\end{array}$ & $\begin{array}{l}\text { Reducción del cholesterol } \\
\text { total en plasma un } 29 \% \text { del } \\
\text { cLDL un } 43 \% \text { y aumento del } \\
\text { cHDL un } 15 \% \text { sin afectar al } \\
\text { TG. }\end{array}$ & Gamez et al., 2005 \\
\hline & $\begin{array}{l}\text { Estudio in vivo con animales } \\
\text { (hamsters). Consumo de } 0 \mathrm{a} \\
1.5 \mathrm{mg} / \mathrm{kg} \text { al día. }\end{array}$ & $\begin{array}{l}\text { Reducción del cholesterol } \\
\text { total en un } 15-25 \% \text { y } \\
\text { aumento del cHDL en un } 7- \\
17 \% \text {. }\end{array}$ & Ng, et al., 2005 \\
\hline & $\begin{array}{l}\text { Estudio in vivo en humanos. } \\
\text { Dosis de } 5 \text { a } 40 \text { mg al día. }\end{array}$ & $\begin{array}{l}\text { Reducción del cholesterol } \\
\text { total, del cLDL en } 16-27 \% \text { y } \\
\text { aumento del cHDL en un } 17 \\
\text { en pacientes } \\
\text { hipercolesterolémicos tipo } \\
2 . \text {. }\end{array}$ & $\begin{array}{l}\text { Castaño et al., 2001; Castaño } \\
\text { et al., 2005; Más et al., 1999; } \\
\text { Alcocer et al., } 1999 .\end{array}$ \\
\hline & $\begin{array}{l}\text { Estudio in vivo en humanos. } \\
\text { Dosis de } 10 \mathrm{mg} / \text { día. }\end{array}$ & $\begin{array}{l}\text { Reducción de los niveles de } \\
\text { colesterol en plasma en un } \\
17.5 \% \text {, del cLDL en un } \\
21.8 \% \text { y aumento del cHDL } \\
\text { en un } 11.3 \% \text { en pacientes } \\
\text { hipercolesterolémicos con } \\
\text { diabetes mellitus no } \\
\text { insulino dependientes. }\end{array}$ & Torres et al., 1995 \\
\hline & $\begin{array}{l}\text { Estudio in vivo en humanos. } \\
\text { Dosis de } 10 \text { a } 20 \mathrm{mg} / \text { dia. }\end{array}$ & $\begin{array}{l}\text { Reducción del cholesterol } \\
\text { total en un } 17-21 \% \text {, del } \\
\text { cLDL en un } 21-29 \% \text { y } \\
\text { aumento del cHDL en un 8- } \\
15 \% \text {. }\end{array}$ & Gouni-Berthold et al., 2002 \\
\hline \multirow[t]{2}{*}{ Catequinas del té } & $\begin{array}{l}\text { Estudio in vitro. Incubación } \\
\text { de la epigallocatequin- } \\
\text { gallate con células hepáticas } \\
\text { HepG2. }\end{array}$ & $\begin{array}{l}\text { Aumento de la actividad del } \\
\text { receptor LDL de } 2 \text { a } 3 \text { veces. }\end{array}$ & Bursill and Roach, 2006 \\
\hline & $\begin{array}{l}\text { Estudio in vivo con animales } \\
\text { (ratas). Consumo de dietas }\end{array}$ & $\begin{array}{l}\text { Aumento de la actividad del } \\
\text { receptor LDL y de la }\end{array}$ & Bursill and Roach, 2007 \\
\hline
\end{tabular}




\begin{tabular}{|c|c|c|c|}
\hline & con un $2 \%$ de catequinas. & proteína de 2.7 a 3.4 veces. & \\
\hline & $\begin{array}{l}\text { Estudio in vivo con animales } \\
\text { (Conejos). Consumo de una } \\
\text { dieta hipercolesterolémica } \\
\text { enriquecida en catequinas. }\end{array}$ & $\begin{array}{l}\text { Regulación de la actividad } \\
\text { del receptor LDL y de } \\
\text { proteína un } 80 \% \text { y } 70 \% \\
\text { respectivamente. }\end{array}$ & Bursill et al., 2007 \\
\hline & $\begin{array}{l}\text { Estudio in vivo con animals } \\
\text { (hamsters). Consumo de } \\
\text { una dieta con un } 0.1 \% \text { de } \\
\text { cholesterol enriquecida en } \\
\text { catequinas. }\end{array}$ & $\begin{array}{l}\text { Reducción del cholesterol } \\
\text { total en plasma y de los } \\
\text { triglicéridos aumentando la } \\
\text { excreción de esteroles. }\end{array}$ & Chan et al., 1999 \\
\hline & $\begin{array}{l}\text { Estudio in vivo en humanos. } \\
\text { Consumo de catequinas en } \\
\text { té. }\end{array}$ & $\begin{array}{l}\text { Reducción de los niveles de } \\
\text { TC en plama y del cLDL en } \\
\text { japoneses y noruegos. }\end{array}$ & $\begin{array}{c}\text { Kono et al., 1992; Stensvold } \\
\text { et al., } 1992\end{array}$ \\
\hline & $\begin{array}{l}\text { Estudio in vivo en humanos. } \\
\text { Consumo de un extracto de } \\
\text { té con una dosis de } \\
\text { catequinas de } 375 \mathrm{mg} \text { al día. }\end{array}$ & $\begin{array}{l}\text { Reducción del TCy del cLDL } \\
\text { en pacientes con niveles de } \\
\text { cholesterol moderados y } \\
\text { altos. }\end{array}$ & Maron et al., 2003 \\
\hline \multirow{3}{*}{ Polifenoles de uva } & $\begin{array}{l}\text { Estudio in vivo en humanos. } \\
\text { Consumo de polvo de uva } \\
\text { liofilizada. }\end{array}$ & $\begin{array}{l}\text { Reducción del nivel de } \\
\text { colesterol LDL en plasma y } \\
\text { de las poliproteínas B y E. }\end{array}$ & Zern et al., 2005 \\
\hline & $\begin{array}{l}\text { Estudio in vivo en humanos } \\
\text { sanos y en pacientes de } \\
\text { hemodiálisis. Consumo de } \\
\text { zumo de uva tinta. }\end{array}$ & \begin{tabular}{llr}
\multicolumn{3}{l}{ Reducción del cLDL y de la } \\
concentración & de & la \\
apoliproteina & B-100 & y \\
aumento & de & la \\
concentración de cHDL y la \\
apoliproteína A-I.
\end{tabular} & Castilla et al., 2006 \\
\hline & $\begin{array}{l}\text { Estudio in vivo en humanos. } \\
\text { Consumo de zumo de uva } \\
\text { tinta. }\end{array}$ & $\begin{array}{l}\text { Reducción de la } \\
\text { susceptibilidad del LDL a la } \\
\text { oxidación y mejora de la } \\
\text { function endotelial. }\end{array}$ & $\begin{array}{c}\text { Stein et al., 1999; Nigdikar } \\
\text { et al., } 1998\end{array}$ \\
\hline \multirow{3}{*}{ Ajo } & $\begin{array}{l}\text { Estudio in vivo con animales } \\
\text { (ratas). Consumo de ajo } \\
\text { fresco y hervido. }\end{array}$ & $\begin{array}{l}\text { Reducción del TC y del TG. } \\
\text { El ajo fresco resultó más } \\
\text { efectivo que el hervido. }\end{array}$ & Thomson et al., 2006 \\
\hline & $\begin{array}{l}\text { Estudio in vivo con animales } \\
\text { (Conejos). Consumo de ajo } \\
\text { en polvo incorporado en la } \\
\text { dieta en un } 1 \% \text {. }\end{array}$ & $\begin{array}{l}\text { Disminución del nivel en } \\
\text { plasma del TC y cLDL y } \\
\text { aumento } \quad \text { de } \\
\text { concentración en cHDL. }\end{array}$ & Kwon et al., 2003 \\
\hline & $\begin{array}{l}\text { Estudio in vivo en humanos. } \\
\text { Consumo de ajor fresco. }\end{array}$ & $\begin{array}{l}\text { Reducción del colesterol en } \\
\text { sangre. }\end{array}$ & $\begin{array}{l}\text { Stevinson et al., 2000; Alder } \\
\text { et al., } 2003\end{array}$ \\
\hline \multirow{3}{*}{ Trigo } & 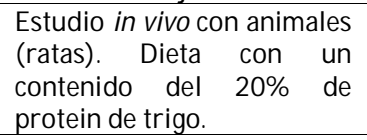 & $\begin{array}{l}\text { Reducción de los niveles de } \\
\text { colesterol en sangre. }\end{array}$ & Tomotake et al., 2007 \\
\hline & $\begin{array}{l}\text { Estudio in vivo con animales } \\
\text { (hamsters). Consumo de } \\
\text { una dieta } \\
\text { hipercolesterolémica } \\
\text { enriquecida en proteína de } \\
\text { trigo y brotes de trigo. }\end{array}$ & $\begin{array}{l}\text { Reducción del TC en plasma } \\
\text { y del TC/ cHDL and } \\
\text { cLDL/ cHDL. }\end{array}$ & $\begin{array}{l}\text { Tomotake et al., 2000; Lin et } \\
\text { al., } 2008\end{array}$ \\
\hline & $\begin{array}{l}\text { Estudio in vivo en humanos. } \\
\text { Consumo de } 100 \mathrm{~g} \text { de trigo al } \\
\text { día. }\end{array}$ & $\begin{array}{l}\text { Reducción del nivel de TC y } \\
\text { del cLDL. }\end{array}$ & He et al., 1995 \\
\hline \multirow{4}{*}{ Bayas rojas } & $\begin{array}{l}\text { Estudio in vivo con animales } \\
\text { (Conejos). Consumo de una } \\
\text { dieta hipercolesterolémica } \\
\text { enriquecida al } 2 \% \text { en polvo } \\
\text { de bayas rojas. }\end{array}$ & $\begin{array}{l}\text { Reducción del TC en sangre } \\
\text { un } 23 \% \text { y de los niveles de } \\
\text { TG en sangre un } 22 \% .51 \% \\
\text { menos acumulación de } \\
\text { colesterol en la aorta. }\end{array}$ & Zhang et al., 2002b \\
\hline & $\begin{array}{l}\text { Estudio in vivo en animales } \\
\text { (hamsters). Consumo en la } \\
\text { dieta del } 0.5 \% \text { de un } \\
\text { extracto de las bayas rojas. }\end{array}$ & $\begin{array}{l}\text { Reducción del TC en plasma } \\
\text { un } 10 \% \text { y del TG un } 13 \% .\end{array}$ & Zhang et al., 2002a \\
\hline & $\begin{array}{l}\text { Estudio in vivo en humanos. } \\
\text { Consumo de una bebida a } \\
\text { base de zumo de bayas } \\
\text { rojas. }\end{array}$ & $\begin{array}{l}\text { Reducción del TC, TG y de la } \\
\text { apo-B en un 15, } 10 \text { y } 8 \% \\
\text { respectivamente. }\end{array}$ & Chen et al., 1995 \\
\hline & $\begin{array}{l}\text { Estudio in vivo en humanos. } \\
\text { Consumo de } 250 \text { mL de una } \\
\text { bebida de bayas rojas } 3 \\
\text { veces al día durante } 4 \\
\text { semanas. }\end{array}$ & $\begin{array}{l}\text { Reducción del TC en un } 7.8 \\
\% \text { y del cLDL en un } 12.4 \% \text {. }\end{array}$ & Ho et al., 2003 \\
\hline Vitamina C & $\begin{array}{l}\text { Estudio in vivo en humanos. } \\
\text { Consumo de } 1 \text { a } 5 \mathrm{~g} \text { de } \\
\text { vitamina C al día durante } 2 \text { - } \\
12 \text { semanas. }\end{array}$ & $\begin{array}{l}\text { Reducción del cholesterol } \\
\text { en } \\
\text { hipercolesterolémicos. }\end{array}$ & McRae, 2006 \\
\hline
\end{tabular}




\begin{tabular}{|c|c|c|c|}
\hline Zumo de mandarina & $\begin{array}{l}\text { Estudio in vivo en humanos. } \\
\text { Consumo de } 500 \mathrm{ml} \text { de } \\
\text { zumo durante } 28 \text { días. }\end{array}$ & $\begin{array}{l}\text { Regular ingestion of } \\
\text { mandarin juice significantly } \\
\text { reduce plasma biomarkers } \\
\text { of lipid and protein } \\
\text { oxidation and enhances the } \\
\text { antioxidant status of } \\
\text { consumers. }\end{array}$ & Codoñer- Franch et al., 2008 \\
\hline Naringina & $\begin{array}{l}\text { Estudio in vivo con animales } \\
\text { (Conejos). } \\
\text { hipercolesterolémica } \\
\text { suplementada con } 0.05 \% \text { de } \\
\text { naringina o } 0.03 \% \text { de } \\
\text { lovastatina durante } 8 \\
\text { semanas. }\end{array}$ & $\begin{array}{l}\text { Disminución del TC y cLDL } \\
\text { aumentando el cHDL/TC. } \\
\text { Preservación de los daños } \\
\text { inducidos en la morfología } \\
\text { de los tejidos por una dieta } \\
\text { alta en colesterol. }\end{array}$ & Seon-Min et al., 2004 \\
\hline
\end{tabular}

En este caso ya se han desarrollado alimentos funcionales que se comercializan en el mercado (Benecol ${ }^{\circledR}$, Danacol ${ }^{\circledR}$, Naturcol ${ }^{\circledR}$, Flora Pro-Activ ${ }^{\circledR} .$. ) generalmente por empresas multinacionales. La mayoría de ellos contienen esteroles vegetales. En todos los casos, están dirigidos a colectivos con un nivel de colesterol elevado pero que no necesitan de un tratamiento farmacológico y las campañas publicitarias recomiendan junto con el producto, el consumo de una dieta saludable con abundantes frutas y verduras. La mayoría son productos líquidos, leche, yogures pero también untables y productos sólidos como los cereales. En todos los casos son productos destinados a ser consumidos durante el desayuno lo que los hace fácilmente incorporables a la dieta habitual. Es más fácil incorporar un único alimento que modificar toda la dieta. Aunque podrían obtenerse mejores resultados si se produjera un cambio total en la dieta, con este tipo de productos pueden obtenerse resultados positivos ya que la mayoría de los estudios in vivo en humanos se han llevado a cabo con individuos que seguían una dieta hipercolesterolémica.

\subsubsection{Obesidad en niños y adolescentes}

La obesidad es una enfermedad crónica de origen multifactorial que se caracteriza por la acumulación excesiva de grasa o la hipertrofia general del tejido adiposo en el cuerpo. La causa de la obesidad es el desequilibrio energético, cuando la ingesta de calorías supera el gasto, el exceso se almacena en el organismo en forma de grasa. Existen multitud de factores que contribuyendo a un mayor consumo y a una disminución del gasto energético son responsables de la obesidad. Entre ellos destacan: disminución de los niveles de trabajo físico, aumento del consumo de alimentos con una mayor densidad energética y factores sociales, económicos, educativos y culturales cuya relación es compleja y que varían enormemente según el país.

El método más ampliamente utilizado para medir e identificar la obesidad es el índice de masa corporal (IMC $=\mathrm{kg} / \mathrm{m}^{2}$ ). Se considera sobrepeso cuando el IMC se encuentra en niveles de 25 a $29.9 \mathrm{~kg} / \mathrm{m}^{2}$ y se considera obesidad cuando el IMC es mayor o igual $30 \mathrm{~kg} / \mathrm{m}^{2}$. Estos umbrales del IMC fueron propuestos por los expertos de la Organización Mundial de la Salud (OMS) y reflejan el riesgo creciente para la salud del exceso de peso a medida que aumenta el IMC por 
encima de un rango óptimo de $21-23 \mathrm{~kg} / \mathrm{m}^{2}$ para adultos de raza caucásica (WHO/ NUT/ NCD, 2000). La relación entre la obesidad y los riesgos para la salud varían entre las diferentes poblaciones. Por ejemplo, los asiáticos son más susceptibles y por tanto, los umbrales de riesgo en el IMC son más bajos que para otras poblaciones. En estos casos, el sobrepeso se define a los $23 \mathrm{~kg} / \mathrm{m}^{2}$.

Si bien el IMC es una medida simple que puede resultar en ocasiones muy útil, debe considerarse una guía aproximada para predecir el riesgo de enfermedad. La distribución y cantidad de grasa del cuerpo también son cruciales para determinar los riesgos asociados con la obesidad. La grasa visceral, sobretodo en la región abdominal, está fuertemente asociada con la diabetes tipo 2 y con el riesgo cardiovascular. En consecuencia, las medidas como la relación cintura/ cadera y la circunferencia de la cintura proporcionan índices más robustos de riesgo para la salud que el IMC sólo (International Association for the Study of Obesity, 2012).

La obesidad es una causa importante de discapacidad y muerte prematura (WHO, 2004). La obesidad aumenta el riesgo de una amplia gama de enfermedades crónicas. El IMC se considera que representa alrededor del $60 \%$ del riesgo de desarrollar diabetes tipo 2, más del $20 \%$ de padecer enfermedades cardiovasculares y entre el 10 y el 30\% para diversos tipos de cáncer. Otras morbilidades incluyen la vesícula biliar, hígado graso, apnea del sueño y osteoartritis.

El sobrepeso y la obesidad son el riesgo principal de defunción a nivel mundial. Al menos 2.8 millones de adultos mueren cada año como consecuencia de tener sobrepeso u obesidad. La figura 1.2 muestra las muertes atribuidas a los 19 factores de riesgo principales (WHO Global Health Risks Report, 2004).

Las estimaciones globales de la OMS en el 2008 determinaron que 1.5 billones de adultos mayores de 20 años tenían sobrepeso y de esos 1.5 billones de adultos con sobrepeso, más de 200 millones de hombres y cerca de 300 millones de mujeres eran obesos. En total, más de uno de cada diez de la población adulta del mundo eran obesos. En la Unión Europea de los 27, aproximadamente el 60 \% de los adultos tenían sobrepeso o son obesos (WHO, 2007).

La obesidad infantil ya es común en los países desarrollados, aunque está aumentando también en los países en vías de desarrollo, sobretodo alrededor de las zonas urbanas. En el año 2004, de acuerdo con los criterios de la International Obesity TaskForce (IOTF), se estimó que el 10\% de los niños en todo el mundo de entre 5 y 17 años tenían sobrepeso y que el 2.3\% eran obesos (Lobstein et al., 2004). Las tasas de prevalencia varían considerablemente entre las diferentes regiones y países, de menos del $5 \%$ en África y partes de Asia a más del $20 \%$ en Europa y más del 30\% en América y algunos países de Oriente Medio. 


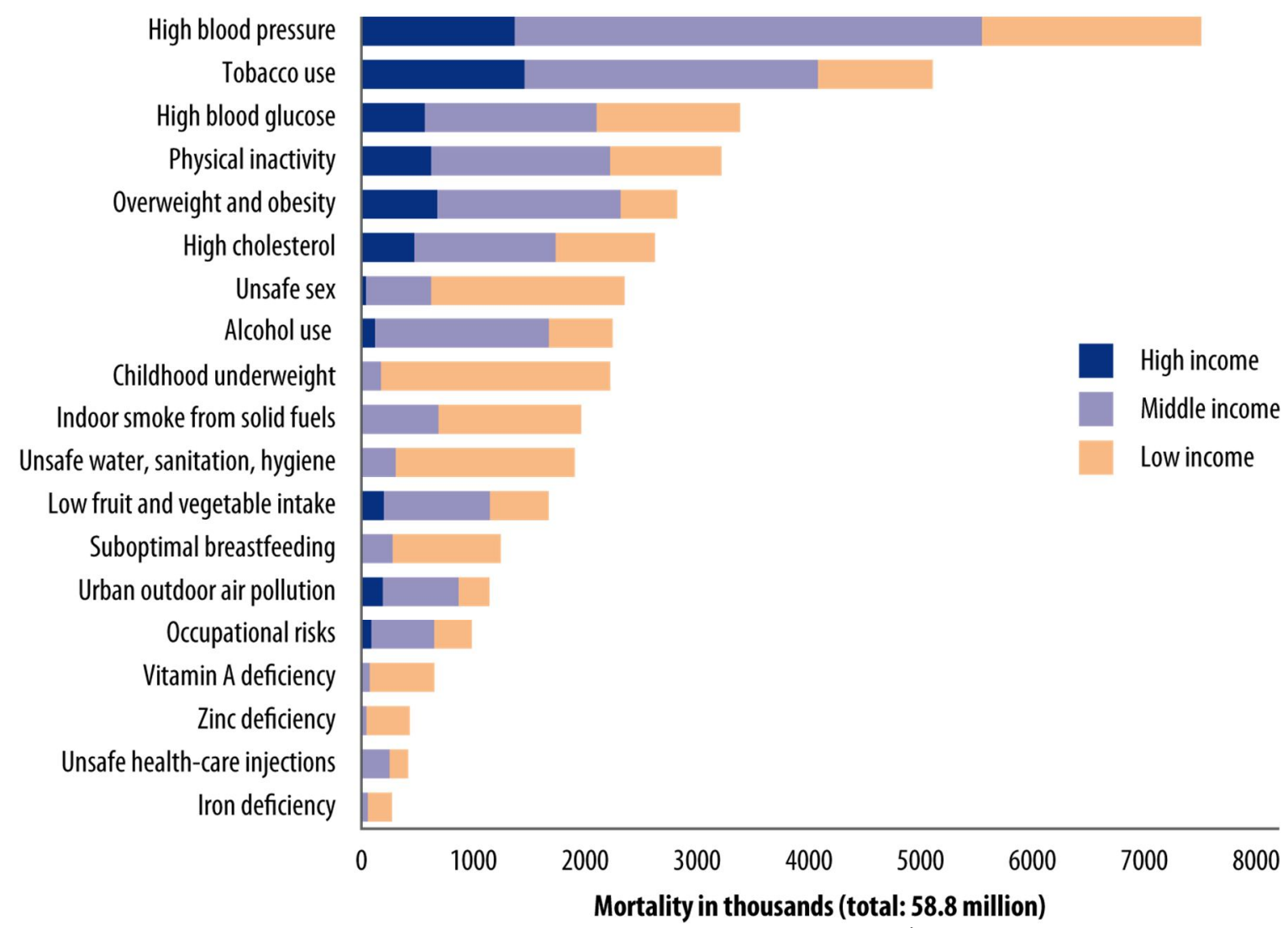

Figura 1.2. Muertes atribuidas a los 19 factores de riesgo principales (Fuente: WHO Global Health Risk Report, 2004)

Convertirse en obesos a edades cada vez más tempranas aumenta los riesgos de padecer problemas de salud. La obesidad infantil se asocia con una mayor probabilidad de obesidad y discapacidad en la edad adulta así como con una muerte prematura. Pero además del riesgo futuro, los niños obesos experimentan dificultades para respirar, aumenta el riesgo de fracturas, hipertensión arterial, marcadores de enfermedad cardiovascular, resistencia a la insulina y efectos psicológicos.

La obesidad tiene importantes costes directos e indirectos para la sociedad que ponen a prueba los recursos sociales y sanitarios. Los costes médicos directos incluyen los servicios de prevención, diagnóstico y tratamiento relacionados con el sobrepeso y las morbilidades asociadas. Las naciones europeas gastan un $2.8 \%$ de sus presupuestos de salud en la obesidad, lo que equivale a un $0.6 \%$ del producto interior bruto (Müller-Riemenschneider et al., 2008). En los EE.UU las estimaciones basadas en los datos del 2008 indican que se gastaron por sobrepeso y obesidad 147 mil millones de dólares (Finkelstein et al., 2009). Aunque los costes indirectos pueden ser sustancialmente más altos, a menudo no se tienen en cuenta. Hacen referencia a la pérdida de ingresos debido a la disminución de la productividad, la reducción de oportunidades y la restricción de actividades, enfermedades, absentismo escolar y muerte prematura.

El sobrepeso y la obesidad así como sus enfermedades asociadas son en gran medida prevenibles. Un apoyo al entorno y las comunidades es fundamental para 
configurar las elecciones de la población, haciendo que la opción más saludable de alimentos y la actividad física regular sean la elección más fácil y por tanto la obesidad pueda prevenirse.

La industria alimentaria puede desempeñar un papel importante en la promoción de dietas saludables reduciendo el contenido en grasa, azúcar y sal de los alimentos procesados, garantizando que las opciones saludables y nutritivas sean accesibles y asequibles a todos los consumidores, realizando campañas publicitarias responsables, garantizando la disponibilidad de alimentos saludables y apoyando la práctica regular de actividad física en el lugar de trabajo.

Adoptada por la Asamblea Mundial de la Salud en 2004, la estrategia global de la OMS sobre la dieta, la actividad física y la salud describe las acciones necesarias para apoyar la alimentación sana y la actividad física regular. La estrategia pide a todas las partes interesadas que actúen a nivel mundial, regional y local para mejorar la alimentación y la actividad física de la población.

En España para combatir este problema el gobierno español desarrolló en 2005 una estrategia para promover el consumo de una dieta saludable y practicar actividad física. La Estrategia para la Nutrición, Actividad Física y Prevención de la Obesidad (NAOS), establece que el gobierno trabaje con la industria alimentaria para promover la producción y distribución de productos alimentarios y bebidas que contribuyan a una dieta más sana y equilibrada. Es probable que esta estrategia haya contribuido a aumentar la concienciación de los consumidores y que haya alentado a la industria alimentaria en la producción de productos más saludables.

Determinados componentes pueden ayudar a la pérdida de peso. La tabla 1.7 incluye algunos estudios in vivo en los que se ha analizado el efecto de un alimento o componente sobre el peso corporal.

Tabla 1.7. Estudios in vivo que analizan el efecto de un alimento o componente sobre el peso corporal.

\begin{tabular}{|c|c|c|c|}
\hline Ingrediente & Estudio & Resultados & Referencia \\
\hline $\begin{array}{l}\text { Epigalocatequina-3-gallate, } \\
\text { extracto de piel de naranja, } \\
\text { de té negro y cafeína, cada } \\
\text { componente sólo y } \\
\text { combinados }\end{array}$ & $\begin{array}{l}\text { Estudio in vivo con animales } \\
\text { (ratones). Consumo de } \\
\text { dietas con alto contenido } \\
\text { graso y 0.1\% EGCg, } 0.2 \% \\
\text { EPN, 0.2\% ETN and } 0.05 \mathrm{CF} \\
\text { solos y combinados durante } \\
10 \text { semanas }\end{array}$ & $\begin{array}{l}\text { Disminución del aumento } \\
\text { de peso y la formación de } \\
\text { tejido adiposo con el } \\
\text { consumo de extracto de } \\
\text { piel de naranja, el extracto } \\
\text { de té negro y la cafeína. }\end{array}$ & Huang et al., 2009 \\
\hline Polifenoles del lichi & $\begin{array}{l}\text { Estudio in vivo en humanos } \\
\text { que tenían una } \\
\text { circunferencia abdominal } \\
\text { mayor de } 85 \mathrm{~cm} \text {. Consumo } \\
\text { de } 200 \mathrm{mg} \text { de oligonol al día } \\
\text { durante } 10 \text { semanas. }\end{array}$ & $\begin{array}{l}\text { Disminución de los } \\
\text { parámetros indicadores del } \\
\text { peso corporal, la } \\
\text { circunferencia abdominal y } \\
\text { la grasa visceral. }\end{array}$ & Nishihira et al., 2009 \\
\hline Chitooligosacáridos & $\begin{array}{l}\text { Estudio in vivo con ratones. } \\
\text { Consumo en una dieta con } \\
\text { alto contenido en grasas de } \\
1 \text { a } 3 \% \text { de } \\
\text { chitooligosacáridos durante } \\
5 \text { meses. }\end{array}$ & $\begin{array}{l}\text { Los animales cuya dieta era } \\
\text { mayor en oligosacáridos } \\
\text { experimentaron un } 15 \% \\
\text { menos de ganancia de peso } \\
\text { que el resto. Mejora de los } \\
\text { parámetros marcadores de } \\
\text { la obesidad. }\end{array}$ & Choi et al., 2012 \\
\hline $\begin{array}{l}\text { Extracto de semillas de } \\
\text { granada }\end{array}$ & $\begin{array}{l}\text { Estudio in vivo con ratones. } \\
\text { Consumo de } 1 \mathrm{~g} \text { de extracto } \\
\text { por cada } 100 \mathrm{~g} \text { de dieta alta } \\
\text { en grasas durante } 78 \text { días. }\end{array}$ & $\begin{array}{l}\text { Reducción del peso corporal } \\
\text { y mejora de las } \\
\text { concentraciones de glucosa } \\
\text { e insulina en ayunas. }\end{array}$ & Vroegrijk et al., 2011 \\
\hline
\end{tabular}




\begin{tabular}{lllll}
\hline $\begin{array}{l}\text { Extracto de hojas } \\
\text { granada }\end{array}$ & de & $\begin{array}{l}\text { Estudio in vivo con ratones. } \\
\text { Consumo de } 800 \mathrm{mg} / \mathrm{kg} \text { de } \\
\text { extracto durante } 5 \text { días. }\end{array}$ & $\begin{array}{l}\text { Reducción del peso corporal } \\
\text { y de los niveles de colesterol } \\
\text { sérico, glucosa y del ratio } \\
\text { colesterol total/ HDL. }\end{array}$ & Lei et al., 2007 \\
\hline Zumo de granada & $\begin{array}{l}\text { Estudio in vivo con ratones } \\
\text { obesos. }\end{array}$ & $\begin{array}{l}\text { Reducción del peso } \\
\text { corporal. }\end{array}$ & Jang et al., 2008 \\
\hline
\end{tabular}

La creación de un alimento funcional para el tratamiento de la obesidad es mucho más difícil que crear uno para el tratamiento de una enfermedad como por ejemplo la osteoporosis. La salud del hueso se puede promover mediante la adición de calcio y otros nutrientes que intervienen en la formación del hueso. Mientras que un alimento funcional para la pérdida de peso tiene que influir de algún modo con los otros alimentos que se consumen con el fin de controlar la ingesta total de calorías. Algunas fibras, por ejemplo, reducen la absorción de las moléculas de colesterol y otras pequeñas moléculas de grasa. Existe la preocupación, sin embargo, de que un alimento funcional que limita la absorción 0 la utilización de una clase particular de nutrientes puede causar deficiencias en vitaminas y minerales y no es recomendable.

El alimento funcional ideal para la pérdida de peso debería controlar la ingesta de calorías, produciendo sensación de saciedad fisiológica (hambre) y psicológica (apetito), estimulando las vías metabólicas que queman calorías y al mismo tiempo debería ser efectivo para las distintas versiones específicas de la enfermedad. Teniendo en cuenta los diferentes factores que pueden causar la obesidad, así como las muchas consecuencias que pueden tener sobre la salud humana, parece difícil que un solo alimento pueda suponer un tratamiento efectivo para todas las personas con sobrepeso. Es más probable que sea una amplia gama de alimentos funcionales las que abordan las diferentes necesidades de control de peso. $\mathrm{O}$ tal vez, un producto único con varios ingredientes funcionales, cada uno de los cuales podría responder a una necesidad de control de peso diferente.

Independientemente del tipo de alimentos funcionales que puedan desarrollarse para bajar de peso, es esencial recordar que el nivel de actividad de quema de calorías en las que una persona se involucra, así como las calorías que consume influencian el peso corporal. Además es importante tener en cuenta los problemas emocionales que subyacen en los comportamientos con la comida de muchas personas. Para maximizar la eficacia de los alimentos funcionales para bajar de peso puede ser necesario utilizarlos conjuntamente con la terapia de comportamiento para así garantizar una adecuada variedad en la dieta, actividad física suficiente y el desarrollo de habilidades para limitar el apetito.

Ya existen en el mercado algunos productos para combatir la obesidad, se trata generalmente de barritas y batidos que ayudan a seguir una dieta hipocalórica administrándose como dieta única o combinado con la dieta habitual. Como ejemplo encontramos los productos OPTIFAST $^{\circledR}$ que se comercializan en el mercado por la multinacional Nestlé ${ }^{\circledR}$ y que se venden actualmente en farmacias. Novartis Nutrition ${ }^{\circledR}$, el fabricante de OPTIFAST ${ }^{\circledR}$ demostró que los individuos que participaban en terapia de conducta durante la pérdida de peso y que mantenían 
un estrecho contacto con un grupo de apoyo durante el mantenimiento tenían el mayor éxito de control de peso. Un estudio durante 5 años de seguimiento demostró que las personas que adoptaron nuevas conductas y contaron con el apoyo necesario para mantener su nuevo y sano estilo de vida fueron capaces de mantener una pérdida de peso médicamente significativa (Reuters, 2000).

Eliminar el consumo de alimentos habituales no es una buena solución, es necesario desarrollar alimentos convencionales de bajo aporte calórico y que incluyan ingredientes que ayuden a perder peso. Como paso previo es necesario investigar ingredientes que ayuden a controlar la obesidad. Todavía no existe un ingrediente claro que ayude a perder peso pero tal y como puede observarse existen muchas líneas de investigación interesantes a seguir.

\subsubsection{Infección por Helicobacter pylori en niños.}

Helicobacter pylori (H. pylori) es un agente etiológico de la gastritis crónica y de la úlcera gastroduodenal y constituye un factor de riesgo para la aparición de linfoma gástrico o adenocarcinoma, sobre todo a medida que persiste la infección. La infección origina un espectro continuo de lesiones que abarcan desde la colonización asintomática (Parsonnet, 1998) hasta la producción de gastritis crónica, úlcera péptica y, eventualmente, cáncer gástrico (Suerbaum \& Michetti, 2002). Su relación con la úlcera gastroduodenal y su inclusión por parte de la International Agency for Research of Cancer (IARC) en 1994 (grupo de estudio del cáncer perteneciente a la Organización Mundial de la Salud) entre los agentes carcinógenos tipo 1, lo ha convertido en uno de los microorganismos de mayor interés en patología humana (Hunt et al., 1998).

Es una de las infecciones más comunes en el hombre, posee una prevalencia a nivel mundial que fluctúa entre el $30 \%$ y el $90 \%$, lo cual depende principalmente del nivel socioeconómico (Pueyo et al., 1998), siendo más frecuente en los países en desarrollo y disminuyendo cuando aumenta el nivel socioeconómico. La colonización por dicho patógeno también depende de otros factores como la virulencia del microorganismo y la susceptibilidad del huésped. En los países en vías de desarrollo, con déficit en los servicios sanitarios, la infección se adquiere principalmente en la infancia, con mayor frecuencia en la edad preescolar y puede afectar a la mayor parte de la población al final de la adolescencia. En los países desarrollados dicha infección es baja en la infancia manifestándose generalmente en la quinta o sexta década de la vida (Marcano, 2003; Sáinz-Samitier, 2000). Se han descrito tasas muy elevadas de infección en países en vías de desarrollo como Bolivia, donde el $70 \%$ de los individuos son seropositivos a los 9 años (Friedman et al., 1998), mientras que la seroprevalencia en niños que viven en naciones industrializadas es mucho menor, 12-15\% a los 9 años en USA (Chong et al., 2003). En España la prevalencia media en niños de población escolar está en torno al 22 $\%$, con tasa similares al resto de países de nuestro entorno (Liberato et al., 2005). 
La erradicación de dicho patógeno se basa actualmente en una terapia con dos o tres antibióticos (amoxicilina, tetraciclina, claritromicina o metronidazol) más un inhibidor de la bomba de protones (omeprazol, lansoprazol, pantoprazol, rabeprazol, esomeprazol) o antagonistas de los receptores $\mathrm{H}_{2}$ (ranitidina, cimetidina, famotidina...). Dicho tratamiento es efectivo en el 85\% de los casos si se sigue durante un período comprendido entre 7 y 14 días (Graham et al., 2000). Sin embargo, se puede producir fallo del tratamiento por la aparición de resistencias a los antimicrobianos o por mala tolerancia de los pacientes a los mismos. Actualmente se están investigando las causas de la resistencia de H. pylori a los antibióticos que se suelen usar en el tratamiento médico y, más concretamente, a la claritromicina y el metronidazol. En Estados Unidos los porcentajes de resistencia a la claritromicina se sitúan en torno al $10 \%$ aunque este valor es muy variable según los autores (Meyer et al., 2002). Mientras que los porcentajes de resistencia al metronidazol superan al $44 \%$ en países como Italia (Glupczynski et al., 2001), pueden llegar a alcanzar porcentajes del $90 \%$ en algunas zonas de países en vías de desarrollo (Alarcón et al., 1999).

Las recomendaciones para su erradicación sólo se efectúan en poblaciones con riesgo de padecer cáncer gástrico (Hunt et al., 1998). En los niños se debe considerar su erradicación en pacientes afectos de gastritis o úlcera pero, sin embargo, no se recomienda el tratamiento erradicador en niños asintomáticos colonizados, sobre todo por la facilidad en la aparición de resistencias de este patógeno y la elevada tasa de recaída después del tratamiento (Gold et al., 2000). Además, otro de los problemas relacionados con el uso de antibióticos, aparte de la aparición de resistencias, es que los últimos estudios científicos apuntan al hecho de que la erradicación total del microorganismo puede ocasionar problemas mayores que su presencia. Se ha comprobado que $H$. pylori no es un simple patógeno y ayuda a regular la cantidad de ácido del estómago e interviene en la regulación de la grelina, la hormona implicada en el apetito que indica, entre otras cosas, que el estómago está lleno y no necesita comida (Blaser, 2005). Por estas razones, es necesario desarrollar alternativas que puedan disminuir la colonización por $\mathrm{H}$. pylori en poblaciones de riesgo y, entre ellas, el desarrollo de alimentos que contengan microorganismos que puedan interferir con $\mathrm{H}$. pylori, resulta interesante.

La tabla 1.8 muestra las cepas de microorganismos cuyo efecto frente a la infección originada por H. pylori ha sido estudiado.

Tabla 1.8. Efecto de determinados microorganismos probióticos sobre la infección ocasionada por Helicobacter pylori.

\begin{tabular}{|c|c|c|c|}
\hline Microorganismos & Tipos de estudio & Resultados & Referencias \\
\hline L. salivarius & $\begin{array}{l}\text { Estudio in vitro y estudio in } \\
\text { vivo con animales de } \\
\text { laboratorio. }\end{array}$ & $\begin{array}{l}\text { Erradica H. pylori mediante } \\
\text { la secreción de ácido } \\
\text { gástrico. Disminuye la } \\
\text { inflamación gástrica } \\
\text { inducida en animales. }\end{array}$ & Aiba et al., 1998 \\
\hline $\begin{array}{c}\text { L. gasseri } \\
\text { OLL2716(LG21) }\end{array}$ & $\begin{array}{l}\text { Estudio in vitro y estudio en } \\
\text { humanos: consumo diario } \\
\text { de } 180 \mathrm{~g} \text { de yogur con una } \\
\text { concentración de } 10^{7} \mathrm{UFC} / \mathrm{g}\end{array}$ & $\begin{array}{l}\text { Mejora significativa en } 31 \\
\text { pacientes infectados y } \\
\text { reduce la inflamación de la } \\
\text { mucosa gástrica tras el }\end{array}$ & Sakamoto et al., 2001 \\
\hline
\end{tabular}




\begin{tabular}{|c|c|c|c|}
\hline & durante 8 semanas. & tratamiento con esta cepa. & \\
\hline Bacillus subtilis 3 & Estudio in vitro. & $\begin{array}{l}\text { Inhibe el crecimiento de H. } \\
\text { pylori debido a la secreción } \\
\text { de antibióticos. }\end{array}$ & Pinchuk et al., 2001 \\
\hline Bacillus clausii & $\begin{array}{l}\text { Estudio en humanos: } \\
\text { suministro diario de } 10^{10} \\
\text { UFC en un producto líquido } \\
\text { durante } 3 \text { semanas junto } \\
\text { con la terapia estándar. }\end{array}$ & $\begin{array}{l}\text { Disminución de los } \\
\text { síntomas provocados por el } \\
\text { tratamiento antibiótico } \\
\text { contra H. pylori comparado } \\
\text { con el grupo placebo. }\end{array}$ & Nista et al., 2004 \\
\hline $\begin{array}{c}\text { L. rhamnosus GG, L. } \\
\text { rhamnosus LC705; B. } \\
\text { breve Bb99; } \\
\text { Propionibacterium } \\
\text { freudenreichii spp. } \\
\text { Shermanii JS }\end{array}$ & $\begin{array}{l}\text { Estudio en humanos: } \\
\text { ingestión diaria de } 130 \mathrm{ml} \\
\text { de producto líquido con una } \\
\text { concentración de } 10^{9} \\
\text { UFC/ ml junto con la terapia } \\
\text { estándar. }\end{array}$ & $\begin{array}{l}\text { Disminución de los } \\
\text { síntomas secundarios al } \\
\text { tratamiento erradicador de } \\
\text { H. pylori en comparación } \\
\text { con el grupo placebo. }\end{array}$ & Myllyluoma et al., 2005 \\
\hline $\begin{array}{l}\text { Ent. Fa ecium; B. subtilis; } \\
\text { Bifidobacterium }\end{array}$ & $\begin{array}{l}\text { Estudio in vitro y estudio in } \\
\text { vivo con animales de } \\
\text { laboratorio. }\end{array}$ & $\begin{array}{l}\text { Producción de componentes } \\
\text { proteicos estables al calor } \\
\text { capaces de inhibir el } \\
\text { crecimiento de las cepas de } \\
\text { H. pylori tanto sensibles } \\
\text { como resistentes al al } \\
\text { antibiótico suministrado. }\end{array}$ & $\begin{array}{l}\text { Pinchuk et al., 2001; Tsai et } \\
\text { al., 2004; Collado et al., } \\
\text { 2005. }\end{array}$ \\
\hline $\begin{array}{l}\text { L. acidophilus LA5+; B. } \\
\text { lactis Bb12 }\end{array}$ & $\begin{array}{l}\text { Estudio en humanos: } \\
\text { suministro diario de } 1010 \\
\text { UFC (yogur) durante } 4 \\
\text { semanas previo al } \\
\text { tratamiento con la terapia } \\
\text { estándar. } \\
\text { esta }\end{array}$ & $\begin{array}{l}\text { Aumento en la erradicación } \\
\text { del H. pylori en } 160 \\
\text { pacientes dispépticos. }\end{array}$ & Sheu et al., 2002. \\
\hline L. reuteri ATCC 55730 & $\begin{array}{l}\text { Estudio en humanos. } \\
\text { Consumo diaria de } 10^{8} \mathrm{UFC} \\
\text { (producto líquido) durante } \\
4 \text { semanas junto con la } \\
\text { terapia estándar. }\end{array}$ & $\begin{array}{l}\text { Reducción significativa del } \\
\text { score GSRS (escala de } \\
\text { síntomas gastrointestinales) } \\
\text { durante el tratamiento } \\
\text { erradicador en comparación } \\
\text { con los que reciben el } \\
\text { placebo. }\end{array}$ & Lionetti et al., 2006. \\
\hline L. acidophilus strain LB & $\begin{array}{l}\text { Estudio en humanos. } \\
\text { Suministro diaria de } 10^{10} \\
\text { UFC (producto líquido) } \\
\text { durante } 10 \text { días junto con la } \\
\text { terapia estándar. }\end{array}$ & $\begin{array}{l}\text { Aumento de la tasa de } \\
\text { erradicación de H. pylori en } \\
\text { un grupo de } 120 \text { pacientes. }\end{array}$ & Canducci et al., 2000. \\
\hline L. casei strain Shirota & $\begin{array}{l}\text { Estudio en humanos. } \\
\text { Ingestión diaria de } 65 \mathrm{ml} \mathrm{de} \\
\text { producto líquido "Yakult" } \\
\text { con una concentración de } \\
10^{8} \text { UFC/ ml durante } 3 \\
\text { semanas. }\end{array}$ & 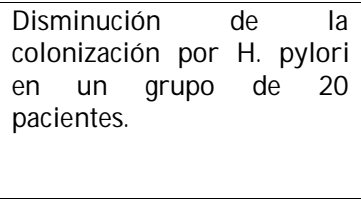 & Cats et al., 2003. \\
\hline L. johnsonii LA1 & $\begin{array}{l}\text { Estudio en humanos. } \\
\text { Consumo diario de } 10^{9} \text { UFC } \\
\text { "Leche LC1" durante } 3 \\
\text { semanas junto con el } \\
\text { suministro de antibióticos. }\end{array}$ & $\begin{array}{l}\text { Reducción de la } \\
\text { colonización de H. pylori; } \\
\text { reducción de la inflamación } \\
\text { y de la gastritis provocada } \\
\text { por H. pylori en } 52 \\
\text { pacientes. }\end{array}$ & Felley et al., 2001. \\
\hline L. acidophilus NAS & $\begin{array}{l}\text { Estudio en humanos. } \\
\text { Ingestión diara de } 10^{9} \text { UFC } \\
\text { (leche) durante } 8 \text { semanas. }\end{array}$ & $\begin{array}{l}\text { Erradicación de H. pylori en } \\
6 \text { de } 14 \text { pacientes. }\end{array}$ & Mrda et al., 1998. \\
\hline $\begin{array}{l}\text { L. casei subsp. rhamnosus } \\
\text { (GG); S. cerevisiae } \\
\text { Boulardii; L. acidophilus; } \\
\text { B. lactis }\end{array}$ & $\begin{array}{l}\text { Estudio en humanos. } \\
\text { Suministro diario de } 10^{10} \\
\text { UFC (producto liquido) } \\
\text { durante 2 semanas junto } \\
\text { con la terapia estándar. }\end{array}$ & $\begin{array}{l}\text { Menor incidencia de efectos } \\
\text { secundarios y mejor } \\
\text { tolerancia al tratamiento en } \\
\text { comparación con el placebo. }\end{array}$ & Cremonini et al., 2002. \\
\hline $\begin{array}{c}\text { L. reuteri strains } \\
\text { (JCM1112, JCM1084, } \\
\text { JCM2762,JCM2763, } \\
\text { JCM2764) }\end{array}$ & Estudio in vitro. & $\begin{array}{l}\text { Prevención de la infección } \\
\text { en un estado inicial de la } \\
\text { colonización por H. pylori } \\
\text { proponiendo que las cepas } \\
\text { de L. reuteri comparten } \\
\text { especificidad de glicolípidos } \\
\text { con H.pylori. }\end{array}$ & Mukai et al., 2002. \\
\hline
\end{tabular}

En distintos estudios clínicos y modelos in vitro se ha demostrado que la asociación de Lactobacillus junto con antibióticos para el tratamiento de H. pylori ejerce un efecto antagonista frente a este microorganismo y disminuye el índice de 
efectos secundarios ocasionados por el tratamiento (Hamilton-Miller, 2003); en cambio, es poco posible la erradicación de dicho patógeno con la utilización de probióticos exclusivamente. Por otra parte, se ha observado que ciertos Lactobacillus son resistentes al $\mathrm{pH}$ gástrico y pueden adherirse y residir en el estómago humano de manera transitoria (Cruchet et al., 2003; Marteau et al., 1997), compitiendo e inhibiendo, en cierto sentido, la colonización por H. pylori. Esta acción es dependiente de la cepa; de esta manera se ha comprobado que L. salivarius suprime $\mathrm{H}$. pylori y reduce la respuesta inflamatoria en el ratón gnobiótico más eficientemente que L. casei (Aiba et al., 1998). De igual forma, L. acidophilus inhibe el crecimiento de $\mathrm{H}$. pylori más eficientemente que otras cepas del mismo género (Mrda et al., 1998; Canducci et al., 2000; Sheu et al., 2002).

La mayoría de los estudios se han realizado en humanos y suministrando productos líquidos, leche o yogur, que contiene un alto contenido de microorganismos (dicho contenido varía entre $10^{7}$ y $10^{9} \mathrm{UFC} / \mathrm{ml}$, según el estudio), pero en ningún caso se trata de un producto sólido. Además, el tratamiento con la cepa en cuestión suele combinarse con la terapia estándar (dos antibióticos más una bomba de protones) y, sólo en algunos casos, se realizan los estudios suministrando únicamente las cepas probióticas (Mrda et al., 1998; Sakamoto et al., 2001; Cats et al., 2003).

Algunos estudios se centran en la combinación de microorganismos probióticos con efecto probado y zumos de frutas o componentes con actividad fisiológica (Gotteland et al., 2008; Zojaji et al., 2009). Además, con el objetivo de favorecer la efectividad del tratamiento con probióticos se han desarrollado micropartículas que encapsulan a los microorganismos probióticos para favorecer el tiempo de residencia en el tracto gastrointestinal (Ko et al., 2011). Además, se han desarrollado nanopartículas (Chang et al., 2011) capaces de liberar de forma controlada, en el sitio específico donde se sitúa $\mathrm{H}$. pylori, el medicamento encargado de erradicar dicho microorganismo.

\subsection{El mercado de los alimentos funcionales en la actualidad. Nichos de oportunidad en el desarrollo de alimentos funcionales.}

A pesar de que nos encontramos en uno de los períodos económicos más desafiantes y difíciles a nivel mundial, el interés de los consumidores por los alimentos funcionales se ha mantenido e incluso ha aumentado desde el inicio de la crisis. Las necesidades de una población cada vez más envejecida, los cambios en el modo de vida, el encarecimiento del sistema de salud, la atención de los medios de comunicación a las innovaciones alimentarias y a los descubrimientos médicos así como la expectativa de un aumento generalizado de los precios han aumentado el compromiso de los consumidores en su salud y bienestar (Jones, 2010).

El éxito en el mercado de este tipo de alimentos pasa por la investigación y la innovación alimentaria, por los avances médicos y por un mayor conocimiento en 
la prevención y mejora de enfermedades crónicas. Muchas empresas multinacionales de alimentación y bebidas han destinado sus presupuestos de investigación y sus estrategias de crecimiento al desarrollo y a la publicidad de alimentos funcionales (The economist, 2009). Todo ello está impulsado por el aumento de los consumidores que demandan alimentos funcionales, principalmente parejas jóvenes (Touhy et al., 2011) y los hogares con hijos (Viamari, 2010). Además, la expansión de los nuevos medios de comunicación más accesibles, específicos y portátiles, permiten que el usuario obtenga información con facilidad y, en muchos casos, de manera inmediata. De esta manera los mercados pueden dividirse en segmentos más pequeños y especializados como los relacionados con el bienestar y la salud (Viamari, 2009).

Tal y como se ha mencionado anteriormente, no existe ni una definición ni una legislación armonizada e internacionalmente aceptada para los alimentos funcionales. Debido a esto, resulta bastante difícil estimar el mercado de este tipo de alimentos puesto que dependiendo de la definición establecida en cada país las cifras resultantes pueden variar (Kotilaine et al., 2006). Teniendo en cuenta la estimación realizada por la revista americana de nutrición y salud "Nutritional Business Journal" (Nutritional Business Journal, 2007a,b) las ventas de alimentos funcionales alcanzan los 85 billones de dólares. Otras estimaciones, sin embargo, sugieren que el mercado de alimentos funcionales es más pequeño. Por ejemplo, Just-Foods (2006) estima el valor del mercado global de alimentos funcionales en 73 billones de dólares, Euromonitor Internacional (2006) presenta una estimación de 70 billones de dólares mientras que Verbeke (2005) sugiere que el mercado es considerablemente menor alcanzando los 50 billones de dólares. Todas las fuentes están de acuerdo, sin embargo, en estimar el crecimiento anual en las ventas de este tipo de alimentos entre el 8 y el 14 \% y sugieren que la demanda continuará creciendo de acuerdo con los cambios demográficos de la población, una mayor esperanza de vida y la aparición de enfermedades relacionadas con el estilo de vida.

Los principales mercados de alimentos funcionales son Japón, Estados Unidos y Europa que alcanzaron en 2007 unas ventas de 11.7, 10.5 y 7.5 billones de dólares y con una cuota de mercado del 34, 28 y $21 \%$ respectivamente. Estos tres mercados abarcan el $90 \%$ de todas las ventas (Bech-Larsen \& Scholderer, 2007). Países en desarrollo como Brasil, Perú y Kenia han comenzado a emerger como exportadores de ingredientes activos y su propia demanda en alimentos funcionales supone una oportunidad para el desarrollo de los mercados domésticos. La India, un país con una fuerte tradición en el consumo de alimentos beneficiosos para la salud, se sitúa entre los diez primeros en la compra de este tipo de alimentos y se espera que el mercado se duplique en los próximos cinco años (Ismail, 2006). En Brasil el sector está creciendo rápidamente y las ventas alcanzaron el billón de dólares en 2009. En China el mercado total de alimentos funcionales supera los 6 billones de dólares. 
En Japón, el lugar de origen de los alimentos funcionales, se lanzaron al mercado más de 1700 productos entre 1988 y 1998 y más de 500 se etiquetaron como FOSHU (Food for Specified Health Uses) en 2005 (Fern, 2007; Side, 2006). En Estados Unidos los alimentos funcionales tienen una cuota de mercado de 2-3 $\%$ del total del mercado de alimentos (Menrad, 2003) y se espera que este porcentaje se duplique en 2008 (Benkouider, 2005). Este crecimiento puede explicarse teniendo en cuenta que la legislación para este tipo de alimentos ha sido y todavía es más favorable que en Europa (Side, 2006).

El mercado europeo es uno de los más importantes y en los últimos años ha aumentado de forma constante la demanda de alimentos funcionales, la cuota de mercado se estima alrededor del uno por ciento del mercado global de alimentos y bebidas. Alemania, Francia, el Reino Unido y Holanda son los países europeos con un mayor mercado de alimentos funcionales (Mäkinen-Aakula, 2006) aunque de acuerdo con las estimaciones de Euromonitor las ventas crecerán notablemente en mercados emergentes como Hungría, Polonia y Rusia (Benkouider, 2005) en donde se esperan crecimientos anuales alrededor del veinte por ciento y en los últimos años ya se han introducido numerosos productos (Kotilaine et al., 2006).

El mercado europeo es heterogéneo y existen grandes diferencias regionales en el uso y la aceptación de este tipo de alimentos. En general, en los países del centro y el norte de Europa el interés de los consumidores en los alimentos funcionales procesados es mayor que en los países mediterráneos en donde los consumidores aprecian más los productos naturales frescos y los consideran mejores para la salud.

El mercado de alimentos funcionales en España crece a medida que los consumidores son cada vez más conscientes de la influencia de la dieta en su salud y bienestar. Desde el año 2000 al 2005 el sector experimentó un crecimiento del $50 \%$. El mercado de alimentos funcionales y bebidas se estimó en 2.7 billones de dólares en el año 2005, un 38 \% más que en 2002. En 2006 el mercado de alimentos funcionales en España representó aproximadamente el $17 \%$ del mercado total de alimentos y se estima que llegue al $40 \%$ en el año 2020 (Monár 2007). Algunos de los principales fabricantes de alimentos funcionales han promovido sus productos en el mercado a través de campañas televisivas que aumentan la concienciación y la aceptación de este tipo de productos e incluso muchos fabricantes de alimentos españoles están lanzando al mercado nuevos productos funcionales con el fin de incrementar sus ventas. Se espera que esta tendencia continúe y los fabricantes desarrollen nuevos productos funcionales destinados a abordar problemas específicos de salud como complemento a sus productos tradicionales. Como ejemplo, recientemente se han introducido en España productos que tienen ingredientes o compuestos específicos que ayudan a mejorar la salud cardiovascular.

Los alimentos funcionales tienen un gran potencial de crecimiento en España, con productos que ya han alcanzado una presencia significativa en el mercado. Por 
ejemplo, el yogur líquido Actimel de Danone alcanzó ventas de 1.5 billones de dólares en 2005 y llegó a tener una penetración del 30 \% en los hogares del país.

Dentro del mercado de alimentos funcionales parece que se está produciendo un cambio en la tendencia de consumo y los consumidores están pasando de consumir productos a los que se les ha eliminado algún ingrediente poco saludable tales como "light" a los productos a los que se les añade algún ingrediente que promueve beneficios adicionales para la salud como los alimentos enriquecidos en vitaminas, fibra, ácidos grasos omega-3...

Según Datamonitor (2007), los principales productos a los que se han incorporado ingredientes funcionales son lácteos (38.9\%), bebidas no alcohólicas $(24.9 \%)$, cereales y productos de panadería (24.6\%), dulces (8.9\%) y aperitivos salados (2.6 \%). En cuanto a productos nuevos que se lanzaron al mercado, los ingredientes que más se incorporaron fueron antioxidantes, licopeno, ácidos grasos omega-3, probióticos e isoflavonas (Sadler, 2005). Las 20 compañías de alimentos funcionales más importantes representan el $70 \%$ del mercado global, con un número reducido de empresas multinacionales que comprenden una parte importante del mercado aunque compañías más pequeñas y locales han sabido mantenerse creando sus propios nichos de mercado. La mayoría de productos son productos desestructurados, aunque con la importancia adquirida en los últimos años por el consumo de frutas y verdurans han aparecido en paquetes de cereales o barritas a las que se les ha añadido una amplia variedad de frutas deshidratadas.

\subsection{Bibliografía citada.}

Adil I.H., Çetin H.I., Yener M.E. \& Bayindirli A. (2007) Subcritical (carbon dioxide + etanol) extraction of polyphenols from apple and peach pomaces, and determination of the antioxidant activities of the extracts. Journal of Supercritical Fluids, 43, 55-63.

Aguilera J.M. (2005) Why food microstructure?. Journal of Food Engineering, 67(12), 3-11.

Aiba Y., Suzuki N., Kabir A.M., Takagi A., \& Koga Y. (1998) Lactic acid-mediated suppression of Helicobacter pylori by the oral administration of Lactobacillus salivarius as a probiotic in a gnotobiotic murine model. American Journal of Gastroenterology, 93, 2097-2101.

Alarcón T., Domingo N., Prieto P., \& López-Brea M. (1999) Clarithromycin resistance stability in Helicobacter pylori: influence of the MIC level and type of mutation in the 23S RNA. Gut, 45, A106.

Alcocer L., Fernández L., Campos E., \& Más R. (1999) A comparative study of policosanol versus acipimox in patients with type II hypercholesterolemia. International Journal of Tissue Reactions, 21, 85-92.

Alder R., Lookinland S., Berry J.A., \& Williams M. (2003) A systematic review of the effectiveness of garlic as an anti-hyperlipidemic agent. Journal of the American Academy of Nurse Practitioners, 15, 120-129. 
Alzamora S.M., Castro M.A., Vidales S.l., Nieto A.B., Salvatori D. (2000) The role of tissue microstructure in the textural characteristics of minimally processed fruits. In 4 minimally processed fruits and vegetables fundamental aspects and applications. Aspen Publishers Inc., Maryland, pp. 153-172 (Chapter 9).

American Dietetic Association. (1999) Position of the American Dietetic Association: functional foods. Journal of the American Dietetic Association, 99, 1278-1285.

Andresen M., Regueira T., Bruhn A., Perez D., Strobel P., Dougnac A., Marshall G., \& Leighton F. (2008) Lipoperoxidation and protein oxidative damage eshibit different kinetics during septic shock. Mediators of Inflammation, 2008, 168652.

Arai S. (1996) Studies on functional foods in Japan - state of the art. Bioscience, Biotechnology and Biochemistry, 60, 9-15.

Azzi A. (2007) Oxidative stress: a dead end or a laboratory hypothesis?. Biochemical and Biophysical Research Communications, 362, 230-232.

Ballard T.S., Mallikarjunan P., Zhou K., \& O'Keefe S. (2010) Microwave-assisted extraction of phenolic antioxidant compounds from peanut skins. Food Chemistry, 120, 1185-1192.

Banegas J.R., Villar F., Pérez C., Jiménez R., Gil E., Muñiz J., \& Juane R. (1993) Estudio epidemiológico de los factores de riesgo cardiovascular en la población española de 35 a 64 años. Revista de Sanidad e Higiene Pública, 67, 419-445.

Barbosa-Cánovas G.V., \& Vega-Mercado H. (1996) Dehydration of Foods. Chapman \& Hall, New York, 53-59

Basu A., \& Imrhan V. (2007) Tomatoes versus lycopene in oxidative stress and carcinogenesis: conclusions from clinical trials. European Journal of Clinical Nutrition, 61, 295-303.

Bech-Larsen T., \& Scholderer J. (2007) Functional Foods in Europe: consumer research, market experiences and regulatory aspects. Trends in Food Science \& Technology, 18, 231-234.

Becker M., Staab D., \& von Bergmann K. (1993) Treatment of severe familial hypercholesterolemia in childhood with sitosterol and sitostanol. Journal of Pediatrics, 122, 292-296.

Benavente-García O., \& Castillo J. (2008) Update on uses and properties of citrus flavonoids: new findings in anticancer, cardiovascular and anti-inflammatory activity. Journal of Agricultural and Food Chemistry, 56, 6185-6205.

Benelli P., Riehl C.A.S., Smânia A., Smânia E.F.A., \& Ferreira S.R.S. (2010) Bioactive extracts of orange (Citrus sinensis L. Osbeck) pomace obtained by SFE and low pressure techniques: Mathematical modeling and extract composition. Journal of Supercritical Fluids, 55, 132-141.

Benkouider C. (2005) The world's emerging markets. Functional Foods \& Nutraceuticals, August, 8-12. 
Bergen W.G., \& Mersmann H.J. (2005) Comparative aspects of lipid metabolism: impact on contemporary research and use of animal models. Journal of Nutrition, 135(11), 2499-2502.

Bhuvaneswari V., Velmurugan B., Abraham S.K., \& Nagini S. (2004) Tomato and garlic by gavage modulate 7,12-dimethylbenz[a]anthraceneinduced genotoxicity and oxidative stress in mice. Brazilian Journal of Medical and Biological Research, 37, 1029-1034.

Biström M., \& Nordström K. (2002) Identification of key success factors of functional dairy foods product development. Trends in Food Science \& Technology, 13, 372-379.

Blaser J. (2005) Helicobacter pylori. Investigación y Ciencia, Abril 2005.

Bleve M., Ciurlia L., Erroi E., Lionetto G., Longo L., Rescio L., Schettino T., \& Vasapollo G. (2008) An innovative method for the purification of anthocyanins from grape skin extracts by using liquid and sub-critical carbon dioxide. Separation and Purification Technology, 64, 192-197.

Block G., Patterson B., \& Subar A. (1992) Fruits, vegetables and cancer prevention: a review of the epidemiological evidence. Nutrition and cancer-An International Journal, 18, 1-29.

Bolin H.R., \& Huxsoll. (1993) Partial drying of cut pears to improve freeze/ thaw texture. Journal of Food Science, 58, 357-360.

Brown M.S., Goldstein J.L., \& Kita T. (1983) Lipoprotein receptors in the liver. Control signals for plasma cholesterol traffic. Journal of Clinicial Investigation, 72, 743-747.

Bursill C.A., Abbey M., \& Roach P.D. (2007) A green tea extract lowers plasma cholesterol by inhibiting cholesterol synthesis and upregulation the LDL receptor in the cholesterol-fed rabbits. Atherosclerosis, 193, 86-93.

Bursill C.A., \& Roach P.D. (2007) A green tea catechin extract upregulates the hepatic low-density lipoprotein receptor in rats. Lipids, 42, 621-627.

Bursill C.A., \& Roach P.D. (2006) Modulation of cholesterol metabolism by the green tea polyphenol (-)-epigallocatechin gallate in cultured human liver (HepG2) cells. Journal of Agricultural Food Chemistry, 54, 1621-1626.

Çam M., \& Hisll Y. (2010) Pressurised water extraction of polyphenols from pomegranate peels. Food Chemistry, 123, 878-885.

Canducci F., Armuzzi A., Cremonini F., Cammarota G., Bartolozzi F., \& Pola P. (2000) A lyophilized and inactivated culture of Lactobacillus acidophilus increases Helicobacter pylori eradication rates. Alimentary Pharmacology \& Therapeutics, 14, 1625-1629.

Casas L., Mantell C., Rodríguez M., Ossa E.J.M.D.L., Roldán A., Ory I.D. \& Blandino A. (2010) Extraction of resveratrol from the pomace of Palomino fino grapes by supercritical carbon dioxide. Journal of Food Engineering, 96, 304-308.

Castaño G., Más R., Fernández L., Illnait J., Mendoza S., Gámez R., Fernández J., \& Mesa M. (2005) A comparison of the effects of D-003 and policosanol (5 and 10 $\mathrm{mg} /$ day) in patients with type II hypercholesterolemia: a randomized, double- 
blinded study. Drugs under Experimental and Clininical Research, 31 (Suppl.), 31-44.

Castaño G., Más R., Fernández L., Illnait J., Gámez R., \& Alvarez E. (2001) Effects of policosanol 20 versus $40 \mathrm{mg} /$ day in the treatment of patients with type II hypercholesterolemia: a 6-month double-blind study. International Journal of Clinical Pharmacology Research, 21, 43-57.

Castilla P., Echarri R., Dávalos A., Cerrato F., Ortega H., Teruel J.L., Lucas M.F., Gómez-Coronado D., Ortuño J., \& Lasunción M.A. (2006) Concentrated red grape juice exerts antioxidant, hypolipidemic, and antiinflammatory effects in both hemodialysis patients and healthy subjects. American Journal of Clinical Nutrition, 84, 252-262.

Castro-Vargas H.I., Rodríguez-Varela L.I., Ferreira S.R.S., \& Parada-Alfonso F. (2010) Extraction of phenolic fraction from guava sedes (Psidium guajava L.) using supercritical carbon dioxide and co-solvents. Journal of Supercritical Fluids, 51, 319-324.

Cats A., Kulpers E.J., Bosschaert M.A., Pot R.G., Vandenbroucke-Gauls C.M., \& Kusters J.G. (2003) Effect of frequent consumption of Lactobacillus casei containing milk drink in Helicobacter pylori colonised subjects. Alimentary Pharmacology \& Therapeutics, 17, 429-435.

Chan P.T., Fong W.P., Huang Y., Ho W.K.K., \& Chen Z.Y. (1999) Jasmine green tea epicatehins are hypolipidemic in hámster (Mesocricetus auratus) fed a high fat diet. Journal of Nutrition, 129, 1094-1101.

Chang C.H., Huang W.Y., Lai C.H., Hsu Y.M., Yao Y.H., Chen T.Y., Wu J.Y., Peng S.F., \& Lin Y.H. (2011) Development of novel nanoparticles shelled with heparin for berberine delivery to treat Helicobacter pylori. Acta Biomaterialia, 7, 593-603.

Chen J.D., Wu Y.Z., Tao Z.L., Chen Z.M., \& Liu X.P. (1995) Hawthorn (Shan Zha) drink and its lowering effect on blood lipid levels in humans and rats. World Review of Nutrition and Dietetics, 77, 147-154.

Chen, L., Remondetto, G.E., \& Subirade, M. (2006). Food protein-based materials as nutraceutical delivery systems. Trends in Food Science and Technology, 17(5), 272-283.

Chen, L., \& Subirade, M. (2007). Effect of preparation conditions on the nutrient release properties of alginate/ whey protein granular microspheres. European Journal of Pharmaceutics and Biopharmaceutics, 65, 354-362.

Chen Z.Y., Jiao R., \& Ma K.Y. (2008) Cholesterol-Lowering Nutraceuticals and Functional Foods. Journal of Agricultural Food Chemistry, 56, 8761-8773.

Chen M., Gu H., Ye Y., Lin B., Sun L., Deng W., Zhang J., \& Liu J. (2010) Protective effects of hesperidin against oxidative stress of tert-butyl hydroperoxide in human epatocytes. Food and Chemical Toxicology, 48, 2980-2987.

Choi E.H., Yang H.P., \& Chun H.S. (2012) Chitooligosaccharide ameliorates dietinduced obesity in mice and affects adipose gene expression involved in adipogenesis and inflammation. Nutrition Research, 32, 218-228 
Chong S.K., Lou Q., Zollinger T.W., Rabinowitz S., Jibaly R., \& Tolia V. (2003) The seroprevalence of Helicobacter pylori in a referal population of children in the United Status. American Journal of Gastroenterology, 98, 2162-2168.

Codoñer-Franch P., López-Jaén A.B., Muñiz P., Sentandreu E., \& Valls-Bellés V. (2008) Mandarin juices improves the antioxidant status of hypercholesterolemic children. Journal of Pediatric Gastroenterology and Nutrition, 47, 349-355.

Codoñer-Franch P., López-Jaén A.B., de la Mano-Hernández A., Sentandreu E., SimóJordá R., \& Valls-Bellés V. (2010) Oxidative markers in children with severe obesity following low-calorie diets supplemented with mandarin juice. Acta Paediatrica, 99, 1841-1846.

Codoñer-Franch P., Valls-Bellés V., Arilla-Codoñer A., \& Alonso-Iglesias E. (2011) Oxidant mechanisms in childhood obesity: the link between inflammation and oxidative stress. Traslational Research, 158, 6, 369-384.

Collado M.C., González A., González R., Hernández M., Ferrus M.A., \& Sanz Y. (2005) Antimicrobial peptides are among the antagonistic metabolites produced by Bifidobacterium against Helicobacter pylori. International Journal of Antimicrobial Agents, 25, 385-391.

Cremonini F., Di Caro S., Covino M., Armuzzi A., Gabrielli M., \& Santarelli L. (2002) Effect of different probiotic preparations on anti-Helicobacter pylori therapy related side effects: A parallel group, triple blind, placebo-controlled study. American Journal of Gastroenterology, 97, 2744-2749.

Cruchet S., Obregon M.C., Salazar G., Diaz E., \& Gotteland M. (2003) Effect of the ingestion of a dietary product containing Lactobacillus johnsonii La1 on Helicobacter pylori colonization in children. Nutrition, 19, 716-721.

Datamonitor. (2007) Functional food \& drink consumption trends. Product code dmcm2982.

http:// www.marketresearchreport.com/ datamonitor/ DMCM2982.htm. Accessed on 13 July 2012.

Demmig-Adams B., \& Adams W.W. (2010) 3rd. Overview of diet-gene interactions and the example of xanthophylls. Advances in Experimental Medicine \& Biology, 698, 17-26.

Devaraj S., Mathur S., Basu A., Aung H.H., Vasu V.T., Meyers S., \& Jialal I. (2008) A Dose-Response Study on the Effects of Purified Lycopene Supplementation on Biomarkers of Oxidative Stress. Journal of the American College of Nutrition, 27, 2, 267-273.

Comisión Europea (2012) Reglamento (UE) № 432/ 2012 de la Comisión de 16 de mayo de 2012. Diario Oficial de la Unión Europea.

Drbohlav J., Roubal P., Binder M., Šalaková A., \& Plechacová, M. (2007) Research and development of functional foods with special regard to dairy foods in the Czech Republic. In Proceedings of the fourth international FFNet meeting on functional foods.

Eberhardt M.V., Lee C.Y., \& Liu R.H. (2000) Antioxidant activity of fresh apples. Nature, 405, 903-4. 
European Comission. (2006) Regulation (EC) No. 1924/2006 of the European Parliament and of the Council of 20 December 2006 on nutrition and health claims made on foods. Official Journal of the European Union, L12, 3-18.

European Commission. (2010) Directorate-General for Research, FP7 cooperationFood. Functional foods, 1-28, Brussels, Belgium.

ftp:/ / ftp.cordis.europa.eu/pub/fp7/ kbbe/ docs/ functional-foods en.pdf Accessed on 13 July 2012.

Euromonitor International. (2006) State of the market: Global fortified/ functional food and beverages. Industry Report. Chicago, IL.

Farbstein D., Kozak-Blickstein A., \& Levy A.P. (2010) Antioxidant vitamins and their use in preventing cardiovascular disease. Molecules, 15, 8098-8110.

Felley C.P., Corthesy-Theulaz I., \& Rivero J.L. (2001) Favourable effect of an acidified milk (LC-I) on Helicobacter pylori gastritis in man. European Journal of Gastroenterology \& Hepatology, 13, 25-29.

Fern E. (2007) Marketing of functional foods: A point of view of the industry. International developments in science and health claims, ILSI international symposium on functional foods in Europe.

Ferrari CKB. (2007) Functional foods and physical activities in health promotion of aging people. Maturitas, 58, 327-339.

Ferrua M.J., Kong F., \& Singh P. (2011) Computational modeling of gastric digestion and the role of food material properties. Trends in Food Science \& Technology, 22(9) 480-491.

Finkelstein E.A., Trogdon J.G., Cohen J.W., \& Dietz W.H. (2009) Annual medical spending attributable to obesity: Payer-and service-specific estimates. Health Affairs, 28(5), w808-w817.

Fito, P. (1994) Modelling of vacuum osmotic dehydration of food. Journal of Food Engineering, 22(1-4), 313-328.

Fito, P., \& Pastor, R. (1994) On some non-diffusional mechanism occurring during vacuum osmotic dehydration. Journal of Food Engineering, 21, 513-519.

Fito, P., Andrés, A., Chiralt, A., \& Pardo, P. (1996) Coupling of hydrodynamic mechanism and deformation relaxation phenomena during vacuum treatments in solid porous food-liquid systems. Journal of Food Engineering, 27, 229-240.

Fitó M., Torre R., \& Covas M.I. (2007) Olive oil and oxidative stress. Molecular Nutrition \& Food Research 51, 1215-1224.

Friedman C., Glynn M.K., Quick R., Khana B., Iihoshi N., \& Revollo C. (1998) Helicobacter pylori: seoincidence in a cohort of rural bolivian children. Journal of Pediatric Gastroenterology \& Nutrition, 27, 477-479.

Gamez R., Maz R., Arruzazabala M.L., Mendoza S., \& Castano G. (2005) Effects of concurrent therapy with policosanol and omega-3 fatty acids on lipid profile and platelet aggregation in rabbits. Drugs R\&D, 6, 11-19.

Garg A., Garg S., Zaneveld L.J.D., \& Singla A.K. (2001) Chemistry and pharmacology of the citrus bioflavonoid hesperidin. Phytotherapy Research, 15, 655-69. 
Giannuzzo A.N., Boggetti H.J., Nazareno M.A. \& Mishima H.T. (2003) Supercritical fluid extraction of naringin from the peel of Citrus paradis. Phytochemical Analysis, 14, 221-223.

Glupczynski Y., Megraud F., Lopez-Brea M., \& Andersen L.P. (2001) European multicentre survey of in vitro antimicrobial resistance in Helicobacter pylori. European Journal of Clinical Microbiology \& Infectious Diseases, 20, 820-823.

Gold B.D., Coletti R.B., \& Abbott M. (2000) Helicobacter pylori infection in children: recommendations for diagnosis and treatment. Journal of Pediatric Gastroenterology and Nutrition, 31, 490-499.

Goli A.H., Barzegar M., \& Sahari M.A. (2005) Antioxidant activity and total phenolic compounds of pistachio (Pistachia vera) hull extracts. Food Chemistry, 92, 521525.

Gotteland M., Andrews M., Toledo M., Muñoz L., Caceres P., Wittig E., Speisky H., \& Salazar G. (2008) Modulation of Helicobacter pylori colonization with cranberry juice and Lactobacillus johnsonii La1 in children. Nutrition, 24, 421-426.

Gouni-Berthold I., \& Berthold H.K. (2002) Policosanol: clinical pharmacology and therapeutic significance of a new lipid-lowering agent. American Heart Journal, 143, 356-365.

Graham D.Y., \& Yamaoka Y. (2000) Disease-specific Helicobacter pylori virulence factors: the unfulfilled promise. Helicobacter, 5, S3-S9.

Gry J., Black L., Eriksen F.D., Pilegaard K., Plumb J., \& Rhodes M. (2007) EuroFIRBASIS a combined composition and biological activity database for bioactive compounds in plant-based foods. Trends in Food Science \& Technology, 18, 434444.

Hamilton-Miller J.M. (2003) The role of probiotics in the treatment and prevention of Helicobacter pylori infection. International Journal of Antimicrobial Agents, $22,360-366$.

Harvey C.J., Thimmulappa R.K., Singh A., Blake D.J., Ling G., Wakabayashi N., Fujii J., Myers A., \& Biswal S. (2009) Nrf2-regulated glutathione recycling independent of biosynthesis is critical for cell survival during oxidative stress. Free Radical Biology \& Medicine, 46, 443-453.

Hathout A.S., Mohamed S.R., El-Nekeety A.A., Hassan N.S., Aly S.E., \& Abdel-Wahhab M.A. (2011). Ability of Lactobacillus casei and Lactobacillus reuteri to protect against oxidative stress in rats fed aflatoxins-contamined diet. Toxicon, 58, 179186.

Hayat K., Zhang X., Chen H., Xia S., Jia C., \& Zhong F. (2010) Liberation and separation of phenolic compounds from citrus mandarin peels by microwave heating and its effect on antioxidant activity. Separation and Purification Technology, 73, 371-376.

He J., Klag M.J., Whelton P.K., Mo J.P., Chen J.Y., Qian M.C., Mo P.S., \& He G.Q. (1995) Oats and buckwheat intakes and cardiovascular disease risk factors in an ethnic minority of China. American Journal of Clinical Nutrition, 61, 366-372.

Health Canada Website. http:/ / hc-sc.gc.ca. Accessed 24 June 2012. 
Hennekens C.H. (1986) Micronutrients and cancer prevention. New England Journal of Medicine, 315, 1288-1289.

Hilliam M. (1998) The market for functional foods. International Dairy Journal, 8, 349-353.

Ho J.H. \& Chang Y.L. (2004) Protective Effects of Quercetin and Vitamin C against Oxidative Stress-Induced Neurodegeneration. Journal of Agricultural and Food Chemistry, 52, 7514-7517.

Ho W.K.K., Chen Z.Y., \& Huang Y. (2003) Crataegus (Hawthorn). In Herbal Medicine and Molecular Basis in Health and Disease Management, Dekker: New York, 471487.

Holm F. (2003) New Functional Food Ingredients Cardiovascular Health. FoodGroup Denmark, Skødstrup, Denmark, 8-31.

Hong N., Yaylayan V.A., Raghavan G.S.V., Paré J.R.J., \& Bélanger J.M.R. (2001) Microwave-assisted extraction of phenolic compounds from grape seed. Natural Product Letters, 15, 197-204.

Huang Y.W., Liu Y., Dushenkov S., Ho C.T., Huang M.T. (2009) Anti-obesity effects of epigallocatechin-3-gallate, orange peel extract, black tea extract, caffeine and their combinations in a mouse model. Journal of Functional Foods, 1, 304-310.

Hunt R., \& Thomson A.B. (1998) Canadian Helicobacter pylori consensus conference. Canadian Association of Gastroenterology. Canadian Journal of Grastroenterology, 12, 31-41.

Inoue T., Tsubaki S., Ogawa K., Onishi K., \& Azuma J. (2010) Isolation of hesperidin from peels of thinned Citrus unshiu fruits by microwave-assisted extraction. Food Chemistry, 123, 542-547.

International Association for the Study of Obesity. www.iaso.org. Accessed 3 July 2012.

Ismail A. (2006) The land of opportunity. Functional Foods and Nutraceuticals, (January), 14-16.

Jang A., Srinivasan P., Lee N.Y., Song H.P., Lee J.W., Lee M., \& Jo C. (2008) Comparison of hypolipidemic activity of synthetic gallic acid-linoleic acid ester with mixture of gallic acid and linoleic acid, gallic acid, and linoleic acid on highfat diet induced obesity in C57BL/ $6 \mathrm{Cr}$ Slc mice. Chemico-Biological Interactions, 174, 109-17.

Jones B. (2010). Prepared Foods exclusive: no functional fad. Prepared Foods Web site.

http:/ / www.preparedfoods.com/ Articles/ newsletter-business/ BNP_GUID_9-52006_A_10000000000000749190. Accessed July 13, 2012

Jones P.J., \& Jew S. (2007) Functional food development: Concept to reality. Trends in Food Science \& Technology, 18, 387-390.

Ju Z.Y., \& Howard L.R. (2005) Subcritical water and sulfured water extraction of anthocyanins and other phenolics from dried red grape skin. Journal of Food Science, 70, S270-S276. 
Just-food. (2006) Global market review of functional foods-forecasts to 2012. http:/ / www .just-food.com/ store/ product.aspx?id =44028\&lk=pop.

Kantan M.B., Grundy S.M., Jones P., Law M., Miettinen T., \& Paoletti R. (2003) Stresa workshop participants. Efficacy and safety of plant stanols and sterols in the management of blood cholesterol levels. Mayo Clinic Proceedings, 78, 965-978.

Kassama L.S., Shi J., \& Mittal G.S. (2008) Optimization of supercritical fluid extraction of lycopene from tomato skin with central composite rotatable design model. Separation and Purification Technology, 60, 278-284.

Kaur S., \& Das M. (2011) Functional Foods: An Overview. Food Science And Biotechnology, 20(4), 861-875.

Keller C. (2006) Trends in beverages and "Measurable Health". In Proceedings of the third functional food net meeting.

Khan M.K., Abert-Vian M., Fabiano-Tixier A.S., Dangles O., \& Chemat F. (2010) Ultrasound-assisted extraction of polyphenols (flavanone glycosides) from orange (Citrus sinensis L.) peel. Food Chemistry, 119, 851-858.

Kim J.Y., Kim D.B., \& Lee H.J. (2006) Regulations on health/functional foods in Korea. Toxicology, 221(1), 112-118.

Ko M.J., Cheigh C.I., Cho S.W., \& Chung M.S. (2011) Subcritical water extraction of flavonol quercetin from onion skin. Journal of Food Engineering, 102, 327-333.

Kono S., Shinchi K., Ikeda N., Yanai F., \& Imanishi K. (1992) Green tea consumption and serum lipid profiles: a cross-sectional study in northern Kyushu. Japan Preventive Medicine, 21, 526-531.

Korzen-Bohr S., \& O'doherty Jensen K. (2006) Heart disease among postmenopausal women: Acceptability of functional foods as a preventive measure. Appetite, 46, 152-163.

Kotilaine L., Rjalahti R., Ragasa C., \& Pehu E. (2006) Health enhancing foods: Opportunities for strengthening the sector in developing countries. World Bank Discussion Paper 30.

Kwon M.J., Song Y.S., Choi M.S., Park S.J., Jeong K.S., \& Song Y.O. (2003) Cholesteryl ester transfer protein activity and atherogenic parameters in rabbits supplemented with colesterol and garlic powder. Life Sciences, 72, 2953-2964.

Lei F., Zhang X.N., Wang W., Xing D.M., Xie W.D., Su H., \& Du L.J. (2007) Evidence of antiobesity effects of the pomegranate leaf extract in high-fat diet induced obese mice. International Journal of Obesity, 31, 1023-9.

Liazid A., Guerrero R.F., Cantos E., Palma M., \& Barroso C.G. (2011) Microwave assisted extraction of anthocyanins from grape skins. Food Chemistry, 124, 1238-1243.

Liberato S., Hernández M., Torroba L., Sánchez F., Ciriza S., Gómez A., \& Chueca M. (2005) Infección por Helicobacter pylori en población infantil: prevalencia, factores asociados e influencia sobre el crecimiento. Anales de Pediatría, 63, 489-494.

Lichtenstein A.H., Jalbert S.M., Adlercreutz H., Goldin B.R., Rasmussen H., Schaefer E.J., \& Ausman L.M. (2002) Lipoprotein response to diets high in soy or animal 
protein with and without isoflavones in moderately hypercholesterolemic subjects. Arteriosclerosis, Thrombosis and Vascular Biology, 22, 1852-1858.

Limón-Pacheco J., \& Gonsebatt M.E. (2009) The role of antioxidants and antioxidant-related enzymes in protective responses to environmentally induced oxidative stress. Mutation Research, 674, 137-147.

Lin L.Y., Peng C.C., Yang Y.L., \& Peng R.Y. (2008) Optimization of bioactive compounds in buckwheat sprouts and their effect on blood cholesterol in hamsters. Journal of Agricultural Food Chemistry, 56, 1216-1223.

Lionetti E., Miniello V.L., Castellaneta S.P., Magista A.M., De canio A., \& Maurogiovanni G. (2006) Lactobacillus reuteri therapy to reduce side-effects during anti-Helicobacter pylori treatment in children: A randomized placebo controlled trial. Alimentary Pharmacology \& Therapeutics, 24, 1461-1468.

Liu S.X., Hou F.F., Guo Z.J., Nagai R., Zhang W.R., Liu Z.Q., Zhou Z.M., Zhou M., Xie D., Wang G.B., \& Zhang X. (2006) Advanced oxidation protein products accelerate atherosclerosis through promoting oxidative stress and inflammation. Arteriosclerosis Thrombosis and Vascular Biology, 26, 1156-1162.

Lobstein T.J., James W.P.T., \& Cole T.J. (2003) Increasing levels of excess weight among children in England. International Journal of Obesity, 27, 1136-1138.

Más R., Castaño G., Illnait J., Fernández L., Fernández J., Alemán C., Pontigas V., \& Lescay M. (1999) Effects of policosanol in patients with type II hypercholesterolemia and additional coronary risk factors. Clinical Pharmacology \& Therapeutics, 65, 439-447.

Mäkinen-Aakula M. (2006) Trends in functional foods dairy market. In Proceedings of the third functional food net meeting.

Manea A. (2010) NADPH oxidase-derived reactive oxygen species: involvement in vascular physiology and pathology. Cell and Tissue Research, 342, 325-339.

Marcano M.J. (2003) Asociación entre infección por Helicobacter pylori y urticaria crónica idiomática. Dermatología Venezolana, 41, 324-331.

Maron D.J., Lu G.P., Cai N.S., Wu Z.G., Li Y.H., Chen H., Zhu J.Q., Jin X.J., Wouters B.C., \& Zhao J. (2003) Cholesterollowering effect of a theaflavin-enriched green tea extract: a randomized controlled trial. Archives of Internal Medicine, 163, 14481453.

Marteau P., Minekus M., Havenaar R., Huis in't Veld J.H. (1997) Survival of lactic acid bacteria in a dynamic model of the stomach and small intestine: Validation and the effects of bile. Journal of Dairy Science, 80, 1031-1037.

McRae M.P. (2006) The efficacy of vitaminC supplementation on reducing total serum cholesterol in human subjects: a review and analysis of 51 experimental trials. Journal of Chiropractic Medicine, 5, 2-12

Menrad K. (2003) Market and marketing of functional foods in Europe. Journal of Food Engineering, 56, 181-188.

Meyer J.M, Silliman N.P, Wang W., Siepman N.Y., Sugg J.E., \& Morris D. (2002) Risk Factors for the Helicobacter pylori resistance in United States: The surveillance 
of H. pylori antimicrobial resistance partnership (SHARP) study 1993-1999. Annals of Internal Medicine, 136, 13-24.

Ministerio de Sanidad y Consumo, Sociedad Española de Cardiología, Sociedad Española de Arterioesclerosis. (2000) Control de la colesterolemia en España, 2000. Un instrumento para la prevención cardiovascular. Revista Española de Salud Pública, 74, 215-253.

Ministry of Health. (1996) The Regulation for Health Foods. Beijing: China Standards.

Monár J. (2007) The Spanish functional food market: Present and future perspectives. Functional FoodNet (FFNet) network meeting, IATA-CSIC.

Monrad J.K., Howard L.R., King J.W., Srinivas K., \& Mauromoustakos A. (2010a) Subcritical solvent extraction of procyanidins from dried red grape pomace. Journal of Agricultural and Food Chemistry, 58, 4014-4021.

Monrad J.K., Howard L.R., King J.W., Srinivas K., \& Mauromoustakos A. (2010b) Subcritical solvent extraction of procyanidins from dried red grape pomace. Journal of Agricultural and Food Chemistry, 58, 2862-2868.

Mrda Z., Zivanovic M., Rasic J., Gajin S., Somer L., \& Trbojevic S. (1998) Therapy of Helicobacter pylori infection using Lactobacillus acidophilus. Meditsinski Pregled, 51, 343-345.

Mukai T., Asasaka T., Sato E., Mori K., Matsumoto M., \& Ohori H. (2002) Inhibition of binding of Helicobacter pylori to the glycolipid receptors by probiotic Lactobacillus reuteri. FEMS Immunology \& Medical Microbiology, 32, 105-110. Müller-Riemenschneider F., Reinhold T., Berghöfer A., \& Willich S.N. (2008) HealthEconomic Burden of Obesity in Europe. European Journal of Epidemiology, 23 (8), 499-509.

Murga R., Ruiz R., Beltran S., \& Cabezas J.L. (2000) Extraction of natural complex phenols and tannins from grape seeds by using supercritical mixtures of carbon dioxide and alcohol. Journal of Agricultrual and Food Chemistry, 48, 3408-3412.

Myllyluoma E., Veijola L., Ahlroos T., Tynkkynen S., Kankuri E., \& Vapaatalo H. (2005) Probiotic supplementation improves tolerance to Helicobacter pylori eradication therapy-A placebo controlled, double-blind randomized pilot study. Alimentary Pharmacology \& Therapeutics, 21, 1263-1272.

Nanetti L., Raffaelli F., Tranquilli A.L., Fiorini R., Mazzanti L., \& Vignini A. (2012) Effect of consumption of dark chocolate on oxidative stress in lipoproteins and platelets in women and in men. Appetite, 58, 400-405.

National Academy of Sciences, Committee on Diet and Health, National Research Council. (1989) Diet and health: implications for reducing chronic disease risk. Washington, DC: National Academy Press.

Ng C.H., Leung K.Y., Huang Y., \& Chen Z.Y. (2005) Policosanol has no antioxidant activity in humans low-density lipoprotein but increases excretion of bile acids in hamsters. Journal of Agricultural Food Chemistry, 53, 6289-6293. 
Nigdikar S.V., Williams N.R., Griffin B.A., \& Howard A.N. (1998) Consumption of red wine polyphenols reduces the susceptibility of low-density lipoproteins to oxidation in vivo. American Journal of Clinical Nutrition, 68, 258-265.

Nishihira J., Sato-Ueshima M., Kitadate K., Wakame K., \& Fujii H. (2009) Amelioration of abdominal obesity by low-molecular-weight polyphenol (Oligonol) from lychee. Journal of Functional Foods, 1, 341-348.

Nista E.C., Candelli M., Cremonini F., Cazzato I.A., Zocco M.A., \& Franceschi F. (2004) Bacillus clausii therapy to reduce side effects of anti-Helicobacter pylori treatment: Randomized, doubleblind, placebo controlled trial. Alimentary Pharmacology \& Therapeutics, 20, 1181-1188.

Nobre B.P., Palavra A.F., Pessoa F.L.P., \& Mendes R.L. (2009) Supercritical $\mathrm{CO}_{2}$ extraction of trans-lycopene from Portuguese tomato industrial waste. Food Chemistry, 116, 680-685.

Ntanios F.Y., van de Kooij A.J., de Deckere E.A., Duchateau G.S., \& Trautwein E.A. (2003) Effects of various amounts of dietary plant sterol esters on plasma and hepatic sterol concentration and aortic foam cell formation of cholesterol-fed hamsters. Atherosclerosis, 169, 41-50.

Nutrition Business Journal. (2007a) The global nutrition industry IV. Nutrition Business Journal, 5/ 6, 3-47.

Nutrition Business Journal. (2007b) Functional foods IX: Healthy foods. Nutrition Business Journal, 2/ 3, 2-11.

Ohama H., Ikeda H., \& Moriyama H. (2006) Health foods and foods with health claims in Japan. Toxicology, 22, 95-111.

Owen A.J., Roach P.D., \& Abbey M. (2004) Regulation of low-density lipoprotein receptor activity by estrogens and phytoestrogens in a HepG2 cell model. Annals of Nutrition and Metabolism, 48, 269-275.

Palma M., \& Taylor L.T. (1999) Extraction of polyphenolic compounds from grape seeds with near critical carbon dioxide. Journal of Chromatography, A, 849, 117124.

Parsonnet J. (1998) Helicobacter pylori: the size of the problem. Gut, 43, S6-S9.

Patil B.S., Jayaprakasha G.K., Murthy K.N.C., \& Vikram A. (2009) Bioactive compounds: Historical perspectives, opportunities, and challenges. Journal of Agricultural and Food Chemistry, 57, 8142-8160.

Pérez-Serradilla J.A., \& Luque de Castro M.D. (2011) Microwave-assisted extraction of phenolic compounds from wine lees and spray-drying of the extract. Food Chemistry, 124, 1652-1659.

Pinchuk I.V., Bressollier P., Verneuil B., Fenet B., Sorokulova I.B., \& Meograud F. (2001) In vitro anti-Helicobacter pylori activity of the probiotic strain Bacillus subtilis 3 is due to secretion of antibiotics. Antimicrobial Agents and Chemotherapy, 45, 3156-3161.

Pinelo M., Ruiz R.A., Sineiro J., Senorans FJ., Reglero G., \& Nunez M.J. (2007) Supercritical fluid and solid-liquid extraction of phenolic antioxidants from 
grape pomace: A comparative study. Europan Food Research and Technology, 226, 199-205.

Plaza M., Cifuentes A., \& Ibáñez E. (2008) In the search of new functional food ingredients from algae. Trends in Food Science \& Technology, 19, 31-39.

Plösch T., Kruit J.K., Bloks V.W., Huijkman N.C., Havinga R., Duchateau G.S., Lin Y., \& Kuipers F. (2006) Reduction of cholesterol absorption by dietary plant sterols and stanols in mice is independent of the Abcg5/8 transporter. Journal of Nutrition, 136, 2135-2140.

Pueyo A.M., Huarte M.P., \& Jiménez C. (1998) Epidemiología de la infección por Helicobacter pylori. Anales del Sistema Sanitario de Navarra, 21, 543-551.

Ramjiganesh T., Roy S., McIntyre J.C., \& LuzFernandez M. (2001) The hypocholesterolaemic effects of sitostanol in the guinea pig are in part related to changes in hepatic lipids and lipoprotein composition. British Journal of Nutrition, 85, 165-172.

Reuters (2000). Reuters News and Abstracting Service: Pariza news conference. Conjugated linoleic acid and the control of cancer and obesity. American Chemical Society Meeting, July 2000.

www.geocities.com/ HotSprings/ 1505/ guide_medlinks.(html\#DAILYHEALTHN EWS)

Rodríguez-Echenique C., Mesa R., Más R., Noa M., Menéndez R., González R.M., Amor A.M., Fraga V., Sotolongo V., \& Laguna A. (1994) Effects of policosanol chronically administered in male monkeys (Macaca arctoides). Food and Chemical Toxicology, 32, 565-575.

Rozzi N.L., Singh R.K., Vierling R.A., \& Watkins B.A. (2002) Supercritical fluid extraction of lycopene from tomato processing by-products. Journal of Agricultural and Food Chemistry, 50, 2638-2643.

Saafi E.B., Louedi M., Elfeki A., Zakhama A., Najjar M.F., Hammami M., \& Achour L. (2011) Protective effect of date palm fruit extract (Phoenix dactylifera L.) on dimethoate induced-oxidative stress in rat liver. Experimental and Toxicologic Pathology, 63, 433-441.

Sabio E., Lozano M., Montero de Espinosa V., Mendes R.L., Pereira A.P., Palavra A.F., \& Coelho J.A. (2003) Lycopene and b-carotene extraction from tomato processing waste using supercritical $\mathrm{CO}_{2}$. Industrial and Engineering Chemistry Research, 42, 6641-6646.

Sadler J. (2005) Innovations in functional foods and drinks. Business Insights Ldt. Management Report.

Sakamoto S., Igarashi M., Kimura K., Takagi A., Miwa T., \& Koga Y., (2001) Suppressive effect of Lactobacillus gasseri OLL2716 (LG21) on Helicobacter pylori infection in humans. Journal of Antimicrobial Chemotherapy, 47, 709-710.

Sáinz-Samitier R, Mearin F., Pique J.M., Saperas E., \& Lanas A. (2000) Enfermedades del estómago y del duodeno. Ferreras-Rozman, Medicina interna.14 ed España: Harcourt, 21, 145-152. 
Sanal I.S., Bayraktar E., Mehmetoglu Ü., \& Çalimli A. (2005) Determination of optimum conditions for $\mathrm{SC}-\left(\mathrm{CO}_{2}+\right.$ ethanol $)$ extraction of b-carotene from apricot pomace using response surface methodology. Journal of Supercritical Fluids, 34, 331-338.

Saviranta N.M.M., Veeroos L., Granlund L.J., Hassinen V.H., Kaarniranta K., \& Karjalainen R.O. (2011) Plant flavonol quercetin and isoflavone biochanin A differentially induce protection against oxidative stress and inflammation in ARPE-19 cells. Food Research International, 44, 109-113.

Seon-Min J., Yong B.P., Myung-Sook C. (2004) Antihypercholesterolemic property of naringin alters plasma and tissue lipids, cholesterol-regulating rnzymes, fecal sterol and tissue morphology in rabbits. Clinical Nutrition, 23, 1025-1034.

Shahidi F. (2009) Nutraceuticals and functional foods: Whole versus processed foods. Trends in Food Science \& Technology, 20, 376-387.

Sheu B.S., Wu J.J., Lo C.Y., Wu H.W., Chen J.H., Lin Y.S. (2002) Impact of supplement with Lactobacillus and Bifidobacterium containing yogurt on triple therapy for Helicobacter pylori eradication. Alimentary Pharmacology \& Therapeutics, 16, 1669-1675.

Shi J., Ho C.T., \& Shahidi F. (2005a) Asian Functional Foods by, CRC Press;

Shi J., Nawaz H., Pohorly J., Mittal G., Kakuda Y., \& Jiang Y. (2005b) Extraction of polyphenolics from plant material for functional foods-engineering and technology. Food Reviews International, 21, 139-166.

Shi J., Yi C., Xue S. J., Jiang Y., Ma Y., \& Li D. (2009) Effects of modifiers on the profile of lycopene extracted from tomato skins by supercritical $\mathrm{CO}_{2}$. Journal of Food Engineering, 93, 431-436.

Shih P.H., Yeh C.T., \& Yen G.C. (2007) Anthocyanins Induce the Activation of Phase II Enzymes through the Antioxidant Response Element Pathway against Oxidative Stress-Induced Apoptosis. Journal of Agricultural and Food Chemistry, 55, 9427-9435.

Side C. (2006) Overview on marketing functional foods in Europe. Functional food network general meeting.

Singh S., Gamlath S., \& Wakeling L. (2007) Nutritional aspects of food extrusion: a review. International Journal of Food Science \& Technology, 42 (8), 916-929.

Singh P.P., \& Saldaña M.D.A. (2011) Subcritical water extraction of phenolic compounds from potato peel. Food Research International, 44, 2452-2458.

Stein J.H., Keevil J.G., Wiebe D.A., Aeschlimann S., \& Folts J.D. (1999) Purple grape juice improves endothelial function and reduces the susceptibility of LDL cholesterol to oxidation in patients with coronary artery disease. Circulation, 100, 1050-1055.

Steinberg F.M., Guthrie N.L., Villablanca A.C., Kumar K., \& Murray M.J. (2003) Soy protein with isoflavones has favorable effect on endothelia function that are independent of lipid and antioxidant effects in healthy postmenopausal women. American Journal of Clinical Nutrition, 78, 123-130. 
Stensvold I., Tverdal A., Solvoll K., \& Fosso P. (1992) Tea consumption. Relationship to cholesterol, blood pressure, and coronary and total mortality. Preventive Medicine, 21, 546-553.

Stevinson C., Pittler M.H., \& Ernst E. (2000) Garlic for treating hypercholesterolemia. A meta-analysis of randomized clinical trials. Annals of Internal Medicine, 133, 420-429.

Suerbaum S., \& Michetti P. (2002) Helicobacter pylori infection. New England Journal of Medicine, 347, 1175-1186.

Temme E.H., van Hoydonck P.G., Schouten E.G., \& Kesteloot H. (2002) Effects of a plant sterol-enriched spread on serum lipids and lipoproteins in mildly hypercholesterolaemic subjects. Acta Cardiologica, 57, 111-115.

Temple N.J. (2000) Antioxidants and disease: more questions than answers. Nutrition Research, 20, 449-59.

The economist. (2009) Nestle: The unrepentant chocolatier. The economist Web site. Accessed July 13, 2012 http:/ / www.economist.com/ node/ 14744982.

Thomson M., Al-Qattan K.K., Bordia T., \& Ali M. (2006) Including garlic in the diet may help lower blood glucose, cholesterol, and triglycerides. Journal of Nutrition, 136, 800S-802S.

Tomotake H., Shimaoka I., Kayashita J., Yokoyama F., Nakajoh M., \& Kato N. (2000) A buckwheat protein product suppresses gallstone formation and plasma choelsteorl more strongly than soy protein isolate in hamsters. Journal of Nutrition, 130, 1670-1674.

Tomotake H., Yamamoto N., Kitabayashi H., Kawakami A., Kayashita J., Ohinata H., Karasawa H., \& Kato N. (2007) Preparation of tartary buckwheat protein product and its improving effect on choelsterol metabolism in rats and mice fed choelsterolenriched diet. Journal of Food Science, 72, S528-S533.

Torres O., Agramonte A.J., Illnait J., Más R., Fernández L., \& Fernández J.C. (1995) Treatment of hypercholesterolemia in NDDM with policosanol. Diabetes Care, 18, 393-397.

Touhy M., Pappalardo G., Manning R., Dugal L.F., \& Levy D. (2011) Leveraging growth in the emerging functional foods industry: trends and market opportunities. PricewaterhouseCoopers Website. Accessed July 13, 2012. http:// www.pwc.com/ us/ transaction-services/ publications/ assets/ functionalfoods.pdf.

Tsai C.C., Huang L.F., Lin C.C., \& Tsen H.Y. (2004) Antagonistic activity against Helicobacter pylori infection in vitro by a strain of Enterococcus faecium TM39. International Journal of Food Microbiology, 96, 1-12.

Turgeon S.L., \& Rioux L.E. (2011) Food matrix impact on macronutrients nutritional properties. Food Hydrocolloids, 25, 1915-1924.

Turner C., Turner P., Jacobson G., Almgren K., Waldebäck M., Sjöberg P., Karlsson E.N., \& Markides K.E. (2006) Subcritical water extraction and b-glucosidasecatalyzed hydrolisis of quercetin glycosides in onion waste. Green Chemistry, 8(11), 949-959. 
Valdecantos M.P., Pérez-Matute P., Quintero P., Martínez J.A. (2010) Vitamin C, resveratrol and lipoic acid actions on isolated rat liver mitocondria: all antioxidants but different. Redox Report, 15, 207-216.

Valko M., Leibfritz D., Moncol J., Cronin M.T., Mazur M., \& Telser J. (2007) Free radicals and antioxidants in a normal physiological functions and human disease. International Journal of Biochemistry \& Cell Biology, 39(1), 44-84.

Van Kleef E., Van Trijp H.C.M., Luning P., \& Jongen W.M.F. (2002) Consumeroriented functional food development: How well do functional disciplines reflect the 'voice of the consumer'? Trends in Food Science \& Technology, 13, 93-101.

Van Kleef E., Van Trijp H.C.M., \& Luning P. (2005) Functional foods: Health claimfood product compatibility and the impact of health claim framing on consumer evaluation. Appetite, 44, 299-308.

Vega P.J., Balaban M.O., Sims C.A., O'Keefe S.F., \& Cornell J.A. (1996) Supercritical carbon dioxide extraction efficiency for carotenes from carrots by RSM. Journal of Food Science, 61, 757-759.

Verbeke W. (2005) Consumer acceptance of functional foods: Socio-demographic, cognitive and attitudinal determinants. Food Quality and Preference, 16, 45-57.

Viamari S. (2009) Health \& wellness: Redefining healthy living. Times and Trends. Supermarket News Web site. Accessed July 13, 2012.

http:/ / supermarketnews.com/ images/ T_T-November-2009-Healthy-living.pdf.

Viamari S. (2010) New product pacesetters: innovating growth in recessionary times. Times and Trends. Supermarket News Web site. Accessed July 13, 2012. http:/ / supermarketnews.com/ images/ T_T-March-2010-NPP.pdf

Vroegrijk I.O., van Diepen J.A., van den Berg S., Westbroek I., Keizer H., Gambelli L., Hontecillas R., Bassaganya-Riera J., Zondag G.C., Romijn J.A., Havekes L.M., \& Voshol P.J. (2011) Pomegranate seed oil, a rich source of punicic acid, prevents diet-induced obesity and insulin resistance in mice. Food and Chemical Toxicology, 49, 1426-30.

Walker R. (1994) Hyperlipidaemia. In Clinical Pharmacy and Therapeutics, Walter, R., Edwards, C., Eds., Churchill Livingstone: New York, 309-325.

Wang Z., Rhee D.B., Lu J., Bohr C.T., Zhou F., Vallabhaneni H., de Souza-Pinto N.C., \& Liu Y. (2010) Characterization of oxidative guanine damage and repair in mammalian telomeres. Plos Genetics, 6(5), e1000951.

Weststrate J.A., \& Meijer G.W. (1998) Plant sterol-enriched margarines and reduction of plasma total- and LDL-cholesterol concentrations in normocholesterolaemic and mildly hypercholesterolaemic subjects. European Journal of Clinical Nutrition, 52, 334-343.

WHO. (2004) "Overweight and obesity (high body mass index)". Chapter 8. In: James WPT et al. (ed.)Comparative quantification of health risks global and regional burden of diseases attributable to selected major risk factors. Geneva: WHO 
WHO. (2004) Global health risks report. Mortality and burden of disease attributable to selected major risks. WHO Library Cataloguing-in-Publication World Health Organization. ISBN 9789241563871 (NLM classification: WA 105).

WHO. (2007) WHO statement: Controlling the global obesity epidemic. http:/ / www.who.int/ nutrition/ topics/ obesity/ en.

WHO/ NUT/ NCD. (2000) Obesity: preventing and managing the global epidemic. Report of a WHO consultation in obesity. WHO TRS 894: Geneva.

Wijngaard H.H., \& Brunton N. (2009) The optimisation of solid-liquid extraction of antioxidants from apple pomace by response surface methodology. Journal of Food Engineering, 96, 134-140.

Wijngaard H., Hossain M.B., Rai D.K., \& Brunton N. (2012) Techniques to extract bioactive compounds from food by-products of plant origin. Food Research International, 46, 505-513.

Wildman. (2006) Classifying nutraceuticals. In Handbook of Nutraceuticals and Functional Foods, Second Edition, Wildman Ed., CRC Publisher, 13-31;

Willett W.C. (1994) Diet and health: what should we eat? Science, 254, 532-37.

Willett W.C. (1995) Diet, nutrition, and avoidable cancer. Environmental Health Perspectives, 103(8), 165-70.

Zern T.L., Wood R.J., Greene C., West K.L., Liu Y.Z., Aggarwal D., Shachter N.S., \& Fernandez M.L. (2005) Grape polyphenols exert a cardioprotective effect in pre- and postmenopausal women by lowering plasma lipids and reducing oxidative stress. Journal of Nutrition, 135, 1911-1917.

Zhang Z., Ho W.K.K., Huang Y., \& Chen Z.Y. (2002a) Hypocholesterolemic activity of hawthorn fruit is mediated by regulation of cholesterol-7R-hydroxylase and acyl CoA: cholesterol acyltransferase. Food Research International, 35, 885-891.

Zhang Z., Ho W.K.K., Huang Y., James A.E., Lam L.W., \& Chen Z.Y. (2002b) Hawthorn fruit is hypolipidemic in rabbits fed a high cholesterol diet. Journal of Nutrition, 132, 5-10.

Zojaji H., Talaie R., Mirsattari D., Haghazali M., Molaei M., Mohsenian N., Derakhshan F., \& Zali M.R. (2009) The efficacy of Helicobacter pylori eradication regimen with and without vitamin $C$ supplementation. Digestive and Liver Disease, 41, 644-647. 
2. OBJETIVOS Y PLAN DE TRABAJO 



\subsection{Justificación e interés de la tesis doctoral.}

Los resultados previos sobre los que se sustentan los objetivos de esta tesis son:

a. El equipo investigador que ha llevado a cabo el proyecto en el que se integra la tesis doctoral ha desarrollado un procedimiento que permite incluir cualquier componente con actividad fisiológica (minerales, vitaminas, microorganismos probióticos, compuestos con actividad antioxidante...) en el interior de una fruta u hortaliza. El procedimiento es objeto de la patente P99 02730-5 titulada "Procedimiento de impregnación de alimentos naturales con productos nutracéuticos y dispositivo para su puesta en práctica". El procedimiento desarrollado se fundamenta en la posibilidad de utilizar la operación de impregnación a vacío como método para modificar la composición de las frutas y hortalizas de una forma controlada sin la necesidad de aplicar altas temperaturas, y permitiendo por tanto conservar las propiedades nutritivas y sensoriales de la fruta fresca inicial. La viabilidad del procedimiento ha sido comprobada a nivel de laboratorio para una amplia gama de frutas, hortalizas y componentes con actividad fisiológica y a nivel de planta piloto para la obtención de hortalizas de cuarta gama enriquecidas en minerales.

b. Gran cantidad de estudios han demostrado los efectos beneficiosos que derivan del consumo de zumos de cítricos. Algunos de los miembros del equipo investigador que ha desarrollado el proyecto en el que se integra la tesis doctoral dirigidos por la Dra. Pilar Codoñer, jefe de la sección de pediatría del Hospital Universitario Dr. Peset de Valencia, han puesto a punto métodos de valoración de la actividad antioxidante y antirradical del zumo de mandarina tanto in vitro como en animales de experimentación. Tanto en las valoraciones in vitro como in vivo los resultados obtenidos han sido positivos, encontrándose una disminución de los parámetros indicadores de estrés oxidativo en los sujetos suplementados.

Las razones anteriores permiten plantear la siguiente hipótesis de partida:

"La utilización de un zumo incorporado en la estructura matricial de una fruta mediante la operación de impregnación a vacío, como vehículo para microorganismos probióticos o componentes fisiológicamente activos, puede mejorar el efecto de los mismos y, al mismo tiempo, hacer posible el desarrollo de alimentos funcionales a base de fruta dirigidos a colectivos de población con problemas muy específicos".

Se considera pertinente realizar la investigación por las siguientes razones:

1. En estos momentos de entre los problemas que preocupan a las autoridades sanitarias se encuentran: 
a. La obesidad en niños y adolescentes. Su incidencia creciente en los últimos años y sus posibles repercusiones en la enfermedad cardiovascular en la época adulta hace necesaria la puesta en marcha de medidas preventivas ya desde los primeros años de la infancia.

b. La infección ocasionada por Helicobacter Pylori. Se han descrito tasas muy elevadas en países en vías de desarrollo como Bolivia (70 \% de individuos seropositivos a los 9 años) mientras que la seroprevalencia de niños que viven en naciones industrializadas es mucho menor (12 $15 \%$ a los 9 años en USA). En España la prevalencia media en niños de edad escolar está en torno al $22 \%$.

2. Se considera que el consumo de frutas y hortalizas desde los primeros años de vida es una de las mejores medidas para prevenir la aparición de enfermedades crónicas en la edad adulta. La OMS ha llegado a establecer la recomendación de consumir cinco raciones diarias de frutas y hortalizas.

3. Diferentes estudios científicos demuestran que algunos componentes de los zumos cítricos poseen actividad antioxidante y actúan sobre el metabolismo de los lípidos.

4. Helicobacter pylori es un agente etiológico de la gastritis crónica y de la úlcera gastroduodenal y constituye un factor de riesgo para la aparición de linfoma gástrico o adenocarcinoma. A pesar de ello no se recomienda el tratamiento erradicador con antibióticos en niños colonizados, entre otras razones por la facilidad en la aparición de resistencias y la elevada tasa de recaídas después del tratamiento.

5. Estudios in vitro han demostrado que diferentes cepas de microorganismos con efecto probiótico pueden inhibir el crecimiento de Helicobacter pylori.

6. Algunos estudios destacan el efecto beneficioso de las matrices alimentarias como las frutas y los zumos sobre la protección y viabilidad de los microorganismos y los compuestos con actividad fisiológica.

7. El procedimiento de inclusión de componentes funcionales con actividad específica en la estructura de frutas u hortalizas frescas (desarrollado por el equipo investigador) suponen una oportunidad para combinar los efectos indicados en los puntos 2, 3 y 5, y proporcionar una alternativa adicional y atractiva que ayude a fomentar el consumo de frutas y hortalizas en la población infantil.

8. Es necesario diseñar el producto final de forma que contenga la mayor cantidad posible de componentes activos (antioxidantes y/ o probióticos), comprobar la actividad funcional del producto desarrollado y su aceptación mediante ensayos en la población infantil.

9. Es necesario diseñar y construir una línea de fabricación del producto a nivel de planta piloto que permita evaluar los aspectos tecnológicos y económicos de la producción industrial del producto desarrollado así como fabricar cantidades suficientes del mismo para realizar los ensayos clínicos, 
la evaluación in vitro de sus propiedades funcionales, la valoración de su aceptación y la vida útil.

\subsection{Objetivos.}

El objetivo general de la tesis doctoral es:

a. El desarrollo tecnológico y la valoración funcional, mediante estudios in vivo, de un alimento funcional de baja humedad a partir de manzana y zumo de mandarina, con efecto sobre el riesgo cardiovascular en niños obesos de edad escolar.

b. El desarrollo y la valoración funcional, mediante una prueba piloto in vivo, de un alimento funcional de baja humedad a partir de manzana y zumo de mandarina, con efecto sobre la infección por Helicobacter pylori en niños infectados de edad escolar.

Para alcanzar el objetivo general se plantean los siguientes objetivos específicos:

1. Realizar una revisión bibliográfica en la que se determine qué tecnologías se utilizan actualmente para el desarrollo de alimentos funcionales.

2. Valorar algunos aspectos tecnológicos, económicos y medioambientales para la implantación industrial del proceso de fabricación del alimento funcional.

3. Determinar el efecto de la operación de homogeneización del zumo de mandarina sobre:

- Propiedades fisicoquímicas

- Propiedades funcionales

- Comportamiento durante la operación de impregnación a vacío.

4. Determinar el efecto del proceso de fabricación del alimento funcional de baja humedad a partir de manzana y zumo de mandarina sobre:

- Propiedades fisicoquímicas

- Propiedades funcionales

- Grado de aceptación.

5. Estudiar in vivo la capacidad antioxidante del alimento funcional y determinar sus efectos sobre la salud en animales de experimentación y humanos.

6. Determinar el efecto del proceso de fabricación del alimento funcional a partir de manzana y zumo de mandarina con microorganismos probióticos sobre:

- Contenido en microorganismos probióticos viables.

- Propiedades fisicoquímicas

- Efecto funcional en niños colonizados por Helicobacter pylori (prueba preliminar). 


\subsection{Plan de trabajo.}

Con el objetivo de facilitar la comprensión al lector, el plan de trabajo se presenta de forma esquemática y se ha subdivido en dos partes. La figura (1) corresponde al plan de trabajo que se ha seguido para completar los objetivos 2, 3, 4 y 5. La figura (2) corresponde al plan de trabajo que se ha seguido para completar el objetivo 6 .

Debido al carácter interdisciplinar de esta tesis doctoral:

a. Las actividades relacionadas con la obtención de un zumo de mandarina de elevada calidad se realizaron en la planta piloto del Instituto Agroalimentario de Tecnología de Alimentos (IATA-CSIC).

b. Las actividades relacionadas con los estudios in vivo llevados a cabo con animales de experimentación se realizaron en el animalario del Departamento de Pediatría, Obstetricia y Ginecología de la Facultad de Medicina y Odontología de la Universidad de Valencia.

c. Las actividades relacionadas con los estudios in vivo en humanos se realizaron en la unidad de pediatría del Hospital Universitario Dr. Peset de Valencia.

d. El resto de actividades se llevaron a cabo en el Instituto Universitario de Ingeniería de Alimentos para el Desarrollo (IU-IAD) de la Universidad Politécnica de Valencia. 

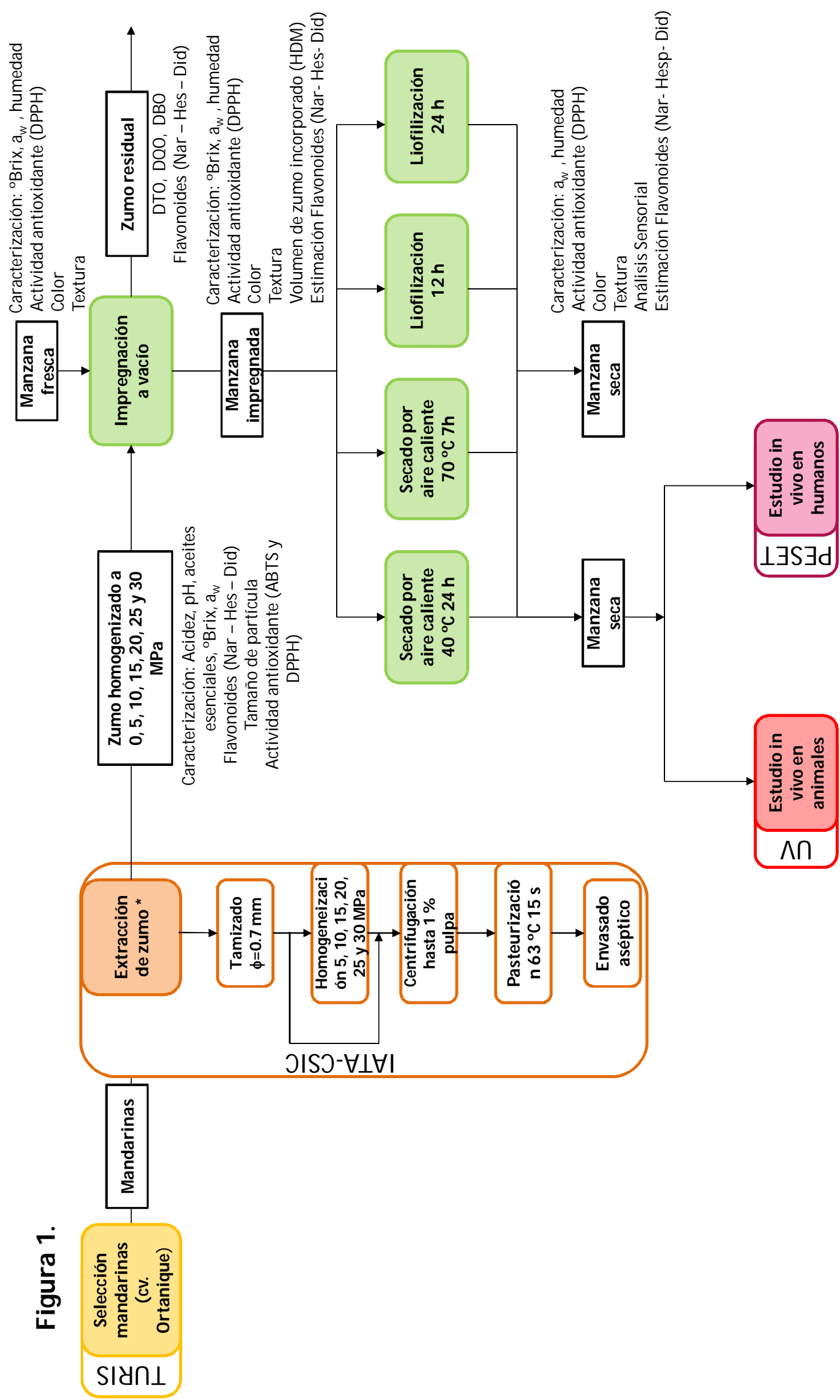


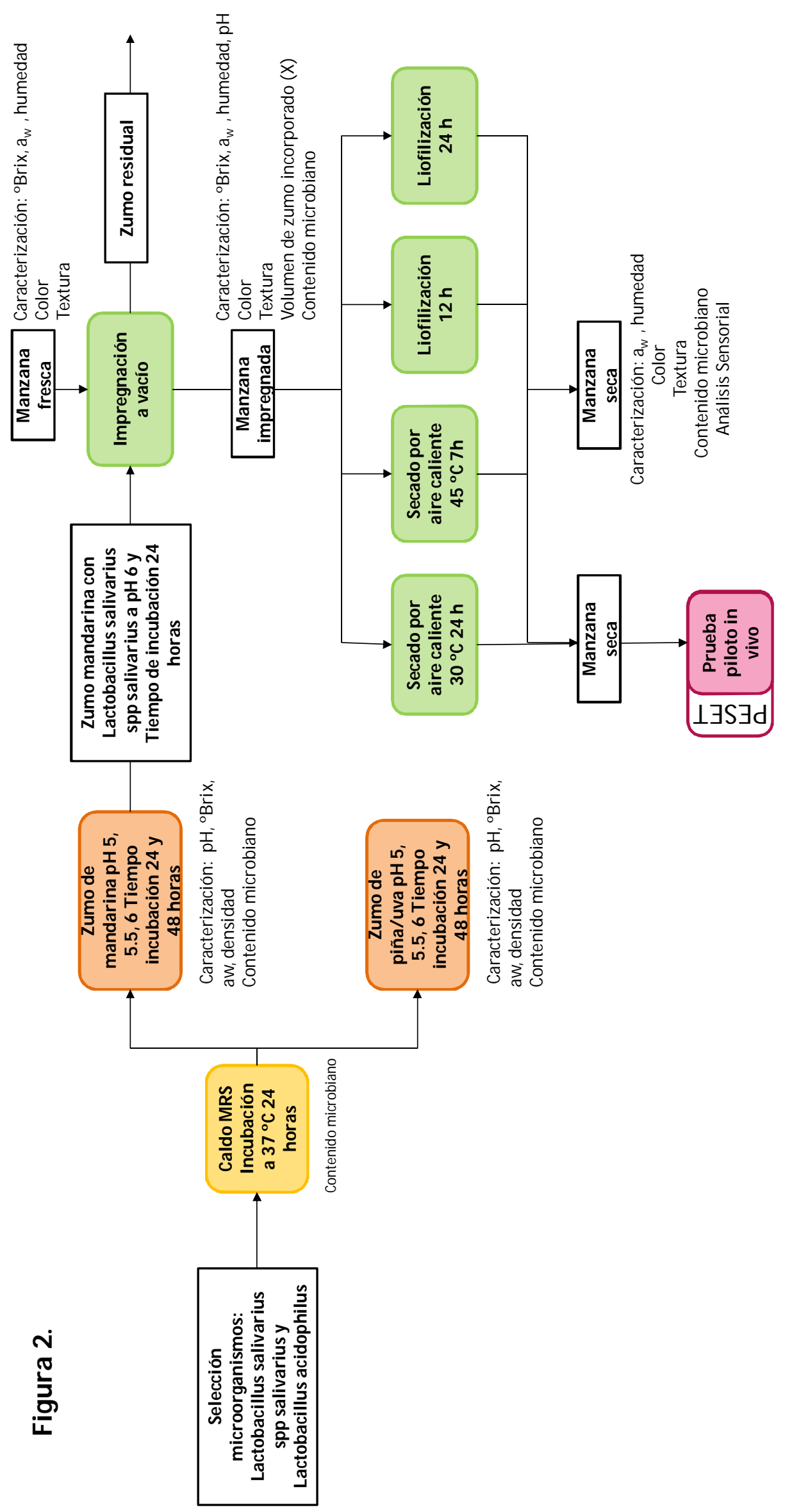


1. Revisión bibliográfica.

2. Valoración de algunos aspectos tecnológicos, económicos y medioambientales para la implantación industrial del proceso de fabricación del alimento funcional. Este estudio se corresponde con el objetivo específico 2 y su plan experimental es el que a continuación se presenta:

a. Definición de las variables relacionadas con el proceso de fabricación.

b. Modelo matemático para el cálculo y dimensionamiento de los equipos a nivel de laboratorio.

c. Aspectos económicos y tecnológicos del proceso de fabricación.

d. Evaluación de los aspectos medioambientales.

- Establecimiento de los puntos críticos del proceso.

- Caracterización medioambiental de la corriente de zumo de mandarina residual:

Determinación de la demanda teórica de oxígeno (DTO).

Determinación de la demanda química de oxígeno (DQO).

Determinación de la demanda biológica de oxígeno (DBO).

- Propuesta de un plan de corrección y depuración.

3. Estudio del efecto de la operación de homogeneización sobre las propiedades fisicoquímicas y funcionales del zumo de mandarina. Estudio de la idoneidad del zumo para su uso en la operación de impregnación a vacío. Este estudio se corresponde con el objetivo específico 3 y su plan experimental es el que a continuación se presenta:

a. Revisión bibliográfica.

b. Extracción del zumo en la planta piloto del IATA-CSIC y obtención de las muestras de zumo sin homogeneizar y homogeneizado a las presiones de 5, 10, 15, 20, 25 y $30 \mathrm{MPa}$.

c. Recepción, caracterización y almacenamiento de las muestras a analizar en congelación a $-18^{\circ} \mathrm{C}$.

d. Determinación del contenido en flavonoides mediante HPLC en el zumo fresco y congelado, sin homogeneizar y homogeneizado a las distintas presiones.

e. Determinación de la distribución y el tamaño de partícula en el zumo sin homogeneizar y homogeneizado a las distintas presiones.

f. Determinación de la pulpa suspendida, la transmitancia y el color en el zumo sin homogeneizar y homogeneizado a las distintas presiones.

g. Determinación de la actividad antirradical en el zumo sin homogeneizar y homogeneizado a las distintas presiones:

- Determinación de la actividad antirradical mediante el método ABTS.

- Determinación de la actividad antirradical mediante el método DPPH. 
- Aplicación del modelo teórico de actividad antioxidante basado en la cinética de reacción de los compuestos con actividad antirradical.

h. Determinación de la composición antirradical del zumo de mandarina sin homogenizar mediante HPLC-MSn.

i. Impregnación a vacío de manzana fresca con el zumo sin homogeneizar y homogeneizado a las distintas presiones y valoración de la cantidad de zumo incorporada a la estructura matricial de la manzana en cada uno de los casos.

4. Determinación del efecto del proceso de fabricación del alimento funcional a partir de manzana y zumo de mandarina sobre las propiedades fisicoquímicas y funcionales del mismo. Evaluación del grado de aceptación mediante análisis sensorial. Este estudio se corresponde con el objetivo específico 4 y su plan experimental es el que a continuación se presenta:

a. Revisión bibliográfica.

b. Extracción del zumo, caracterización y obtención de las muestras de zumo sin homogeneizar y homogeneizado a las presiones de 5, 10, 15, 20, 25 y $30 \mathrm{MPa}$.

c. Análisis de la operación de impregnación a vacío. Determinación del contenido en flavonoides del zumo sin homogeneizar y homogeneizado a las distintas presiones antes y después de la operación de impregnación a vacío.

d. Estabilización de las muestras de manzana impregnadas mediante secado por aire caliente a $40{ }^{\circ} \mathrm{C}$ durante 24 horas y aire caliente a $70{ }^{\circ} \mathrm{C}$ hasta alcanzar la misma humedad final.

e. Estabilización de las muestras de manzana impregnadas mediante liofilización durante 12 y 24 horas.

f. Caracterización de las muestras de manzana frescas, impregnadas y deshidratadas mediante las diferentes técnicas.

g. Determinación de las propiedades ópticas y mecánicas de los productos desarrollados utilizando las diferentes técnicas y condiciones de deshidratación.

h. Análisis sensorial de los alimentos funcionales obtenidos.

i. Estimación del contenido en flavonoides de la manzana impregnada y deshidratada mediante secado por aire caliente a $40^{\circ} \mathrm{C}$.

j. Determinación de la actividad antirradical de la manzana fresca, impregnada y deshidratada mediante secado por aire caliente a $40 \stackrel{\circ}{\circ}$ : Aplicación del modelo teórico de actividad antioxidante basado en la cinética de reacción de los distintos compuestos con actividad antirradical.

k. Determinación de la composición antirradical de la manzana impregnada y deshidratada mediante secado por aire caliente a $40{ }^{\circ} \mathrm{C}$ utilizando HPLC-MSn. 
5. Estudio in vivo de la capacidad antioxidante del alimento funcional desarrollado y sus efectos sobre la salud.

a. Estudio en animales de experimentación.

b. Estudio en humanos.

6. Determinación del efecto del proceso de fabricación de un alimento funcional de baja humedad a partir de manzana y zumo de mandarina con microorganismos probióticos sobre el contenido en microorganismos viables, las propiedades fisicoquímicas y funcionales en contra de la infección ocasionada por Helicobacter pylori. Este estudio se corresponde con el objetivo específico 6 y su plan experimental es el que a continuación se presenta:

a. Revisión bibliográfica

b. Recuperación de las cepas liofilizadas (L. salivarius spp. salivarius CECT 4063 y L. acidophilus CECT 903).

c. Preparación de los medios de crecimiento a partir de zumos comerciales de mandarina y piña/ uva a tres $\mathrm{pH}$ diferentes y caracterización fisicoquímica de los mismos.

d. Transferencia de los microorganismos desde los medios de crecimiento base a los zumos comerciales e incubación durante dos tiempos diferentes ( 24 y 48 horas).

e. Recuento de los microorganismos en los distintos medios de crecimiento preparados y selección de la disolución de impregnación con mayor contenido microbiano.

f. Ensayos de impregnación a vacío con la disolución de impregnación seleccionada.

g. Recuento de microorganismos viables en las muestras impregnadas.

h. Estabilización de las muestras impregnadas mediante secado por aire caliente a 30 y $45^{\circ} \mathrm{C}$ durante 24 horas.

i. Rehidratación de las muestras deshidratadas con zumo de mandarina comercial durante 24 horas.

j. Recuento de microorganismos viables en las muestras rehidratadas.

k. Cálculo de microorganismos en las muestras deshidratadas.

l. Estabilización de las muestras impregnadas mediante liofilización durante 12 y 24 horas.

m. Rehidratación de las muestras liofilizadas con zumo de mandarina comercial durante 24 horas.

n. Recuento de microorganismos viables en las muestras rehidratadas.

o. Cálculo de microorganismos en las muestras deshidratadas.

p. Caracterización de las muestras de manzana frescas, impregnadas y deshidratadas mediante las diferentes técnicas. 
q. Determinación de las propiedades ópticas y mecánicas de los productos desarrollados utilizando las diferentes técnicas de deshidratación

r. Prueba piloto in vivo (en colaboración con el Hospital Universitario Dr. Peset de Valencia). 
3. RESULTADOSY DISCUSIÓN 

3.1. Revisión bibliográfica sobre las tecnologías utilizadas en el desarrollo de alimentos funcionales. 



\section{Functional foods development: Trends and technologies.}

E. Betoret, N. Betoret, D. Vidal and P. Fito*

a Institute of Food Engineering for Development, Department of Food Technology, Universidad Politécnica de Valencia, Camino de Vera s/ n, 46022 Valencia, Spain.

* Corresponding author. Address: Institute of Food Engineering for Development, Department of Food Technology, Universidad Politécnica de Valencia, Camino de Vera s/n, 46022 Valencia, Spain. Tel.: +34 96387 7367. Fax.: +34 96387 7056. E-mail address: pfito@tal.upv.es

The aim of this work is to make an overview on the emerging technologies and traditionally used to develop functional foods. In this way, we classified the technologies used in three main groups and analyzed the research tendency since the year 2000 until now. Thus, while traditional techniques are the most commonly used for development of functional foods, from years 2000 until 2010 the techniques aimed towards personalized nutrition have grown greatly.

\section{Introduction.}

In the last decades consumer demands in the field of food production has changed considerably. Consumers more and more believe that foods contribute directly to their health (Mollet \& Rowland, 2002). Today foods are not intended to only satisfy hunger and to provide necessary nutrients for humans but also to prevent nutrition-related diseases and improve physical and mental well-being (Takachi, Manami, Junko, Norie, Motoki, Shizuka, Hiroyasu, Yoshitaka, \& Shoichiro, 2008; Nöthlings, Murphy, Wilkens, Henderson, \& Kolonel, 2007). According to the World Health Organization and the Food and Agriculture Organization, several dietary patterns along with lifestyle habits constitute major modifiable risk factors in relation to the development of coronary heart disease, cancer, type 2 diabetes, obesity, osteoporosis and periodontal disease (WHO, 2003). In this regard, functional foods play an outstanding role (Figure 1). The increasing demand on such foods can be explained by the increasing cost of healthcare, the steady increase in life expectancy and the desire of older people for improved quality of their later years (Roberfroid, 2007).

Innovation is today's business mantra. Experts proclaim daily that the only hope for business survival is the ability to continue innovating. In this context, the development of new functional food products turns out to be increasingly challenging, as it has to fulfil the consumer's expectancy for products that are simultaneously relish and healthy (Shah, 2007). 


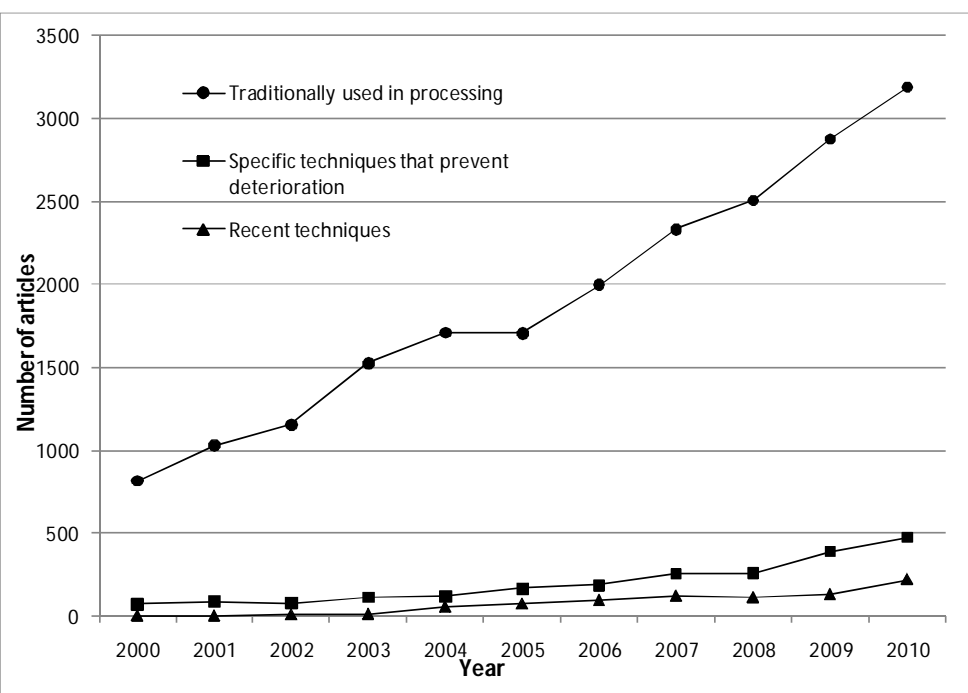

Figure 1. Tendency of the articles related to functional food with the time.

Developing a new functional food is an expensive process. Product development requires detailed knowledge of the products and the customers, which is why quantitative and qualitative marketing studies must be carried out before launching any product on the market (Beardsworth \& Keil, 1992). The high reported failure rates for new international functional foods suggest a failure to manage the customer knowledge effectively, as well as a lack of knowledge management between the functional disciplines involved in the new product development process (Jousse, 2008). The methodologies that advance a firm's understanding of customer's choice motives and values, and its knowledge of management process, can increase the chances of new product success in the international market. The commercial success of functional products ultimately depends on taste, appearance, price, and health claim appeal to consumers. They need to receive a comprehensible and reasonable message about the physiological effects of food in humans, without appearing to be exaggerated; moreover, all the factors mentioned previously influence directly the consumers' attitudes toward effective purchase, which is necessary for the maintenance of industry. In summary, the food industry takes into consideration many variables to develop or reengineer functional products, such as sensory acceptance, stability, price, chemical, functional properties (Granato, Branco, \& Nazzaro, 2010) and convenience. A great variability of techniques are required in order to meet needs and expectancies in the area of functional foods. The aim of this review is to make an overview on the emerging technologies and traditionally used to develop functional foods. In this way, we classified the technologies used in three main groups and analyzed the research tendency since the year 2000 until now (Figure 2 ). The first group is formed by the technologies traditionally used in food processing, formulation and blending and cultivation and breeding. The second group is constituted by the technologies that forming a structure try to prevent the deterioration of physiologically active compounds; microencapsulation, edible films and coatings and vacuum impregnation are part of this group. Finally, the 
third group we classified is formed by those technologies, recent technologies, aimed to design personalized functional foods.

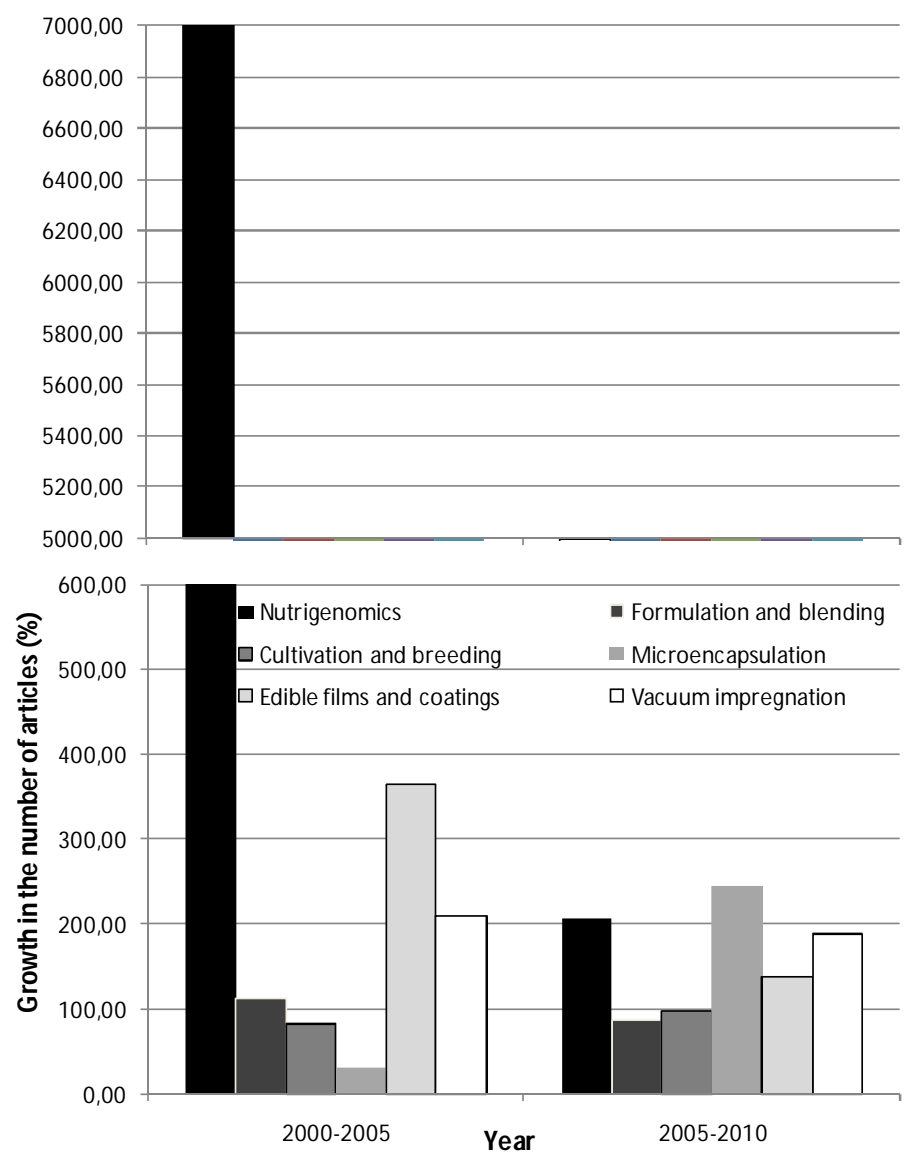

Figure 2. Growth in the number of articles (\%) over the years.

\section{Adaptation of general technologies traditionally used in food processing.}

\subsection{Formulation and blending.}

Formulation and blending constitutes a simply and cheap technology to develop new functional foods and has been widely used in food processing. Its use in functional food development has a long history for the successful control of deficiencies of vitamins A and D, several B vitamins (thiamine, riboflavin and niacin), iodine and iron. Salt iodization was introduced in the early 1920s in both Switzerland (Burgi, Supersaxo, \& Selz, 1990) and the United States of America (Marine \& Kimball, 1920) and has since expanded progressively all over the world to the extent that iodized salt is now used in most countries. From the early 1940s onwards, the fortification of cereal products with thiamine, riboflavin and niacin (Kyritsi, Tzia, \& Karathanos, 2011) has become common practice. Margarine was fortified with vitamin A (FAO \& WHO, 2006) in Denmark and milk with vitamin D (FAO \& WHO, 2006) in the United States, then enriched with phytosterols and used 
by patients with high cardiovascular risk (Laforest, Moulin, Schwalm, Le Jeunne, Chretin, Kitio, Massol, \& Van Ganse, 2007). Folic acid fortification of wheat (Samaniego-Vaesken, Alonso-Aperte, \& Varela-Moreiras, 2010) became widespread in the Americas, a strategy adopted by Canada and the United States and about 20 Latin American countries. In more recent years, the emergence of dietary compounds with health benefits offered an excellent opportunity to improve public health and thus, this category of compounds received much attention from the scientific community, consumers and food manufacturers. The list of dietary active compounds (vitamins, probiotics, bioactive peptides, antioxidants...) is endless and the type of final products obtained is growing steadily (Wildman, 2006). From the classical enriched milks (Kim, Ko, Park, Kim, Ha, \& Cho, 2010; Alzate, Pérez-Conde, Gutiérrez, \& Cámara, 2010) and yogurts (Karaaslan, Ozden, Vardin, \& Turkoglu, 2011; Zare, Boye, Orsat, Champagne, \& Simpson, 2011) through infant formula enriched with prebiotics (Alliet, Scholtensc, Raes, Hensen, Jongen, Rummens, Boehm, \& Vandenplas, 2007), probiotics (Puccio, Cajozzo, Meli, Rochat, Grathwohl, \& Steenhout, 2007), vitamins (Chávez-Servín, Castellote, \& López-Sabater, 2008) and long chain polyunsaturated fatty acids (Chávez-Servín, Castellote, Martín, Chifré, \& López-Sabater, 2009) to provide infants with the required nutrients for optimal growth and development, until juices mainly enriched with flavonoids (González-Molina, Moreno, \& GarcíaViguera, 2009), vitamins (Rivas, Rodrigo, Company, Sampedro, \& Rodrigo, 2007) and resveratrol (González-Barrio, Vidal-Guevara, Tomás-Barberán, \& Espín, 2009), snacks (Da Costa, Ferraz, Ros-Polski, Quast, Collares Queiroz, \& Steel, 2009), pastas rich in legumes (Petitot, Boyer, Minier, \& Micard, 2010) and meats enriched with large number of bioactive compounds (Jiménez-Colmenero, Sánchez-Muniz, \& Olmedilla-Alonso, 2010; Zhang, Xiao, Samaraweera, Lee, \& Ahn, 2010) are being developed by formulation.

\subsection{Cultivation and animal breeding techniques.}

Agriculture and livestock provide the primary source of the nutrients required by human. There is a general consensus among nutritionist that the best way to tackle micronutrient deficiency is through diversification in diet to include vegetables, fruits, meat and fish (FAO \& WHO, 2001). However, this is not always possible. Agriculture and livestock have been traditionally presented a way to obtain products with high nutrients. In cases where agronomic and breeding approaches cannot achieve significant improvement of food products, biotechnology offers a useful alternative (Zhao \& Shewry, 2011).

Biotechnology has been practised in crops and animal breeding since the beginning of human history. The evaluation and selection of different breeds started with the domestication of animal and plant species around 12.000 years ago, which was led by the wish to obtain desired traits, dictated by social, 
nutritional and environmental needs with no understanding of the molecular processes involved (National Research Council, 1989).

Going not so far in time, with the use of molecular biology tools and the development of genetically modified seeds, the biotechnology turned into a modern technique which offers an additional way to modify composition of foods. The most known enriched crop product is the Golden Rice (Ye, Al-Babili, Kloti, Zhang, Lucca, Beyer, \& Potrykus, 2000) that has $1.6 \mu \mathrm{g} / \mathrm{g}$ total carotenoids in the rice endosperm. The second generation of Golden Rice (Golden Rice 2) (Paine, Shipton, Chaggar, Howells, Kennedy, Vernon, Wright, Hinchliffe, Adams, Silverstone, \& Drake, 2005) contains up to $37 \mu \mathrm{g} / \mathrm{g}$ of total carotenoids. A recent clinical trial shows that the Golden Rice 2 is an effective source of vitamin A for humans, with a b-carotene to retinol conversion efficiency (Tang, Qin, Dolnikowski, Russell, \& Grusak, 2009), and locally adapted varieties of Golden rice are expected to reach the market in 2012 (Potrykus, 2010). The fortification of vitamin A has been carried out also in other food crops like potato (Tanumihardjo, Bouis, Hotz, Meenakshi, \& McClafferty, 2008) and maize (Zhu, Naqvi, Breitenbach, Sandmann, Christou, \& Capell, 2008). Tomato (De La Garza, Gregory, \& Hanson, 2007) and rice grain (Storozhenko, De Brouwer, Volckaert, Navarrete, Blancquaert, Zhang, Lambert, \& Van der Straeten, 2007) have been fortificated in folates and corn seeds and soybean seeds (Karunanandaa, Qi, Hao, Baszis, Jensen, Wong, Jiang, Venkatramesh, Gruys, Moshiri, Post-Beittermiller, Weiss, \& Valentin, 2005) in vitamin E. Furthermore, an attractive alternative is to synthetise LC-PUFs in plants, notably in oilseeds to replace the fatty acids which are usually stored on triacylglicerol (reviewed by Venegas-Caleron, Sayanova, \& Napier, 2010).

Animal breeding also offers the possibility to obtain improved food products. In this way, a lot of studies have been done to examine the sources of nutrients available for inclusion in animal diets and their subsequent transfer into products obtained. Matsushita, Tazinafo, Padre, Oliveira, Souza, Visentainer, Macedo, \& Ribas, (2007) carried out and study in which characterized the fatty acids profiles and physico-chemical parameters of milk samples from Saanen goats fed diets enriched with $3 \%$ of three different vegetable oils (soybean, canola and sunflower). The milks obtained presented different concentration of conjugated linoleic acid (CLA) depending on the vegetable oil added to animal fed. In addition (Laible, 2009), many other milk modifications have been suggested to improve the nutritional quality of milk and it's processing into dairy products. Woods \& Fearon in 2009 examined in a review the sources of fatty acids available for inclusion in animal diets and their subsequent transfer into meat, eggs or milk. Juniper, Phipps, Ramos-Morales, \& Bertin, (2009) determined the concentration of total selenium and the proportion of total (Se) comprised as selenomethionine and selenocysteine, as well as meat quality of lambs offered diets with an increasing dose rate of selenized enriched yeast or sodium selenite. 


\section{Specific technologies for the manufacture of functional food that prevent the deterioration of physiologically active compounds.}

\subsection{Microencapsulation.}

Microencapsulation is the envelopment of small solid particles, liquid droplets or gases in a coating (Thies, 1987). Microencapsulation is based on the embedding effect of a polymeric matrix, which creates a microenvironment in the capsule able to control the interactions between the internal part and the external one (Borgogna, Bellich, Zorzin, Lapasin, \& Cesàro, 2010). Microencapsulation allows the protection of a wide range of materials of biological interest, from small molecules and protein (enzymes, hormones,...) to cells of bacterial, yeast and animal origin (Thies, 2005). For this reason such versatile technology is widely studied and exploited in the high technological fields of biomedicine and biopharmaceutics, for application ranging from cell therapy to drug delivery (Smidsrød \& Skjak-Braek, 1990). The same characteristics make microencapsulation suitable for food industry applications, in particular for the production of high value aliments and nutraceuticals.

Many encapsulation procedures have been proposed but none of them can be considered as a universally applicable procedure for bioactive food components. This is caused by the fact that individual bioactive food components have their own characteristic molecular structure (Augustin \& Hemar, 2009). However compatibility with the bioactives is not the only requirement an encapsulation procedure has to meet. It also should have specific characteristics to withstand influences from the environment (Augustin and Hemar, 2009).

An important requirement is that the encapsulation system has to protect the bioactive component from chemical degradation (e.g., oxidation or hydrolysis) to keep the bioactive component fully functional. A major obstacle in the efficacious delivery of bioactive food components is not only the hazardous events that occur during passage through the gastrointestinal tract but also the deleterious circumstances during storage in the product that serves as vehicle for the bioactive components (de Vos, Faas, Spasojevic, \& Sikkema, 2010). Many food components may interfere with the bioactivity of the added bioactive food component. It is therefore mandatory that the encapsulation procedure protects the bioactive component during the whole period of processing, storage, and transport (Gibbs, Kermasha, Alli, \& Mulligan, 1999). Another requirement is that the encapsulation system allows an efficient package load (McClements, Decker, \& Park, 2009a; McClements, Decker, Park, \& Weiss, 2009b). How 'efficient' this package load should be depends on the type of molecule that is desired as bioactive component and the specific product that serves as vehicle. Administration of large structures such as probiotics will require a higher efficiency of package than molecular structures such as vitamins. When choosing an encapsulation system with high package efficiency, it is always essential to choose a system that can be easily 
incorporated into the food without interfering with the texture and taste of the food. And, last but certainly not least, it might be necessary to design the encapsulation system as such that the bioactive component is released in a specific site of the gastrointestinal tract (de Vos et al., 2010).

The studies addresses a broad array of questions and challenges related to microencapsulation in four main research directions:

- Microencapsulating materials

- Wall (matrix) materials for microencapsulation.

- Processes for microencapsulation.

- Properties and functionality of encapsulated systems.

Some studies have reported the success on some microencapsulation materials. Several biopolymers, such as starch, hydrocolloids, whey proteins, gelatins and maltodextrins, have already been tested as encapsulating materials by spray drying (Gharsallaoui, Roudaut, Chambin, Voilley, \& Saurel, 2007). Proteins have a potential role as substrates for the development of delivery systems due to their good functional properties and high nutritional value (Chen, Remondetto, \& Subirade, 2006). Proteins from soy bean have been used in the microencapsulation of orange oil emulsion by spray drying, being effective in the retention and protection against oxidation, due to its emulsification activity (Kim \& Morr, 1996). Rodrigues Pereira, Saraiva, Carvalho, Andrade, Pedrosa, \& Pierucci, (2009) have been able to obtain microparticles of ascorbic acid by spray drying using protein isolates of green pea and cowpea. Also by spray drying technique Sansone, Picerno, Mencherini, Villecco, D'Ursi, Aquino, \& Lauro, (2011) produced naringerin and quercetin particles using a combination of cellulose acetate phthalate (CAP) as coating gastro resistant polymer and swelling or surfactant agents as enhancers of dissolution rate. Presence of a combination of CAP and surfactants or swelling agents in the formulation produced microparticles with good resistance at low $\mathrm{pH}$ of the gastric fluid and complete flavonoids release in the intestinal environment. The microencapsulation improved the technological characteristics of the powders such as morphology and size, gave long-lasting storage stability and reserved the antioxidant properties.

Some studies have reported the success on encapsulating bioactive compounds. The most commonly applied bioactive food molecules that are already encapsulated in industrial applications are lipids, proteins, and carbohydrates (Augustin and Hemar, 2009). Lipids include fatty acids, phospholipids, carotenoids, and oil-soluble vitamins (Hämäläinen, Nieminen, Vuorela, Heinonen, \& Moilanen, 2007; McClements et al., 2009a,b). They cannot be easily solved in food products because of their extreme low solubility in water and poly-unsaturated fatty acids, which are highly susceptible to oxidation, and are now widely applied in powdered products thanks to encapsulation processes that form an effective barrier for oxygen (de Vos et al., 2010). Therefore many different approaches of encapsulation have been proposed for encapsulation of lipids in order to be able to apply them in a large variety of food products (McClements et al., 2009a,b). Bioactive proteins 
also might require encapsulation. Many food derived peptides act as growth factor, anti-hypertensive agent, antioxidant or immune regulatory factor (Hartmann \& Meisel, 2007; McClements et al., 2009a,b). Some of these proteins have to reach the site of uptake in the small bowel in an intact conformation in order to exert a beneficial health effect (de Vos et al., 2010). Most peptides even require hydrolysis in the stomach and small intestine in order to release specific bioactive peptides or amino acids (McClements et al., 2009a,b). Thus whether encapsulation for proteins has to be considered depends on the type of protein, its envisioned health effect and the product that serves as vehicle for the bioactive protein (de Vos et al., 2010). Carbohydrates that can benefit from microencapsulation are mainly bioactive carbohydrates that are found in dietary fibers (Redgwell \& Fischer, 2005). The fibers or its components that would benefit most from encapsulation are the soluble non-digestible polysaccharides. These fibers have been included for cholesterol reduction, reduction of glycemic fluctuations, prevention of constipation, prebiotic effects, and even for the prevention of cancer (McClements et al., 2009a,b; Redgwell and Fischer, 2005). The main challenge in this area is not to target the fibers to specific parts of the gut but to increase the amount of fibers in food in order to achieve the aforementioned health benefits (de Vos et al., 2010). The major encapsulation effort in this area is therefore improving the food load of fibers by packing enough fibers in capsules without interfering with the product quality such as changes in texture, mouth feel, or flavour (de Vos et al., 2010).

Encapsulation methods have been also widely applied to enhance viability of probiotic bacteria in commercial products.

Several authors studied the probiotic strain survival under simulated gastrointestinal conditions (Mokarram, Mortazavi, Habibi Najafi, \& Shahidi, 2009) and similarly for liquidbased products such as dairy products (Kailasapathy, 2006). Hou, Lin, Wang, \& Tzen, in 2003 developed a technique to protect Lactobacillus delbrueckii ssp. bulgaricus by encapsulation of bacterial cells within artificial sesame oil emulsions. In 2004, Krasaekoopt, Bhandari, \& Deeth, evaluated the influence of coating materials on some properties of alginate beads and survivability of microencapsulated probiotic bacteria. In the same way, Ross, Gusils, \& Gonzalez, (2008) improved a microencapsulating method using non fat milk cell suspension mixed with sodium alginate solution to increase a strain survival. Mokarram et al., (2009) studied the influence of multi stage coating on the properties of alginated beads and the survivability of microencapsulated Lactobacillus bacteria in the beads coated with one or two layers of alginate. In 2010, Weinbreck, Bodnár, \& Marco, evaluated the use of microencapsulation to maintain probiotic Lactobacillus rhamnosus GG (LGG) viability during exposure to detrimentally high levels of water activity in order to lengthen the shelf-life of probiotic bacteria in dry products such as infant formula powder.

Even if microencapsulation would be able to enhance the survival rate of probiotics this would not immediately imply that we will increase functional survival (de Vos et al., 2010). During recent years it has become clearer that 
probiotic effects are determined by the presence of specific bioactive molecules or effector molecules in the cell envelope of probiotic bacteria (van Baarlen, Troost, van Hemert, van der Meer, de Vos, de Groot, Hooiveld, Brummer, \& Kleerebezem, 2009; Kleerebezem \& Vaughan, 2009; Konstantinov, Smidt, de Vos, Bruijns, Singh, Valence, Molle, Lortal, Altermann, Klaenhammer, \& van Kooyk, 2008). These effector molecules are (glyco) proteins and have to be preserved in order to achieve functional effects (Konstantinov et al., 2008). The survival of these effector molecules in the product and during passage in the gastrointestinal tract is even more important than the survival of numbers of probiotics. The effector molecules that are presently identified (Konstantinov et al., 2008) are susceptible for the acidic circumstances and digestive enzymes in the stomach at beginning of the small bowel. Preserving and protecting these effector molecules will be a major challenge in the near future (Ledeboer, Nauta, Sikkema, Laudund, Niederberger, \& Sijbesma, 2006).

\subsection{Edible films and coatings.}

Any type of material used for enrobing (i.e. coating or wrapping) various food to extend shelf life of the product that may be eaten together with food with or without further removal is considered an edible film or coating (Pavlath \& Orts, 2009). Edible films and coatings are applied on many products to control moisture transfer, gas exchange or oxidation processes. For film-forming materials dispersed in aqueous solutions, solvent removal is required to achieve solid film formation and control of its properties (Hernández-Izquierdo \& Krochta, 2008). Edible films can be formed via two main processes: a "wet process" in which biopolymers are dispersed or solubilised in a film-forming solution (solution casting) followed by the evaporation of the solvent, and a "dry process" which relies on the thermoplastic behaviour exhibited by some proteins and polysaccharides at low moisture levels in compression moulding and extrusion (Liu, Kerry, \& Kerry, 2006).

One major advantage of using edible films and coatings is that they have a high potential to carry active ingredients such as antibrowning agents, colorants, flavours, nutrients, spices and antimicrobial compounds that can extend product shelf-life, reduce the risk of pathogen growth on food surfaces and provide specific nutrients that affect beneficially one or more functions of the body.

Some studies have reported the effect of the addition of active compounds in the functionality of edible films. For instance, Mei \& Zhao (2003) evaluated the feasibility of milk protein-based edible films to carry high concentrations of calcium (5 or $10 \% \mathrm{w} / \mathrm{v})$ and vitamin E $(0.1 \%$ or $0.2 \% \mathrm{w} / \mathrm{v})$. In contrast, Park \& Zhao (2004) reported that the water barrier property of the chitosan-based films was improved by increasing the concentration of mineral (5-20\% w/ v zinc lactate) or vitamin E in the film matrix. Nevertheless, the tensile strength of the films was affected by the incorporation of high concentrations of calcium or vitamin $\mathrm{E}$. 
Gómez-Estaca, Montero, Giménez, \& Gómez-Guillén, (2007) studied the effect of functional edible film enriched with oregano or rosemary extract, a gelatinechitosan film-coating and/ or high pressure processing on the microbiological and oxidative stability of cold-smoked sardine. Films enriched with oregano or rosemary extract were able to slow lipid oxidation, but they failed to slow microbial growth. Gómez-Guillén, Ihl, Bifani, Silva, \& Montero, (2007) obtained edible films based on tuna-fish gelatine with extracts of two murta ecotypes leaves (Ugni molinae Turcz). The edible films of tuna-fish gelatine were transparent and showed acceptable mechanical properties and barrier properties to water vapour and UV light. In the case of films with Soloyo Grande ecotypes, it was possible to increase significantly the antioxidant properties of the film, when natural extracts with high polyphenols content were added, producing only minor modifications of the film properties. When using an extract with a bigger content of polyphenols, like the Soloyo Chico ecotype, the antioxidant capacity of the film was increased, but the mechanical properties were decreased, due to a greater interaction between polyphenols and proteins.

Several researchers have endeavoured to incorporate minerals, vitamins and fatty acids into edible film and coating formulations to enhance the nutritional value of some fruits and vegetables, where these micronutrients are present in low quantities. Tapia, Rojas-Graü, Carmona, Rodríguez, Soliva-Fortuny, \& MartinBelloso, (2008) reported that the addition of ascorbic (1\% w/v) to the alginate and gellanbased edible coatings helped to preserve the natural ascorbic acid content in fresh-cut papaya, thus helping to maintain its nutritional quality throughout storage. Han, (2002) indicate that chitosan-based coatings had capability to hold high concentrations of calcium or vitamin E, thus significantly increasing their content in fresh and frozen strawberries and red raspberries. Similarly, Hernández-Muñoz, Almenar, Ocio, \& Gavara, (2006) observed that chitosan-coated strawberries retained more calcium gluconate $(3079 \mathrm{~g} / \mathrm{kg}$ dry matter) than strawberries dipped into calcium solutions $(2340 \mathrm{~g} / \mathrm{kg})$.

The addition of probiotics to obtain functional edible films and coatings has been scarcely studied. Tapia, Rojas-Graü, Rodríguez, Ramírez, Carmona, \& MartinBelloso, (2007) developed the first edible films for probiotic coatings on fresh-cut apple and papaya, observing that both fruits were successfully coated with alginate or gellan film-forming solutions containing viable $10^{6} \mathrm{cfu} / \mathrm{g}$ bifidobacteria.

\subsection{Vacuum impregnation.}

Vacuum impregnation has been considered as a useful way to introduce desirable solutes into the porous structure of foods, conveniently modify their original composition as an implement for development of new products. Physiologically active compounds may be introduced into fruit and vegetable products using this technique without modifying their integrity. This so-called 
'direct-formulation' distinguishes it from other processing methods (Mavroudis, Gekas, \& Sjoholm, 1998a,b; Torreggiani, 1993).

The use of vacuum impregnation to develop functional foods can be orientated in two ways. On one hand, several studies use the vacuum impregnation technique to modify desirable the original composition of one porous food. Fito, Chiralt, Betoret, Gras, Cháfer, Martínez-Monzó, Andrés, \& Vidal, (2001) first evaluated the feasibility of using vacuum impregnation for mineral fortification of fruits and vegetables from an engineering point of view. Mathematical models were developed to determine the concentration of different minerals in impregnation solutions required to achieve a $20-25 \%$ dietary reference intake (DRI) fortification in $200 \mathrm{~g}$ of samples. Following the modelling prediction, experimental validation confirmed that VI could be an effective method for the enrichment of fruits and vegetables with minerals, vitamins or other physiologically active components. Gras, Vidal, Betoret, Chiralt, \& Fito, (2003) evaluated calcium fortification of eggplants, carrots, and oyster mushroom using VI with sucrose solutions, and found that raw material variability induces significant differences in the final impregnation level. Xie \& Zhao $(2003 a, b)$ studied calcium and zinc fortification of fruits using VI processing of high fructose corn syrup solution containing calcium and/ or zinc in fresh-cut apples, strawberry slices, and whole marionberry. Cortés, Osorio, \& García, (2007) developed apple products enriched with Vitamin E (100\% IDR/ $200 \mathrm{~g}$ fresh apple) and evaluated the shelf life of the products after drying at $40^{\circ} \mathrm{C}$ in function of colour, texture and stability of vitamin $\mathrm{E}$ at different storage conditions. Anino, Salvatori, \& Alzamora, (2006) analyzed the ability of apple matrix for calcium incorporation by two different impregnation techniques (in vacuum or at atmospheric pressure) and determined the effect of these treatments on material compression behaviour. Some authors studied the effect of the mineral fortification of fruits on posterior osmotic dehydration operation (Barrera, Betoret, \& Fito, 2004; Barrera, Betoret, Corell, \& Fito, 2009; Moraga, Moraga, Fito, \& Martínez-Navarrete, 2009).

Betoret, Puente, Diaz, Pagán, García, Gras, Marto, \& Fito, (2003) developed probiotic-enriched dried fruits using VI technique by applying VI process either with commercial apple juice containing Saccharomyces cerevisiae, or with whole milk or apple juice containing $10^{7}$ or $10^{8} \mathrm{cfu} / \mathrm{ml}$ of Lactobacillus casei (spp. rhamnosus). It was reported that dried apple samples could contain about $10^{6}$ cfu/g Lactobacillus casei (spp. rhamnosus), a similar level to that in commercial dairy products.

More recently, some studies are focused on the protection this technology can provide to the active compounds. Watanabe, Yoshimoto, Okada, \& Nomura, (2011) studied the effect of impregnation using sucrose solution on stability of anthocyanin in strawberry jam. Strawberry jam mixed with or produced from strawberry impregnated with sucrose from 0.29 to $1.46 \mathrm{~mol} / \mathrm{L}$ was prepared, and the stability of anthocyanin in the jam was evaluated. Results obtained suggested that the impregnation of sucrose in advance of the jam preparation stabilized the 
anthocyanin in the jam more strongly than the mere addition of sucrose during the preparation.

\section{Recent technologies that contribute to a custom designed functional foods: Nutrigenomics.}

While a number of formal definitions exist; in essence nutrigenomics (sometimes called nutritional genomics) considers the interactions between foods or dietary supplements and an individual's genome, and the consequent downstream effects on their phenotype. It recognizes that appropriate dietary advice for one individual may be inappropriate, or actual harmful, to another. The field has the potential to provide tailored nutritional advice or develop specialist food products for population or for individuals and is still considered as an emerging science (Ferguson, Philpott, \& Barnett, 2010).

The key steps involve the following considerations:

1. Ferguson, 2009:

- Evidence for bioactivity.

- Mechanism of action.

- Enhancing levels via diet.

- Influence of genotype on bioactivity.

2. Ferguson et al., 2010:

- Identification of a genetic component to the disorder.

- Size of the component in relation to other causes of diseases susceptibility.

- Identification of the gene(s) associated with the effect.

- Functional variants in those genes.

- Interaction of those variants with diet and/ or other environmental factors to cause the phenotype.

Sutton, (2007) demonstrated that aqueous extracts of kiwifruit and avocado had very low cytotoxicity and high anti-inflammatory activity in a Crohn's genespecific assay. Non-aqueous extracts of kiwifruit, blueberry, avocado and broccoli had similarly high anti-inflammatory activity, albeit with slightly higher cytotoxicity than the aqueous extracts. Also Sutton, in 2007 has used functional snack bar products to deliver targeted glycaemic impacts.

Fenech, Baghurst, Luderer, Turner, Record, Ceppi, \& Bonassi, (2005) carried out a study in which illustrate the strong impact of nine micronutrients and their interactions on genome damage depending on level of intake. The micronutrients were vitamin E, calcium, folate, retinol, nicotin acid, B-carotene, riboflavin, pantothenic acid and biotin.

Ferguson et al., (2010) studies aimed to understand how different foods or food components might interact with a particular genotype to cause the chronic intestinal inflammation which is a hallmark of Crohn's disease. The model Interleukin-10 Gene-Deficient (IL10//-) Mouse has been used to test the efficacy of potential food components including polyunsaturated fatty acids (Knoch, Barnett, 
McNabb, Park-Ng, Zhu, Nones, Dommels, Knowles, \& Roy, 2009), fish oils (Hegazi, Saad, Mady, Matarese, O'Keefe, \& Kandil, 2006), flaxseed oil (Cohen, Moore, \& Ward, 2005), and some probiotics (McCarthy, O'Mahony, O'Callaghan, Sheil, Vaughan, Fitzimons, Fitzgibbon, O'Sullivan, Kiely, Collins, \& Shanahan, 2003). The Multidrug Resistance Gene-Deficient $\left(\mathrm{mrd}^{-1 /-}\right)$ Mouse model is another tool (Ferguson et al., 2010) used to understand the development of intestinal inflammation (Dommels, Butts, Zhu, Davy, Martell, Hedderly, Barnett, Broadley, \& Roy, 2007), and to test the efficacy of food components such as curcumin and rutin (Nones, Dommels, Martell, Butts, McNabb, Park-Ng, Zhu, Hedderley, Barnett, \& Roy, 2009) and green tea (Nones, Dommels, Martell, Butts, McNabb, Park-Ng, Barnett, Zhu, Hedderley, \& Roy, 2008) on the prevention of this phenotype.

While nutrigenomics can suppose a wide window of opportunities in the area of functional foods the field itself is still in its infancy and there are some aspects not well clarified yet. For example Ronteltap, van Trijp, Renes, \& Frewer, (2007) affirmed the nutrigenomics area is not well demarcated yet. Also, Ronteltap et al., (2007) showed that there is no unanimity among experts concerning the definition of nutrigenomics, its development over time and the critical factors that determine its success or failure. Furthermore, by its very nature, nutrigenomics gives rise to a number of ethical and legal issues. Experts recognize this as a critical factor for its development (Chadwick, 2004; Penders, Horstman, Saris, \& Vos, 2007).

Being more accurate in practical problem science has, Ferguson et al., (2010) affirmed the Nutrigenomics New Zealand model provides an approach towards personalized, genotype-based nutrition that has the potential to provide food products and personalized advice to benefit health at the individual or population level. There is convincing evidence that SNPs (Single Nucleotide Polymorphisms) in certain genes may profoundly influence the biological response to nutrients. However, effects of single-gene variants on risk or risk factor levels of a complex disease tend to be small and inconsistent. Increased sensitivity of current biological measurements, plus methods of integrating information on combinations of relevant SNPs or CNVs (Copy Number Variations) in different genes, will become necessary to move the field to a higher dimension. Many of the challenges are in bioinformatics, especially in relation to reducing the complexity of multidimensional data sets (Kaput \& Dawson, 2007). To date, there are only sporadic examples of clinical trials utilizing these technologies, and we have not investigated potential adverse effects of a genotype-derived dietary intervention. There are a considerable number of issues to be addressed before genomic approaches can become an acceptable method to guide food development or nutritional recommendations.

\section{Conclusions.}

There is no doubt that functional food development has a great interest from consumers, industries, governments and universities. From the research and 
development point of view functional foods represent an opportunity to obtain innovative products that satisfy considerably this demand that already exists. The technologies mainly used as it is possible to see in the figure 2, has changed considerably over the years. Thus, while traditional techniques are the most commonly used for development of functional foods, from years 2000 until 2010 the techniques aimed towards personalized nutrition have grown greatly.

There is a group of technologies, which have grown significantly, that form a structure aimed to prevent the deterioration of physiologically active compounds. In this way, it is important to note the importance of the relationship "structureproperty". The functional effect of a food or food component depends on the active component gaining access to the functional target site. However, foods are mostly complex mixtures of macro- and micro- components that can trap active compound, modulate its release or inhibit its activity (Chen, Remondetto, \& Subirade, 2006; Chen \& Subirade, 2007). Thus, the food matrix both in its raw state, after storage or culinary preparation can have a significant influence on the activity or release on the key components. Selection and development of an appropriate food vehicle that maintain the active molecular form until the time of consumption, and deliver this form to the physiological target within the organism, is an important step to the success of a functional food. As an example, it has been demonstrated that plant sterol efficacy differs across various matrices, the milk matrix being almost three times more effective than in bread or cereal (Jones \& Jew, 2007).

\section{Acknowledgments.}

The authors acknowledge the Ministerio de Ciencia e Innovación for its contribution throughout the projects AGL2009-09905 and PET2008_0015.

\section{References.}

Alliet, P., Scholtensc, P., Raes, M., Hensen, K., Jongen, H., Rummens, J-L., Boehm, G., \& Vandenplas, Y. (2007). Effect of prebiotic galacto-oligosaccharide, longchain fructooligosaccharide infant formula on serum cholesterol and triacylglycerol levels. Nutrition, 23, 719-723.

Alzate, A., Pérez-Conde, M. C., Gutiérrez, A. M., \& Cámara, C. (2010). Seleniumenriched fermented milk: A suitable dairy product to improve selenium intake in humans. International Dairy Journal, 20, 761-769.

Anino, S. V., Salvatori, D. M., \& Alzamora, S. M. (2006). Changes in calcium level and mechanical properties of apple tissue due to impregnation with calcium salts. Food Research International, 39, 154-164.

Augustin, M. A., \& Hemar, Y. (2009). Nano- and micro-structured assemblies for encapsulation of food ingredients. Chemical Society Reviews, 38, 902-912. 
Barrera, C., Betoret, N., Corell, P., \& Fito, P. (2009). Effect of osmotic dehydration on the stabilization of calcium-fortified apple slices (var. Granny Smith): Influence of operating variables on process kinetics and compositional changes. Journal of Food Engineering, 92, 416-424.

Barrera, C., Betoret, N., \& Fito, P. (2004). Ca2+ and Fe2+ influence on the osmotic dehydration kinetics of apple slices (var. Granny Smith). Journal of Food Engineering, 65, 9-14.

Beardsworth, A. D., \& Keil, E. T. (1992). The vegetarian option: varieties, conversions, motives and careers. The Sociological Review, 40, 255.

Betoret, N., Puente, L., Diaz, M. J., Pagán, M. J., García, M. J., Gras, M. L., Marto, J., \& Fito, P. (2003). Development of probiotic enriched dried fruits by vacuum impregnation. Journal of Food Engineering, 56(2-3), 273-277.

Borgogna, M., Bellich, B., Zorzin, L., Lapasin, R., \& Cesàro, A. (2010). Food microencapsulation of bioactive compounds: Rheological and thermal characterisation of non-conventional gelling system. Food Chemistry, 122, 416-423.

Burgi, H., Supersaxo, Z., \& Selz, B. (1990). Iodine deficiency diseases in Switzerland one hundred years after Theodor Kocher's survey: a historical review with some new goitre prevalence data. Acta Endocrinologica, 123, 577-590.

Chadwick, R. (2004). Nutrigenomics, individualism and public health. Proceedings of the Nutrition Society, 63, 161-166.

Chávez-Servín, J. L., Castellote, A. I., \& López-Sabater, M. C. (2008). Vitamins A and E content in infant milk-based powdered formulae after opening the packet. Food Chemistry, 106, 299-309.

Chávez-Servín, J. L., Castellote, A. I., Martín, M., Chifré, R., \& López-Sabater, M. C. (2009). Stability during storage of LC-PUFA-supplemented infant formula containing single cell oil or egg yolk. Food Chemistry, 113, 484-492.

Chen, L., Remondetto, G.E., \& Subirade, M. (2006). Food protein-based materials as nutraceutical delivery systems. Trends in Food Science and Technology, 17(5), 272-283.

Chen, L., \& Subirade, M. (2007). Effect of preparation conditions on the nutrient release properties of alginate/ whey protein granular microspheres. European Journal of Pharmaceutics and Biopharmaceutics, 65, 354-362.

Cohen, S. L., Moore, A. M., \& Ward, W. E. (2005). Flaxseed oil and inflammationassociated bone abnormalities in interleukin-10 knockout mice. The Journal of Nutritional Biochemistry, 16, 368-374.

Cortés, M., Osorio, A., \& García, E. (2007). Air dried apple fortified with vitamin e using matrix engineering. VITAE, Revista de la Facultad de Química Farmacéutica, 14(2), 17-26.

Da Costa, P. F. P., Ferraz, M. B. M., Ros-Polski, V., Quast, E., Collares Queiroz, F. P., \& Steel, C. J. (2009) Functional extruded snacks with lycopene and soy protein. Ciência e Tecnología de Alimentos. Campinas ISSN 0101-2061. 
de La Garza, R. I. D., Gregory, J. F., \& Hanson, A. D. (2007). Folate biofortification of tomato fruit. Proceedings of the National Academy of Sciences of the United States of America, 104, 4218-4222.

de Vos, P., Faas, M. M., Spasojevic, M., \& Sikkema, J. (2010). Encapsulation for preservation of functionality and targeted delivery of bioactive food components. International Dairy Journal, 20, 292-302.

Dommels, Y. E., Butts, C., Zhu, S. T., Davy, M., Martell, S., Hedderly, D., Barnett, M. P., Broadley, K., \& Roy, N. C. (2007). Characterization of inflammation in mdr1a $-/$ - mice and identification of related gene expression changes in colonic epithelial cells. Genes and Nutrition, 2, 209-223.

FAO, WHO. (2001). Human Vitamin and Mineral Requirements. Report of a Joint FAO/ WHO Expert Consultation, Bangkok, Thailand. Food and Nutrition Division, FAO Rome.

FAO, WHO. (2006). Guidelines on food fortification with micronutrients. Geneva: WHO Press.

Fenech, M., Baghurst, P., Luderer, W., Turner, J., Record, S., Ceppi, M., \& Bonassi, S. (2005). Low intake of calcium, folate, nicotinic acid, vitamin E, retinol, bcarotene and high intake of pantothenic acid, biotin and riboflavin are significantly associated with increased genome instability results from a dietary intake and micronucleus index survey in South Australia. Carcinogenesis, 26(5), 991-999.

Ferguson, L. R. (2009). Nutrigenomics Approaches to Functional Foods. Journal of the American Dietetic Association, 109, 452-458.

Ferguson, L. R., Philpott, M., \& Barnett, M. P. G. (2010). Nutrigenomics: Integrating Genomic Approaches into Nutrition Research. Molecular Diagnostics, 347363

Fito, P., Chiralt, A., Betoret, N., Gras, M., Chafer, M., Martinez-Monzó, J., Andrés, A., \& Vidal, D. (2001). Vacuum impregnation and osmotic dehydration in matrix engineering application in functional fresh food development. Journal of Food Engineering, 49, 175-183.

Gharsallaoui, A., Roudaut, G., Chambin, O., Voilley, A., \& Saurel, R. (2007). Applications of spray-drying in microencapsulation of food ingredients: An overview. Food Research International, 40(9), 1107-1121.

Gibbs, B. F., Kermasha, S., Alli, I., \& Mulligan, C. N. (1999). Encapsulation in the food industry: a review. International Journal of Food Science and Nutrition, 50, 213-224.

Gómez-Estaca, J., Montero, P., Giménez, B., \& Gómez-Guillén, M. C. (2007). Effect of functional edible films and high pressure processing on microbial and oxidative spoilage in cold-smoked sardine (Sardina pilchardus). Food Chemistry, 105, 511-520.

Gómez-Guillén, M. C., Ihl, M., Bifani, V., Silva, A., \& Montero, P. (2007). Edible films made from tuna-fish gelatin with antioxidant extracts of two different murta ecotypes leaves (Ugni molinae Turcz). Food Hydrocolloids, 21, 1133-1143. 
González-Barrio, R., Vidal-Guevara, M. L., Tomás-Barberán, F. A., \& Espín, J. C. (2009). Preparation of a resveratrol-enriched grape juice based on ultraviolet C-treated berries. Innovative Food Science and Emerging Technologies, 10, 374-382.

González-Molina, E., Moreno, D. A., \& García-Viguera, C. (2009). A new drink rich in healthy bioactives combining lemon and pomegranate juices. Food Chemistry, 115, 1364-1372.

Granato, D., Branco, G. F., \& Nazzaro, F. (2010). Functional Foods and Nondairy Probiotic Food Development: Trends, Concepts and Products. Comprehensive Reviews in Food Science and Food Safety, 9, 292-302.

Gras, M. L., Vidal, D., Betoret, N., Chiralt, A., \& Fito, P. (2003). Calcium fortification of vegetables by vacuum impregnation. Journal of Food Engineering, 56(2-3), 279-284.

Hämäläinen, M., Nieminen, R., Vuorela, P., Heinonen, M., \& Moilanen, E. (2007). Anti-inflammatory effects of flavonoids: genistein, kaempferol, quercetin, and daidzein inhibit STAT-1 and NF-kappaB activations, whereas flavone, isorhamnetin, naringenin, and pelargonidin inhibit only NF-kappaB activation along with their inhibitory effect on iNOS expression and NO production in activated macrophages. Mediators of Inflammation, 2007, Article ID 45673.

Han, J. (2002). Protein-based edible films and coatings carrying antimicrobial agents. In A. Gennadios (Ed.), Protein-based films and coatings (pp. 485498). Florida: CRC Press.

Hartmann, R., \& Meisel, H. (2007) Food-derived peptides with biological activity: from research to food applications. Current Opinion in Biotechnology, 18, 163-169.

Hegazi, R. A., Saad, R. S., Mady, H., Matarese, L. E., O’Keefe, S., \& Kandil, H. M. (2006). Dietary fatty acids modulate chronic colitis, colitis-associated colon neoplasia and COX-2 expression in IL-10 knockout mice. Nutrition, 22, 275282.

Hernandez-Izquierdo, V. M., \& Krochta, J. M. (2008). Thermoplastic Processing of Proteins for Film Formation-A Review. Journal of Food Science, 73(2), R30R39.

Hernández-Muñoz, P., Almenar, E., Ocio, M. J., \& Gavara, R. (2006). Effect of calcium dips and chitosan coatings on postharvest life of strawberries (Fragaria ananassa). Postharvest Biology and Technology, 39, 247-253.

Hou, R. C. W., Lin, M. Y., Wang, M. M. C., \& Tzen, J. T. C. (2003). Increase of Viability of Entrapped Cells of Lactobacillus delbrueckii ssp. Bulgaricus in Artificial Sesame Oil Emulsions. Journal of Dairy Science, 86, 424-428.

Jiménez-Colmenero, F., Sánchez-Muniz, F. J., \& Olmedilla-Alonso, B. (2010). Design and development of meat-based functional foods with walnut: Technological, nutritional and health impact. Food Chemistry, 123, 959-967. 
Jones, P. J., \& Jew, S. (2007). Functional food development: concept to reality. Trends in Food Science and Technology, 18, 387-390.

Jousse, F. (2008). Modeling to improve the efficiency of product and process development. Comprehensive Reviews in Food Science and Food Safety, 7, 175-181.

Juniper, D. T., Phipps, R. H., Ramos-Morales, E., \& Bertin, G. (2009). Effects of dietary supplementation with selenium enriched yeast or sodium selenite on selenium tissue distribution and meat quality in lambs. Animal Feed Science and Technology, 149, 228-239.

Kailasapathy, K. (2006). Survival of free and encapsulated probiotic bacteria and their effect on the sensory properties of yoghurt. LWT-Food Science and Technology, 39, 1221-1227.

Kaput, J., \& Dawson, K. (2007). Complexity of type 2 diabetes mellitus data sets emerging from nutrigenomic research: a case for dimensionality reduction?. Mutation Research, 622, 19-32.

Karaaslan, M., Ozden, M., Vardin, H., \& Turkoglu, H. (2011). Phenolic fortification of yogurt using grape and callus extracts. LWT - Food Science and Technology, 44, 1065-1072.

Karunanandaa, B., Qi, Q. G., Hao, M., Baszis, S. R., Jensen, P. K., Wong, Y. H. H., Jiang, J., Venkatramesh, M., Gruys, K. J., Moshiri, F., Post-Beittermiller, D., Weiss, J. D., \& Valentin, H. E. (2005). Metabolically engineered oilseed crops with enhanced seed tocopherol. Metabolic Engineering, 7, 384-400.

Kim, J., Ko, Y., Park, Y-K., Kim, N-I., Ha, W-K., \& Cho, Y. (2010). Dietary effect of lactoferrin-enriched fermented milk on skin surface lipid and clinical improvement of acne vulgaris. Nutrition, 26, 902-909.

Kim, Y. D., \& Morr, C. V. (1996). Microencapsulation properties of gum arabic and several food proteins: Spray dried orange oil emulsion particles. Journal of Agriculture and Food Chemistry, 44(5), 1314-1320.

Kleerebezem, M., \& Vaughan, E. E. (2009). Probiotic and gut lactobacilli and bifidobacteria: molecular approaches to study diversity and activity. Annual Reviews of Microbiology, 63, 269-290.

Knoch, B., Barnett, M., McNabb, W., Park-Ng, Z., Zhu, S., Nones, K., Dommels, Y., Knowles, S., \& Roy, N. (2009). Genome-wide analysis of genes involved in eicosapentaenoic acid-induced modulation of colonic inflammation. Journal of Nutrigenetics and Nutrigenomics, 2(1), 9-28.

Konstantinov, S. R., Smidt, H., de Vos, W. M., Bruijns, S. C., Singh, S. K., Valence, F., Molle, D., Lortal, S., Altermann, E., Klaenhammer, T. R., \& van Kooyk, Y. (2008). S layer protein A of Lactobacillus acidophilus NCFM regulates immature dendritic cell and T cell functions. Proceedings of the National Academy of Sciences of the United States of America, 105, 19474-19479.

Krasaekoopt, W., Bhandari, B., \& Deeth, H. (2004). The influence of coating materials on some properties of alginate beads and survivability of 
microencapsulated probiotic bacteria. International Dairy Journal, 14, 737 743

Kyritsi, A., Tzia, C., \& Karathanos, V. T. (2011). Vitamin fortified rice grain using spraying and soaking methods. LWT - Food Science and Technology, 44, 312320.

Laforest, L., Moulin, P., Schwalm, M. S., Le Jeunne, P., Chretin, S., Kitio, B., Massol, J., \& Van Ganse, E. (2007). Use of margarine enriched in phytosterols by patients at high cardiovascular risk and treated by hypolipidemic drugs. Nutrition, Metabolism \& Cardiovascular Diseases, 17, 657-665.

Laible, G. (2009). Enhancing livestock through genetic engineering - Recent advances and future prospects. Comparative immunology, Microbiology and infectious diseases, 32, 123-137.

Ledeboer, A. M., Nauta, A., Sikkema, J., Laulund, E., Niederberger, P., \& Sijbesma, W. (2006). Survival of probiotics. European Dairy Magazine, 4, 31-32.

Liu, L., Kerry, J. F., \& Kerry, J. P. (2006). Effect of food ingredients and selected lipids on the physical properties of extruded edible films/casings. International Journal of Food Science and Technology, 41, 295-302.

Marine, D., \& Kimball, O. P. (1920). Prevention of simple goiter in man. Archives of Internal Medicine, 25, 661-672.

Matsushita, M., Tazinafo, N. M., Padre, R. G., Oliveira, C. C., Souza, N. E., Visentainer, J. V., Macedo, F. A. F., \& Ribas, N. P. (2007). Fatty acid profile of milk from Saanen goats fed a diet enriched with three vegetable oils. Small Ruminant Research, 72, 127-132.

Mavroudis, N. E., Gekas, V., \& Sjoholm, I. (1998b). Osmotic dehydration of applesShrinkage phenomena and the significance of initial structure on mass transfer rates. Journal of Food Engineering, 38, 101-123.

Mavroudis, N. E., Gekas, V., \& Sjoholm, I. (1998a). Osmotic dehydration of applesEffects of agitation and raw material characteristics. Journal of Food Engineering, 35, 191-209.

McCarthy, J., O'Mahony, L., O'Callaghan, L., Sheil, B., Vaughan, E. E., Fitzsimons, N., Fitzgibbon, J., O'Sullivan, G. C., Kiely, B., Collins, J. K., \& Shanahan, F. (2003). Double blind, placebo controlled trial of two probiotic strains in interleukin 10 knockout mice and mechanistic link with cytokine balance. Gut, 52, 975980.

McClements, D. J., Decker, E. A., \& Park, Y. (2009a). Controlling lipid bioavailability through physicochemical and structural approaches. Critical Reviews in Food Science and Nutrition, 49, 48-67.

McClements, D. J., Decker, E. A., Park, Y., \& Weiss, J. (2009b). Structural design principles for delivery of bioactive components in nutraceuticals and functional foods. Critical Reviews in Food Science and Nutrition, 49, 577-606.

Mei, Y., \& Zhao, Y. (2003). Barrier and mechanical properties of milk protein-based edible films incorporated with nutraceuticals. Journal of Agricultural and Food Chemistry, 51, 1914-1918. 
Mokarram, R. R., Mortazavi, S. A., Habibi Najafi, M. B., \& Shahidi, F. (2009). The influence of multi stage alginate coating on survivability of potential probiotic bacteria in simulated gastric and intestinal juice. Food Research International, 42, 1040-1045

Mollet, B., \& Rowland, I. (2002). Functional foods: At the frontier between food and pharma. Current Opinion in Biotechnology, 13, 483-485.

Moraga, M. J., Moraga, G., Fito, P. J., \& Martínez-Navarrete, N. (2009). Effect of vacuum impregnation with calcium lactate on the osmotic dehydration kinetics and quality of osmodehydrated grapefruit. Journal of Food Engineering, 90, 372-379.

National Research Council. (1989). Past experience with genetic modification of plants and their introduction into the environment (pp. 16-36). Washington DC: National Academy Press.

Nones, K., Dommels, Y., Martell, S., Butts, C., McNabb, W., Park-Ng, Z., Zhu, S., Hedderley, D., Barnett, M., \& Roy, N. (2009). The effects of dietary curcumin and rutin on colon inflammation and gene expression in mdr1a -/ - mice, a model of inflammatory bowel diseases. British Journal of Nutrition, 101, 169-181.

Nones, K., Dommels, Y., Martell, S., Butts, C., McNabb, W., Park-Ng, Z., Barnett, M., Zhu, S. T., Hedderley, D., \& Roy, N. (2008). Effect of green tea extract on colon inflammation and gene expression in mdr1a -/- mice. Journal of Nutrigenetics and Nutrigenomics, 1, 82.

Nöthlings, U., Murphy, S. P., Wilkens, L. R., Henderson, B. E., \& Kolonel, L. N. (2007). Flavonols and pancreatic cancer risk - The multiethnic cohort study. American Journal of Epidemiology, 166 (8), 924-931.

Paine, J. A., Shipton, C. A., Chaggar, S., Howells, R. M., Kennedy, M. J., Vernon, G., Wright, S. Y., Hinchliffe, E., Adams, J. L., Silverstone, A. L., \& Drake, R., (2005). Improving the nutritional value of Golden Rice through increased provitamin A content. Nature Biotechnology, 23, 482-487.

Park, S., \& Zhao, Y. (2004). Incorporation of a high concentration of mineral or vitamin into chitosan-based films. Journal of Agricultural and Food Chemistry, 52, 1933-1939.

Pavlath, A. E., \& Orts, W. (2009). Edible Films and Coatings: Why, What, and How?. Embuscado, M. E., Huber K. C. (Eds.) Edible Films and Coatings for Food Applications (pp. 1-23). New York: Springer. (Chapter 1).

Penders, B., Horstman, K., Saris, W. H. M., \& Vos, R. (2007). From individuals to groups: a review of the meaning of 'personalized' in nutrigenomics. Trends in Food Science \& Technology, 18, 333-338

Petitot, M., Boyer L., Minier, C., \& Micard, V. (2010). Fortification of pasta with split pea and faba bean flours: Pasta processing and quality evaluation. Food Research International, 43, 634-641.

Potrykus, I. (2010). Regulation must be revolutionized. Nature, 466, 561. 
Puccio, G., Cajozzo, C., Meli, F., Rochat, F., Grathwohl, D., \& Steenhout, P. (2007). Clinical evaluation of a new starter formula for infants containing live Bifidobacterium longum BL999 and prebiotics. Nutrition, 23, 1-8.

Redgwell, R. J., \& Fischer, M. (2005). Dietary fiber as a versatile food component: an industrial perspective. Molecular Nutrition and Food Research, 49, 521-535.

Rivas, A., Rodrigo, D., Company, B., Sampedro, F., \& Rodrigo, M. (2007). Effects of pulsed electric fields on water-soluble vitamins and ACE inhibitory peptides added to a mixed orange juice and milk beverage. Food Chemistry, 104, 1550-1559.

Roberfroid, M. B. (2007). Concepts and strategy of functional food science: the European perspective. The American Journal of Clinical Nutrition, 71, 16601664.

Rodrigues Pereira, H. V., Saraiva, K. P., Carvalho, L. M. J., Andrade, L. R., Pedrosa, C., \& Pierucci, A. P. T. R. (2009). Legumes seeds protein isolates in the production of ascorbic acid microparticles. Food Research International, 42, 115-121.

Ronteltap, A., van Trijp, J. C. M., Renes, R. J., \& Frewer, L. J. (2007). Consumer acceptance of technology-based food innovations: Lessons for the future of nutrigenomics. Appetite, 49, 1-17.

Ross, G. R., Gusils, C., \& Gonzalez, S. N. (2008). Microencapsulation of Probiotic Strains for Swine Feeding. Biological \& Pharmaceutical Bulletin, 31(11), 2121-2125.

Samaniego-Vaesken, M. L., Alonso-Aperte, E., \& Varela-Moreiras, G. (2010). Analysis and evaluation of voluntary folic acid fortification of breakfast cereals in the Spanish market. Journal of Food Composition and Analysis, 23, 419-423.

Sansone, F., Picerno, P., Mencherini, T., Villecco, F., D’Ursi, A. M., Aquino, R. P., \& Lauro, M. R. (2011). Flavonoid microparticles by spray-drying: Influence of enhancers of the dissolution rate on properties and stability. Journal of Food Engineering, 103, 188-196.

Shah, N. P. (2007). Functional cultures and health benefits. International Dairy Journal, 17, 1262-1277.

Smidsrød, O., \& Skjak-Braek, G. (1990). Alginate as immobilization matrix for cells. Trends in Biotechnology, 8, 71-78.

Storozhenko, S., De Brouwer, V., Volckaert, M., Navarrete, O., Blancquaert, D., Zhang, G. F., Lambert, W., \& Van der Straeten, D. (2007). Folate fortification of rice by metabolic engineering. Nature Biotechnology, 25, 1277-1279.

Sutton, K. H. (2007) Considerations for the successful development and launch of personalised nutrigenomic foods. Mutation Research, 622, 117-121.

Takachi, R., Manami, I., Junko, I., Norie, K., Motoki, I., Shizuka, S., Hiroyasu, I., Yoshitaka, T., \& Shoichiro, T. (2008). Fruit and Vegetable intake and risk of total cancer and cardiovascular disease - Japan public health center-based prospective study. American Journal of Epidemiology, 167 (1), 59-70. 
Tang, G. W., Qin, J., Dolnikowski, G. G., Russell, R. M., \& Grusak, M. A. (2009). Golden Rice is an effective source of vitamin A. American Journal of Clinical Nutrition, 89, 1776-1783.

Tanumihardjo, S. A., Bouis, H., Hotz, C., Meenakshi, J. V., \& McClafferty, B. (2008). Biofortification of staple crops: An emerging strategy to combat hidden hunger. Comprehensive Reviews in Food Science and Food Safety, 7, 329-334.

Tapia, M. S., Rojas-Grau, M. A., Carmona, A., Rodriguez, F. J., Soliva-Fortuny, R., \& Martin-Belloso, O. (2008). Use of alginate and gellan-based coatings for improving barrier, texture and nutritional properties of fresh-cut papaya. Food Hydrocolloids, 22, 1493-1503.

Tapia, M. S., Rojas-Graü, M. A., Rodríguez, F. J., Ramírez, J., Carmona, A., \& MartinBelloso, O. (2007). Alginate- and gellanbased edible films for probiotic coatings on fresh-cut fruits. Journal of Food Science, 72, E190-E196.

Thies, C. (1987). Microencapsulation. In Encyclopedia of Polymer Science and Engineering (pp. 724-745). Mark, H. F., Bikales, N. M., Overberger, C. G., Menges, G. \& Kroschwitz, J.I., (Eds.). New York: John Wiley \& Sons.

Thies, C. (2005). A survey of microencapsulation processes. In, Microencapsulation (pp. 1-20) Benita, S. (Ed.). New York: Marcel Dekker Inc.

Torreggiani, D. (1993). Osmotic dehydration in fruit and vegetable processing. Food Research International, 26, 59-68.

Van Baarlen, P., Troost, F. J, van Hemert, S., van der Meer, C., de Vos, W. M., de Groot, P. J., Hooiveld, G. J., Brummer, R. J., \& Kleerebezem, M. (2009). Differential NF-kB pathways induction by Lactobacillus plantarum in the duodenum of healthy humans correlating with immune tolerance. Proceedings of the National Academy of Sciences of the United States of America, 106, 2371-2376.

Venegas-Caleron, M., Sayanova, O., \& Napier, J. A. (2010). An alternative to fish oils: Metabolic engineering of oil-seed crops to produce omega-3 long chain polyunsaturated fatty acids. Progress in Lipid Research, 49, 108-119.

Watanabe, Y., Yoshimoto, K., Okada, Y., \& Nomura, M. (2011). Effect of impregnation using sucrose solution on stability of anthocyanin in strawberry jam. LWT - Food Science and Technology, 44, 891-895.

Weinbreck, F., Bodnár, I., \& Marco, M. L. (2010). Can encapsulation lengthen the shelf-life of probiotic bacteria in dry products?. International Journal of Food Microbiology, 136, (2010) 364-367

WHO (2003). Diet, nutrition and the prevention of chronic diseases. WHO technical report series 916. Geneva, Switzerland.

http:/ / www.fao.org/ docrep/ 005/ AC911E/ AC911E00.HTM\#Contents Accessed 14.01.2011.

Wildman, R. E. C. (2006). Classifying nutraceuticals. In Handbook of Nutraceuticals and Functional Foods, (2nd ed.), Wildman Ed., CRC Publisher, 13-31. 
Woods, V. B., \& Fearon, A. M. (2009). Dietary sources of unsaturated fatty acids for animals and their transfer into meat, milk and eggs: A review. Livestock Science, 126, 1-20.

Xie, J., \& Zhao, Y. (2003a). Nutritional enrichment of fresh apple (Royal Gala) by vacuum impregnation. International Journal of Food Science and Nutrition, 54, 387-398.

Xie, J., \& Zhao, Y. (2003b). Improvement of physicochemical and nutritional qualities of frozen Marionberry by vacuum impregnation pretreatment with cryoprotectants and minerals. Journal of Horticultural Science and Biotechnology, 78, 248-253.

Ye, X. D., Al-Babili, S., Kloti, A., Zhang, J., Lucca, P., Beyer, P., \& Potrykus, I. (2000). Engineering the provitamin A (beta-carotene) biosynthetic pathway into (carotenoid-free) rice endosperm. Science, 287, 303-305.

Zare, F., Boye, J. I., Orsat, V., Champagne, C., \& Simpson, B. K. (2011). Microbial, physical and sensory properties of yogurt supplemented with lentil flour. Food Research International, doi:10.1016/j.foodres.2011.01.002

Zhang, W., Xiao, S., Samaraweera, H., Lee, E. J., \& Ahn, D. U. (2010). Improving functional value of meat products. Meat Science, 86, 15-31.

Zhao, F-J., \& Shewry, P. R. (2011). Recent developments in modifying crops and agronomic practiceto improve human health. Food Policy, 36, S94-S10.

Zhu, C. F., Naqvi, S., Breitenbach, J., Sandmann, G., Christou, P., \& Capell, T. (2008). Combinatorial genetic transformation generates a library of metabolic phenotypes for the carotenoid pathway in maize. Proceedings of the National Academy of Sciences of the United States of America, 105, 1823218237. 
Desarrollo tecnológico y valoración funcional de aperitivos de manzana y zumo de mandarina 
3.2. Valoración de algunos aspectos tecnológicos, económicos y medioambientales para la implantación industrial del proceso de fabricación del alimento funcional 

Nomenclatura utilizada para calcular las necesidades de espacio de los equipos y conocer las relaciones entre las variables.

\begin{tabular}{|c|c|c|}
\hline SIMBOLO & VARIABLE & UNIDADES \\
\hline $\mathrm{D}$ & $\begin{array}{l}\text { Masa diaria de snack que debe consumir } \\
\text { cada paciente }\end{array}$ & $\mathrm{kg} /$ día paciente \\
\hline $\mathrm{T}$ & Duración del tratamiento & días \\
\hline$t_{t}$ & Duración máxima del proceso de fabricación & días trabajo \\
\hline$n_{p}$ & Número de pacientes & pacientes \\
\hline $\mathrm{F}$ & Número de piezas de fruta & manzanas \\
\hline $\mathrm{U}$ & Número de unidades & discos \\
\hline $\mathrm{U}_{\mathrm{d}}$ & Número de unidades por día & discos/ día \\
\hline $\mathrm{U}_{\mathrm{IV}}$ & Número de unidades por impregnación & discos/impregnación \\
\hline $\mathrm{n}_{\mathrm{u}}$ & Número de unidades por pieza & discos/manzana \\
\hline $\mathrm{n}_{\mathrm{IV}}$ & Número de impregnaciones al día & Impregnaciones/ día \\
\hline$m_{f u}$ & Masa de una unidad de producto fresco & $\mathrm{kg} /$ disco fresco \\
\hline $\mathrm{m}_{\text {iu }}$ & $\begin{array}{l}\text { Masa de una unidad de producto } \\
\text { impregnado }\end{array}$ & $\begin{array}{l}\mathrm{kg} / \text { disco } \\
\text { impregnado }\end{array}$ \\
\hline $\mathrm{m}_{\mathrm{su}}$ & Masa de una unidad de producto seco & $\mathrm{kg} /$ disco seco \\
\hline $\mathrm{m}_{\mathrm{F}}$ & Masa de una pieza de fruta & $\mathrm{kg} / \mathrm{manzana}$ \\
\hline $\mathrm{m}_{1}$ & $\begin{array}{l}\text { Masa de líquido de impregnación mínima } \\
\text { necesaria }\end{array}$ & $\mathrm{kg} \mathrm{zumo/kg} \mathrm{fruta}$ \\
\hline $\mathrm{M}_{\mathrm{F}}$ & Masa de piezas de fruta & kg manzanas \\
\hline $\mathrm{M}_{\mathrm{f}}$ & Masa de producto fresco & $\mathrm{kg}$ discos frescos \\
\hline $\mathrm{M}_{\mathrm{s}}$ & Masa de producto seco & kg snack \\
\hline $\mathrm{V}_{\mathrm{IV}}$ & $\begin{array}{l}\text { Volumen de líquido necesario en una } \\
\text { impregnación }\end{array}$ & $\begin{array}{l}\text { L } \\
\text { zumo/impregnación }\end{array}$ \\
\hline $\mathrm{V}$ & Volumen de líquido necesario & L zumo \\
\hline $\mathrm{F}_{\mathrm{z}}$ & $\begin{array}{l}\text { Número de piezas de fruta necesarias para } \\
\text { obtener el líquido de impregnación }\end{array}$ & Mandarinas \\
\hline$\eta_{z}$ & Rendimiento en zumo & $\%$ \\
\hline $\mathrm{r}_{\mathrm{IV}}$ & $\begin{array}{l}\text { Número de reutilizaciones del líquido de } \\
\text { impregnación }\end{array}$ & Reutilizaciones \\
\hline $\mathrm{h}$ & Altura & M \\
\hline $\mathrm{W}$ & Anchura & $\mathrm{M}$ \\
\hline $\mathrm{e}$ & Grosor & $\mathrm{M}$ \\
\hline S & Superficie necesaria & $\mathrm{m}^{2}$ \\
\hline $\mathrm{S}_{\mathrm{u}}$ & Superficie necesaria por unidad & $\mathrm{m}^{2}$ \\
\hline $\mathrm{S}_{\mathrm{b}}$ & Sobredimensionamiento & $\%$ \\
\hline $\begin{array}{l}\text { Subíndices } \\
\text { MAX O MIN }\end{array}$ & \multicolumn{2}{|c|}{ Hacen referencia a dimensiones o capacidades máximas o mínimas } \\
\hline $\begin{array}{l}\text { Superíndices } \\
\mathrm{H}_{\mathrm{O}} \mathrm{V}\end{array}$ & \multicolumn{2}{|c|}{$\begin{array}{l}\text { Hacen referencia a la posición de las unidades de fruta en los } \\
\text { equipos en horizontal o vertical }\end{array}$} \\
\hline $\begin{array}{l}\text { Superíndices } \\
\mathrm{IV}_{\mathrm{O}} \mathrm{SEC}\end{array}$ & \multicolumn{2}{|c|}{ Hacen referencia al equipo de impregnación a vacío o al secador } \\
\hline $\begin{array}{l}\text { Superíndice } \\
\text { sb }\end{array}$ & \multicolumn{2}{|c|}{ Hace referencia a la aplicación del sobredimensionamiento } \\
\hline
\end{tabular}


Uno de los objetivos de esta tesis doctoral es el diseño, la construcción y la puesta en marcha de una planta piloto que permita la fabricación de alimentos funcionales naturales de baja humedad. El diseño de la planta ha permitido evaluar aspectos tecnológicos y económicos del proceso de fabricación así como establecer los parámetros de operación óptimos de dicho proceso para el posterior diseño y la construcción de la planta a escala industrial.

Las tecnologías empleadas en la fabricación de alimentos funcionales naturales de baja humedad han sido la impregnación a vacío y el secado por aire caliente (Figura 1). La planta piloto se ha diseñado con el objetivo de producir la cantidad de alimento funcional necesario para llevar a cabo los estudios in vivo realizados en esta tesis siguiendo las normas vigentes para equipos destinados a la industria alimentaria y se ha procurado que el diseño permita el desarrollo de productos diferentes para así mejorar las posibilidades de transferencia de la tecnología.

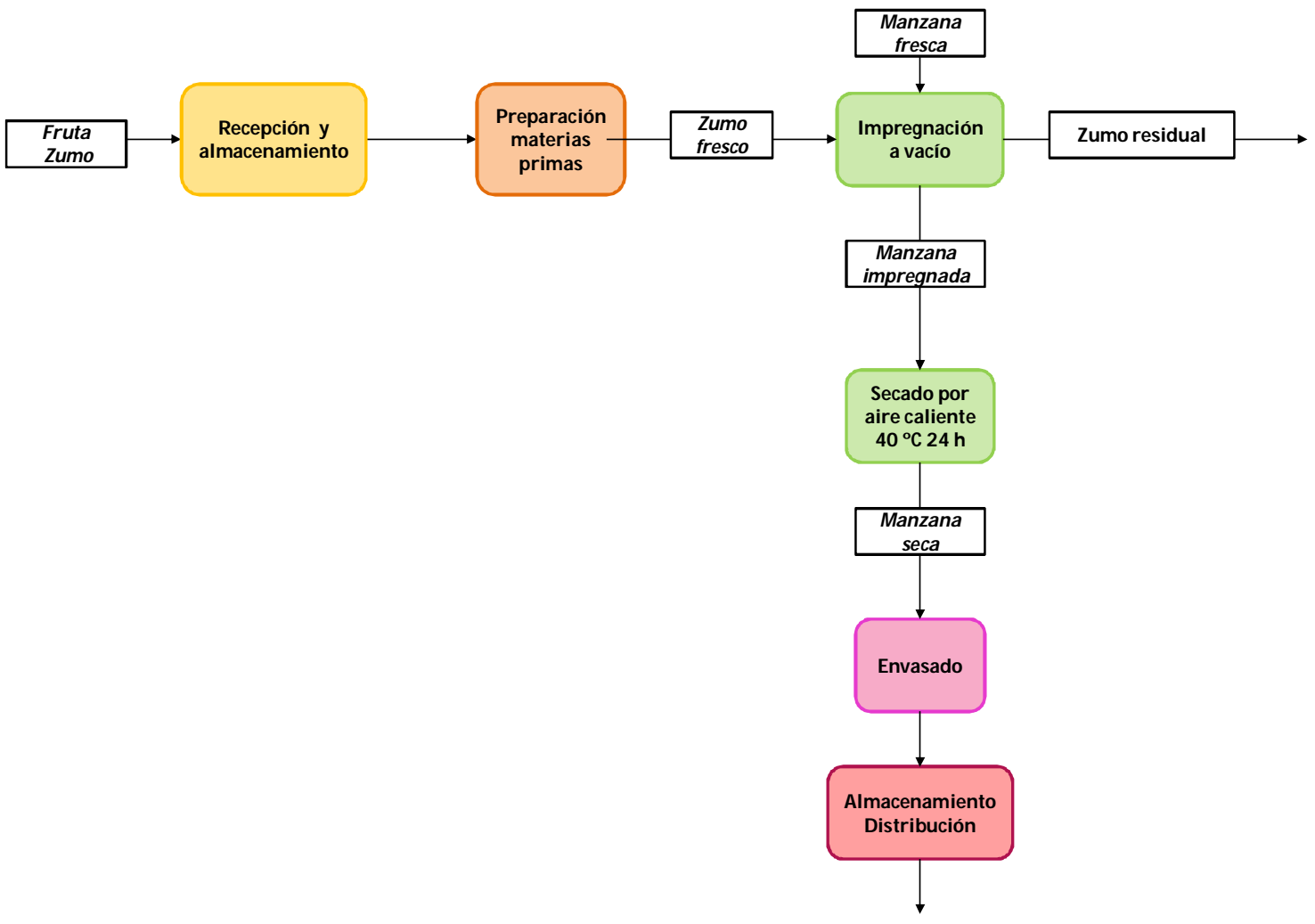

Figura 1. Diagrama de flujo del proceso de fabricación del alimento funcional.

De entre todos los criterios posibles, se ha considerado la necesidad de espacio de los productos a procesar como el factor limitante en la elección de los equipos de la planta. En el cálculo de las necesidades de espacio de los productos a procesar se han tenido en cuenta las variables inherentes a los pacientes, a las materias primas, al proceso y a los equipos que se detallan a continuación: 
- Variables relacionadas con los pacientes.

Este grupo de variables incluye aquéllas que afectan directamente a la realización de los ensayos clínicos e influyen en la valoración in vivo de la funcionalidad del alimento.

Se requiere un número de pacientes $\left(n_{p}\right)$ mínimo que consuma una determinada cantidad del alimento funcional (D), durante un tiempo determinado (T) para llevar a cabo los estudios in vivo de forma adecuada.

El número de pacientes $\left(\mathrm{n}_{\mathrm{p}}\right)$ mínimo se establece teniendo en cuenta un nivel de confianza del $95 \%(a=0,05 ; \mathrm{Za}=1,96)$, un error máximo admitido del $8 \%$ (la amplitud del IC será 16) y un valor de prevalencia conocido por la bibliografía del 6\%. En este caso el tamaño de la muestra necesario debería ser de 35. En este trabajo se han recogido datos de 48 niños y la duración del tratamiento (T) se ha establecido considerando los resultados obtenidos en estudios previos.

La dosis (D) se ve influida por la composición final que debe tener el producto para que el alimento funcional aporte la cantidad de componente fisiológicamente activo (CAF) deseado.

- Variables relacionadas con las materias primas.

Este grupo está formado por aquellas variables que relacionadas con las características y las propiedades de las materias primas afectan directamente al proceso de fabricación. Por ejemplo, la porosidad y las propiedades mecánicas del producto considerado así como las propiedades fisicoquímicas del líquido de impregnación determinan la cantidad de CAF incorporado en el producto final.

Se ha definido la unidad de impregnación (u) como la parte de una pieza de fruta que tiene el formato adecuado para llevar a cabo la operación de impregnación a vacío. De cada pieza de fruta puede obtenerse un determinado número de unidades de impregnación $\left(\mathrm{n}_{\mathrm{u}}\right)$

Las dimensiones de la unidad de impregnación alto (h), ancho (w) y espesor (e), determinan la superficie necesaria de la unidad de impregnación ( $\left.\mathrm{S}_{u}\right)$. La cantidad de líquido de impregnación $\left(\mathrm{m}_{\mathrm{l}}\right)$ necesario para que la unidad fresca $\left(\mathrm{m}_{\mathrm{f}}\right)$ se impregne correctamente, así como su capacidad para eliminar agua durante el secado $\left(\mathrm{m}_{\mathrm{s}}\right)$ permiten determinar las necesidades en materias primas $\left(\mathrm{M}_{\mathrm{f}} ; \mathrm{M}_{\mathrm{s}} ; \mathrm{V}_{\mathrm{IV}}\right.$; V).

Dependiendo de las características del líquido de impregnación se establecen unos criterios u otros de reutilización del mismo $\left(\mathrm{r}_{\mathrm{IV}}\right)$. Si se trata de un zumo, es necesario conocer el rendimiento en zumo $\left(r_{z}\right)$ con el fin de determinar la cantidad de fruta necesaria para obtener el líquido de impregnación $\left(\mathrm{F}_{\mathrm{z}}\right)$. 
- Variables relacionadas con el proceso.

Este grupo de variables está formado por aquéllas que afectan directamente a la duración y al desarrollo del proceso de fabricación del alimento funcional.

Se requiere un determinado número de días de trabajo máximo $\left(\mathrm{t}_{\mathrm{t}}\right)$ para que desde la fabricación del producto funcional hasta el consumo del mismo por los pacientes no se supere el tiempo de almacenamiento máximo establecido. Además los equipos de trabajo y las operaciones previas necesarias como el lavado, el corte y la preparación en general de las materias primas determinan el número de operaciones que es posible realizar en un día de trabajo ( $\mathrm{n}_{\mathrm{IV}}$ ).

- Variables relacionadas con los equipos.

Este grupo de variables afectan directamente al cálculo de las necesidades de espacio de los equipos de la planta piloto. Es necesario considerar un cierto sobredimensionamiento $\left(\mathrm{S}_{\mathrm{b}}\right)$ de la producción por las posibles pérdidas de producto durante el proceso de fabricación. La posición de las muestras en los equipos, la superficie que ocupa una unidad de impregnación $\left(\mathrm{S}_{\mathrm{u}}\right)$ así como la cantidad de producto funcional que se debe fabricar al día $\left(\mathrm{U}_{\mathrm{d}}\right)$ influyen directamente sobre las necesidades de espacio de los equipos de la planta piloto (S). 


\section{Diagrama del proceso de cálculo.}

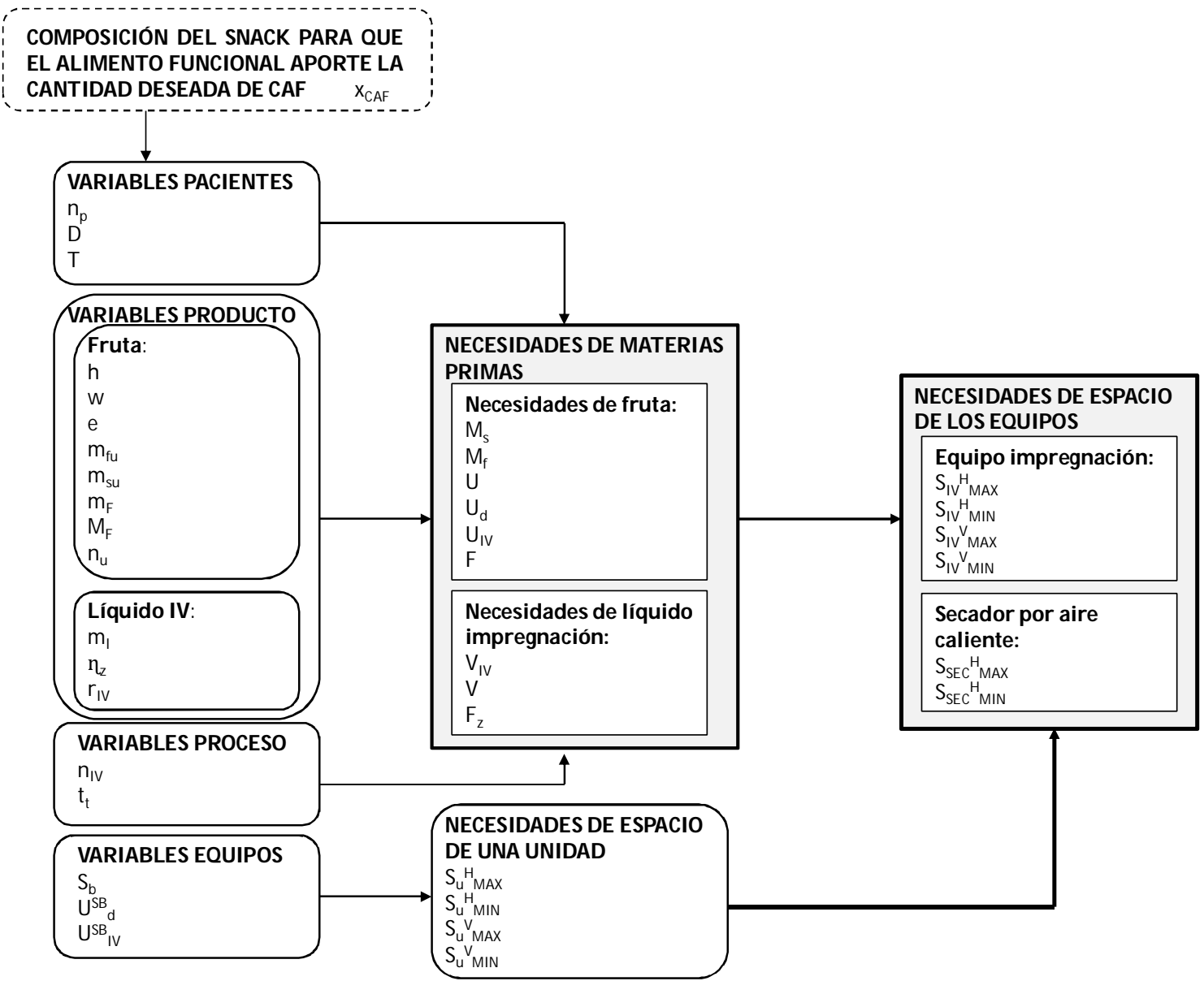

Figura 2. Diagrama del proceso de cálculo utilizado para conocer las necesidades de materias primas y equipos.

\section{Secuencia de cálculo.}

\section{Cálculo de las necesidades de materias primas}

La cantidad de alimento funcional seco que es necesario obtener para realizar los estudios in vivo se calcula a partir del número de pacientes, la dosis y el tiempo de tratamiento:

$$
\mathrm{M}_{\mathrm{S}}=\mathrm{D} \cdot \mathrm{T} \cdot \mathrm{n}_{\mathrm{p}}
$$

A partir de la cantidad de alimento funcional seco y la masa de una unidad de impregnación al inicio y al final del proceso es posible calcular la cantidad de producto fresco necesario:

$$
\mathrm{M}_{\mathrm{f}}=\mathrm{M}_{\mathrm{s}} \cdot \frac{\mathrm{m}_{\mathrm{fu}}}{\mathrm{m}_{\mathrm{su}}}
$$

Utilizando la cantidad de producto fresco necesaria y el peso de una unidad de impregnación es posible calcular el número de unidades necesario para cubrir las necesidades del estudio in vivo:

$$
\mathrm{U}=\frac{\mathrm{M}_{\mathrm{f}}}{\mathrm{m}_{\mathrm{fu}}}
$$


Conocido el número total de unidades necesarias es posible calcular el número de unidades que se necesita impregnar en un día para cumplir con los requerimientos establecidos y no superar el tiempo de almacenamiento máximo de las muestras:

$$
\mathrm{U}_{\mathrm{d}}=\frac{\mathrm{U}}{\mathrm{t}_{\mathrm{t}}}
$$

Sabiendo el número de impregnaciones que pueden llevarse a cabo en un día es posible conocer el número de unidades que se deben impregnar en una impregnación:

$$
\mathrm{U}_{\mathrm{IV}}=\frac{\mathrm{U}_{\mathrm{d}}}{\mathrm{n}_{\mathrm{IV}}}
$$

Conociendo el número de piezas de fruta total obtenido a partir del número de unidades totales y el número de unidades que es posible obtener de una pieza de fruta es posible calcular la cantidad de fruta necesaria:

$$
\mathrm{M}_{\mathrm{F}}=\frac{\mathrm{U}}{\mathrm{n}_{\mathrm{u}}} \cdot \mathrm{m}_{\mathrm{F}}
$$

Por otra parte, conociendo la cantidad de líquido de impregnación necesario para que se impregne correctamente un gramo de fruta fresca y las unidades a impregnar es posible calcular el volumen de líquido necesario en una impregnación:

$$
\mathrm{V}_{\mathrm{IV}}=\mathrm{m}_{\mathrm{fu}} \cdot \frac{\mathrm{m}_{\mathrm{I}}}{\mathrm{m}_{\mathrm{f}}} \cdot \frac{0.1}{\mathrm{n}_{\mathrm{IV}}}
$$

A partir del volumen de líquido necesario en una impregnación y teniendo en cuenta el número de impregnaciones que es posible realizar en un día, la reutilización del líquido de impregnación y los días de trabajo es posible calcular el volumen total necesario de líquido de impregnación:

$$
\mathrm{V}=\frac{\mathrm{V}_{\mathrm{IV}} \cdot \mathrm{n}_{\mathrm{IV}} \cdot \mathrm{t}_{\mathrm{t}}}{\mathrm{r}_{\mathrm{IV}}}
$$

Conocido el volumen total del líquido de impregnación necesario y el rendimiento en zumo es posible calcular la cantidad de fruta necesaria para obtener el volumen total del líquido de impregnación:

$$
\mathrm{F}_{\mathrm{z}}=\frac{\mathrm{V}}{\eta_{\mathrm{z}}}
$$

2. Cálculo de las necesidades de espacio de una unidad de impregnación.

Para calcular la superficie de una unidad de impregnación se ha considerado el espacio que ocupan las muestras en posición horizontal y en vertical y además se han tenido en cuenta unas necesidades de espacio máximas y mínimas.

La unidad de impregnación en posición horizontal ocupa una superficie máxima:

$$
\mathrm{S}_{\mathrm{uMAX}}^{\mathrm{H}}=\mathrm{h}_{\text {MAX }} \cdot \mathrm{w}_{\text {MAX }}
$$

La unidad de impregnación en posición horizontal ocupa una superficie mínima:

$$
\mathrm{S}_{\mathrm{uMIN}}^{\mathrm{H}}=\mathrm{h}_{\text {MIN }} \cdot \mathrm{w}_{\text {MIN }}
$$

La unidad de impregnación en posición vertical ocupa una superficie máxima: 


$$
\mathrm{S}_{\mathrm{uMAX}}^{\mathrm{V}}=\mathrm{h}_{\text {MAX }} \cdot \mathrm{e}_{\text {MAX }}
$$

La unidad de impregnación en posición vertical ocupa una superficie mínima:

$$
\mathrm{S}_{\mathrm{uMIN}}^{\mathrm{V}}=\mathrm{h}_{\mathrm{MIN}} \cdot \mathrm{e}_{\mathrm{MIN}}
$$

3. Cálculo de las necesidades de espacio del equipo de impregnación a vacío.

Para calcular la superficie necesaria del equipo de impregnación a vacío se ha considerado el espacio que ocupan las muestras en posición horizontal y en vertical y además se han tenido en cuenta unas necesidades de espacio máximas y mínimas.

La superficie necesaria máxima del equipo de impregnación si las muestras se colocan en posición horizontal:

$$
\mathrm{S}_{\text {IVMAX }}^{\mathrm{H}}=\mathrm{S}_{\mathrm{uMAX}}^{\mathrm{H}} \cdot \mathrm{U}_{\mathrm{IV}}
$$

La superficie necesaria mínima del equipo de impregnación si las muestras se colocan en posición horizontal:

$$
\mathrm{S}_{\text {IVMIN }}^{\mathrm{H}}=\mathrm{S}_{\mathrm{uMIN}}^{\mathrm{H}} \cdot \mathrm{U}_{\mathrm{IV}}
$$

La superficie necesaria máxima del equipo de impregnación si las muestras se colocan en posición vertical:

$$
\mathrm{S}_{\text {IVMAX }}^{\mathrm{V}}=\mathrm{S}_{\mathrm{uMAX}}^{\mathrm{V}} \cdot \mathrm{U}_{\mathrm{IV}}
$$

La superficie necesaria mínima del equipo de impregnación si las muestras se colocan en posición vertical:

$$
\mathrm{S}_{\mathrm{IVMIN}}^{\mathrm{V}}=\mathrm{S}_{\mathrm{UMIN}}^{\mathrm{V}} \cdot \mathrm{U}_{\mathrm{IV}}
$$

4. Cálculo de las necesidades de espacio del secador por aire caliente.

Para calcular la superficie necesaria del secador por aire caliente se ha considerado el espacio que ocupan las muestras en posición horizontal y vertical, las necesidades de espacio máximas y mínimas y se ha tenido en cuenta que el secador debe tener capacidad para secar durante 24 horas todas las muestras producidas durante el día.

La superficie necesaria máxima del secador por aire caliente si las muestras se colocan en posición horizontal:

$$
\mathrm{S}_{\text {SECMAX }}^{\mathrm{H}}=\mathrm{S}_{\mathrm{UMAX}}^{\mathrm{H}} \cdot \mathrm{U}_{\mathrm{d}}
$$

La superficie necesaria mínima del secador por aire caliente si las muestras se colocan en posición horizontal:

$$
\mathrm{S}_{\mathrm{SECMIN}}^{\mathrm{H}}=\mathrm{S}_{\mathrm{UMIN}}^{\mathrm{H}} \cdot \mathrm{U}_{\mathrm{d}}
$$

La superficie necesaria máxima del secador por aire caliente si las muestras se colocan en posición vertical:

$$
\mathrm{S}_{\text {SECMAX }}^{\mathrm{V}}=\mathrm{S}_{\text {UMAX }}^{\mathrm{V}} \cdot \mathrm{U}_{\mathrm{d}}
$$

La superficie necesaria mínima del secador por aire caliente si las muestras se colocan en posición vertical:

$$
\mathrm{S}_{\mathrm{SECMIN}}^{\mathrm{V}}=\mathrm{S}_{\mathrm{UMIN}}^{\mathrm{V}} \cdot \mathrm{U}_{\mathrm{d}}
$$




\section{Ejemplo de aplicación.}

Se ha fabricado un alimento funcional natural de baja humedad a partir de manzana (cv. Granny Smith) y zumo de mandarina (cv. Ortanique). Tanto la manzana como el zumo de mandarina son alimentos ampliamente consumidos en todo el mundo. Son bien conocidos sus efectos beneficiosos sobre la salud debido a su elevado contenido en flavonoides y en compuestos antioxidantes. Además, las características estructurales de la manzana y sus propiedades mecánicas aseguran, tal y como se ha demostrado en estudios previos, una buena impregnación.

Se ha elegido manzana de la variedad Granny Smith debido a que se encuentra disponible en los mercados locales durante todo el año y a que sus características fisicoquímicas prácticamente no varían. Se ha elegido zumo de mandarina de la variedad Ortanique por ser la variedad que más contenido tiene en hesperidina.

Para el establecimiento de la dosis de alimento funcional se ha tenido en cuenta que 40 gramos de producto seco deben proporcionar la misma cantidad de hesperidina que $250 \mathrm{ml}$ de zumo de mandarina fresco. Estudios previos han demostrado que el consumo de medio litro de zumo de mandarina diario durante un período de 28 días disminuye los marcadores del estrés oxidativo y mejora las defensas antioxidantes en niños obesos.

El número de pacientes se ha establecido teniendo en cuenta un nivel de confianza del $95 \%(a=0,05 ; Z a=1,96)$, un error máximo admitido del 8\% (la amplitud del IC será 16) y un valor de prevalencia conocido por la bibliografía del 6 $\%$. Considerando que el estudio in vivo se ha realizado en niños de entre 8 y 11 años y teniendo en cuenta las posibles bajas que pueden producirse durante el tratamiento por consumo inadecuado del alimento funcional, por el no cumplimiento de las especificaciones establecidas por las pediatras o por la renuncia de los propios pacientes, se ha considerado un número de pacientes un $50 \%$ superior al mínimo necesario (60 pacientes). El tiempo de tratamiento de 28 días se ha establecido teniendo en cuenta los resultados obtenidos en estudios previos. El estudio in vivo se ha realizado, por razones de manejo y gestión de los pacientes, en dos años consecutivos, de tal manera que la planta piloto se ha diseñado para producir la cantidad de alimento funcional necesario en un año de estudio. Olo que es lo mismo, el necesario para 30 pacientes.

En este caso la unidad de impregnación se ha establecido en un disco de manzana y a partir de rodajas de manzana de $0.5 \mathrm{~cm}$ de espesor y utilizando dos cilindros de dimensiones 6.6 y $2.1 \mathrm{~cm}$ se han obtenido discos de $6.6 \mathrm{~cm}$ de alto, 6.6 $\mathrm{cm}$ de ancho y $0.5 \mathrm{~cm}$ de espesor.

Utilizando la ecuación 1 se ha determinado la cantidad de alimento funcional necesario $(33.6 \mathrm{~kg})$ para realizar el estudio y con la ecuación 2 la cantidad de producto fresco $(235.2 \mathrm{~kg})$.

Se ha establecido en 20 días los días máximos de trabajo posibles ya que éste ha sido el tiempo máximo de almacenamiento establecido empíricamente y el 
alimento funcional se ha decidido suministrar a los pacientes en dos tandas, cada 15 días.

Previamente a ser impregnadas es necesario lavar, cortar y homogenizar las manzanas en discos. Estas operaciones previas junto con el tiempo necesario para realizar la operación de impregnación a vacío han determinado que como máximo es posible realizar 6 impregnaciones al día.

Se han calculado los discos de manzana necesarios en total (15680 discos), por cada día de trabajo (784 discos) y por cada impregnación (131 discos) utilizando las ecuaciones 3,4 y 5 respectivamente.

Sabiendo que de cada manzana pueden obtenerse 5 discos se ha calculado la cantidad de manzanas necesarias (3136 manzanas) mediante la ecuación 6 y la cantidad de fruta $(627 \mathrm{~kg})$ utilizando la ecuación 7.

En estudios previos se ha demostrado que para llevar a cabo una adecuada impregnación son necesarios 10 gramos de zumo por cada gramo de manzana fresca. De esta forma es posible reutilizar 3 veces el líquido de impregnación sin alterar sus características de forma significativa. Con estas dos premisas se ha calculado utilizando las ecuaciones 8 y 9 el volumen de líquido de impregnación necesario en una impregnación (22 litros) así como el volumen total (862 litros). Además sabiendo que el rendimiento en zumo de la mandarina Ortanique es del 50 $\%$ y teniendo en cuenta las pérdidas en cada etapa del proceso de extracción son necesarios $1725 \mathrm{~kg}$ de mandarina para obtener el volumen suficiente de líquido de impregnación.

Se ha determinado la superficie de equipo que necesita un disco de manzana para su procesado. Para ello se ha tenido en cuenta que la posición de los discos en los equipos puede ser horizontal o vertical y además se ha considerado un espacio mínimo y máximo. Así, utilizando las ecuaciones 11, 12, 13, 14 las necesidades de espacio de un disco de manzana en horizontal van desde 57.76 a $73.96 \mathrm{~cm}^{2}$ y en vertical van desde 11.4 a $21.5 \mathrm{~cm}^{2}$.

Debido a las posibles pérdidas que pueden producirse durante el proceso por roturas, caídas o fallos en la impregnación o durante el proceso de secado, se ha considerado un sobredimensionamiento de la instalación del 10\%. Para colocar las muestras en el equipo de impregnación se ha diseñado un sistema de bandejas y rejillas que asegura que todos los discos están completamente sumergidos en el líquido de impregnación.

Con el objetivo de minimizar el espacio del equipo de impregnación, favorecer la eliminación del gas durante la primera etapa de la impregnación a vacío y aumentar el rendimiento real de la operación, se ha decidido colocar las muestras en vertical y utilizando las ecuaciones 17 y 18 se han calculado las necesidades de espacio del equipo, que van desde 1639 a $3090 \mathrm{~cm}^{2}$.

Se ha diseñado un equipo de impregnación a vacío formado por una cámara de vacío de acero inoxidable con un volumen interior de 128 litros y una bomba de membrana (MPC 601Zp). El interior de la cámara contiene 3 soportes de dimensiones 480 x $490 \mathrm{~mm}$ donde se colocan los recipientes con la disolución de 
impregnación y en cuyo interior se colocan los discos de manzana utilizando para ello, tal y como se ha dicho, un sistema de rejillas. Cada bandeja es capaz de soportar una carga máxima de $20 \mathrm{~kg}$. Con el fin de asegurar el mantenimiento del vacío interior se ha colocado una junta de caucho en el borde delantero del armazón interior. Todos los elementos de mando y control, así como la palanca de accionamiento de la válvula de cierre, la válvula de admisión de aire y el vacuómetro analógico, están dispuestos en un panel modular.

Para favorecer la eliminación de agua de las muestras mediante la circulación de aire se ha decidido colocar en el secador los discos de manzana en posición horizontal de tal manera que el aire los atraviese transversalmente. De este modo y teniendo en cuenta que en el secador deben caber todos los discos procedentes de las 6 impregnaciones que se llevan a cabo en un día, mediante las ecuaciones 19 y 20 se han calculado las necesidades de espacio del equipo que van desde 4.9 a 6.4 $\mathrm{m}^{2}$.

Así, se ha diseñado un equipo de secado por aire caliente que consta de un ventilador que impulsa el aire ambiente hacia el interior de la cámara, una resistencia eléctrica de $500 \mathrm{~W}$ que calienta el aire hasta la temperatura deseada y una cámara de secado. La cámara de secado de acero inoxidable consta de siete bandejas perforadas de dimensiones $500 \times 800 \mathrm{~mm}$.

Si bien no se ha llevado a cabo el escalado a nivel industrial, la instalación es suficiente para producir el alimento funcional necesario para realizar las actividades relacionadas con esta tesis, supone un primer paso para ello y además, se ha desarrollado un modelo matemático en el que se establecen las relaciones entre todas las variables implicadas.

Además, en un futuro se pretende automatizar el traslado de la carga desde la cámara de impregnación hasta la cámara de secado así como el envasado con la finalidad de reducir la mano de obra necesaria y aumentar el rendimiento del proceso de fabricación. 


\section{Fotos de los equipos y del proceso de desarrollo del alimento funcional.}

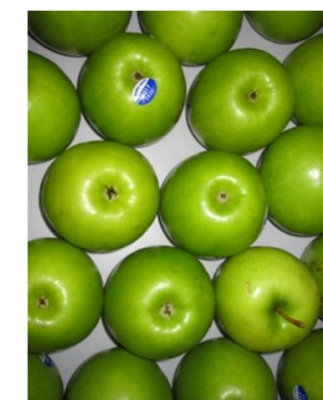

Manzana fresca (cv. Granny Smith)

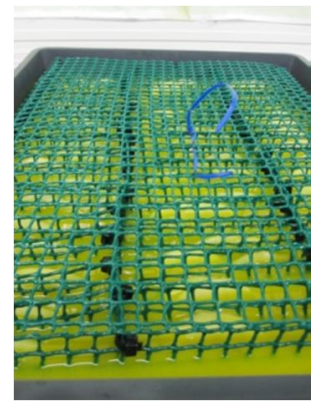

Discos de manzana sumergidos en el líquido de impregnación.

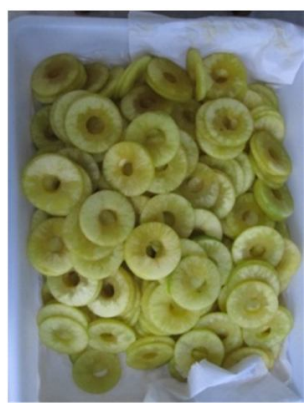

Discos de manzana impregnados.

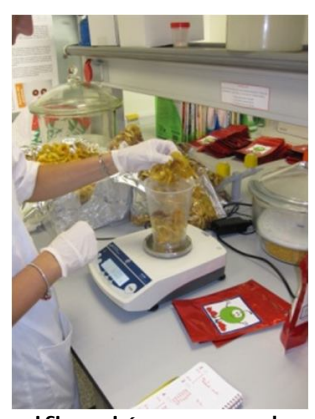

Dosificación y pesado del alimento funcional.

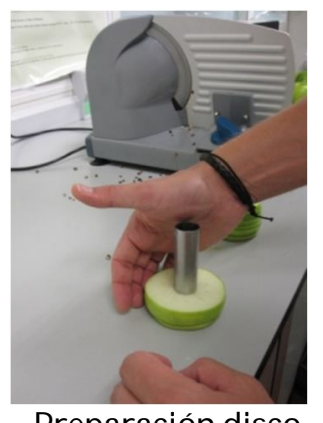

Preparación disco, cilindro interno.

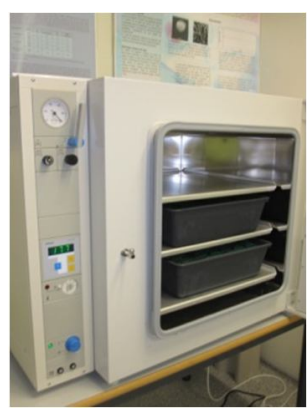

Equipo de impregnación. Bandejas y panel de control.

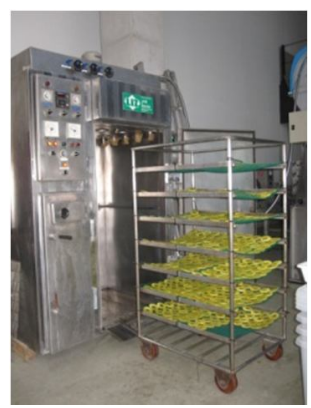

Colocación de los discos en el secador

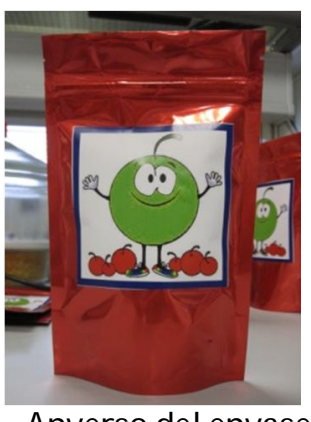

Anverso del envase del alimento funcional.

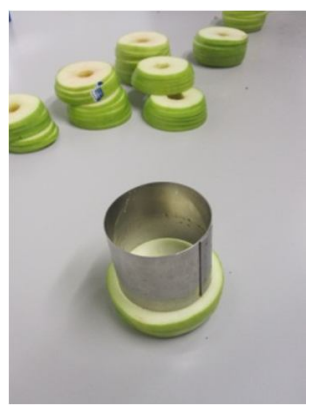

Preparación disco, cilindro externo.

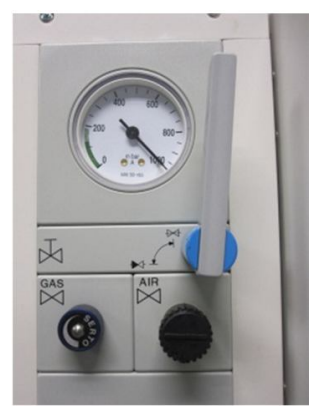

Detalle panel de control.

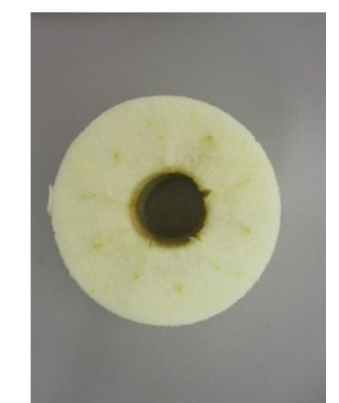

Disco de manzana sin pepitas y sin piel.

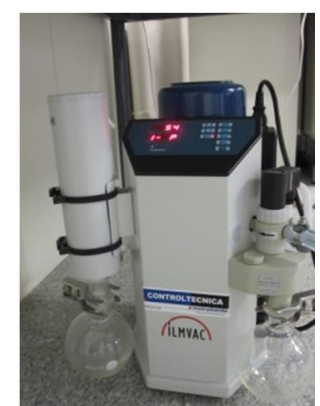

Bomba de membrana. Panel de control.

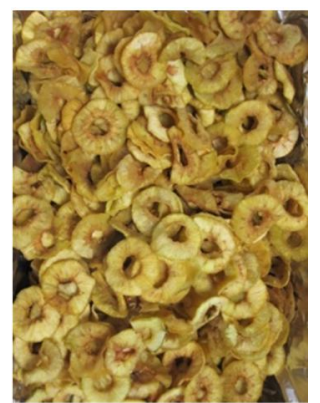

Detalle del secador. Panel de control.

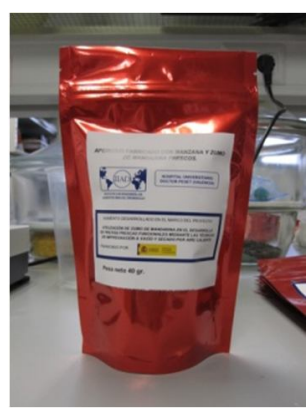

Reverso del envase del alimento funcional.
Discos de manzana deshidratados.

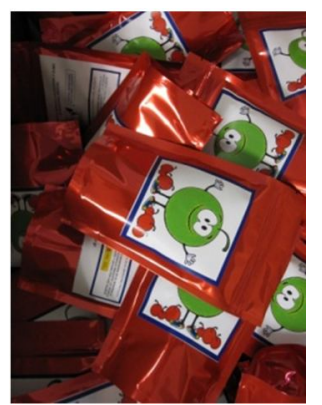

Figura 3. Fotos de los equipos y del proceso de desarrollo del alimento funcional. 


\section{Consideraciones económicas y tecnológicas.}

Con el objetivo de conocer la viabilidad económica de la producción del alimento funcional desarrollado se ha llevado a cabo un plan económico-financiero de la línea de fabricación utilizando la plantilla desarrollado por el Instituto IDEAS $^{\circledR}$ de la Universidad Politécnica de Valencia. Se ha determinado el precio mínimo del alimento funcional necesario para cubrir gastos teniendo en cuenta varios supuestos:

a. Considerando únicamente costes de funcionamiento sin considerar la adquisición y amortización de equipos.

b. Considerando que el alimento funcional se elabora en una empresa que fabrica ya aperitivos y únicamente se necesita el equipo de impregnación a vacío.

c. Considerando que para la elaboración del alimento funcional es necesario implementar toda la línea de producción.

En los supuestos b y c se ha considerado que los equipos están diseñados para una producción continua de $20 \mathrm{~kg} / \mathrm{h}$ siguiendo las normas vigentes para equipos destinados a la industria alimentaria y suponiendo que en ambos casos se necesita un operario que trabaje en la línea la jornada completa.

En las figuras 4, 5 y 6, se muestran, respectivamente, las entradas y salidas de la planta piloto para el caso de una bolsa de producto seco, para el caso de que la producción se lleve a cabo durante 1 hora con una producción de $20 \mathrm{~kg} / \mathrm{h}$, para el caso de que la producción se lleve a cabo durante 1 mes de trabajo (30 días trabajando 8 horas al día).

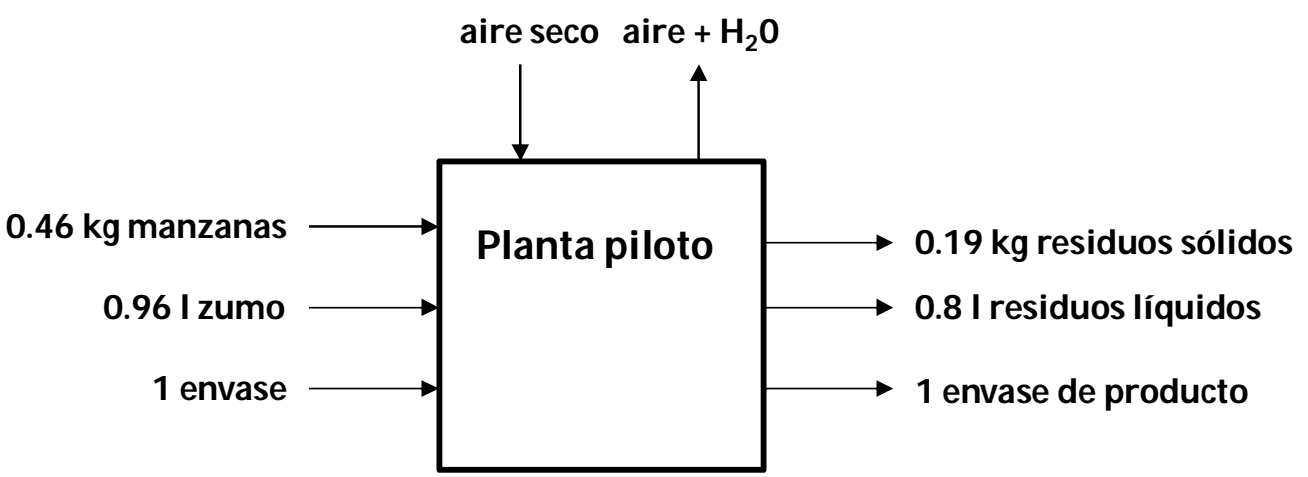

Figura 4. Entradas-salidas de la planta piloto para 1 envase de producto. 


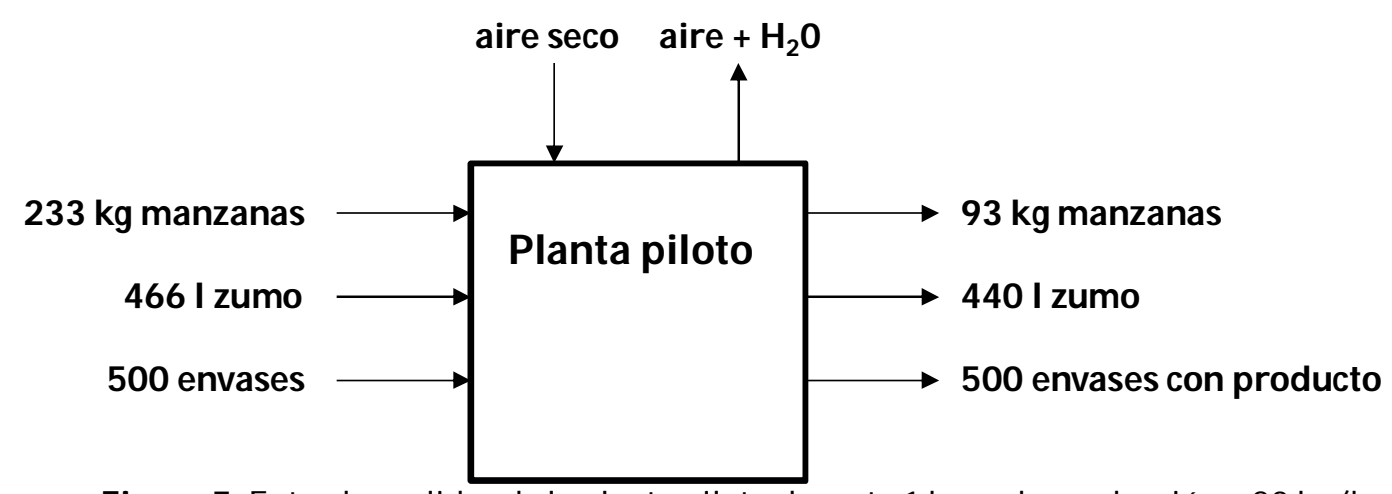

Figura 5. Entradas-salidas de la planta piloto durante 1 hora de producción a 20 kg/ h.

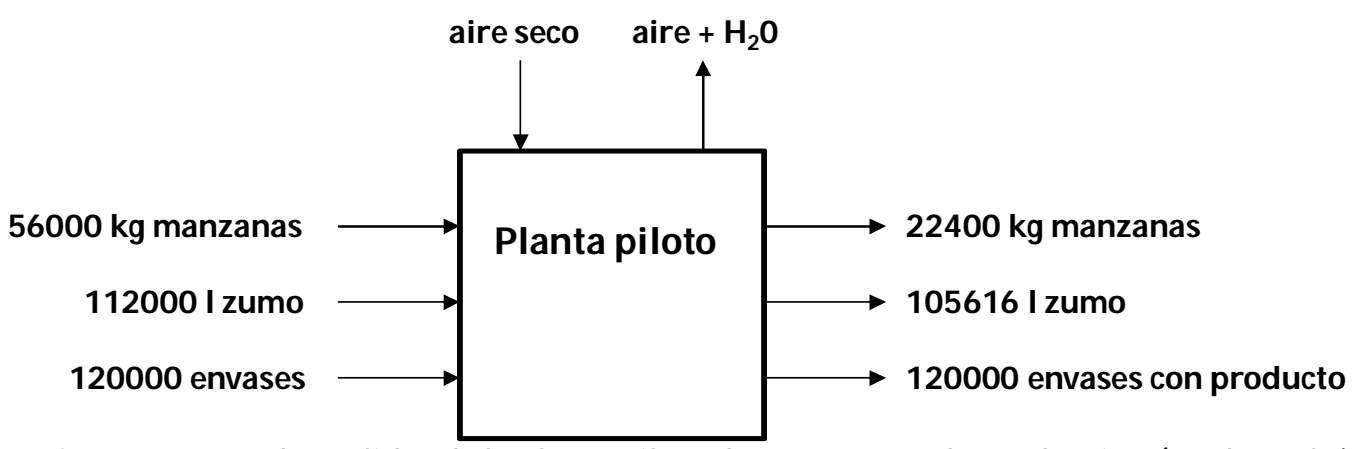

Figura 6. Entradas-salidas de la planta piloto durante 1 mes de producción (30 días 8 h/ día).

En el análisis de costes se han tenido en cuenta tanto los costes directos como los costes indirectos. Los costes directos son los costes generados de manera directa por la actividad productiva (materias primas, subcontrataciones, distribución...). Los costes indirectos son los costes generados por el funcionamiento de la empresa independientemente de la producción (gastos generales, amortización del inmovilizado, gastos de personal...).

Se ha establecido un precio mínimo unitario de la bolsa de $40 \mathrm{~g}$ de alimento funcional teniendo en cuenta los gastos de personal y materias primas y otro precio unitario considerando además la amortización de la maquinaria necesaria.

- Caso b. Si el alimento se elabora en una empresa que fabrica ya aperitivos y únicamente se necesita el equipo de impregnación a vacío:

El coste de personal es de 2123.33 euros al mes teniendo en cuenta que un trabajador a jornada completa tiene un sueldo de 1633.33 euros/mes brutos y considerando además los gastos de la seguridad social del trabajador.

Si la empresa ya fabrica aperitivos de baja humedad y sólo se tiene que añadir a la línea el equipo de impregnación a vacío, el coste de maquinaria asciende a 200000 euros.

Si los equipos están diseñados para una producción de $20 \mathrm{~kg} / \mathrm{h}$ eso supone una producción de 500 bolsas/ hora y 120000 bolsas/mes. Para ello, se necesitan al mes $56000 \mathrm{~kg}$ de manzana fresca con un coste de 0.4 euros/ kg y 112000 litros de zumo con un coste de 0.35 euros/ l. Esto supone un coste total en materias primas 
de 61600 euros/mes. Y si se tiene en cuenta que cada envase impreso tiene un precio de 0.05 euros el coste total de los envases es de 6000 euros al mes.

Se ha tenido en cuenta que el coste total relativo al gasto en agua y electricidad es de 1050 euros al mes teniendo en cuenta que la electricidad cuesta 0.15 euros/ Kwh y el agua 1.4 euros/ $\mathrm{m}^{3}$.

El precio mínimo unitario de la bolsa de alimento funcional es de 0.60 euros teniendo en cuenta los gastos de personal y materias primas. El precio mínimo unitario del paquete de alimento funcional es de 0.75 euros teniendo en cuenta los gastos de los equipos con un período de amortización de 11 meses.

- Caso c. Si para la elaboración del alimento funcional es necesario implementar toda la línea de producción:

En este caso, al igual que en el anterior, el coste de personal es de 2133.33 euros al mes teniendo en cuenta que un trabajador a jornada completa tiene un sueldo de 1633.33 euros/mes brutos y considerando además los gastos de la seguridad social del trabajador.

$\mathrm{Si}$ la empresa tiene que construir toda la línea de fabricación del alimento funcional el coste de equipos de la línea asciende a 500.000 euros (cámara de refrigeración, cámara de congelación, agitadores, cortadora, peladora, equipo de impregnación a vacío, equipo de secado por aire caliente, envasadoras).

$\mathrm{Al}$ igual que en el caso anterior se ha considerado una producción continua de 20 kg/hora que son 500 bolsas/hora y 120000 bolsas/mes. Para ello serían necesarios al mes $56000 \mathrm{~kg}$ de manzana fresca y 112000 litros de zumo, con un coste respectivamente de 0,4 y 0,35 euros/ kg o litro supondrían un coste total para la empresa de 61.600 euros / mes. Con un coste de envases total de 6000 euros al mes a 0.05 euros el envase impreso.

El coste de agua y electricidad de 1050 euros al mes teniendo en cuenta que el $\mathrm{kw} / \mathrm{h}$ cuesta 0.15 euros y el $\mathrm{m}^{3}$ de agua 1.4 euros.

En este caso además se han considerado gastos de equipos y aplicaciones informáticas necesarias para un control de la línea.

En este caso el precio mínimo unitario de la bolsa de alimento funcional es de 0.60 euros al igual que en el supuesto anterior teniendo en cuenta los gastos de personal y de materias primas. El precio unitario de la bolsa de alimento funcional es de 0.75 euros teniendo en cuenta los gastos de maquinaria y un período de amortización de 3 años y 3 meses. El precio unitario de la bolsa de alimento funcional es de 0.95 euros teniendo en cuenta los gastos de maquinaria y un período de amortización de 12 meses.

\section{Aspectos medioambientales.}

De todas las corrientes de salida del sistema, la que puede resultar más problemática desde el punto de vista medioambiental, por el gran volumen que 
representa, es la corriente del zumo de mandarina después de la operación de impregnación a vacío.

Se ha realizado una caracterización medioambiental de dicha corriente para poder aplicar la legislación vigente de vertidos y determinar si sus características permiten el vertido directo al colector de aguas de la instalación, o en su caso, si fuera necesario un tratamiento, proponer algunas posibles soluciones y así minimizar el impacto medioambiental de la planta.

Se ha determinado la demanda teórica de oxígeno, la demanda química de oxígeno y la demanda biológica de oxígeno del zumo residual de mandarina (cv. Ortanique).

- Demanda teórica de oxígeno.

La demanda teórica de oxígeno es la cantidad estequiométrica de oxígeno necesaria para oxidar totalmente un determinado compuesto. A partir de la composición del zumo se ha calculado la demanda teórica de oxígeno teniendo en cuenta todos los compuestos susceptibles de ser oxidados y calculando la cantidad estequiométrica de oxígeno necesaria para oxidarlos totalmente.

En 100 gr de zumo hay 86.06 gr de agua, 10.74 gr de hidratos de carbono de los cuales $6.14 \mathrm{gr}$ son de sacarosa, $2.24 \mathrm{gr}$ son de glucosa y $2.36 \mathrm{gr}$ son de fructosa, $0.89 \mathrm{gr}$ de grasas que corresponden fundamentalmente a los aceites esenciales, $1.19 \mathrm{gr}$ proteínas y $1.12 \mathrm{gr}$ otros componentes de los cuales $0.85 \mathrm{gr}$ son de ácido cítrico, 0.21 son de ácido málico, 0.042 gr son de vitamina C y 0.02 gr son de flavonoides.

Así, para oxidar totalmente un litro de zumo se necesitan teóricamente $126599.7 \mathrm{mg} \mathrm{O}_{2} / \mathrm{l}$ zumo residual.

\section{- Demanda química de oxígeno.}

La demanda química de oxigeno es la cantidad de oxígeno disuelto consumida durante la oxidación por vía química de la materia orgánica presente, en este caso, en el zumo de mandarina.

Para determinar la demanda química de oxígeno se ha realizado una determinación fotométrica. Para ello, se ha utilizado el Test 0-33 del fotómetro Nanocolor y el kit de reactivos DQO 300. El kit de reactivos consta de 20 tubos de test de DQO 300. Cada tubo de test contiene, dicromato potásico $\mathrm{K}_{2} \mathrm{Cr}_{2} \mathrm{O}_{7}$, ácido sulfúrico $80 \%$ y sulfato de mercurio en una cantidad menor al $0.5 \%$. Para la determinación se añaden $2 \mathrm{ml}$ de muestra en el tubo de test, se agita y se coloca en el bloque calefactor durante 2 horas a $148^{\circ} \mathrm{C}$. Se ha utilizado una disolución del zumo 1:500 para que el resultado se encontrara dentro del rango de medición del test.

La principal reacción química que tiene lugar es:

$$
\text { Mat. orgánica }+\mathrm{Cr}_{2} \mathrm{O}_{7}^{2-}+\mathrm{H}^{+} \stackrel{\text { catalizador+calor }}{\longrightarrow} \mathrm{Cr}^{3+}+\mathrm{CO}_{2}+\mathrm{H}_{2} \mathrm{O}
$$


Determinándose tras la oxidación el descenso de concentración de cromato.

El valor de DQO que se ha obtenido en la disolución 1:500 es de $131 \mathrm{mg} \mathrm{O}_{2} /$ l. El valor de DQO del zumo de mandarina es de $65500 \mathrm{mg} \mathrm{O} / \mathrm{l}$ zumo residual.

\section{- Demanda biológica de oxígeno.}

La demanda bioquímica de oxígeno después de $\mathrm{n}$ días $\left(\mathrm{DBO}_{\mathrm{n}}\right)$ es la concentración máxima de oxígeno disuelto consumida, en condiciones definidas por la oxidación bioquímica de las materias orgánicas y/ o inorgánicas en el agua, en un período de incubación de $n$ días.

Normalmente se utiliza el valor de $\mathrm{DBO}_{5}$ pero son necesarios unos 15 - 20 días para que se consuma el 90-99 \% de la materia orgánica.

Para realizar la determinación se ha inoculado el zumo de mandarina con agua residual y se ha utilizado el equipo Oxidirect que determina la DBO midiendo la variación de presión en un sistema cerrado. El equipo consta de 6 botellas de DBO, 6 sensores de DBO, 6 caperuzas aislantes, 6 imanes de agitación, 1 tabla de agitación con 6 departamentos, 2 matraces aforados (157 y $428 \mathrm{ml}$ ), 1 sistema integrado de medida, líquido inhibidor de la nitrificación (ATH), disolución de hidróxido de potasio (KHO $45 \%$ ).

Durante la determinación de la DBO las bacterias consumen el oxígeno disuelto en la muestra, que es reemplazado por oxígeno del aire contenido en la botella. El dióxido de carbono producido es eliminado por el hidróxido de potasio. Esto crea un descenso en la presión del interior del sistema que es cuantificado por el sensor de DBO y expresado en $\mathrm{mg} / \mathrm{l}$ de DBO. Ha sido necesario utilizar una disolución del zumo 1:25 para que el resultado se encontrara dentro del rango de medición del test. Los valores obtenidos de DBO hasta alcanzar los 15 días de incubación se muestran en la Tabla 1.

Tabla 1. Valores de la Demanda Biológica de Oxígeno por litro de zumo determinados durante 15 días de incubación.

\begin{tabular}{|c|c|}
\hline Días & $\mathrm{DBO}_{\mathrm{mg} \mathrm{O}} \mathrm{O}_{2} / \mathrm{l}$ zumo \\
\hline 1 & $66.7 \pm 28.2$ \\
\hline 2 & $137.3 \pm 27.4$ \\
\hline 3 & $217 \pm 22$ \\
\hline 4 & $278.7 \pm 18.5$ \\
\hline 5 & $297 \pm 12$ \\
\hline 6 & $291 \pm 32$ \\
\hline 7 & $323.3 \pm 16.8$ \\
\hline 8 & $349 \pm 26$ \\
\hline 9 & $348.7 \pm 50.6$ \\
\hline 10 & $366.3 \pm 40.5$ \\
\hline 11 & $383 \pm 41$ \\
\hline 12 & $397.7 \pm 45.1$ \\
\hline 13 & $436.7 \pm 47.5$ \\
\hline 14 & $447 \pm 39$ \\
\hline 15 & $445 \pm 39$ \\
\hline
\end{tabular}


El valor de $\mathrm{DBO}_{5}$ que se ha obtenido en la disolución 1:25 es de $297 \mathrm{mg} \mathrm{O} /$ l. El valor de $\mathrm{DBO}_{5}$ del zumo de mandarina es de $7425 \mathrm{mg} \mathrm{O} / \mathrm{l}$ de zumo residual. El valor de $\mathrm{DBO}_{15}$ es de $11125 \mathrm{mg} \mathrm{O}_{2} / \mathrm{l}$ de zumo residual.

Los límites de $\mathrm{DQO}$ y $\mathrm{DBO}_{5}$ establecidos por la ley son de 125 y $25 \mathrm{mg} \mathrm{O}_{2} / \mathrm{l} \mathrm{de}$ zumo residual respectivamente. Los niveles de $\mathrm{DQO}_{\text {y }}$ de $\mathrm{DBO}_{5}$ del zumo sobrepasan los límites, por lo que se considera necesario llevar a cabo una depuración del mismo antes de verterlo al cauce público.

La legislación fundamental a seguir es:

\section{- A nivel de la Unión Europea (UE):}

La directiva 91/271/ CEE sobre el tratamiento de las aguas residuales urbanas. Esta directiva se refiere a la recogida, tratamiento y vertido de las aguas residuales urbanas, así como al tratamiento y vertido de las aguas residuales de algunos sectores industriales, en concreto de los agroalimentarios. La finalidad de la directiva es proteger el medio ambiente contra todo deterioro debido al vertido de esas aguas y establece requisitos específicos para los vertidos de aguas industriales residuales y biodegradables procedentes de algunos sectores industriales.

\section{- A nivel estatal:}

El Real Decreto 509/1996 del 15 de Marzo en el que se establecen las normas aplicables al tratamiento de aguas residuales urbanas. Indica los límites de vertido que tendrán que cumplir las aguas residuales que van a verterse al cauce público.

El Real Decreto 606/ 2003 del 23 de Mayo por el que se modifica el Real Decreto 849/ 86 del Reglamento del Dominio Público Hidráulico en el que se desarrollan las autorizaciones y el canon de vertidos.

\section{- A nivel autonómico:}

Ley 2/1992 del 26 de marzo de Saneamiento de Aguas Residuales de la Comunidad Valenciana.

Antes de proceder a la depuración y eliminación del zumo resultante de la impregnación, convendría plantearse la posibilidad de reutilización del mismo. La obtención de aceites esenciales, flavonoides u otros componentes fisiológicamente activos e incluso la reutilización como ingrediente en la fabricación de otros productos como zumos, néctares o concentrados podrían ser algunas alternativas.

El tratamiento de las aguas residuales restantes puede llevarse a cabo mediante tratamientos físicos, químicos o biológicos. 
Con el objetivo de minimizar cada vez más los vertidos se están implementando en la industria tratamientos entre los cuales destacan las operaciones con membranas (ósmosis inversa, ultrafiltración...).

A continuación, en la figura 7, se muestra un esquema básico de una posible planta de tratamiento de aguas residuales procedentes de la planta piloto y se detallan las operaciones empleadas.

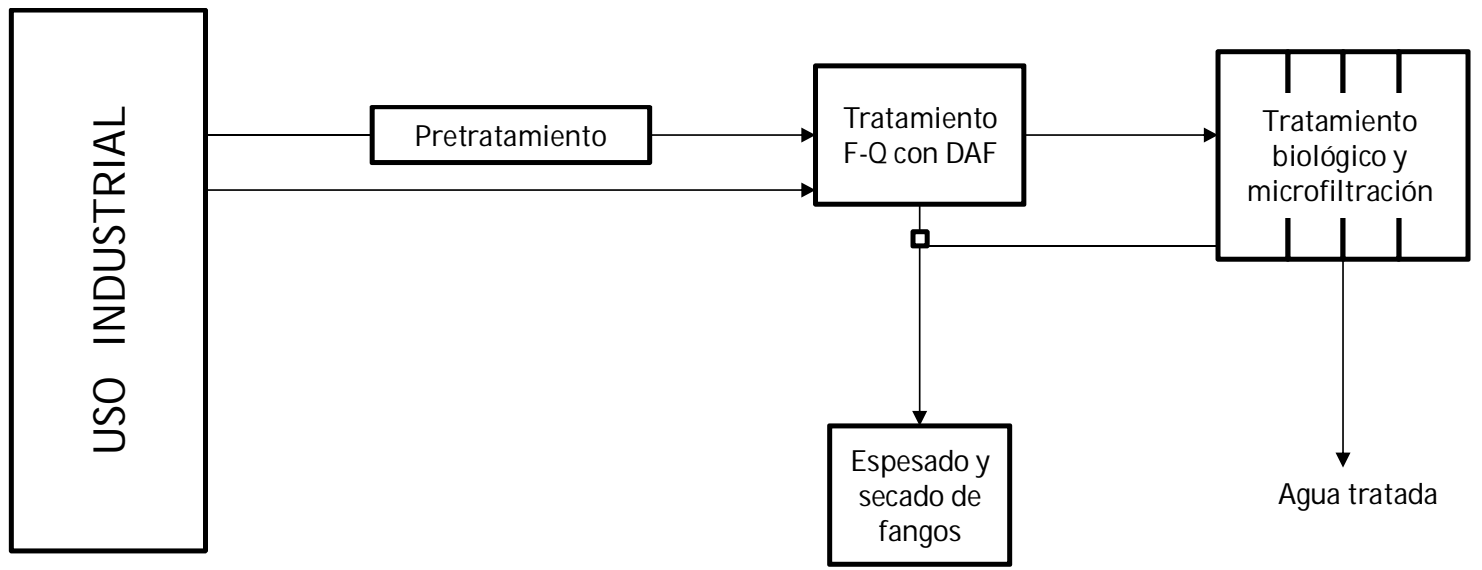

Figura 7. Esquema de la planta de depuración propuesta. Adaptado de (Zarzo-Martínez, D. Conclusiones de las jornada científico-tecnológica. Agua en la industria: uso sostenible.)

Las distintas operaciones del proceso de depuración son:

- Pretratamiento.

Puede ser necesario para algunas corrientes procedentes del uso industrial como el zumo residual procedente de la operación de impregnación a vacío. En otras corrientes como el agua de limpieza de los equipos no es necesario llevar a cabo esta operación.

- Tratamiento físico químico con equipo de flotación (DAF).

En un equipo DAF las burbujas de pocas micras de tamaño se producen por la disolución de aire en el agua residual a elevadas presiones seguidas por su subsecuente descarga a presión atmosférica. Cuando la presión es reducida a condiciones atmosféricas, el aire disuelto, presente en exceso hasta saturación, es descargado como burbujas muy finas adhiriéndose por sí mismas a los sólidos en suspensión. Las partículas aire-sólido flotan hacia la superficie de la celda de flotación y se separan mediante un rascador. Para conseguir el efecto de flotación se usa un sistema de recirculación y presurización.

- Tratamiento biológico por aireación prolongada con nitrificacióndesnitrificación.

En este caso la aireación se lleva a cabo por difusores y soplantes.

- Microfiltración a través de membranas.

En la microfiltración se eliminan los sólidos en suspensión residuales presentes después del tratamiento químico o biológico. Este tipo de membranas tienen un tamaño de poro de $0.1-10 \mu \mathrm{m}$.

- Recirculación de agua (reactor biológico y depósito de membranas)

- Bombeo de fangos en exceso 
- Espesado de fangos por gravedad y secado mediante centrífuga.

El espesado de fangos se emplea para aumentar el contenido en sólidos del fango por eliminación de la fracción líquida del mismo. En el secado de fangos el uso de centrífugas por su gran capacidad de eliminación de agua redunda en una disminución del volumen del fango resultante muy conveniente para el trasporte y compostaje.

En cualquier caso, siguiendo el modelo de depuración propuesto o cualquier otro, sería necesario considerar el tratamiento o la reutilización del zumo residual procedente de la operación de impregnación a vacío por el gran volumen que representa en todo el proceso de fabricación. 
Desarrollo tecnológico y valoración funcional de aperitivos de manzana y zumo de mandarina 
3.3. Efecto de la presión de homogeneización sobre las propiedades fisicoquímicas $\mathrm{y}$ funcionales del zumo de mandarina. Estudio de la idoneidad del zumo para su uso en la operación de impregnación a vacío. 

Journal of Food Engineering 92 (2009) 18 - 23

Contents lists available at ScienceDirect

Journal of Food Engineering

journal homepage: www.elsevier.com/locate/jfoodeng

\section{Effects of pressure homogenization on particle size and the functional properties of citrus juices.}

E. Betoreta ${ }^{a}$ N. Betoreta ${ }^{a}$ J.V. Carbonellb and P. Fito*a

a Institute of Food Engineering for Development, Department of Food Technology, Universidad Politécnica de Valencia, Camino de Vera s/ n, 46022 Valencia, Spain.

b Instituto de Agroquímica y Tecnología de Alimentos (IATA-CSIC), Avda. Agustín Escardino 7, 46980 Paterna, Valencia, Spain.

* Corresponding author. Address: Institute of Food Engineering for Development, Department of Food Technology, Universidad Politécnica de Valencia, Camino de Vera s/n, 46022 Valencia, Spain. Tel.: +34 96387 7367. Fax.: +34 96387 7056. E-mail address: pfito@tal.upv.es

\section{A R T I CLE INFO ABSTR A C T}

\section{Article history:}

Received 2 June 2008

Received in revised form

26 September 2008

Accepted 17 October 2008

Available online 5

November 2008

\section{Keywords:}

Flavonoids

Particle size

Cloudiness

Color

Citrus juice

Homogenization

\begin{abstract}
Homogenization is useful in the citrus industry to improve the quality of citrus juices. The aim of this work was to study the effect of the homogenization pressures $0,5,10,15,20,25$ and $30 \mathrm{MPa}$ on the particle size distribution, colour, cloudiness, and flavonoid content of fresh citrus juices to determine the ideal conditions of juices to be used in the development of functional fresh fruit. The results showed that homogenization pressure affected the particle size distribution and colour of the citrus juices, which made it possible to define different sample groups on the basis of the applied pressure. In fresh juice the contents of the flavonoids were not affected by homogenization pressure but after five months stored juice the content of the flavonoid hesperidin was affected.
\end{abstract}

\section{Introduction.}

The beneficial effects of citrus fruit consumption on human health have long been known. The antioxidant and antiradical properties of some of the compounds in fruit, particularly in the juice of the fruit, are responsible for these effects.

Flavonoids are the most studied compounds in juice known to have antioxidant and antiradical activities. The activity of flavonoids has been shown in vitro (Bocco et al., 1998; Rapisarda et al., 2000; Burda and Oleszek, 2001) and in vivo. It is known that flavonoids have important health-related properties, such as 
antimicrobial (Bylka et al., 2004), anticarcinogenic (Benavente-Garcia et al., 1997; Kohno et al., 2001), antiaggregative (Middleton et al., 2000) properties and are known to protect against cardiovascular diseases (Hollman et al., 1996). Moreover, it is important to note that no adverse physiological reactions to the consumption of flavonoids have been described.

Narirutin, hesperidin, and didymin belong to the flavanona glycosides group and are the most abundant flavonoids in mandarin orange juice. They have antioxidant activity and appear to influence lipid metabolism. Different studies have shown that hesperidin can inhibit chemically induced breast cancer (So et al., 1996), bladder cancer (Yang et al., 1997), and colon cancer (Tanaka et al., 1997; Miyagi et al., 2000) in laboratory animals.

The characteristics of mandarin orange juice mentioned above make it suitable as a medium to develop fresh and functional foods via vacuum impregnation (Fito et al., 2000).

It is important to consider that the cloudiness of citrus juice is an indicator of quality. Citrus juice clouds contain cellular organelles and membranes, chromatophores, oil droplets, flavonoid crystals, and cell wall fragments such as pectin, cellulose, and hemicellulose (Baker and Cameron, 1999).

Orange cloud particles range in size from 400 to $5000 \mathrm{~nm}$; particles smaller than $2000 \mathrm{~nm}$ are the most stable (Buslig and Carter, 1974). Thus, an easy way to increase the cloudiness of citrus juices is to reduce the size of the cloud particles. Homogenization is a process that involves applying pressure to liquids to fragment the solid particles and oil droplets into smaller particles. Thus, homogenization is useful in the citrus industry for increasing the yield of citrus juices (Lortkipanidze et al., 1972) and for improving some quality factors of citrus juices, such as viscosity (Crandall and Davis, 1991), colour (Lee and Coates, 2004), cloudiness (Baker, 1977), and the stability of suspended solids (Carle et al., 1998). Homogenization converts the sensible pulp to background pulp (Kupper et al., 1987), which modifies the flavour of the juice (Marsh et al., 2006).

Homogenization can also be applied like pre-treatment in other processes where the particle size affects the efficiency and yield of the process, and to the quality factors of the final products (membrane processes, vacuum impregnation). For to have impregnated food with functional value added, mandarin juice has to include the most part of the pulp, because of some functional components are there (Garau et al., 2007). Pulp of citrus juices has big size of particles that can be inconvenient for to introduce the juice inside of the fruit extracellular spaces. Reducing particle size by homogenization pressures and centrifugating after it for to eliminate biggest particles can help to introduce more quantity of juice and therefore functional components inside of fruit structure by vacuum impregnation. References about the quantitative effect of the homogenization on the particle size in citrus juices have not been found, but it is possible that different homogenization conditions cause different distribution of cloud particle size, affecting physical properties of treated juices. 
The aim of this work was to study the effect of homogenization pressure on the particle size distribution, colour, cloudiness, and flavonoid content of fresh citrus juices to determine the ideal conditions of juices to be used in the development of functional fresh fruit.

\section{Materials and methods.}

\subsection{Sample preparation.}

Ortanique fruit, a hybrid of tangerine and sweet orange (Citrus sinensis x Citrus reticulata), and Salustiana oranges (C. sinensis) were harvested in an orchard located in Vilamarxant (Valencia), Spain, and used immediately for juices preparation. Two different juices were prepared, one from Ortanique fruits and another from Salustiana fruits. The fruits were washed by immersing them in tap water, drained, and squeezed in an industrial extractor with finger cups (Exzel, Luzzysa; El Puig, Valencia, Spain). Raw juice coming for each variety was homogenized with a Manton-Gaulin pilot homogenizer (model 15M8TBA) at different pressures, centrifuged with a Westfalia centrifuge (model SAOH 205), pasteurized at $63^{\circ} \mathrm{C}$ for $15 \mathrm{~s}$, collected in sterile jars, and quickly frozen at $-18{ }^{\circ} \mathrm{C}$ until analyzed. The preparation of the juices was carried out according to the patent PO/ 2007/042593 titled "Method of obtaining refrigerated pasteurized citrus juices" (Izquierdo et al., 2007).

\subsection{Brix, acidity, and essential oils.}

Total soluble solids were measured as Brix with a digital refractometer (Pal-1; Atago Co., Ltd., Tokyo, Japan). Total titratable acidity was assessed by titration with $0.1 \mathrm{~N} \mathrm{NaOH}$ and expressed as the percentage of citric acid. Recoverable essential oils were determined by bromate titration, according to the Scott Method (Scott and Veldhuis, 1966). The values provided are the average of three replicates.

\subsection{Suspended pulp and cloudiness.}

To measure the suspended pulp, a graduated centrifuge tube with a conical bottom was filled with $10 \mathrm{ml}$ of juice. The sample was centrifuged with Eppendorf Refrigerated Multipurpose centrifuge (model 5804R) for $10 \mathrm{~min}$ at $365 \mathrm{~g}$ at $27^{\circ} \mathrm{C}$ and then the pulp volume was read (FMC FoodTech, 2005). The supernatants were collected, and their transmittance was analyzed for cloudiness at $650 \mathrm{~nm}$ with a UV/Visible spectrophotometer (Ultrospec 3300 pro; Amersham Bioscience, Piscataway, NJ, USA.). The values provided are the average of three replicates. 


\subsection{Particle size.}

Particle size was determined by using Malvern Mastersizer equipment (Model 2000; Malvern Instruments Limited, Worcestershire, U.K.) with a short-wavelength blue light source in conjunction with forward and backscatter detection to enhance sizing performance in the range 0.02-2000 $\mu \mathrm{m}$. The values 1.73 and 1.33 were used for the refractive indices of cloud and dispersed phase, respectively, and 0.1 was used for the absorption index of cloud particles (Corredig et al., 2001). To measure the sizes of the particles the equipment is using laser diffraction technique and because of this the particle size distribution obtained was based on volume, i.e., the particle size interval obtained represented the total volume (\%) of all particles with a diameter included in this interval in relation to the total volume of all particles in the distribution. In the case of monomodal distributions, the particle size was described by the volume-weighted mean diameter $(D[4,3])$ (Eq.(1)) and the diameter corresponding at the maximum value of the peak ( $\left.D_{\text {peak }}\right)$

$$
D[4,3]=\sum_{i} n_{i} d_{i}^{4} / \sum_{i} n_{i} d_{i}^{3}
$$

where $n_{i}$ is the number of particles of diameter $d_{i}$. The values provided are the average of at least three replicates.

\subsection{Colour.}

Colour was measured with a Hunter colorimeter (Labscan II model controlled by a computer) following the indications described by Bayarri et al. (2001). Samples were contained in optical glass cells $3.8 \mathrm{~cm}$ high and $6 \mathrm{~cm}$ in diameter. The results were provided in a CIELAB system for illuminant D65 and a 10ำ angle of vision. The registered parameters were as follows: L* (brightness), a* (redgreen component), $b^{*}$ (yellow-blue component), $h_{a b}$ (hue, attribute related to the differences in absorbance at different wavelengths and considered the qualitative attribute of colour) (Eq. (2)), and $\mathrm{C}_{\mathrm{ab}}$ (chrome, quantitative attribute of colourfulness) (Eq. (3)). The global colour difference $(\Delta \mathrm{E})$ was calculated by using equation 4 . The values provided are the average of three replicates.

$$
\begin{gathered}
h_{a b}^{*}=\arctan \left(\mathrm{b}^{*} / \mathrm{a}^{*}\right) \\
C_{a b}^{*}=\left[\left(a^{*}\right)^{2}+\left(b^{*}\right)^{2}\right]^{\frac{1}{2}} \\
\Delta E=\left[\left(\Delta L^{*}\right)^{2}+\left(\Delta a^{*}\right)^{2}+\left(\Delta b^{*}\right)^{2}\right]^{\frac{1}{2}}
\end{gathered}
$$

\subsection{Flavonoids.}

The content of the flavonoids narirutin, hesperidin, and didymin was determined using high-performance liquid chromatography (HPLC). An Alliance 
2996 chromatograph (Waters) was used with a diode array detector (DAD) and filled with a C18 reversed-phase column $(250 \times 4.6 \mathrm{~mm}$ and $5 \mu \mathrm{m}$; Luna II Phenomenex). For the extraction of flavonoids, juice samples were centrifuged for $15 \mathrm{~min}$ at $1400 \mathrm{rpm}$ at $4{ }^{\circ} \mathrm{C}$ using a Meldifriger SL centrifuge. The supernatant was filtered using a Whatman no1 filter; $30 \mathrm{ml}$ of the filtered samples was passed through a Sep-Pack C18 cartridge, and the cartridge was cleaned with $5 \mathrm{ml}$ of water and eluted with $5 \mathrm{ml}$ of water:acetonitrile in proporcion (4:6, v/v). Two hundred fifty milliliters of cumaric acid $(1 \mu \mathrm{g} / \mu \mathrm{l})$ was added to the eluate. The resulting sample was filtered using an Albet nylon membrane filter with a pore diameter of $0.45 \mu \mathrm{m}$. Finally, a $1 \mathrm{ml}$ aliquot was collected, and $5 \mu \mathrm{l}$ was injected into the HPLC system. A solution of water:tetrahydrofuran (solvent A) and a solution of acetonitrile:tetrahydrofuran (solvent B) were used for the mobile phase. The HPLC system was operated in gradient at a flow rate of $1 \mathrm{ml} / \mathrm{min}$. Flavonoids were detected at a wavelength of $280 \mathrm{~nm}$. The values provided are the average of three replicates.

\subsection{Statistical analysis.}

All the values provided are the average of at least three replicates and to determine the significant differences of the results an Analysis of Variance test was carried out (One-way ANOVA or Multifactor ANOVA) with confidence level of 95\% $(\mathrm{p}<0.05)$ using the program STATGRAPHICS PLUS v.5.1.

\section{Results and discussion.}

Fresh juice samples were characterized by measuring the following: contents of soluble solids, essential oils, and suspended pulp; acidity; maturity index; and $\mathrm{pH}$. The results are shown in Table 1.

Table 1. Characteristics of fresh citrus juices (mean \pm standard deviation).

\begin{tabular}{lcc}
\hline & Ortanique & Salustiana \\
\hline Brix & $12.9 \pm 0.1$ & $12.7 \pm 0.1$ \\
Acidity & $1.28 \pm 0.56$ & $1.10 \pm 0.75$ \\
Maturity index Brix/ Acidity) & $10.08 \pm 0.32$ & $12.12 \pm 0.51$ \\
Essential oils (\%) & $0.045 \pm 0.003$ & $0.044 \pm 0.004$ \\
Suspended pulp (\%) & $25.0 \pm 1.3$ & $16.5 \pm 1.0$ \\
pH & $3.42 \pm 0.02$ & $3.50 \pm 0.03$ \\
\hline
\end{tabular}

The results of the cloudiness and suspended pulp determinations are shown in Table 2.

The precipitated volume and supernatant transmittance in samples centrifuged at $365 \mathrm{~g}$ decreased as the homogenization pressure increased. When the pressure increased from 0 to $15 \mathrm{MPa}$, the changes in both variables were higher than when the pressure increased from 15 to $30 \mathrm{MPa}$. 
The low values obtained in transmittance show the high level cloudiness and suspended pulp in juice that increased when the homogenization pressure increased.

Table 2. Effect of homogenization pressure on the suspended pulp and cloudiness of Ortanique and Salustiana juices (mean \pm standard desviation.

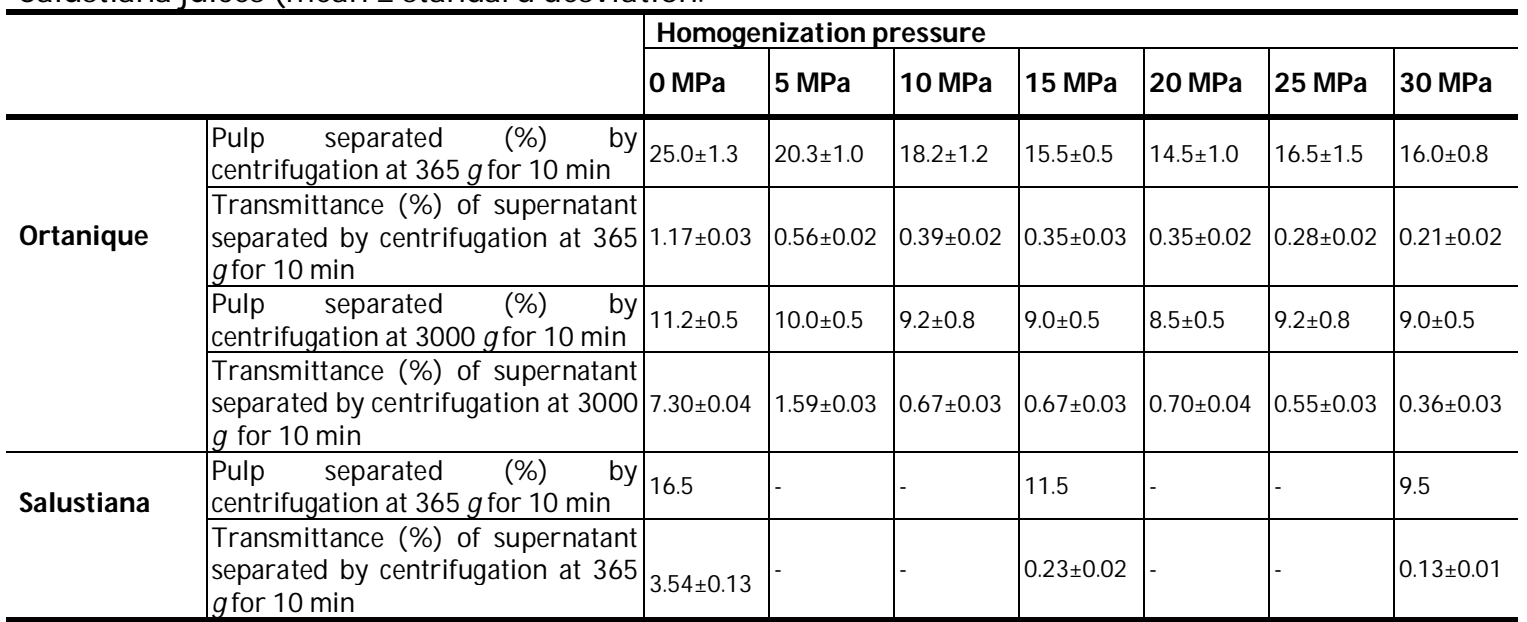

The particle size distribution in Ortanique juice samples not homogenized or homogenized at $5,10,15,20,25$, and $30 \mathrm{MPa}$ and in Salustiana juice not homogenized or homogenized at 15 and $30 \mathrm{MPa}$ is shown in Figs. 1 and 2, respectively. Particle size showed a distribution between 0.5 and $1000 \mu \mathrm{m}$, with irregular peaks between 100 and $1000 \mu \mathrm{m}$ and with a natural evolution to smaller sizes when the homogenization pressure increased.

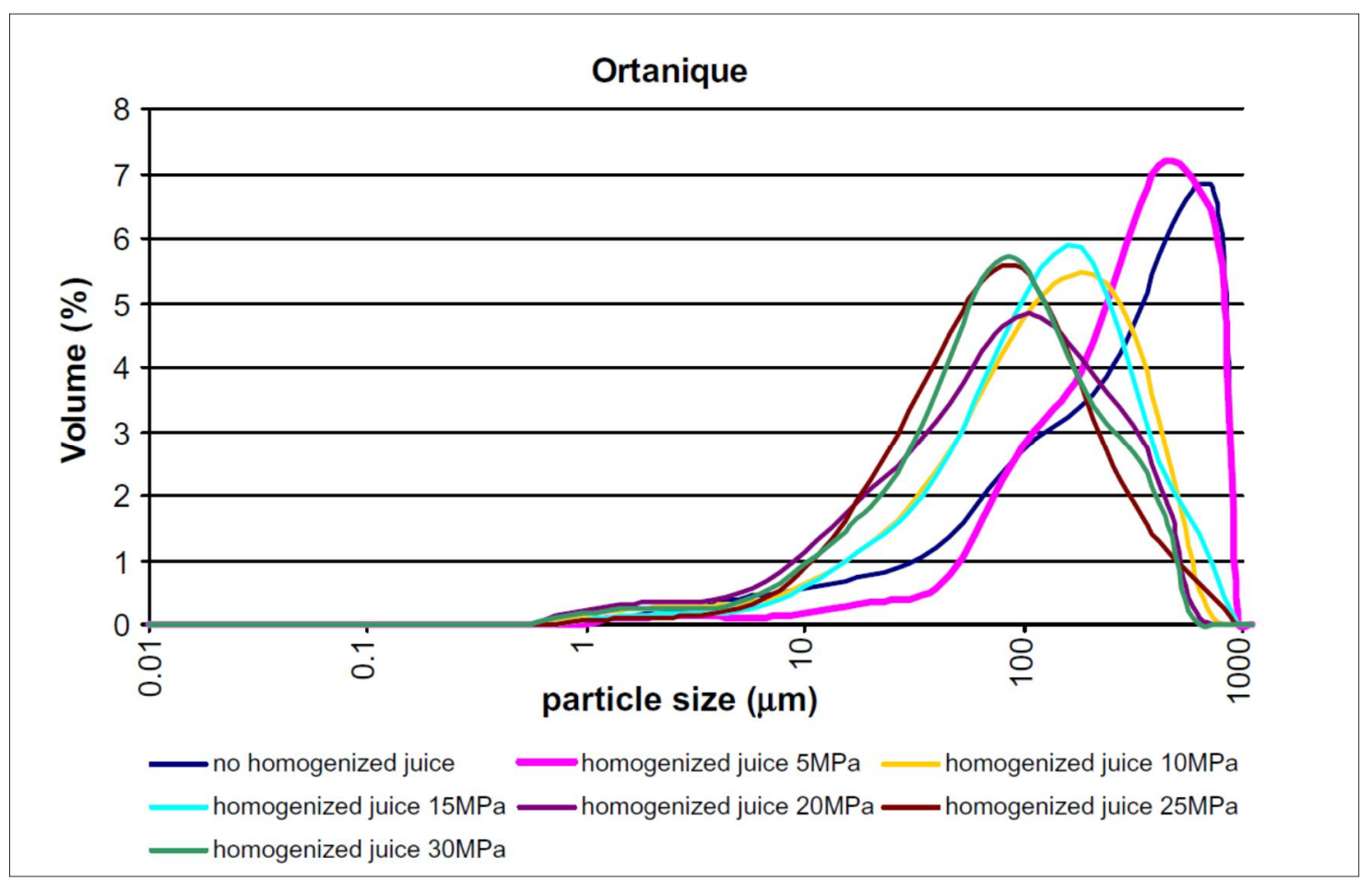

Figure 1. Effect of homogenization pressure on particle size of citrus juices. 


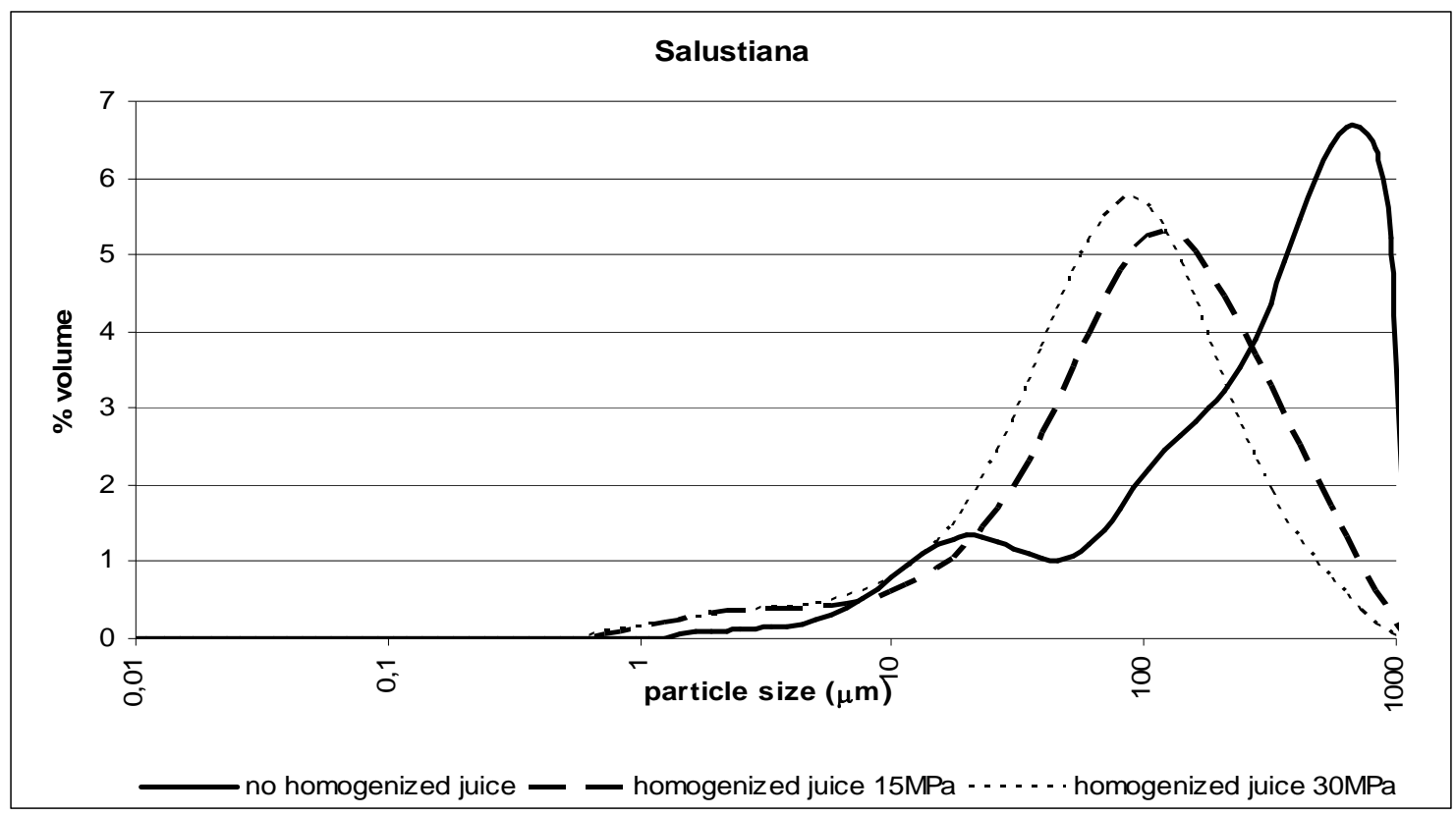

Figure 2. Effect of homogenization pressure on particle size of citrus juices.

The particle size parameters for Ortanique juice and Salustiana juice are shown in Tables 3 and 4, respectively. The mean $D[4,3]$ and $D_{\text {peak values for Ortanique }}$ juice and Salustiana juice decreased as the homogenization pressure increased. An analysis of variance with confidence level of 95\% ( $p<0.05)$ was conducted to determine the significance of the differences in these two variables as a function of homogenization pressure. For Ortanique juice, the analysis showed a significant effect of homogenization pressure on both $\mathrm{D}[4,3]$ and $\mathrm{D}_{\text {peak. }}$

Table 3. Effect of homogenization pressure on the particle size of Ortanique juice (mean \pm standard desviation).

\begin{tabular}{lll}
\hline Homogenization pressure (MPa) & D[4,3] & Dpeak \\
\hline 0 & $346.3 \pm 12.1^{\mathrm{a}}$ & $710.3 \pm 18.5^{\mathrm{a}}$ \\
5 & $372.1 \pm 1.9^{\mathrm{a}}$ & $503.0 \pm 7.8^{\mathrm{a}}$ \\
10 & $171.01 \pm 7.4^{\mathrm{b}}$ & $206.5 \pm 2.5^{\mathrm{b}}$ \\
15 & $180.6 \pm 3.1^{\mathrm{b}}$ & $166.9 \pm 10.8^{\mathrm{b}}$ \\
20 & $130.3 \pm 3.6^{\mathrm{c}}$ & $114.5 \pm 1.7^{\mathrm{c}}$ \\
25 & $123.2 \pm 8.6^{\mathrm{c}}$ & $90.7 \pm 1.3^{\mathrm{c}}$ \\
30 & $122.9 \pm 2.2^{\mathrm{c}}$ & $90.7 \pm 1.2^{\mathrm{c}}$ \\
\hline
\end{tabular}

${ }^{*}$ Values with different superscript letters in a column are significantly different $(\mathrm{P} \leq 0.05)$.

Table 4. Effect of homogenization pressure on the particle size of Salustiana juice (mean \pm standard desviation).

\begin{tabular}{lll}
\hline Homogenization pressure (MPa) & $\mathbf{D}[\mathbf{4 , 3}]$ & $\mathbf{D}_{\text {peak }}$ \\
\hline 0 & $340.3 \pm 8.5^{\mathrm{a}}$ & $552.4 \pm 41.8^{\mathrm{a}}$ \\
15 & $150.1 \pm 4.8^{\mathrm{b}}$ & $95.9 \pm 1.4^{\mathrm{b}}$ \\
30 & $107.7 \pm 4.1^{\mathrm{c}}$ & $70.8 \pm 1.0^{\mathrm{c}}$ \\
\hline
\end{tabular}

$*$ Values with different superscript letters in a column are significantly different $(\mathrm{P} \leq 0.05)$.

The analysis of variance for $\mathrm{D}[4,3]$ in Ortanique juice clearly showed three sample groups: one group was composed by homogenized samples at 0 and $5 \mathrm{MPa}$, a second group was composed by homogenized samples at 10 and $15 \mathrm{MPa}$, and a 
third group was composed by homogenized samples at 20, 25, and $30 \mathrm{MPa}$ (Fig. 3). The analysis of variance for Dpeak showed significant differences between juice samples homogenized at 0 and $5 \mathrm{MPa}$; the remainder of the samples were in the same groups as shown for D[4,3] (Fig. 3). In this case, the analysis showed four sample groups: one group was composed by unhomogenized samples, a second group was composed by homogenized samples at $5 \mathrm{MPa}$, a third group was composed by homogenized samples at 10 and $15 \mathrm{MPa}$, and a fourth group was composed by homogenized samples at 20,25, and $30 \mathrm{MPa}$.

For both $\mathrm{D}[4,3]$ and $\mathrm{D}_{\text {peak }}$ in Salustiana juice, the biggest differences were observed between the unhomogenized samples, the samples homogenized at 5 $\mathrm{MPa}$, and the remainder of the samples (Fig. 4). In case of Salustiana juice samples showed a significant effect of homogenization pressure in both $\mathrm{D}[4,3]$ and $\mathrm{D}_{\text {peak. }}$.

Colour was measured in the unhomogenized and homogenized samples of Ortanique juice and Salustiana juice. The effect of homogenization pressure on the CIE-L*a*b* parameters, psychrometric coordinates chrome $\left(\mathrm{C}^{*} \mathrm{ab}\right)$, and hue $\left(\mathrm{h}^{*} \mathrm{ab}\right)$ are shown in Tables 5 and 6 , respectively. Brightness $\left(\mathrm{L}^{*}\right)$ and colorfulness $\left(\mathrm{C}^{*}\right.$ ab) were greater in Salustiana juice than in Ortanique juice. Moreover, component a* was greater and component $b^{*}$ smaller in Ortanique juice than in Salustiana juice. This means a yellow colour for Salustiana juice and as red colour for Ortanique juice.

Table 5. Effect of homogenization pressure on CIE-L*a*b* parameters in Ortanique juice (mean \pm standard desviation).

\begin{tabular}{llllll}
\hline $\begin{array}{l}\text { Homogenization } \\
\text { pressure (MPa) }\end{array}$ & $\mathbf{L}^{*}$ & $\mathbf{a}^{*}$ & $\mathbf{b}^{*}$ & $\mathbf{C}^{*}$ & $\mathbf{h}^{*}{ }_{\text {ab }}$ \\
\hline $\mathbf{0}$ & $52.01 \pm 0.03^{\mathrm{a}}$ & $14.27 \pm 0.5^{\mathrm{a}}$ & $74.06 \pm 0.13^{\mathrm{a}}$ & $75.42 \pm 0.12^{\mathrm{a}}$ & $79.09 \pm 0.06^{\mathrm{a}}$ \\
$\mathbf{5}$ & $51.47 \pm 0.03^{\mathrm{a}}$ & $14.455 \pm 0.014^{\mathrm{a}}$ & $75.22 \pm 0.12^{\mathrm{a}}$ & $76.59 \pm 0.12^{\mathrm{a}}$ & $79.122 \pm 0.008^{\mathrm{a}}$ \\
$\mathbf{1 0}$ & $53.72 \pm 0.04^{\mathrm{b}}$ & $15.53 \pm 0.02^{\mathrm{b}}$ & $80.45 \pm 0.05^{\mathrm{b}}$ & $81.94 \pm 0.05^{\mathrm{b}}$ & $79.08 \pm 0.02^{\mathrm{a}}$ \\
$\mathbf{1 5}$ & $54.02 \pm 0.06^{\mathrm{b}}$ & $15.47 \pm 0.06^{\mathrm{b}}$ & $81.753 \pm 0.112^{\mathrm{b}}$ & $83.20 \pm 0.110^{\mathrm{b}}$ & $79.28 \pm 0.04^{\mathrm{a}}$ \\
$\mathbf{2 0}$ & $53.83 \pm 0.03^{\mathrm{b}}$ & $13.000 \pm 0.014^{\mathrm{c}}$ & $80.502 \pm 0.015^{\mathrm{b}}$ & $81.546 \pm 0.013^{\mathrm{b}}$ & $80.8262 \pm 0.0112^{\mathrm{b}}$ \\
$\mathbf{2 5}$ & $55.8 \pm 0.3^{\mathrm{c}}$ & $17.815 \pm 0.019^{\mathrm{d}}$ & $86.3 \pm 0.2^{\mathrm{c}}$ & $88 . \pm 0.3^{\mathrm{c}}$ & $78.33 \pm 0.09^{\mathrm{c}}$ \\
$\mathbf{3 0}$ & $53.95 \pm 0.17^{\mathrm{b}}$ & $15.19 \pm 0,06^{\mathrm{b}}$ & $82.2 \pm 0.2^{\mathrm{b}}$ & $83.6 \pm 0.2^{\mathrm{b}}$ & $79.537 \pm 0.015^{\mathrm{a}}$ \\
\hline
\end{tabular}

$*$ Values with different superscript letters in a column are significantly different $(\mathrm{P} \leq 0.05)$.

Table 6. Effect of homogenization pressure on CIE-L*a*b* parameters of Salustiana juice (mean \pm standard desviation).

\begin{tabular}{llllll}
\hline $\begin{array}{l}\text { Homogenization } \\
\text { pressure (MPa) }\end{array}$ & $\mathbf{L}^{*}$ & $\mathbf{a}^{*}$ & $\mathbf{b}^{*}$ & $\mathbf{C}^{*}{ }_{\mathbf{a b}}$ & $\mathbf{h}^{*} \mathbf{a b}$ \\
\hline $\mathbf{0}$ & $70.36 \pm 1.48^{\mathrm{a}}$ & $4.88 \pm 0.18^{\mathrm{a}}$ & $99.46 \pm 2.47 \mathrm{a}$ & $99.58 \pm 2.46^{\mathrm{a}}$ & $87.19 \pm 0.09^{\mathrm{a}}$ \\
$\mathbf{1 5}$ & $72.13 \pm 1.13^{\mathrm{a}}$ & $3.72 \pm 0.17 \mathrm{~b}$ & $95.17 \pm 1.63^{\mathrm{b}}$ & $95.24 \pm 1.62^{\mathrm{b}}$ & $87.76 \pm 0.06^{\mathrm{b}}$ \\
$\mathbf{3 0}$ & $72.77 \pm 0.59^{\mathrm{a}}$ & $8.33 \pm 0.23^{\mathrm{c}}$ & $101.62 \pm 0.62^{\mathrm{a}}$ & $101.96 \pm 0.62^{\mathrm{a}}$ & $85.31 \pm 0.22^{\mathrm{c}}$ \\
\hline
\end{tabular}

To determine the significance of the differences in colour coordinates as a function of homogenization pressure in Ortanique juice samples an analysis of variance was conducted. The analysis showed a significant effect of homogenization pressure on all of the variables examined. 
CIE-L*a*b* coordinates increased with increases in homogenization pressure, up to $25 \mathrm{MPa}$. For to explain the drop observed in parameters for the homogenization pressure of $30 \mathrm{MPa}$ we suggest that the aggregation of the smallest particles when the homogenization pressure of $30 \mathrm{MPa}$ and the sedimentation of them after centrifugation step can affect $L^{*} a^{*}$ and $b^{*}$ parameters. More analysis at different homogenization pressures would be necessary to confirm this effect. As observed for particle size parameters, sample groups were observed. One group was composed by homogenized samples at 0 and $5 \mathrm{MPa}$; a second group was composed by homogenized samples at 10,15, 20, and $30 \mathrm{MPa}$; and a third group was composed by homogenized samples at $25 \mathrm{MPa}$.

On the basis of the psychrometric coordinates chrome $\left(\mathrm{C}^{*} \mathrm{ab}\right)$, the values tendency and samples groups are the same as for the CIEL*a*b* coordinates. On the basis of hue $\left(\mathrm{h}^{*} \mathrm{ab}\right)$, however, the differences were compensated.

The brightness of the Salustiana juice samples increased as the homogenization pressure increased. The values for $\mathrm{a}^{*}$ and $\mathrm{b}^{*}$ were greater in samples homogenized at $30 \mathrm{MPa}$ than in nonhomogenized samples and were smaller in samples homogenized at $15 \mathrm{MPa}$ than in nonhomogenized samples. In the case of Salustiana juice, like for Ortanique juice the $L^{*} a^{*}$ and $b^{*}$ parameters increase with homogenization pressure. However, for the drop observed when $30 \mathrm{MPa}$ homogenization pressure we suggest that the aggregation of the smallest particles when the homogenization pressure is $30 \mathrm{MPa}$ and the sedimentation of them after centrifugation step can affect $\mathrm{L}^{*} \mathrm{a}^{*}$ and $\mathrm{b}^{*}$ parameters and make the colour more similar to unhomogenized juice. More analysis at different pressures would be necessary to confirm this effect.

We were unable to find any published studies of the relation between visual perception of colour changes in mandarin or orange juice and global colour differences $(\Delta \mathrm{E})$. We found a few studies that were conducted using similar juice products, which indicated that an $\Delta \mathrm{E}$ value less than 1.0 unit was not possible to detect in Star Ruby grapefruit juices (Soon-Mi and Gun-Hee, 2002), whereas an $\Delta \mathrm{E}$ value of 2.0 was detected in carrot juice (Hongmei et al., 2007, quoting Francis and Clydesdale, 1975). Thus, it is possible that colour is first detected at a homogenization pressure of $5 \mathrm{MPa}$ and becomes obvious at a pressure of $10 \mathrm{MPa}$. The greatest colour differences in Ortanique mandarin juice were found at a homogenization pressure of $25 \mathrm{MPa}$.

Flavonoids narirutin, hesperidin and didymin were analyzed in Ortanique mandarin juices no homogenized and homogenized at 5, 10, 15, 20, 25 and $30 \mathrm{MPa}$ frozen and stored during five months and also in Ortanique mandarin juices no homogenized and homogenized at 5, 10, 15, 20, 25 and $30 \mathrm{MPa}$ without freeze and store.

An auto-scaled chromatogram was obtained for $75 \mathrm{~min}$, being time retention of narirutin $46 \mathrm{~min}$ and $48 \mathrm{~min}$ and $59 \mathrm{~min}$ approximately time retention for hesperidin and didymin. The retention time for cumaric acid was $49 \mathrm{~min}$. 
The effect of homogenization pressure on the flavonoid content of Ortanique juice is shown in Tables 7 and 8 .

Table 7. Effect of homogenization pressure on the flavonoid content in Ortanique juices that has been frozen and stored during five months (mean \pm standard desviation).

\begin{tabular}{lccc}
\hline $\begin{array}{c}\text { Homogenization pressure } \\
\text { (MPa) }\end{array}$ & $\begin{array}{c}\text { Narirutin } \\
\text { (mg/ / })\end{array}$ & $\begin{array}{c}\text { Hesperidin } \\
\text { (mg/ L) }\end{array}$ & $\begin{array}{c}\text { Didymin } \\
\text { (mg/ L) }\end{array}$ \\
\hline 0 & $47.1 \pm 4.9$ & $45.0 \pm 7.4$ & $10.1 \pm 1.3$ \\
5 & $43.3 \pm 1.9$ & $33.5 \pm 7.5$ & $8.5 \pm 0.4$ \\
10 & $45.2 \pm 0.4$ & $34.2 \pm 4.9$ & $9.2 \pm 0.2$ \\
15 & $46 \pm 1.2$ & $33.7 \pm 2.1$ & $9 \pm 0.3$ \\
20 & $47 \pm 0.8$ & $33 \pm 0.6$ & $10 \pm 0.2$ \\
25 & $46.4 \pm 1.4$ & $29.7 \pm 0.4$ & $9.5 \pm 0.1$ \\
30 & $47.3 \pm 0.2$ & $28.9 \pm 0.3$ & $9.5 \pm 0.2$ \\
\hline
\end{tabular}

Table 8. Effect of homogenization pressure on the flavonoid content in fresh Ortanique juices that has not been frozen and stored (mean \pm standard desviation).

\begin{tabular}{lccc}
\hline $\begin{array}{c}\text { Homogenization pressure } \\
\text { (MPa) }\end{array}$ & $\begin{array}{c}\text { Narirutin } \\
(\mathbf{m g} / \mathbf{L})\end{array}$ & $\begin{array}{c}\text { Hesperidin } \\
\text { (mg/ L) }\end{array}$ & $\begin{array}{c}\text { Didymin } \\
(\mathbf{m g} / \mathbf{L})\end{array}$ \\
\hline 0 & $41,745 \pm 0,017^{\mathrm{a}}$ & $116,6 \pm 3,2^{\mathrm{a}}$ & $14,0 \pm 0,3^{\mathrm{a}}$ \\
5 & $41,70 \pm 2,03^{\mathrm{a}}$ & $121,4 \pm 5,9^{\mathrm{a}}$ & $15,7 \pm 1,4^{\mathrm{a}}$ \\
10 & $41,94 \pm 1,12^{\mathrm{a}}$ & $115,7 \pm 1,9^{\mathrm{a}}$ & $18,8 \pm 2,1^{\mathrm{a}}$ \\
15 & $43,60 \pm 0,16^{\mathrm{a}}$ & $134,1 \pm 0,7^{\mathrm{a}}$ & $16,5 \pm 0,2^{\mathrm{a}}$ \\
20 & $47,1 \pm 0,2^{\mathrm{a}}$ & $112,7 \pm 1,8^{\mathrm{a}}$ & $16,5 \pm 0,2^{\mathrm{a}}$ \\
25 & $46,7 \pm 1,4^{\mathrm{a}}$ & $79,9 \pm 1,9^{\mathrm{a}}$ & $14,2 \pm 0,5^{\mathrm{a}}$ \\
30 & $50,57 \pm 0,13^{\mathrm{a}}$ & $106,3 \pm 0,3^{\mathrm{a}}$ & $16,437 \pm 0,108^{\mathrm{a}}$ \\
\hline
\end{tabular}

Narirutin was the most abundant flavonoid in the juice samples frozen and stored during five months. However, like the references consulted (Sentandreu, 2006) noted that hesperidin is the most abundant flavonoid in fresh mandarin juice. The juice samples were obtained by heating the fruit at $63 \stackrel{\circ}{\circ} \mathrm{C}$ for $15 \mathrm{sec}$, and then samples were then frozen at $-18{ }^{\circ} \mathrm{C}$ until analyzed. According to DhuiqueMayer et al. (2007) hesperidin has a very high thermal stability, and no significant losses of this flavonoid were observed with heat treatment at $90{ }^{\circ} \mathrm{C}$ for $240 \mathrm{~min}$. It is possible that the lower content of hesperidin observed after five months of freeze and store is the result from the freezing and storage processes.

The contents of the flavonoids narirutin and didymin were not affected by homogenization, whereas the content of hesperidin was affected in the juice five months frozen and stored. An analysis of variance with confidence level of $95 \%$ ( $p$ $<0.05$ ) was conducted to determine the significance of the differences in flavonoid contents as a function of homogenization pressure. The analysis showed a different effect of homogenization pressure in all three of these flavonoids.

In the analyzed fresh juice, without freeze and store, the contents of the flavonoids were not affected by homogenization pressure but after five months frozen and stored juice the content of hesperidin was. Significant differences in the hesperidin content were observed between the nonhomogenized juice and the homogenized juices, but no significant differences were observed between the homogenized juices. No significant differences in the narirutin and didymin 
contents were observed between the juice samples. It is possible that the structural differences between hesperidin and the rest of flavonoids determine the stability of this molecule in solution during storing period.

\section{Conclusion.}

On the basis of the observed effects of homogenization pressure on particle size, colour, and flavonoid content of the juice samples, the following conclusions were drawn: the homogenization pressure affected the particle size distribution and colour of the citrus juices, which made it possible to define different sample groups on the basis of the applied pressure. In fresh juice the contents of the flavonoids were not affected by homogenization pressure but after five months stored juice the content of the flavonoid hesperidin was. To develop functional fresh fruit, the application of a homogenization pressure of at least $20 \mathrm{MPa}$ to mandarin juice 1) is suitable for use in a posterior vacuum impregnation operation, because of the decrease in particle size; 2) does not negatively affect the colour of juice; and 3) has practically no influence on the total flavonoid content.

\section{Acknowledgments.}

This research was supported by the Spanish Government (Ministerio de Educación y Ciencia, project AGL2006-05809ALI) and FEDER founds. The authors also acknowledge the Conselleria de Agricultura, Pesca y Alimentación (Generalitat Valenciana) for its contribution throughout the AGROALIMED program and to the Politechnical University of Valencia for its contribution throughout the UPV22 project.

\section{References.}

Baker, R.A., 1977. Process to control juice cloud. Symposium of the international society of citriculture. Proceedings of the International Society of Citriculture, 751-755.

Baker, R.A., Cameron, R.G., 1999. Clouds of citrus juices and juice drinks. Food Technology 53, 64-69.

Bayarri, S., Calvo, C., Costell, E., Durán, L., 2001. Influence of color on perception of sweetness and fruit flavour of fruit drinks. Food Science and Technology International 7 (5), 399-404.

Benavente-Garcia, O., Castillo, J., Marin, F.R., Ortuño, A., Del Rio, J.A., 1997. Uses and properties of citrus flavonoids. Journal of Agricultural and Food Chemistry 45, 4505-4515.

Bocco, A., Cuvelier, M.E., Richard, H., Berset, C., 1998. Antioxidant activity and phenolic composition of citrus peel and seed extracts. Journal of Agricultural and Food Chemistry 46, 2123-2129. 
Burda, S., Oleszek, W., 2001. Antioxidant and antiradical activities of flavonoids. Journal of Agricultural and Food Chemistry 49, 2774-2779.

Buslig, B.S., Carter, R.D., 1974. Particle size distribution in orange juices. Proceedings of Florida State Horticultural Society 87, 302-305.

Bylka, W., Matlawska, I., Pilewsky, N.A., 2004. Natural flavonoids as antimicrobial agents. Journal of the American Nutraceutical Association 7, 24-31.

Carle, R., Jauss, A., Fuesser, H., 1998. Cloud stability of pulp-containing tropical fruit nectars. Fruit Processing 8 (7) (266-268, 270-272).

Corredig, M., Kerr, W., Wicker, L., 2001. Particle size distribution of orange juice cloud after addition of sensitized pectin. Journal of Agricultural and Food Chemistry 48, 4918-4923.

Crandall, P.G., Davis, K.C., 1991. Viscosity reduction and reformation of structure in orange concentrate as affected by homogenization within commercial taste evaporators. Journal of Food Science 56, 1360-1364.

Dhuique-Mayer, C., Tbatou, M., Carail, M., Caris-Veyrat, C., Dornier, M., Amiot, M.J., 2007. Thermal degradation of antioxidants micronutrients in citrus juice. Kinetics and newly formed compounds. Journal of Agricultural and Food Chemistry 55 (10), 4209-4216.

Fito, P., Chiralt, A., Betoret, N., Gras, M.L., Cháfer, M., Martínez-Monzó, J., Andrés, A., Vidal, D., 2000. Vacuum impregnation and osmotic dehydration in matrix engineering. Application in functional fresh food development. Journal of Food Engineering 49, 175-183.

FMC FoodTech. (2005). Laboratory manual. Procedures for analysis of citrus products, Fourth ed. (pp. 49-50). Manual No 054R10020.000. Francis, F.J., Clydesdale, F.M., 1975. Food Colorimetry: Theory and Applications. The AVI Publishing Co., Inc., Westport, CT.

Garau, M.C., Simal, S., Roselló, C., Femenia, A., 2007. Effect on air-drying temperature on physico-chemical properties of dietary fibre and antioxidant capacity or orange (Citrus aurantium v Canoneta) by-products. Food Chemistry 104, 1014-1024.

Hollman, P.C.H., Hertog, M.G.L., Katan, M.B., 1996. Analysis and health effects of flavonoids. Food Chemistry 57, 43-46.

Hongmei, L., Ying, S., Yuanying, N., Xiaojun, L., Xiaosong, H., Jihong, W., Fang, C. (2007). The effect of enzymatic mash treatment, pressing, centrifugation, homogenization, deaeration, sterilization and storage on carrot juice. Journal of Food Process Engineering, 30, 421-435, http:// www.fmctechnologies.com/ upload/proceduresbook_001.pdf>(accessed June 2007).

Izquierdo, L., Carbonell, J.V., Navarro, J.L., Sendra, J.M., 2007. Method of Obtaining Refrigerated Pasteurized Citrus Juices. Patent WO/2007/042593. Consejo Superior de Investigaciones Científicas, Spain.

Kohno, H., Taima, M., Sumida, T., Azuma, Y., Ogawa, H., Tanaka, T., 2001. Inhibitory effect of mandarin juice rich in b-cryptoxanthin and hesperidin on 4- 
(methylnitrosamino)-1-(3-pyridyl)-1-butanone-induced

pulmonary tumorigenesis in mice. Cancer Letters 174, 141-150.

Kupper, P.L., Moore, K.L., Swaine, R.L. (1987). Fruit juice containing diet beverage. US Patent 4690827.

Lee, H.S., Coates, G.A. (2004). Pigment extraction system and method. US patent US20040258809-A1.

Lortkipanidze, R.K., Anikeichik, N.M., Yakobashvili, R.A., Bolkovadze, M.K., 1972. Homogenizer in citrus juice production line. Konservnaya i Ovoshchesushil'naya Promyshlennost 7, 9-10.

Marsh, K.B., Friel, E.N., Gunson, A., Lund, C., MacRae, E., 2006. Perception of flavour in standardised fruit pulps with additions of acids or sugars. Food Quality and Preference 17 (5), 376-386.

Middleton Jr., E., Kandaswami, C., Theoharides, T.C., 2000. The effects of plant flavonoids on mammalian cells: implications for inflammation, heart disease, and cancer. Pharmacological Reviews 52, 673-751.

Miyagi, Y., Om, A.S., Chee, K.M., Bennink, M.R., 2000. Inhibition of azoxymethaneinduced colon cancer by orange juice. Nutrition and Cancer 36, 224-229.

Rapisarda, F., Fanella, F., Maccarone, E., 2000. Reliability of analytical methods for determining anthocyanins in blood orange juices. Journal of Agricultural and Food Chemistry 48, 2249-2252.

Scott, W.C., Veldhuis, M.K., 1966. Rapid estimation of recoverable oil in citrus juices by bromate titration. Journal of the Association of Official Analytical Chemists $49,628-633$.

Sentandreu, E. (2006). Determinación de la actividad antirradical de zumos cítricos y caracterización de zumos de mandarina en función de su contenido en flavonoides y de su actividad antirradical. Tesis doctoral. Universidad de Valencia.

So, F.V., Guthrie, N., Chambers, A.F., Moussa, M., Carroll, K.K., 1996. Inhibition of human breast cancer cell proliferation and delay of mammary tumorigenesis by flavonoids and citrus juices. Nutrition and Cancer 262, 167-181.

Soon-Mi, S., Gun-Hee, K., 2002. Color changes and carotenoid pigment loss in retentate from star Ruby grapefruit juice under refrigerated conditions. Food Science and Technology Research 8, 244-246.

Tanaka, T., Makita, H., Kawabata, K., Mori, H., Kakumoto, M., Satoh, K., Hara, A., Sumida, T., Tanaka, T., Ogawa, H., 1997. Hemoprevention of azoxymethaneinduced rat colon carcinogenesis by the naturally occurring flavonoids, diosmin and hesperidin. Carcinogenesis 18, 957-965.

Yang, M., Tanaka, T., Hirose, Y., Deguchi, T., Mori, H., Kawada, Y., 1997. Chemopreventive effects of diosmin and hesperidin on N-butyl-N-(4 hydroxybutyl) nitrosamine-induced urinary-bladder carcinogenesis in male ICR mice. International Journal of Cancer 73, 719-724. 
Desarrollo tecnológico y valoración funcional de aperitivos de manzana y zumo de mandarina 


\section{Homogenization pressures applied to citrus juices manufacturing. Functional properties and application.}

E. Betoret ${ }^{a}$, E. Sentandreu ${ }^{b}$, N. Betoret ${ }^{a}$, and P. Fito*a

a Institute of Food Engineering for Development, Department of Food Technology, Universidad Politécnica de Valencia, Camino de Vera s/ n, 46022 Valencia, Spain.

b Instituto de Agroquímica y Tecnología de Alimentos (IATA-CSIC), Avda. Agustín Escardino 7, 46980 Paterna, Valencia, Spain.

* Corresponding author. Address: Institute of Food Engineering for Development, Department of Food Technology, Universidad Politécnica de Valencia, Camino de Vera s/n, 46022 Valencia, Spain. Tel.: +34 96387 7367. Fax.: +34 96387 7056.E-mail address: pfito@tal.upv.es

A R T I C LE IN F O

Article history:

Received 25 October 2011

Received in revised form

29 December 2011

Accepted 28 January 2012

Available on line 9

February 2012

Keywords:

Citrus juices

Homogenization pressure

Suspended solids

Antiradical activity

Vacuum impregnation

\section{A B S T R A C T}

Homogenization is a unit operation that can be incorporated in citrus juice manufacturing to improve chemical and physical characteristics relevant for use in subsequent processing operations. The aim of this study was to evaluate the effect of different homogenization pressures on suspended solids and antiradical activity in mandarin low pulp juice (LPJ) and to understand their influence on a posterior vacuum impregnation operation. We found the pressure treatments applied to LPJ do not have negative effects on antiradical activity or functional compounds in the juice. In the vacuum impregnation study we found that more LPJ was introduced into the structural matrix of apples when homogenized at higher pressures and therefore more functional compounds may be introduced due to pulp stability and particle size reduction.

\section{INTRODUCTION.}

Citrus juices are popular healthy drinks enjoyed all over the world and in Spain in particular (Pérez-López et al., 2006). The popularity of citrus juices is due not only to its beneficial health effects but also because of its pleasant and refreshing flavor. A number of antioxidants are naturally present in orange juice and they may confer protection against certain degenerative diseases (Polydera et al., 2005).

The quality of a manufactured product starts with the nature and quality of the raw materials. Moreover, the technological operations involved in its 
transformation also play an important role. The citrus processing industry follows the demands of the market for processed products that have characteristics resembling the fresh product (Crupi \& Rispoli, 2002). The operations involved in the manufacture of fresh juice include extraction, sieving, centrifugation, evaporation, mixing and storage. During this process products have to maintain their chemical and physical characteristics as well as their sensory attributes, making the storage conditions critical to this end (Crupi \& Rispoli, 2002). Consumers expect products with a high organoleptic quality, including not only appearance but also aroma, color, flavor and texture. Continuous technological improvements have enabled the citrus industry to excel in quality with the result that today citrus juices are better tasting and more like fresh squeezed juice than ever before (Izquierdo et al., 2007).

Additionally, other operations can be introduced in the citrus juice manufacturing process in order to improve the chemical and physical characteristics of the juice. For example, homogenization is an operation that can be used in the citrus industry for increasing the yield of citrus juices (Lortkipanidze et al., 1972) and for improving quality factors such as viscosity (Crandall \& Davis, 1991; Patrignani et al., 2009), shelf-life (Maresca et al., 2011), color (Lee \& Coates, 2004), cloudiness (Baker, 1977) and the stability of suspended solids (Carle et al., 1998). Compared with other treatments applied to juices, homogenization pressures have been found to be less destructive to low molecular weight food compounds that can be related to sensory and nutritional qualities. This is thought to be due to the limited effect of homogenization on the covalent bonds of low molecular-mass compounds (Oey et al., 2008). Homogenization pressures have also been shown to be effective in the inactivation of different microorganisms in orange juice (Basak et al., 2002) and can be applied as a pretreatment in other processes where the particle size affects the efficiency and the yield of the process and to the quality factors of the final products (e.g. membrane processes, vacuum impregnation) (Betoret et al., 2009).

Vacuum impregnation technology work by means of pressure gradients to incorporate components into the structural matrix of porous foods without substantially modifying its organoleptic properties (Fito et al., 1996). To incorporate the maximum quantity of liquid into a porous food structure it is necessary that some characteristics like density, particle size and suspended solids are appropriate.

Most of the studies done on homogenization have used pressures above 100 $\mathrm{MPa}$ and there has not been any study on the effect of homogenization on a posterior unit operation.

The aim of this study is to describe the effect of homogenization pressure on both suspended solids and antiradical activity, to relate these ones with other known aspects of mandarin low-pulp juice as particle size and flavonoids content and to understand its influence in a posterior vacuum impregnation operation. 


\section{MATERIAL AND METHODS.}

\subsection{Reagents and standards.}

Methanol (spectrophotometric grade), DPPH (94.6\% purity), ABTS•+ and Trolox, all with $95 \%$ purity were acquired from Sigma (Sigma Aldrich Co., St. Louis, MO, USA). Mass spectrometry grade Acetonitrile (ACN), water, tetrahydrofurane (THF) and formic acid were obtained from Scharlab (Scharlab S.L., Barcelona, Spain). Nylon $0.45 \mu \mathrm{m}$ filters were purchased from Teknokroma (Teknokroma Ltd, Barcelona, Spain).

\subsection{Food materials and sample preparation.}

Mandarin juice was prepared as in a previous study (Betoret et al., 2009). Briefly, Ortanique fruit, a hybrid of tangerine and sweet orange (Citrus sinensis $\mathrm{x}$ Citrus reticulata) was harvested in an orchard located in Turís (Valencia), Spain. The fruits were immediately washed by immersing them in tap water, drained and squeezed in an industrial extractor with finger cups (Exzel, Luzzysa; El Puig, Valencia, Spain). Raw juice was homogenized with a Manton-Gaulin pilot homogenizer (model 15M8TBA) at different pressures $(0,5,10,15,20,25$ and 30 $\mathrm{MPa}$ ), centrifuged with a Westfalia centrifuge (model SAOH 205) and the low pulp juice pasteurized at $63^{\circ} \mathrm{C}$ for $15 \mathrm{~s}$ for microbial inactivation, collected in sterile jars, and quickly frozen at $-18 \stackrel{\circ}{ } \mathrm{C}$ until analyzed and used for vacuum impregnation.

Apples (cv. Granny Smith) from a local market were used for the vacuum impregnation. Peeled apples were cut into disc-shaped samples ( $5 \mathrm{~mm}$ thick, with a $65 \mathrm{~mm}$ external diameter and $20 \mathrm{~mm}$ internal diameter) following their vertical axes. Three samples were obtained from each apple.

\subsection{Physiochemical characterization.}

Total soluble solids were measured in Brix units with a refractometer (ABBE ATAGO, NAR T3, Japan) at $20{ }^{\circ} \mathrm{C}$ and $\mathrm{pH}$ values were determined with a potentiometer (micropH CRISON, 2001). Total titratable acidity was assessed by titration with $0.1 \mathrm{~N} \mathrm{NaOH}$ and expressed as the percentage of citric acid. Recoverable essential oils were determined by bromated titration, according to the Scott Method (Scott \& Veldhuis, 1966). The density of the LPJ was determined with a liquid picnometer. The values stated are the average of three replicates. 
2.3 Determination of suspended pulp and cloudiness.

To measure the suspended pulp, a graduated centrifuge tube with a conical bottom was filled with $10 \mathrm{ml}$ of LPJ. The sample was centrifuged in an Eppendorf Refrigerated Multipurpose Centrifuge (model 5804R) for 10 min at $3000 \mathrm{~g}$ at $27^{\circ} \mathrm{C}$ and then the pulp volume was read (FMC FoodTech, 2005). The supernatants were collected, and their transmittance was analyzed for cloudiness at $650 \mathrm{~nm}$ with a UV/Visible spectrophotometer (Ultrospec 3300 pro; Amersham Bioscience, Piscataway, NJ, USA). The values provided are the average of three replicates.

\subsection{Determination of antiradical activity in juice by the ABTS method.}

This ABTS test was based on the method proposed by Polydera et al. (2005). A volume of $15.3 \mu \mathrm{l}$ LPJ homogenized at different pressures was added to ABTS*+ solution. The absorbance was measured with a spectrophotometer Beckman Coulter DU 730 Life Science model every $30 \mathrm{~s}$ for a total time of $30 \mathrm{~min}$. The results were expressed as TEAC (Trolox Equivalent Antiradical Capacity). The values provided are the average of three replicates.

2.5 Determination of antiradical activity in juice by the DPPH method and kinetic modelling.

This DPPH test was based on the method proposed by Brand-Williams et al. (1995). A set of cuvettes with different volumes ( $V_{0}$, between 10-70 $\mu \mathrm{L}$ ) of samples were prepared containing $1.9 \mathrm{~mL}$ of DPPH ${ }^{*}$ in methanol, adding methanol to yield a final volume of $2 \mathrm{~mL}$ (giving a final concentration of DPPH around $100 \mu \mathrm{mol} \mathrm{L}^{-1}$ ). Cuvettes were end-capped immediately, shaken by hand and placed in the spectrophotometer for analysis. Reaction time data were corrected taking into account the time at which the juice was added and the time given by the spectrophotometer. As a general rule, samples yielding an asymptotic value for $\mathrm{DPPH}^{\cdot}$ concentration lower than $10 \%$ or greater than $90 \%$ of its initial concentration were discarded. The absorbance was measured with a spectrophotometer (Beckman Coulter model DU 730 Life Science) at $515 \mathrm{~nm}$ every $2 \mathrm{~min}$ for a total time of $70 \mathrm{~min}$. The results were expressed as mmols of ascorbic acid per liter of juice. A calibration curve of absorbance vs. concentration of DPPH ${ }^{*}$ was obtained to determine the molar extinction coefficient $(\varepsilon)$ of the antiradical probe that was $1.12 \times 10^{4} \mathrm{~L} \mathrm{~mol}^{-1}$. The values provided are the average of three replicates.

In the present work, experimental data were fitted using the theoretical kinetic model developed by Sentandreu et al. (2008) which proposed a multi-purpose equation to determine antiradical activity from any mixture of antiradicals, that is: 


$$
\mathrm{y}-\mathrm{y}_{\mathrm{s}}=\frac{\mathrm{y}_{1}\left(\mathrm{y}_{0}-\mathrm{y}_{1}\right)}{\mathrm{y}_{1}-\mathrm{y}_{0}\left(1-\mathrm{e}^{(\mathrm{k} 1 / \sigma 1) \mathrm{y} 1 \mathrm{t}}\right)}+\frac{\mathrm{y}_{2}\left(\mathrm{y}_{0}-\mathrm{y}_{2}\right)}{\mathrm{y}_{2}-\mathrm{y}_{0}\left(1-\mathrm{e}^{\left(\rho_{2} / \sigma 2\right) \mathrm{y} 2 t}\right)}+\frac{\mathrm{y}_{3}\left(\mathrm{y}_{0}-\mathrm{y}_{3}\right)}{\mathrm{y}_{3}-\mathrm{y}_{0}\left(1-\mathrm{e}^{\left(\rho_{3} / \sigma 3\right) \mathrm{y}_{3}}\right)}
$$

With the constraint:

$$
\mathrm{y}_{3}=2 \mathrm{y}_{0}+\mathrm{y}_{\mathrm{s}}-\mathrm{y}_{1}-\mathrm{y}_{2}
$$

That is three rates-three stoichiometric constants, in which $\mathrm{y}$ is the concentration of $\mathrm{DPPH}^{*}\left(\mu \mathrm{mol} \mathrm{L}^{-1}\right)$ at any time; $\mathrm{y}_{0}$, is the initial concentration of $\mathrm{DPPH}^{\bullet}\left(\mu \mathrm{mol} \mathrm{L} \mathrm{L}^{-1}\right) ; \mathrm{y}_{\mathrm{s}}$, is the experimental $\mathrm{DPPH} \cdot$ concentration $\left(\mu \mathrm{mol} \mathrm{L}^{-1}\right)$ asymptote; $\mathrm{y}_{1}, \mathrm{y}_{2}$ and $\mathrm{y}_{3}$ are the $\mathrm{DPPH} \cdot$ concentration asymptote $\left(\mu \mathrm{mol} \mathrm{L}^{-1}\right)$ that would be reached due solely to the ultra fast, fast and slow antiradical activities; $\mathrm{k}_{1}$, is the rate constant ( $\mathrm{L} /(\mathrm{mol} \mathrm{min})$ ) of ultra fast antiradical activity; $\rho_{2}$ and $\rho_{3}$ are the pseudo rate constants $(\mathrm{L} /(\mathrm{mol} \mathrm{min})$ ) corresponding to fast and slow antiradical activities; $\sigma_{1}, \sigma_{2}$ and $\sigma_{3}$ are the stoichiometric constants of ultra fast, fast and slow antiradical activities; and t equals time.

This model allows the accurate prediction of the asymptotic value of the reduction processes by mixtures of antiradicals at intermediate times of reaction, 60-90 minutes. Results correspond to averages of antiradical activities (total, $A_{t}$; cumulative ultra fast, $\mathrm{A}_{1}$; cumulative fast, $\mathrm{A}_{2}$; and cumulative slow antiradical activities, $A_{3}$; finally having $A_{t}=A_{1}+A_{2}+A_{3}$ ). Experimental data were fit using SigmaPlot 10.0.

\subsection{HPLC-ESI/ MS ${ }^{\mathrm{n}}$ analysis.}

Chromatographic separation was carried out using a Thermo Surveyor Plus HPLC (Thermo Scientific, San José, CA, USA), equipped with a quaternary pump, vacuum degasser, temperature-controlled autosampler and temperaturecontrolled column oven. The column used was a $250 \mathrm{nn}$ x $2.1 \mathrm{~mm}$ i.d, $3 \mu \mathrm{m}$, YMC C18 pack-pro (YMC Europe GmbH, Dinslaken, Germany). Chromatographic conditions were as follows: injection volume, $5 \mu \mathrm{L}$; flow rate, $0.2 \mathrm{~mL} / \mathrm{min}$; oven temperature, $24{ }^{\circ} \mathrm{C}$; autosampler temperature, $10{ }^{\circ} \mathrm{C}$; solvent A, water/ THF/ formic acid (97.9:2.0:0.1 v/ v); solvent B, acetonitrile/ THF/ formic acid $(97.9: 2.0: 0.1 \mathrm{v} / \mathrm{v})$; elution began with $0 \%$ B, linear 0-45\% B in 60 min, linear 45-100\% B in 20 min, purging with $100 \%$ B during $20 \mathrm{~min}$ and re-equilibration of the column for $40 \mathrm{~min}$.

MS analysis and fragmentation experiments were performed on a ThermoFinnigan LCQ Advantage (Thermo Scientific, San José, CA, USA) ion trap mass spectrometer equipped with an electrospray, ESI, source. All instruments were operated by Thermo Xcalibur v. 2.06 (Thermo Scientific, San José, CA, USA). Samples were analyzed either in negative and positive ion mode, both in the range $\mathrm{m} / \mathrm{z}$ 100-2000, under the following conditions: (A) negative ion mode: source voltage, $4.0 \mathrm{kV}$; capillary voltage, $-9 \mathrm{~V}$; capillary temperature, $300{ }^{\circ} \mathrm{C}$; seath gas 
flow, 50 (arbitrary units); sweep gas flow, 20 (arbitrary units); AGC off ion time, 5 ms; full MAX ion time, 300 ms; full micro scans, 3; MSn MAX ion time, 400 ms; MSn microscans, 3. (B) positive ion mode: same conditions as described for negative ion mode with the exception of capillary voltage, $+9 \mathrm{~V}$ and $\mathrm{MS}^{\mathrm{n}} \mathrm{MAX}$ ion time, $600 \mathrm{~ms}$.

To optimize data acquisition from samples, three simultaneous scan analyses were carried out per run: MS (event 1, full MS analysis), MS2 (event 2, mass analysis determined from scan event 1) and $\mathrm{MS}^{3}$ (event 3, mass analysis determined from scan event 2) analysis, all through a Data Dependent Analysis in negative and positive ionization modes with the following settings: default isolation width, 2.0; normalized collision energy, 35\% (arbitrary units); minimal signal required, 50000 ions; exclusion mass width, 3.0; reject mass width, 1.0; dynamic exclusion parameters: repeat count, 3 ; repeat duration, 0.5 min; exclusion list size, 25; exclusion duration, $1.0 \mathrm{~min}$; isotopic data dependent not enabled.

\subsection{Vacuum impregnation operation.}

The vacuum impregnation experiments were performed on a pilot scale using equipment designed at the Institute of Food Engineering for Development of the Polytechnic University in Valencia (Spain) (Fito et al., 2001). A vacuum pressure of 50 mbar was applied for 10 min after which atmospheric pressure was restored. The samples were left submerged in the mandarin LPJ for a further $10 \mathrm{~min}$. The amount of LPJ introduced into the structural matrix of apple, recorded as the volumetric impregnation parameter $(\mathrm{X})$, was determined at each homogenization pressure following the experimental design described by Fito et al. (1996). The values provided are the average of three replicates.

\subsection{Statistical analysis.}

To determine statistical significance an analysis of variance (ANOVA) test was carried out with 95\% confidence levels $(\mathrm{p} \leq 0.05$ ) using the program STATGRAPHICS PLUS v.5.1.

\section{RESULTSAND DISCUSSION.}

3.1 Characterization of juices and evaluation of suspended pulp and turbidity.

Fresh juice samples were characterized by measuring acidity, soluble solids content, maturity index, $\mathrm{pH}$, density and essential oils. The results are shown in Table 1. 
Table 1. Physiochemical characteristics of fresh mandarin juice (mean \pm standard deviation).

\begin{tabular}{lc}
\hline & Ortanique \\
\hline Acidity (\%) & $1.410 \pm 0.017$ \\
Brix & $12.67 \pm 0.06$ \\
Maturity index (Brix/ Acidity) & $8.98 \pm 0.15$ \\
pH & $3.23 \pm 0.03$ \\
Density (g cm & -3 \\
Essential oils (\%) & $1.0519 \pm 0.0016$ \\
\hline
\end{tabular}

Turbidity is a desirable characteristic in citrus juices, and cloud stability is one of the criteria of quality (Rothschild \& Karsenty, 1974). Cloud loss is a major quality defect in citrus juices and its retention is one of the main reasons for the level of heating in commercial pasteurization (Goodner et al., 1999). The results of the cloudiness and suspended pulp determinations are shown in Table 2.

Table 2. Suspended pulp and cloudiness of Low Pulp Juice in relation to the homogenization pressure applied (mean \pm standard deviation).

\begin{tabular}{ccc}
\hline $\begin{array}{c}\text { Homogenization } \\
\text { pressure (MPa) }\end{array}$ & $\begin{array}{c}\text { Pulp separated (\%) by } \\
\text { centrifugation at 3000 g for } \\
\mathbf{1 0} \text { minutes. }\end{array}$ & $\begin{array}{c}\text { Transmittance (\%) of } \\
\text { supernatant separated by } \\
\text { centrifugation at 3000 g } \\
\text { for 10 minutes. }\end{array}$ \\
\hline 0 & $11.2 \pm 0.5^{\mathrm{a}}$ & $7.30 \pm 0.04^{\mathrm{a}}$ \\
5 & $10.0 \pm 0.5^{\mathrm{b}}$ & $1.59 \pm 0.03^{\mathrm{b}}$ \\
10 & $9.2 \pm 0.8^{\mathrm{b}, \mathrm{c}}$ & $0.67 \pm 0.03^{\mathrm{c}}$ \\
15 & $9.0 \pm 0.5^{\mathrm{b}, \mathrm{c}}$ & $0.70 \pm 0.04^{\mathrm{c}}$ \\
20 & $8.5 \pm 0.5^{\mathrm{c}}$ & $0.55 \pm 0.03^{\mathrm{d}}$ \\
25 & $9.2 \pm 0.8^{\mathrm{b}, \mathrm{c}}$ & $0.55 \pm 0.03^{\mathrm{d}}$ \\
30 & $9.0 \pm 0.5^{\mathrm{b}, \mathrm{c}}$ & $0.36 \pm 0.03^{\mathrm{e}}$ \\
\hline Values with different superscripts in the same line are significantly different $(\mathrm{p} \leq 0,05)$.
\end{tabular}

Citrus juice clouds contain cellular organelles and membranes, chromatophores, oil droplets, flavonoid crystals and cell wall fragments such as pectin, cellulose and hemicellulose (Baker \& Cameron, 1999). The pulp also contains some functional components (Garau et al., 2007). Introducing the homogenization operation in the extraction process of citrus juices can affect the stability of suspended pulp and hence the functional components suspended in the cloud. After homogenization, the centrifugation operation eliminates the majority of the pulp that is not stable. The instability of suspended pulp can thereby affect the levels of beneficial compounds in the juice if those compounds are lost with the pulp or dragged out of the juice by it.

Centrifugation at different speeds allows for the evaluation of different kinds of pulp that are more or less stable in the cloud of the juice. Some studies have reported data on suspended pulp after centrifugation at $3000 \mathrm{~g}$ (Carbonell et al., 2011; Sentandreu et al., 2011). In the current study the centrifugation speed used was also $3000 \mathrm{~g}$. As expected, the levels of suspended pulp and transmittance decrease as the homogenization pressure increases. In both parameters the changes observed up to $10 \mathrm{MPa}$ are greater than those observed at higher pressures. Above $10 \mathrm{MPa}$ the low transmittance values indicate a high level of cloudiness and suspended pulp in LPJ that increases with homogenization 
pressure. This effect can be explained taking into account that the homogenization pressure has converted sensible pulp to background pulp (Kupper et al., 1987) and the cloud particles are more stable.

\subsection{Antiradical determination.}

Two analytical methods have been proposed for determining the total antiradical activity of LPJ samples, though each of them presents some limitations (Leong \& Shui, 2002; Prior et al., 2005). The DPPH• method is more sensitive to hydrophobic flavanones while the ABTS method is more sensitive to hydrophilic antiradicals like vitamin C (Del Caro et al., 2004). The ABTS free radical decoloration and the $\mathrm{DPPH}^{\cdot}$ free radical-scavenging assays are useful tools to evaluate antiradical activities of different fruits (Gil et al., 2000; Leong \& Shui, 2002) including oranges, grapefruits and lemons. The results are presented in Table 3. The ABTS test indicated significant differences $(p \leq 0.05)$ between nonhomogenized and samples homogenized at 20,25 and $30 \mathrm{MPa}$ but it is possible to observe that differences are minor. While no significant differences were observed at the different pressures, a slight increase in antiradical activity was observed as homogenization pressure increased.

The lack of initial data points in the experimental curves obtained in the DPPH* assay made it impossible to differentiate between ultra-fast and fast antiradical kinetics given that ascorbic acid is by far the main antiradical contributor. The antiradical activity of mandarin LPJ can be summarized as the sum of the cumulative non-slow antiradical activity (nearly all of which is the ultra-fast antiradical activity of ascorbic acid, $\mathrm{A}_{1}$ ) and the cumulative slow antiradical activity $\left(\mathrm{A}_{3}\right)$, having really two rates-two stoichiometric constants, which makes it possible to simplify Eq. (1) to:

$$
\mathrm{y}-\mathrm{y}_{\mathrm{s}}=\frac{\mathrm{y}_{1}\left(\mathrm{y}_{0}-\mathrm{y}_{1}\right)}{\mathrm{y}_{1}-\mathrm{y}_{0}\left(1-\mathrm{e}^{(\mathrm{k} 1 / \sigma 1) \mathrm{y} 1 t}\right)}+\frac{\mathrm{y}_{3}\left(\mathrm{y}_{0}-\mathrm{y}_{3}\right)}{\mathrm{y}_{3}-\mathrm{y}_{0}\left(1-\mathrm{e}^{\left(\rho_{3} / \sigma 3\right) \mathrm{y} 3 t}\right)}
$$

With the constraint:

$$
\mathrm{y}_{3}=2 \mathrm{y}_{0}+\mathrm{y}_{\mathrm{s}}-\mathrm{y}_{1}
$$

Experimental curves were fitted using Eq. (3), having a correlation coefficient of $\mathrm{r}^{2}>0.999$ in all cases. The results are presented in Table 3 . In our case, no significant differences were found in the values obtained for the two antiradical activity parameters, neither with total antiradical activity $\left(\mathrm{A}_{\mathrm{t}}\right)$, nor at any level of homogenization pressure applied. These results are in agreement with those from Suárez-Jacobo et al. (2011) who determined the main components in apple juice did not change due to high pressure processing such that there was no difference among high pressure treated, raw and pasteurized juices. Moreover, antiradical 
activity of the LPJ was not smaller than that of an industrial, pasteurized mandarin juice (cv. Ortanique) which is $A_{t}=2.132 \mathrm{mmol} \mathrm{L}^{-1}$ equivalents of ascorbic acid (Sentandreu., 2006).

Table 3. Antiradical activity of mandarin Low Pulp Juice in relation to the homogenization pressure applied (mean \pm standard deviation).

\begin{tabular}{ccccc}
$\begin{array}{c}\text { Homogenization } \\
\text { pressure (MPa) }\end{array}$ & $\begin{array}{c}\mathbf{A B T S} \\
\mathbf{m M}_{\text {trolox }} / \mathbf{m l}_{\text {sample }}\end{array}$ & $\mathbf{A}_{\mathbf{t}}$ & $\begin{array}{c}\text { DPPH· } \\
\mathbf{A}_{\mathbf{1}}\end{array}$ & $\mathbf{A}_{\mathbf{3}}$ \\
\hline $\mathbf{0}$ & $1.02 \pm 0.04^{\mathrm{a}}$ & $2.8 \pm 0.2^{\mathrm{a}}$ & $2.29 \pm 0.16^{\mathrm{a}}$ & $0.47 \pm 0.07^{\mathrm{a}}$ \\
$\mathbf{5}$ & $1.08 \pm 0.06^{\mathrm{a}, \mathrm{b}}$ & $2.7 \pm 0.5^{\mathrm{a}}$ & $2.3 \pm 0.5^{\mathrm{a}}$ & $0.440 \pm 0.005^{\mathrm{a}}$ \\
$\mathbf{1 0}$ & $1.2 \pm 0.2^{\mathrm{a}, \mathrm{b}}$ & $3.0 \pm 0.7^{\mathrm{a}}$ & $2.6 \pm 0.7^{\mathrm{a}}$ & $0.401 \pm 0.013^{\mathrm{a}}$ \\
$\mathbf{1 5}$ & $1.2 \pm 0.2^{\mathrm{a}, \mathrm{b}}$ & $2.50 \pm 0.07^{\mathrm{a}}$ & $2.08 \pm 0.03^{\mathrm{a}}$ & $0.42 \pm 0.04^{\mathrm{a}}$ \\
$\mathbf{2 0}$ & $1.28 \pm 0.08^{\mathrm{b}}$ & $2.8 \pm 0.2^{\mathrm{a}}$ & $2.27 \pm 0.09^{\mathrm{a}}$ & $0.54 \pm 0.12^{\mathrm{a}}$ \\
$\mathbf{2 5}$ & $1.26 \pm 0.13^{\mathrm{b}}$ & $3.2 \pm 0.2^{\mathrm{a}}$ & $2.57 \pm 0.16^{\mathrm{a}}$ & $0.60 \pm 0.12^{\mathrm{a}}$ \\
$\mathbf{3 0}$ & $1.271 \pm 0.107 \mathrm{~b}$ & $2.70 \pm 0.07^{\mathrm{a}}$ & $2.21 \pm 0.05^{\mathrm{a}}$ & $0.49 \pm 0.02^{\mathrm{a}}$ \\
\hline
\end{tabular}

$*$ Values with different superscripts in the same column are significantly different $(p \leq 0.05)$. $\mathrm{DPPH} \cdot$ results expressed as mmol L-1 equivalents of ascorbic acid.

\subsection{Antiradical composition.}

A great variety of components that exhibit antiradical activities are contained in citrus juices, such as flavonoids (Sendra et al., 1988), ascorbic acid (Johnston \& Bowling, 2002), anthocyanins (Rapisarda et al., 2000) and cinnamic acid derivatives (Robards \& Antolovich, 1995), among others. In the current study the antiradical composition of LPJ was determined by HPLC-MS $\mathrm{n}_{\mathrm{n}}$ analysis. All the identified compounds are shown in Table 4 where they are classified according to their antiradical activity kinetics when reacting with DPPH'. Thus we have ascorbic acid as the only component with ultra fast antiradical kinetics due to its vinyl alcohol group. The fast+slow kinetics group includes chlorogenic acid and leucenin-2 due to their isolated p-catechol groups. The antiradical behavior of rutin depends on the media. Under in vitro conditions it presents fast+slow antiradical kinetics as in the case of chlorogenic acid. However, if the rutinoside moiety is removed from the molecule by chemical or enzymatic conditions, the flavonol group located at C-3 becomes active, having an antiradical kinetic activity very similar to a vinyl alcohol group (Sendra et al., 2007) while still keeping the activity from its free p-catechol group. Compounds 4, 5, 6, 8, 9, 12 and 13 present only slow antiradical kinetics due to their isolated hydroxyl groups, meanwhile compounds 10 and 11 present only slow antiradical kinetics under in vitro conditions, but as in the case of rutin, after removing the sugar moieties, the flavonol group in C-3 becomes active, thus conferring ultra fast and slow antiradical kinetics.

Finally, the group of fully-methoxylated flavones (FMFs) from LPJ deserves a special mention (peaks 14 to 18 in Table 4). Under in vitro conditions these metabolites completely lack antiradical activity because all of their hydroxyl groups are methylated. However, these compounds turn active when methyl groups are changed to hydroxyl groups during digestion after which they have strong in vivo antioxidant activity (Walle, 2007). 
Table 4. Antiradicals identified in non-homogenized mandarin Low Pulp Juice.

\begin{tabular}{|c|c|c|c|c|c|c|}
\hline Peak no. & Rt (min) & $* \mathbf{M}-/ \mathbf{M}^{+}$ & $* * \mathbf{M S}^{2}$ & ****MS $\mathbf{M S}^{3}$ & $\begin{array}{c}\text { Tentative } \\
\text { identification }\end{array}$ & $\begin{array}{c}\text { DPPH } \\
\text { Antiradical } \\
\text { activity } \\
\text { kinetics }\end{array}$ \\
\hline 1 & 3.75 & $175.1^{-}$ & 115 & - & Ascorbic acid & ultra fast \\
\hline 2 & 33.32 & $353.0^{-}$ & 191,179 & $\begin{array}{c}\text { 173, 127, } \\
\mathbf{8 5}\end{array}$ & Chlorogenic acid & fast+slow \\
\hline 3 & 34.32 & $609.2^{-}$ & $\begin{array}{c}591,519, \\
\mathbf{4 8 9}, 399 \\
369\end{array}$ & $399, \mathbf{3 6 9}$ & $\begin{array}{l}\text { Luteolin-6,8-di-C- } \\
\text { glucoside (Leucenin- } \\
\text { 2) }\end{array}$ & fast+slow \\
\hline 4 & 36.64 & $593.2^{-}$ & $\begin{array}{c}575,503 \\
\mathbf{4 7 3}, 383, \\
353\end{array}$ & 383,353 & $\begin{array}{l}\text { Apigenin-6,8-di-C- } \\
\text { glucoside (Vicenin-2) }\end{array}$ & slow \\
\hline 5 & 37.19 & $741.2^{-}$ & $\begin{array}{l}579, \mathbf{4 3 3} \\
271\end{array}$ & 271 & $\begin{array}{l}\text { Naringenin-7-O- } \\
\text { rutinoside- } 4^{\prime}-\mathrm{O}- \\
\text { glucoside }\end{array}$ & slow \\
\hline 6 & 39.85 & 771.1- & $\begin{array}{c}609, \mathbf{4 6 3} \\
301\end{array}$ & 301 & $\begin{array}{l}\text { Hesperetin-7-O- } \\
\text { rutinose-3'-O- } \\
\text { glucoside }\end{array}$ & slow \\
\hline 7 & 44.97 & $609.2^{-}$ & 301, 271 & $\begin{array}{l}271,255, \\
\mathbf{1 7 9}, 151\end{array}$ & Rutin & fast+slow \\
\hline 8 & 47.12 & 579.2 & 271 & 151 & Narirutin & slow \\
\hline 9 & 47.80 & $577.1^{-}$ & 269 & 269, 225 & Isorhoifolin & slow \\
\hline 10 & 48.00 & $623.3^{-}$ & $\begin{array}{l}\text { 315, 300, } \\
271\end{array}$ & $\begin{array}{c}\text { 300, 271, } \\
151\end{array}$ & $\begin{array}{l}\text { Isorhamnetin-3-O- } \\
\text { rutinoside }\end{array}$ & slow \\
\hline 11 & 48.34 & $479.0^{+}$ & 317 & 317 & $\begin{array}{c}\text { Isorhamnetin-3-O- } \\
\text { hexoside }\end{array}$ & slow \\
\hline 12 & 48.55 & $609.2^{-}$ & 301 & $\begin{array}{c}\text { 286, } 283, \\
242,199 \\
125\end{array}$ & Hesperidin & slow \\
\hline 13 & 56.99 & $593.2^{-}$ & 285 & 285, 243 & Didymin & slow \\
\hline 14 & 65.91 & $373.2^{+}$ & 358,343 & 343 & Isosinensetin & none \\
\hline 15 & 70.51 & $373.2^{+}$ & $\begin{array}{l}\text { 358, 343, } \\
329,312 \\
\end{array}$ & $\begin{array}{c}343,329 \\
\mathbf{3 1 2}\end{array}$ & Sinensetin & none \\
\hline 16 & 71.71 & $343.2^{+}$ & 328,313 & 313 & $\begin{array}{l}\text { Tetramethyl-O- } \\
\text { isoscutellarein }\end{array}$ & none \\
\hline 17 & 73.41 & $403.2^{+}$ & 388,373 & 373 & $\begin{array}{l}\text { Hexamethyl-O- } \\
\text { quercetagetin }\end{array}$ & none \\
\hline 18 & 75.08 & $403.2^{+}$ & 388, 373 & 373 & Nobiletin & none \\
\hline 19 & 75.80 & $343.2^{+}$ & $\begin{array}{l}\text { 328, 313, } \\
299,282\end{array}$ & $299, \mathbf{2 8 2}$ & $\begin{array}{l}\text { Tetramethyl-O- } \\
\text { scutellarein }\end{array}$ & none \\
\hline 20 & 76.84 & $433.1^{+}$ & 418, 403 & 403 & Heptamethoxyflavone & none \\
\hline 21 & 78.28 & $373.2^{+}$ & 358, 343 & 343 & Tangeretin & none \\
\hline
\end{tabular}

*LC-MS electrospray ionization mode (ESI): $\mathrm{M}$, negative; $\mathrm{M}^{+}$, positive.

**In bold, most abundant ions generated at $\mathrm{MS}^{2}$ and $\mathrm{MS}^{3}$ stages.

***MS3 from most abundant ion generated at MS² stage.

Of the components identified in this study it is known the most abundant flavonoids in the mandarin juice are hesperidin, narirutin and didymin. In these ones the effect of the homogenization pressure has been studied (Betoret et al., 2009). 


\subsection{Vacuum impregnation experiments.}

In a previous study (Betoret et al., 2009) we found the content of flavonoids narirutin, hesperidin and didymin were maintained suspended in the cloud in nonhomogenized and homogenized LPJ at 5, 10, 15, 20, 25 and $30 \mathrm{MPa}$. Homogenization pressure is a mechanical process that does not affect the content of flavonoids in the juice overall, but it may produce changes in the content of flavonoids suspended in the cloud. Hesperidin was the major flavonoid in all samples followed by narirutin and didymin. Although it is important to note the small variation obtained in data, the narirutin and didymin profile showed a tendency to increase with the homogenization pressure. Hesperidin molecules are almost insoluble in aqueous solutions $(15 \mathrm{mg} / \mathrm{L})$ and tend to crystallize quickly. The size of the crystals increases to a certain critical point, at which they precipitate (Ben-Shalom \& Pinto, 1999). Pectin apparently provides a nucleation site for this process (Baker \& Cameron, 1999). The molecular mass of the pectin involved is an important factor in the stability of the complex, with higher masses favoring stability (Ben-Shalom \& Pinto, 1999). Homogenization pressure may contribute to hesperidin and other flavonoid stability in the juice cloud. We found this occurred until pressures of $10 \mathrm{MPa}$ above which we observed a slight decrease. The heat produced by the homogenizer at higher pressures may produce this effect, since hesperidin precipitates more easily when exposed to acidity and heat (Lacroix et al., 2005). Pressure homogenization produces an increase of 19.5 ${ }^{\circ} \mathrm{C} \pm 3{ }^{\circ} \mathrm{C}$ each $100 \mathrm{MPa}$ (Guamis, 2009). This means at $20 \mathrm{MPa}$ the mandarin juice can reach temperatures over $30^{\circ} \mathrm{C}$ if the juice goes into the homogenizer at room temperature $\left(25^{\circ} \mathrm{C}\right)$.

It is clear that homogenization pressure can affect stability of suspended particles. This is important when homogenization pressure is applied prior to other operations or processes in which the suspended solids affect the efficiency and the yield of the process or the quality of the final product. This occurs for example in the case of vacuum impregnation operation. Physiologically active compounds may be introduced into fruits and vegetable products using this technique without modifying their integrity (Betoret et al., 2011). This so-called "direct formulation" distinguishes it from other processing methods (Mavroudis et al., 1998a,b; Torregiani, 1993). The use of vacuum impregnation to produce enriched fruit requires that the impregnation liquid can be introduced into the pores or intercellular spaces. In a previous study (Betoret et al., 2009) we found pressure homogenization of mandarin juice led to a natural evolution to smaller particle sizes as homogenization pressure increased. A significant effect on both variables studied $\mathrm{D}[4,3]$ and $\mathrm{D}_{\text {peak }}$ was found.

In this study we were able to quantify the volume of LPJ introduced into apples by employing the hydrodynamic model proposed by Fito (1994) and Fito \& Pastor (1994) and by following the experimental design described by Fito et al. (1996). The volumetric impregnation parameter $(\mathrm{X})\left(\mathrm{m}^{3}\right.$ incorporated juice $\cdot \mathrm{m}^{-3}$ fresh apple $)$ is 
reported for each homogenization pressure (Table 5). A slight increase in incorporated LPJ was observed as the homogenization pressure increased to 15 , 25 and $30 \mathrm{MPa}$. Taking into account the pore size of the apple (6.64 \pm 0.24 Tm) (Bazharl \& Ngadi, 2003), a reduction in the size of the cloud particles by pressure homogenization may facilitate the incorporation of the LPJ into the intercellular spaces. When suspended pulp is cloud stable this can help the stability of functional compounds and therefore the potential to incorporate these compounds into the structural matrix of apple by vacuum impregnation also increases.

Table 5. Volume of juice incorporated into apples by vacuum impregnation in relation to the homogenization pressure applied (mean \pm standard deviation).

\begin{tabular}{cc}
$\begin{array}{c}\text { Homogenization } \\
\text { pressure (MPa) }\end{array}$ & $\begin{array}{c}\mathbf{X} \mathbf{( m}^{\mathbf{3}} \text { incorporated juice }^{\bullet} \\
\left.\mathbf{m}^{-3} \text { fresh apple }\right)\end{array}$ \\
\hline $\mathbf{0}$ & $0.098 \pm 0.012^{\mathrm{a}}$ \\
$\mathbf{5}$ & $0.13 \pm 0.02^{\mathrm{b}}$ \\
$\mathbf{1 0}$ & $0.14 \pm 0.02^{\mathrm{b}}$ \\
$\mathbf{1 5}$ & $0.19 \pm 0.03^{\mathrm{c}}$ \\
$\mathbf{2 0}$ & $0.1455 \pm 0.0107^{\mathrm{b}}$ \\
$\mathbf{2 5}$ & $0.17 \pm 0.02^{\mathrm{b}, \mathrm{c}}$ \\
$\mathbf{3 0}$ & $0.196 \pm 0.015^{\mathrm{c}}$ \\
\hline rent superscripts in a column are significantly different $(\mathrm{p} \leq 0.05)$.
\end{tabular}

\section{CONCLUSIONS.}

Applying homogenization pressures from 0 to $30 \mathrm{MPa}$ in low pulp mandarin juice is favorable for a subsequent implementation of a vacuum impregnation operation and therefore for the development of a functional product. Furthermore pressure treatments applied to LPJ do not have negative effects on antiradical activity and functional compounds. Higher pressures led to greater incorporation of LPJ into the structural matrix of apple, which may indicate that more functional compounds would also be introduced due to pulp stability and particle size reduction.

\section{ACKNOWLEDGEMENTS.}

The authors acknowledge the Ministerio de Ciencia e Innovación of Spain for its contribution to projects AGL2009-09905 and PET2008_0015.

\section{REFERENCES.}

Baker, R.A. (1977). Process to control juice cloud. Symposium of the international society of citriculture. Proceedings of the International Society of Citriculture, pp 751-755.

Baker, R.A., \& Cameron, R.G. (1999). Clouds of citrus juices and juice drinks. Food Technology, 53, 64-69. 
Basak, S., Ramaswamy, H.S., \& Piette, J.P.G. (2002). High pressure destruction kinetics of Leuconostoc mesenteroides and Sacharomyces cerevisiae in single strength and concentrated orange juice. Innovative Food Science and Emerging Technologies, 3, 223-231.

Bazhal, M.I., \& Ngadi, M.O. (2003). Influence of pulsed electroplasmolysis on the porous structure of apple tissue. Biosystems Engineering, 86, 51-57.

Ben-Shalom, N., \& Pinto, R. (1999). Natural coloidal particles: the mechanism of the specific interaction between hesperidin and pectin. Carbohydrate Polymers, 38, 179-182.

Betoret, E., Betoret, N., Carbonell, J.V., \& Fito, P. (2009). Effects of pressure homogenization on particle size and the functional properties of citrus juices. Journal of Food Engineering, 92, 18-23.

Betoret, E., Betoret, N., Vidal, D., \& Fito, P. (2011). Functional foods development: Trends and technologies. Trends in Food Science \& Technology, 22, 498-508.

Brand-Williams, W., Cuvelier, M.E., \& Berset, C. (1995). Use of a free radical method to evaluate antioxidant activity. Lebensmittel Wissenschaft und Technologie, 28, 25-30.

Carbonell, J.V., Tárrega, A., Gurrea, M.C., \& Sentandreu, E. (2011). Chilled orange juices stabilized by centrifugation and differential heat treatments applied to low pulp and pulpy fractions. Innovative Food Science and Emerging Technologies, 12, 315-319.

Carle, R., Jauss, A., \& Fuesser, H. (1998). Cloud stability of pulp-containing tropical fruit nectars. Fruit Processing, 8(7), (266-268, 270-272).

Crandall, P.G., \& Davis, K.C. (1991). Viscosity reduction and reformation of structure in orange concentrate as affected by homogenization within commercial taste evaporators. Journal of Food Science, 56, 1360-1364.

Crupi, F., \& Rispoli, G. (2002). Citrus juices technology. In: Dugo, G., Giacomo, A. Citrus. The genus citrus. Taylor \& Francis, London, 77-113.

Del Caro, A., Piga, A., Vacca, V., \& Aggabio, M. (2004). Changes of flavonoids, vitamin $\mathrm{C}$ and antioxidant capacity in minimally processed citrus segments and juices during storage. Food Chemistry, 84, 99-105.

Fito, P. (1994). Modelling of vacuum osmotic dehydration of food. Journal of Food Engineering, 22(1-4), 313-328.

Fito, P., \& Pastor, R. (1994). On some non-diffusional mechanism occurring during vacuum osmotic dehydration. Journal of Food Engineering, 21, 513-519.

Fito, P., Andrés, A., Chiralt, A., \& Pardo, P. (1996). Coupling of hydrodynamic mechanism and deformation relaxation phenomena during vacuum treatments in solid porous food-liquid systems. Journal of Food Engineering, 27, 229-240.

Fito, P., Chiralt, A., Betoret, N., Gras, M.L., Cháfer, M., Martínez-Monzó, J., Andrés, A., $\&$ Vidal, D. (2001). Vacuum impregnation and osmotic deshydratation in matrix engineering. Application in functional fresh food development. Journal of Food Engineering, 49, 175-183. 
FMC FoodTech. (2005). Laboratory manual. Procedures for analysis of citrus products, Fourth ed. (pp. 49-50). Manual No 054R10020.000.

Garau, M.C., Simal, S., Roselló, C., \& Femenia, A., (2007). Effect on air-drying temperature on physico-chemical properties of dietary fibre and antioxidant capacity or orange (Citrus aurantium v Canoneta) by-products. Food Chemistry, 104, 1014-1024.

Gil, M.I., Tomás-Barberán, F.A., Hess-Pierce, B., Holcroft, D.M., \& Kader, A.A. (2000). Antioxidant activity of pomegranate juice and its relationship with phenolic composition and processing. Journal of Agricultural and Food Chemistry, 48, 4581-4589.

Goodner, J.K., Braddock, RJ., Parish, M.E., \& Sims, C.A. (1999). Cloud stabilization of orange juice by high pressure processing. Journal of Food Science, 64, 699-700.

Guamis, B. (2009). Aplicaciones de la ultra alta presión homogenización para la industria alimentaria, farmacéutica y cosmética. In: Jornada Técnica sobre Tecnologías transversales de interés para la Industria Alimentaria, Farmacéutica y Cosmética, December 2009, Barcelona, Spain.

Izquierdo, L., Carbonell, J.V., Navarro, J.L., \& Sendra, J.M. (2007). Method of Obtaining Refrigerated Pasteurized Citrus Juices. Patent WO/ 2007/ 042593. Consejo Superior de Investigaciones Científicas, Spain.

Johnston, C.S., \& Bowling, D.L. (2002). Stability of ascorbic acid in commercially available orange juices. Journal of the American Dietetic Association, 102, 525529.

Kupper, P.L., Moore, K.L., \& Swaine, R.L. (1987). Fruit juice containing diet beverage. US Patent 4690827.

Lacroix, N., Fliss, I., \& Makhlouf, J. (2005). Inactivaction of pectin methylesterase and stabilization of opalescence in orange juice by dynamic high pressure. Food Research International, 38, 569-576.

Lee, H.S., \& Coates, G.A. (2004). Pigment extraction system and method. US patent US20040258809-A1.

Leong, L.P., \& Shui, G. (2002). An investigation of antioxidant capacity of fruits in Singapore markets. Food Chemistry, 76, 69-75.

Lortkipanidze, R.K., Anikeichik, N.M., Yakobashvili, R.A., \& Bolkovadze, M.K. (1972). Homogenizer in citrus juice production line. Konservnaya i Ovoshchesushil'naya Promyshlennost, 7, 9-10.

Maresca, P., Donsì, F., \& Ferrari, G. (2011). Application of a multi-pass highpressure homogenization treatment for the pasteurization of fruit juices. Journal of Food Engineering, 104, 364-372.

Mavroudis, N.E., Gekas, V., \& Sjoholm, I. (1998a). Osmotic dehydration of applesEffects of agitation and raw material characteristics. Journal of Food Engineering, 35, 191-209.

Mavroudis, N.E., Gekas, V., \& Sjoholm, I. (1998b). Osmotic dehydration of applesShrinkage phenomena and the significance of initial structure on mass transfer rates. Journal of Food Engineering, 38, 101-123. 
Oey, I., Van der Plancken, I., Van Loey, A., \& Hendrickx, M. (2008). Does high pressure processing influence nutritional aspects of plant based food systems?. Trends in Food Science and Technology, 19, 300-308.

Patrignani, F., Vannini, L., Kamdem, S.L.S., Lanciotti, \& R.,Guerzoni, M.E. (2009). Effect of high pressure homogenization on Saccharomyces cerevisiae inactivation and physic-chemical features in apricot and carrot juices. International Journal of Food Microbiology, 136, 26-31.

Pérez-López, A., Saura, D., Lorente, J., \& Carbonell-Barrachina, A.A. (2006). Limonene, linalool, $\alpha$-terpineol, and terpinen-4-ol as quality control parameters in mandarin juice processing. European Food Research and Technology, 222, 281-285.

Polydera, A.C., Stoforos, N.G., Taoukis, P.S. (2005). Effect of high hydrostatic pressure treatment on post processing antioxidant activity of fresh Navel orange juice. Food Chemistry, 91, 495-503.

Prior, R.L., Wu , X., \& Schaich, K. (2005). Standarized methods for the determination of antioxidant capacity and phennolics in foods and dietary supplements. Journal of Agricultural and Food Chemistry, 53, 4290-4302.

Rapisarda, F., Fanella, F., \& Maccarone, E. (2000). Reliability of analytical methods for determining anthocyanins in blood orange juices. Journal of Agricultural and Food Chemistry, 48, 2249-2252.

Robards, K., \& Antolovich, M. (1995). Methods for assessing the authenticity of orange juice. Analyst, 120, 1-28.

Rothschild, G., \& Karsenty, A. (1974). Influence of holding time before pasteurization, pasteurization and concentration on the turbidity of citrus juices. Journal of Food Science, 39(5), 1042-1044.

Scott, W.C., \& Veldhuis, M.K. (1966). Rapid estimation of recoverable oil in citrus juices by bromate titration. Journal of the Association of Official analytical Chemists, 49, 628-633.

Sendra, J.M., Navarro, J.L., \& Izquierdo, L. (1988). C18 solid-phase isolation and highperformance liquid chromatography-ultraviolet diode array determination of fully methoxylated flavones in citrus juices. Journal of Chromatographic Science, 26, 443-448.

Sendra, J.M., Sentandreu, E., \& Navarro, J.L. (2007). Kinetic model for the antiradical activity of the isolated p-catechol group (3', 4'-dihydroxybenzene) in flavanone type structures using the free stable radical 2,2-diphenyl-1picrylhydrazyl (DPPH·) as the antiradical probe. Journal of Agricultural and Food Chemistry, 55 (14), 5512-5522.

Sentandreu E. (2006). Determinación de la actividad antirradical de zumos cítricos y caracterización de zumos de mandarina en función de su contenido en flavonoides y de su actividad antirradical. Doctoral Thesis. Consejo Superior de Investigaciones Científicas Instituto de Agroquímica y Tecnología de Alimentos.

Sentandreu, E., Navarro, J.L., \& Sendra, J.M. (2008). Reduction kinetics of the antiradical probe 2,2-Diphenyl-1-picrylhydrazyl in methanol and acetonitrile 
by the antiradical activity of protocatechuic acid and protocatechuic acid methyl ester. Journal of Agricultural and Food Chemistry, 56, 4928-4936.

Sentandreu, E., Gurrea, M.C., Betoret, N., \& Navarro, J.L. (2011). Changes in orange juice characteristics due to homogenization and centrifugation. Journal of Food Engineering, 105, 241-245.

Suárez-Jacobo, A., Rüfer, C.E., Gervilla, R., Guamis, B., Roig-Sagués, A.X., \& Saldo, J. (2011). Influence of ultra-high pressure homogenisation on antioxidant capacity, polyphenol and vitamin content of clear apple juice. Food Chemistry, $127,447-454$.

Torreggiani, D. (1993). Osmotic dehydration in fruit and vegetable processing. Food Research International, 26, 59-68.

Walle, T. (2007) Methoxylated flavones, a superior cancer chemopreventive flavonoid subclass?. Seminars in Cancer Biology, 17, 354-362. 
3.4. Efecto del proceso de fabricación del alimento funcional a partir de manzana y zumo de mandarina sobre las propiedades fisicoquímicas y funcionales del mismo. Evaluación del grado de aceptación. 

Innovative Food Science and Emerging Technologies (Accepted manuscript) doi:10.1016/j.ffet.2012.07.003

Contents lists available at SciVerse ScienceDirect

Innovative Food Science and Emerging Technologies journal homepage: www.elsevier.com/locate/ifset

\section{Technological development and functional properties of an apple snack rich in flavonoid from mandarin juice.}

E. Betoreta, E. Sentandreub ${ }^{b}$ N. Betoreta, P. Codoñer-Franchc, V. Valls-Bellésc and P. Fito*a

a Institute of Food Engineering for Development, Department of Food Technology, Universidad Politécnica de Valencia, Camino de Vera s/ n, 46022 Valencia, Spain.

b Instituto de Agroquímica y Tecnología de Alimentos (IATA-CSIC), 46980 Paterna, Valencia, Spain.

c Department of Pediatrics, Obstetrics, and Gynecology. Facultad de Medicina y Odontología, Universidad de Valencia, Avenida Blasco Ibáñez, 15, 46010 Valencia (Spain).

* Corresponding author. Address: Institute of Food Engineering for Development, Department of Food Technology, Universidad Politécnica de Valencia, Camino de Vera s/n, 46022 Valencia, Spain. Tel.: +34 96387 7367. Fax.: +34 96387 7056. E-mail address: pfito@tal.upv.es

\begin{tabular}{|c|c|}
\hline ARTICLE INFO & ABST RACT \\
\hline $\begin{array}{l}\text { Keywords: } \\
\text { Functional foods } \\
\text { Citrus juices } \\
\text { Vacuum impregnation } \\
\text { Flavonoid } \\
\text { Antiradical activity }\end{array}$ & $\begin{array}{l}\text { The development of functional foods has evolved considerably over } \\
\text { the years. The technological ability to produce a food with enhanced } \\
\text { physiologically active compounds has grown significantly. The aim of } \\
\text { this work was to study the incorporation of the beneficial } \\
\text { compounds from mandarin low pulp juice into an apple snack using } \\
\text { vacuum impregnation technology and to test if the final product } \\
\text { exhibited the functional properties and components of both raw } \\
\text { materials. Forty grams of final product made using mandarin juice } \\
\text { homogenized at } 15 \mathrm{MPa} \text { could provide the same quantity of } \\
\text { hesperidin as } 250 \mathrm{~mL} \text { of fresh mandarin juice. We also performed a } \\
\text { chromatographic determination of the components in the final } \\
\text { product and we also assessed its antioxidant activity. }\end{array}$ \\
\hline
\end{tabular}

\section{INTRODUCTION.}

The development of functional foods is on the rise as food manufacturers respond to increasing consumer demand. Natural foods such as fruits and vegetables represent the simplest form of functional foods and can be a good source of functional compounds (Day et al., 2009). For example some common 
fruits, such as citrus juices and apples which are highly consumed all over the world, are rich in functional compounds. Consumption of citrus juices affects the concentration of vitamin $\mathrm{C}$ in blood as well as biomarkers of antioxidant status (Sanchez-Moreno et al., 2003). These juices are also bioactive against a number of diseases, such as coronary insufficiency (Rouseff \& Nagy, 1994) some age-related disorders (Baghurst, 2003), and they may reduce the risk of some cancers (Block et al., 1992; Steinmez \& Potter, 1996; So et al., 1996). The great number of bioactive compounds present in citrus juices (including L-ascorbic acid, flavonoids, carotenoids, and cinnamic acid derivatives among others) is thought to be responsible for these effects. Similarly, apples are a good source of vitamins, minerals and dietary fibre. Recent studies have linked high apple consumption with decreased risk of cardiovascular disease, diabetes and some cancers (Boyer \& Liu, 2004; McCann et al., 2007).

From a manufacturing point of view, the technologies used to developed functional foods have evolved considerably over the years. Historically traditional techniques such as formulation and blending that generally produce nonstructured products have been the most commonly used for development of functional foods. However, during the last few years a group of emerging technologies (e.g., microencapsulation, edible films and coatings and vacuum impregnation) have grown significantly in popularity because of the interest in forming a structure that prevents the deterioration of physiologically active compounds (Betoret et al., 2011a; Suárez-Jacobo et al., 2011).

The functional effect of a food depends on the active components gaining access to the functional target site. Selection and development of an appropriate food vehicle that maintains the active molecular form until the time of consumption and delivery of this form to the physiological target site within the organism is key to the ultimate success of functional foods (Jones \& Jew, 2007). One technology useful in the production of functional foods is vacuum impregnation (VI) which utilizes pressure gradients to incorporate active functional components into the structural matrix of porous food items without substantially modifying their organoleptic properties (Fito et al., 1996). VI has been successfully used to incorporate vitamins (Cortés et al., 2007), minerals (Gras et al., 2003; Xie \& Zhao, 2003a,b; Barrera et al., 2004) and probiotic microorganisms (Betoret et al., 2003; Betoret et al., 2011b) into fruits and vegetables. More recently, one study focused on the potential for VI to protect active compounds within foods, with successful results (Watanabe et al., 2011).

The development of a functional product combining apples with mandarin juice would be very interesting for several reasons. It would represent a novel product for the functional food industry, and it could also combine the beneficial effects of both sources into one food item, or even enhance the beneficial components in the juice by protecting them through inclusion into a food structure. VI technology allows for the introduction of mandarin juice into the structural porous matrix of apples. Because the final product would be highly unstable due to its high water 
content, it should be stabilized by applying a preservation method, such as a drying procedure, to increase its shelf life.

The aim of this work was to study the incorporation of bioactive compounds from mandarin low pulp juice (LPJ) into an apple snack by using VI and air drying technologies. The compositional and functional properties of the resultant product were also assessed.

\section{MATERIALS AND METHODS.}

\subsection{Reagents and standards.}

Methanol (spectrophotometric grade), DPPH• with $95 \%$ purity was acquired from Sigma (Sigma Aldrich Co., St. Louis, MO, USA). Mass spectrometry grade acetonitrile (ACN), water, tetrahydrofurane (THF) and formic acid were purchased from Scharlab (Scharlab S.L., Barcelona, Spain). Nylon $0.45 \mu \mathrm{m}$ filters were obtained from Teknokroma (Teknokroma LTd., Barcelona, Spain).

\subsection{Food materials and sample preparation.}

Mandarin juice was obtained as previously described by Betoret et al. (2009). Ortanique fruit, a hybrid of tangerine and sweet orange (Citrus sinensis x Citrus reticulata) was harvested in an orchard located in Turís (Valencia), Spain, and squeezed immediately for juice preparation. The fruits were washed by immersion in tap water, after which they were drained, and squeezed in an industrial extractor with finger cups (Exzel, Luzzysa; El Puig, Valencia, Spain). Raw juice was divided into two fraction and the low pulp juice fraction was homogenized with a Manton-Gaulin pilot homgenizer (model 15M8TBA) at 0, 5, 10, 15, 20, 25 and 30 $\mathrm{MPa}$, centrifuged with a Westfalia centrifuge (model SAOH 205), and pasteurized at $63^{\circ} \mathrm{C}$ for $15 \mathrm{~s}$. From now on, this fraction thus treated will be referred to mandarin low pulp juice (LPJ). A portion of the LPJ was collected in sterile jars and quickly frozen at $-18 \stackrel{\circ}{ } \mathrm{C}$ until further use and the other was maintained fresh for immediate determination of the content of the three main flavonoids.

Apples (cv. Granny Smith) were obtained from a local market. Peeled apples were cut into-disc-shaped samples $(5 \mathrm{~mm}$ thick, with a $65 \mathrm{~mm}$ external diameter and $20 \mathrm{~mm}$ internal diameter) following their vertical axis. Three samples were obtained from each apple and utilized for VI.

\subsection{Physicochemical characterization.}

Total soluble solids were measured in Brix units with a refractometer (ABBE ATAGO, NAR T3, Japan) at $20 \mathrm{oC}$ and $\mathrm{pH}$ values were determined with a potentiometer (micropH CRISON, 2001). Water activity was measured using a dewpoint hygrometer (DECAGÓN Aqualab CX-2, \pm 0.003 ) and the water content 
was quantified by vacuum drying at $60{ }^{\circ} \mathrm{C}$ until a constant weight was achieved (method 20.013, AOAC, 1980). The values stated are the average of three replicates.

\subsection{Flavonoids.}

To determine the contents of the flavonoids narirutin, hesperidin and didymin we followed the same procedure as described by Betoret et al. (2009). Briefly, fresh LPJ samples were centrifuged for $15 \mathrm{~min}$ at $1400 \mathrm{rpm}$ at $4{ }^{\circ} \mathrm{C}$ using a Meldifriger S.L. centrifuge. The supernatant was filtered using a Whatman $\mathrm{n} \mathbf{0} 1$ filter; $30 \mathrm{~mL}$ of each filtered sample was passed through a Sep-Pack C18 cartridge, and the cartridge was cleaned with $5 \mathrm{~mL}$ of water and eluted with $5 \mathrm{~mL}$ of water:acetonitrile ( $4: 6 \mathrm{v} / \mathrm{v})$. Next $250 \mathrm{~mL}$ of cumaric acid $(1 \mathrm{~g} / \mathrm{L})$ was added to the eluate. The resulting sample was filtered using an Albet nylon membrane filter with a pore diameter of $0.45 \mu \mathrm{m}$. Finally, a $1 \mathrm{~mL}$ aliquot was collected, and $5 \mu \mathrm{L}$ was injected into the HPLC system.

An Alliance 2996 chromatograph from Waters (Waters Co, Milford, Mass., USA) coupled to a diode array detector (DAD) was used. Separation was performed in a $250 \mathrm{~mm} \times 4.6 \mathrm{~mm}$ and $5 \mu \mathrm{m}$ Luna II C18 column from Phenomenex (Luna II, Phenomenex, Torrance, USA). A solution of water:tetrahydrofuran (98.75:1.25) (solvent A) and a solution of acetonitrile:tetrahydrofuran (98.75:1.25) (solvent B) were used for the mobile phase. The flow rate was $1 \mathrm{~mL} / \mathrm{min}$ and flavonoids were detected at a wavelength of $280 \mathrm{~nm}$. The values provided are the average of three replicates.

2.5 Determination and kinetic modelling of antiradical activity in juice by the DPPH method.

Slices of fresh apples, impregnated apples and impregnated plus dehydrated apples were separately freeze-dried by milling with liquid nitrogen using an IKA analytical mill (A 11 basic, IKA Werke GmbH \& Co. KG, Staufen, Germany). Two grams of powder from the fresh the impregnated plus dehydrated apples were weighed and extracted by adding $2 \mathrm{~mL}$ of $\mathrm{MeOH} /$ water (80:20), vortexed and homogenized during 5 consecutive cycles of $10 \mathrm{sec}$ at 20,000 rpm using an IKA DI 25 Basic dispersion unit (IKA Werke GmbH \& Co. KG, Staufen, Germany) at room temperature. Next the samples were centrifuged at $5000 \mathrm{rpm}$ for $5 \mathrm{~min}$ and the supernatants filtered through $0.45 \mu \mathrm{m}$ nylon filters. A set of cuvettes with different volumes $\left(\mathrm{V}_{\mathrm{o}}\right.$ between 10-70 $\mu \mathrm{l}$ ) of samples were prepared containing $1.9 \mathrm{ml}$ of DPPH in methanol, with additional methanol added to yield a final volume of $2 \mathrm{ml}$ (giving a final concentration of DPPH around $100 \mu \mathrm{mol} / \mathrm{L}$ ). Absorbance was measured using an Amersham 3300 pro spectrophotometer (Amersham Pharmacia Biotech, Cambridge, England), set at $515 \mathrm{~nm}$. Spectrophotometric quartz (3.5 mL capacity and $1 \mathrm{~cm}$ path-length) cuvettes were used. Six samples 
plus a blank were simultaneously analyzed at a sampling rate of one point per two minutes. Automatic acquisition of data was stopped after a reaction time of 90 minutes. All samples were extracted and analyzed in triplicate at room temperature.

To determine the antiradical capacity of the samples, a calibration curve of absorbance versus the concentration of DPPH. was obtained to determine the molar extinction coefficient $(\varepsilon)$ of the antiradical probe. This value was determined to be $1.12 \times 10^{4} \mathrm{~L} / \mathrm{mol}$.

The experimental data were fit using the theoretical kinetic model developed by Sentandreu et al. (2008). This model allows the accurate prediction of the asymptotic value of the reduction processes occurring in mixtures of antiradicals at intermediate times of reaction, from 60-90 minutes. The results correspond to averages of antiradical activities (such that total antiradical activity $=A_{t}$; cumulative ultra fast antiradical activity $=A_{1}$; cumulative fast activity $=A_{2}$; cumulative slow antiradical activities $=A_{3}$; and $A_{t}=A_{1}+A_{2}+A_{3}$ ). Experimental data were graphed using the software SigmaPlot 10.0.

\subsection{HPLC-ESI/ MS ${ }^{\mathrm{n}}$ analysis.}

The samples analyzed by LC-MS ${ }^{n}$ were aliquots of the same samples used in the antiradical activity determination.

Chromatographic separation and $\mathrm{MS}^{\mathrm{n}}$ conditions of analysis were the same as previously described by Betoret et al. (2012) except with the addition of a complementary MS ${ }^{\mathrm{n}}$ analysis. Briefly, chromatographic separation was carried out using a Thermo Surveyor Plus HPLC (Thermo Scientific, San José, CA, USA), equipped with a quaternary pump, vacuum degasser, temperature-controlled autosampler and temperature-controlled column oven. The column used was a $250 \mathrm{nn}$ x $2.1 \mathrm{~mm}$ i.d., $3 \mu \mathrm{m}$, YMC C-18 pack-pro (YMC Europe GmbH, Dinslaken, Germany). Chromatographic conditions were as follows: injection volume, $5 \mu \mathrm{L}$; flow rate, $0.2 \mathrm{~mL} / \mathrm{min}$; oven temperature, $24{ }^{\circ} \mathrm{C}$; autosampler temperature, $10{ }^{\circ} \mathrm{C}$; solvent A, water/ THF/ formic acid (97.9:2.0:0.1 v/v/v); solvent B, acetonitrile/ THF/ formic acid (97.9:2.0:0.1 v/ v/v); elution began with $0 \% \mathrm{~B}$, linear $0-45 \%$ B in 60 min, linear $45-100 \%$ B in 20 min, purging with 100\% B during 20 $\mathrm{min}$ and re-equilibration of the column for $40 \mathrm{~min}$.

In addition to using a data-dependent analysis with simultaneous MS, MS 2 and MS $^{3}$ analyses for each run (previously used to study Ortanique juices), the impregnated samples were also analyzed using a separate, neutral-loss triple play analysis. Thus, to study the components attached to sugar moieties, the neutral loss experiment had three scan events: full MS (scan event 1), MS2 of ions with neutral loss masses with $\mathrm{m} / \mathrm{z}$ 132, 146, 162, 308, and 324 (scan event 2) and MS3 of the most abundant ions generated in the scan event 2 (scan event 3 ). Separate injections were performed to study the presence of flavanols, listing in the neutral 
loss mass list of the scan event 2 the $\mathrm{m} / \mathrm{z} 272$ for (epi)afzelechins, m/ z 288 for (epi)catechins and m/ z 304 for (epi)gallocatechins.

\subsection{Production of enriched, dried apple.}

Figure 1 shows the flow chart of the process that was employed to produce enriched, dried apple slices.

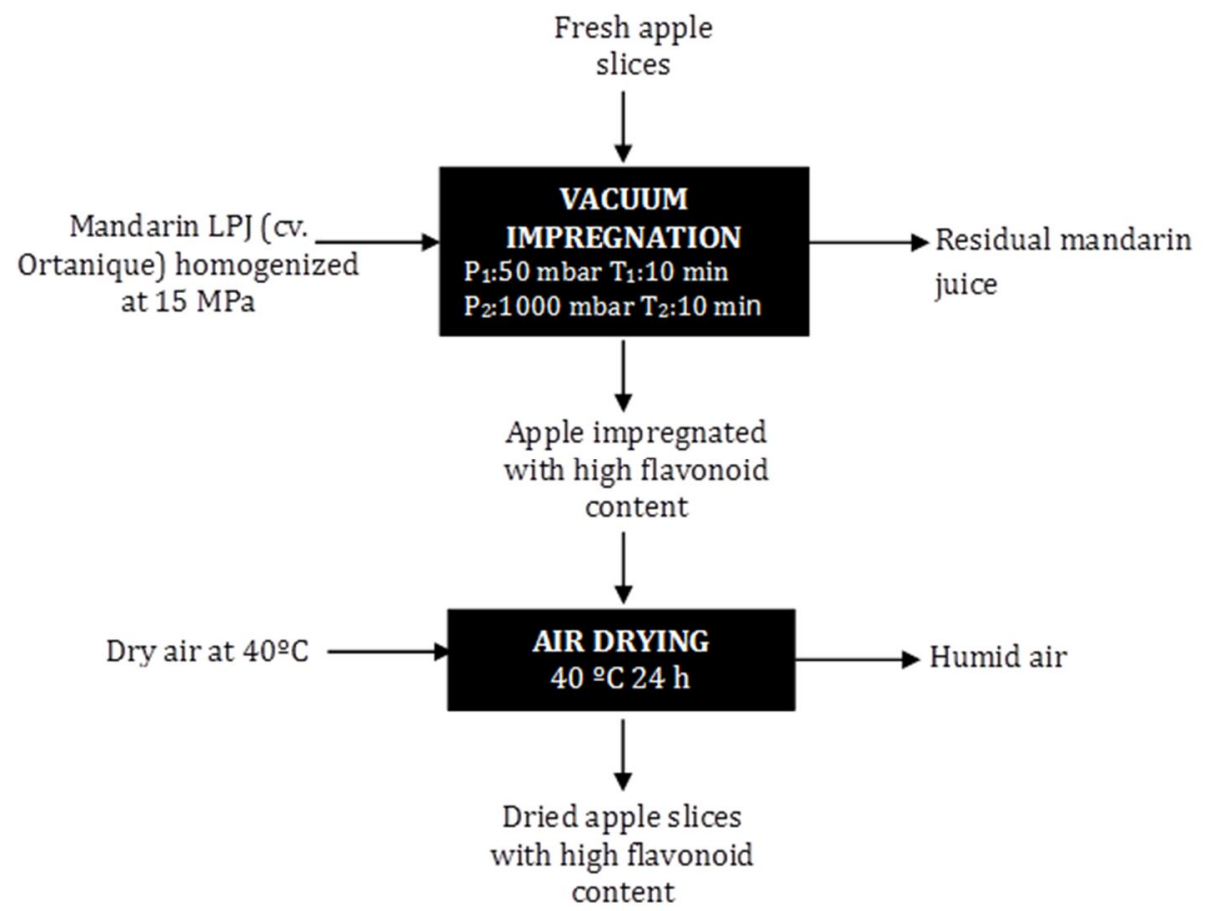

Figure 1. Production of flavonoid-enriched, dried apple slices.

The VI experiments were performed on a pilot scale using equipment designed in the Institute of Food Engineering for Development of the Polytechnic University in Valencia, Spain (Fito et al., 2001). A vacuum pressure of 50 mbar was applied for 10 min to the apple samples immersed in the mandarin LPJ and then the samples were homogenized at different pressures after which atmospheric pressure was restored. The samples were left submerged in the mandarin LPJ for a further 10 $\min$.

Impregnated apple samples were dried for $24 \mathrm{~h}$ using an air dryer ( $\mathrm{LIZ}^{\circledR}$, Construcciones mecánicas José Lizondo, Barcelona, España) at $40{ }^{\circ} \mathrm{C}$ under a flow rate of $4 \mathrm{~m} / \mathrm{s}$.

\subsection{Statistical analysis.}

To determine statistical significance analyses of variance tests were carried out (ANOVAs) with 95\% confidence levels (with significance determined by $\mathrm{p} \leq 0.05$ ) using the program STATGRAPHICS PLUS v.5.1. 


\section{RESULTS AND DISCUSSION.}

\subsection{Vacuum impregnation operation.}

The utility of VI for the production of apple slices enriched with mandarin LPJ requires that the LPJ can be introduced into the pores or intercellular spaces of the apple matrix. Thus the levels of cloud and particle size in the mandarin LPJ can affect the efficiency and the yield of the operation as well as the quality of the final product. The effect of homogenization pressures on functional properties of mandarin LPJ has been studied previously (Betoret et al., 2009; Betoret et al., 2012). Homogenization pressures from 0 to $30 \mathrm{MPa}$ reduce the particle size, increase the level of cloudiness, improve the colour and do not have negative effects on antiradical activity or functional compounds in the LPJ. Furthermore, it has been possible to quantify the volume of LPJ homogenized at different pressures that can be introduced into apples (Betoret et al., 2012) by following the experimental design described by Fito et al. (1996). Homogenization has also been used successfully for a subsequent VI operation, such that higher pressures led to greater incorporation of LPJ into the structural matrix of apple (Betoret et al., 2012).

VI is a mass transfer operation that takes place in a complex cellular and porous structure. A homogeneous VI means that all components of a substrate are incorporated equally. A non homogeneous impregnation may be due to instability of particles in the juice cloud. Furthermore, an unequal distribution of components can occur when local pressure gradients in the apple produce irregular flows of juice through the structure and consequently the beneficial components of the LPJ accumulate in some areas and are not distributed evenly although homogeneous impregnation has been achieved.

In our case, a homogeneous impregnation is required to be able to estimate the quantity of beneficial compounds introduced into the apple matrix by using the model developed by Fito et al. (1996).

One way to verify is the impregnation is homogeneous is to compare the flavonoid content in the residual LPJ after VI with that obtained before impregnation at each homogenization pressure. Table 1 shows the content of the three main flavonoids determined in fresh mandarin LPJ before VI (Betoret et al., 2009). Table 2 shows the content of the flavonoids in the residual mandarin LPJ after VI. Except for the non-homogenized LPJ, the flavonoid concentration in the residual juice was not different $(p \geq 0.05)$ to that obtained before impregnation and in these cases it can be assumed homogeneous impregnation was achieved. 
Table 1. Content of flavonoids in the fresh mandarin LPJ before vacuum impregnation (mean \pm

\begin{tabular}{|c|c|c|c|}
\hline $\begin{array}{c}\text { Homogenization } \\
\text { pressure (MPa) }\end{array}$ & $\begin{array}{c}\text { Narirutin } \\
(\mathrm{mg} / \mathrm{L})\end{array}$ & $\begin{array}{l}\text { Hesperidin } \\
\text { (mg/ L) }\end{array}$ & $\begin{array}{c}\text { Didymin } \\
\text { (mg/ L) }\end{array}$ \\
\hline 0 & $41.745 \pm 0.017 \mathrm{a}$ & $116.6 \pm 3.2^{\mathrm{a}}$ & $14.0 \pm 0.3^{a}$ \\
\hline 5 & $41.70 \pm 2.03^{a}$ & $121.4 \pm 5.9^{a}$ & $15.7 \pm 1.4^{\mathrm{a}}$ \\
\hline 10 & $41.94 \pm 1.12^{\mathrm{a}}$ & $115.7 \pm 1.9^{a}$ & $18.8 \pm 2.1^{\mathrm{a}}$ \\
\hline 15 & $43.60 \pm 0.16^{a}$ & $134.1 \pm 0.7 \mathrm{a}$ & $16.5 \pm 0.2^{\mathrm{a}}$ \\
\hline 20 & $47.1 \pm 1.4^{\mathrm{a}}$ & $112.7 \pm 1.8^{a}$ & $16.5 \pm 0.2^{\mathrm{a}}$ \\
\hline 25 & $46.7 \pm 1.4^{\mathrm{a}}$ & $79.9 \pm 1.9$ a & $14.2 \pm 0.5^{a}$ \\
\hline 30 & $50.57 \pm 2.3^{a}$ & $106.3 \pm 0.3^{a}$ & $16.437 \pm 0.108^{a}$ \\
\hline
\end{tabular}

$*$ Values with different superscript letters in a column are significantly different $(\mathrm{p} \leq 0.05)$.

Table 2. Content of flavonoids in the residual mandarin LPJ after vacuum impregnation (mean \pm standard deviation).

\begin{tabular}{cccc}
\hline $\begin{array}{c}\text { Homogenization } \\
\text { pressure (MPa) }\end{array}$ & $\begin{array}{c}\text { Narirutin } \\
(\mathbf{m g} / \mathbf{L})\end{array}$ & $\begin{array}{c}\text { Hesperidin } \\
(\mathbf{m g} / \mathbf{L})\end{array}$ & $\begin{array}{c}\text { Didymin } \\
(\mathbf{m g} / \mathbf{L})\end{array}$ \\
\hline $\mathbf{0}$ & $37.8 \pm 0.6^{\mathrm{b}}$ & $100.6 \pm 0.6^{\mathrm{b}}$ & $12.414 \pm 0.007^{\mathrm{b}}$ \\
$\mathbf{5}$ & $39.0 \pm 3.6^{\mathrm{a}}$ & $114.41 \pm 6.12^{\mathrm{a}}$ & $14.7 \pm 1.8^{\mathrm{a}}$ \\
$\mathbf{1 0}$ & $41.53 \pm 2.14^{\mathrm{a}}$ & $114.1 \pm 4.9^{\mathrm{a}}$ & $19.0 \pm 0.7^{\mathrm{a}}$ \\
$\mathbf{1 5}$ & $43.1 \pm 0.8^{\mathrm{a}}$ & $134.8 \pm 0.7^{\mathrm{a}}$ & $17.0 \pm 0.3^{\mathrm{a}}$ \\
$\mathbf{2 0}$ & $47.7 \pm 1.8^{\mathrm{a}}$ & $110.91 \pm 2.08^{\mathrm{a}}$ & $16.4 \pm 0.5^{\mathrm{a}}$ \\
$\mathbf{2 5}$ & $46.602 \pm 1.004^{\mathrm{a}}$ & $91.8 \pm 1.7^{\mathrm{a}}$ & $14.2 \pm 0.3^{\mathrm{a}}$ \\
$\mathbf{3 0}$ & $49.0 \pm 2.3^{\mathrm{a}}$ & $100.422 \pm 3.119^{\mathrm{a}}$ & $15.6 \pm 0.9^{\mathrm{a}}$ \\
\hline
\end{tabular}

*Values with ${ }^{\mathrm{b}}$ superscript are significantly different to those analysed before vacuum impregnation (Table 1) $(\mathrm{p} \leq 0.05)$.

Changes in flavonoid content were calculated using equation 1, for each homogenization pressure (Figure 2).

$$
\Delta \mathrm{M}=\left(\mathrm{m}_{\mathrm{f}}-\mathrm{m}_{0}\right) / \mathrm{m}_{0}
$$

Where: $\mathrm{m}_{\mathrm{f}}$ is the content of flavonoids in mandarin LPJ after $\mathrm{VI}(\mathrm{mg} / \mathrm{L})$; $\mathrm{m}_{0}$, is the content of flavonoids in mandarin LPJ before VI ( $\mathrm{mg} / \mathrm{L}$ ).

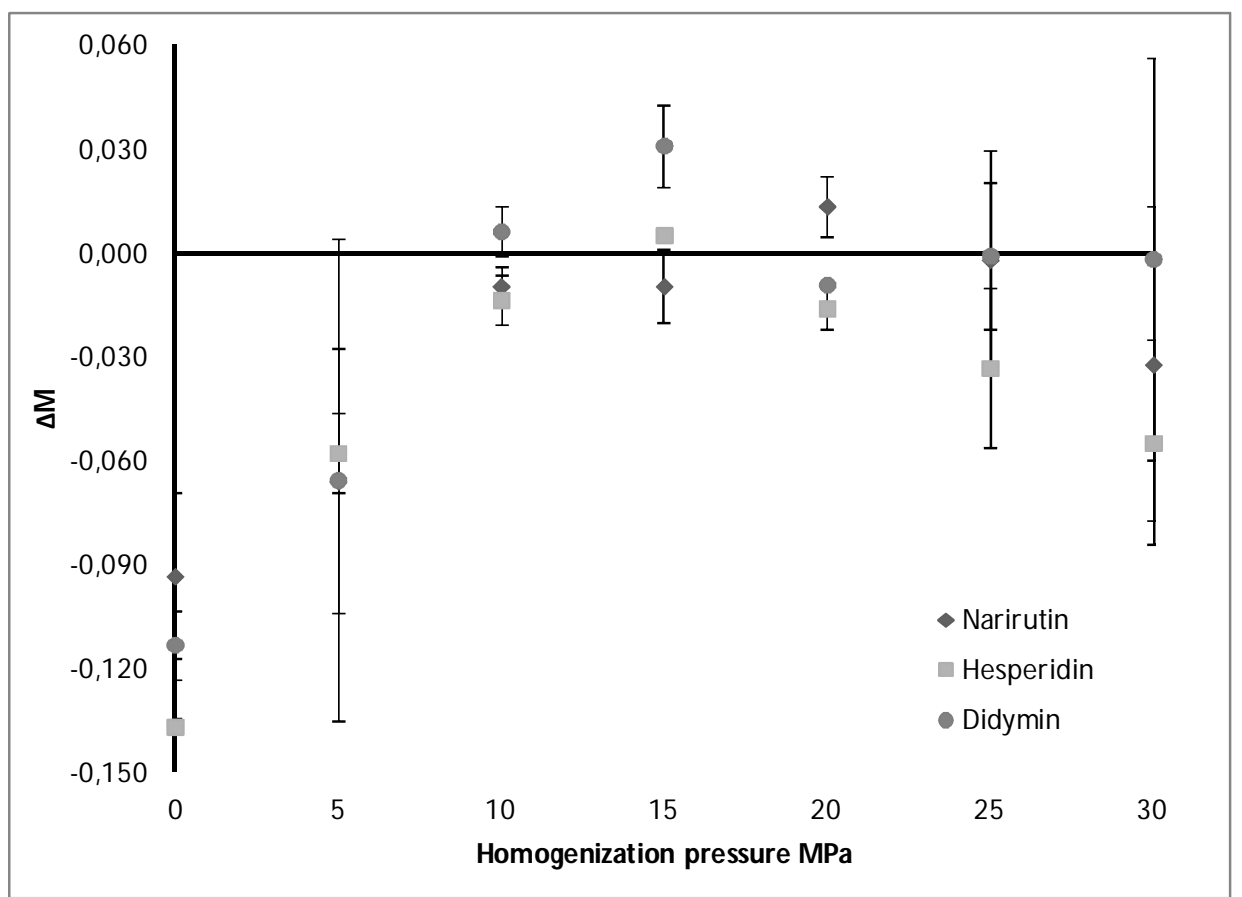

Figure 2a. Mass changes in narirutin, hesperidin and didymin calculated at each homogenization pressure. 


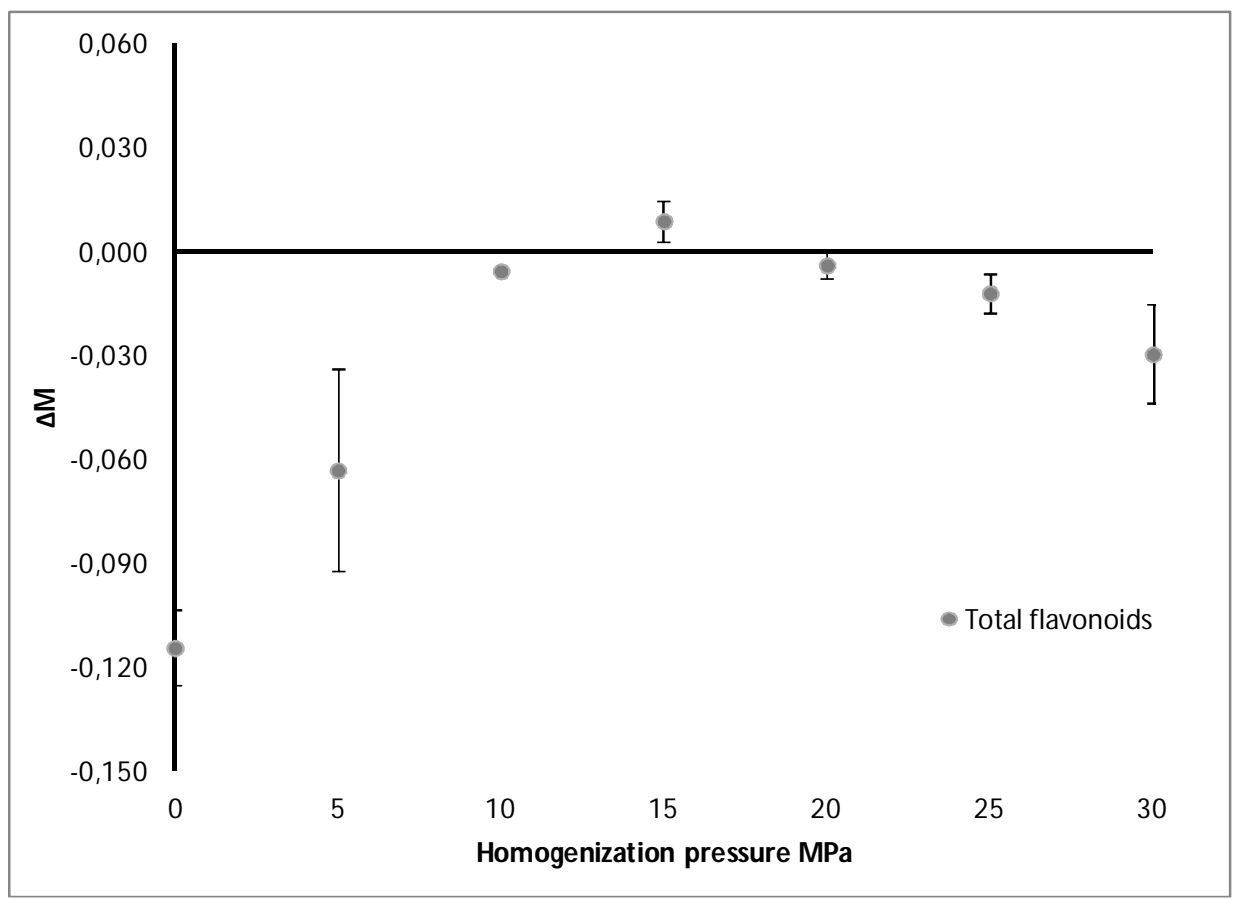

Figure 2b. Mass changes in total flavonoid content calculated at each homogenization pressure.

A value less than zero means the content of flavonoids after impregnation is smaller than that before $\mathrm{VI}$ and therefore the operation has not been homogeneous. There has been a flux of components into the apple matrix in a selective way. A value greater than zero means some components stay in the LPJ and are introduced into the apple. In this case the impregnation again cannot be considered as homogeneous. Values close to zero are expected when homogeneous VI has been achieved. As can be observed in the Figure 2, the three flavonoids are generally impregnated at the same level although higher pressures (25 and 30 $\mathrm{MPa}$ ) results in a less homogeneous impregnation of hesperidin. The nonhomogenized samples gave values far from zero and, as verified statistically, there were differences in the flavonoid content before and after VI. Samples homogenized at pressures of 5 and $30 \mathrm{MPa}$ showed mass changes, however in the statistical analysis no differences were observed probably due to high deviation in the values obtained. Intermediate homogenization pressures from 10 to $25 \mathrm{MPa}$ do not induce mass changes and therefore the impregnation can be considered homogeneous.

Once the impregnation is established as homogeneous, the quantity of functional components incorporated into the apple can be estimated using the content of LPJ functional components and the volume of mandarin LPJ introduced into the apple's structural matrix. 


\subsection{Estimation of flavonoid content.}

The model obtained by Fito et al. (1996) can be use to predict the beneficial compounds introduced in the structural matrix of a fruit or vegetable when impregnation is homogeneous. The model was developed by considering the structural properties of food matrices and the physicochemical characteristics of solutions. The water activity value of mandarin LPJ was similar to that of the apple that was impregnated. Therefore, it was expected that during the VI the only transfer mechanism would be hydrodynamic (Fito et al., 1996) and the characteristics of the fresh apple would not be highly altered. Following this model and using the values of volumetric impregnation (X) from Betoret et al. (2012), the flavonoid content ( $\mu g_{\text {flavonoid }} / g_{\text {impregnated }}$ ) in the impregnated apple was estimated theoretically (Equation 2, below).

$$
\mathrm{X}_{\mathrm{IVf}}=\left(\mathrm{x}_{\mathrm{mj}} \cdot \mathrm{X} \cdot\left(\rho_{\mathrm{mj}} / \rho_{\mathrm{ff}}\right)+\mathrm{X}_{\mathrm{ff}}\right) /\left(1+\mathrm{X} \cdot\left(\rho_{\mathrm{mj}} / \rho_{\mathrm{ff}}\right)\right)
$$

Where: X, volumetric impregnation $\left(\mathrm{cm}^{3} \cdot \mathrm{cm}^{-3}\right.$ sample); $\mathrm{x}$, flavonoids content ( $\mathrm{g} \cdot \mathrm{g}$

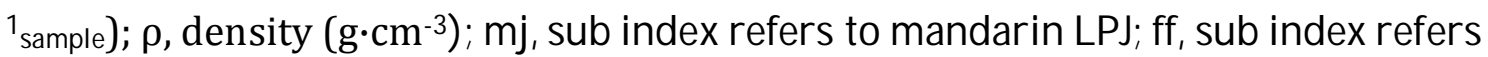
to fresh fruit; IVf, sub index refers to impregnated fruit.

The estimated narirutin, hesperidin and didymin in the impregnated apple are shown in Table 3.

Table 3. Content of flavonoids in the impregnated apple after vacuum impregnation (mean \pm standard deviation).

\begin{tabular}{cccc}
\hline $\begin{array}{c}\text { Homogenization } \\
\text { pressure (MPa) }\end{array}$ & $\begin{array}{c}\text { Narirutin } \\
\left(\mu \mathbf{g} / \mathbf{g}_{\text {impregnated }}\right)\end{array}$ & $\begin{array}{c}\text { Hesperidin } \\
\left(\mu \mathbf{g} / \mathbf{g}_{\text {impregnated }}\right)\end{array}$ & $\begin{array}{c}\text { Didymin } \\
\left(\mu \mathbf{g} / \mathbf{g}_{\text {impregnated }}\right)\end{array}$ \\
\hline $\mathbf{1 0}$ & $4.9 \pm 0.8^{\mathrm{a}, \mathrm{b}}$ & $13.5 \pm 2.4^{\mathrm{a}, \mathrm{b}}$ & $2.2 \pm 0.4^{\mathrm{b}}$ \\
$\mathbf{1 5}$ & $6.6 \pm 0.8^{\mathrm{c}}$ & $20.4 \pm 2.5^{\mathrm{d}}$ & $2.5 \pm 0.3^{\mathrm{c}}$ \\
$\mathbf{2 0}$ & $5.7 \pm 0.4^{\mathrm{b}, \mathrm{c}}$ & $13.6 \pm 0.9^{\mathrm{a}, \mathrm{c}}$ & $2.00 \pm 0.13^{\mathrm{b}}$ \\
$\mathbf{2 5}$ & $6.5 \pm 0.8^{\mathrm{c}}$ & $11.0 \pm 1.3^{\mathrm{a}, \mathrm{b}}$ & $2.0 \pm 0.2^{\mathrm{b}}$ \\
\hline
\end{tabular}

Hesperidin, narirutin and didymin content in dried apple were estimated by mass balances (Betoret et al., 2011b) and are shown in Table 4.

Table 4. Content of flavonoids in the dehydrated apple (mean \pm standard deviation).

\begin{tabular}{|c|c|c|c|}
\hline $\begin{array}{c}\text { Homogenization } \\
\text { pressure (MPa) }\end{array}$ & $\begin{array}{l}\text { Narirutin } \\
\left(\mu \mathrm{g} / \mathrm{g}_{\text {dried }}\right)\end{array}$ & $\begin{array}{c}\text { Hesperidin } \\
\left(\mu \mathrm{g} / \mathrm{g}_{\text {dried }}\right)\end{array}$ & $\begin{array}{c}\text { Didymin } \\
\left(\mu \mathrm{g} / \mathrm{g}_{\text {dried }}\right)\end{array}$ \\
\hline 10 & $29.9 \pm 5.2^{\mathrm{a}, \mathrm{b}}$ & $82.5 \pm 14.4^{\mathrm{a}, \mathrm{b}}$ & $13.4 \pm 2.3^{3}$ \\
\hline 15 & $40.4 \pm 5.0^{c}$ & $124.3 \pm 15.4^{\mathrm{d}}$ & $15.3 \pm 1.9$ \\
\hline 20 & $34.8 \pm 2.2^{b, c}$ & $83.3 \pm 5.4^{\mathrm{b}, \mathrm{c}}$ & $12.2 \pm 0.8^{1}$ \\
\hline 25 & $39.4 \pm 4.8^{c}$ & $67.4 \pm 8.2^{\mathrm{a}, \mathrm{b}}$ & $12.0 \pm 1.5^{\mathrm{t}}$ \\
\hline
\end{tabular}

*Values with different superscript in a column are significantly different $(\mathrm{p} \leq 0.05)$.

We found that air drying the impregnated apple slices at $40^{\circ} \mathrm{C}$ did not affect the flavonoid content. This agrees with Dhuique-Mayer et al. (2007), who showed that hesperidin has a very high thermal stability, and observed no significant losses of this flavonoid with heat treatment at $90{ }^{\circ} \mathrm{C}$ during $240 \mathrm{~min}$. 
The combination of VI and air drying allows for the development of a potential snack food consisting of dried apple slices that are rich in flavonoids from mandarin juice. Previous studies have demonstrated the consumption of $500 \mathrm{~mL}$ mandarin juice for 4 weeks exerts a significant, positive effect on oxidation biomarkers and enhances the antioxidant defenses of hypercholesterolemic children (Codoñer-Franch et al., 2008; Codoñer-Franch et al., 2010). Taking into account the product developed can be packed in portions of 40 grams, 40 grams of our product using mandarin juice homogenized at $15 \mathrm{MPa}$ could provide the same quantity of hesperidin as $250 \mathrm{~mL}$ of mandarin juice (Table 5).

Table 5. Total dry product required to provide the same amount of flavonoids included in $500 \mathrm{~mL}$ of mandarin juice.

\begin{tabular}{cccc}
\hline $\begin{array}{c}\text { Homogenization } \\
\text { pressure (MPa) }\end{array}$ & $\begin{array}{c}\text { Narirutin } \\
\text { (gdried product) }\end{array}$ & $\begin{array}{c}\text { Hesperidin } \\
\text { (gdried_product) }\end{array}$ & $\begin{array}{c}\text { Didymin } \\
\text { (gdried_product) }\end{array}$ \\
\hline $\mathbf{1 0}$ & 176 & 121 & 21.3 \\
$\mathbf{1 5}$ & 130 & 80 & 18.6 \\
$\mathbf{2 0}$ & 151 & 119 & 23.3 \\
$\mathbf{2 5}$ & 134 & 148 & 23.8 \\
\hline
\end{tabular}

3.3 Effects of processing on the functional properties of the apple snack.

The mandarin LPJ samples which allowed a homogeneous impregnation were the samples homogenized at 10,15, 20 and $25 \mathrm{MPa}$. We chose to use the mandarin LPJ homogenized at $15 \mathrm{MPa}$ and developed an impregnated apple snack for which the physicochemical and functional properties were determined. The physicochemical characteristics determined in the samples at each stage of the process are shown in Table 6. As expected, VI did not significantly alter the characteristics of the fresh apple. However, the high values of water activity in the impregnated apples made them highly unstable. Fortunately, after hot air drying, the resulting low value obtained for water activity does not permit the growth of fungi or other harmful microorganisms for at least two weeks when stored at room temperature (Betoret et al., 2003).

Table 6. Physicochemical characteristics of fresh, impregnated and dried apple slices (mean \pm standard deviation).

\begin{tabular}{cccc}
\hline & Brix & $\mathbf{a}_{\mathbf{w}}$ & $\begin{array}{c}\text { Moisture content } \\
\left(\mathbf{g}_{\text {water }} \cdot \mathbf{g}^{-1} \text { sample) }\right.\end{array}$ \\
\hline Mandarin juice & $12.67 \pm 0.06$ & $0.987 \pm 0.002$ & $0.865 \pm 0.002$ \\
Fresh apple & $12.4 \pm 0.4$ & $0.9837 \pm 0.0006$ & $0.8497 \pm 0.0009$ \\
$\begin{array}{c}\text { Impregnated apple } \\
\text { Impregnated dried }\end{array}$ & $12.57 \pm 0.15$ & $0.98 \pm 0.02$ & $0.850 \pm 0.004$ \\
apple & - & $0.501 \pm 0.002$ & $0.144 \pm 0.012$ \\
\hline
\end{tabular}

Free radical-induced oxidative damage is strongly implicated in the development of a number of common chronic disease states (Ames et al., 1995; Diplock, 1998), and many of the health benefits associated with consumption of vegetables and fruits have been linked to their potent antioxidant properties (Halliwell et al., 2005). It was reported that oxidative stress, which occurs when 
free radical formation exceeds the body's ability to protect itself, forms the biological basis of chronic conditions, such as arteriosclerosis (Briones-Labarca et al., 2011).

The antiradical activity of the apple slices at each stage of the process is shown in Table 7. As explained in the materials and method section, the model proposed by Sentandreu et al. (2008) was used to determine the antiradical activity of the different samples. In this model, the antiradical activity $\left(\mathrm{A}_{\mathrm{t}}\right)$ of a natural extract is the sum of three individual activities corresponding to the antiradical kinetics of the bioactive compounds involved in the reaction.

Table 7. Total and partial antiradical activities of apple slices (mean \pm standard deviation).

\begin{tabular}{lcccc}
\hline & $\mathbf{A}_{\mathbf{t}}$ & $\mathbf{A}_{\mathbf{1}}$ & $\mathbf{A}_{\mathbf{2}}$ & $\mathbf{A}_{\mathbf{3}}$ \\
\hline $\begin{array}{l}\text { Fresh apple } \\
\text { Impregnated }\end{array}$ & $0.151 \pm 0.009$ & $0.034 \pm 0.002$ & $0.029 \pm 0.002$ & $0.088 \pm 0.005$ \\
$\begin{array}{l}\text { apple } \\
\begin{array}{l}\text { Impregnated } \\
\text { dried apple }\end{array}\end{array}$ & $0.171 \pm 0.005$ & $0.0363 \pm 0.0014$ & $0.033 \pm 0.002$ & $0.101 \pm 0.003$ \\
\hline
\end{tabular}

Results expressed as $\mu \mathrm{g}$ ascorbic acid/mg of freeze dried powder.

As shown in Table 7, the impregnation of apple slices, whether fresh or dried, with mandarin juice resulted in increased antiradical capacities mainly due to the incorporation of citrus antiradicals. Although all type of antiradical activities were improved, impregnation especially increased the slow antiradical activity. The ultra fast and fast antiradical activities were partially affected by ascorbic acid and phenolics with free p-catechol groups, respectively. In all cases, impregnation seems to be very useful for the incorporation of functional components into a porous structure to obtain a more stable and healthy product, thanks to the increased antiradical properties. This is important because products made in this way would be protected against oxidative processes during their manufacturing and storage periods (Blanda et al., 2008) and additionally; they could promote antioxidant responses in humans after their consumption. The increase in antiradical activity in the impregnated, dried samples can also be explained by taking into account that heat applied during the dehydration process is the main cause of the depletion of antioxidant compounds, but heat can also induce the formation of compounds, such as melanoidins in the Maillard reaction, which can contribute to antioxidant activity (Nicoli et al., 1997; Anese et al., 1999). Moreover, heat can increase the level of free flavonols which have antioxidant activity (Stewart et al., 2000).

Table 8 shows the composition of impregnated apple extracts, both fresh and dried, which indicates that only ascorbic acid and chlorogenic acid are present in both mandarin juice and apple varieties. The bioactive metabolites were classified according to their in vitro antiradical activity kinetics, as reported by Betoret et al. (2012) which includes a full description of the components of Ortanique juice. Under in vivo conditions and due to metabolic processes, some apple compounds turn active, such as compound number 2 which changes from no activity to slow 
kinetic activity due to the regeneration of the free hydroxyl group of the coumaric acid aglycon after deglycosilation. Meanwhile, compound number 3 changes from no activity to fast+slow antiradical activity due to the regeneration of the free $\mathrm{p}$ catechol group of the ferulic acid aglycon by demethylation and deglycosilation processes. Interestingly, apple components with just slow antiradical kinetics (compounds 22, 24, 27, 29 and 31) show constant activity constant after metabolization because only free hydroxyl groups are regenerated.

Table 8. Antiradicals identified in the impregnated apple samples.

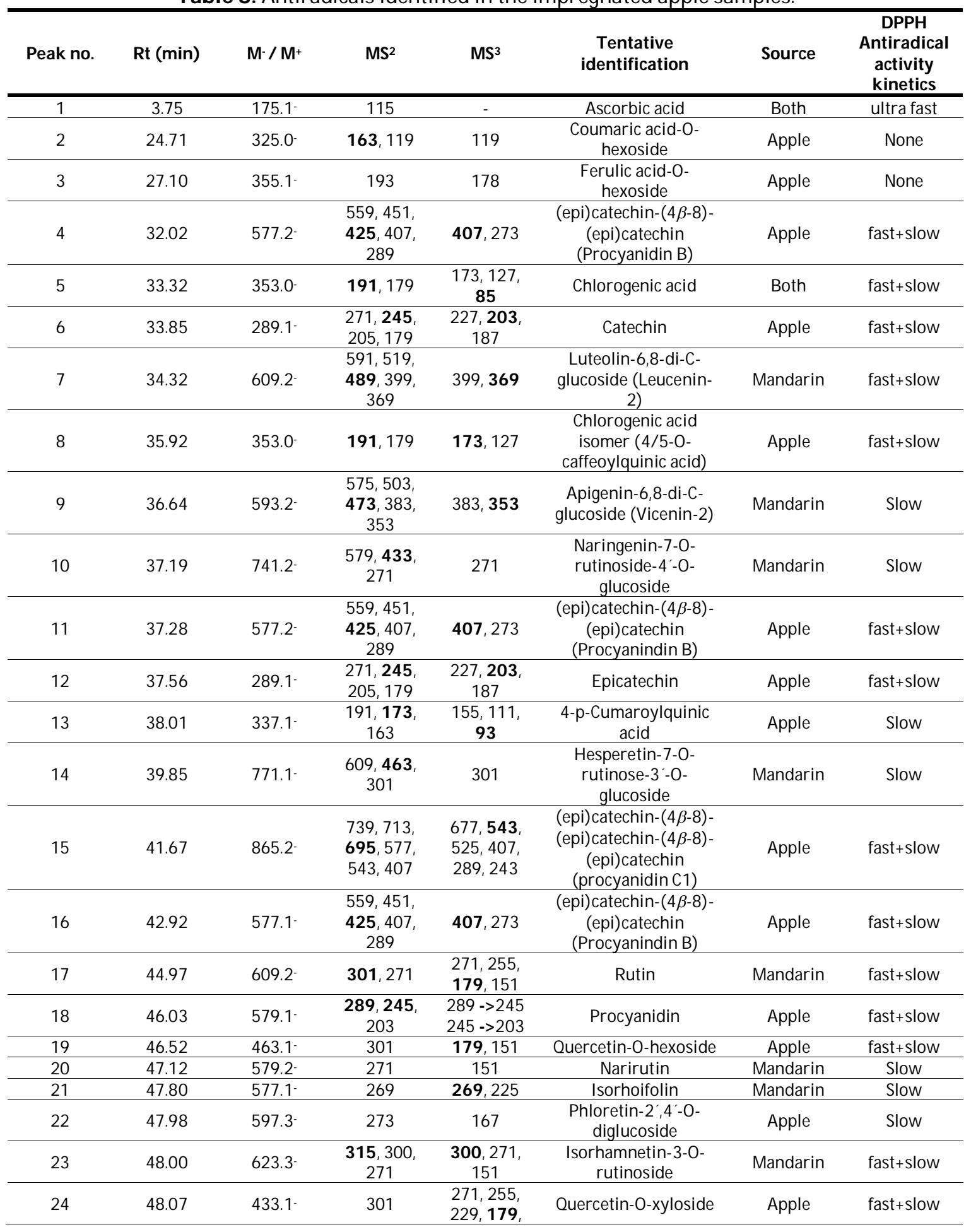




\begin{tabular}{|c|c|c|c|c|c|c|c|}
\hline & & & & 151 & & & \\
\hline 25 & 48.34 & $479.0^{+}$ & 317 & 317 & $\begin{array}{l}\text { Isorhamnetin-O- } \\
\text { hexoside }\end{array}$ & Mandarin & Slow \\
\hline 26 & 48.55 & $609.2^{-}$ & 301 & $\begin{array}{c}\mathbf{2 8 6}, 283 \\
242,199 \\
125\end{array}$ & Hesperidin & Mandarin & Slow \\
\hline 27 & 49.59 & 567.3 & 273,167 & 167 & $\begin{array}{l}\text { Phloretin-2'-0- } \\
\text { xylohexoside }\end{array}$ & Apple & Slow \\
\hline 28 & 49.64 & 433.1- & 301 & $\begin{array}{c}271,255, \\
229,179, \\
151\end{array}$ & $\begin{array}{l}\text { Quercetin-3-O- } \\
\text { pentoside }\end{array}$ & Apple & fast-slow \\
\hline 29 & 50.17 & 567.3 & 273,167 & 167 & $\begin{array}{l}\text { Phloretin-2'-0- } \\
\text { xylohexoside }\end{array}$ & Apple & Slow \\
\hline 30 & 50.26 & $447.2^{-}$ & 301 & $\begin{array}{c}271,255, \\
229,179, \\
151\end{array}$ & $\begin{array}{l}\text { Quercetin-3-O- } \\
\text { rhamnoside }\end{array}$ & Apple & fast+slow \\
\hline 31 & 53.41 & $435.1^{-}$ & 273, 167 & 167 & Phloridzin & Apple & Slow \\
\hline 32 & 56.99 & 593.2 & 285 & $\mathbf{2 8 5}, 243$ & Didymin & Mandarin & Slow \\
\hline 33 & 65.91 & $373.2^{+}$ & 358,343 & 343 & Isosinensetin & Mandarin & None \\
\hline 34 & 70.51 & $373.2^{+}$ & $\begin{array}{l}\mathbf{3 5 8}, 343, \\
329,312\end{array}$ & $\begin{array}{c}343,329, \\
\mathbf{3 1 2}\end{array}$ & Sinensetin & Mandarin & None \\
\hline 35 & 71.71 & $343.2^{+}$ & 328,313 & 313 & $\begin{array}{l}\text { Tetramethyl-O- } \\
\text { isoscutellarein }\end{array}$ & Mandarin & None \\
\hline 36 & 73.41 & $403.2^{+}$ & 388, 373 & 373 & $\begin{array}{l}\text { Hexamethyl-O- } \\
\text { quercetagetin }\end{array}$ & Mandarin & None \\
\hline 37 & 75.08 & $403.2^{+}$ & 388, 373 & 373 & Nobiletin & Mandarin & None \\
\hline 38 & 75.80 & $343.2^{+}$ & $\begin{array}{l}\text { 328, 313, } \\
299,282\end{array}$ & 299, 282 & $\begin{array}{c}\text { Tetramethyl-O- } \\
\text { scutellarein }\end{array}$ & Mandarin & None \\
\hline 39 & 76.84 & $433.1^{+}$ & 418, 403 & 403 & Heptamethoxyflavone & Mandarin & None \\
\hline 40 & 78.28 & $373.2^{+}$ & $\mathbf{3 5 8}, 343$ & 343 & Tangeretin & Mandarin & None \\
\hline
\end{tabular}

\section{CONCLUSIONS.}

The bioactive compounds of mandarin LPJ have successfully been incorporated into the structural matrix of fresh apple slices with no negative effects on their antiradical capacities following impregnation and air drying. Such incorporation is reflected in the increase of the compositional complexity of the impregnated apples where the components of the mandarin juice are added to those of the apple alone, as well as in their improved antiradical capacities when compared to fresh apple extracts, demonstrating their potential interest as a commercial functional food product.

\section{ACKNOWLEDGEMENTS.}

The authors acknowledge the Ministerio de Ciencia e Innovación of Spain for its contribution through projects AGL2009-09905 and PET2008_0015.

\section{REFERENCES.}

Ames, B. N., Gold, L. S., and Willett, W. C. The causes and prevention of cancer. Proceedings of the National Academy of Sciences of the United States of America 92 (1995), pp. 5258-5265. 
Anese, M., Manzocco, L., Nicoli, M. C., and Lerici, C. R. Antioxidant properties of tomato juice as affected by heating, Journal of Agricultural and Food Chemistry 79 (1999), pp. 750-754.

AOAC. (1980). Association of official analytical chemists. Official Methods of analysis, 20.013. Washington DC.

Baghurst, K. (2003). The health benefits of citrus juices. CSIRO, Health Sciences and Nutrition. Sydney NSW 2000.

Barrera, C., Betoret, N., and Fito, P. Ca2+ and Fe2+ influence on the osmotic dehydration kinetics of apple slices (var. Granny Smith). Journal of Food Engineering 65 (2004), pp. 9-14.

Betoret, N., Puente, L., Díaz, M. J., Pagán, M. J., García, M. J., Gras, M. L., MartínezMonzó, J., and Fito, P. Development of probiotic-enriched dried fruits by vacuum impregnation. Journal of Food Engineering 56 (2003), pp. 273-277.

Betoret, E., Betoret, N., Carbonell, J. V., and Fito, P. Effects of pressure homogenization on particle size and the functional properties of citrus juices. Journal of Food Engineering 92 (2009), pp. 18-23.

Betoret, E., Betoret, N., Vidal, D., and Fito, P. Functional foods development: Trends and technologies. Trends in Food Science \& Technology 22 (2011a), pp. 498-508.

Betoret, E., Betoret, N., Arilla, A., Bennár, M., Barrera, C., Codoñer, P., and Fito, P. Non invasive methodology to produce a probiotic low humid apple snack with potential effect against Helicobacter pylori. Journal of Food Engineering (2011b), doi:10.1016/j.jfoodeng.2011.04.027.

Betoret, E., Sentandreu, E., Betoret, N., and Fito, P. Homogenization pressures applied to citrus juices manufacturing. Functional properties and application. Journal of Food Engineering (2012), doi:10.1016/j.jfoodeng.2012.01.035.

Blanda, G., Cerretani, L., Bendini, A., Cardinali, A., Scarpellini, A., and Lercker, G. Effect of vacuum impregnation on the phenolic content of Granny Smith and Stark Delicious frozen apple cvv. European Food Research and Technology 226 (2008), pp. 1229-1237.

Block, G., Patterson, B., and Subar, A. Fruits, vegetables and cancer prevention: a review of the epidemiological evidence. Nutrition and cancer-An International Journal 18 (1992), pp. 1-29.

Boyer, J., and Liu, R. H. Apple phytochemicals and their health benefits. Nutrition Journal 3 (2004), pp. 1-15.

Briones-Labarca, V., Venegas-Cubillos, G., Ortiz-Portilla, S., Chacana-Ojeda, M., and Maureira, H. Effects of high hydrostatic pressure (HHP) on bioaccessibility, as well as antioxidant activity, mineral and starch contents in Granny Smith apple. Food Chemistry 128 (2011), pp. 520-529.

Codoñer-Franch, P., López-Jaén, A. B., Muñiz, P., Sentrandreu, E., and Valls-Bellés, V. Mandarin Juice Improves the Antioxidant Status of Hypercholesterolemic Children. Journal of Pediatric Gastroenterology and Nutrition 47 (2008), pp. 349-355. 
Codoñer-Franch, P., López-Jaén, A. B., de la Mano-Hernández, A., Sentrandreu, E., Simó-Jordá, R., and Valls-Bellés, V. Oxidative markers in children with severe obesity following low-calorie diets supplemented with mandarin juice. Acta Paediatrica 99 (2010), pp. 1841-1846.

Cortés, M., Osorio, A., and García, E. Air dried apple fortified with vitamin e using matrix engineering. VITAE, Revista de la Facultad de Química Farmacéutica 14 (2007), pp. 17-26.

Day, L., Seymour, R. B., Pitts, K. F., Konczak, I., and Lundin, L. Incorporation of functional ingredients into foods. Trends in Food Science \& Technology 20 (2009), pp. 388-395.

Dhuique-Mayer, C., Tbatou, M., Carail, M., Caris-Veyrat, C., Dornier, M., and Amiot, M. J. Thermal degradation of antioxidants micronutrients in citrus juice. Kinetics and newly formed compounds. Journal of Agricultural and Food Chemistry 55 (2007), pp. 4209-4216.

Diplock, A. T., Charleux, J. L., Crozier-Willi, G., Kok, F. J., Rice-Evans, C., and Roberfroid, M. Functional food science and defence against reactive oxidative species. British Journal of Nutrition 80 (1998), pp. S77-S112.

Fito, P., Andrés, A., Chiralt, A., and Pardo, P. Coupling of hydrodynamic mechanism and deformation relaxation phenomena during vacuum treatments in solid porous food-liquid systems. Journal of Food Engineering 27 (1996), pp. 229240.

Fito, P., Chiralt, A., Betoret, N., Gras, M. L., Cháfer, M., Martínez-Monzó, J., Andrés, A., and Vidal, D. Vacuum impregnation and osmotic deshydratation in matrix engineering. Application in functional fresh food development. Journal of Food Engineering 49 (2001), pp. 175-183.

Gras, M. L., Vidal, D., Betoret, N., Chiralt, A., and Fito, P. Calcium fortification of vegetables by vacuum impregnation. Journal of Food Engineering 56 (2003), pp. 279-284.

Halliwell, B., Rafter, J., and Jenner, A. Health promotion by flavonoids, tocopherols, tocotrienols, and other phenols: Direct or indirect effects? Antioxidant or not? American Journal of Clinical Nutrition 81 (2005), pp. 268S-276S.

Jones, P. J., and Jew, S. Functional food development: concept to reality. Trends in Food Science and Technology 18 (2007), pp.387-390.

McCann, M. J., Gill, C. I. R., O’Brien, G., Rao, J. R., McRoberts, W. C., Hughes, P., McEntee, R., and Rowland, I. R. Anti-cancer properties of phenolics from Apple waste on colon carcinogenesis in vitro. Food and Chemical Toxicology 45 (2007), pp. 224-1230.

Nicoli, M. C., Anese, M., Parpinel, M. T., Franceschi, S., Lerici, C. R. Study on loss and/ or formation of antioxidants in food during processing and storage. Cancer Letters 11 (1997), pp. 71-74.

Rouseff, R. L., and Nagy, S. Health and nutritional benefits of citrus fruits components. Food Technology 48 (1994), pp. 125-132. 
Sanchez-Moreno, C., Cano, M. P., de Ancos, B., Plaza, L., Olmedilla, B., Granado, F., and Martín, A. Effect of orange juice intake on Vitamin $\mathrm{C}$ concentrations and biomarkers of antioxidant status in humans. American Journal of Clinical Nutrition 78 (2003), pp.454-460.

Sentandreu, E. Determinación de la actividad antirradical de zumos cítricos y caracterización de zumos de mandarina en función de su contenido en flavonoides y de su actividad antirradical. Doctoral Thesis. Consejo Superior de Investigaciones Científicas Instituto de Agroquímica y Tecnología de Alimentos. (2006).

Sentandreu, E., Navarro, J. L., and Sendra, J. M. Reduction kinetics of the antiradical probe 2,2-Diphenyl-1-picrylhydrazyl in methanol and acetonitrile by the antiradical activity of protocatechuic acid and protocatechuic acid methyl ester. Journal of Agricultural and Food Chemistry 56 (2008), pp. 4928-4936.

So, F. V., Guthrie, N., Chambers, A. F., Moussa, M., and Carroll, K. K. Inhibition of human breast cancer cell proliferation and delay of mammary tumorigenesis by flavonoids and citrus juices. Nutrition and Cancer 262 (1996), pp. 167-181.

Steinmetz, K. A., and Potter, J. D. Vegetables, fruit and cancer prevention: a review. Journal of the American Dietetic Association 53 (1996), pp. 536-543.

Stewart, A. J., Bozonnet, S., Mullen, W., Jenkins, G. I., Michael, E. J., Crozier, A. Occurrence of flavonols in tomatoes and tomato-based products. Journal of Agricultural and Food Chemistry 48 (2000), pp. 2663-2669.

Suárez-Jacobo, A., Rüfer, C. E., Gervilla, R., Guamis, B., Roig-Sagués, A. X., and Saldo, $\mathrm{J}$. Influence of ultra-high pressure homogenisation on antioxidant capacity, polyphenol and vitamin content of clear apple juice. Food Chemistry 127 (2011), pp. 447-454.

Xie, J., and Zhao, Y. Nutritional enrichment of fresh apple (Royal Gala) by vacuum impregnation. International Journal of Food Science and Nutrition 54 (2003a), pp. 387-398.

Xie, J., and Zhao, Y. Improvement of physicochemical and nutritional qualities of frozen Marionberry by vacuum impregnation pretreatment with cryoprotectants and minerals. Journal of Horticultural Science and Biotechnology 78 (2003b), pp. 248-253.

Watanabe, Y., Yoshimoto, K., Okada, Y., and Nomura, M. Effect of impregnation using sucrose solution on stability of anthocyanin in strawberry jam. LWT Food Science and Technology 44 (2011), pp. 891-895. 
Desarrollo tecnológico y valoración funcional de aperitivos de manzana y zumo de mandarina 
*Nota al lector: Los resultados presentados a continuación son resultados complementarios al desarrollo de un alimento funcional enriquecido con zumo de mandarina y con alto contenido en flavonoides. Estos resultados se encuentran pendientes de publicación.

\title{
Efecto de diferentes técnicas y condiciones de deshidratación sobre las propiedades ópticas y mecánicas de un alimento funcional de manzana de baja humedad enriquecido con zumo de mandarina. Análisis sensorial.
}

\begin{abstract}
Resumen
Se ha desarrollado un alimento funcional a base de manzana y zumo de mandarina utilizando para ello la técnica de impregnación a vacío. Para estabilizar el alimento funcional se han utilizado diferentes condiciones y técnicas de deshidratación. Concretamente se ha utilizado el secado por aire caliente a $40{ }^{\circ} \mathrm{C}$ y $70{ }^{\circ} \mathrm{C}$ y la liofilización durante 12 y 24 horas. En los diferentes productos desarrollados se han determinado las propiedades ópticas y mecánicas y se ha estudiado su evolución a lo largo del proceso de fabricación. Para completar el estudio se ha llevado a cabo una prueba sensorial con el fin de evaluar el grado de aceptación de los diferentes productos por parte del consumidor. La operación de liofilización ha permitido obtener productos de menor contenido en agua, más crujientes y de color más parecido a la manzana fresca, mientras que el secado por aire caliente ha permitido obtener productos menos crujientes y de un color más anaranjado. De forma global la preferencia de los consumidores hacia los productos funcionales desarrollados fue de mayor a menor y clasificándolas mediante el método de deshidratación: liofilización 24 horas > secado por aire caliente $40^{\circ} \mathrm{C}>$ secado por aire caliente $70^{\circ} \mathrm{C}>$ liofilización 12 horas.
\end{abstract}

Palabras clave: alimento funcional, zumo de mandarina, secado por aire caliente, liofilización

\section{INTRODUCCION}

En los últimos años se ha incrementado el interés por los alimentos funcionales naturales a los que se les ha aumentado el contenido de compuestos que ya estaban presentes en la composición natural del mismo (Spence, 2006). A este respecto han adquirido una gran importancia los compuestos fenólicos presentes en las frutas y hortalizas.

De forma específica, los zumos de cítricos contienen una gran variedad de componentes que exhiben actividades antioxidante y antirradical, tales como el ácido ascórbico (Johnston y Bowling, 2002), los flavonoides (Sendra et al., 1988), los carotenoides (Goodner et al., 2001), las antocianinas (sólo en zumos de variedades pigmentadas) (Rapisarda et al., 2000), y los derivados del ácido cinámico (Robards y Antolovich, 1995), entre otros. De todos los componentes de los cítricos con actividad antioxidante y antirradical, los flavonoides son los más estudiados. Su actividad ha sido demostrada tanto in vitro como in vivo (Bocco et al., 1998; Rapisarda et al., 1999; Burda y Oleszek, 2001; Vinson et al., 2002), por lo que puede afirmarse que exhiben importantes propiedades relacionadas con la salud, tales como antimicrobiana (Bylka et al., 2004), anticancerígena (BenaventeGarcia et al., 1997; Kohno et al., 2001), protección frente a enfermedades coronarias (Hollman et al., 1996) y antiagregación de plaquetas (Middleton et al., 2000). Además es importante hacer énfasis en el hecho de que no se ha descrito ningún efecto fisiológico adverso como consecuencia de la ingesta de este tipo de compuestos. 
La hesperidina es el flavonoide más abundante del zumo de mandarina. Se ha demostrado que es capaz de inhibir el cáncer de mama (So et al., 1996), de vejiga (Yang et al., 1997) y de colon (Tanaka et al., 1997; Miyagi et al., 2000) inducido químicamente en animales de laboratorio. Posee actividad antioxidante y parece ser que también actúa sobre el metabolismo de los lípidos.

En esta tesis doctoral se ha aplicado la metodología de impregnación a vacío para el desarrollo de un producto con elevado contenido en zumo de mandarina, y por tanto en antioxidantes naturales, con potencial para disminuir el estrés oxidativo y/ o aumentar las defensas antioxidantes, destinado a niños obesos con riesgo de padecer patologías en la edad adulta. Se trata de un producto desarrollado por incorporación de zumo de mandarina en el interior de la estructura matricial de manzana fresca. Con el fin de incorporar a la estructura matricial de la manzana la mayor cantidad posible de componentes fisiológicamente activos y desarrollar un producto de alta calidad que conserve las características sensoriales del zumo de mandarina se han llevado a cabo estudios que han permitido establecer las condiciones de extracción óptimas. Más concretamente, se ha estudiado el efecto de la operación de homogeneización sobre las propiedades fisicoquímicas y funcionales del zumo, analizando su efecto sobre la operación de impregnación a vacío. Para estabilizar el producto, las condiciones temperatura-tiempo deben asegurar la obtención de un producto estable y aceptado por el consumidor de tal forma que los daños causados sobre los componentes fisiológicamente activos por temperatura sean mínimos. La ventaja del producto desarrollado es que, el consumo de una ración ( $\sim 40$ g), puede proporcionar la cantidad de componentes beneficiosos naturales presentes en 250 $\mathrm{ml}$ de zumo de mandarina natural recién exprimido.

\section{MATERIAL Y MÉTODOS}

2.1 Material vegetal. Obtención de muestras.

El zumo de mandarina se obtuvo mediante el procedimiento descrito por Betoret et al., 2009. Se recolectaron mandarinas cv. Ortanique (híbrido de tangerina y naranja dulce (C.sinensis x C.reticulata)) en un campo localizado en Turís (Valencia) y se utilizaron inmediatamente en la preparación del zumo. Los frutos se lavaron por inmersión, se escurrieron y se exprimieron en un extractor industrial de copas ranuradas (Exzel, Luzzysa, El Puig, Valencia, Spain). El zumo resultante se tamizó utilizando un tamiz de 0,7 mm de diámetro, se homogeneizó utilizando un homogeneizador piloto Manton-Gaulin modelo (15M8TBA) a $15 \mathrm{MPa}$, se centrifugó en una centrífuga piloto Westfalia que permite recoger una fracción suero del $75 \%$ del volumen inicial con un 1\% de pulpa y el zumo resultante (LPJ) se pasteurizó a $63^{\circ} \mathrm{C}$ durante un período de tiempo de 15 segundos. Se recogió en tarros de vidrio esterilizados y se congeló inmediatamente a $-18 \stackrel{0}{\circ} \mathrm{C}$ hasta la realización de los análisis. 
Las manzanas (cv. Granny Smith) se adquirieron de un supermercado local, se cortaron en discos de $5 \mathrm{~mm}$ de espesor en dirección perpendicular al eje longitudinal y con un diámetro externo e interno de 65 y $21 \mathrm{~mm}$ respectivamente.

\subsection{Caracterización fisicoquímica.}

Se midieron los sólidos solubles totales con un refractómetro digital (ABBE ATAGO, NAR T3, Japan) termostatado a $20 \stackrel{\circ}{\circ}$. La acidez total se determinó por valoración con hidróxido sódico $0.1 \mathrm{~N}$ y se expresó como porcentaje de ácido cítrico. Los aceites esenciales recuperables se determinaron por valoración con bromato de acuerdo con el método Scout (Scout and Veldhius, 1966). El pH se midió con un potenciómetro (micropH CRISON, 2001). La actividad de agua se midió utilizando un higrómetro de punto de rocío (DECAGON, Aqualab CX-2, \pm 0.003). La humedad se determinó siguiendo el método oficial 20.013 de secado en estufa de vacío a $60{ }^{\circ} \mathrm{C}(\mathrm{AOAC}, 1980)$ para frutas ricas en azúcar. Todas las medidas se realizaron por triplicado

\subsection{Desarrollo del alimento funcional.}

El alimento funcional de baja humedad impregnado con zumo de mandarina y con alto contenido en flavonoides se obtuvo siguiendo la metodología descrita previamente en Betoret et al., 2012.

Los experimentos de impregnación a vacío se llevaron a cabo a nivel de planta piloto utilizando el equipo diseñado en el Instituto Universitario de Ingeniería de Alimentos para el Desarrollo de la Universidad Politécnica de Valencia (España). Las muestras de manzana se sumergieron en el zumo de mandarina y se aplicó una presión de vacío al sistema de 50 mbar durante 10 minutos, después de los cuales se restauró la presión atmosférica. Las muestras se mantuvieron sumergidas en el zumo durante 10 minutos adicionales.

Las muestras de manzana impregnada se deshidrataron utilizando para ello dos métodos de deshidratación diferentes: el secado por aire caliente y la liofilización.

Las muestras se secaron por aire caliente utilizando un secador (LIZ Construcciones José Lizondo, Barcelona). Con el objetivo de evaluar el efecto de la temperatura de secado sobre las propiedades ópticas y mecánicas del producto final, las muestras impregnadas se deshidrataron a $40{ }^{\circ} \mathrm{C}$ y un flujo de aire de 4 $\mathrm{m} / \mathrm{s}$ durante 24 horas y a $70{ }^{\circ} \mathrm{C}$ durante el tiempo necesario hasta alcanzar el mismo contenido en agua.

Las experiencias de liofilización se llevaron a cabo en un liofilizador (LIOALFA

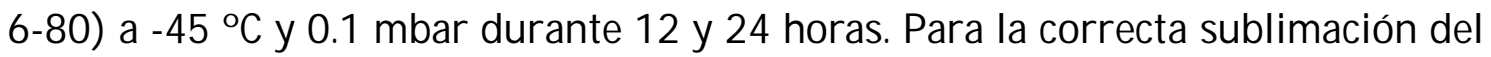
agua contenida en las muestras, éstas se congelaron en un ultracongelador (Dycometal, Barcelona, España) a - $45^{\circ} \mathrm{C}$ durante 6 horas. 


\subsection{Determinación de las propiedades ópticas.}

El color de las muestras se midió con un espectrocolorímetro (MINOLTA modelo CM-1000R) utilizando el iluminante D65 y el observador de $10^{\circ}$ como referencia. En el caso de las muestras de zumo, el color se midió por transmitancia Las muestras se introdujeron en celdas de vidrio óptico de $3.8 \mathrm{~cm}$ de alto y $6 \mathrm{~cm}$ de diámetro. En el caso de las muestras sólidas de manzana, por tratarse de muestras traslúcidas, las medidas se realizaron por reflectancia, tanto sobre fondo blanco como sobre fondo negro.

Se obtuvieron las coordenadas de color en el espacio CIE L*a*b*. L* es un indicador de la luminosidad, a* indica la cromaticidad en el eje verde (-) a rojo (+) y b* la cromaticidad en el eje azul (-) a amarillo (+). También se calculó el parámetro diferencia global de color $\Delta \mathrm{E}$ (ec. 1) que cuantifica la diferencia total de color entre muestras. Todas las medidas se realizaron por triplicado.

$$
\Delta E=\sqrt{\left(\Delta L^{*}\right)^{2}+\left(\Delta a^{*}\right)^{2}+\left(\Delta b^{*}\right)^{2}}
$$

Los valores obtenidos a partir de las determinaciones realizadas sobre las muestras de manzana se corrigieron de acuerdo con la teoría de Kubelka-Munk de dispersión de luz múltiple (Judd y Wyszecki, 1975; Hutchings, 1999; Talens et al., 2002) que describe las propiedades ópticas de las muestras a cualquier longitud de onda mediante un coeficiente de dispersión (S) y otro de absorción (K) (ecuaciones 2 a 5).

$$
\begin{gathered}
\frac{K}{S}=\frac{\left(1-R_{\infty}\right)^{2}}{2 R_{\infty}} \\
R_{\infty}=a-b \\
a=\frac{1}{2}\left[R-\frac{R_{0}-R-R_{g}}{R_{0} R_{g}}\right] \\
b=\sqrt{a^{2}-1}
\end{gathered}
$$

Donde:

$\mathrm{R}_{\infty}$ es la reflectancia infinita

$\mathrm{R}$ es la reflectancia de la muestra determinada sobre fondo blanco

$\mathrm{R}_{\mathrm{g}}$ es la reflectancia del fondo blanco

$\mathrm{R}_{0}$ es la reflectancia de la muestra determinada sobre fondo negro 
2.5 Determinación de las propiedades mecánicas.

Las propiedades mecánicas de las muestras de manzana impregnadas y deshidratadas se evaluaron mediante un ensayo de punción sobre las caras planas de los discos de manzana en un analizador de textura Stable Micro Systems mod. TA.XT plus junto al software Textura exponent 32. El equipo se configuró de manera que la penetración de la muestra por parte del punzón fuera completa. Las condiciones específicas del ensayo se resumen en la tabla 1.

Los parámetros que se han tenido en cuenta a la hora de caracterizar el comportamiento de las muestras frente al avance del punzón fueron:

- La fuerza de fractura $\left(F_{F}\right)$, expresada en Newton

- La distancia recorrida por el punzón hasta que se produce la fractura de la muestra $\left(d_{F}\right)$, expresada en $\mathrm{mm}$

- El área comprendida bajo la curva hasta la rotura de la muestra (A), expresada en Newton·mm.

Tabla 1. Condiciones específicas de los ensayos de punción.

\begin{tabular}{l|l}
\hline \multicolumn{1}{l|}{$\begin{array}{l}\text { Modo de ensayo: } \\
\text { Velocidad: }\end{array}$} & Punción \\
\hline \multicolumn{1}{r}{ Pre-ensayo: } & $1 \mathrm{~mm} / \mathrm{s}$ \\
\hline \multicolumn{1}{r}{ Ensayo: } & $2 \mathrm{~mm} / \mathrm{s}$ \\
\hline Distancia: & $10 \mathrm{~mm} / \mathrm{s}$ \\
\hline Tipo de activación: & $10 \mathrm{~mm}$ \\
\hline Fuerza de activación: & Fuerza \\
\hline Temperatura: & $0.04093 \mathrm{~N}$ \\
\hline Celda de carga: & $24 \stackrel{\circ}{ } \mathrm{C}$ \\
\hline Sonda: & $50 \mathrm{Kg}$ \\
\hline
\end{tabular}

\subsection{Análisis sensorial.}

Para evaluar el grado de aceptación del alimento de manzana funcional obtenido por las diferentes técnicas de deshidratación se procedió a su análisis sensorial por medio de una prueba de ordenación (Normas UNE, 1997). Este tipo de prueba permite determinar en una serie de productos cuál es el más aceptable o el preferido.

Para realizar la prueba sensorial se constituyó un panel de 30 jueces no entrenados. Los atributos elegidos para el análisis fueron apariencia visual, color, sabor, textura y preferencia global.

A cada juez se le presentaron las cuatro muestras estabilizadas con las diferentes técnicas de deshidratación en distinta posición para evitar el efecto de orden (comparación con la primera muestra), a cada muestra se le asignó un código arbitrario de tres cifras.

A los jueces se les pidió puntuar los distintos atributos en una escala hedónica semiestructurada que contenía 9 casillas. Los dos extremos estaban definidos con 
la frase "me disgusta mucho" y "me gusta mucho", además de una frase adicional en el punto intermedio "ni me gusta ni me disgusta".

Los resultados obtenidos se evaluaron con un análisis de la varianza de Friedman (ecuación 6). Esta técnica permite ordenar las muestras para el atributo escogido en una escala de intensidad, indicando mediante una escala numérica las diferencias entre las muestras y la significación de esas diferencias.

$$
F_{\text {FRIEDMAN }}=\frac{12}{J P(P+1)} \sum R c^{2}-3 J(P+1)
$$

Donde:

J es el número de catadores

P es el número de muestras

$\mathrm{R}_{\mathrm{c}}$ es la suma de las ordenaciones atribuidas al conjunto $\mathrm{P}$ de muestras para los jueces.

En caso de obtener un valor de $\mathrm{F}$ superior al valor crítico correspondiente al número de jueces, el número de muestras y el nivel de significación del $95 \%$, para identificar qué pares de muestras difieren estadísticamente entre sí, a partir de la suma de los valores de ordenaciones, se utiliza un análogo de prueba de diferencias mínimas significativas de Fisher. Siendo i y j dos muestras y $R_{i}$ y $R_{j}$ sus sumas de ordenaciones y utilizando una aproximación normal las dos muestras serán diferentes si:

$$
\left|R_{i}-R_{j}\right| \geq 1.960 \frac{\sqrt{J P(P+1)}}{6}
$$

Siendo $1.960=\mathrm{t}_{0.025}$ con un nivel de 0.05 .

El análisis sensorial se realizó en la sala de catas del Instituto Universitario de Ingeniería de Alimentos para el Desarrollo de la Universidad Politécnica de Valencia. Esta sala está normalizada según la norma UNE 87-004-79 "Análisis Sensorial. Guía para la instalación de una sala de cata".

\subsection{Análisis estadístico.}

El análisis estadístico de los resultados se llevó a cabo mediante el programa Statgraphics plus versión 5.1. Con el fin de determinar el nivel de significación de las diferencias observadas se realizaron análisis simples de la varianza (ANOVA). 


\section{RESULTADOS Y DISCUSIÓN}

\subsection{Caracterización fisicoquímica de las muestras.}

Las características fisicoquímicas del zumo de mandarina se muestran en la tabla 2. Los valores obtenidos no difieren significativamente de los obtenidos en otros ensayos llevados a cabo en esta tesis.

Tabla 2. Características fisicoquímicas del zumo de mandarina (promedio \pm desviación estándar).

\begin{tabular}{ll}
\hline & $\begin{array}{l}\text { Zumo de mandarina 15 } \\
\text { MPa }\end{array}$ \\
\hline Brix & $12.90 \pm 0.12$ \\
Acidez (\%) & $1.28 \pm 0.56$ \\
Índice de madurez (Brix/ Acidez) & $10.08 \pm 0.32$ \\
Aceites esenciales (\%) & $0.045 \pm 0.003$ \\
Pulpa suspendida (\%) & $25.0 \pm 1.3$ \\
pH & $3.42 \pm 0.02$ \\
\hline
\end{tabular}

Las características fisicoquímicas de las muestras de manzana determinadas en cada etapa del proceso y para las diferentes técnicas de deshidratación empleadas se muestran en la tabla 3. El valor de la actividad de agua del zumo de mandarina fue similar al valor de la manzana fresca por lo que se esperó que el único mecanismo implicado en la operación de impregnación a vacío fuera el hidrodinámico (Fito et al., 1996). El valor tan elevado de la actividad de agua en las muestras impregnadas las hace muy inestables. Después del secado por aire caliente o la liofilización los valores resultantes de la actividad de agua no permiten el crecimiento de hongos u otros microorganismos durante al menos dos semanas almacenadas a temperatura ambiente (Betoret et al., 2003).

Tabla 3. Características fisicoquímicas de la manzana fresca, impregnada y deshidratada mediante los diferentes métodos empleados (promedio \pm desviación estándar).

\begin{tabular}{lccc}
\hline & Brix & $\mathbf{a}_{\mathbf{w}}$ & Humedad (gagua / gmuestra) \\
\hline Zumo & $12.67 \pm 0.06$ & $0.987 \pm 0.002$ & $0.865 \pm 0.002$ \\
Manzana fresca & $12.4 \pm 0.4$ & $0.9837 \pm 0.0006$ & $0.84 \pm 0.04$ \\
Manzana impregnada & $12.57 \pm 0.15$ & $0.98 \pm 0.02$ & $0.85 \pm 0.07$ \\
SAC 40 -C & - & $0.501 \pm 0.002$ & $0.067 \pm 0.02$ \\
SAC 70 @C & - & $0.512 \pm 0.014$ & $0.07 \pm 0.08$ \\
LIO 12 h & - & $0.486 \pm 0.023$ & $0.059 \pm 0.04$ \\
LOO 14 h & - & $0.473 \pm 0.018$ & $0.054 \pm 0.05$
\end{tabular}

3.2 Efecto del proceso sobre las propiedades ópticas y mecánicas del alimento funcional.

En la tabla 4 se muestran las coordenadas de color en el espacio CIE L*a*b* de las diferentes muestras analizadas, así como las diferencias de color $(\Delta \mathrm{E})$ calculadas respecto a la muestra fresca. 
Tabla 4. Coordenadas CIE L*a*b* de las muestras en cada etapa del proceso y diferencias de color calculadas respecto la manzana fresca (promedio \pm desviación estándar).

\begin{tabular}{lcccc}
\hline & $\mathbf{L}^{*}$ & $\mathbf{a}^{*}$ & $\mathbf{b}^{*}$ & $\mathbf{\Delta E}$ \\
\hline Zumo & $24.212 \pm 0.008^{\mathrm{a}}$ & $20.12 \pm 0.03^{\mathrm{d}}$ & $41.36 \pm 0.05^{\mathrm{c}, \mathrm{d}}$ & - \\
Manzana fresca & $72.86 \pm 0.13^{\mathrm{e}}$ & $-1.5 \pm 0.3^{\mathrm{a}}$ & $10.5 \pm 0.8^{\mathrm{a}}$ & - \\
Manzana IV & $34.6 \pm 0.6^{\mathrm{b}}$ & $-0.7 \pm 0.2^{\mathrm{a}}$ & $9.5 \pm 0.6^{\mathrm{a}}$ & $38.3 \pm 0.6$ \\
SAC 40 @C & $63.7 \pm 0.7^{\mathrm{c}}$ & $10.2 \pm 0.4^{\mathrm{c}}$ & $43 \pm 2^{\mathrm{d}}$ & $36 \pm 2$ \\
SAC 70 9C & $69.2 \pm 1.1^{\mathrm{d}}$ & $10.7 \pm 1 .^{\mathrm{c}}$ & $44 \pm 2^{\mathrm{d}}$ & $36 \pm 2$ \\
LIO 12 h & $82.1 \pm 0.3^{\mathrm{f}}$ & $6.6 \pm 0.4^{\mathrm{b}}$ & $39 \pm 2^{\mathrm{b}, \mathrm{c}}$ & $30 \pm 2$ \\
LIO 24 h & $82.4 \pm 1.4^{\mathrm{f}}$ & $6.1 \pm 0.9^{\mathrm{b}}$ & $37 \pm 5^{\mathrm{b}}$ & $30 \pm 5$ \\
\hline
\end{tabular}

* Valores con distinto superíndice en una columna son estadísticamente diferentes $(\mathrm{p} \leq 0.05)$.

En las muestras impregnadas el valor de las coordenadas $\mathrm{a}^{*} \mathrm{y} \mathrm{b}^{*}$ es muy similar al obtenido en las muestras frescas. El valor de la coordenada $a^{*}$ es considerablemente inferior al de la coordenada b* lo que indica que el color amarillo-verdoso característico de la fruta fresca se mantiene, aunque el descenso en la coordenada $a^{*}$ resulta en una evolución hacia el color amarillo cuando el zumo de mandarina penetra en el interior de la estructura de la manzana. Los cambios de color observados en la luminosidad de las muestras impregnadas ( $\left.\mathrm{L}^{*}\right)$ pueden atribuirse al incremento en la traslucidez como resultado de la salida de gas ocluido y la entrada de zumo en la estructura promovidos durante la operación de impregnación a vacío.

Las coordenadas CIEL*a*b* de las muestras secas fueron significativamente diferentes a las obtenidas en las impregnadas y frescas. En este caso, los cambios observados en la luminosidad pueden explicarse teniendo en cuenta los cambios que tienen lugar en la estructura del tejido (Lewiki, 1998), fundamentalmente la disminución de la porosidad, la contracción y la desestructuración (Maskan, 2001; Lewiki y Jakubczyk, 2004). Sin embargo, en las muestras liofilizadas se produjo un aumento considerable en el valor de la luminosidad, por el menor contenido en agua y la formación de una estructura porosa.

En cuanto a la coordenada cromática $\mathrm{a}^{*}$, ésta aumentó considerablemente en las muestras deshidratadas, especialmente en aquellas secadas con aire caliente. Esta tendencia de las muestras deshidratadas hacia una tonalidad más anaranjada puede explicarse como resultado de reacciones de pardeamiento enzimático y no enzimático.

Hay básicamente dos tipos de reacciones no enzimáticas asociadas a la pérdida de color en los alimentos: una debida a reacciones de azúcares reductores y aminoácidos y otra debida a reacciones de oxidación (Cortés et al., 2008). En el caso concreto de las muestras secadas con una corriente de aire a $40 \stackrel{\circ}{ } \mathrm{C}$ durante 24 horas, el oscurecimiento se debió fundamentalmente a reacciones de oxidación debidas al mayor tiempo de exposición al aire. En el caso de las muestras secadas con una corriente de aire a $70{ }^{\circ} \mathrm{C}$, en las que el tiempo de exposición se redujo hasta 7 horas, estos cambios en la coloración se debieron fundamentalmente al empleo de altas temperaturas, lo que pudo desencadenar reacciones de pardeamiento enzimático. El menor incremento en el valor de la coordenada a* experimentado por parte de las muestras liofilizadas puede ser atribuido al empleo 
de bajas temperaturas durante el proceso y a la ausencia de exposición al aire durante la sublimación del agua congelada presente en el alimento.

Por lo que respecta a la coordenada cromática b*, ésta evolucionó de forma similar a como lo hizo la coordenada cromática a*, aumentando significativamente su valor como consecuencia de la deshidratación, pero especialmente tras el secado con aire caliente. Esto se traduce en que el color de las muestras evolucionó durante la deshidratación hacia una tonalidad más amarillenta. En la figura 1 se representan las coordenadas cromáticas $\mathrm{a}^{*}$ y b*, observándose la evolución de color para cada técnica de deshidratación.

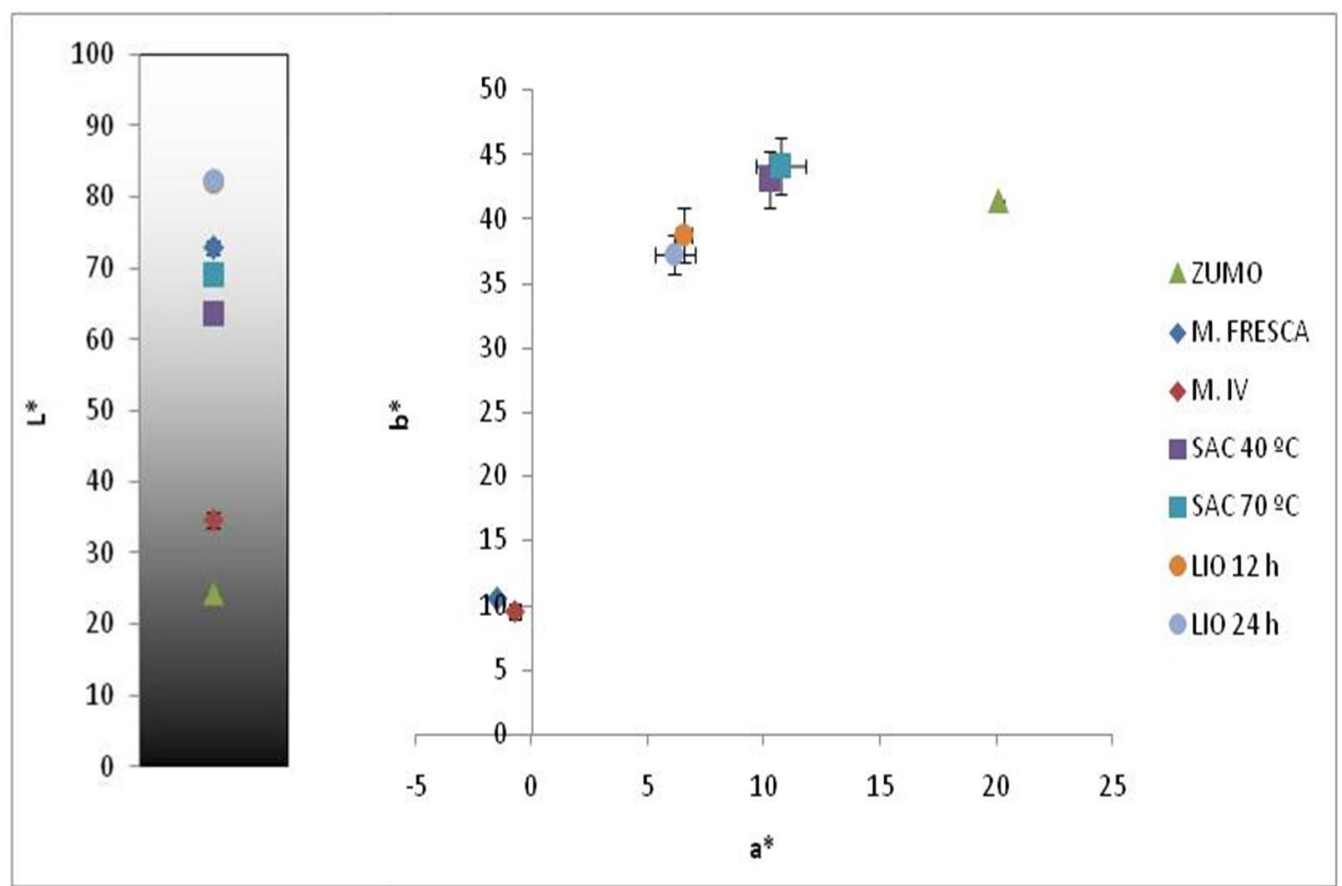

Figura 1. Diagrama cromático $\mathrm{L}^{*} \mathrm{a}{ }^{*} \mathrm{~b}^{*}$ del zumo, la manzana fresca, impregnada y deshidratada mediante los diferentes métodos empleados.

Para entender mejor estos cambios en las propiedades ópticas, en la figura 2 se muestra el aspecto final de las muestras impregnadas y deshidratadas por las diferentes técnicas empleadas en este estudio.

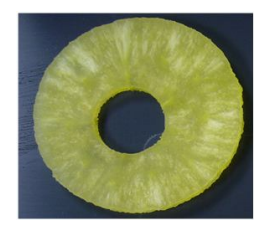

Mimpregnada

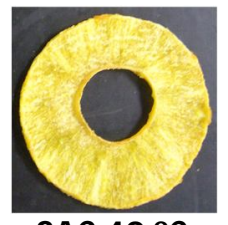

$\mathrm{SAC} 40^{\circ} \mathrm{C}$

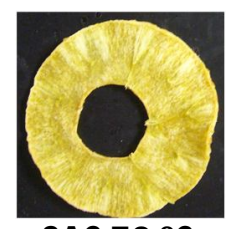

SAC $70 \div$

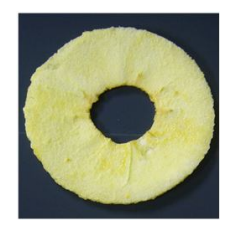

LIO 12 h

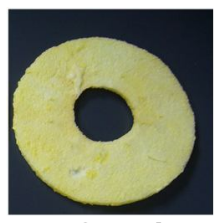

LIO 24 h

Figura 2. Imágenes de la manzana impregnada y deshidratada mediante secado por aire caliente y liofilización.

Los parámetros medidos para caracterizar las muestras frescas, impregnadas y deshidratadas se muestras en la tabla 5. 
Tabla 5. Propiedades mecánicas de las muestras sólidas de manzana (promedio \pm desviación estándar).

\begin{tabular}{lccc}
\hline & $\mathbf{A}(\mathbf{N} \cdot \mathbf{m m})$ & $\mathbf{F}_{\mathbf{F}} \mathbf{( N )}$ & $\left.\mathbf{d}_{\mathbf{F}} \mathbf{( m m}\right)$ \\
\hline Manzana fresca & $10.7 \pm 1.0^{\mathrm{b}, \mathrm{c}}$ & $3.6 \pm 0.5^{\mathrm{a}}$ & $2.3 \pm 0.7^{\mathrm{a}}$ \\
Manzana IV & $13 \pm 4^{\mathrm{c}}$ & $3.9 \pm 0.2^{\mathrm{a}}$ & $2.1 \pm 0.1^{\mathrm{a}}$ \\
SAC 40 OC & $10.2 \pm 0.4^{\mathrm{a}, \mathrm{b}, \mathrm{c}}$ & $12.6 \pm 1.4^{\mathrm{c}}$ & $4.7 \pm 0.7^{\mathrm{c}}$ \\
SAC 70 9C & $9.0 \pm 0.8^{\mathrm{a}, \mathrm{b}}$ & $12.5 \pm 1.5^{\mathrm{c}}$ & $4.3 \pm 0.5^{\mathrm{c}}$ \\
LIO 12 h & $9.7 \pm 1.1^{\mathrm{a}, \mathrm{b}}$ & $8.0 \pm 0.7^{\mathrm{b}}$ & $4.7 \pm 0.4^{\mathrm{c}}$ \\
LIO 24 h & $8 \pm 4^{\mathrm{a}}$ & $9 \pm 3^{\mathrm{b}}$ & $3.3 \pm 1.0^{\mathrm{b}}$ \\
\hline
\end{tabular}

* Valores con distinto superíndice en una columna son estadísticamente diferentes $(\mathrm{p} \leq 0.05)$.

Según Prothon et al. (2001), la fuerza máxima requerida para atravesar la muestra está relacionada con la resistencia del producto a la rotura y el área encerrada bajo la curva está relacionada con la energía empleada en romper la muestra. Los principales cambios inducidos por los tratamientos de deshidratación que afectan a las propiedades mecánicas de los tejidos vegetales son pérdida de la turgencia celular, alteración de la lámina media, alteración en la resistencia de la pared celular, cambios en las fracciones volumétricas de gas y liquido así como cambios en el tamaño y la forma de las muestras (Chiralt et al., 2001).

Las muestras impregnadas mostraron una fuerza de fractura y una distancia parecida a las muestras frescas aunque se necesitó mayor energía para romper las mismas debido a la salida de gas y la incorporación de zumo en la estructura vegetal después de la operación de impregnación a vacío. Las muestras deshidratadas fueron más resistentes a la fractura pero experimentaron una mayor deformación hasta el punto de rotura que las impregnadas.

Comparando los valores de fuerza máxima obtenidos para las muestras deshidratadas por las diferentes técnicas estudiadas se puede observar que las muestras liofilizadas durante 12 y 24 horas presentaron una resistencia a la rotura significativamente inferior a la de las muestras estabilizadas mediante secado por aire caliente a 40 y $70{ }^{\circ}$ C. Esto podría explicarse en términos del menor contenido en agua alcanzado por las muestras al final del proceso de liofilización, pero también en función de los diferentes cambios estructurales experimentados por el tejido vegetal dependiendo de la técnica de estabilización empleada. Así, la eliminación del agua congelada en el alimento mediante sublimación favorece la formación de una estructura porosa, mientras que la evaporación del agua asociada al secado convectivo implica mayores cambios en el volumen de las muestras y favorece el colapso de su estructura (Contreras, 2004).

$\mathrm{El}$ análisis de los valores de la distancia recorrida por el émbolo hasta romper la muestra puso de manifiesto una tendencia similar a la comentada anteriormente para la fuerza máxima, por lo que se confirma que las muestras secadas con aire caliente alcanzaron, con independencia de la temperatura del aire de secado, un estado gomoso al final del proceso. Por el contrario, la menor deformación previa a la fractura experimentada por las muestras liofilizadas, especialmente durante 24 horas, unido a su menor contenido en agua, indica que éstas alcanzaron un estado más crujiente al final del proceso. 
Con respecto a los valores obtenidos para el área encerrada bajo la curva, las muestras estabilizadas con las diferentes técnicas de deshidratación ensayadas presentaron valores similares entre sí y ligeramente inferiores a los de las muestras de manzana fresca e impregnada.

En la figura 3 se muestran las curvas de fuerza-distancia características de las muestras de manzana sólidas en las diferentes etapas del proceso.

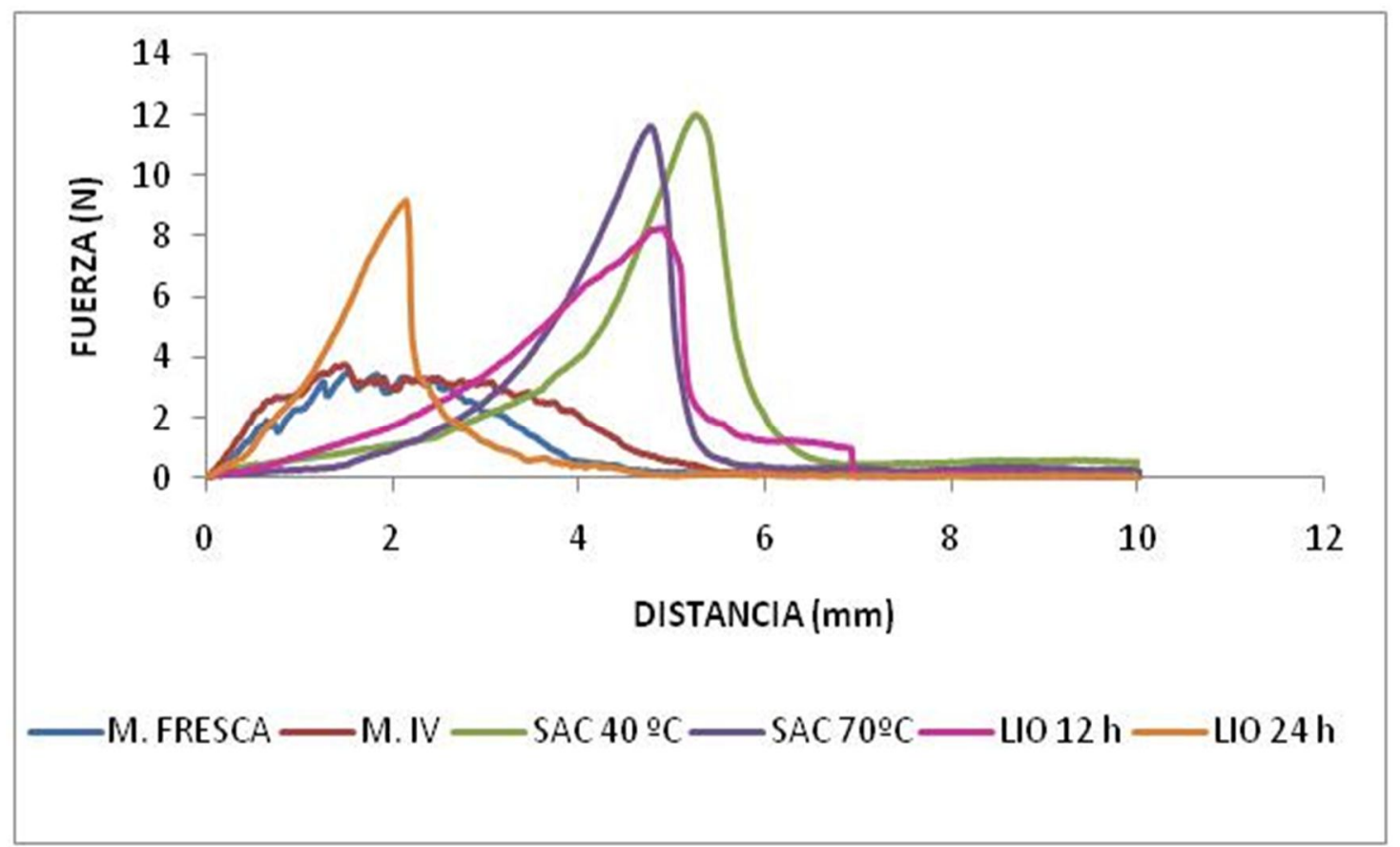

Figura 3. Curvas fuerza-distancia de las muestras de manzana obtenidas en las diferentes etapas del proceso.

Las curvas de las muestras deshidratadas presentaron, con independencia de la técnica empleada, la forma típica de los productos viscoelásticos, caracterizada por un único punto de fractura cuando se alcanza la fuerza máxima y una deformación pronunciada, lo que podría estar asociado con el estado gomoso alcanzado por estas muestras al final del proceso. En cambio, las curvas obtenidas para las muestras frescas e impregnadas mostraron una serie de picos que indican múltiples fracturas tras alcanzar la fuerza máxima, lo que podría estar asociado a la turgencia celular del tejido.

\subsection{Análisis sensorial.}

El análisis de la varianza de Friedman aplicado a los datos obtenidos en la evaluación sensorial puso de manifiesto la existencia de diferencias significativas entre las muestras deshidratadas mediante las diferentes técnicas empleadas para todos los atributos estudiados (tabla 6). 
Tabla 6. Resultados del análisis de la varianza de Friedman.

\begin{tabular}{lccc}
\hline Atributo & $\mathbf{F}_{\text {FRIEDMAN }}$ & $\mathbf{x}_{\mathbf{2}}(\boldsymbol{\alpha}=\mathbf{0 . 0 1})$ & $\mathbf{x}_{\mathbf{2}}(\boldsymbol{\alpha}=\mathbf{0 . 0 5})$ \\
\hline Aspecto visual & 2233.08 & 11.345 & 7.815 \\
Color & 2160.36 & 11.345 & 7.815 \\
Sabor & 1908.7 & 11.345 & 7.815 \\
Textura & 1739.2 & 11.345 & 7.815 \\
\hline
\end{tabular}

Como el valor obtenido es mucho mayor, hay pruebas estadísticas suficientes para concluir que existen diferencias significativas entre las muestras estabilizadas mediante las diferentes técnicas de deshidratación en todos los atributos estudiados. Para determinar entre que pares de muestras existen diferencias estadísticas, se realizo un análogo de prueba de diferencias mínimas significativas de Fisher obteniéndose los siguientes resultados (tabla 7) para los distintos atributos estudiados:

Tabla 7. Diferencias significativas entre pares de muestras para los distintos atributos estudiados.

\begin{tabular}{|c|c|c|c|}
\hline \multicolumn{4}{|c|}{ Atributo } \\
\hline Aspecto visual & Color & Sabor & Textura \\
\hline SAC $40^{\circ}$ C-LIO $12 \mathrm{~h}$ & SAC $40^{\circ} \mathrm{C}-\mathrm{LIO} 12 \mathrm{~h}$ & SAC $40^{\circ} \mathrm{C}-\mathrm{LIO} 24 \mathrm{~h}$ & SAC $40^{\circ}$ C-LIO $24 \mathrm{~h}$ \\
\hline SAC $40^{\circ} \mathrm{C}-\mathrm{LIO} 24 \mathrm{~h}$ & SAC $40^{\circ} \mathrm{C}-\mathrm{LIO} 24 \mathrm{~h}$ & SAC $70^{\circ} \mathrm{C}-\mathrm{LIO} 24 \mathrm{~h}$ & SAC $70^{\circ}$ C-LIO $12 \mathrm{~h}$ \\
\hline SAC $70^{\circ} \mathrm{C}-\mathrm{LIO} 12 \mathrm{~h}$ & SAC $70^{\circ} \mathrm{C}-\mathrm{LIO} 12 \mathrm{~h}$ & & SAC $70^{\circ}$ C-LIO $24 \mathrm{~h}$ \\
\hline SAC $70^{\circ}$ C-LIO $24 \mathrm{~h}$ & SAC $70^{\circ} \mathrm{C}-\mathrm{LIO} 24 \mathrm{~h}$ & & LIO 12h-LIO 24h \\
\hline
\end{tabular}

Como se muestra en la figura 4, todos los parámetros evaluados fueron puntuados, con independencia de la técnica de deshidratación empleada, con valores comprendidos entre 5 y 7 sobre una escala de 9, lo que indica una buena aceptación en general por parte del consumidor. Según los datos obtenidos, las muestras preferidas por los jueces en todos los atributos estudiados fueron las liofilizadas frente a las muestras secadas con aire caliente, siendo especialmente notables las diferencias encontradas entre su apariencia visual y su color.

Entre las muestras liofilizadas, las procesadas durante 24 horas fueron mejor valoradas por los jueces que las procesadas 12 horas en todos los atributos menos en el color. Como revela el estudio de las propiedades ópticas, las muestras liofilizadas 24 horas presentaron un color más blanquecino y las liofilizadas 12 horas presentaron una tonalidad más amarillenta. La mayor puntuación obtenida en el atributo textura por parte de las muestras liofilizadas durante 24 horas podría estar relacionado con la textura más crujiente de las mismas, tal y como se ha comentado al analizar las propiedades mecánicas.

Respecto a las muestras secadas con aire caliente, se ve una clara tendencia por parte de los consumidores hacia las muestras secadas a $40{ }^{\circ} \mathrm{C}$, las cuales obtuvieron una mayor puntuación en todos los atributos evaluados. 


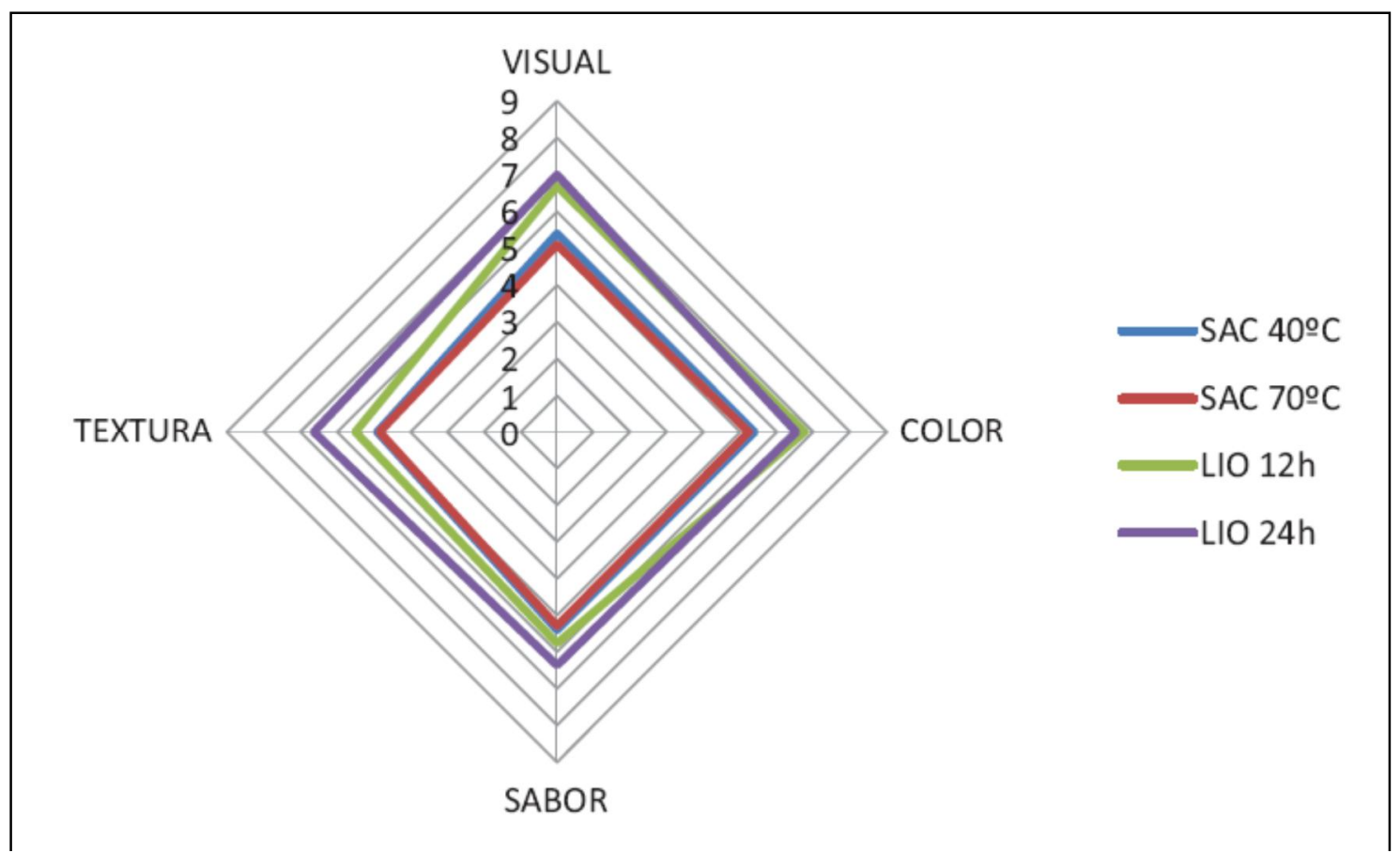

Figura 4. Gráfico radial de la prueba sensorial de ordenación de las muestras deshidratadas mediante diferentes métodos.

Al preguntar a los jueces qué muestra les había gustado más de forma global, las muestras liofilizadas durante 24 horas fueron elegidas por el $64 \%$ de los jueces, seguidas de las muestras secadas por aire caliente a $40^{\circ} \mathrm{C}$, que fueron elegidas por el $23 \%$ de los jueces (figura 5). A pesar de que la puntuación otorgada por los jueces a las muestras liofilizadas durante 12 horas fue mayor para todos los atributos evaluados que la otorgada a cualquiera de las muestras secadas por aire caliente, su aceptación global fue la que obtuvo una menor puntuación.

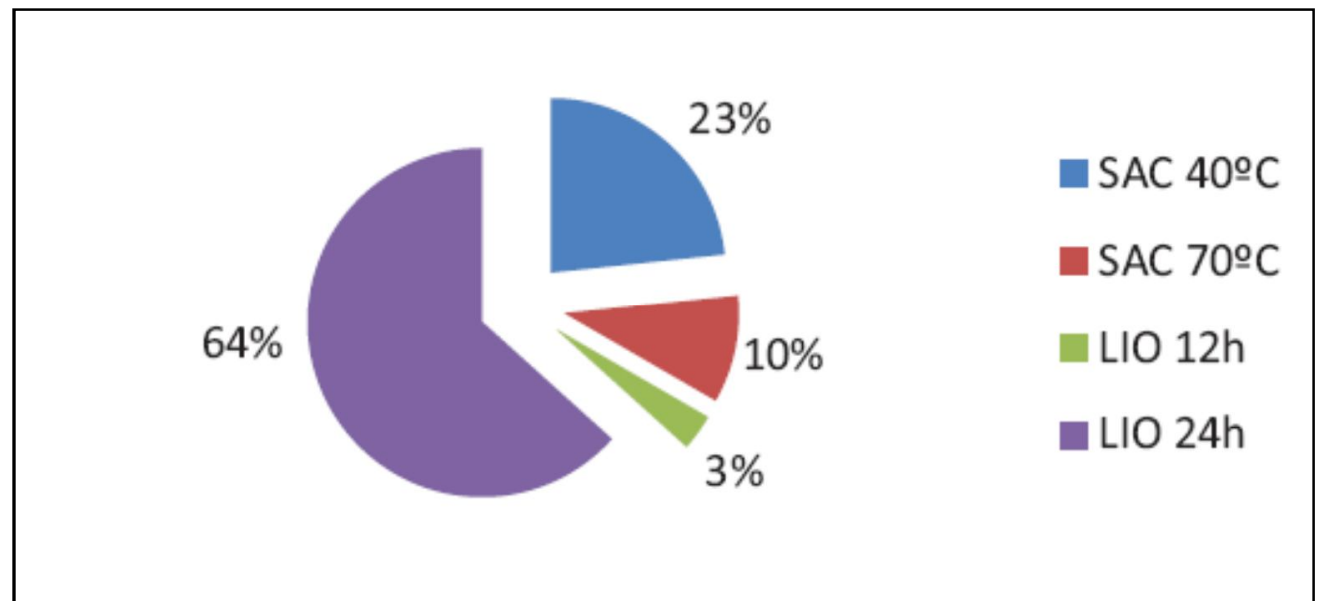

Figura 5. Porcentajes de preferencia global de las muestras deshidratadas.

\section{CONCLUSIONES}

La operación de liofilización ha permitido obtener productos de menor contenido en agua, más crujientes y de color más parecido a la manzana fresca 
mientras que el secado por aire caliente ha permitido obtener productos con mayor contenido en agua, menos crujientes y de un color más anaranjado. Los resultados obtenidos en el análisis sensorial determinan que las preferencias de los consumidores en cuanto a un atributo concreto difieren de las preferencias globales.

Mejorar la crujencia de la muestra secada a $40{ }^{\circ} \mathrm{C}$ por incorporación de algún componente o con otra técnica adicional como la fritura podría mejorar su aceptación por encima de la liofilizada durante 24 horas.

\section{REFERENCIAS}

A.O.A.C. (1980). Association of Official Analytical Chemist. Official Methods of Analysis. Washington.

Benavente-García O., Castillo J., Marín F.R., Ortuño A., \& Del Río J.A. (1997). Uses and properties of citrus flavonoids. Journal of Agricultural and Food Chemistry, $45,4505-4515$.

Betoret E., Betoret N., Carbonell J.V., \& Fito P. (2009). Effects of pressure homogenization on particle size and the functional properties of citrus juices. Journal of Food Engineering, 92, 18-23.

Betoret N., Puente L., Díaz M.J., Pagan M.J., García M.J., Gras M.L., Martínez-Monzó J., \& Fito P. (2003). Development of probiotic-enriched dried fruits by vacuum impregnation. Journal of Food Engineering, 56, 2-3, 273-277.

Bocco A., Cuvelier M.E., Richard H., \& Berset C. (1998). Antioxidant activity and phenolic composition of citrus peel and seed extracts. Journal of Agricultural and Food Chemistry, 46, 2123-2129.

Burda S., \& Oleszek W. (2001). Antioxidant and antiradical activities of flavonoids. Journal of Agricultural and Food Chemistry, 49, 2774-2779.

Bylka W., Matlawska I., \& Pilewsky N.A. (2004). Natural flavonoids as antimicrobial agents. Journal of the American Nutraceutical Association, 7, 24-31.

Chiralt A., Fito P., Andrés A., Barat J.M., Martinez-Monzo J., \& Martinez-Navarrete N. (1999). Vacuum impregnation: a tool in minimally processing of foods. En: Processing of Foods: Quality Optimization and Process Assesment. Eds: F.A.R. Oliveira y J.C. Oliveira. CRC Press, Boca Ratón, 341-356.

Contreras C., Martín M.E., Martín-Navarrete N., \& Chiralt A. (2004). Effect of vacuum impregnation and microwave application on structuralchanges which occurred during air-drying of apple. Swiss Society of Food Science and Technology LWT, 38, 471-477.

Cortés M., \& Chiralt A. (2008).Kinetic of colour change of air dried fortified apples with vitamin e. Vitae, 15, 1, 8-16. ISSN 0121-4004.

Fito P., Andrés A., Chiralt A., \& Pardo P. (1996). Coupling of hydrodynamic mechanism and deformation relaxation phenomena during vacuum treatments in solid porous foodliquid systems. Journal of Food Engineering, 27, 229-240. 
Goodner K.L., Rouseff R.L., \& Hofsommer H.J. (2001). Orange, mandarin, and hybrid classification using multivariate statistics based on carotenoid profiles. Journal of Agricultural and Food Chemistry, 49, 1145-1150.

Hollman P.C.H., Hertog M.G.L., \& Katan M.B. (1996). Analysis and health effects of flavonoids. Food Chemistry, 57, 43-46.

Hutchings J.B. (1999). Food and color appearance. 2nd ed. Maryland: Chapman and Hall Food Science Book, Aspen Publication.

Johnston C.S., \& Bowling D.L. (2002). Stability of ascorbic acid in commercially available orange juices. Journal of the American Dietetic Association, 102, 525529.

Judd D.B., \& Wyszecki G. (1975). Color in business, science and industry. New York: John Wiley and Sons.

Kohno H., Taima M., Sumida T., Azuma Y., Ogawa H., \& Tanaka T. (2001). Inhibitory effect of mandarin juice rich in $\beta$-cryptoxanthin and hesperidin on 4(methylnitrosamino)-1-(3-pyridyl)-1-butanone-induced tumorigenesis in mice. Cancer Letters,174, 141-150.

pulmonary

Lewicki P. (1998). Effect of pre-drying treatment, drying and rehydration on plant tissue properties: a review. International Journal of Food Properties, 1 (1), 1-22.

Lewicki P.P., \& Jakubczyk E. (2004). Effect of hot air temperature on mechanical properties of dried apples. Journal of Food Engineering, 64, 3, 307-314.

Maskan M. (2001). Drying shrinkage and rehydration characteristics of kiwifruits during microwave drying. Journal of Food Engineering, 48, 177-182.

Middleton E.Jr., Kandaswami C., \& Theoharides T.C. (2000). The effects of plant flavonoids on mammalian cells: implications for inflammation, heart disease, and cancer. Pharmacological Reviews, 52, 673-751.

Miyagi Y., Om A.S., Chee K.M., \& Bennink M.R. (2000). Inhibition of azoxymethane induced colon cancer by orange juice. Nutrition \& Cancer, 36, 224-9.

NORMA UNE. (1979). Análisis sensorial. Guía para la instalación de una sala de cata. UNE 87-004-79. AENOR NA. 71970. Madrid. España.

NORMAS UNE. (1997). Análisis sensorial. Tomo 1. Alimentación. UNE 87- 006-92. AENOR N.A. 71970. Madrid. España.

Prothon F., Ahrné L., Funebo T., Kidman S., Langton M., \& Sjoholm I. (2001). Effects of combined osmotic and microwave dehydration of apple on texture, microstructure and rehydration characteristics. Lebensmittel Wissenchaft und Technologie, 34, 95-101.

Rapisarda F., Fanella F., \& Maccarone E. (2000). Reliability of analytical methods for determining anthocyanins in blood orange juices. Journal of Agricultural and Food Chemistry, 48, 2249-2252.

Robards K., \& Antolovich M. (1995). Methods for assessing the authenticity of orange juice. Analyst, 120, 1-28.

Sendra J.M., Navarro J.L., \& Izquierdo L. (1988). C18 solid-phase isolation and high performance liquid chromatography-ultraviolet diode array determination of 
fully methoxylated flavones in citrus juices. Journal of Chromatographic Science, $26,443-448$.

So F.V., Guthrie N., Chambers A.F., Moussa M., \& Carroll K.K. (1996). Inhibition of human breast cancer cell proliferation and delay of mammary tumorigenesis by flavonoids and citrus juices. Nutrition \& Cancer, 262, 167-81.

Spence J.T. (2006). Challenges related to the composition of functional foods. Journal of Food Composition and Análisis, 19, S4-S6.

Talens P., Martínez-Navarrete N., Fito P., \& Chiralt A. (2002). Changes in optical and mechanical properties during osmodehydrofreezing of kiwifruit. Innovative Food Science \& Emerging Technologies, 3, 191-199.

Tanaka T., Makita H., Kawabata K., Mori H., Kakumoto M., \& Satoh, K. (1997). Chemoprevention of azoxymethane induced rat colon carcinogenesis by the naturally occurring flavonoids, diosmin and hesperidin. Carcinogenesis, 18, 957-65.

Yang M., Tanaka T., Hirose Y., Deguchi T., Mori H., \& Kawada Y. (1997). Chemopreventive effects of diosmin and hesperidin on N-butyl-N(4hydroxybutyl) nitrosamine-induced urinary-bladder carcinogenesis in male ICR mice. International Journal of Cancer, 73, 719-24. 
3.5. Estudio in vivo de la capacidad antioxidante del alimento funcional desarrollado y sus efectos sobre la salud. 

*Nota al lector: Los resultados presentados a continuación son resultados complementarios al desarrollo de un alimento funcional enriquecido con zumo de mandarina y con alto contenido en flavonoides. Estos resultados se encuentran pendientes de publicación.

\title{
Dried apple enriched with mandarin juice by vacuum impregnation counteracts the liver oxidative effect of tamoxifen in rats.
}

\begin{abstract}
We have investigated the effects of a product made of apple dehydrated enriched by vacuum impregnation of mandarin juice in decreasing oxidative stress biomarkers in rat induced liver injury by tamoxifen. A experimental design was undertaken in six groups of animals. One group fed a standard diet. Two groups were supplemented with $0.745 \mathrm{~g} / \mathrm{d}$ of apples snacks/day either impregnated or not with mandarin juice during 28 days. Three groups of rats were treated with tamoxifen $1.54 \mathrm{mg} / \mathrm{kg} /$ day during 21 days; of these, one group was supplemented with the apple snacks and the other with the apple snacks impregnated with mandarin juice. Plasma aminotransferases were determined as index of hepatocellular damage and interleukin- 6 as measure of inflammation. Plasma and liver carbonyl groups, indicative of protein oxidation, and $\alpha$ tocopherol as evaluation of antioxidant defense were measured. The modified base 8hydroxydexyguanosine as indicative of DNA damage was determined in liver. Tamoxifen induced an increase in aminotranferases and both plasma and liver markers of oxidative stress and DNA damage that decrease significantly after apple snack consumption; in most of cases they even reach normal values as those achieved previous to induce the injury with tamoxifen. The effect of the mandarin juice incorporated to the structure of apple mainly accounts for increasing levels of $\alpha$ tocopherol in plasma and liver. The present study shown the potential protective action of the products made of dehydrated apple either impregnated or not with mandarin juice by vacuum impregnation for counteracting the chemically induced liver injury in rats.
\end{abstract}

Keywords: antioxidants, apple, citrus, 8-dehydroxydeoxyguanosine, protein oxidation, tamoxifen.

\section{INTRODUCTION}

In recent years, special interest has been directed towards the antioxidant capacity of fruits and vegetables. Prevention from oxidative stress plays a beneficial role in the development of many process related to free radical production such as degenerative diseases and mutagenesis or the action of certain drugs whose metabolism induces the formation of reactive oxygen species. The intake of a diet rich in antioxidant compounds can prevent some oxidative-related disorders and organ toxicity events either directly neutralizing reactive oxygen species (Kujawska et al., 2011) or modulating gene expression that contributes to oxidative stress (Soyalan et al., 2011).

Between the fruits highly consumed, citrus and apples have been proven to have beneficial effects against a number of diseases, such as cardiovascular disease, diabetes and some cancers as well as some age-related disorders (Buscemi et al., 2012; Jedrychowski et al., 2010). These protective effects can be related to the actions of specific compounds such as vitamin $C$ and polyphenols on inflammation and oxidative stress (Bouayed et al., 2011). Although during the last 
years a lot of studies have demonstrated the beneficial effect of phytochemicals on health (Eilat-Adar and Goldbourt, 2010) there is a growing knowledge about arguing that consumption of foodstuffs can exert more beneficial effects than active components alone, the various nutrients provided by foodstuffs can have a relevant synergistic action (Garg et al., 2001).

As a consequence, fruit derived products are an emerging area within functional foods. Recently, we have developed an apple snack rich in flavonoids from mandarin juice by using vacuum impregnation (VI) and air drying technologies (Betoret et al., in press). The product can combine the beneficial effect of both sources into one food item, or even enhance the beneficial compounds in the juice by protecting them through inclusion into a food structure. The snack developed can be an alternative within the existing functional food products enhancing the fruit based functional ones. This product can be consumed as a snack or as ingredient in breakfast products mainly by children. In this sense, functional food development requires assessment for its efficacy and safety through in vivo proof-of-concept testing for potential health claims (Jones et al., 2008). Therefore, in the present study, we examined the effects of adding to the experimentation animals' diet a foodstuff made by apple dehydrated enriched by VI of mandarin juice. We assessed the bioavailability by measuring the antioxidant capacity of serum by their ferric reducing antioxidant potential (FRAP) and 2,2'azino-bis(3-ethylbenzothiazoline-6-sulphonic acid) (ABTS) methods.

Furthermore, we conducted a study to evaluate the effects of this foodstuff consumption in decreasing oxidative stres mainly due to a counteraction of free radicals. With this end we have designed an experimental study in rats using a prooxidative agent to induced liver injury, tamoxifen (TAM), 1-[4-(2-dimethylaminoethoxy) phenyl]-1,2-diphenyl-1-butene, a non-steroidal anti-estrogen drug, one of the therapies most commonly used in breast cancer but that can be accompanied with adverse effects, particularly liver toxicity as a result of the reactive oxygen species generated during its metabolic process (Nazarewicz et al.,2007). In this way, we have determined the protection in a model in vivo used for evaluating hepatotoxicity in rodents.

\section{MATERIAL AND METHODS}

\subsection{Reagents and standards.}

ABTS and 2,4,6-tris(2-pyridyl)-s-triazine was acquired from Sigma (Sigma Aldrich Co., St. Louis, MO, USA). Methanol, acetonitrile and dichloromethane (HPLC grade) were purchased from Scharlau (Scharlab S.L., Barcelona, Spain). Citrate tamoxifen (T9262) was acquired from Sigma (Sigma Aldrich Co., St Louis, MO, USA). Other chemicals were obtained from Sigma-Aldrich (St. Louis, MO, U.S.A) and Fluka (Buchs, Switzerland). 


\subsection{Food materials.}

Mandarin juice was obtained as previously described by Betoret et al. (2009). In brief, Ortanique fruit was harvested in an orchard located in Turís (Valencia), Spain, and squeezed immediately for juice preparation. The fruits were washed by immersion in tap water, after which they were drained, and squeezed in an industrial extractor with finger cups (Exzel, Luzzysa; El Puig, Valencia, Spain). Raw juice was divided into two fraction and the low pulp juice fraction was homogenized with a Manton-Gaulin pilot homogenizer (model 15M8TBA) at 15 $\mathrm{MPa}$, centrifuged with a Westfalia centrifuge (model SAOH 205), and pasteurized at $63{ }^{\circ} \mathrm{C}$ for $15 \mathrm{~s}$.

Apples (cv. Granny Smith) were obtained from a local market. Peeled apples were cut into-disc-shaped samples ( $5 \mathrm{~mm}$ thick, with a $65 \mathrm{~mm}$ external diameter and $20 \mathrm{~mm}$ internal diameter) following their vertical axis. Three samples were obtained from each apple and utilized for VI.

\subsection{Snack preparation.}

We prepared two types of snack: a snack made of apple dehydrated exclusively and a snack made of apple dehydrated enriched with mandarin juice by VI. The snacks were obtained following the methodology previously described in (Betoret et al., in press). The VI experiments were performed on a pilot scale using equipment designed in the Institute of Food Engineering for Development of the Polytechnic University in Valencia, Spain (Fito et al., 2001). A vacuum pressure of 50 mbar was applied for 10 min to the apple samples immersed in the mandarin juice after which atmospheric pressure was restored. The samples were left submerged in the mandarin juice for a further $10 \mathrm{~min}$. Apple samples were dried for $24 \mathrm{~h}$ using an air dryer (LIZ®, Construcciones mecánicas José Lizondo, Barcelona, España) at $40{ }^{\circ} \mathrm{C}$ under a flow rate of $4 \mathrm{~m} / \mathrm{s}$. Final concentration achieved was $20 \mathrm{~mL}$ of juice/100 g of apple. 40 grams of dehydrated snack impregnated with mandarin juice contains the same amount of flavonoids as 250 $\mathrm{ml}$ of fresh mandarin juice (Betoret et al., in press). Composition of the snacks are shown in Table 1.

\subsection{Animals.}

Female Wistar rats (12 weeks old and around 250-300 g weight each) were used in this study. Animals were kept on standard laboratory diet (IPM R-20 marketed by Panlab, Barcelona, Spain) and tab water ad libitum through the experiments. Temporary cannulation of the lateral tail vein (23G cannula, Chiron Biosciencies, Kent, UK) was performed in the biovailability study. To obtain a larger amount of plasma, animals were anesthetized with halothane and quickly the intracardiac blood sample was collected into a heparinized tube and 
centrifuged. To obtain liver we proceeded to subsequent cervical dislocation of the animal. Then, it was sectioned longitudinally the animal and the liver was removed immediately by dissection and washed in ice-cold isotonic saline. The liver was wrapped in aluminum foil and freeze up to $-80^{\circ} \mathrm{C}$. The method outlined by Santos et al. (2002) was used to obtain liver homogenates. Livers were homogenized with $5 \mathrm{~mL}$ of buffer (250 mM sucrose, $1 \mathrm{mM}$ EGTA, $5 \mathrm{mM}$ Hepes-KOH pH: 7.4)/ $1 \mathrm{~g}$ of tissue, using Junke and Kunkel homogenizer (Staufen, Germany). Subsequently, it was centrifuged $900 \mathrm{~g}$ for 10 minutes at $4{ }^{\circ} \mathrm{C}$ and was filtered through of three layers of gauze to obtain the liver homogenate. All animal experiments were approved by the Institutional Animal Ethics Committee.

\subsection{Bioavailability of the snack antioxidants.}

The total antioxidant capacity was determined in plasma at times $0,30,60$ and 90 minutes with ABTS and FRAPS methodologies after supplementation of the snacks enriched with mandarin juice.

The ABTS assay was followed the method proposed by Miller and Rice Evans (1997) and modified by Re et al. (1999), based on the oxidation of ABTS with potassium persulfate to form the radical monocation ABTS $\bullet+$, which is reduced in the presence of hydrogen-donating antioxidants. The reagent ABTS $\bullet+$, was generated by the reaction $7 \mathrm{mM}$ solution of ABTS with $2.45 \mathrm{mM}$ potassium persulfate solution in a proportion 1:1. The assay was made up with $2.970 \mathrm{~mL}$ of ABTS + and $30 \mu \mathrm{L}$ of plasma. The method determine the decolorization of the $\mathrm{ABTS} \bullet+$, through measuring the reduction of the radical cation in the absorbance at $734 \mathrm{~nm}$.

The FRAP assay was determined using the method proposed by Benzie and Strain (1996).This method is based on ferric to ferrous ion reduction at low $\mathrm{pH}$ causes a colored ferrous-tripyridyltriazine complex. The reaction mixture was prepared by mixing 10 volumes of $300 \mathrm{mM}$ sodium acetate to $\mathrm{pH}: 3.6,1$ volume of $40 \mathrm{mM}$ 2,4,6-tris(2-pyridyl)-s-triazine and 1 volume of $20 \mathrm{mM} \mathrm{FeCl} 3.50 \mu \mathrm{l}$ of plasma was added to $2.950 \mathrm{~mL}$ of the reagent mixture. The mixture reactive was incubated at $37{ }^{\circ} \mathrm{C}$ for 30 minutes in darkness. FRAP values were obtained by comparing the absorbance change at $593 \mathrm{~nm}$ in test reaction mixtures with those containing ferrous ions in known concentration.

\subsection{Experimental design.}

The snack supplementation period was 28 days and the period of tamoxifen treatment (21 days) started one week after supplementation. Each animal was eating $0.745 \mathrm{~g}$ of snack per day, which is equivalent to $40 \mathrm{~g}$ of snack consumed per day by a child of $30-40 \mathrm{~kg}$.

The rats were randomly assigned into 6 groups of 10 animals each as follows:

- CONTROL group: untreated rats with standard diet. 
- TAM group: rats on standard diet that were orally administered $1.54 \mathrm{mg}$ of tamoxifen/ $\mathrm{kg}$ body weight daily during a period of 21 days.

- TAM+APPLE group: rats supplemented diet with apple snack without mandarin juice during 28 days and TAM orally administered (1.54 mg of tamoxifen/ $\mathrm{kg}$ body weight daily) during 21 days.

- TAM+APPLE+VIM group: rats supplemented diet with apple snack impregnated of mandarin juice by VI during 28 days and TAM orally administered (1.54 mg of tamoxifen/ kg body weight daily) during 21 days.

- APPLE group: rats supplemented diet with apple snack during 28 days.

- APPLE+VIM group: rats supplemented diet with apple snack impregnated of mandarin juice by VI.

Twenty four hours after the last treatment, animals were subjected to anesthesia with halothane and quickly the intracardiac blood sample and liver were obtained following the procedure described above.

\subsection{Analytical methods.}

The liver injury was evaluated by the measurement of the levels of alanine aminotransferase (ALT) and aspartate aminotransferase (AST) in plasma by means of the kits from Linear Chemicals, S.L. (Barcelona, Spain).

To evaluate protein oxidation, the carbonyl groups (CG) released during the incubation with 2,4-dinitrophenylhydrazine of plasma and liver homogenate were measured using the method reported by Levine et al. (1990) with some modifications introduced by Tian et al. (1998).The samples were centrifuged at $13000 \mathrm{rpm}$ for $10 \mathrm{~min}$. Then, $20 \mu \mathrm{L}$ of this plasma or liver homogenate were placed in a $1.5 \mathrm{~mL}$ eppendorf, and $400 \mu \mathrm{L}$ of $10 \mathrm{mM} 2,4$ dinitrophenylhydrazine / $2.5 \mathrm{M}$ $\mathrm{ClH}$ and $400 \mu \mathrm{L}$ of $2.5 \mathrm{M} \mathrm{ClH}$ to were added. This mixture was incubated for 1 hour at room temperature. Protein precipitation was performed using with $1 \mathrm{~mL}$ of $100 \%$ of TCA, washed twice with ethanol/ethyl acetate $(1 / 1, \mathrm{v} / \mathrm{v})$, and centrifugation at $12600 \mathrm{rpm}$ for $3 \mathrm{~min}$. Finally, $1.5 \mathrm{~mL}$ of $6 \mathrm{~N}$ guanidine, $\mathrm{pH} 2.3$, was added and the samples were incubated in a $37^{\circ} \mathrm{C}$ water bath for $30 \mathrm{~min}$ and were centrifuged at $12600 \mathrm{rpm}$ for $3 \mathrm{~min}$. The carbonyl content was calculated from peak absorption $(373 \mathrm{~nm}$ ) using an absorption coefficient of $22.000 \mathrm{M}-1 \mathrm{~cm}-1$ and was expressed as $\mathrm{nmol} / \mathrm{mg}$ protein. The protein content was determined by the Lowry method using bovine serum albumin as standard.

The concentration of 8-hydroxydeoxyguanosine (8OHdG), an oxidized nucleoside of DNA, was used to assess the damage to DNA. DNA was extracted from the samples by proteinase $\mathrm{K}$ digestion in combination with DNeasy Blood \& Tissue kit (QIAGEN, Hilden, Germany). Briefly, $0.5 \mu \mathrm{g}$ DNA/ $\mu \mathrm{L}$ of samples were incubated with 100 units of DNase I in $40 \mu \mathrm{L} 10 \mathrm{mM}$ Tris- $\mathrm{ClH}$ at $37^{\circ} \mathrm{C}$ for $1 \mathrm{~h}$. The $\mathrm{pH}$ of the reaction mixture was then lowered with $15 \mu \mathrm{L}$ of $0.5 \mathrm{M}$ sodium acetate (pH: 5.1), $10 \mu \mathrm{L}$ of nuclease P1 (five units) and incubated for $1 \mathrm{~h}$. Readjustment of $\mathrm{pH}$ with $100 \mu \mathrm{L}$ of $0.4 \mathrm{M}$ Tris- $\mathrm{ClH}$ (pH: 7.8) was followed by the addition of three 
units of alkaline phosphatase; samples were incubated for longer than an hour. Analysis of $8 \mathrm{OHdG}$ concentration in liver homogenate was determined by means of a commercially available competitive enzyme linked immunosorbent assay kit (8OHdG EIA of Cayman Chemical Company, Ann Arbor, MI, USA).

Levels of $\alpha$-tocopherol, an antioxidant defense marker, were determined by HPLC following the methodology proposed by Arnaud et al. (1991). $200 \mu \mathrm{L}$ of plasma or liver homogenate with $100 \mu \mathrm{L}$ of ethanol and $500 \mu \mathrm{L}$ of hexane were centrifuged at $2000 \mathrm{rpm}$ for 5 minutes, and were reflected the organic phase, which was dried with dry N2; and, finally, it was resuspended with $200 \mu \mathrm{L}$ of mobile phase. Chromatographic conditions consisted of a column Kromasil 100 C18 (250 mm x $4.6 \mathrm{~mm}, 5 \mu \mathrm{m}$ particle size) that was obtained from Teknokroma (Teknokroma LTd., Barcelona, Spain). We used an isocratic mode with a mixture of acetonitrile/ dichloromethane/ methanol (70/20/10, v/v/v). The flow rate was of $1.2 \mathrm{~mL} / \mathrm{min}$ at room temperature. The chromatograms were followed at $291 \mathrm{~nm}$.

As inflammation marker, we determined the interleukin 6 levels in plasma using the ELISA kit de Diaclone Research (Besançon, France) following manufacturer instructions.

\subsection{Statistical analysis.}

SPSS v 17.0 (SPSS, Inc., Chicago, IL, USA) was used for statistical analysis. To compare the values between the different groups of animals an analysis of variance (ANOVA) test was carried out with Bonferroni post hoc test to identify which groups are significantly different from which other groups. In the study of bioavailability, a Friedman's test that measures analysis of variance by ranks was used to compare observations repeated on the same subjects. Results are presented as mean \pm standard error of the mean (SEM), and $p<0.05$ was considered statistically significant.

\section{RESULTS}

\subsection{Bioavailability of the snack antioxidants.}

Figure 1 shows the antioxidant capacity of plasma at 30,60 and 90 minutes after the intake of snacks. We observe an increase in the antiradical activity after 30 minutes that it is significant by the ABTS method. At 60 minutes the maximum antiradical activity values were achieved, being significant statistically by both ABTS and FRAP methods. The values decrease until normal levels after 90 minutes. 

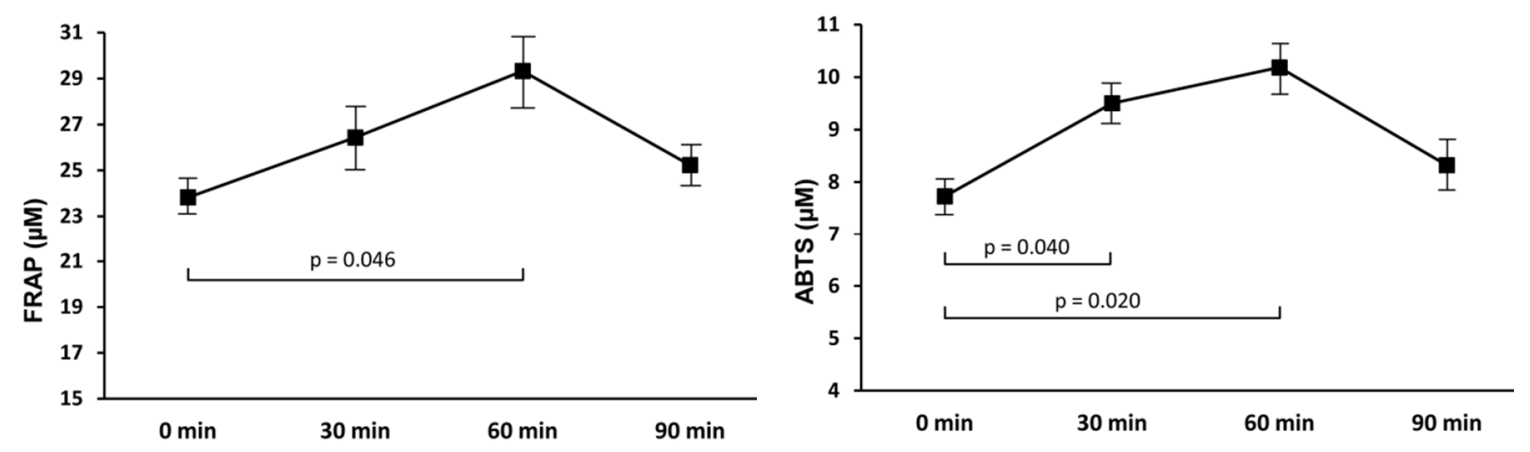

Figure 1. Serum antioxidant capacity of rats after ingestion of the apple snack impregnated with mandarin juice $(n=5)$.

3.2 Effect of TAM on the parameters of liver injury and oxidative/ antioxidative status in liver and plasma.

The administration of TAM increased significantly the activity of both enzymes when compared with control group (Figure 2). In addition, the marker of protein oxidation, CG, and the interleukine 6, a multifunctional proinflammatory cytokine were increased in plasma. On the contrary, the $\alpha$-tocopherol, indicative of antioxidant defense, was decreased in the animals treated with TAM (Figure 3). Similar results were observed in liver (Figure 4). Furthermore, the marker of DNA damage, $80 \mathrm{HdG}$, that was additionally determined in liver, was significantly increased. All these data suggest an important liver toxicity and inflammation induced by reactive oxygen species in the animals treated with TAM.
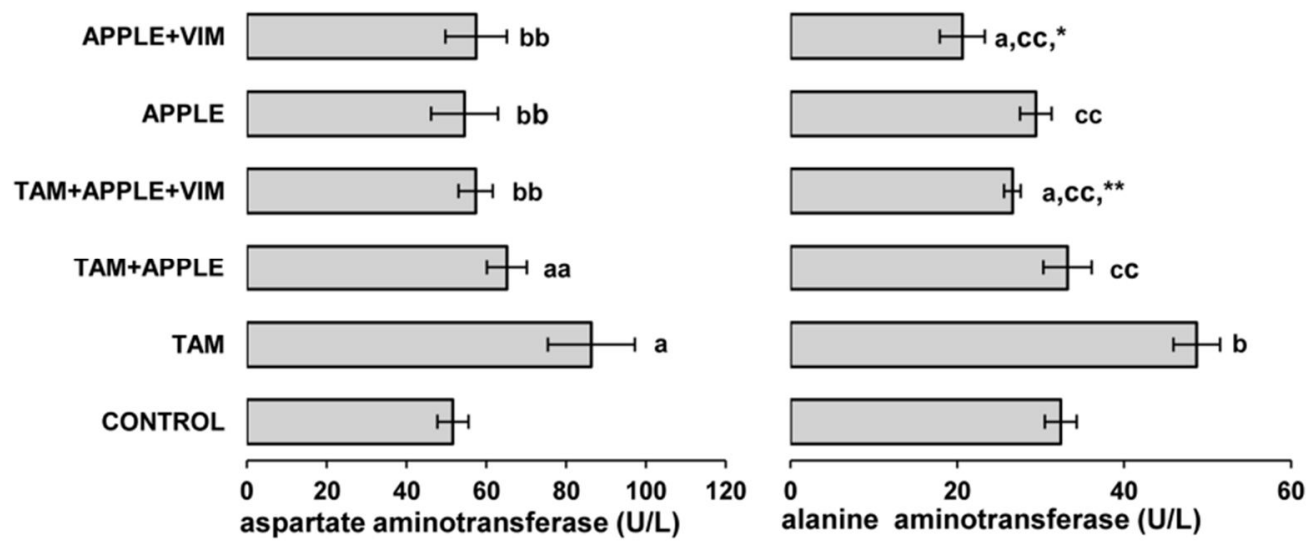

Figure 2. Aspartate aminotransferase and alanine aminotransferase values in plasma of rats $(\mathrm{n}=$ 10 rats per group). ap $<0.001$, bp $<0.0001$, vs CONTROL. aap $<0.05$, bbp $<0.01$, ccp $<0.0001$ vs TAM group. *p <0.05 vs APPLE group; **p <0.05 vs TAM+APPLE group 

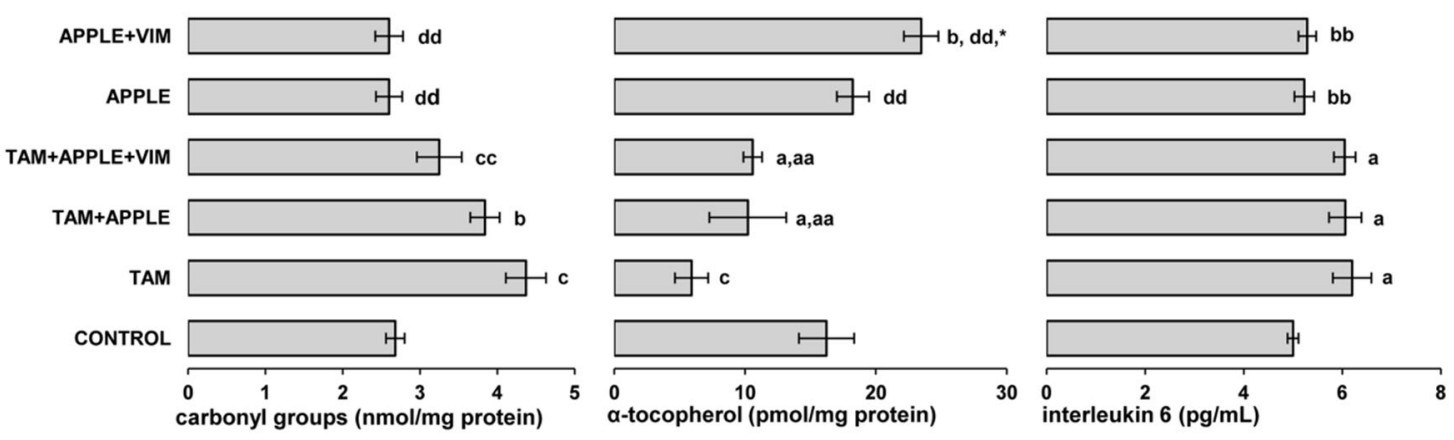

Figure 3. Carbonyl groups, $\alpha$-tocopherol, and interleukin 6 values in plasma of rats $(\mathrm{n}=10$ rats per group). ap $<0.01$, bp $<0.001$, cp $<0.0001$ vs CONTROL group. aap $<0.05$, bb $<<0.01$, ccp $<0.001$, ddp $<$ 0.0001 vs TAM group. ${ }^{*} \mathrm{p}<0.01$ vs APPLE group.
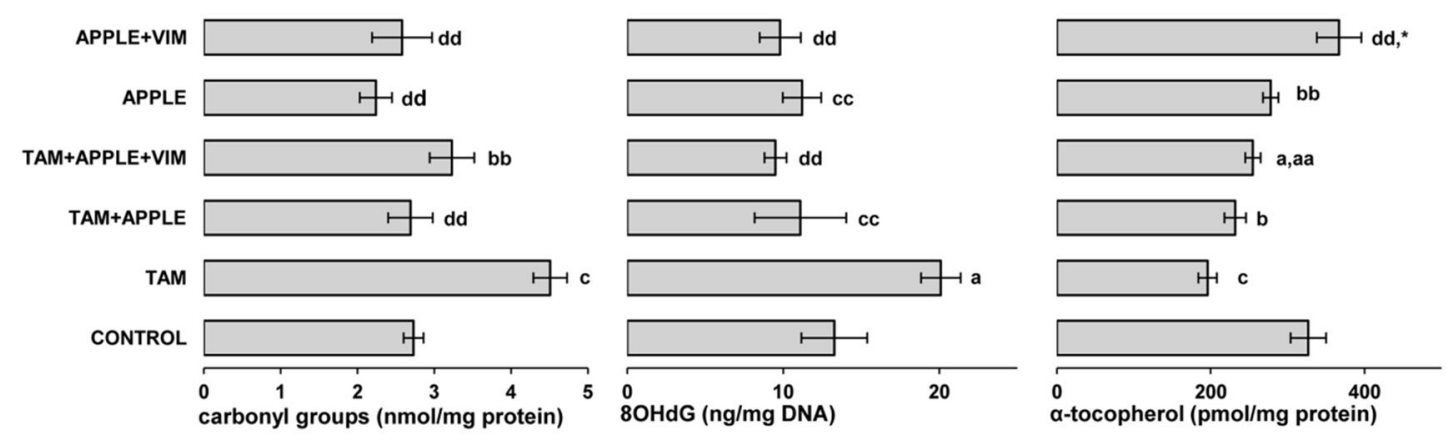

Figure 4. Carbonyl groups, $80 \mathrm{HdG}$, and $\alpha$-tocopherol values in the liver of rats $(\mathrm{n}=10$ rats per group). ap < <.01, bp <0.001, cp <0.0001 vs CONTROL group. aap $<0.05$, bbp $<0.01$, ccp $<0.001$, ddp $<$ 0.0001 vs TAM group. $* \mathrm{p}<0.001$ vs APPLE group.

\subsection{Snack supplementation effect.}

The parameters related to oxidative stress, liver injury and inflammation were measured in plasma and liver of rats that had not been stress induced by TAM [Groups CONTROL, APPLE and APPLE+VIM]. The Figure 2 shows the results of liver enzymes. The plasma levels of ALT and AST from animals that have followed a standard diet and those that receive snack supplementation with and without mandarin juice did not differ. Moreover, either the supplementation with the snack impregnated or not does not modify essentially the markers of protein and DNA oxidation either in plasma or liver (Figure 3 and 4). However, the $\alpha$-tocopherol levels both in plasma (Figure 3) and liver (Figure 4) were significantly increased in the rats supplemented with the snack impregnated with mandarin juice (APPLE+VIM group) with respect the rats supplemented with the nonimpregnated snack (APPLE group).

\subsection{Snack supplementation effect on tamoxifen toxicity.}

The TAM-treated rats along with snack suplementation with and without mandarin juice showed ALT and AST levels significantly decreased in comparing to the TAM-treated group (Figure 2).The effect was more marked in the case of ALT 
levels in rats supplemented with the snack impregnated with mandarin juice (TAM+APPLE+VIM group).

Figure 3 shows the results obtained in the six groups of animals included in the experiment with respect the parameters related to oxidative stress and inflammation measured in plasma. Protein damage reflected in an increase in carbonyl groups levels after TAM treatment decreases considerably in the rats supplemented with the snack impregnated with mandarin juice (TAM+APPLE+VIM group). This significant decrease was not noted in the case of the non-impregnated snack (TAM+APPLE group). Moreover, the $\alpha$-tocopherol levels that were decreased significantly after TAM treatment were partially restored by the addition of the snacks to the diet of animals. On the other hand, we have not found differences with respect the marker of inflammation interleukin 6 in the groups of rats supplemented with the snack either impregnated or not with mandarin juice.

In the Figure 4 are shown the results found in the six groups of animals with respect the parameters related to protein oxidation, DNA damage and $\alpha$ tocopherol level measured in the liver homogenate. The protein and DNA oxidative damage that was increased significantly after TAM decrease until normal values after supplementation with the snack. There were not differences between the results obtained after supplementation with the snack impregnated or not with mandarin juice. Contrarily, the $\alpha$-tocopherol levels in liver homogenate obtained from rats after supplementation with the snack impregnated with mandarin juice (TAM+APPLE+VIM group) were significantly higher than those obtained in rats feed with the snack no impregnated (TAM+APPLE group).

\section{DISCUSSION}

In the present study, we confirmed our previous hypothesis that the consumption of the apple snacks counteract liver toxicity produced by TAM administration in rats, probably as a result of reducing the oxidative protein and DNA status. The additional effect of the mandarin juice included into the snack development was manifested by enhancing the antioxidant defense.

As it was expected, TAM in toxic doses produces liver injury in the animals. This fact is shown by the increased activity of ALT and AST in plasma and it can be attributed to hepatic structural damage as these enzymes are normally localized in the cytoplasm (ALT) and mitochondria (AST) of hepatocytes and are released into the circulation after cellular damage has occurred. Also, oxidative stress evaluated by a combination of biomarkers that represent different aspects of oxidative damage or antioxidant capacity was present after TAM administration.

It was previously shown the presence of lipoperoxidation in the pathogenesis of TAM-induced liver toxicity (Albukhari et al., 2009). In addition, protein carbonylation is one of the reactions set into motion as a consequence of the formation of oxygen radicals in cells and tissues (Grattagliano et al., 2009). CG are formed early and circulate in the blood for longer periods, compared with the 
other parameters of oxidative stress (Dalle-Donne et al., 2003).Thus, the quantification of CG could be used to measure the extent of oxidative modification to cellular proteins. In this sense, the content of CG generated by oxidation of proteins significantly increases both in plasma and liver homogenate of the animals treated with TAM indicating a deep damage to cells.

A significant increase in the modified nucleoside base $80 \mathrm{HdG}$ in the liver homogenate that reflects DNA covalent modifications was also noted. This alteration in the DNA structure may be at the basis of apoptosis induced by TAM but also is responsible of liver damage (Zhao et al., 2009). All these findings suggest a liver injury promoted by TAM administration and the presence of oxidative stress.

With respect to antioxidant defense, it has been described that TAM alters the endogenous antioxidant glutathione (Albukhari et al., 2009). We have found that $\alpha$-tocopherol a major exogenous antioxidant that acts as a "scavenger" capturing the reactive oxygenic species, was also decreased in the liver and at plasmatic level after TAM treatment, probably as a consequence of its consumption in the situation of enhanced oxidative stres. In general, to prevent or slow down the consequences of oxidative stress induced by free radicals, a sufficient amount of endogenous and exogenous antioxidants is needed. Exogenous antioxidants are provided by the diet. It is known that fruits and vegetables contain a wide variety of antioxidant substances such as vitamins, phenolic compounds and carotenoids that may help to protect cellular systems from oxidative damage. These particular constituents in foods might exert synergistic antioxidant actions or protect by different mechanisms. It is also important to take into account that some compounds with limited direct antioxidant activity might exert antioxidant action in vivo by upregulating endogenous antioxidant factors.

The specific characteristics of fruits have lead to an emerging area in agroalimentary industry in which fruit based functional foods are in progress (Fito et al., 2001). Characterisation of food properties and analysis of bioactive composition are not the only requirement during food research and product development but also the evaluation of the beneficial effects that can exert those bioactive components in vivo studies to verify health content claims. In this sense, the antiradical activity of the product used in the present study (slices of dehydrated apple enriched with mandarin juice by VI) has been evaluated in a previous work; their antioxidant compounds derived from apple and from mandarin juice also have been identified (Betoret et al., in press). In the current study we have proven the effect in vivo. Our results show that after dietary supplementation with this product the antioxidant capacity increases after 30 minutes and are maximally available 60 minutes after ingestion. Hence, we can infer that the developed product has antioxidant effect in vivo. This result agrees with those obtained by other authors in which humans were supplemented with apple juice and increase their antioxidant capacity (Vieira et al., 2012). 
We have also observed a normalisation in the levels of hepatic enzymes in the rats supplemented with the snacks after the injury provoked by TAM. Thus, the action of this food product might be to down regulate ongoing oxidative stress and/ or inflammatory processes induced by TAM, allowing for the recovery of function of cellular homeostasis. In the present experiment, we have demonstrated that the supplementation with apple snacks markedly attenuated hepatic protein and DNA oxidation induced by the xenobiotic, which is consistent with welldocumented in vitro free radical-scavenging ability and antioxidant activity of the apple products (Kujawska et al., 2011).

Protein carbonyl content is by far the most common marker of protein oxidation. CG are relatively difficult to induce compared to other products of protein oxidation. Thus, they are reflective of more severe cases of oxidative stress. In rats treated with TAM dose used here, the concentration of serum protein carbonyls was distinctly increased. We have noted a significant protective effect with a decrease in this biomarker mostly in the animals supplemented with the apple snacks VI, suggesting the action of specific compounds present in mandarin juice and not in the apple (Choi, 2008). Because TAM contributes to increased free radical production in many ways (Nazarewicz et al., 2007) the administration of specific agents with antioxidant or free radical-scavenging activity could be important for the protection against its deleterious action.

DNA damage results from the balance between the action of xenobiotic metabolites and the power of numerous possible counteracting systems, such as endogenous antioxidant defense and repair of the occurring lesions. Both apples (Poulsen et al., 2011) and citrus (Razo-Aguilera et al., 2011) show a strong protective effect against hydrogen peroxide-induced DNA damage. Hence, a product that combines these two fruits could be effective. However, the incorporation of mandarin juice to the snacks did not offer an additional advantage.

Determination of $\alpha$-tocopherols may contribute to the information on the antioxidant status at hepatic level. Moreover, it is known from previous studies that the concentration of this antioxidant in the blood decreases as a consequence of increased oxidative load (Patil et al., 2008). On that account it was expected that the concentration of $\alpha$-tocopherol in plasma would decrease in TAM toxicity as occurs in the experiment. Animals from the group fed with the apple snack VI of mandarin juice presents the highest plasma $\alpha$-tocopherol concentration that was statistically different from the apple snack without VI. This difference was also noted in liver. These results may be due to the high content on vitamin $C$ of mandarin juice because, in addition to scavenging reactive oxygen species, ascorbic acid can prevent the loss of lipophilic antioxidant $\alpha$-tocopherol by repairing tocopheryl radicals (Bruno et al., 2006).

A possible explanation for the greater effect of the snacks impregnated with mandarin juice in several markers of oxidative stress may be found in the synergistic activity of different natural antioxidants in the product that therefore 
may be more effective than supplementation with only apple snacks. According to data in the literature apples contain more phenols (Jung et al., 2009) and mandarins more vitamin $\mathrm{C}$ and specific flavonoids and carotenoids (Sentandreu et al., 2007). This finding is in accordance with that of previous studies in which animals supplemented with different fruits shown different responses in the parameters of oxidative stress (Pajk et al., 2006).

In general terms, we have found that both plasma and liver markers of oxidative stress decrease significantly after snack consumption, in most of cases they even reach normal values as those achieved previous to induce the stress with TAM. The plasma CG and ALT decrease more markedly after consumption of impregnated snack with respect the non impregnated snack. The effect of the mandarin juice incorporated into the structure of apple mainly accounts for the increasing observed in $\alpha$-tocopherol levels suggesting that at least some of the beneficial effects of these enriched diets in snacks VI might be exerted through to the downregulation of oxidative alteration of macromolecules.

\section{CONCLUSION}

In summary, the present study has shown the potential protective action of a foodstuff made of apple and mandarin by preventing damage of essential cellular macromolecules in the conditions of chemically induced oxidative stress in rat. Our results indicate that feeding of the snack impregnated with mandarin juice has an antioxidant effect in vivo and may prevent the toxicity generated after TAM supplementation in rats. The overall protective effect of the impregnated snack is probably due to a counteraction of free radicals by its antioxidant nature and/ or to its ability to restore the normalcy in tissue under oxidative stress. However, the precise molecular mechanism by which the impregnated snack exerts its protective action against oxidative damage remains to be established.

\section{ACKNOWLEDGEMENTS}

Authors acknowledge Ministerio de Ciencia e Innovación of Spain for its contribution through projet PET2008_0015.

\section{REFERENCES}

Albukhari, A.A., Gashlan, H.M., El-Beshbishy, H.A., Nagy, A.A., Abdel-Naim, A.B., 2009. Caffeic acid phenethyl ester protects against tamoxifen-induced hepatotoxicity in rats. Food Chem. Toxicol. 47:1689-1695.

Arnaud, J., Fortis, I., Blachier, S., Kia, D., Favier, A., 1991. Simultaneous determination of retinol, alpha-tocopherol and beta-carotene in serum by isocratic high-performance liquid chromatography. J. Chromatogr. 572, 103116. 
Benzie, I.F., Strain, J.J., 1999. Ferric reducing/antioxidant power assay: direct measure of total antioxidant activity of biological fluids and modified version for simultaneous measurement of total antioxidant power and ascorbic acid concentration. Methods Enzymol. 299, 15-27.

Betoret, E., Betoret, N., Carbonell, J.V., Fito, P., 2009. Effects of pressure homogenization on particle size and the functional properties of citrus juices. J. Food Eng. 92, 18-23.

Betoret, E., Sentandreu, E., Betoret, N., Codoñer-Franch, P., Valls-Bellés, V., Fito, P. (in press). Technological development and functional properties of an apple snack rich in flavonoid form mandarin juice. Inn. Food Sci. Emerg. Technol. doi: 10.1015/ j.ifset.2012.07.003.

Bruno, R.S., Leonard, S.W., Atkinson, J., Montine, T.J., Amakrishnan, R., Bray, T.M., Traber, M.G., 2006. Faster plasma vitamin E disappearance in smokers is normalized by vitamin C supplementation. Free Radic. Biol. Med. 40, 689-697.

Bouayed, J., Hoffmann, L., Bohn, T., 2011. Antioxidative mechanisms of whole-apple antioxidants employing different varieties from Luxembourg. J. Med. Food 14, 1631-1637.

Buscemi, S., Rosafio, G., Arcoleo, G., Mattina, A., Canino, B., Montana, M., Verga, S., Rini, G., 2012 Effects of red orange juice intake on endothelial function and inflammatory markers in adult subjects with increased cardiovascular risk. Am. J. Clin. Nutr. 95,1089-1095.

Choi, E.J., 2008. Antioxidative effects of hesperetin against 7,12dimethylbenz(a)anthracene-induced oxidative stress in mice. Life Sci., 82, 1059-1064.

Dalle-Donne, I., Rossi, R., Giustarini, D., Milzani, A., Colombo, R., 2003. Protein carbonyl groups as biomarkers of oxidative stress. Clin. Chim. Acta 329, 23-38.

Eilat-Adar, S., Goldbourt, U., 2010. Nutritional recommendations for preventing coronary heart disease in women: evidence concerning whole foods and supplements. Nutr. Metab. Cardiovasc. Dis. 20, 459-466.

Fito, P., Chiralt, A., Betoret, N., Gras, M. L., Cháfer, M., Martínez-Monzó, J., Andrés, A., Vidal, D., 2001. Vacuum impregnation and osmotic dehydration in matrix engineering: Application in functional fresh food development. J. Food Eng. 49, 175-183.

Garg, A., Garg, S., Zaneveld, L.J., Singla, A.K., 2001. Chemistry and pharmacology of the Citrus bioflavonoid hesperidin. Phytother. Res. 15, 655-669.

Grattagliano, I., Bonfrate, L., Diogo, C.V., Wang, H.H., Wang, D.Q., Portincasa, P., 2009. Biochemical mechanisms in drug-induced liver injury: certainties and doubts. World J. Gastroenterol. 21, 4865-4876.

Jedrychowski, W., Maugeri, U., Popiela, T., Kulig, J., Sochacka-Tatara, .E, Pac, A., Sowa, A., Musial, A., 2010. Case-control study on beneficial effect of regular consumption of apples on colorectal cancer risk in a population with relatively low intake of fruits and vegetables. Eur.J. Cancer Prev. 19, 42-47. 
Jones, P.J., Asp, N.G., Silva, P., 2008. Evidence for health claims on foods: how much is enough? Introduction and general remarks. J. Nutr. 138, 1189S-1191S.

Jung, M., Triebel, S., Anke, T., Richling, E., Erkel, G., 2009. Influence of apple polyphenols on inflammatory gene expression. Mol. Nutr. Food. Res. 53, 12631268.

Kujawska, M., Ignatowicz, E., Ewertowska, M., Markowski, J., Jodynis-Liebert, J., 2011. Cloudy apple juice protects against chemical-induced oxidative stress in rat. Eur.J. Nutr. 50, 53-60.

Levine, R.L., Garland, D., Oliver, C.N., Amici, A., Climent, I., Lenz, A.G., Ahn, B.W., Shaltiel, S., Stadtman, E.R., 1990. Determination of carbonyl content in oxidatively modified proteins. Methods Enzymol. 186, 464-478.

Miller, N.J., Rice-Evans, C.A., 1997. Factors influencing the antioxidant activity determined by the ABTS.+ radical cation assay. Free Radic. Res. 26, 195-199.

Nazarewicz, R.R., Zenebe, W.J., Parihar, A., Larson, S.K, Alidema, E., Choi, J., Ghafourifar, P., 2007. Tamoxifen induces oxidative stress and mitochondrial apoptosis via stimulating mitochondrial nitric oxide synthase. Cancer Res. 67, 1282-1290.

Pajk, T., Rezar, V., Levart, A., Salobir, J., 2006. Efficiency of apples, strawberries, and tomatoes for reduction of oxidative stress in pigs as a model for humans. Nutrition 22, 376-384.

Patil, S.B., Kodliwadmath, M.V., Kodliwadmath, S.M, 2008. Lipid peroxidation and antioxidant status in hypertensive pregnancies.Clin. Exp. Obstet. Gynecol. 35, 272-274

Poulsen, M., Mortensen, A., Binderup, M.L., Langkilde, S., Markowski, J., Dragsted, L.O., 2011. The effect of apple feeding on markers of colon carcinogenesis. Nutr. Cancer. 63, 402-409.

Razo-Aguilera, G., Baez-Reyes, R., Alvarez-González, I., Paniagua-Pérez, R., Madrigal-Bujaidar, E., 2011. Inhibitory effect of grapefruit juice on the genotoxicity induced by hydrogen peroxide in human lymphocytes. Food Chem. Toxicol. 49, 2947-2953.

Re, R., Pellegrini, N., Proteggente, A., Pannala, A., Yang, M., Rice-Evans, C., 1999. Antioxidant activity applying an improved ABTS radical cation decolorization assay. Free Radic. Biol. Med. 26, 1231-1237.

Santos, D.L., Moreno, A.J., Leino, R.L., Froberg, M.K., Wallace, K.B., 2002. Carvedilol protects against doxorubicin-induced mitochondrial cardiomyopathy. Toxicol. Appl. Pharmacol. 185, 218-227.

Sentandreu, E., Izquierdo, L., Sendra, J.M., 2007. Differentiation of juices from clementine (Citrus clementina), clementine-hybrids and satsuma (Citrus unshiu) cultivars by statistical multivariate discriminant analysis of their flavanone-7-0-glycosides and fully methoxylated flavones content as determined by liquid chromatography. Eur. Food Res. Technol. 2007; 224, 421429 . 
Soyalan, B., Minn, J., Schmitz, H.J., Schrenk, D., Will, F., Dietrich. H., Baum, M., Eisenbrand, G., Janzowski, C., 2011. Apple juice intervention modulates expression of ARE-dependent genes in rat colon and liver. Eur. J. Nutr. 50, 135143.

Tian, L., Cai, Q., Wei, H., 1998. Alterations of antioxidant enzymes and oxidative damage to macromolecules in different organs of rats during aging. Free Radic. Bio.l Med. 24, 1477-1484.

Vieira, F.G., Di Pietro, P.F., da Silva, E.L., Borges, G.S., Nunes, E.C., Fett, R.. 2012. Improvement of serum antioxidant status in humans after the acute intake of apple juices. Nutr. Res. 2012, 32, 229-232.

Zhao, L., Krishnan, S., Zhang, Y., Schenkman, J.B., Rusling, J.F., 2009. Differences in metabolite-mediated toxicity of tamoxifen in rodents versus humans elucidated with DNA/microsome electro-optical arrays and nanoreactors. Chem. Res. Toxicol. 22, 341-347. 
Desarrollo tecnológico y valoración funcional de aperitivos de manzana y zumo de mandarina 


\section{Dried apple snacks enriched with mandarin juice improves antioxidant capacity and decreases inflammation in obese children.}

Pilar Codoñer-Franch a,b,*, Ester Betoret c, Noelia Betoret c, Ana B. López-Jaén b, Victoria Valls-Bellés ${ }^{b}$, Fito $\mathrm{P}^{\mathrm{c}}$.

a Department of Pediatrics, Dr. Peset University Hospital, Avenida de Gaspar Aguilar 90, 46017 Valencia, Spain.

b Department of Pediatrics, Obstetrics and Gynecology, University of Valencia, Avenida de Blasco Ibañez 15, 46010 Valencia, Spain.

c Institute of Food Engineering for Development, Department of Food Technology, Universidad Politécnica de Valencia, Camino de Vera s/ n, 46022 Valencia, Spain

*Corresponding author: Dr P Codoñer-Franch, Department of Pediatrics, Dr. Peset University Hospital, Avenida Gaspar Aguilar 90, 46017 Valencia, Spain. Telephone number: +34961622389. Fax number: +34963864815. E-mail: pilar.codoner@uv.es.

\section{A R T I CLE INFO ABSTRACT}

Article history:

Received 31 October 2012

Received in revised form

Accepted

Available online

Keywords:

Antioxidants

Apple

Cardiovascular risk

Citrus juice

Vacuum impregnation
Few children meet the daily recommendations of fruits and vegetables to ensure an adequate intake of antioxidants. The goal of food industry is obtaining products with a favorable action on health. We have used vacuum impregnation to introducing mandarin juice into the structure of apples, to obtain a product rich in flavonoids and vitamin $\mathrm{C}$ which can be consumed as snack. A four-week intervention study was conducted in 41 obese children to examine whether the dietary intake of the snacks ( $40 \mathrm{~g} /$ day) is associated with a modification of oxidative status, biomarkers of systemic inflammation and cardiometabolic risk factors. An improvement in systolic blood pressure and lipid profile was noted. A significant increase in the antioxidant capacity of serum (ABTS and FRAP assays) and a reduction in DNA oxidative damage and in inflammatory markers was found. Overall, short-term intake of the product ameliorates several risk factors for atherosclerosis.

\section{INTRODUCTION.}

A large body of evidence indicates that the risk of degenerative diseases such as obesity, atherosclerosis, diabetes and cancer is considerably lower in people who consume above average amount of fruits and vegetables (Boeing, et al., in press). Various plant-derived compounds such as fiber or antioxidants may account for these protective effects (Holt et al., 2009). Antioxidants including tocopherols, ascorbic acid, vitamin A or its precursor, beta-carotene and other phytochemicals (polyphenol) can modulate the maintenance of oxidant-antioxidant balance and may thereby influence the health status. Widely recognized as the best approach to ensure an adequate intake of antioxidant nutrients are at least 5 servings of fruits 
and vegetables a day (Nicklas, Johnson, \& American Dietetic Association, 2004). However this is not always a practical recommendation because of variations in individual dietary practices or preferences. In fact, specific studies carried out in children shown that few children meet these recommendations (Pabayo, Spence, Casey, \& Storey, 2012). In this sense, the intake of products especially rich in these bioactive compounds can be an interesting approach.

The increasing interest of people for the consumption of foods that have a beneficial effect on health has oriented both the research and the production in food industry towards the goal of obtaining such products. Apples are one of the main sources of dietary antioxidants including the phenolic compounds. Furthermore, apples can be used as a source for the production of healthy products. Another fruits rich in antioxidant compounds and vitamin $\mathrm{C}$ are the citrus. We previously have found that the intake of a natural product with a great amount of specific flavonoids and carotenoids such as mandarin juice (Sentandreu, Izquierdo \& Sendra, 2007) exert a beneficial effect on hypercholesterolemic (Codoñer-Franch et al., 2008) and obese children (Codoñer-Franch et al, 2010) that can avoid or delay the development of comorbidities.

Vacuum impregnation (VI) is a new technology to introduce the compounds in the internal structure of fruit and vegetables. In fact, application of VI process using fruit juices is an excellent way of producing fortified or value-added fruit products (Joshi, \& Rupasinghe 2010). VI can be used to introducing mandarin juice into the structure of apples, so that the product, slices of apple dried which can be consumed as snacks, becomes strengthened with ascorbic acid and flavonoids solely present in citrus fruits, with a higher antiradical potential (Betoret, et al, in press). The food matrix provided by apples can serve to deliver bioactive substances in a highly amount than the originally present in these fruits and can account for the cooperative interaction of antioxidative nutrients (Singh, Beloy, McInerney, \& Day 2012). Moreover, the matrix may protect at this turn against oxidative stress of the compounds included. Thus, it is expected that the action in vivo can be enhanced with respect the original fruits.

The aim of the present study was to evaluate the effect of incorporating snacks made of dried apple enriched with mandarin juice in the mild energy-restricted diets of obese children. We try to provide useful information about antioxidant and anti-inflammatory potential of the product in vivo. In this way, we conducted an intervention study to examine whether the dietary intake of the snacks is associated with a modification of oxidative status and biomarkers of systemic inflammation, such as high-sensitivity C-reactive protein (CRP), tumor necrosis factor $\alpha$ (TNF- $\alpha$ ), interleukin- $1 \alpha$ (IL- $1 \alpha)$ and Interleukin-6 (IL-6) in obese children.

\section{SUBJECTS AND METHODS.}

To investigate this hypothesis we prospectively undertake a follow-up study during 4 weeks in 48 obese children ( 24 boys) aged between 9 to 15 years 
recruited at the outpatient Pediatric Gastroenterology and Nutrition Clinic of Dr Peset University Hospital where they were referred for their primary care pediatrician for diagnosis and treatment of obesity. All children were free of infectious or inflammatory illness, as was determined by the clinical history. Inclusion criteria were body mass index z-score $\geq 2$ standard deviations according to the Spanish cards. Exclusion criteria were secondary obesity, weight change $( \pm 3$ $\mathrm{kg}$ ) or vigorous exercise within three months before the start of the study, use of vitamin supplements or refusal to take the product. The children were asked to follow a mild energy restricted diet consisting in $-20 \%$ with respect to the individual energy expenditure calculated by Harrris-Benedict equation applying the WHO's correction factors on physical activity. The physical activity pattern was evaluated assigning to each activity the metabolic equivalent.

The follow-up was established for four weeks based in our previous studies (Codoñer-Franch et al., 2008) (Codoñer-Franch et al, 2010). At the inclusion in the study the children underwent medical examination that includes anthropometry [weight, height, waist and hip circumferences and fat mass percentage by a bioelectrical impedance instrument with eight-contact electrodes (BC-418MA; Tanita Europe BV, Hoofddorp, The Netherlands)], measurement of arterial blood pressure and pubertal status evaluation. A blood sample was obtained to biochemical parameters, performed in the Clinical Analytical Laboratory of the Hospital, and markers of oxidative status and inflammation. Participants were instructed not to change their diet or physical activity level during the 4 weeks of the intervention period.

Macronutrient and micronutrient intake during weeks 4 was assessed. The subject's parents recorded what and how much the children ate and drank for three days on a food record. To follow the dietary intake, the parents were interviewed by a nutritionist at a baseline and each two weeks of the intervention period, and dietary records were analyzed using the software Alimentación y Salud, BitASDE (General Médica Farmacéutica, Granada, Spain).

There were two contact clinic visits in the intervention period for each participant (Time 1: Initial, at the inclusion in the study; and Time 2: Endpoint, after four weeks). The subjects' parents or guardians were given the 2 weeks supply at each visit and they ensured that the child took the $40 \mathrm{~g} /$ day (one bag) of supplement. After de 28 day supplement period, subjects returned for clinic visit with anthropometric measurements taken and to give their second sample (endpoint). A dietary record corresponding to the last three days of the 28 day period was collected and compared with baseline and intermediate records. Blood samples from fasting subjects were collected at baseline and after $4 \mathrm{wk}$ and were analyzed in a blinded fashion.

The study followed the Helsinki guidelines and all participants and their parents gave their written informed consent to participate. The protocol was approved by the Ethics Committee of Dr Peset University Hospital. 


\subsection{Fruit based functional product.}

The product used in this research has been specifically designed to carry out this study and it is not a commercial product. The specifications and the product development process have been published in a previous study (Betoret et al., in press).

The fruit based functional product was made from fresh apples and mandarin juice with the addition of any ingredient extra. Apples (cv. Granny Smith) were obtained from a local market. Peeled apples were cut into-disc-shaped samples ( 5 $\mathrm{mm}$ thick, with a $65 \mathrm{~mm}$ external diameter and $20 \mathrm{~mm}$ internal diameter) following their vertical axis. Mandarin (cv. Ortanique) fruits were harvested in an orchard located in Turís (Valencia), Spain, and squeezed immediately for juice preparation. The fruits were washed by immersion in tap water, after which they were drained, and squeezed in an industrial extractor with finger cups (Exzel, Luzzysa; El Puig, Valencia, Spain). Raw juice was divided into two fraction and the low pulp juice fraction was homogenized with a Manton-Gaulin pilot homogenizer (model 15M8TBA) at $15 \mathrm{MPa}$, centrifuged with a Westfalia centrifuge (model SAOH 205), and pasteurized at $63^{\circ} \mathrm{C}$ for $15 \mathrm{~s}$ (Betoret, Betoret, Carbonell, \& Fito, 2009).

The fresh apple slices were impregnated with mandarin juice on a pilot scale using equipment designed in the Institute of Food Engineering for Development of the Polytechnic University in Valencia, Spain following a vacuum technology for impregnation previously used by our group (Fito et al., 2001). A vacuum pressure of 50 mbar was applied. Each apple slice was impregnated $20 \% \mathrm{v} / \mathrm{v}$ and forty grams of snack contained the same amount of flavonoid as $250 \mathrm{ml}$ of mandarin juice. Physicochemical characteristics (moisture content, water activity and soluble solids content) and functional properties (antiradical activity and flavonoids content) of the snack were determined following the procedure described in (ref snack). Vitamin C was analyzed by HPLC (Plaza et al., 2011). All the values are expressed in Table 1.

Table 1. Physicochemical characteristics and composition of the dried apple snack enriched in mandarin juice by vacuum impregnation.

\begin{tabular}{|c|c|}
\hline Energy (kcal/ gsample) & $0.55 \pm 0.02$ \\
\hline Moisture content ( $\left.g_{\text {water }} / g_{\text {sample }}\right)$ & $0.144 \pm 0.012$ \\
\hline Water activity $\left(a_{w}\right)$ & $0.501 \pm 0.002$ \\
\hline Vitamin C ( $\left.\mu \mathrm{g} / \mathrm{g}_{\text {sample }}\right)$ & $16.56 \pm 2.03$ \\
\hline Narirutin ( $\left.\mu \mathrm{g} / \mathrm{g}_{\mathrm{sample}}\right)$ & $40.4 \pm 5.0$ \\
\hline Hesperidin $\left(\mu \mathrm{g} / \mathrm{g}_{\text {sample }}\right)$ & $124.3 \pm 15.4$ \\
\hline Didymin ( $\left.\mu \mathrm{g} / \mathrm{g}_{\text {sample }}\right)$ & $15.3 \pm 1.9$ \\
\hline Total carotenoids $\left(\mu \mathrm{g} / \mathrm{g}_{\text {sample }}\right)$ & $0.647 \pm 0.390$ \\
\hline Antiradical activity $\left(\mathbf{A}_{t}\right)\left(\mathrm{mg}_{\text {ascorbic acid }} / \mathrm{mg}_{\text {sample }}\right)$ & $1.86 \pm 0.03$ \\
\hline
\end{tabular}

Values expressed as mean $\pm \mathrm{SD}(\mathrm{n}=3)$.

After manufacturing process, the snacks were packed in portions of $40 \mathrm{~g}$. The bags used were acquired from Swiss Pack ${ }^{\circledR}$, with opaque material in order to avoid moisture gain and oxidation of the product. The bags were totally sealed 
after fulfilled and were provided to the patients so that were consumed in a period of 2 weeks maximum.

\subsection{Blood samples.}

Blood samples were centrifuged at $3500 \mathrm{rpm}$ for 20 minutes to obtain cell pellet and plasma. Aliquots were obtained, frozen at $-80^{\circ} \mathrm{C}$ in the first hour after collection and stored in Eppendorf tubes until they were processed. Serum glucose, total cholesterol, high-density lipoprotein cholesterol (HDL-C), low-density lipoprotein cholesterol (LDL-C), triglycerides, uric acid, and alanine aminotransferase (ALT), and were measured using direct methods (Aeroset System $\left.{ }^{\circledR}\right)$. Insulin determination, homocystein, and folic acid were measured using the automatyzed electrochemoluminescence immunoassay (Architect c8000®), both (Architect c800 ${ }^{\circledR}$ and the Aeroset System ${ }^{\circledR}$ ) from Abbott Clinical Chemistry (Wiesbaden, Germany). Apoproteins A1 and B were measured using kinetic nephelometry (Immage ${ }^{\circledR}$ Beckman Coulter Inc. Brea, California, U.S.A).

\subsection{Antioxidant status.}

The total antioxidant capacity was determined in the plasma of children using two methods. 1) The ferric reducing antioxidant power (FRAP) method of Benzie and Strain (Benzie, \& Strain, 1996); this method measures the increasing of the absorbance occurred at $593 \mathrm{~nm}$ due to the formation of tripyridyl-s-trizine complexes with ferric (II) (TPTZ-Fe (II)) in the presence of a reductive agent; 2) The 2,2'-azinobis (3-ethylbenzothiazoline-6-sulfonic acid) (ABTS) radical cation decolorization assay was determined according the procedure of $\mathrm{Re}$ et al. (Re et al., 1999), which is based on the reduction of ABTS+• radicals by antioxidants of the plant product.

For the quantification of 8-hydroxydeoxyguanosine (8-OHdG) levels in DNA, a marker of oxidative DNA damage, the DNA was extracted from the samples by proteinase $\mathrm{K}$ digestion in combination with DNeasy Blood \& Tissue kit (QIAGEN, Hilden, Germany. Analysis of 8-OHdG was determined by ELISA using the kit 8-OHdG-EIA-Biotech (Oxis Health Products Inc., Portland, OR, USA).

\subsection{Inflammatory markers assay}

High-sensitivity CRP was measured by nephelometry (Immage Nephelometer ${ }^{\circledR}$, Beckman Coulter Inc. Brea, California, U.S.A). IL-6, IL-1 $\alpha$ and TNF- $\alpha$ were determined in plasma, using the Diaclone Research ELISA kits( IL-6 ELISpot Set, catalogue № 856.021.001, IL-1 $\alpha$ ELISA Set catalogue № 851.600.001, TNF- $\alpha$ ELISpot Set catalogue № 856.041.001) (Diaclone Research, Besancon, France) according to the manufacturer's instructions. 


\subsection{Statistical analysis.}

Sample size was calculated by considering TNF- $\alpha$ as the main variable and applying our previous values for the standard deviation of this marker (CodoñerFranch et al., 2011). We assumed that an arbitrary difference of 0.5 would be clinically relevant. The power of rejecting the null hypothesis was calculated at $80 \%$. The sample size required was a minimum of 36 patients. The paired Student t-test was applied to detect differences before and after nutritional intervention. All reported $\mathrm{p}$ values are for a two-tailed t-test, with statistical significance set at $\mathrm{P}$ $<0.05$.

\section{RESULTS.}

A total of 41 subjects study (20 boys and 21 girls, $11.8 \pm 2.8$ years) of the 48 recruited reported a full completion of the study; thus, the reported compliance was of $85 \%$.

Table 2. Anthropometric and biochemical data of the 41 obese children at baseline and after supplementation with the dried apple snack enriched in mandarin juice by vacuum impregnation.

\begin{tabular}{|c|c|c|c|c|}
\hline & Baseline & Enpoint & Change & Pvalue \\
\hline Weight (kg) & $67 \pm 17$ & $67 \pm 18$ & $0.02 \pm 1.82$ & 0.845 \\
\hline Height $(\mathrm{cm})$ & $156 \pm 16$ & $157 \pm 16$ & $1.1 \pm 3.3$ & 0.040 \\
\hline Body mass index $\left(\mathrm{kg} / \mathrm{m}^{2}\right)$ & $26.8 \pm 3.5$ & $26.5 \pm 3.9$ & $-0.4 \pm 1.3$ & 0.082 \\
\hline Waist circumference (cm) & $90 \pm 12$ & $90 \pm 12$ & $-0.4 \pm 4.9$ & 0.596 \\
\hline Impedance index $\left(\mathrm{cm}^{2} / \Omega\right)$ & $40 \pm 11$ & $40 \pm 10$ & $0.6 \pm 6.3$ & 0.610 \\
\hline Fat mass index $\left(\mathrm{kg} / \mathrm{m}^{2}\right)$ & $10.0 \pm 2.8$ & $10.1 \pm 3.2$ & $0.2 \pm 1.9$ & 0.488 \\
\hline Systolic blood pressure (mmHg) & $118 \pm 9$ & $115 \pm 11$ & $-3.3 \pm 9.5$ & 0.030 \\
\hline Diastolic blood pressure(mmHg) & $69 \pm 10$ & $67 \pm 8$ & $-0.5 \pm 13.7$ & 0.146 \\
\hline Insulin (pmol/ L) & $122 \pm 72$ & $122 \pm 82$ & $0.3 \pm 51.0$ & 0.974 \\
\hline Glucose (mmol/ L) & $5.22 \pm 0.44$ & $5.11 \pm 0.44$ & $-0.1 \pm 0.4$ & 0.071 \\
\hline HOMA-IR & $4.0 \pm 2.3$ & $3.9 \pm 2.7$ & $-0.06 \pm 1.90$ & 0.833 \\
\hline Total cholesterol (mmol/ L) & $4.17 \pm 0.91$ & $4.14 \pm 0.75$ & $-0.02 \pm 0.39$ & 0.698 \\
\hline HDL-cholesterol (mmol/ L) & $1.11 \pm 0.23$ & $1.17 \pm 0.21$ & $0.05 \pm 0.12$ & 0.024 \\
\hline Triglycerides (mmol/ L) & $1.17 \pm 0.60$ & $1.04 \pm 0.45$ & $-0.13 \pm 0.41$ & 0.046 \\
\hline Apoprotein A1 (g/L) & $1.28 \pm 0.20$ & $1.35 \pm 0.22$ & $0.07 \pm 0.17$ & 0.020 \\
\hline Apoprotein B (g/ L) & $0.77 \pm 0.22$ & $0.73 \pm 0.19$ & $-0.03 \pm 0.10$ & 0.042 \\
\hline Uric acid $(\mu \mathrm{mol} / \mathrm{L})$ & $261 \pm 77$ & $262 \pm 71$ & $-0.8 \pm 52.0$ & 0.917 \\
\hline Folic acid (nmol/ L) & $17.2 \pm 8.8$ & $17.4 \pm 10.2$ & $0.5 \pm 4.5$ & 0.959 \\
\hline Homocysteine ( $\mu \mathrm{mol} / \mathrm{L})$ & $61.4 \pm 22.2$ & $62.1 \pm 24.4$ & $1.0 \pm 6.6$ & 0.559 \\
\hline Weight (kg) & $67 \pm 17$ & $67 \pm 18$ & $0.02 \pm 1.82$ & 0.845 \\
\hline Height $(\mathrm{cm})$ & $156 \pm 16$ & $157 \pm 16$ & $1.1 \pm 3.3$ & 0.040 \\
\hline
\end{tabular}

HOMA-IR: homeostasis model assessment of insulin resistance; HDL: high-density lipoprotein. Values are expressed as the means $\pm \mathrm{SD}$.

There were no significant differences between nutrient intakes, exclusive of supplement at time 1 and at time 2. Macronutrient intake was similar at both times. There was a slight reduction in energy and an increase in vitamin $\mathrm{C}$ intake. Data of anthropometric measurements, clinical and biochemical variables before and after intervention are listed in Table 2 . 
Results of the incorporating the snack in the diet does not induced a weight loss or promoted waist circumference or fat mass reduction. However, an improvement in systolic blood pressure, lipid markers (increase in HDL-cholesterol and apoprotein A1 and decrease in triacylglycerols and apoprotein B) were noted.

We have assessed the effects of ingestion of the apple snack enriched with mandarin juice on oxidative status of the obese children. The comparison between antioxidant capacity and $8 \mathrm{OH}-\mathrm{dG}$ before and after nutritional intervention are shown in Table 3. A significant and comparable increase in the antioxidant capacity of serum, measured by ABTS and FRAP assays was found in relation to the baseline values. Indeed, the antioxidant activity statistically increased after the intervention period. We then analysed the effect of the apple snack consumption on DNA damage. The results show a significant reduction in the marker of DNA oxidative damage, the modified base 8-OHdG. Overall, these results shown a decrease in oxidative stress in the children after the intake of the snack.

Table 3. Antioxidant capacity and oxidative damage to DNA of the 41 obese children at baseline and after supplementation with the dried apple snack enriched in mandarin juice by vacuum impregnation.

\begin{tabular}{ccccc}
\hline & Baseline & Enpoint & Change & P value \\
\hline Serum FRAP(mM/ L) & $1.12 \pm 0.26$ & $1.23 \pm 0.29$ & $0.11 \pm 0.27$ & 0.025 \\
Serum ABTS (mM/ L) & $2.60 \pm 1.00$ & $2.88 \pm 1.07$ & $0.28 \pm 0.79$ & 0.035 \\
Urinary 8OhdG (ng/ mL) & $28.1 \pm 4.3$ & $25.1 \pm 3.7$ & $-1.64 \pm 4.11$ & 0.030 \\
\hline
\end{tabular}

FRAP, ferric reducing antioxidant power; ABTS, 2,2'-azino-bis(3-ethylbenzothiazoline-6-sulphonic acid). Data are mean \pm SD.

Interestingly, the markers of inflammation, TNF- $\alpha$, IL- $1 \alpha$ and IL- 6 also decreased after the intervention period with respect to baseline values (Table 4). These results cannot be attributed to weight reduction, caloric deprivation or modification of lifestyle because the children do not modified these parameters within the time of intervention. Likewise, there was no difference between percentage of energy provided by macronutrients before and after intervention.

Table 4. Markers of inflammation of the 41 obese children at baseline and after supplementation with the dried apple snack enriched in mandarin juice by vacuum impregnation.

\begin{tabular}{lcccc}
\hline & Baseline & Enpoint & Change & Pvalue \\
\hline Interleukin 1 $\mathbf{\alpha}(\mathbf{p g} / \mathbf{m L})$ & $3.04 \pm 0.21$ & $2.93 \pm 0.16$ & $-0.11 \pm 0.31$ & 0.044 \\
Interleukin 6 (pg/ mL) & $7.1 \pm 2.2$ & $6.5 \pm 2.3$ & $-0.55 \pm 1.36$ & 0.028 \\
TNF- $\boldsymbol{\alpha}(\mathbf{p g} / \mathbf{m L})$ & $26.6 \pm 5.3$ & $23.4 \pm 7.0$ & $-3.15 \pm 8.2$ & 0.017 \\
hs-CRP (mg/ L) & $2.86 \pm 4.31$ & $1.64 \pm 2.96$ & $-1.21 \pm 4.07$ & 0.060 \\
\hline
\end{tabular}

TNF- $\alpha$ : tumor necrosis factor $\alpha$; hs-CRP: high-sensitivity C-reactive protein. Data are mean \pm SD.

\section{DISCUSSION.}

The main objective of the present study was to investigate whether the intake of a product made of dehydrated apple enriched with mandarin juice affect oxidative status and inflammatory markers in obese children. Our study indicates that short-term intake ( 4 weeks) has major effects on antioxidant capacity of 
plasma, decreases inflammatory systemic markers and ameliorates several cardiovascular risk factors.

Natural foods such as fruits and vegetables are a good source of functional compounds (Valtueña et al., 2008). For example some common fruits, such as citrus juices and apples which are highly consumed all over the world, are rich in bioactive compounds. Between these, certain food-derived components, chemopreventive agents against oxidative damage such as vitamins and phenolics, have received a great deal of attention as a useful strategy for the management of chronic disease. Consumption of citrus juices affects the concentration of vitamin $C$ in blood as well as biomarkers of antioxidant status (Codoñer-Franch, López-Jaén, Muñiz, Sentandreu, \& Valls-Bellés, 2008). These juices are also bioactive against a number of diseases, such as coronary insufficiency (Gorinstein et al., 2004) some age-related disorders (Gao, Cassidy, Schwarzschild, Rimm, \& Ascherio, 2012), and they may reduce the risk of some cancers (Tanaka, Tanaka, Tanaka, \& Kuno, 2011). The great number of bioactive compounds present in citrus juices (including Lascorbic acid, flavonoids and carotenoids among others) is thought to be responsible for these effects. Similarly, apples are a good source of vitamins, polyphenols, minerals and dietary fiber; several studies have linked high apple consumption with decreased risk of cardiovascular disease, diabetes and some cancers (Boyer \& Liu, 2004).

Importance for consumers is that plants offer protection against many degenerative diseases. In this way, fruit derived products are an emerging area within functional foods to improve their health. However, the effect of a single food, nutrient, or food group is not always clear; consumption of foodstuffs can exert more benefit that active components alone because the various nutrients provided by foodstuffs may have a relevant synergic effect. Thus, discovering new combination of natural substances would be an important step. VI technology allows the introduction of mandarin juice into the structural porous matrix of apples. The development of a functional fruit based product combining apples with mandarin juice by VI is very interesting for several reasons. It could combine the beneficial effects of both sources into one food item, or even enhance the beneficial components in the juice by protecting them through inclusion into a food structure. Although some recent studies have shown the antioxidant power of products made with different vegetable matrix such as fruit chips consisted of dried fruits or vegetables (Gramza-Michałowska \& Człapka-Matyasik, 2011) few studies have looked to see the effect in vivo of a product made with a vegetable matrix with VI of fruit juice.

Because of hypothesized effects of fiber on satiety, dried fruit could have a role in reducing prevalence of overweight and obesity. Mandarin juice has also an effect in obese children (Codoñer-Franch et al., 2010). In our study, weight, waist circumference and impedance index was essentially unchanged from baseline. However, a slight BMI change of -0.3 units was noted due to continued growth in 
height. This is a classical goal for the treatment of obesity in children: maintaining the weight whereas height continues to increase.

Altered lipoprotein profile is an important factor in cardiovascular risk. Moreover, the increase of high-density lipoproteins (HDL) plays a key role in the prevention of cardiovascular diseases. We have found an increase in $\mathrm{HDL}$ cholesterol and Apo A1 and a decrease in triglycerides and Apo B which can be protective with regard to cardiovascular risk. It has been shown that citrus juice increased free cholesterol transfer to HDL and decreased triglyceride transfer to HDL (Cesar, Aptekmann, Araujo, Vinagre \& Maranhão, 2010). A daily intake of citrus juice $(750 \mathrm{~mL} /$ day of orange juice) may have a beneficial effect on lipoprotein profiles (Kurowska et al., 2000). However, it is difficult to ensure compliance with these large amounts in children. Apples, on the other hand, have lipid lowering effects mainly attributed to their content in fibers and polyphenols (Lee, Kim, Kim, Lee \& Lee, 2003). In the product studied we can hypothesized that it would be a synergy between flavonoids specifically present in apples (quercetin) and flavonoids specifically present in mandarin juice (flavanones and polymetoxyflavones) (Sentandreu, Izquierdo \& Sendra, 2007) and vitamin C that can modify the lipid profile and can reduce the cardiometabolic risk by mediating the oxidant and proinflammatory process.

The novelty of our work is the demonstration that the compounds present in the product can act in vivo as antioxidants, lowering the inflammatory response and decreasing some cardiovascular risk factors in obese children. These findings are important because the modification of the redox state in adipose tissue could be a therapeutic tool against future metabolic complications in obesity.

The impregnation of apple slices with mandarin juice might result in increased antiradical capacities (Betoret et al., in press).The finding of an improved oxidative status in the subjects after the intake of the product suggests the bioavailability of the compounds and the possibility of the attenuation of the oxidative injury.

Obesity is associated with a long-term inflammatory condition expressed by an increase in CRP levels and it causes an unusual production of proinflammatory cytokines (Cesari et al., 2003) including IL-1 $\alpha$, IL- 6 and TNF- $\alpha$. IL-1 $\alpha$ plays a major role in vascular wall inflammation by activating endothelial cells and monocytes, inducing other cytokines, chemokines and growth factors, and supporting proliferation of smooth muscle cells all of which contribute to atherogenesis (Waehre et al. 2004). It is now well known that IL-6 production by adipose tissue is enhanced in obesity. IL-6 is a multifunctional cytokine acting on many cells and tissues and one of its main effects is the induction of hepatic CRP production. TNF$\alpha$ is a nonspecific indicator of inflammatory processes, and its plasma concentration highly correlates with cardiovascular disease risk. Elevated plasma TNF- $\alpha$ concentrations are also linked to cancer processes. These specific circulating markers of inflammation could play a detrimental role in the development of premature atherosclerosis (Ikonomidis et al., in press). The major effect observed in our study was the reduction in plasma TNF- $\alpha$, IL-1 $\alpha$ and IL-6 
concentrations within short time of intake of the apple snack enriched with mandarin juice. The reduction on markers of inflammation and oxidative stress in obese subjects may offer a strategy to prevent the factors involved in the early onset of cardiovascular risk.

The use of the antioxidans of naturally occurring substances in foodstuffs instead of synthetic antioxidants that may have potential toxicity is nowadays highly demanded (Kyselova, 2011). In this sense, one possible way to improve the quality of the diet is through the fruit and vegetable snacks supply. Theoretical controversy emerges however, because snacking has been linked to increase in total energy supply, particularly in adolescents (Piernas \& Popkin, 2010). In fact snacks are obesity promoters because they are high-fat and high-sugar foods. As the salty snacks and chips are a very popular part of modern youth diet, we can to replace them with other products that are sensory similiar (crispness, thickness), but carry significantly higher amount of potentially bioactive compounds. Healthy snacks would be easily accepted if its sensory characteristics of palatability and consistency are adequate to children.

The present study has limitations, including the relatively low number of subjects studied. Thus, relationships cannot be inferred to general population. One possible limitation could be that the intervention might induce changes in macronutrient intake, such as fat and carbohydrates. The analysis of the food records, however, indicated that the macronutrient intakes were similar in baseline and endpoint. This suggests that the observed changes in inflammatory markers concentrations were specifically related to the snack intake.

On the other hand, this study design has several strengths, notably the meticulous longitudinal analyses of a well-characterized cohort, and measurement of many inflammatory mediators reported to be associated with atherosclerosis.

Thus, the incorporation of the snack of apple dried enriched with mandarin juice into the diet promotes the consumption of better-for-you foods and not only increases healthy bioactive compounds but also secondarily could decrease the intake of snacks with solid fat and added sugars calories. Both effects can counteract the deleterious consequence of childhood obesity. In terms of prevention, health professionals should continue to encourage consumption of all fruit, including dried fruit, as part of a healthy diet and overall healthy lifestyle.

\section{ACKNOWLEDGEMENTS.}

Supported by Ministerio de Ciencia e Innovación of Spain for its contribution through projet PET2008_0015.

\section{CONFLICT OF INTERESTS.}

The authors declare no conflict of interest 


\section{REFERENCES.}

Benzie, I.F.F., \& Strain J.J. (1996). Ferric reducing ability of plasma (FRAP) as a measure of antioxidant power: The FRAP assay. Analytical Biochemistry, 239(1), 70-76.

Betoret, E., Betoret, N., Carbonell, J. V., \& Fito, P. (2009). Effects of pressure homogenization on particle size and the functional properties of citrus juices. Journal of Food Engineering, 92(1), 18-23.

Betoret, E., Sentandreu, E., Betoret, N., Codoñer-Franch, P., Valls-Bellés, V., \& Fito, P. (in press).Technological development and functional properties of an apple snack rich in flavonoid form mandarin juice. Innovative Food Science and Emerging Technologies, doi 10.1015/j.ifset.2012.07.003.

Boein,. H., Bechthold, A., Bub, A., Ellinger, S., Haller, D., Krokem A., et al. (in press). Critical review: vegetables and fruit in the prevention of chronic diseases. European Journal of Nutrition, doi: 10.1007/ s00394-012-0380-y.

Boyer, J. \& Liu, R.H. (2004). Apple phytochemicals and their health benefits. Nutrition Journal, 12, 3:5

Cesar, T.B., Aptekmann, N.P., Araujo, M.P., Vinagre, C.C., \&.Maranhão, R.C. (2010). Orange juice decreases low-density lipoprotein cholesterol in hypercholesterolemic subjects and improves lipid transfer to high-density lipoprotein in normal and hypercholesterolemic subjects. Nutrition Research, 30(10):689-694.

Cesari, M., Penninx, B.W., Newman, A.B., Kritchevsky, S.B., Nicklas, B.J., SuttonTyrrell, K., et al. (2003). Inflammatory markers and cardiovascular disease (The Health, Aging and Body Composition [Health ABC] Study). The American Journal of Cardiology, 92(5), 522-528.

Codoñer-Franch, P., López-Jaén, A.B., De La Mano-Hernández, A., Sentandreu, E., Simó-Jordá, R., \& Valls-Bellés, V. (2010). Oxidative markers in children with severe obesity following low-calorie diets supplemented with mandarin juice. Acta Paediatrica, 99(12), 1841-1846.

Codoñer-Franch, P., López-Jaén, A.B., Muñiz, P., Sentandreu, E., \& Bellés. V.V. (2008). Mandarin juice improves the antioxidant status of hypercholesterolemic children. Journal of Pediatric Gastroenterology and Nutrition, 47(3), 349-355.

Codoñer-Franch, P., Tavárez-Alonso, S., Murria-Estal, R., Megías-Vericat, J., Tortajada-Girbés, M., \& Alonso-Iglesias, E. (2011). Nitric oxide production is increased in severely obese children and related to markers of oxidative stress and inflammation. Atherosclerosis, 215(2), 475-480.

Fito, P., Chiralt, A., Betoret, N., Gras, M. L., Cháfer, M., Martínez-Monzó, J., et al. (2001). Vacuum impregnation and osmotic dehydration in matrix engineering: Application in functional fresh food development. Journal of Food Engineering, 49(2-3), 175-183. 
Gerhauser, C. (2008). Cancer chemopreventive potential of apples, apple juice, and apple components. Planta Medica, 74(13), 1608-1624.

Gorinstein, S., Caspi, A., Libman, I., Katrich, E., Lerner, H.T., \& Trakhtenberg, S. (2004). Fresh israeli jaffa sweetie juice consumption improves lipid metabolism and increases antioxidant capacity in hypercholesterolemic patients suffering from coronary artery disease: studies in vitro and in humans and positive changes in albuminand fibrinogen fractions. Journal of Agricultural and Food Chemistry, 52(16): 5215-5222.

Gramza-Michałowska, A., \& Człapka-Matyasik, M. (2011). Evaluation of the antiradical potential of fruit and vegetable snacks. Acta Scientarum Polonorum Technologia Alimentaria, 10(1):63-72.

Holt, E.M., Steffen, L.M., Moran, A., Basu, S., Steinberger, J., Ross, J.A., et al. (2009). Fruit and vegetable consumption and its relation to markers of inflammation and oxidative stress in adolescents. Journal of the American Dietetic Association, 109(3), 414-421.

Ikonomidis, I., Michalakeas, C.A., Parissis, J., Paraskevaidis, I., Ntai, K., Papadakis, J., et al. (in press). Inflammatory markers in coronary artery disease. Biofactors, doi: $10.1002 /$ biof.1024.

Joshi, A.P., \& Rupasinghe, H.P.V, (2010). Optimization of bioactive fortification in apple snacks through Vacuum Impregnation using Response Surface Methodology. Food and Nutrition Sciences, 2, 45-52.

Kurowska, E.M., Spence, J.D., Jordan J, Wetmore, S., Freeman, D.J., Piché, L.A. et al. (2000). HDL-cholesterol-raising effect of orange juice in subjects with hypercholesterolemia. The American Journal of Clinical Nutrition, 72(5), 10951100.

Kyselova, Z (2011). Toxicological aspects of the use of phenolic compounds in disease prevention. Interdisciplinary Toxicology, 4(4),173-183.

Lee,K.W., Kim, Y.J., Kim, D.O., Lee, H.J., \& Lee, C.Y. (2003). Major phenolics in apple and their contribution to the total antioxidant capacity. Journal of Agricultural and Food Chemistry, 51(22), 6516-6520.

Nicklas, T., Johnson R., \& American Dietetic Association (2004). Position of the American Dietetic Association: Dietary guidance for healthy children ages 2 to 11 years. Journal of the American Dietetic Association, 104(4), 660-677.

Pabayo, R., Spence, J.C., Casey, L., \& Storey, K. (2012). Food consumption patterns in preschool children. Canadian Journal of Dietetic Practice and Research, 73(2), 66-71.

Piernas, C., \& Popkin, B.M. (2010). Dynamics of U.S. child snacking: movement toward constant eating. Health Affairs, 29(3):398-404

Plaza, L., Crespo, I., Pascual-Teresa, S., Ancos, B., Sánchez-Moreno, C., Muñoz, M. \& Cano, M.P. (2011). Impact of minimal processing on orange bioactive compounds during refrigerated storage. Food Chemistry, 124(2), 646-651. 
Re, R., Pellegrini, N., Proteggente, A., Pannala, A., Yang, M., \& Rice-Evans, C. (1999). Antioxidant activity applying an improved ABTS radical cation decolorization assay. Free Radical Biology and Medicine, 26(9-10), 1231-1237.

Sentandreu, E., Izquierdo, L., \&.Sendra, J.M. (2007). Differentiation of juices from clementine (Citrus clementina), clementine-hybrids, and Satsuma (Citrus unshiu) cultivars by statistical multivariate discriminant analysis of their flavanone-7-0-glycosides and fully methoxylated flavones content as determined by liquid chromatography. European Food Research and Technology; 224(4), 421-429.

Singh, D.P., Beloy, J., McInerney, J.K., \& Day, L. (2012). Impact of boron, calcium and genetic factors on vitamin $\mathrm{C}$, carotenoids, phenolic acids, anthocyanins and antioxidant capacity of carrots (Daucus carota). Food Chemistry, 132(3), 11611170.

Tanaka, T, Tanaka, T., Tanaka, M., \& Kuno, T. (2012). Cancer chemoprevention by citrus pulp and juices containing high amounts of $\beta$-cryptoxanthin and hesperidin. Journal of Biomedicine and Biotechnology, 2012:516981.

Valtueña, S., Pellegrini, N., Franzini, L., Bianchi, M.A., Ardigó, D., Del Rio, D., et al. (2008). Food selection based on total antioxidant capacity can modify antioxidant intake, systemic inflammation, and liver function without altering markers of oxidative stress. The American Journal of Clinical Nutrition, 87(5):1290-1297.

Waehre, T., Yndestad, A., Smith, C., Haug, T., Tunheim, S.H., Gullestad, L., et al. (2004). Increased expression of interleukin-1 in coronary artery disease with downregulatory effects of $\mathrm{HMG}-\mathrm{CoA}$ reductase inhibitors. Circulation, 109(16),1966-1972. 
Desarrollo tecnológico y valoración funcional de aperitivos de manzana y zumo de mandarina 
3.6. Efecto del proceso de fabricación del alimento funcional a partir de manzana y zumo de mandarina con microorganismos probióticos sobre el contenido en microorganismos viables y las propiedades fisicoquímicas y funcionales en contra de la infección ocasionada por Helicobacter pylori. 



\section{No invasive methodology to produce a probiotic low humid apple snack with potential effect against Helicobacter pylori.}

E. Betoret ${ }^{a}$, N. Betoret ${ }^{a}$, A. Arillaa, M. Bennára , C. Barreraa , P. Codoñerb and P. Fito*a a Institute of Food Engineering for Development, Department of Food Technology, Universidad Politécnica de Valencia, Camino de Vera s/ n, 46022 Valencia, Spain.

b Department of Pediatrics, Obstetrics, and Gynecology. Facultad de Medicina y Odontología, Universidad de Valencia, Avenida Blasco Ibáñez, 15, 46010 Valencia (Spain).

* Corresponding author. Address: Institute of Food Engineering for Development, Department of Food Technology, Universidad Politécnica de Valencia, Camino de Vera s/n, 46022 Valencia, Spain. Tel.: +34 96387 7367. Fax.: +34 96387 7056. E-mail address: pfito@tal.upv.es

\section{A R T I CLE INFO A B S TRACT}

Article history: Available online 28 April 2011

Keywords:

Probiotic

Lactobacillus salivarius

spp. salivarius

Mandarin juice

Pineapple/ grape juice Vacuum impregnation Helicobacter pylori
A probiotic low humid apple snack with potential effect against the infection caused by Helicobacter pylori has been developed from apple (cv. Granny Smith) and mandarin juice with a high microbial content of Lactobacillus salivarius spp. salivarius, by vacuum impregnation and hot air drying techniques. The moisture content reached in the final product $\left(0.144 \pm 0.012 \mathrm{~g}_{\text {water }} \cdot \mathrm{g}^{-1}\right.$ sample $)$ ensured stability, and although the drying process affected the microbial content, the concentration in the final product $(9.486 \pm 0.013) \cdot 10^{7}$ $\mathrm{CFU} \cdot \mathrm{g}^{-1}$ dry sample) was sufficient to confirm that with this procedure it is possible to obtain a stable probiotic fruit with a low moisture content. Additionally, a preliminary in vivo test with five dyspeptic children was undertaken that suggested the possible effect of this new product on Helicobacter pylori as measured by a standard infection indicator.

\section{INTRODUCTION.}

Probiotics are defined as live microbial food ingredients that have a beneficial effect on human health (Salminen et al., 1999) or as live microbial food supplements which beneficially affect the host by improving the intestinal microbial balance (Fuller, 1989). Scientific evidence suggests that probiotic bacteria, consumed at high levels (109-1011 CFU per day) can decrease the incidence, duration, and severity of some intestinal illnesses (Sanders, 1999). For example, it has been shown that Lactobacillus salivarius suppress Helicobacter 
pylori and reduces the inflammatory responses in gnobiotic mice better than $\mathrm{L}$. casei (Aiba et al., 1998) and L. acidophilus has been demonstrated to inhibit $\mathrm{H}$. pylori better than other strains (Mrda et al., 1998; Canducci et al., 2000; Sheu et al., 2002). H. pylori is an etiologic agent of chronic gastritis and gastroduodenal ulcers and its inclusion by the International Agency for Research on Cancer in 1994 as a carcinogenic agent type 1, has turned it into one of the most interesting microorganisms in human pathology. In developing countries $\mathrm{H}$. pylori can affect up to $90 \%$ of the population and its treatment is based on antibiotic therapy, but this has the disadvantages of being expensive, risks poor compliance, causes side effects and in particular, encouraging the emergence of resistance (Gold et al., 2000).

Currently, industrial probiotic foods are mainly dairy products, which have a microbial content in excess of $10^{6} \mathrm{CFU} \cdot \mathrm{cm}^{-3}$ at the end of their shelf life (Ouwehand et al., 1999). However, lactose intolerance and the cholesterol content are two drawbacks related to their consumption. Techniques such as vacuum impregnation though, make it possible to obtain fruit and vegetables enriched with probiotic microorganisms or minerals (Betoret et al., 2003). Vacuum impregnation allows, by means of pressure gradients, the incorporation of components into the structural matrix of foodstuffs without substantially modifying its organoleptic properties (Patent P99 02730-5 titled "Procedimiento de impregnación de alimentos naturales con productos nutracéuticos y dispositivo para su puesta en práctica"). The pressure gradients created in this system and the capillary pressure at the entrance of the pores produces an important transference of gas and liquid between the solid and the impregnating liquid (Fito et al., 2001; Betoret et al., 2003; Cháfer et al., 2003; Alzamora et al., 2005). Following vacuum impregnation, fruit and vegetables are highly unstable due to their high water content, and therefore it is necessary to apply a preservation method to increase their shelf life.

The development of a functional food from fresh fruit or vegetables with high microorganism content is extremely interesting not only because it represents an opportunity within the functional food industry but also because it can be used to reduce the disadvantages and side effects of traditionally used treatments. In order to commercialise a functional product it is necessary to prove scientifically, using both in vitro and in vivo studies its beneficial effects (Regulation CE № 1924/ 2006). In the case of $H$. pylori infections, these studies should be directed towards reducing infection (Hamilton-Miller, 2003). To determine levels of infection, the breath test using labelled urea has been used extensively in studies (Michetti et al., 1999; De Vrese and Schrenmeir, 2000; Sakamoto et al., 2001).

The aim of this research is to determine both adequate material and process conditions to develop a probiotic low humid apple snack with potential effect against infection caused by Helicobacter pylori. 


\section{MATERIALS AND METHODS.}

\subsection{Bacterial cultures.}

Lactobacillus salivarius spp. salivarius CECT 4063 and Lactobacillus acidophilus CECT 903 were obtained from the Spanish Type Culture Collection (CECT).

\subsection{Food materials.}

Apples (cv. Granny Smith) from a local market were used to be vacuum impregnated. Peeled apples were cut into disc-shaped samples ( $5 \mathrm{~mm}$ thick, with a $65 \mathrm{~mm}$ external diameter and $20 \mathrm{~mm}$ internal diameter) following their vertical axis. Three samples were obtained from each apple and utilised for vacuum impregnation. Two commercial fruit juices, mandarin Don Simon ${ }^{\circledR}$ and pineapple/ grape Don Simon ${ }^{\circledR}$, were selected as the impregnation liquid in order to minimise the effects on the characteristics of the fresh fruit.

\subsection{Impregnation liquid preparation.}

Lyophilised cultures were recovered following growth on MRS broth for $24 \mathrm{~h}$ at $37^{\circ} \mathrm{C}$. The cultures were then transferred into mandarin and pineapple/ grape juices where the $\mathrm{pH}$ of the juices had been adjusted by the addition of sodium bicarbonate $\mathrm{pH}$ 5, 5.5 and 6. Four millilitres MRS broth with microorganism content of $10^{9} \mathrm{CFU} / \mathrm{ml}$ were added to $1 \mathrm{~L}$ of juice. The inoculated juices were grown for 24 and 48 hours at $37^{\circ} \mathrm{C}$ resulting in 12 different growth media: 6 mandarin and 6 pineapple/ grape juices. The mandarin juice inoculated with L. salivarius spp. salivarius at $\mathrm{pH} 6$ and after 24 hours incubation was achieved with maximum microbial content and was selected as impregnation liquid. The values stated are the average of five replicates.

\subsection{Physicochemical characterisation.}

Total soluble solids were measured in Brix units with a refractometer (ABBE ATAGO, NAR T3, Japan) at $20^{\circ} \mathrm{C}$ and $\mathrm{pH}$ values were determined with a potentiometer (micropH CRISON, 2001). The density of the juices was determined with a liquid picnometer. Water activity was measured using a dewpoint hygrometer (DECAGÓN Aqualab CX-2, $\pm 0,003$ ) and the water content was quantified by vacuum drying at $60^{\circ} \mathrm{C}$ until a constant weight was achieved (method 20.013 AOAC, 1980). The values stated are the average of three replicates. 


\subsection{Microbial content.}

The microbial content was determined following growth in MRS agar mandarin juice and pineapple/ grape juice with $\mathrm{pH}$ values of 5, 5.5, 6 were counted on double layer MRS agar following incubation for 24 hours at $37 \stackrel{\circ}{\circ}$.

To determine the microbial content of the impregnated samples, 5 grams of sample were mixed and crushed with $45 \mathrm{ml}$ of buffered peptone water, following $10^{-1}$ to $10^{-8}$ dilutions the lactobacilli were counted on double layer MRS agar after incubation for 24 hours at $37 \stackrel{\circ}{\circ}$.

To determine the microbial content of the dried samples, these were rehydrated with mandarin juice $(\mathrm{pH} 6)$ at a ratio of $50 \mathrm{~cm}^{3}{ }_{\text {liquid }} \cdot \mathrm{g}^{-1}$ sample at $25{ }^{\circ} \mathrm{C}$ over 24 hours. Following rehydration, the microbial content was determined as for the impregnated samples. For the dried samples, the microbial content was estimated with the mass balance performed in the rehydration operation (Betoret et al., 2003). The values stated are the average of ten replicates.

\subsection{Methodology to produce probiotic enriched dried apple.}

In the Figure 1 it is shown the flow chart to produce probiotic enriched dried apple.

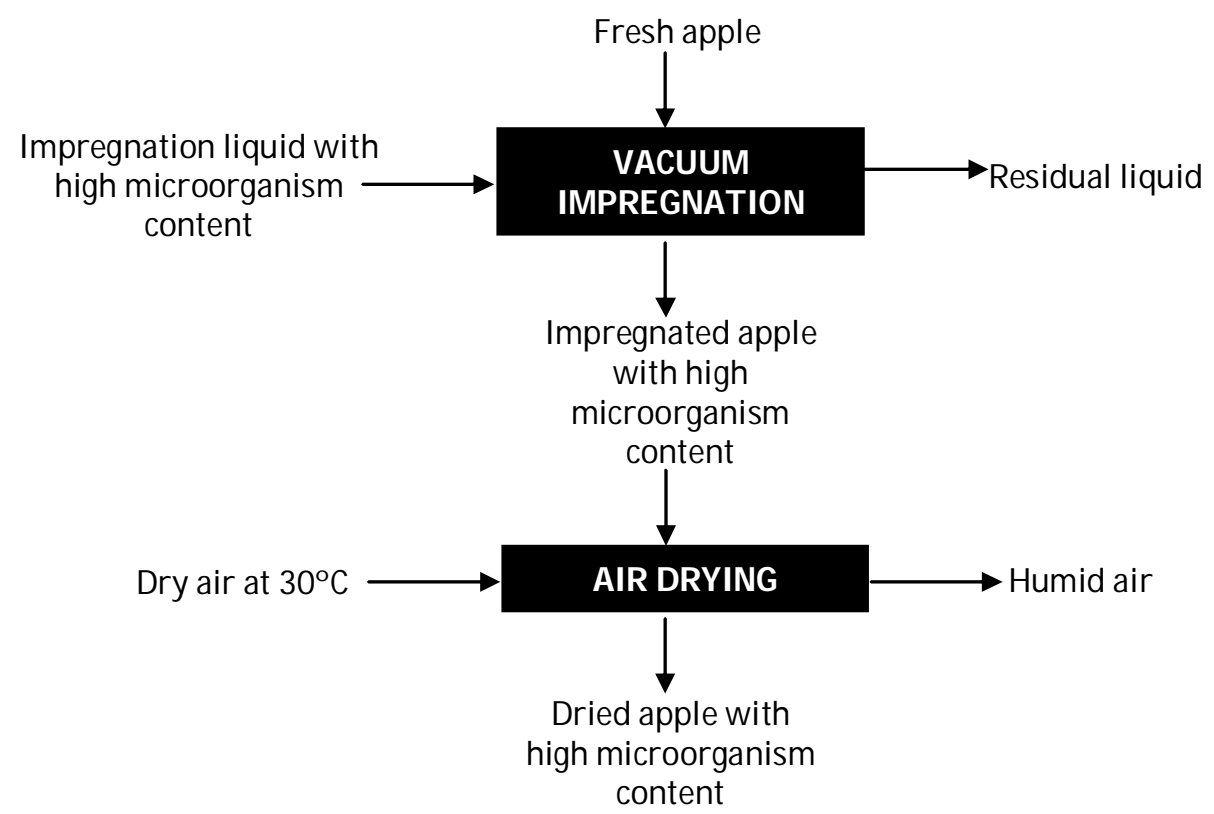

Figure 1. Flow chart to produce probiotic enriched dried apple.

The vacuum impregnation experiments were performed on a pilot scale using equipment designed in the Institute of Food Engineering for Development of the Polytechnic University in Valencia (Spain) (Fito et al., 2001). A vacuum pressure of 50 mbar was applied for $10 \mathrm{~min}$ and then atmospheric pressure was restored. The 
samples were left submerged in the impregnation liquid for a further 10 minutes. The values stated are the average of ten replicates.

Impregnated apple samples were dried for 24 hours using a pilot scale air dryer (Martín, 2002) at $30^{\circ} \mathrm{C}$ under a flow rate of $4 \mathrm{~m} / \mathrm{s}$.

\subsection{Preliminary in vivo study.}

A preliminary study was undertaken involving 5 children ( 3 girls and 2 boys, age 11 years) chronically infected with $H$. pylori and patients of the Gastroenterology Paediatric office in Hospital Universitario Dr. Peset in Valencia. The children's diagnosis was confirmed before commencing treatment by the breath test using labelled ${ }^{13} \mathrm{C}$ urea (commercial test TAU-KIT ${ }^{\circledR}$ ) (Michetti et al., 1999; De Vrese and Schrenmeir, 2000; Sakamoto et al., 2001). TAU-KIT is a breath test suitable for in vivo diagnosis of gastroduodenal Helicobacter pylori infection. Each soluble tablet contains $100 \mathrm{mg}$ of ${ }^{13} \mathrm{C}$-urea and excipients. During the 28 day study, $30 \mathrm{~g}$ of the dried product with a moisture content of $0.144 \pm 0.012 \mathrm{~g}_{\text {water }} \cdot \mathrm{g}$ $1_{\text {sample }}$ and microorganism content of $(9.5 \pm 0.2) \cdot 10^{7} \mathrm{CFU} \cdot \mathrm{g}^{-1}$ dried sample was supplied daily to each child. At the end of the study the urea breath test was repeated. The study has been done following rigorous ethical standards. An ethical approval was obtained by the Hospital Universitario Dr. Peset and the Universidad Politécnica de Valencia to carry out the study.

\subsection{Statistical analysis.}

To determine the statistical significance of the results obtained, an analysis of variance test was carried out (ANOVA) with $95 \%$ confidence levels ( $p \leq 0.05$ ) using the program STATGRAPHICS PLUS v.5.1.

\section{RESULTSAND DISCUSSION.}

\subsection{Use of mandarin and pineapple/ grape juices as the impregnation liquid.}

The use of vacuum impregnation to obtain fruit enriched with probiotic microorganisms requires that the impregnation liquid is able to enter the pores or intercellular spaces. However certain physicochemical properties of the impregnation liquid are required; the $\mathrm{pH}$ of the impregnation liquid and the fruit must be such to allow growth of the microorganism, the viscosity of the impregnation liquid should also allow flux inside the pores or intercellular spaces (Martínez-Monzó et al., 1998) and as much as possible the natural characteristics of the impregnated fruit should not be affected. Furthermore, the concentration of microorganisms in the impregnation liquid must be sufficiently high enough to

obtain adequate levels of microorganisms in the impregnated fruit. Some physicochemical properties of commercial mandarin and pineapple/grape juice 
were determined and the results are shown in Table 1. Martinez-Monzó (1998) studied pectin dissolutions and determined viscosities below $10 \mathrm{mPa}$.s do not affect impregnation procedure. In our case, concentration and composition of impregnation liquid ensure not reach this value of viscosity at any time of the process.

Table 1. Physicochemical properties $(\mathrm{pH}$, water activity, sugar content and density) of the commercial mandarin, pineapple/ grape juices and the $\mathrm{pH}$ adjusted mandarin juice selected for vacuum impregnation (mean \pm standard deviation).

\begin{tabular}{ccccc}
\hline Juice & $\mathbf{p H}$ & $\mathbf{a}_{\mathbf{w}}$ & Brix & $\begin{array}{c}\text { Density } \\
\mathbf{( g \cdot c m}^{-3} \mathbf{)}\end{array}$ \\
\hline $\begin{array}{c}\text { Mandarin } \\
\begin{array}{c}\text { Pineapple/ grape } \\
\text { Mandarin }\end{array}\end{array}$ & $3.58 \pm 0.02^{\mathrm{a}}$ & $0.983 \pm 0.002^{\mathrm{c}}$ & $12.11 \pm 0.02^{\mathrm{e}}$ & $1.045 \pm 0.002^{\mathrm{h}}$ \\
impregnation liquid & $5.96 \pm 0.06^{\mathrm{b}}$ & $0.982 \pm 0.002^{\mathrm{c}}$ & $14.21 \pm 0.02^{\mathrm{f}}$ & $1.055 \pm 0.002^{\mathrm{h}}$ \\
& & $0.987 \pm 0.002^{\mathrm{d}}$ & $11.90 \pm 0.02^{\mathrm{e}}$ & $1.085 \pm 0.002^{\mathrm{i}}$ \\
\hline
\end{tabular}

*Values with different superscript letters are significantly different $(\mathrm{P} \leq 0.05)$

The growth media was prepared as described and inoculated with strains of the microorganisms under consideration. The cultures were incubated for 24 or 48 hours to obtain the maximum possible concentration of microorganisms. The final microbial content for each medium is shown in Table 2.

Table 2. Microbial content obtained following growth of Lactobacillus species in each of the juices tested, with differing $\mathrm{pH}$ and incubation times (mean \pm standard deviation). The highest microbial content is shown in bold.

\begin{tabular}{|c|c|c|c|c|}
\hline \multirow{2}{*}{ Strain } & \multirow{2}{*}{ Juice } & \multirow{2}{*}{ pH } & \multicolumn{2}{|c|}{$\begin{array}{c}\text { Microbial content } \\
\left(\mathrm{CFU} \cdot \mathrm{cm}^{-3}\right)\end{array}$} \\
\hline & & & 24 hours incubation & 48 hours incubation \\
\hline \multirow{6}{*}{ 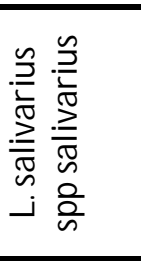 } & & 4.96 & $(7.228 \pm 0.005) \cdot 10^{6} \mathrm{a}$ & $(4.236 \pm 0.009) \cdot 10^{6 \mathrm{e}}$ \\
\hline & Pineapple/ grape & 5.50 & $(2.704 \pm 0.012) \cdot 10^{7 b}$ & $(1.07 \pm 0.02) \cdot 10^{7 f}$ \\
\hline & juice & 5.96 & $(3.027 \pm 0.007) \cdot 10^{7 b}$ & $(1.32 \pm 0.02) \cdot 10^{7 f}$ \\
\hline & & 4.96 & $(1.563 \pm 0.012) \cdot 10^{8 c} \mathrm{c}$ & $(1.905 \pm 0.013) \cdot 10^{7 g}$ \\
\hline & Mandarin juice & 5.50 & $(2.495 \pm 0.005) \cdot 10^{8 d}$ & $(2.377 \pm 0.013) \cdot 10^{7 \mathrm{~h}}$ \\
\hline & & 5.96 & $(2.754 \pm 0.012) \cdot 10^{8 d}$ & $(4.955 \pm 0.007) \cdot 10^{7 i}$ \\
\hline \multirow{6}{*}{ 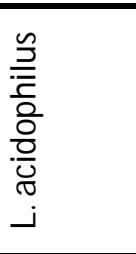 } & & $\overline{5.01}$ & $(8.128 \pm 0.004) \cdot 10^{5 a}$ & $(2.24 \pm 0.03) \cdot 10^{6 g}$ \\
\hline & Pineapple/ grape & 5.53 & $(1.452 \pm 0.009) \cdot 10^{5 b}$ & $(1.079 \pm 0.014) \cdot 10^{6} \mathrm{~h}$ \\
\hline & juice & 6.01 & $(4.416 \pm 0.003) \cdot 10^{4} \mathrm{c}$ & $(1.832 \pm 0.005) \cdot 10^{5 i}$ \\
\hline & & 4.96 & $(4.416 \pm 0.008) \cdot 10^{4 d}$ & $(1.20 \pm 0.02) \cdot 10^{5 j}$ \\
\hline & Mandarin juice & 5.50 & $(2.553 \pm 0.008) \cdot 10^{4} \mathrm{e}$ & $(4.909 \pm 0.004) \cdot 10^{4 k}$ \\
\hline & & 5.96 & $(1.20 \pm 0.03) \cdot 10^{4 \mathrm{f}}$ & $(1.637 \pm 0.015) \cdot 10^{41}$ \\
\hline
\end{tabular}

*Values for each strain with different superscript letters are significantly different $(\mathrm{P} \leq 0.05)$.

A multiple analysis of variance (95 \% confidence levels) showed that the different juices, $\mathrm{pH}$ and incubation periods have statistically significant effects on the microbial content. In addition, there were no double interactions in the model, suggesting that the effect a single factor has on the microbial content is independent of the other factors. From this analysis L. salivarius growth, results in higher microbial content than L. acidophilus under the experimental conditions tested. Furthermore, as shown in table 2, the highest microbial content $\left(10^{8}\right.$ $\mathrm{CFU} \cdot \mathrm{cm}^{-3}$ ) was obtained with L. salivarius, cultured in mandarin juice at $\mathrm{pH} 5.96$, 
following incubation for 24 hours. Therefore, this growth medium was selected as the impregnation liquid.

In order to analyze any changes that the growth of the microorganism produced in the mandarin juice which had been selected as the impregnation liquid, some physicochemical parameters were determined (Table 1). It was noted that the sugar content of this inoculated juice was slightly below that of the commercial juice. This was thought to be due to the growing microorganism utilising some of the available sugars. The inoculated mandarin juice was slightly denser than fresh mandarin juice, although these differences were minimal.

3.2 Physicochemical characterisation and microbial content in impregnated samples.

The physicochemical characteristics (pH, water activity, moisture content) and microorganism content determined in the samples at each stage of the process are shown in Table 3.

Table 3. Determination of moisture content, water activity, $\mathrm{pH}$ and microorganism content in the impregnated samples (mean \pm standard deviation).

\begin{tabular}{lcccc}
\hline & $\begin{array}{c}\text { Moisture content } \\
\left(\mathbf{g}_{\text {water }} \cdot \mathbf{g}^{-1} \text { sample) }\right.\end{array}$ & $\mathbf{a}_{\mathbf{w}}$ & $\mathbf{p H}$ & $\begin{array}{c}\text { Microorganism content } \\
\left(\mathbf{C F U} \cdot \mathbf{g}^{-1} \text { sample) }\right.\end{array}$ \\
\hline MRS & $0.947 \pm 0.002$ & - & $6.4 \pm 0.2$ & $(1.288 \pm 0.016) \cdot 10^{9}$ \\
Mandarin & $0.865 \pm 0.002$ & $0.987 \pm 0.002$ & $5.39 \pm 0.06$ & $(2.754 \pm 0.012) \cdot 10^{8}$ \\
juice & $0.8731 \pm 0.0012$ & $0.990 \pm 0.002$ & $3.33 \pm 0.02$ & 0 \\
$\begin{array}{l}\text { Fresh apple } \\
\text { Impregnated } \\
\text { apple }\end{array}$ & $0.883 \pm 0.002$ & $0.991 \pm 0.002$ & $4.01 \pm 0.02$ & $(1.51 \pm 0.07) \cdot 10^{8}$ \\
\hline
\end{tabular}

The water activity value of mandarin juice (Table 3 ) was similar to that of the apple that was to be impregnated (Table 3). Therefore, it was expected that during the vacuum impregnation, the only transfer mechanism would be hydrodynamic (Fito et al., 1996) and the characteristics of the fresh apple would not be highly altered (Table 3).

In vacuum impregnation experiments performed using mandarin juice with a microbial content as in Table 3, following the theory of the hydrodynamic model proposed by Fito, 1994; Fito and Pastor in 1994 and Fito et al., 1996 it was possible to calculate the values of volumetric deformation $\left(\gamma=-0.14 \pm 0.07 \mathrm{~cm}^{3} \cdot \mathrm{cm}^{-}\right.$ ${ }^{3}$ sample), effective porosity $\left(\varepsilon_{0}=0.201 \pm 0.012 \mathrm{~cm}^{3} \mathrm{~cm}^{-3}\right.$ sample $)$ and the volumetric impregnation levels reached $\left(\mathrm{X}=0.1954 \pm 0.0106 \mathrm{~cm}^{3} \cdot \mathrm{cm}^{-3}\right.$ sample) in the samples. These values are similar to those obtained in previous studies with apple juice (Betoret et al., 2003).

Taking into account the pore size of the apple $(6.64 \pm 0.24 \mu \mathrm{m})$ (Bazhal et al., 2003 ) and the size of the individual Lactobacillus cells (0.7 x $1.6 \mu \mathrm{m})$ (Zapata et al., 2009) a homogeneous impregnation was achieved. Additionally, it was possible to estimate theoretically the microbial content of the impregnated samples (Equation $1)$. 
Where:

$$
x_{f I V}=\frac{x_{L I V} \cdot X \cdot \frac{\rho_{L I V}}{\rho_{f f}}}{1+X \cdot \frac{\rho_{L I V}}{\rho_{f f}}}
$$

m; mass ( $\mathrm{g}$ )

$\mathbf{x}$; microorganism content ( $\mathrm{CFU} / \mathrm{g}$ or $\mathrm{CFU} / \mathrm{ml}$ )

$\mathbf{X}$; volumentric impregnation $\left(\mathrm{cm}^{3} / \mathrm{cm}^{3}\right.$ sample)

p; density $\left(\mathrm{g} / \mathrm{cm}^{3}\right)$

fIV; sub index referred to impregnated fruit

ff; sub index referred to fresh fruit

LIV; sub index referred to impregnation liquid

IV; sub index referred to impregnation operation

The estimated microbial content in the apple following vacuum impregnation was $(1.04 \pm 0.08) \cdot 10^{8} \mathrm{CFU} \cdot \mathrm{g}^{-1}$. This calculated value is similar to that obtained

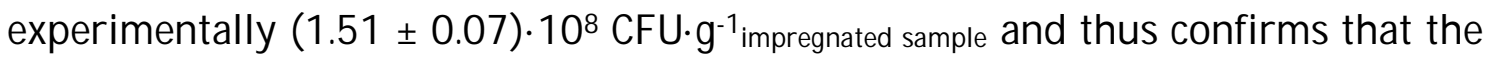
impregnation operation was homogeneous and the principal transfer mechanism was hydrodynamic.

The high values of water activity in the impregnated samples (Table 3) made them highly unstable. Following hot air drying, the resulting low value obtained for water activity (Table 4) does not permit the growth of fungi or other harmful microorganisms and dried samples are stable without losing their probiotic effect for at least two weeks when stored at room temperature (Betoret et al., 2003).

\subsection{Microbial determination in the dried samples.}

In order to determine the microbial content of the dried samples and due to their low humidity content, those must be rehydrated. The microbial content of the rehydrated samples and the microbial content of the residual rehydration liquid were required.

In the case of a system consisting in a impregnated apple immersed in a sterile liquid medium and subjected to the rehydration operation, the general microorganism content balance equation is:

Where:

$$
\sum x_{s} \cdot m_{s}-\sum x_{e} \cdot m_{e}+\left(\frac{M \cdot d x}{d t}\right)=G_{j}
$$

m; mass flow $(\mathrm{g} / \mathrm{s})$

M; Total mass ( $\mathrm{g}$ )

$\mathbf{x}$; microorganism content $(\mathrm{CFU} / \mathrm{g})$

Gj; generated microorganism content ( $\mathrm{CFU} / \mathrm{s})$

s; sub index referred to flow outputting

e; sub index referred to flow inputting

Assuming as hypothesis the total mass in the system does not vary with time.

The equation 2 stays: 


$$
\sum x_{s} \cdot m_{s}=\sum x_{e} \cdot m_{e}+G_{j}(E q .3)
$$

If applied to the rehydration operation showed in the Figure 2:

$$
m_{d f} \cdot x_{d f}+m_{l r h} \cdot x_{l r h}=m_{f r} \cdot x_{f r}+m_{l r} \cdot x_{l r}+G_{j}
$$

Where sub index:

df; dry fruit

lrh; rehydration liquid

fr; rehydrated fruit

Ir; residual rehydration liquid

Taking into account that the microbial concentration in rehydration liquid is zero, the microbial content of dry sample can be calculated as follows:

$$
x_{d f}=\frac{m_{f r} \cdot x_{f r}+m_{l r} \cdot x_{l r}-m_{l r h} \cdot x_{l r h}+G_{j}}{m_{d f}}
$$

We consider there is no generation of microorganism during rehydration. In fact, means that the calculated microbial content is the minimum possible.

Table 4 shows the physicochemical characteristics (water activity, moisture content) and microorganism content determined in the dry samples.

Table 4. Determination of moisture content, water activity and microorganism content in the dried samples (mean \pm standard deviation).

\begin{tabular}{lccc}
\hline & $\begin{array}{c}\text { Moisture content } \\
\left(\mathbf{g}_{\text {water }} \cdot \mathbf{g}^{-1} \text { sample) }\right.\end{array}$ & $\mathbf{a}_{\mathbf{w}}$ & $\begin{array}{c}\text { Microorganism content } \\
\left(\mathbf{C F U} \cdot \mathbf{g}^{-1} \text { sample }\right)\end{array}$ \\
\hline Impregnated \& dried apple & $0.144 \pm 0.012$ & $0.501 \pm 0.002$ & $(9.5 \pm 0.2) \cdot 10^{7}$ \\
Rehydrated apple & - & - & $(2.47 \pm 0.12) \cdot 10^{7}$ \\
Residual rehydration liquid & - & - & $(1.14 \pm 0.16) \cdot 10^{4}$ \\
\hline
\end{tabular}

As it is possible to see, the microbial content of the rehydrated samples was slightly less than that of the impregnated samples prior to drying (Table 4). This reduction in microbial content could be explained by a possible transfer of $\mathrm{L}$. salivarius spp. salivarius from the surface or near pores of apple to the rehydration liquid. To compare the microbial content of the impregnated and the dried samples, then the microbial content of both was expressed per gram of dry matter, resulting on microbial content of impregnated samples $(1.51 \pm 0.07) \cdot 10^{8} \mathrm{CFU} \cdot \mathrm{g}^{-1} \mathrm{dry}$ matter and microbial content of dry samples $(9.5 \pm 0.2) \cdot 10^{7} \mathrm{CFU}^{-1} \mathrm{~g}^{-1}$ dry matter

Air drying of the impregnated samples resulted in a 1-log fold reduction in microbial content. Despite the observed reduction, the final product had a high microbial content as the viable count of L. salivarius spp. salivarius was very close to $10^{8} \mathrm{CFU} \cdot \mathrm{g}^{-1}$, This new product manufactured from apple and mandarin juice achieved the $10^{7} \mathrm{CFU} \cdot \mathrm{g}^{-1}$ of sample, this value corresponds to average values found in commercial probiotic dairy products and according to the literature would be sufficient to be potentially effective against $H$. pylori infections (Cruchet et al., 2003; De Champs et al., 2003). 


\subsection{Preliminary in vivo test.}

The ${ }^{13} \mathrm{C}$ urea breath test was undertaken by all participants at the start and end of the study. After oral ingestion, the urea reaches the gastric mucosa. In the presence of $\mathrm{H}$. pylori, the ${ }^{13} \mathrm{C}$-urea is metabolized by the enzyme urease:

$$
2 \mathrm{H}_{2} \mathrm{~N}\left({ }^{13} \mathrm{CO}\right) \mathrm{NH}_{2}+2 \mathrm{H}_{2} \mathrm{O} \rightarrow 4 \mathrm{NH}_{3}+2^{13} \mathrm{CO}_{2}
$$

Urease is produced in the stomach only by $\mathrm{H}$. pylori. Other urease-producing bacteria rarely have been found in the gastric flora. Carbon dioxide diffuses into the blood vessels. From there it is transported as bicarbonate to the lungs and released as ${ }^{13} \mathrm{CO}_{2}$ in expired air. In the presence of bacterial urease, the ratio of carbon isotopes ${ }^{13} \mathrm{C} /{ }^{12} \mathrm{C}$ change significantly. The proportion of ${ }^{13} \mathrm{CO}_{2}$ in exhaled air samples was determined by mass spectrometry isotope ratio (IRMS) and set as absolute difference (value $\Delta \delta$ ) between the values at 0 and 30 minutes. The critical point to determine, H. pylori negative or positive is the value of $\Delta \delta 4 \%$ to $5 \%$, which means that an increase in value over $\Delta \delta 4 \%$ to $5 \%$ indicates that there is infection. In the absence of bacterial urease, all administered urea, after absorption in the gastrointestinal tract, is metabolized as endogenous urea.

During the 28 day study, each child daily received $30 \mathrm{~g}$ of the dried product with a moisture content of $0.144 \pm 0.012 \mathrm{~g}_{\text {water }} \cdot \mathrm{g}^{-1}$ sample and a microorganism content of $(2.850 \pm 0.003) \cdot 10^{9} \mathrm{CFU} \cdot$ day $^{-1}$. According to the literature, the consumption of $10^{9} \mathrm{CFU}$ per day of L. salivarius spp. salivarius for four weeks is sufficient to have an effect on H. pylori infection (Aiba et al., 1998). In all patients was possible to detect a decrease in the values of ${ }^{13} \mathrm{C}$ for the basal sample in the expired breath. Four of the five children who took part in the study completed the 28 days treatment; whilst one child (with values from $6 \mathrm{ppm}$ at the start to $5 \mathrm{ppm}$ at the end of the study) ate the product only for the first 15 days. Two children (one with values from 5 to $0.3 \mathrm{ppm}$ and the other with values from 6 to $4 \mathrm{ppm}$ ) reported improvements in their previous symptoms, which consisted of abdominal problems and aerophagia. Although five patients are not enough to establish significance, the results obtained suggest an improvement in the symptoms caused by the infection and therefore it is necessary to carry out further studies involving more patients to properly evaluate the effectiveness of the food. During the study, the children were asked by qualified personnel about the appearance, flavour and consistency of the product. While the flavour was acceptable, both the appearance and consistency of product were not liked and all would have preferred to eat a crisper product.

\section{CONCLUSIONS.}

The nutritional and physicochemical properties of mandarin juice (with the $\mathrm{pH}$ adjusted to 6) resulted in $10^{8} \mathrm{CFU} \cdot \mathrm{cm}^{-3}$ of L. salivarius spp. salivarius, following 24 hours incubation, allowing this solution to be used as the liquid medium for vacuum impregnation of samples of fresh apple. 
The impregnation parameters obtained and the microorganism content achieved confirmed the validity of this approach to the development of a natural low moisture content food with a probiotic effect.

Further studies involving more patients are needed to properly evaluate the effectiveness of this food; however the L. salivarius spp. salivarius microbial content in the final product and the results of the in vivo pilot test confirm the potentially beneficial effects against $\mathrm{H}$. pylori infection.

\section{REFERENCES.}

A.O.A.C., (1980). Association of official analytical chemist. Official Methods of Analysis, 20013. Washington, D.C.

Aiba Y., Suzuki N., Kabir A.M., Takagi A., Koga, Y. (1998). Lactic acid-mediated suppression of Helicobacter pylori by the oral administration of Lactobacillus salivarius as a probiotic in a gnotobiotic murine model. American Journal of Gastroenterology, 93, 2097-2101.

Alzamora S.M., Salvatori D., Tapia M.S., López-Malo A., Welti-Chames J., Fito P. (2005). Novel functional foods from vegetable matrices impregnated with biologically active compounds. Journal of Food Engineering, 67, 205-214.

Bazhal M.I., Ngadi M.O. (2003). Influence of pulsed electroplasmolysis on the porous structure of apple tissue. Biosystems Engineering, 86, 51-57.

Betoret N., Puente L., Díaz M.J., Pagán M.J., García M.J., Gras M.L., Martínez-Monzó J., Fito P. (2003). Development of probiotic-enriched dried fruits by vacuum impregnation. Journal of Food Engineering, 56, 273-277.

Canducci F., Armuzzi A., Cremonini F., Cammarota G., Bartolozzi F., Pola P., Gasbarrini G., Gasbarrini A. (2000). A lyophilized and inactivated culture of Lactobacillus acidophilus increases Helicobacter pylori eradication rates. Alimentary Pharmacology \& Therapeutics, 14, 1625-9.

Cháfer M., González-Martínez C., Fernández B., Pérez L., Chiralt, A. (2003). Effect of Blanching and Vacuum Pulse Application on Osmotic Dehydration of Pear. Food Science and Technology International, 9, 321-328.

Cruchet S., Obregon M.C., Salazar G., Diaz E., Gotteland M., (2003). Effect of the ingestion of a dietary product containing Lactobacillus johnsonii La1 on Helicobacter pylori colonization in children. Nutrition, 19, 716-721.

De Champs C., Maroncle N., Balestrino D., Rich C., Forestier C. (2003). Persistence of colonization of intestinal mucosa by a probiotic strain, Lactobacillus casei subsp. Rhamnosus Lcr35, after oral consumption. Journal of Clinical Microbiology, 41, 3, 1270-1273.

De Vrese M., Schrezenmeir J. (2000). Einfluss probiotischer Bifidobakterien auf die Helicobacter pylori activitat. Federal Dairy Center, Annual report.

Fito P. (1994). Modelling of vacuum osmotic dehydration of food. Journal of Food Engineering, 22, 1-4, 313-328. 
Fito P., Andrés A., Chiralt A., Pardo P. (1996). Coupling of hydrodinamic mechanism and deformation relaxation phenomena during vaccuum treatments in solid porous food-liquid systems. Journal of Food Engineering, 27, 229-240.

Fito P., Chiralt A., Betoret N., Gras M.L., Cháfer M., Martínez-Monzó J., Andrés A., Vidal D. (2001). Vacuum impregnation and osmotic deshydratation in matrix engineering. Application in functional fresh food development. Journal of Food Engineering, 49, 175-183.

Fito P., Pastor R. (1994). On some non-difusional mechanism occurring during vacuum osmotic dehydration. Journal of Food Engineering, 21, 513-519.

Fuller R. (1989). Probiotics in man and animals. Journal of Applied bacteriology, 66, 365-378.

Gold B.D., Colletti R.B., Abbott M., Czinn S.J., Elitsur Y., Hassall E., Macarthur C., Snyder J., Sherman P.M. (2000). Helicobacter pylori Infection in Children: Recommendations for Diagnosis and Treatment. Journal of Pediatric Gastroenterology and Nutrition, 31, 490-497.

Hamilton-Miller J.M.T. (2003). The role of probiotics in the treatment and prevention of Helicobacter pylori infection. International Journal of Antimicrobial Agents, 22, 360-366.

Martin, E. (2002). Utilización de microondas en el secado por aire caliente de manzana (var. Granny Smith). Influencia del pretratamiento por impregnación a vacío. Universidad Politécnica de Valencia. Tesis doctoral.

Martínez-Monzó J., Martínez-Navarrete N., Chiralt A., Fito P. (1998). Mechanical and structural changes in apple (var. Granny Smith) due to vacuum impregnation with cryoprotectants. Journal of Food Science, 63, 499-503.

Michetti P., Dorta G., Wiesel P.H., Brassart D., Verdu E., Herranz M., Felley C., Porta N., Rouvet M., Blum A.L., Corthésy-Theulaz I. (1999). Effect of whey-based culture supernatant of Lactobacillus acidophilus (johnsonii) La1 on Helicobacter pylori infection in humans. Digestion, 60(3), 203-9.

Mrda Z., Zivanovic M., Rasic J., Gajin S., Somer L., Trbojevic S. (1998). Therapy of Helicobacter pylori infection using Lactobacillus acidophilus. Meditsinski Pregled, 51, 343-345.

Ouwehand, A., Kirjavainen, P., Shortt, C., Salminen, S. (1999). Probiotics: mechanisms and stabilised effect. International Dairy.Journal, 9, 43-52.

Patent P99 02730-5 titled "Procedimiento de impregnación de alimentos naturales con productos nutracéuticos y dispositivo para su puesta en práctica"

Reglamento (CE) № 1924/2006 del parlamento europeo y del consejo de 20 de diciembre de 2006 relativo a las declaraciones nutricionales y de propiedades saludables en los alimentos.

Sakamoto I., Igarashi M., Kimura K., Takagi A., Miwa T., Koga Y. (2001). Suppressive effect of Lactobacillus gasseri OLL 2716 (LG21) on Helicobacter pylori infection in humans. Journal of Antimicrobial Chemotherapy, 47, 5, 709-710.

Salminen S., Ouwehand A., Benno Y., Lee Y.K. (1999). Probiotics: how should they be defined?. Trends in Food Science \& Technology, 10, 3, 107-110. 
Sanders M. E. (1999). Probiotics. Food Technology, 53, 67-77.

Sheu B.S., Wu J.J., Lo C.Y., Wu H.W., Chen J.H., Lin Y.S., Lin M.D. (2002). Impact of supplement with Lactobacillus- and Bifidobacterium-containing yogurt on triple therapy for Helicobacter pylori eradication. Alimentary Pharmacology \& Therapeutics, 16, 9, 1669-1675.

Zapata S., Muñoz J., Ruiz O.S., Montoya O.I., Gutiérrez P.A. (2009). Isolation of Lactobacillus plantarum LPBM10 and partial characterization of its bacteriocin. Revista de la facultad de química farmacéutica, 16, 1, 75-82. 
Desarrollo tecnológico y valoración funcional de aperitivos de manzana y zumo de mandarina 
*Nota al lector: Los resultados presentados a continuación son resultados complementarios al desarrollo de un alimento funcional enriquecido con zumo de mandarina y microorganismos probióticos. Estos resultados se encuentran pendientes de publicación.

\section{Aplicación de diferentes técnicas de deshidratación en la estabilización de un alimento funcional a base de fruta con efecto probiótico contra la infección ocasionada por Helicobacter pylori.}

\section{Resumen}

Se ha desarrollado un alimento funcional con efecto probiótico a base de manzana y zumo de mandarina utilizando para ello la técnica de impregnación a vacío. Para estabilizar el alimento funcional se han utilizado diferentes condiciones y técnicas de deshidratación. Concretamente se ha utilizado el secado por aire caliente a $30^{\circ} \mathrm{C}$ y $45^{\circ} \mathrm{C}$ y la liofilización durante 12 y 24 horas en muestras de espesor 2.5 y $7 \mathrm{~mm}$. En los diferentes productos desarrollados se han determinado las propiedades ópticas y mecánicas y se ha estudiado su evolución a lo largo del proceso de fabricación. La operación de liofilización ha permitido obtener productos de menor contenido en agua, más crujientes y de color más parecido a la manzana fresca, mientras que el secado por aire caliente ha permitido obtener productos menos crujientes y de un color más anaranjado. $\mathrm{Ni}$ el espesor ni el método de deshidratación empleado ha tenido un efecto significativo sobre el contenido en Lactobacillus salivarius spp. salivarius. Además, en todos los casos se han obtenido niveles superiores a $10^{6} \mathrm{UFC} / \mathrm{g}$ por lo que todos los productos desarrollados tendrían un efecto potencial en contra de la infección ocasionada por Helicobacter pylori.

Palabras clave: alimento probiótico, zumo de mandarina, secado por aire caliente, liofilización.

\section{INTRODUCCION}

Helicobacter pylori es una de las infecciones más comunes en el hombre. En los países en desarrollo puede afectar al $90 \%$ de la población y su tratamiento se basa en una terapia con dos o tres antibióticos más un inhibidor de la bomba de protones $\mathrm{o}$ antagonistas de los receptores $\mathrm{H}_{2}$. Dicho tratamiento es efectivo en el $85 \%$ de los casos. Sin embargo, se puede producir fallo del tratamiento por la aparición de resistencias a los antimicrobianos o por la mala tolerancia de los pacientes a los mismos. Además, otro de los problemas relacionados con el uso de antibióticos es el alto coste de los mismos para familias de bajo nivel socioeconómico (Gold et al. 2000). Se ha demostrado que L. salivarius es capaz de reducir la infección por Helicobacter pylori en ratones infectados disminuyendo la respuesta inflamatoria y que además es capaz de actuar mejor que otras cepas como pueden ser L. Casei (Aiba et al., 1998) y L. acidophilus (Mrda et al., 1998; Canducci et al., 2000; Sheu et al., 2002).

En esta tesis doctoral ha sido posible desarrollar un alimento natural con efecto potencial para actuar contra la infección ocasionada por Helicobacter pylori, dirigido fundamentalmente a una población escolar y con el fin de que pudiera ser consumido como aperitivo o como ingrediente en productos de desayuno. En la prueba piloto in vivo que se realizó en niños infectados de forma crónica con el microorganismo Helicobacter pylori y seguidos en consultas externas de la unidad 
pediátrica de gastroenterología del Hospital Universitario Dr. Peset, se evaluó mediante encuesta la aceptación del alimento funcional. En general, la consistencia del producto no parece ser una característica claramente aceptada por los niños. En todos los casos se señaló la crujencia como una característica deseable en el producto. El sabor fue aceptado por todos los niños, incluso dos de los cinco decidieron consumir el alimento sólo sin mezclarlo con otro.

En base a los puntos expuestos se ha considerado necesario llevar a cabo una mejora del producto en cuanto a consistencia, utilizando para ello diferentes técnicas de deshidratación. En los estudios anteriores se utilizaron discos de manzana de $5 \mathrm{~mm}$ de espesor y como técnica de estabilización se utilizó el secado por aire caliente a $30^{\circ} \mathrm{C}$. La temperatura de secado es un punto crítico del proceso de fabricación ya que ha de ser lo suficientemente elevada como para obtener un producto con bajo contenido en agua pero lo suficientemente baja para no destruir a los microorganismos probióticos. Se considera la temperatura de $40 \stackrel{\circ}{ } \mathrm{C}$ como una temperatura límite para la supervivencia de los microorganismos. El objetivo del presente trabajo es estudiar el efecto de diferentes técnicas (secado por aire caliente y liofilización), condiciones de deshidratación (30 y $45^{\circ} \mathrm{C}$ en el secado por aire caliente y 12 y 24 horas en la liofilización) y espesores de muestra (2.5 y 7 $\mathrm{mm}$ ) sobre las propiedades ópticas y mecánicas del alimento funcional desarrollado así como evaluar el efecto de los distintos procesos de fabricación sobre el contenido en microorganismos probióticos.

\section{MATERIAL Y MÉTODOS}

\subsection{Cepa de microorganismo.}

La cepa del microorganismo Lactobacillus salivarius spp. salivarius CECT 4063 utilizado en este estudio se obtuvo de la Colección Española de Cultivos Tipo (CECT).

\subsection{Material vegetal. Obtención de muestras.}

El medio de crecimiento utilizado fue zumo de mandarina 100\% exprimida (Don Simon), que se adquirió en un supermercado local y que fue elegido porque en estudios anteriores (Arilla., 2008) resultó ser el medio más adecuado para el crecimiento del Lactobacillus salivarius spp. salivarius.

Las manzanas (cv. Granny Smith) se adquirieron de un supermercado local, se cortaron en discos de 2.5 y $7 \mathrm{~mm}$ de espesor en dirección perpendicular al eje longitudinal y con un diámetro externo e interno de 65 y $21 \mathrm{~mm}$ respectivamente. 


\subsection{Preparación del líquido de impregnación.}

El cultivo liofilizado se recuperó mediante resuspensión y siembra en caldo MRS Broth e incubación durante $24 \mathrm{~h}$ a $37^{\circ} \mathrm{C}$. El microorganismo se transfirió al zumo de mandarina comercial al que previamente se le añadió levadura y se le modificó el pH a 6 para favorecer el crecimiento del mismo. Se añadieron $4 \mathrm{ml}$ de caldo MRS broth con un crecimiento microbiano de $10^{9} \mathrm{UFC} / \mathrm{ml}$ a 1 litro de zumo. El zumo inoculado se incubó durante 24 horas a $37^{\circ} \mathrm{C}$.

\subsection{Caracterización fisicoquímica.}

Se midieron los sólidos solubles totales con un refractómetro digital (ABBE ATAGO, NAR T3, Japan) termostatado a $20 \stackrel{\circ}{\circ}$. El pH se midió con un potenciómetro (micropH CRISON, 2001). La actividad de agua se midió utilizando un higrómetro de punto de rocío (DECAGON, Aqualab CX-2, \pm 0.003 ). La humedad se determinó siguiendo el método oficial 20.013 de secado en estufa de vacío a 60 ${ }^{\circ} \mathrm{C}$ (AOAC, 1980) para frutas ricas en azúcar. Todas las medidas se realizaron por triplicado

\subsection{Contenido microbiano.}

El método utilizado para determinar el recuento de viables en las muestras impregnadas y en el zumo fue mediante siembra en placa por profundidad con doble capa de MRS agar, incubación a $37^{\circ} \mathrm{C} C$ durante 24 horas y conteo.

Para determinar el contenido microbiano de las muestras secas éstas se rehidrataron previamente con zumo de mandarina $(\mathrm{pH} 6)$ utilizando una relación $50 \mathrm{~mL}$ de zumo de mandarina por gramo de manzana y manteniendo las muestras sumergidas durante 24 horas (Betoret et al., 2003). El contenido microbiano se estimó mediante un balance de masa llevado a cabo en la operación de rehidratación (Betoret et al., 2012). Todas las medidas se realizaron por triplicado.

\subsection{Desarrollo del alimento funcional.}

El alimento funcional impregnado con zumo de mandarina y con alto contenido en microorganismos probióticos se obtuvo siguiendo la metodología descrita previamente en Betoret et al., 2012.

Los experimentos de impregnación a vacío se llevaron a cabo a nivel de planta piloto utilizando el equipo diseñado en el Instituto Universitario de Ingeniería de Alimentos para el Desarrollo de la Universidad Politécnica de Valencia (España). Las muestras de manzana se sumergieron en el zumo de mandarina y se aplicó una presión de vacío al sistema de 50 mbar durante 10 minutos, después de los cuales se restauró la presión atmosférica. Las muestras se mantuvieron sumergidas en el zumo durante 10 minutos adicionales. 
Las muestras de manzana impregnada se deshidrataron utilizando para ello dos métodos de deshidratación diferentes: el secado por aire caliente y la liofilización.

Las muestras se secaron por aire caliente utilizando un secador (LIZ, Construcciones mecánicas José Lizondo, Barcelona, España). Con el objetivo de evaluar el efecto de la temperatura de secado sobre las propiedades ópticas y mecánicas del producto final, las muestras impregnadas se deshidrataron a $30 \stackrel{\circ}{\circ}$ y a $45^{\circ} \mathrm{C}$ con un flujo de aire de $4 \mathrm{~m} / \mathrm{s}$ durante 24 horas.

Las experiencias de liofilización se llevaron a cabo en un liofilizador (LIOALFA 6-80) a -45 ํ y 0.1 mbar durante 12 y 24 horas. Para la correcta sublimación del agua contenida en las muestras, éstas se congelaron en un ultracongelador (Dycometal, Barcelona, España) a - $45^{\circ} \mathrm{C}$ durante 6 horas.

2.6 Determinación de las propiedades ópticas.

El color de las muestras se midió con un espectrocolorímetro (MINOLTA modelo CM-1000R) utilizando el iluminante D65 y el observador de $10 \stackrel{0}{ }$ como referencia. En el caso de las muestras de zumo, el color se midió por transmitancia y las muestras se introdujeron en celdas de vidrio óptico de $3.8 \mathrm{~cm}$ de alto y $6 \mathrm{~cm}$ de diámetro. En el caso de las muestras sólidas de manzana, por tratarse de muestras traslúcidas, las medidas se realizaron por reflectancia, tanto sobre fondo blanco como sobre fondo negro.

Se obtuvieron las coordenadas de color en el espacio CIE L*a*b* y las coordenadas psicrométricas tono $\left(\mathrm{h}_{\mathrm{ab}}\right)$ (ec.x) y croma $\left(\mathrm{C}_{\mathrm{ab}}\right)$ (ec.x). $\mathrm{L}^{*}$ es un indicador de la luminosidad, a* indica la cromaticidad en el eje verde (-) a rojo (+) y b* la cromaticidad en el eje azul (-) a amarillo (+). $\mathrm{C}^{*}$ ab es la medida de las saturación o croma de un color y $\mathrm{h}^{*}$ ab es el ángulo que mide la tonalidad indicando la orientación relativa del color respecto al origen de 0 . También se calculó el parámetro diferencia global de color $\Delta \mathrm{E}$ (ec. 1) que cuantifica la diferencia total de color entre muestras. Todas las medidas se realizaron por triplicado.

$$
\Delta E=\sqrt{\left(\Delta L^{*}\right)^{2}+\left(\Delta a^{*}\right)^{2}+\left(\Delta b^{*}\right)^{2}}
$$

Los valores obtenidos a partir de las determinaciones realizadas sobre las muestras de manzana se corrigieron de acuerdo con la teoría de Kubelka-Munk de dispersión de luz múltiple (Judd y Wyszecki, 1975; Hutchings, 1999; Talens et al., 2002) que describe las propiedades ópticas de las muestras a cualquier longitud de onda mediante un coeficiente de dispersión (S) y otro de absorción (K) (ecuaciones 2 a 5$)$.

$$
\frac{K}{S}=\frac{\left(1-R_{\infty}\right)^{2}}{2 R_{\infty}}
$$




$$
\begin{gathered}
R_{\infty}=a-b \\
a=\frac{1}{2}\left[R-\frac{R_{0}-R-R_{g}}{R_{0} R_{g}}\right] \\
b=\sqrt{a^{2}-1}
\end{gathered}
$$

Donde:

$\mathrm{R}_{\infty}$ es la reflectancia infinita

$\mathrm{R}$ es la reflectancia de la muestra determinada sobre fondo blanco

$\mathrm{R}_{\mathrm{g}}$ es la reflectancia del fondo blanco

$\mathrm{R}_{0}$ es la reflectancia de la muestra determinada sobre fondo negro

\subsection{Determinación de las propiedades mecánicas.}

Las propiedades mecánicas de las muestras de manzana frescas, impregnadas y deshidratadas se evaluaron mediante un ensayo de punción sobre las caras planas de los discos de manzana llevado a cabo en un analizador de textura Stable Micro Systems mod. TA.XT plus junto al software Textura exponent 32. El equipo se configuró de manera que la penetración de la muestra por parte del punzón fuera completa. Las condiciones específicas del ensayo se resumen en la tabla x.

Los parámetros que se han tenido en cuenta a la hora de caracterizar el comportamiento de las muestras frente al avance del punzón fueron:

- La fuerza de fractura $\left(F_{F}\right)$, expresada en Newton

- La distancia recorrida por el punzón hasta que se produce la fractura de la muestra $\left(\mathrm{d}_{\mathrm{F}}\right)$, expresada en milímetros

- El área comprendida bajo la curva hasta la rotura de la muestra (A), expresada en Newton por milímetros.

Tabla 1. Condiciones específicas de los ensayos de punción.

\begin{tabular}{l|l}
\hline \multicolumn{1}{l|}{$\begin{array}{l}\text { Modo de ensayo: } \\
\text { Velocidad: }\end{array}$} & Punción \\
\hline \multicolumn{1}{r}{ Post ensayo: } & $10 \mathrm{~mm} / \mathrm{s}$ \\
\hline & $10 \mathrm{~mm}$ \\
\hline Distancia: & Fuerza \\
\hline Tipo de activación: & $0.04093 \mathrm{~N}$ \\
\hline Fuerza de activación: & $24 \stackrel{\mathrm{o}}{\mathrm{C}}$ \\
\hline Temperatura: & $50 \mathrm{Kg}$ \\
\hline Celda de carga: & $\mathrm{P} / 2(\phi=2 \mathrm{~mm})$ \\
\hline Sonda: &
\end{tabular}




\subsection{Análisis estadístico.}

El análisis estadístico de los resultados se llevó a cabo mediante el programa Statgraphics plus versión 5.1. Con el fin de determinar el nivel de significación de las diferencias observadas se realizaron análisis de la varianza (ANOVA).

\section{RESULTADOS Y DISCUSIÓN}

\subsection{Caracterización fisicoquímica de las muestras.}

La obtención de frutas enriquecidas con microorganismos probióticos a partir de la operación de impregnación a vacío es posible siempre que el líquido de impregnación presente características favorables capaces de promover el flujo hacia los espacios intercelulares de dichas frutas. La densidad y la viscosidad del líquido de impregnación son las propiedades que influyen en mayor medida sobre la cantidad de líquido incorporado en el proceso de impregnación. Además, en el caso de enriquecimiento con microorganismos probióticos, tanto el $\mathrm{pH}$ del líquido de impregnación como el de la fruta deben ser adecuados ya que determinaran la supervivencia de los microorganismos. Las características fisicoquímicas del zumo de mandarina se muestran en la tabla 2.

Tabla 2. Características fisicoquímicas del zumo de mandarina (promedio \pm desviación estándar).

\begin{tabular}{lccc}
\hline & Zumo de mandarina & $\begin{array}{c}\text { Zumo + levadura }+ \\
\mathbf{N a H C O}_{3}\end{array}$ & Líquido de impregnación \\
\hline $\mathbf{p H}$ & $3.523 \pm 0.006$ & $5 \pm 0$ & $5.70 \pm 0.01$ \\
$\mathbf{0}$ Brix & $12.4 \pm 0.01$ & $11.72 \pm 0.13$ & $11.9 \pm 0.012$ \\
Densidad $\left(\mathbf{g} / \mathbf{c m}^{\mathbf{3}}\right)$ & $1.048 \pm 0.002$ & $1.0482 \pm 0.002$ & $1.085 \pm 0.002$ \\
\hline
\end{tabular}

El líquido de impregnación presenta valores superiores al zumo y se encuentra en el rango de 5.5-6 que es el óptimo para un adecuado crecimiento de la cepa en estudio. Además existe una pequeña diferencia entre los sólidos solubles del zumo y los del líquido de impregnación que se deben a que L. salivarius spp. salivarius es una bacteria ácido láctica que durante su crecimiento fermenta los azúcares y produce ácido láctico. La densidad del zumo comercial es similar a la que posteriormente se obtuvo en el zumo con el $\mathrm{pH}$ corregido, en cambio tras la inoculación la densidad en el líquido de impregnación aumentó ligeramente pero no como para afectar al proceso de impregnación a vacío.

Las características fisicoquímicas de las muestras de manzana determinadas en cada etapa del proceso y para las diferentes técnicas de deshidratación empleadas se muestran en la tabla 3. 
Tabla 3. Características fisicoquímicas de la manzana fresca, impregnada y seca por los diferentes métodos de deshidratación empleados (promedio \pm desviación estándar).

\begin{tabular}{|c|c|c|c|c|c|}
\hline & $\begin{array}{l}\text { Espesor } \\
(\mathrm{mm})\end{array}$ & $\begin{array}{l}\text { Humedad } \\
\left.\text { (g } \text { gagua }_{\text {a }} \mathbf{g}_{\text {muestra }}\right)\end{array}$ & $\mathbf{a}_{\mathbf{w}}$ & Brix & $\mathbf{p H}$ \\
\hline Manzana fresca & 2.5 & $0.872 \pm 0.005$ & $0.991 \pm 0.002$ & $12.9 \pm 0.5$ & $3.33 \pm 0.02$ \\
\hline & 7 & $0.874 \pm 0.006$ & $0.992 \pm 0.012$ & & \\
\hline Manzana IV & $\begin{array}{c}2.5 \\
7\end{array}$ & $\begin{array}{l}0.863 \pm 0.001 \\
0.858 \pm 0.002\end{array}$ & $\begin{array}{l}0.984 \pm 0.002 \\
0.983 \pm 0.015\end{array}$ & $12.2 \pm 0.3$ & $4.01 \pm 0.01$ \\
\hline $\mathrm{M}_{\mathrm{IV}}+\mathrm{SAC} 30^{\circ} \mathrm{C}$ & $\begin{array}{c}2.5 \\
7\end{array}$ & $\begin{array}{l}0.089 \pm 0.011 \\
0.121 \pm 0.011\end{array}$ & $\begin{array}{c}0.53 \pm 0.02 \\
0.551 \pm 0.013\end{array}$ & - & - \\
\hline $\mathrm{M}_{\mathrm{IV}}+\mathrm{SAC} 45^{\circ} \mathrm{C}$ & $\begin{array}{c}2.5 \\
7\end{array}$ & $\begin{array}{l}0.052 \pm 0.007 \\
0.138 \pm 0.010\end{array}$ & $\begin{array}{c}0.49 \pm 0.02 \\
0.571 \pm 0.013\end{array}$ & - & - \\
\hline $\mathrm{M}_{\mathrm{IV}}+\mathrm{LIO} 12 \mathrm{~h}$ & $\begin{array}{c}2.5 \\
7\end{array}$ & $\begin{array}{l}0.073 \pm 0.005 \\
0.123 \pm 0.005\end{array}$ & $\begin{array}{l}0.510 \pm 0.021 \\
0.530 \pm 0.003\end{array}$ & - & - \\
\hline $\mathrm{M}_{\mathrm{IV}}+\mathrm{LIO} 24 \mathrm{~h}$ & $\begin{array}{c}2.5 \\
7\end{array}$ & $\begin{array}{l}0.054 \pm 0.004 \\
0.056 \pm 0.002\end{array}$ & $\begin{array}{l}0.481 \pm 0.012 \\
0.480 \pm 0.015\end{array}$ & & _ \\
\hline
\end{tabular}

La técnica de impregnación a vacío se aplicó a discos de manzana de 2.5 y $7 \mathrm{~mm}$ de espesor. En alimentos porosos, cuando se aplica vacío bajo condiciones controladas y se emplean disoluciones isotónicas como medio de impregnación, se producen cambios composicionales debido a la entrada, por gradientes de presión, de la disolución hacia el interior del alimento, ocupando el volumen disponible en los espacios intercelulares. Los resultados obtenidos indican que no hay prácticamente diferencias entre las características fisicoquímicas de muestras frescas y muestras impregnadas. Los valores de humedad y actividad de agua de la manzana fresca fueron elevados como es de esperar por tratarse de una fruta y además son muy parecidos a los obtenidos en muestras de manzana impregnada. Los valores de sólidos solubles son similares en ambos casos y en cuanto al $\mathrm{pH}$ se observa un pequeño aumento debido a la influencia del líquido de impregnación.

Se alcanzaron humedades más bajas en las muestras de menor espesor y deshidratadas por liofilización. Los bajos valores de actividad de agua obtenidos en las muestras deshidratadas por los dos métodos no permiten el crecimiento de hongos u otros microorganismos nocivos en las mismas y aseguran su estabilidad sin perder su efecto probiótico durante al menos dos semanas almacenadas a temperatura ambiente (Betoret et al., 2003).

3.2 Efecto del proceso sobre las propiedades ópticas y mecánicas del alimento funcional.

En la tabla 4 se muestran las coordenadas de color en el espacio CIE L*a*b*, así como las coordenadas psicrométricas croma $\left(\mathrm{C}_{\mathrm{ab}}\right)$ y tono $\left(\mathrm{h}_{\mathrm{ab}}\right)$. 
Tabla 4. Contenido microbiano de los medios y de las muestras de manzana en cada etapa del proceso de fabricación (promedio \pm desviación estándar).

\begin{tabular}{|c|c|c|c|c|c|c|}
\hline & $\begin{array}{l}\text { Espesor } \\
(\mathrm{mm})\end{array}$ & $\mathbf{L}^{*}$ & a* & $\mathbf{b}^{*}$ & $\mathrm{C}_{\mathrm{ab}}$ & $\mathbf{h}_{a b}$ \\
\hline Manzana fresca & 2.5 & $77.1 \pm 1.3^{a}$ & $-2.2 \pm 0.4^{a}$ & $12.0 \pm 1.9^{a}$ & $12.2 \pm 1.9^{a}$ & $100.46 \pm 1.12^{\mathrm{a}}$ \\
\hline Manzana iresca & 7 & $76 \pm 2^{a}$ & $-1.4 \pm 0.4^{\mathrm{a}}$ & $10.93 \pm 1.03^{a}$ & $11.03 \pm 1.02^{\mathrm{a}}$ & $98 \pm 2^{\mathrm{a}}$ \\
\hline & 2.5 & $55 \pm 2^{b}$ & $-1.1 \pm 0.3^{a}$ & $13.9 \pm 1.2^{\mathrm{a}}$ & $14.0 \pm 1.2^{\mathrm{a}}$ & $94.33 \pm 0.91^{b}$ \\
\hline Manzana iv & 7 & $35.0 \pm 1.7 \mathrm{c}$ & $-0.6 \pm 0.4^{a}$ & $9.7 \pm 1.6^{a}$ & $9.7 \pm 1.6^{\mathrm{a}}$ & $93 \pm 2^{b}$ \\
\hline $\mathrm{M}_{\mathrm{IV}}+\mathrm{SAC} 30^{\circ} \mathrm{C}$ & 2.5 & $65 \pm 2^{\mathrm{d}}$ & $7.6 \pm 1.6^{\mathrm{b}}$ & $53 \pm 5^{b, c}$ & $54 \pm 6^{\mathrm{b}, \mathrm{c}}$ & $81.96 \pm 1.12^{c}$ \\
\hline & 7 & $66 \pm 5^{d}$ & $6.5 \pm 1.6^{b}$ & $54 \pm 6^{b, c}$ & $55 \pm 6^{b, c}$ & $83.3 \pm 1.2^{c}$ \\
\hline $\mathrm{M}_{\mathrm{IV}}+\mathrm{SAC} 45^{\circ} \mathrm{C}$ & $\begin{array}{c}2.5 \\
7\end{array}$ & $\begin{array}{l}56 \pm 4^{b} \\
53 \pm 4^{b}\end{array}$ & $\begin{array}{c}13 \pm 3^{c} \\
10.6 \pm 2.1^{d}\end{array}$ & $\begin{array}{c}60 \pm 6^{c} \\
53 \pm 6^{b, c}\end{array}$ & $\begin{array}{c}61 \pm 6^{c} \\
54 \pm 6^{b, c}\end{array}$ & $\begin{array}{c}78 \pm 3^{\mathrm{d}} \\
78.68 \pm 1.7 \mathrm{~d}\end{array}$ \\
\hline MIV + LIO $12 \mathrm{~h}$ & $\begin{array}{c}2.5 \\
7\end{array}$ & $\begin{array}{c}85.7 \pm 1.3 \mathrm{e} \\
86 \pm 3 \mathrm{e}, \mathrm{f}\end{array}$ & $\begin{array}{c}5 \pm 2 \mathrm{~b}, \mathrm{e} \\
3.3 \pm 0.7 \mathrm{e}\end{array}$ & $\begin{array}{l}47 \pm 3^{b} \\
41 \pm 3^{d}\end{array}$ & $\begin{array}{l}47 \pm 3^{b} \\
41 \pm 3^{d}\end{array}$ & $\begin{array}{c}84 \pm 2^{c, e} \\
85.4 \pm 0.7 \mathrm{e}\end{array}$ \\
\hline $\mathrm{M}_{\mathrm{IV}}+\mathrm{LIO} 24 \mathrm{~h}$ & $\begin{array}{c}2.5 \\
7\end{array}$ & $\begin{array}{c}88.0 \pm 1.4^{\mathrm{f}} \\
87 \pm 2^{\mathrm{e}, \mathrm{f}}\end{array}$ & $\begin{array}{l}0.6 \pm 0.3^{\mathrm{f}} \\
1.0 \pm 0.6^{\mathrm{f}}\end{array}$ & $\begin{array}{l}39 \pm 2^{d} \\
39 \pm 2^{d}\end{array}$ & $\begin{array}{l}39 \pm 2^{d} \\
39 \pm 2^{d}\end{array}$ & $\begin{array}{l}89.1 \pm 0.4^{\mathrm{f}} \\
88.5 \pm 0.8^{\mathrm{f}}\end{array}$ \\
\hline
\end{tabular}

* Valores con distinto superíndice en una columna son estadísticamente diferentes ( $\mathrm{p} \leq 0.05)$.

El análisis estadístico de los datos obtenidos permitió afirmar que, con un nivel de confianza del $95 \%$, las muestras presentaron un color más anaranjado a medida que aumentó la temperatura del aire empleado en el proceso de secado. Las muestras impregnadas presentaron valores de $a^{*}$ considerablemente inferiores a los de la coordenada $b *$, lo que indica que éstas mantuvieron el color verdoso característico del tejido de manzana fresco. Se reportaron diferencias significativas entre las muestras procesadas a diferentes temperaturas, pero no entre las muestras con diferentes espesores (figura 1).

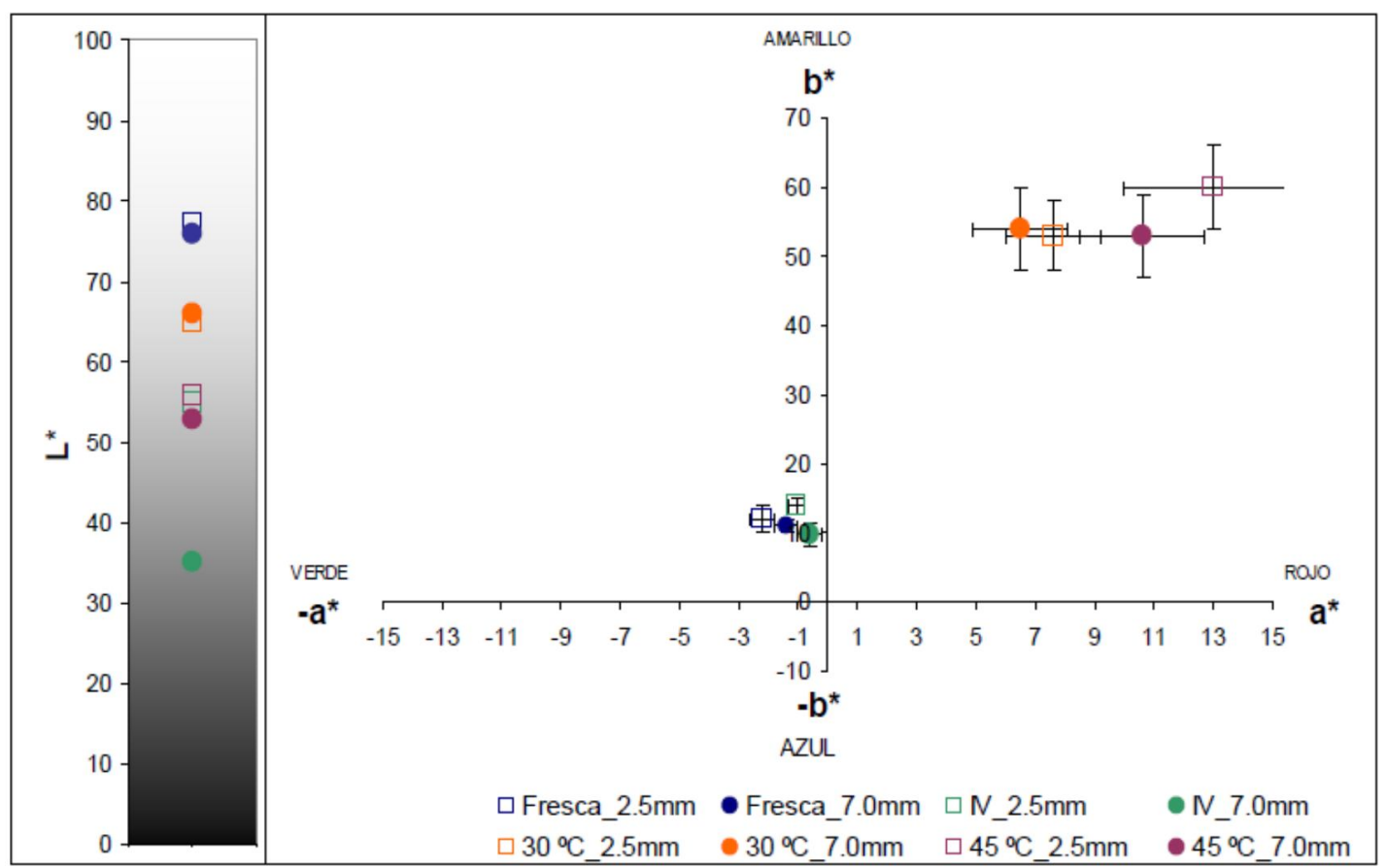

Figura 1a. Distribución de las coordenadas CIE L*a*b* de las muestras frescas, impregnadas y secadas por aire caliente. 


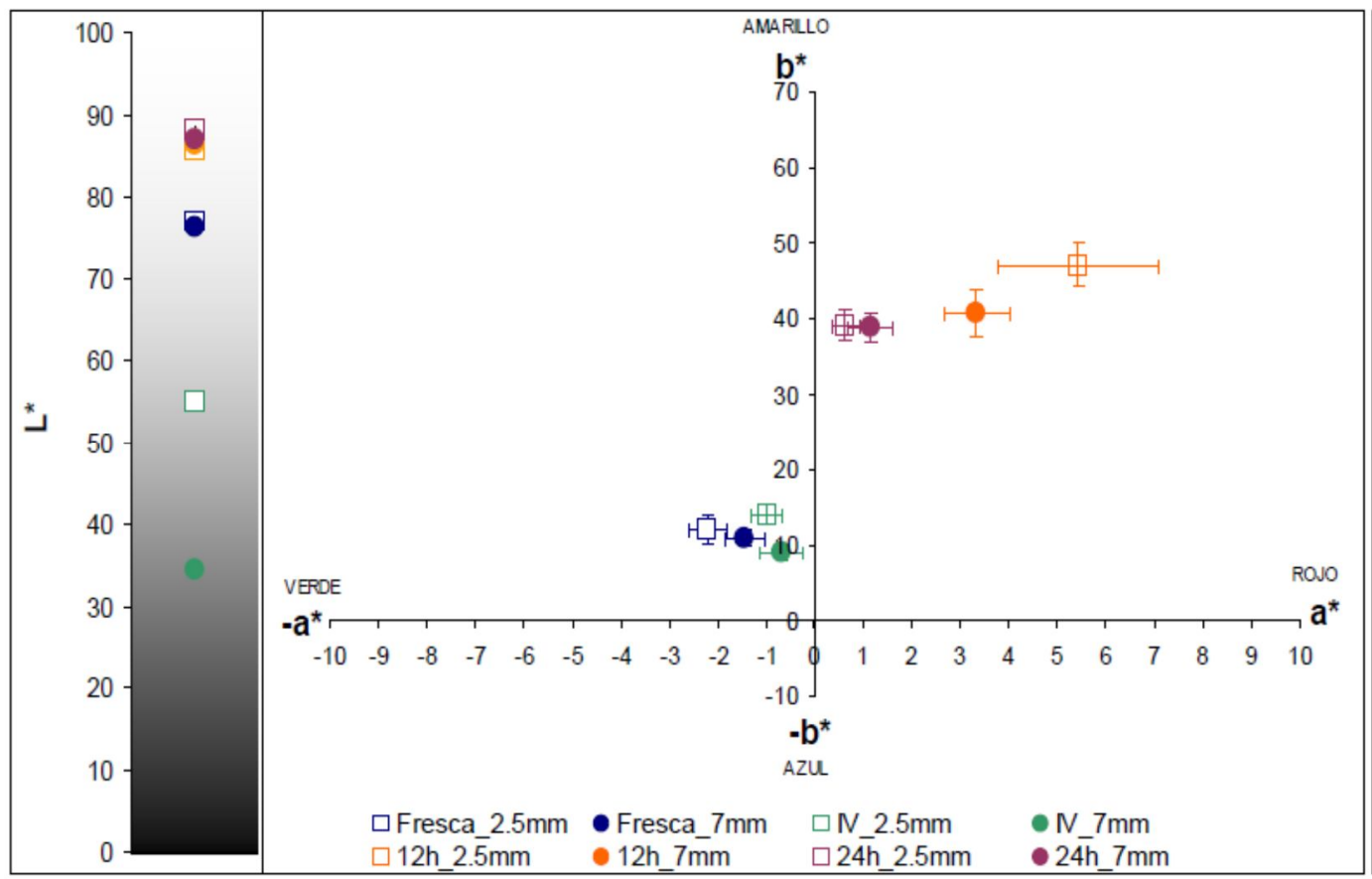

Figura 1b. Distribución de las coordenadas CIE L*a*b* de las muestras frescas, impregnadas y liofilizadas.

La influencia que las variables de proceso ejercieron sobre el valor de las coordenadas psicrométricas fue similar al comentado para las coordenadas de color en el espacio CIE L*a*b*. Las muestras liofilizada presentaron valores de las coordenadas de color en el espacio CIE L*a*b* y de las coordenadas psicrométricas croma $\left(\mathrm{C}_{\mathrm{ab}}\right)$ y tono $\left(\mathrm{h}_{\mathrm{ab}}\right)$ significativamente más elevados. Por lo que respecta al aumento en la luminosidad experimentado por las muestras liofilizadas, éste puede deberse a que, tras la liofilización, los espacios intercelulares que estaban llenos de líquido en las muestras impregnadas aparecen llenos de aire, confiriendo al tejido un aspecto más opaco y un color más blanquecino.

En la tabla 5 se muestran los parámetros utilizados en la determinación de las propiedades mecánicas de las muestras en cada etapa del proceso de fabricación.

Tabla 5. Contenido microbiano de los medios y de las muestras de manzana en cada etapa del proceso de fabricación (promedio \pm desviación estándar).

\begin{tabular}{|c|c|c|c|c|}
\hline & Espesor (mm) & $F_{F}(N)$ & $d_{F}(m m)$ & $\mathbf{A}(\mathbf{N} \cdot \mathbf{m m})$ \\
\hline \multirow{2}{*}{ Manzana fresca } & 2.5 & $1.787 \pm 0.112^{\mathrm{a}}$ & $2.1 \pm 0.4^{\mathrm{a}}$ & $5.7 \pm 0.8^{\mathrm{a}}$ \\
\hline & 7 & $2.0 \pm 0.4^{\mathrm{a}}$ & $3.6 \pm 0.6^{b}$ & $11 \pm 2^{\mathrm{b}}$ \\
\hline \multirow{2}{*}{ Manzana IV } & 2.5 & $2.0 \pm 0.6^{\mathrm{a}}$ & $1.5 \pm 0.2^{c}$ & $5 \pm 2^{\mathrm{a}}$ \\
\hline & 7 & $1.82 \pm 0.13^{a}$ & $2.8 \pm 1.1^{\mathrm{a}}$ & $9.9 \pm 0.6^{b}$ \\
\hline \multirow{2}{*}{$\mathrm{M}_{\mathrm{IV}}+\mathrm{SAC} 30^{\circ} \mathrm{C}$} & 2.5 & $10 \pm 2^{b}$ & $3.8 \pm 0.7 \mathrm{~b}$ & $18 \pm 5^{c}$ \\
\hline & 7 & $12 \pm 2^{c}$ & $4.3 \pm 0.6^{b}$ & $27 \pm 5^{d}$ \\
\hline \multirow{2}{*}{$\mathrm{M}_{\mathrm{IV}}+\mathrm{SAC} 45^{\circ} \mathrm{C}$} & 2.5 & $7 \pm 3^{d}$ & $3.0 \pm 1.3^{a}$ & $12 \pm 5^{b}$ \\
\hline & 7 & $22 \pm 2^{e}$ & $4.9 \pm 0.8^{\mathrm{b}}$ & $47 \pm 7 \mathrm{e}$ \\
\hline \multirow{2}{*}{$\mathrm{M}_{\mathrm{IV}}+\mathrm{LIO} 12 \mathrm{~h}$} & 2.5 & $6.0 \pm 0.8^{\mathrm{d}}$ & $4.6 \pm 0.6^{b}$ & $19 \pm 4^{c}$ \\
\hline & 7 & $7.74 \pm 1.0^{\mathrm{d}}$ & $7 \pm 2^{d}$ & $27 \pm 4^{d}$ \\
\hline \multirow{2}{*}{$\mathrm{M}_{\mathrm{IV}}+\mathrm{LIO} 24 \mathrm{~h}$} & 2.5 & $4.5 \pm 0.7^{\mathrm{f}}$ & $2.4 \pm 0.6^{\mathrm{a}}$ & $9 \pm 3^{b}$ \\
\hline & 7 & $4.6 \pm 1.0^{\mathrm{f}}$ & $2.6 \pm 1.0^{a}$ & $13 \pm 2^{b}$ \\
\hline
\end{tabular}

*Valores con distinto superíndice en una columna son estadísticamente diferentes ( $\mathrm{p} \leq 0.05)$. 
Como se puede observar en la tabla 5, la fuerza máxima necesaria para atravesar completamente las muestras impregnadas fue significativamente menor a la necesaria para romper las muestras sometidas al proceso de secado por aire caliente. Las muestras de mayor espesor presentaron valores de fuerza máxima significativamente superiores a los de las muestras de menor espesor procesadas a la misma temperatura. El menor contenido en agua alcanzado por éstas al final del proceso de secado por aire caliente es suficiente para justificar su mayor fragilidad. La distancia recorrida por el émbolo hasta romper la muestra puso de manifiesto que, con independencia del espesor de las muestras y de la temperatura del aire, las muestras secadas por aire caliente experimentaron una deformación previa a su fractura mayor que las muestras impregnadas. El área encerrada bajo la curva experimentó una evolución muy similar a la de la fuerza máxima, de manera que las muestras que alcanzaron un menor contenido en agua al final del proceso de secado fueron las que necesitaron más energía para su rotura.

La liofilización aumentó significativamente la dureza de las muestras, especialmente en el caso de las muestras procesadas durante 12 horas, que fueron las que presentaron un mayor contenido en agua al final del proceso. Esta misma diferencia en el contenido en agua justificaría la mayor fragilidad de las muestras procesadas durante 24 horas y, entre las muestras procesadas durante 12 horas, la mayor fragilidad de las muestras de menor espesor en comparación con las de mayor espesor.

En los valores de distancia y área encerrada bajo la curva el efecto fue similar al de la fuerza máxima, observándose diferencias significativas entre tratamientos y entre espesores, excepto en el caso de muestras liofilizadas durante 24 horas.

En la figura 2 se muestran las curvas de fuerza-distancia características de las muestras de manzana sólidas en las diferentes etapas del proceso.

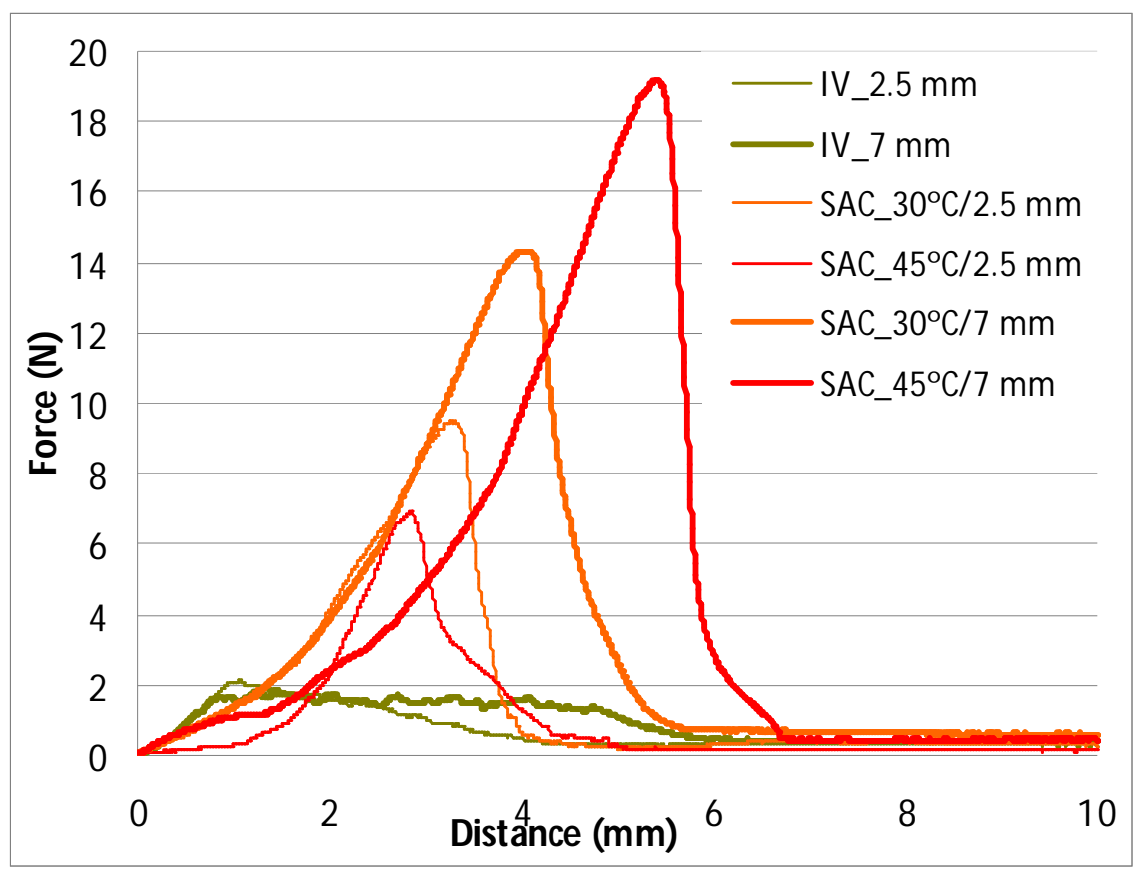

Figura 2a. Curvas fuerza-distancia de las muestras frescas, impregnadas y secadas por 


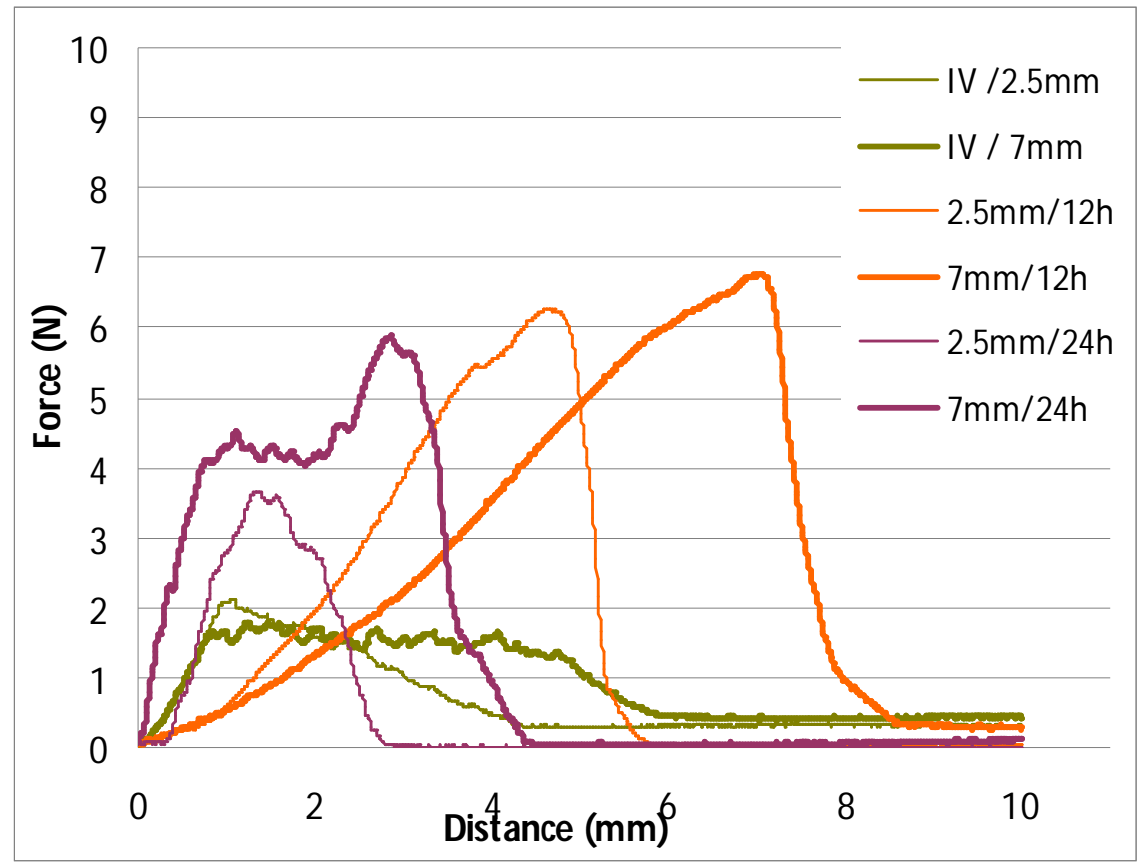

Figura 2b. Curvas fuerza-distancia de las muestras frescas, impregnadas y liofilizadas.

Las muestras secas presentan un único punto de fractura cuando se alcanza la fuerza máxima y presentan una pendiente bastante pronunciada. Ésta pendiente podría estar relacionada con el estado gomoso alcanzado por todas las muestras al final del proceso de secado. En cambio, en las curvas obtenidas para las muestras impregnadas tras alcanzar la fuerza máxima se observan una serie de picos que indican múltiples fracturas probablemente asociadas a la turgencia celular del tejido. Tanto en los tratamientos a $30^{\circ} \mathrm{C}$ como en los de $45^{\circ} \mathrm{C}$ se ve claramente que las muestras de espesor $7 \mathrm{~mm}$ sufren una mayor deformación previa a la fractura que las muestras de espesor $2.5 \mathrm{~mm}$. Las muestras de espesor $2.5 \mathrm{~mm}$ tras el proceso de secado a $45^{\circ} \mathrm{C}$ son las que antes alcanzan la fuerza máxima y por tanto las más frágiles. Esta característica está relacionada con su menor contenido en agua.

La forma de las curvas de las muestras liofilizadas durante 24 horas resultó, con independencia del espesor, más parecida a la de las muestras impregnadas, presentando múltiples fracturas y una deformación menor previa a la fractura. Este comportamiento resulta lógico si se tiene en cuenta que a mayor tiempo de liofilización, las muestras están más deshidratadas y son más sensibles a la fractura y, en consecuencia, más crujientes. Siguiendo con este razonamiento, las muestras liofilizadas durante 12 horas, por presentar un mayor contenido en agua al final del proceso, experimentaron una deformación previa a una única fractura, lo que evidencia que estas muestras son más gomosas, especialmente aquellas de mayor espesor. 
3.3 Efecto del proceso de fabricación sobre el contenido microbiano de las muestras de manzana.

En la tabla 6 se muestra el contenido microbiano del caldo MRS, del líquido de impregnación y de las muestras de manzana en cada etapa del proceso de fabricación. Tal y como se ha dicho en el apartado de materiales y métodos el contenido microbiano en el caldo MRS, el líquido de impregnación y en la manzana impregnada se determinó directamente mediante siembra en profundidad con doble capa de agar mientras que en el caso de las muestras deshidratadas se estimó mediante un balance de masas realizado en la operación de rehidratación y siguiendo las hipótesis establecidas en Betoret et al., 2012.

Tabla 6. Contenido microbiano de los medios y de las muestras de manzana en cada etapa del proceso de fabricación (promedio \pm desviación estándar).

\begin{tabular}{ccc}
\hline & $\begin{array}{c}\text { Espesor } \\
(\mathbf{m m})\end{array}$ & \multicolumn{2}{c}{ Contenido microbiano (UFC/ ml ó g) } \\
\hline Caldo MRS & - & $(9.88 \pm 0.53) \cdot 10^{8}$ \\
Líquido impregnación & - & $(3 \pm 2) \cdot 10^{8}$ \\
Manzana impregnada & 2.5 & $(1 \pm 2) \cdot 10^{8}$ \\
& 7 & $(1 \pm 2) \cdot 10^{8}$ \\
$\mathbf{M}_{\mathbf{I V}}+$ SAC 30 oC & 2.5 & $(2.7 \pm 0.2) \cdot 10^{7}$ \\
& 7 & $(2 \pm 2) \cdot 10^{7}$ \\
$\mathbf{M}_{\mathbf{I V}}+$ SAC 45 oC & 2.5 & $(8.29 \pm 1.04) \cdot 10^{7}$ \\
& 7 & $(9 \pm 1) \cdot 10^{6}$ \\
$\mathbf{M}_{\mathbf{I V}}+$ LIO 12 h & 2.5 & $(7 \pm 4) \cdot 10^{7}$ \\
& 7 & $(8 \pm 9) \cdot 10^{8}$ \\
$\mathbf{M}_{\mathbf{I V}}+$ LIO 24 h & 2.5 & $(2 \pm 2) \cdot 10^{9}$ \\
& 7 & $(9 \pm 14) \cdot 10^{8}$ \\
\hline
\end{tabular}

El análisis estadístico, realizado con la finalidad de evaluar el efecto que el método de deshidratación y el espesor de las muestras ejercen sobre el contenido microbiano de las mismas, puso de manifiesto, con un nivel de confianza del $95 \%$, que los niveles de las variables consideradas no ejercen efecto significativo alguno sobre la variable respuesta.

En diferentes estudios se ha comprobado que para que un alimento probiótico tenga un efecto beneficioso contra la colonización por Helicobacter pylori es necesario que al menos presente una cantidad de microorganismos de $10^{6} \mathrm{UFC} \cdot \mathrm{cm}^{-}$ 3 al final de su vida útil (Ouwehand et al., 1999), y se recomienda un consumo diario superior a $10^{9} \mathrm{UFC/} \mathrm{día} \mathrm{(De} \mathrm{Champs} \mathrm{et} \mathrm{al.,} \mathrm{2003).} \mathrm{Para} \mathrm{los} \mathrm{dos} \mathrm{métodos} \mathrm{de}$ deshidratación empleados así como en ambos espesores de muestra considerados se alcanzaron niveles superiores a $10^{6} \mathrm{UFC} / \mathrm{g}$ por lo que el alimento funcional tendría, en todos los casos, efecto potencial contra la infección ocasionada por Helicobacter pylori. 


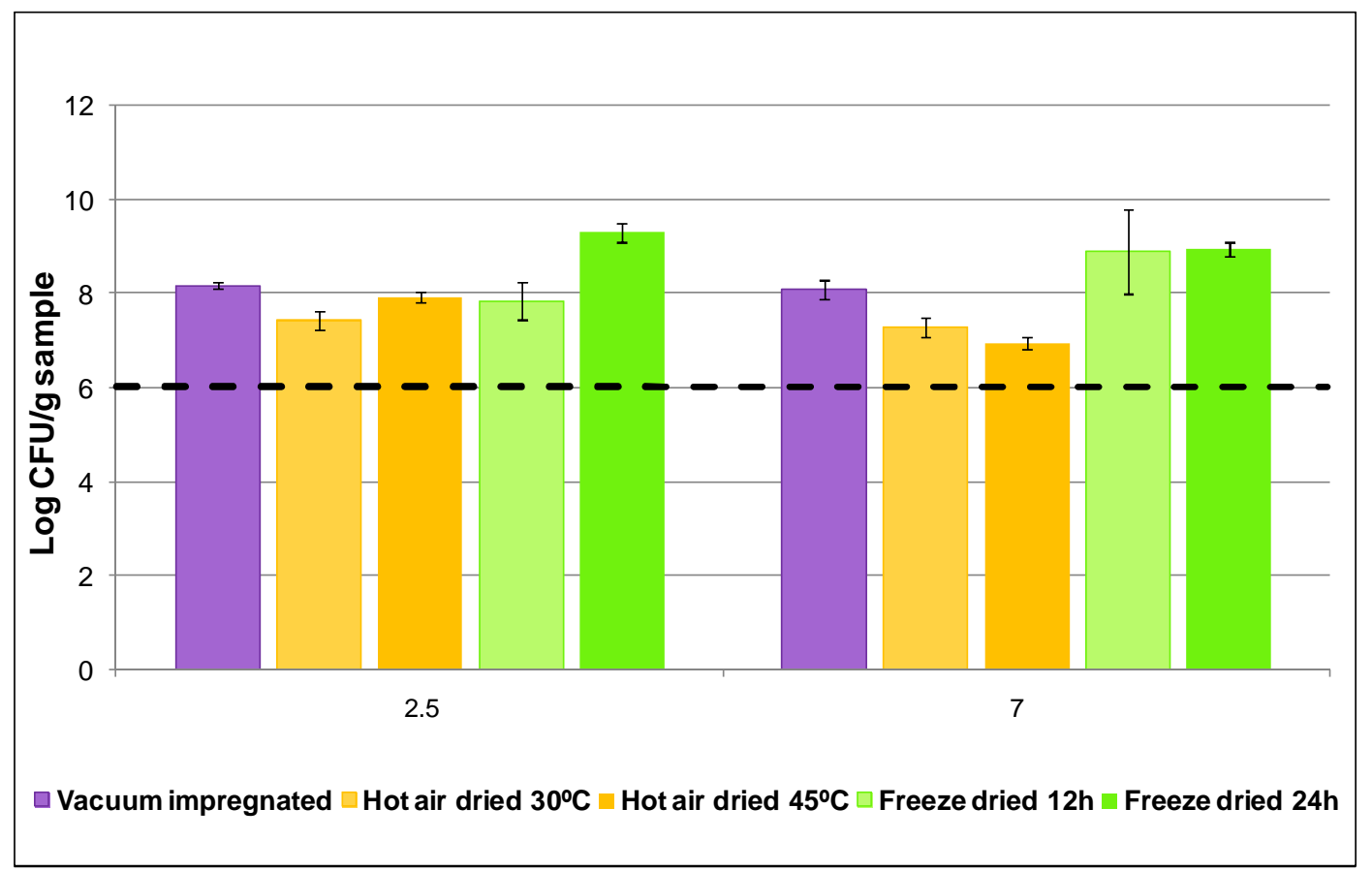

Figura 3. Niveles de microorganismos con la línea discontinua como límite para el efecto contra Helicobacter pylori.

\section{CONCLUSIONES}

Los productos obtenidos mediante las técnicas de deshidratación estudiadas en este trabajo presentaron un contenido microbiano igual o superior a $10^{6} \mathrm{UFC} / \mathrm{g}$, de manera que está garantizado su efecto potencial contra la infección ocasionada por Helicobacter pylori. Las propiedades mecánicas y ópticas de las muestras deshidratadas fueron diferentes dependiendo del método de deshidratación empleado, debido fundamentalmente a los diferentes niveles de humedad alcanzados por las muestras al final del proceso. De forma general, para obtener un producto crujiente y blanquecino sería recomendable aplicar un proceso de liofilización durante 24 horas a muestras de $2.5 \mathrm{~mm}$ de espesor. Mediante la técnica de secado por aire caliente se obtienen, con independencia del espesor, productos gomosos y de color anaranjado. La elección del proceso más adecuado dependerá de las características buscadas en el producto final.

\section{BIBLIOGRAFÍA CITADA.}

A.O.A.C. (1980). Association of Official Analytical Chemist Official Methods of Analysis. Washington.

Arilla A. (2008). Combinación de las técnicas de impregnación a vacío y secado por aire caliente en la obtención de alimentos probióticos a partir de manzana con efecto contra la infección por Helicobacter Pylori. Universidad Politécnica de Valencia. (Escuela Técnica Superior de Ingenieros Agrónomos). Trabajo fin de carrera. 
Betoret N., Puente L., Díaz M.J., Pagan M.J., García M.J., Gras M.L., Martínez-Monzó J., \& Fito P. (2003). Development of probiotic-enriched dried fruits by vacuum impregnation. Journal of Food Engineering, 56, 2-3, 273-277.

Canducci F., Cremonini F., Armuzzi A., Di Caro S., Gabrielli M., Santarelli L., Nista E., Lupascu A., De Martini D., \& Gasbarrini A. (2002). Probiotics and Helicobacter pylori eradication. Digestive and Liver Disease, 34, S81-S82.

Gold B.D., Coletti R.B., \& Abbot M. (2000). Helicobacter pylori infection in children: recommendations for diagnosis and treatment. Journal of Pediatric Gastroenterology and Nutrition, 31, 490-499.

Hutchings J.B. (1999). Food and color appearance. 2nd ed. Maryland: Chapman and Hall Food Science Book, Aspen Publication.

Judd D.B., \& Wyszecki G. (1975). Color in business, science and industry. New York: John Wiley and Sons.

Ouwehand A.C., Derrien M., de Vos W., Tiihonen K., \& Rautonen N. (2005). Prebiotics and other microbial substrates for gut functionality. Current Opinion in Biotechnology, 16, 212-217.

Talens P., Martínez-Navarrete N., Fito P., \& Chiralt A. (2002). Changes in optical and mechanical properties during osmodehydrofreezing of kiwifruit. Innovative Food Science \& Emerging Technologies, 3, 191-199. 
4. DISCUSIÓNGENERAL DE RESULTADOS 

El zumo de mandarina y las manzanas son dos alimentos ampliamente consumidos en todo el mundo y sus efectos beneficiosos sobre la salud se conocen desde hace mucho tiempo. Se ha demostrado el efecto del zumo de mandarina sobre algunas enfermedades tales como la insuficiencia coronaria (Rouseff \& Nagy, 1994) y algunos desórdenes relacionados con la edad (Baghurst, 2003), así como su efecto preventivo contra el riesgo de padecer algunos tipos de cáncer (Block et al., 1992; Steinmez \& Potter, 1996; So et al., 1996). El consumo de zumos cítricos afecta a la concentración de la vitamina $C$ en sangre, así como a los marcadores del estado antioxidante (Sanchez-Moreno et al., 2003). De la misma manera el consumo de manzana se ha relacionado con la disminución del riesgo de padecer una enfermedad cardiovascular, diabetes y algunos tipos de cáncer (Boyer \& Liu, 2004; McCann et al., 2007).

Teniendo en cuenta la importancia que están adquiriendo las tecnologías que forman una estructura dirigida a prevenir el deterioro de los compuestos fisiológicamente activos y el hecho de que los alimentos enteros pueden ejercer efectos más beneficiosos que los compuestos aislados, esta tesis plantea cubrir todas las etapas necesarias en el proceso de innovación industrial aplicando el método científico. Concretamente, se aborda el desarrollo de un alimento funcional a partir de manzana (cv. Granny Smith) y zumo de mandarina (cv. Ortanique) utilizando la técnica de impregnación a vacío y valorando su eficacia mediante estudios in vivo. Adicionalmente, se han incluido microorganismos probióticos al desarrollo del alimento con el fin de valorar su efecto contra la infección por Helicobacter pylori.

\subsection{Desarrollo de un alimento funcional a partir de manzana y zumo de mandarina.}

La primera parte del trabajo se dirigió a obtener un zumo de mandarina de alta calidad. Las continuas mejoras tecnológicas han permitido a la industria de cítricos conseguir una excelente calidad; en la actualidad los zumos de cítricos tienen mejor sabor y más parecido al zumo fresco recién exprimido que nunca. La preparación de los zumos utilizados en esta tesis se llevó a cabo siguiendo el procedimiento de obtención patentado WO/2007/042593 y titulado "Procedimiento de obtención de zumos cítricos pasteurizados y refrigerados" (Izquierdo et al., 2007). Este procedimiento permite la obtención de dos fracciones de zumos, una rica en pulpa y otra con bajo contenido en la misma, de tal manera que a cada una se le da un tratamiento térmico diferente con el objetivo de preservar las características típicas de los zumos frescos. En este trabajo se ha utilizado la fracción de zumo con bajo contenido en pulpa (LPJ).

El procedimiento de obtención mencionado anteriormente incluye la operación de homogeneización, que obviamente afecta a las propiedades fisicoquímicas del zumo. Este efecto y sobretodo el efecto sobre las partículas en suspensión es importante cuando la operación de homogeneización se aplica previamente a otras 
operaciones o procesos en los que los sólidos en suspensión afectan a la eficiencia $\mathrm{y}$ al rendimiento del proceso o a la calidad del producto final. Esto es lo que ocurre en el caso de la impregnación a vacío. La utilización de la impregnación a vacío requiere que el líquido de impregnación pueda ser introducido en los poros o los espacios intercelulares del alimento que se desea impregnar.

Se estudió la idoneidad del zumo para su uso en la operación de impregnación a vacío. Concretamente, se determinó el efecto de la presión de homogeneización sobre la pulpa suspendida y la turbidez, la distribución del tamaño de partícula, el color, la actividad antirradical y el contenido en flavonoides de los zumos frescos de cítricos con bajo contenido en pulpa (LPJ) con el fin de determinar las condiciones ideales para su uso en el desarrollo de una fruta fresca funcional.

- La centrifugación a diferentes velocidades permite la determinación de diferentes clases de pulpa que son más o menos estables en la nube del zumo. Se determinó el volumen de precipitado y la transmitancia del sobrenadante a 365 y 3000 g. A estos niveles de centrifugación los niveles de pulpa suspendida y transmitancia disminuyeron a medida que aumentó la presión de homogeneización. En ambos parámetros los cambios observados hasta $10 \mathrm{MPa}$ fueron mayores que los observados a mayores presiones. Por encima de los $10 \mathrm{MPa}$ los bajos valores de transmitancia obtenidos indicaron un elevado nivel de turbidez y de pulpa suspendida en el zumo (LPJ) que aumentó con la presión de homogeneización. Este efecto puede explicarse teniendo en cuenta que la presión de homogeneización convierte la pulpa sensible a pulpa de fondo (Kupper et al., 1987) y las partículas de la nube son más estables.

- La distribución del tamaño de partícula en el zumo de mandarina LPJ mostró una distribución entre 0.5 y $1000 \mu \mathrm{m}$, con picos irregulares entre 100 y $1000 \mu \mathrm{m}$ y con una evolución natural hacia tamaños más pequeños a medida que aumentó la presión de homogeneización. El análisis del D[4,3] y del $D_{\text {peak }}$ permitió diferenciar varios grupos de muestras: un primer grupo formado por las muestras homogeneizadas a 0 y $5 \mathrm{MPa}$, un segundo grupo formado por las muestras homogeneizadas a 10 y $15 \mathrm{MPa}$, y un tercer grupo formado por las muestras homogeneizadas a 20, 25, y $30 \mathrm{MPa}$.

- Las coordenadas de color CIE-L*a*b* del zumo LPJ aumentaron con la presión de homogeneización hasta una presión de $25 \mathrm{MPa}$. La disminución de las coordenadas a la presión de $30 \mathrm{MPa}$ puede explicarse teniendo en cuenta la agregación de las partículas más pequeñas y la posterior sedimentación de las mismas después de la centrifugación. Las mayores diferencias de color se observaron a la presión de $25 \mathrm{MPa}$.

- Se determinó la actividad antirradical de las muestras de zumo con bajo contenido en pulpa (LPJ) mediante dos métodos diferentes, el ABTS y el $\mathrm{DPPH}$, aunque cada uno de ellos presenta unas determinadas limitaciones (Leong \& Shui, 2002; Prior et al., 2005). Por ejemplo el método DPPH es más 
sensible a las flavononas hidrofóbicas mientras que el ABTS es más sensible a los antirradicales hidrofílicos como la vitamina C (Del Caro et al., 2004).

Los resultados obtenidos con el método ABTS mostraron diferencias significativas ( $\mathrm{p} \leq 0.05$ ) entre las muestras no homogeneizadas y las homogeneizadas a 20, 25 and $30 \mathrm{MPa}$ aunque las diferencias observadas fueron mínimas. No se encontraron diferencias significativas a las diferentes presiones aplicadas pero se observó un ligero aumento de la actividad antirradical a medida que aumentó la presión de homogeneización.

Para determinar la actividad antirradical de las muestras de zumo mediante el método DPPH se utilizó el modelo propuesto por Sentandreu et al. (2008). En este modelo la actividad antirradical $\left(A_{t}\right)$ de un extracto natural es la suma de tres actividades antirradicales que corresponden, cada una de ellas, a la cinética de reacción de los componentes incluidos en la reacción. En nuestro caso, no se encotraron diferencias significativas en los tres parámetros de actividad antirradical, ni con la actividad antirradical total $\left(A_{t}\right)$, a ningún nivel de presión de homogeneización aplicado. Estos resultados coinciden con los obtenidos por Suárez-Jacobo et al. (2011) quien determinó que los principales componentes del zumo de manzana no cambian con el procesado a altas presiones. Además la actividad antirradical del zumo (LPJ) obtenida no fue menor que la obtenida de un zumo de mandarina (cv. Ortanique) industrial pasteurizado $\left(A_{t}=2.132\right.$ $\mathrm{mmol} / \mathrm{L}$ equivalentes de ácido ascórbico (Sentandreu., 2006)).

- Los zumos de cítricos contienen una gran variedad de componentes que exhiben actividad antirradical tales como los flavonoides (Sendra et al., 1988), el ácido ascórbico (Johnston \& Bowling, 2002), las antocianinas (Rapisarda et al., 2000) y los derivados del ácido cinámico (Robards \& Antolovich, 1995), entre otros. La composición antiradical del LPJ se determinó mediante el análisis por HPLC-MSn. Los componentes identificados se clasificaron de acuerdo con su cinética antirradical de reacción con el DPPH. De todos los componentes identificados en este estudio, se sabe que los flavonoides más abundantes del zumo de mandarina son la hesperidina, la narirrutina y la didimina. En éstos se estudió el efecto de la presión de homogeneización.

Se determinó el contenido en los flavonoides hesperidina, narirrutina y didimina suspendidos en la nube de los zumos (LPJ) no homogeneizados y homogeneizados a las presiones de 5, 10, 15, 20, 25 and $30 \mathrm{MPa}$. La homogeneización es un proceso mecánico que no afecta al contenido total de los flavonoides del zumo pero que puede producir cambios sobre los flavonoides suspendidos en la nube. La hesperidina fue el flavonoide mayoritario en todas las muestras seguido por la narirrutina y la didimina. Aunque es importante tener en cuenta la pequeña variación obtenida en los datos, la narirrutina y la didimina mostraron una tendencia a aumentar con la presión de homogeneización. Las moléculas de hesperidina son casi 
insolubles en disoluciones acuosas (15 $\mathrm{mg} / \mathrm{L})$ y tienden a cristalizar rápidamente. El tamaño de los cristales aumentan hasta un tamaño crítico alcanzado el cual precipitan (Ben-Shalom \& Pinto, 1999). La aplicación de presiones de homogeneización puede contribuir mantener la hesperidina y otros flavonoides estables en la nube del zumo. Esto ocurrió hasta presiones de $10 \mathrm{MPa}$ a partir de las cuales se observó un ligero descenso. El calor producido en el homogeneizador a altas presiones puede contribuir a este efecto, teniendo en cuenta que la hesperidina precipita más fácilmente cuando está expuesta a condiciones de acidez y calor (Lacroix et al., 2005). La presión de homogenización produce un aumento de temperatura de $19.5 \pm 3{ }^{\circ} \mathrm{C}$ cada $100 \mathrm{MPa}$ (Guamis, 2009). Esto significa que el zumo de mandarina puede alcanzar temperaturas superiores a $30^{\circ} \mathrm{C}$ si el zumo entra en el homogeneizador a temperatura ambiente $\left(25^{\circ} \mathrm{C}\right)$.

- La impregnación a vacío (IV) es una operación de transferencia de materia que tiene lugar en una estructura celular compleja. Se cuantificó el volumen de LPJ introducido en los discos de manzana utilizando el modelo hidrodinámico propuesto por Fito (1994) y Fito \& Pastor (1994) siguiendo el procedimiento experimental descrito por Fito et al. (1996). El parámetro de impregnación volumétrica $(\mathrm{X}) \quad\left(\mathrm{m}^{3}{ }_{\text {zumo }}\right.$ incorporado $/ \mathrm{m}^{3}$ manzana fresca $)$ se determinó para cada presión de homogeneización. Se observó un ligero aumento de la cantidad de zumo incorporado a las presiones de 15, 25 y 30 $\mathrm{MPa}$. Teniendo en cuenta el tamaño de poro de la manzana (6.64 $\pm 0.24 \mu \mathrm{m})$ (Bazharl \& Ngadi, 2003), una reducción en el tamaño de las partículas de la nube del zumo mediante la operación de homogeneización puede facilitar la incorporación de LPJ en los espacios intercelulares de la manzana. Si la pulpa suspendida se mantiene estable formando la nube del zumo esto puede ayudar a la estabilidad de los compuestos funcionales y por tanto a la incorporación potencial de estos componentes en la estructura matricial de la manzana mediante la aplicación de una presión de homogeneización.

\section{La segunda parte del trabajo se dirigió al desarrollo tecnológico del alimento funcional.}

- Si la IV se realiza de forma homogénea, todos los componentes del líquido de impregnación se incorporan igualmente en el alimento. Una impregnación no homogénea puede deberse a la inestabilidad de las partículas en la nube del zumo. Si la IV se lleva a cabo de forma uniforme es posible cuantificar la cantidad de componentes funcionales incorporados a la matriz estructural de la manzana mediante el modelo desarrollado por Fito et al. (1996). El modelo fue desarrollado teniendo en cuenta las propiedades estructurales de las matrices alimentarias y las propiedades fisicoquímicas de las soluciones de impregnación. Siguiendo este modelo y utilizando los valores de la impregnación volumétrica (X), se estimó

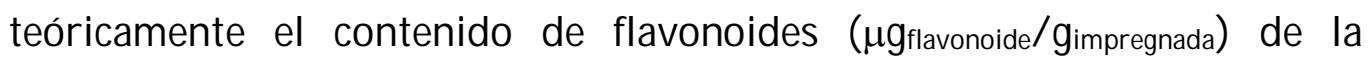
manzana impregnada. El contenido en hesperidina, narirrutina y didimina 
de la manzana deshidratada se estimó mediante balances de masa. Para ello se consideró que el secado por aire caliente a $40{ }^{\circ} \mathrm{C}$ de las manzanas impregnadas no afectó al contenido en flavonoides. Esto coincide con Dhuique-Mayer et al. (2007), quien demostró que la hesperidina tiene una gran estabilidad térmica y no observó pérdidas significativas de este flavonoides después de someterlo a un tratamiento térmico de $90{ }^{\circ} \mathrm{C}$ durante $240 \mathrm{~min}$.

Se eligió el zumo de mandarina LPJ homogeneizado a 15 MPa y se desarrolló un aperitivo de manzana y zumo de mandarina y se evaluaron las propiedades fisicoquímicas y funcionales del producto en cada etapa del proceso de desarrollo. La IV no alteró de forma significativa las características de la manzana fresca. Sin embargo, los elevados valores de actividad de agua obtenidos en la manzana impregnada la hacen altamente inestable. Después del secado con aire caliente el valor de actividad de agua obtenido fue lo suficientemente bajo como para no permitir el crecimiento de hongos u otros microorganismos dañinos durante al menos dos semanas almacenado a temperatura ambiente (Betoret et al., 2003).

- Se determinó la actividad antirradical de los discos de manzana en cada etapa del proceso de desarrollo. Las manzanas impregnadas con el zumo de mandarina y deshidratadas, resultaron en valores de la actividad antirradical más elevados, debido a la incorporación de los componentes funcionales del zumo a la matriz estructural de la manzana. Aunque aumentó el valor de todas las actividades antirradicales, la impregnación a vacío especialmente mejoró la actividad antirradical lenta. El aumento de la actividad antirradical de las muestras impregnadas y deshidratadas puede explicarse teniendo en cuenta que el calor aplicado durante el proceso de deshidratación es el principal responsable de la destrucción de componentes antioxidantes pero también puede inducir la formación de compuestos, como las melanoidinas generadas en la reacción de Maillard, que pueden contribuir a la actividad antirradical (Nicoli et al., 1997; Anese et al., 1999). Además, el calor puede aumentar el nivel de flavonoles libres que también contribuyen a la actividad antirradical (Stewart et al., 2000). La composición de los extractos de manzana impregnados y deshidratados indicó que únicamente el ácido ascórbico y el ácido clorogénico están presentes tanto en el zumo de mandarina como en la manzana. Los compuestos fisiológicamente activos identificados se clasificaron de acuerdo con su cinética de actividad antirradical in vitro.

- Con el objetivo de obtener un producto estable y aceptado por el consumidor se utilizó el secado por aire caliente a $40{ }^{\circ} \mathrm{C}$ y $70 \stackrel{\circ}{\circ} \mathrm{C}$ y la liofilización durante 12 y 24 horas para estabilizar el alimento funcional. Se determinaron las propiedades ópticas y mecánicas de los diferentes productos obtenidos y se determinó su evolución a lo largo del proceso de fabricación. 
En las muestras de manzana fresca el valor de la coordenada $a^{*}$ fue menor que el valor de la coordenada b* lo que indica el color amarillo-verdoso propio de la fruta fresca. La disminución en el valor de la coordenada a* indica una evolución hacia una tonalidad amarillenta al incorporar el zumo de mandarina en la estructura matricial de la manzana. Los cambios en la luminosidad de la manzana impregnada ( $\left.L^{*}\right)$ pueden atribuirse a un incremento en la traslucidez como resultado del intercambio gas-zumo de mandarina promovido durante la operación de IV. Los principales cambios observados en las muestras deshidratadas puede explicarse teniendo en cuenta los cambios ocurridos en su estructura durante la operación de deshidratación (Lewiki, 1998) básicamente un descenso en la porosidad, contracción y desintegración (Maskan, 2001; Lewiki \& Jakubczyk, 2004). El aumento de la luminosidad observado en las muestras liofilizadas puede deberse al menor contenido en agua y a la formación de una estructura porosa. El valor de las coordenadas $\mathrm{a}^{*}$ y b* indica una evolución a tonos anaranjados en las muestras deshidratadas por aire caliente probablemente debido a las reacciones de pardeamiento y una evolución hacia tonos amarillentos en las muestras liofilizadas debido a las bajas temperaturas utilizadas en el proceso y a la ausencia de exposición al aire durante la sublimación del agua congelada de la muestra. Los principales cambios inducidos por los procesos de deshidratación y que afectan a las propiedades mecánicas de los tejidos vegetales son la pérdida de la turgencia celular, la alteración de la lámina media, el deterioro de la fuerza de la pared celular, cambios en los volúmenes de gas y líquido así como cambios en el tamaño y la forma de las muestras (Chiralt et al., 2001). Las curvas de las muestras deshidratadas presentaron, independientemente de la técnica de deshidratación empleada, la forma típica de productos viscoelásticos, caracterizada por un único punto de fractura cuando se alcanzó la fuerza máxima seguido de una deformación pronunciada y que puede estar asociada con el estado gomoso de las muestras alcanzado al final del proceso. Por otra parte, las curvas obtenidas para las muestras frescas e impregnadas mostraron varios picos, lo que indica múltiples fracturas al alcanzar la fuerza máxima, y podría estar asociado con la turgencia celular del tejido.

- Con el objetivo de obtener un producto de calidad que fuera aceptado por los consumidores se llevó a cabo un análisis sensorial. En el análisis sensorial, todos los atributos evaluados se puntuaron con valores entre 5 y 7 en una escala de 9, indicando en general una buena aceptación de los productos obtenidos. Para todos los parámetros establecidos, el panel de jueces prefirió las muestras liofilizadas frente a las deshidratadas por aire caliente, siendo especialmente remarcables las diferencias obtenidas en la apariencia visual y el color. Cuando se les preguntó sobre la preferencia global, el $64 \%$ de los jueces eligió las muestras liofilizadas durante 24 
horas, seguidas de las muestras deshidratadas por aire caliente a $40{ }^{\circ} \mathrm{C}$ elegidas por el $23 \%$ de los jueces. Aunque la valoración de los atributos de las muestras liofilizadas durante 12 horas fue mayor en todos los casos que la valoración de los atributos de las muestras deshidratadas por aire caliente, su aceptación global obtuvo la menor puntuación. Las muestras deshidratadas por aire caliente fueron aceptadas en segundo lugar. Comparando el precio y la aceptació de la deshidratación por aire caliente y la tecnología de liofilización se eligió el secado por aire caliente a $40{ }^{\circ} \mathrm{C}$ durante 24 horas para estabilizar el producto funcional.

Estudios previos han demostrado que el consumo de $500 \mathrm{~mL}$ de zumo de mandarina durante 4 semanas ejerce un efecto significativo y positivo en los biomarcadores propios de la oxidación y aumenta las defensas antioxidantes de niños hipercolesterolémicos (Codoñer-Franch et al., 2008; Codoñer-Franch et al., 2010). Teniendo en cuenta los aspectos expuestos, referentes tanto al efecto de la operación de homogeneización como al de la IV de manzana con zumo de mandarina homogeneizado a $15 \mathrm{MP}$ y considerando que el producto desarrollado puede ser envasado en porciones de 40 gramos. 40 gramos del producto desarrollado utilizando zumo de mandarina homogeneizado a 15 MPa podría contener la misma cantidad de hesperidina que $250 \mathrm{~mL}$ de zumo de mandarina fresco.

La tercera parte del trabajo se dirigió a la evaluación in vivo del alimento funcional desarrollado. La caracterización de las propiedades de los alimentos y el análisis de la composición bioactiva no son el único requisito durante la investigación en alimentos y el desarrollo de productos sino también la evaluación mediante estudios in vivo de los efectos beneficiosos que estos componentes pueden ejercer sobre la salud.

- El primer estudio in vivo se llevó a cabo en animales de experimentación con el objetivo de identificar el efecto del consumo del aperitivo de manzana enriquecido en zumo de mandarina en la reducción del estrés oxidativo inducido mediante la acción del tamoxifeno.

El tratamiento con tamoxifeno (TAM) produjo una lesión hepática en los animales de experimentación. Este efecto se demostró en los mayores niveles de alanina aminotransferasa (ALT) y aspartato aminotransferasa (AST) observados en plasma y puede atribuirse al daño hepático estructural. Estas enzimas están normalmente localizadas en el citoplasma (ALT) y en las mitocondrias (AST) de los hepatocitos y se liberan en la circulación tras el daño celular. Además, el estrés oxidativo, evaluado mediante una combinación de biomarcadores, quedó patente después de la administración del TAM.

Los resultados obtenidos demostraron que la suplementación diaria del producto desarrollado aumentó la capacidad antioxidante en plasma después de 30 minutos hasta llegar a un máximo registrado a los 60 minutos de la ingestión. Puede afirmarse que nuestro producto tiene un 
efecto antioxidante in vivo. Este resultado coincide con los obtenidos por otros autores en los que los pacientes suplementados con zumo de manzana aumentaron su capacidad antioxidante (Vieira et al., 2012).

Se observó una normalización en los niveles de enzimas hepáticas en las ratas suplementadas con los aperitivos después de la lesión provocada por TAM. Por lo tanto, una acción de este producto podría ser la de disminuir el estrés oxidativo y/o los procesos inflamatorios inducidos por el TAM, permitiendo la recuperación de la homeostasis celular.

El contenido en proteínas carbonilo (CG) es el marcador más común de oxidación proteica. Los CGs son relativamente difíciles de inducir si los comparamos con otros productos resultantes de la oxidación proteica. Son un reflejo de los casos más graves de estrés oxidativo. En las ratas tratadas con TAM, la concentración en suero de proteínas carbonilo aumentó claramente. Se observó un importante efecto protector, reflejado en la reducción del contenido en CG, en los animales suplementados con el aperitivo de manzana y especialmente en los animales suplementados con el aperitivo de manzana IV con zumo de mandarina, lo que sugiere la acción de los compuestos fisiológicamente activos presentes en el zumo (Choi, 2008).

Debido a que el TAM contribuye a incrementar la producción de radicales libres de muchas maneras (Nazarewicz et al., 2007) la administración de agentes específicos con actividad antioxidante o capacidad para captar radicales libres puede disminuir sus efectos perjudiciales. Los daños al ADN son el resultado de un desequilibrio entre la acción de los metabolitos xenobióticos y el poder de numerosos sistemas que contrarresten su acción, como los mecanismos endógenos de defensa antioxidante y los mecanismos de reparación de las lesiones producidas. Ambos, las manzanas (Poulsen et al., 2011) y los cítricos (Razo-Aguilera et al., 2011) han demostrado un fuerte efecto protector contra el daño en el $\mathrm{ADN}$ inducido por peróxido de hidrógeno. Por tanto, un producto que combina estas dos frutas debería ser efectivo. Sin embargo, los resultados obtenidos en este estudio indican que la incorporación de zumo de mandarina a la manzana no tuvo un efecto protector adicional frente al daño en el ADN.

La determinación de $\alpha$-tocoferol puede resultar relevante para conocer el estado antioxidante del hígado. Además, se sabe que la concentración de este antioxidante en la sangre disminuye como consecuencia de un aumento en la carga oxidativa (Patil et al., 2008). Tras la administración del TAM la concentración de $\alpha$-tocoferol en plasma se redujo considerablemente. Tras el consumo de los aperitivos, los animales presentaron niveles más elevados de $\alpha$-tocoferol en sangre, siendo significativamente superior los niveles de aquéllos que consumieron el aperitivo de manzana sin IV. Una posible explicación para el mayor efecto sobre los marcadores de estrés oxidativo observado tras el consumo de los aperitivos de manzana enriquecidos con 
zumo de mandarina es el efecto sinérgico de los diferentes compuestos fisiológicamente activos presentes en el producto desarrollado.

De acuerdo con la bibliografía la manzana contien más fenoles (Jung et al., 2009) y las mandarinas contienen más vitamina $C$, flavonoides específicos y carotenoides (Sentandreu et al., 2007). Este resultado coincide con estudios previos en los que animales suplementados con diferentes frutas muestran diferentes respuestas en los parámetros de estrés oxidativo (Pajk et al., 2006).

En términos generales, el estudio demuestra que los marcadores del estrés oxidativo disminuyen significativamente tanto en plasma como en hígado después del consumo de los aperitivos desarrollados. En la mayoría de los casos, incluso se alcanzan los valores normales previos a la inducción del estrés con TAM. El CG en plasma y los niveles de ALT disminuyen más notablemente después del consumo del aperitivo de manzana enriquecido con zumo de mandarina que del aperitivo de manzana sólo. El efecto del zumo incorporado en la manzana también se observó en el aumento de los niveles de $\alpha$-tocoferol, lo que sugiere que al menos alguno de los efectos beneficiosos de una dieta con aperitivos enriquecidos puede ser la disminución en la oxidación de macromoléculas.

- El segundo estudio in vivo que se llevó a cabo en niños obesos demostró que el consumo durante un período corto de tiempo (4 semanas) del producto desarrollado tiene efectos sobre la actividad antioxidante en plasma, disminuye los marcadores relacionados con la inflamación y reduce varios factores de riesgo de enfermedad cardiovascular.

En este estudio el peso, la circunferencia de la cintura y el índice de impedancia se mantuvieron sin cambios desde el valor basal. Sin embargo se observó una ligera disminución de -0.3 unidades del IMC debido al contínuo crecimiento en altura. Este es un objetivo clásico para el tratamiento de la obesidad en niños: el mantenimiento del peso mientras que la altura sigue aumentando.

El perfil de lipoproteínas alteradas es un factor importante de riesgo cardiovascular. Además, el aumento de lipoproteínas de alta densidad (HDL) juega un papel importante en la prevención de enfermedades cardiovasculares. Se observó un aumento del colesterol HDL y de la Apo A1 y una disminución de los triglicéridos y de la Apo B, que pueden proteger del riesgo cardiovascular. Se ha demostrado que el zumo de cítricos aumenta la transferencia de colesterol libre a HDL y disminuye la transferencia de triglicéridos a HDL (Cesar et al., 2010). En el producto desarrollado puede suponerse que es una combinación entre los flavonoides presentes específicamente en las manzanas (quercetina) y los flavonoides específicamente presentes en el zumo de mandarina (flavanonas y polymetoxyflavones) (Sentandreu et al., 2007) y la vitamina C lo que puede modificar el perfil lipídico y puede reducir el riesgo 
cardiometabólico mediante el proceso oxidante y proinflamatorio. Los compuestos presentes en el producto pueden actuar como antioxidantes in vivo, reduciendo la respuesta inflamatoria y la disminución de algunos factores de riesgo cardiovascular en niños obesos. La modificación del estado redox en el tejido adiposo puede ser una herramienta terapéutica contra futuras complicaciones metabólicas de la obesidad. Una mejora del estado oxidativo en los sujetos después de la toma del producto sugiere que la biodisponibilidad de los compuestos y la posibilidad de la atenuación de la lesión oxidativa.

La obesidad está asociada con una condición inflamatoria de larga duración expresada por un aumento en los niveles de CRP y causa una producción inusual de las citoquinas proinflamatorias (Cesari et al., 2003), incluyendo IL-1 $\alpha$, IL-6 y TNF- $\alpha$. IL-1 $\alpha$ juega un papel importante en la inflamación de la pared vascular mediante la activación de las células endoteliales y los monocitos, en la inducción de otras citoquinas, quimiocinas y factores de crecimiento, y en la proliferación de células musculares lisas contribuyendo todos ellos a la aterogénesis (Waehre et al. 2004). Es bien conocido que la IL-6 producida por el tejido adiposo se aumenta en la obesidad. IL-6 es una citoquina multifuncional que actúa en muchas células y tejidos y uno de sus principales efectos es la inducción de la producción hepática de CRP. TNF- $\alpha$ es un indicador no específico de los procesos inflamatorios, y su concentración en plasma está altamente correlacionada con el riesgo de enfermedad cardiovascular. Elevadas concentraciones plasmáticas de TNF$\alpha$ también están vinculadas a procesos cancerígenos. Estos marcadores específicos circulantes de inflamación podrían desempeñar un papel perjudicial en el desarrollo de la aterosclerosis prematura (Ikonomidis et al., En proceso). El principal efecto observado en este estudio fue la reducción de las concentraciones en plasma de TNF- $\alpha$, IL- $1 \alpha$ e IL- 6 dentro del poco tiempo de ingesta del aperitivo de manzana enriquecida con zumo de mandarina. La reducción de los marcadores de inflamación y del estrés oxidativo en pacientes obesos puede ofrecer una estrategia para prevenir los factores implicados en la aparición temprana del riesgo cardiovascular. Comer entre horas se ha relacionado con un aumento de la oferta total de energía, especialmente en los adolescentes (Piernas y Popkin, 2010). De hecho los aperitivos son promotores de la obesidad, ya que generalmente se trata de alimentos ricos en grasa y azúcar. Los aperitivos salados y las patatas fritas son una parte muy popular de la dieta de la juventud moderna, y podemos sustituirlos por otros productos que sean sensorialmente parecidos (crujencia, espesura), pero que lleven una cantidad significativamente mayor de compuestos potencialmente bioactivos. De esta manera, los aperitivos saludables serían fácilmente aceptados si sus características sensoriales de sabor y de consistencia fueran aceptadas por los niños. 
El presente estudio tiene limitaciones, como el relativamente bajo número de sujetos estudiados. Por lo tanto, las relaciones encontradas no pueden inferirse a la población general. Una posible limitación podría ser que el estudio de intervención puede inducir cambios en la ingesta de macronutrientes, como la grasa y los carbohidratos. El análisis de los registros alimentarios, sin embargo, indicaron que la ingesta de macronutrientes fue similar al principio y al final del estudio. Esto sugiere que los cambios observados en las concentraciones de marcadores inflamatorios pueden relacionarse específicamente con el consumo de aperitivos. Por otra parte, el diseño del estudio tiene varios puntos fuertes como los meticulosos análisis longitudinales de una cohorte bien caracterizada y la medición de varios parámetros inflamatorios asociados con la aterosclerosis.

Por lo tanto, la incorporación a la dieta de un aperitivo de manzana enriquecida con zumo de mandarina promueve el consumo de alimentos funcionales y no sólo incrementa el consumo de compuestos bioactivos saludables, sino que también en segundo lugar podría disminuir la ingesta de aperitivos ricos en grasa sólida y azúcares añadidos. Ambos efectos pueden contrarrestar las consecuencias perjudiciales de la obesidad infantil. En términos de prevención, los profesionales de la salud deben seguir fomentando el consumo de fruta, incluyendo frutas secas, como parte de una dieta saludable y un estilo de vida saludable en general.

\subsection{Desarrollo de un alimento funcional con elevado contenido en microorganismos probióticos a partir de manzana y zumo de mandarina con efecto contra la infección por Helicobacter pylori.}

La obtención de una fruta enriquecida en microorganismos probióticos mediante la operación de impregnación a vacío requiere que el líquido de impregnación sea capaz de entrar en los poros o los espacios intercelulares de la matriz estructural de la fruta. El pH del líquido de impregnación y de la fruta debe permitir el crecimiento de los microorganismos y la viscosidad del líquido de impregnación deber permitir el flujo en el interior de los poros y de los espacios intercelulares (Martínez-Monzó et al., 1998) y la concentración de los microorganismos en el líquido de impregnación debe ser los suficientemente elevada como para permitir la obtención de niveles adecuados de microorganismos en la fruta impregnada.

La primera parte del trabajo se dirigió al estudio de los diferentes medios de crecimiento y posibles líquidos de impregnación. Se utilizaron dos microorganismos diferentes L. salivarius spp. salivarius y L. acidophilus, dos zumos comerciales, zumo de mandarina y zumo de piña/ uva y tres pHs diferentes $5,5.5$ y 6. Los diferentes zumos, pHs y períodos de incubación han tenido efectos 
significativos sobre el crecimiento de los microorganismos probióticos estudiados. El crecimiento de L. salivarius spp. salivarius, fue más elevado que el de L. acidophilus en las condiciones experimentales estudiadas. El crecimiento microbiano más elevado $\left(10^{8} \mathrm{CFU} \cdot \mathrm{cm}^{-3}\right)$ se obtuvo para L. salivarius spp. salivarius, en zumo de mandarina a pH 5.96, después de un período de incubación de 24 horas.

La segunda parte del trabajo se dirigió al desarrollo tecnológico del alimento funcional y a la valoración mediante un test preliminar in vivo de su efecto potencial contra la infección por Helicobacter pylori.

- En los experimentos de impregnación a vacío llevados a cabo utilizando zumo de mandarina, y de acuerdo con la teoría del modelo hidrodinámico propuesta por Fito (1994); Fito \& Pastor en 1994 y Fito et al., (1996) se estimó el contenido microbiano teórico de las muestras impregnadas. El contenido microbiano estimado de la manzana impregnada fue de (1.04 \pm $0.08) \cdot 10^{8} \mathrm{UFC} / \mathrm{g}$. Este valor fue similar al obtenido experimentalmente

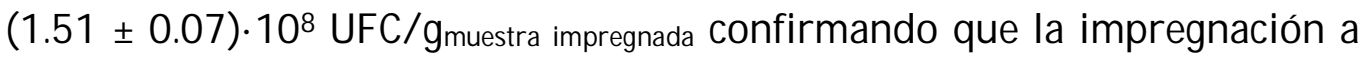
vacío resultó homogénea y el principal mecanismo implicado de transferencia de materia fue el mecanismo hidrodinámico.

Con el objetivo de determinar el contenido microbiano de las manzanas deshidratadas y debido a su bajo contenido en agua, éstas deben rehidratarse. Para calcular el contenido microbiano de las manzanas deshidratas mediante un balance de microorganismos deben conocerse el contenido microbiano de las manzanas rehidratadas así como el contenido microbiano del líquido de rehidratación. En el cálculo se consideró que no existe generación de microorganismos durante el proceso de rehidratación. Lo que significa que el contenido microbiano calculado en la muestra deshidratada corresponde al valor mínimo posible. El secado por aire caliente de las muestras impregnadas resultó en la reducción de una unidad logarítmica del contenido microbiano. A pesar de la reducción observada, el producto final alcanzó un contenido en microorganismos viables $\mathrm{L}$. salivarius spp. salivarius muy cercano a $10^{8} \mathrm{UFC} / \mathrm{g}$. Este nuevo producto desarrollado a partir de manzana y zumo de mandarina alcanzó $10^{7}$ $\mathrm{UFC} / \mathrm{g}_{\text {muestra }}$, que corresponde a un valor medio alcanzado en los productos lácteos probióticos comerciales y de acuerdo con la bibliografía es suficiente para tener un efecto potencial contra la infección por H. pylori (Cruchet et al., 2003; De Champs et al., 2003).

- El efecto potencial del producto en contra de la infección por Helicobacter pylori se evaluó mediante un test preliminar in vivo en 5 pacientes diagnosticados y tratados en la consulta de pediatría del Hospital Dr. Peset de Valencia. El test del aliento con ${ }^{13} \mathrm{C}$ urea se realizó por todos los participantes al inicio y al final del estudio. Durante los 28 días que duró el estudio, cada niño consumió $30 \mathrm{~g}$ diarios del producto probiótico desarrollado con un contenido en agua de $0.144 \pm 0.012$ gagual gmuestra y con 
un contenido microbiano de $(2.850 \pm 0.003) \cdot 10^{9} \mathrm{UFC} /$ día. De acuerdo con la bibliografía consultada, el consumo de $10^{9} \mathrm{CFU}$ de L. salivarius spp. salivarius al día durante cuatro semanas es suficiente para tener un efecto contra la infección por H. pylori (Aiba et al., 1998). Se observó en todos los pacientes una disminución del valor de ${ }^{13} \mathrm{C}$ de la muestra basal. Aunque cinco pacientes no son suficientes para establecer un efecto significativo, los resultados obtenidos sugieren una mejora de los síntomas causados por la infección y por tanto, es necesario llevar a cabo más estudios con más pacientes para evaluar de forma adecuada el consumo del alimento. Durante el estudio, se preguntó a los niños sobre la apariencia, el sabor y la consistencia del producto. Mientras que el sabor fue aceptado, la apariencia y la consistencia del producto no fueron aceptados y los niños anunciaron su preferencia por consumir un producto más crujiente.

- Con el objetivo de obtener un producto aceptado por el consumidor se utilizó el secado por aire caliente a 30 y $45 \stackrel{\circ}{\circ}$ y la liofilización durante 12 y 24 horas para estabilizar el alimento funcional. Se determinaron las propiedades ópticas, mecánicas y el contenido microbiano así como su evolución a lo largo del proceso de fabricación. Los resultados obtenidos después de la operación de impregnación a vacío mostraron que las propiedades fisicoquímicas de las muestras frescas e impregnadas prácticamente no cambiaron. Además los bajos valores de actividad de agua obtenidos al final de los dos métodos de deshidratación aplicados no permiten el crecimiento de hongos $u$ otros microorganismo dañinos durante al menos dos semanas almacenados a temperatura ambiente (Betoret et al., 2003).

En las muestras de manzana fresca el valor de la coordenada a* es menor que el valor de la coordenada b* lo que indica el color amarillo-verdoso propio de la fruta fresca. La disminución en el valor de la coordenada $a^{*}$ indicó una evolución hacia una tonalidad amarillenta cuando el zumo de mandarina se incorpora en la estructura matricial de la manzana. Los cambios en la luminosidad de la manzana impregnada ( $\mathrm{L}^{*}$ ) puede atribuirse a un incremento en la traslucidez como resultado del intercambio gas-zumo de mandarina promovido durante la operación de impregnación a vacío.

El aumento de la luminosidad observado en las muestras liofilizadas puede deberse al menor contenido en agua y a la formación de una estructura porosa. El valor de las coordenadas a* y b* indica una evolución a tonos anarjados en las muestras deshidratadas por aire caliente probablemente debido a las reacciones de pardeamiento y una evolución hacia tonos amarillentos en las muestras liofilizadas debido a las bajas temperaturas utilizadas en el proceso y a la ausencia de exposición al aire durante la sublimación del agua congelada de la muestra.

- Los principales cambios inducidos por los procesos de deshidratación y que afectan a las propiedades mecánicas de los tejidos vegetales son pérdida de 
la turgencia celular, alteración de la lámina media, deterioro de la fuerza de la pared celular, cambios en los volúmenes de gas y líquido así como cambios en el tamaño y la forma de las muestras (Chiralt et al., 2001). Las curvas de las muestras deshidratadas presentaron, independientemente de la técnica de deshidratación empleada, la forma típica de productos viscoelásticos, caracterizada por un único punto de fractura cuando se alcanza la fuerza máxima seguido de una deformación pronunciada y que puede estar asociada con el estado gomoso de las muestras alcanzado al final del proceso. Por otra parte, las curvas obtenidas para las muestras frescas e impregnadas mostraron varios picos lo que indica múltiples fracturas al alcanzar la fuerza máxima, y que podría estar asociado con la turgencia celular del tejido.

- El análisis estadístico llevado a cabo demostró que el método de deshidratación empleado así como el espesor de la muestra no tiene un efecto significativo sobre el crecimiento microbiano. De acuerdo con Ouwehand et al., 1999 se requiere un contenido mínimo de $10^{6} \mathrm{UFC} / \mathrm{cm}^{3}$ en un producto al final de su vida útil para tener un efecto potencial en contra de la colonización por Helicobacter pylori y se recomienda un consumo diario mayor de $10^{9} \mathrm{CFU}$ / day (De Champs et al., 2003). Para ambos métodos de deshidratación empleados y ambos espesores de muestra empleados se alcanzaron niveles de microorganismos en el producto superiores a $10^{6}$ $\mathrm{UFC} / \mathrm{g}$ por lo que el producto funcional desarrollado tiene un efecto potencial en contra de la infección por Helicobacter pylori en todos los casos.

\subsection{Bibliografía citada.}

Aiba Y., Suzuki N., Kabir A.M., Takagi A., \& Koga, Y. (1998) Lactic acid-mediated suppression of Helicobacter pylori by the oral administration of Lactobacillus salivarius as a probiotic in a gnotobiotic murine model. American Journal of Gastroenterology, 93, 2097-2101.

Anese M., Manzocco L., Nicoli M.C., \& Lerici C.R. (1999) Antioxidant properties of tomato juice as affected by heating, Journal of Agricultural and Food Chemistry, 79, 750-754.

Baghurst K. (2003). The health benefits of citrus juices. CSIRO, Health Sciences and Nutrition. Sydney NSW 2000.

Bazhal M.I., \& Ngadi M.O. (2003) Influence of pulsed electroplasmolysis on the porous structure of apple tissue. Biosystems Engineering, 86, 51-57.

Ben-Shalom N., \& Pinto R. (1999) Natural coloidal particles: the mechanism of the specific interaction between hesperidin and pectin. Carbohydrate Polymers, 38, 179-182.

Betoret N., Puente L., Díaz M.J., Pagán M.J., García M.J., Gras M.L., Martínez-Monzó J., \& Fito P. (2003) Development of probiotic-enriched dried fruits by vacuum impregnation. Journal of Food Engineering 56, 273-277. 
Block G., Patterson B., \& Subar A. (1992) Fruits, vegetables and cancer prevention: a review of the epidemiological evidence. Nutrition and cancer-An International Journal, 18, 1-29.

Boyer J., \& Liu R.H. (2004) Apple phytochemicals and their health benefits. Nutrition Journal, 3, 1-15.

Cesar T.B., Aptekmann N.P., Araujo M.P., Vinagre C.C., \&. Maranhão R.C. (2010) Orange juice decreases low-density lipoprotein cholesterol in hypercholesterolemic subjects and improves lipid transfer to high-density lipoprotein in normal and hypercholesterolemic subjects. Nutrition Research, 30(10):689-694.

Cesari M., Penninx B.W., Newman A.B., Kritchevsky S.B., Nicklas B.J., Sutton-Tyrrell, K., Rubin S.M., Ding J., Simonsick E.M., Harris T.B., \& Pahor M. (2003) Inflammatory markers and cardiovascular disease (The Health, Aging and Body Composition [Health ABC] Study). The American Journal of Cardiology, 92(5), 522-528.

Chiralt A., Martínez-Navarrete N., Martínez-Monzó J., Talens P., Moraga G., Ayala A., \& Fito P. (2001) Changes in mechanical properties throughout osmotic processes: Cryoprotectant effect. Journal of Food Engineering, 49, 129-135.

Choi E.J. (2008) Antioxidative effects of hesperetin against 7,12dimethylbenz(a)anthracene-induced oxidative stress in mice. Life Science, 82, 1059-1064.

Codoñer-Franch P., López-Jaén A.B., Muñiz P., Sentrandreu E., \& Valls-Bellés V. (2008) Mandarin Juice Improves the Antioxidant Status of Hypercholesterolemic Children. Journal of Pediatric Gastroenterology and Nutrition, 47, 349-355.

Codoñer-Franch P., López-Jaén A.B., De La Mano-Hernández A., Sentandreu E., Simó-Jordá R., \& Valls-Bellés V. (2010) Oxidative markers in children with severe obesity following low-calorie diets supplemented with mandarin juice. Acta Paediatrica, 99(12), 1841-1846.

Cruchet S., Obregon M.C., Salazar G., Diaz E., \& Gotteland M. (2003) Effect of the ingestion of a dietary product containing Lactobacillus johnsonii La1 on Helicobacter pylori colonization in children. Nutrition, 19, 716-721.

De Champs C., Maroncle N., Balestrino D., Rich C., \& Forestier C. (2003) Persistence of colonization of intestinal mucosa by a probiotic strain, Lactobacillus casei subsp. Rhamnosus Lcr35, after oral consumption. Journal of Clinical Microbiology, 41, 3, 1270-1273.

Del Caro A., Piga A., Vacca V., \& Aggabio M. (2004) Changes of flavonoids, vitamin C and antioxidant capacity in minimally processed citrus segments and juices during storage. Food Chemistry, 84, 99-105.

Dhuique-Mayer C., Tbatou M., Carail M., Caris-Veyrat C., Dornier M., \& Amiot M.J. (2007) Thermal degradation of antioxidants micronutrients in citrus juice. Kinetics and newly formed compounds. Journal of Agricultural and Food Chemistry 55 (10), 4209-4216. 
Fito P. (1994) Modelling of vacuum osmotic dehydration of food. Journal of Food Engineering, 22(1-4), 313-328.

Fito P., \& Pastor R. (1994) On some non-diffusional mechanism occurring during vacuum osmotic dehydration. Journal of Food Engineering, 21, 513-519.

Fito P., Andrés A., Chiralt A., \& Pardo P. (1996) Coupling of hydrodynamic mechanism and deformation relaxation phenomena during vacuum treatments in solid porous food-liquid systems. Journal of Food Engineering, 27, 229-240.

Guamis B. (2009) Aplicaciones de la ultra alta presión homogenización para la industria alimentaria, farmacéutica y cosmética. In: Jornada Técnica sobre Tecnologías transversales de interés para la Industria Alimentaria, Farmacéutica y Cosmética, December 2009, Barcelona, Spain.

Ikonomidis I., Michalakeas C.A., Parissis J., Paraskevaidis I., Ntai K., Papadakis J., Anastasiou-Nana M., \& Lekakis J. (2012) Inflammatory markers in coronary artery disease. Biofactors, doi: 10.1002/ biof.1024.

Izquierdo L., Carbonell J.V., Navarro J.L., \& Sendra J.M. (2007) Method of Obtaining Refrigerated Pasteurized Citrus Juices. Patent WO/2007/042593. Consejo Superior de Investigaciones Científicas, Spain.

Johnston C.S., \& Bowling D.L. (2002) Stability of ascorbic acid in commercially available orange juices. Journal of the American Dietetic Association, 102, 525529.

Jung M., Triebel S., Anke T., Richling E., \& Erkel G. (2009) Influence of apple polyphenols on inflammatory gene expression. Molecular Nutrition \& Food Research, 53, 1263-1268.

Kupper P.L., Moore K.L., \& Swaine R.L. (1987) Fruit juice containing diet beverage. US Patent 4690827.

Lacroix N., Fliss I., \& Makhlouf J. (2005) Inactivaction of pectin methylesterase and stabilization of opalescence in orange juice by dynamic high pressure. Food Research International, 38, 569-576.

Leong L.P., \& Shui G. (2002) An investigation of antioxidant capacity of fruits in Singapore markets. Food Chemistry, 76, 69-75.

Lewicki P. (1998) Effect of pre-drying treatment, drying and rehydration on plant tissue properties: a review. International Journal of Food Properties, 1 (1), 1-22.

Lewicki P.P., \& Jakubczyk E. (2004) Effect of hot air temperature on mechanical properties of dried apples. Journal of Food Engineering, 64, 3, 307-314.

Maskan M. (2001). Drying shrinkage and rehydration characteristics of kiwifruits during microwave drying. Journal of Food Engineering, 48, 177-182.

Martínez-Monzó J., Martínez-Navarrete N., Chiralt A., \& Fito P. (1998). Mechanical and structural changes in apple (var. Granny Smith) due to vacuum impregnation with cryoprotectants. Journal of Food Science, 63, 499-503.

McCann M.J., Gill C.I.R., O'Brien G., Rao J.R., McRoberts W.C., Hughes P., McEntee R., \& Rowland I.R. (2007) Anti-cancer properties of phenolics from Apple waste on colon carcinogenesis in vitro. Food and Chemical Toxicology, 45, 224-1230. 
Nazarewicz R.R., Zenebe W.J., Parihar A., Larson S.K, Alidema E., Choi J., \& Ghafourifar P. (2007) Tamoxifen induces oxidative stress and mitochondrial apoptosis via stimulating mitochondrial nitric oxide synthase. Cancer Research, 67, 1282-1290.

Nicoli M.C., Anese M., Parpinel M.T., Franceschi S., \& Lerici C.R. (1997) Study on loss and/or formation of antioxidants in food during processing and storage. Cancer Letters, 11, 71-74.

Pajk T., Rezar V., Levart A., \& Salobir J. (2006) Efficiency of apples, strawberries, and tomatoes for reduction of oxidative stress in pigs as a model for humans. Nutrition, 22, 376-384.

Patil S.B., Kodliwadmath M.V., \& Kodliwadmath S.M. (2008) Lipid peroxidation and antioxidant status in hypertensive pregnancies. Clinical \& Experimental Obstetrics \& Gynecology, 35, 272-274

Piernas C., \& Popkin B.M. (2010) Dynamics of U.S. child snacking: movement toward constant eating. Health Affairs, 29(3):398-404

Poulsen M., Mortensen A., Binderup M.L., Langkilde S., Markowski J., \& Dragsted L.O. (2011) The effect of apple feeding on markers of colon carcinogenesis. Nutrition and Cancer, 63, 402-409.

Prior R.L., Wu X., \& Schaich K. (2005) Standarized methods for the determination of antioxidant capacity and phennolics in foods and dietary supplements. Journal of Agricultural and Food Chemistry, 53, 4290-4302.

Rapisarda F., Fanella F., \& Maccarone E. (2000) Reliability of analytical methods for determining anthocyanins in blood orange juices. Journal of Agricultural and Food Chemistry, 48, 2249-2252.

Razo-Aguilera G., Baez-Reyes R., Alvarez-González I., Paniagua-Pérez R., \& Madrigal-Bujaidar E. (2011) Inhibitory effect of grapefruit juice on the genotoxicity induced by hydrogen peroxide in human lymphocytes. Food \& Chemical Toxicology, 49, 2947-2953.

Robards K., \& Antolovich M. (1995) Methods for assessing the authenticity of orange juice. Analyst, 120, 1-28.

Rouseff R.L., \& Nagy S. Health and nutritional benefits of citrus fruits components. Food Technology 48 (1994), pp. 125-132.

Sanchez-Moreno C., Cano M.P., de Ancos B., Plaza L., Olmedilla B., Granado F., \& Martín A. (2003) Effect of orange juice intake on Vitamin C concentrations and biomarkers of antioxidant status in humans. American Journal of Clinical Nutrition, 78, 454-460.

Sendra J.M., Navarro J.L., \& Izquierdo L. (1988) C18 solid-phase isolation and highperformance liquid chromatography-ultraviolet diode array determination of fully methoxylated flavones in citrus juices. Journal of Chromatographic Science, 26, 443-448.

Sentandreu E. (2006) Determinación de la actividad antirradical de zumos cítricos y caracterización de zumos de mandarina en función de su contenido en 
flavonoides y de su actividad antirradical. Tesis doctoral. Universidad de Valencia.

Sentandreu E., Izquierdo L., \& Sendra J.M. (2007) Differentiation of juices from clementine (Citrus clementina), clementine-hybrids and satsuma (Citrus unshiu) cultivars by statistical multivariate discriminant analysis of their flavanone-7-0-glycosides and fully methoxylated flavones content as determined by liquid chromatography. European Food Research \& Technology, 224, 421-429.

Sentandreu E., Navarro J.L., \& Sendra J.M. (2008) Reduction kinetics of the antiradical probe 2,2-Diphenyl-1-picrylhydrazyl in methanol and acetonitrile by the antiradical activity of protocatechuic acid and protocatechuic acid methyl ester. Journal of Agricultural and Food Chemistry, 56, 4928-4936.

So F.V., Guthrie N., Chambers A.F., Moussa M., \& Carroll K.K. (1996) Inhibition of human breast cancer cell proliferation and delay of mammary tumorigenesis by flavonoids and citrus juices. Nutrition and Cancer, 262, 167-181.

Steinmetz K.A., \& Potter J.D. (1996) Vegetables, fruit and cancer prevention: a review. Journal of the American Dietetic Association, 53, 536-543.

Stewart A.J., Bozonnet S., Mullen W., Jenkins G.I., Michael E.J., \& Crozier A. (2000) Occurrence of flavonols in tomatoes and tomato-based products. Journal of Agricultural and Food Chemistry, 48, 2663-2669.

Suárez-Jacobo A., Rüfer C.E., Gervilla R., Guamis B., Roig-Sagués A.X., \& Saldo J. (2011) Influence of ultra-high pressure homogenisation on antioxidant capacity, polyphenol and vitamin content of clear apple juice. Food Chemistry, 127, 447-454.

Vieira F.G., Di Pietro P.F., da Silva E.L., Borges G.S., Nunes E.C., \& Fett, R. (2012) Improvement of serum antioxidant status in humans after the acute intake of apple juices. Nutrition Research, 32, 229-232.

Waehre T., Yndestad A., Smith C., Haug T., Tunheim, S.H., Gullestad, L., Frøland S.S., Semb A.G., Aukrust P., \& Damås J.K. (2004) Increased expression of interleukin1 in coronary artery disease with downregulatory effects of HMG-CoA reductase inhibitors. Circulation, 109(16), 1966-1972. 
5. CONCLUSIONES 

1. No hay duda de que el desarrollo de alimentos funcionales tiene un gran interés para los consumidores, las empresas, los gobiernos y las universidades. Desde el punto de vista de la investigación y el desarrollo, los alimentos funcionales representan una oportunidad para obtener productos innovadores que satisfagan considerablemente la demanda que existe en la actualidad. Las tecnologías mayoritariamente utilizadas en el desarrollo de este tipo de productos han cambiado a lo largo de los años. Así, mientras que las técnicas tradicionales han sido las más ampliamente utilizadas desde el 2000 hasta el 2010, las técnicas dirigidas hacia una nutrición personalizada han crecido enormemente.

2. De acuerdo con el efecto de la presión de homogeneización sobre el tamaño de partícula, el color y el contenido en flavonoides del zumo de mandarina, pueden afirmarse las siguientes conclusiones: las presiones de homogeneización aplicadas afectan a la distribución del tamaño de partícula y al color de los zumos, haciendo posible diferenciar grupos de muestras en función de las presión aplicada. En el zumo fresco, el contenido en flavonoides no se ve afectado por la presión de homogeneización pero en el zumo almacenado durante cinco meses el contenido en hesperidina sí que se ve afectado. La aplicación de presiones de homogeneización desde 0 a 30 MPa en zumo de mandarina con bajo contenido en pulpa es favorable para la aplicación posterior de la operación de impregnación a vacío y por tanto para el desarrollo de un producto funcional. Además, la aplicación de estas presiones no tiene efectos negativos sobre la actividad antirradical y los compuestos funcionales del zumo. La aplicación de presiones más elevadas suponen una mayor incorporación de zumo en la matriz estructural de la manzana, lo que puede favorecer la incorporación de componentes funcionales debido a la estabilidad de la pulpa y a la reducción del tamaño de partícula.

3. Los componentes bioactivos del zumo de mandarina con bajo contenido en pulpa se han incorporado a la matriz estructural de discos frescos de manzana sin afectar negativamente a la actividad antirradical de la misma determinada después de la operación de impregnación y el secado por aire caliente. Dicha incorporación se ve reflejada en el aumento de la complejidad composicional de la manzana impregnada donde los componentes del zumo de mandarina se han añadido a los propios de la manzana y en la mejora de la capacidad antirradical de la manzana impregnada frente a la obtenida en manzana fresca, demostrando así su potencial interés como alimento funcional.

4. Los estudios in vivo han demostrado la acción potencial protectora del alimento desarrollado a partir de manzana y zumo de mandarina previniendo el daño a macromoléculas celulares esenciales en condiciones de estrés oxidativo químicamente inducido en ratas. Los resultados obtenidos indican que la alimentación con un aperitivo impregnado con zumo de mandarina tiene un efecto antioxidante in vivo y puede prevenir la toxicidad generada después de la suplementación con tamoxifeno en ratas. El efecto protector 
general del aperitivo impregnado se debe probablemente a la neutralización de radicales libres debida a su naturaleza antioxidante o a su habilidad para restaurar la normalidad de un tejido que se encuentra bajo estrés oxidativo. Sin embargo, queda por establecer el mecanismo molecular por el cual el aperitivo impregnado ejerce su efecto protector en contra del daño oxidativo.

5. La incorporación del aperitivo a una dieta moderadamente baja en energía de niños obesos ha resultado en una mejora de la presión arterial sistólica y del perfil lipídico. La ingesta del aperitivo ha aumentado de forma significativa las defensas antioxidantes y ha disminuido los marcadores relacionados con el daño oxidativo al ADN y con la inflamación. De forma general, el consumo a corto plazo del producto desarrollado disminuye los factores de riesgo relacionados con la aterosclerosis.

6. Las propiedades nutricionales y fisicoquímicas del zumo de mandarina (con el $\mathrm{pH}$ ajustado a 6) resultan en $10^{8} \mathrm{CFU} \cdot \mathrm{cm}^{-3}$ de L. salivarius spp. salivarius, después de un período de incubación de 24 horas, permitiendo que la solución se utilice como el líquido de impregnación de muestras de manzana fresca. Los parámetros de impregnación obtenidos así como el contenido microbiano alcanzado confirman la validez de la técnica para el desarrollo de un alimento natural bajo en humedad y con efecto probiótico. Es necesario llevar a cabo un estudio in vivo con más pacientes para evaluar de forma adecuada la efectividad del producto; sin embargo, los niveles de L. salivarius spp. salivarius alcanzados en el producto final y el test in vivo preliminar llevado a cabo confirman el efecto potencial del producto contra la infección por Helicobacter pylori.

7. En esta tesis doctoral se ha llevado a cabo el desarrollo de un alimento funcional a partir de manzana y zumo de mandarina cubriendo todas las etapas necesarias del proceso de innovación industrial y aplicando el método científico. Más concretamente, se ha llevado a cabo la definición de las propiedades del producto final y de su estructura, alcanzando al final del proceso de desarrollo unas propiedades físicas, químicas y funcionales adecuadas; el desarrollo de un proceso alimentario innovador, de bajo coste y baja complejidad desde un punto de vista tecnológico; y la valoración in vivo de las propiedades funcionales del producto desarrollado, en animales de experimentación y en niños seguidos en la consulta de pediatría del Hospital Dr. Peset. 
1. There is no doubt that functional food development has a great interest from consumers, industries, governments and universities. From the research and development point of view functional foods represent an opportunity to obtain innovative products that satisfy considerably this demand that already exists. The technologies mainly used have changed considerably over the years. Thus, while traditional techniques are the most commonly used for development of functional foods, from years 2000 until 2010 the techniques aimed towards personalized nutrition have grown greatly.

2. On the basis of the observed effects of homogenization pressure on particle size, colour, and flavonoid content of the juice samples, the following conclusions were drawn: the homogenization pressure affected the particle size distribution and colour of the citrus juices, which made possible to define different sample groups on the basis of the applied pressure. In fresh juice the contents of the flavonoids were not affected by homogenization pressure but after five months stored juice the content of the flavonoid hesperidin was. Applying homogenization pressures from 0 to $30 \mathrm{MPa}$ in low pulp mandarin juice is favourable for a subsequent implementation of a vacuum impregnation operation and therefore for the development of a functional product. Furthermore pressure treatments applied to low pulp juice do not have negative effects on antiradical activity and functional compounds. Higher pressures led to greater incorporation of low pulp juice into the structural matrix of apple, which may indicate that more functional compounds would also be introduced due to pulp stability and particle size reduction.

3. The bioactive compounds of mandarin low pulp juice have successfully been incorporated into the structural matrix of fresh apple slices with no negative effects on their antiradical capacities following impregnation and air drying. Such incorporation is reflected in the increase of the compositional complexity of the impregnated apples where the components of the mandarin juice are added to those of the apple alone, as well as in their improved antiradical capacities when compared to fresh apple extracts, demonstrating their potential interest as a commercial functional food product.

4. The in vivo studies have shown the potential protective action of a foodstuff made of apple and mandarin by preventing damage of essential cellular macromolecules in the conditions of chemically induced oxidative stress in rat. Our results indicate that feeding of the snack impregnated with mandarin juice has an antioxidant effect in vivo and may prevent the toxicity generated after tamoxifen supplementation in rats. The overall protective effect of the impregnated snack is probably due to a counteraction of free radicals by its antioxidant nature and/ or to its ability to restore the normalcy in tissue under oxidative stress. However, the precise molecular mechanism by which the impregnated snack exerts its protective action against oxidative damage remains to be established. 
5. The incorporation of the snack into the mild-energy diet of obese children showed an improvement in systolic blood pressure and lipid profile. A significant increase in the antioxidant capacity of serum and a reduction in DNA oxidative damage and in inflammatory markers was found. Overall, shortterm intake of the product ameliorates several risk factors for atherosclerosis.

6. The nutritional and physicochemical properties of mandarin juice (with the $\mathrm{pH}$ adjusted to 6) resulted in $10^{8} \mathrm{CFU} \cdot \mathrm{cm}^{-3}$ of L. salivarius spp. salivarius, following 24 hours incubation, allowing this solution to be used as the liquid medium for vacuum impregnation of samples of fresh apple. The impregnation parameters obtained and the microorganism content achieved confirmed the validity of this approach to the development of a natural low moisture content food with a probiotic effect. Further studies involving more patients are needed to properly evaluate the effectiveness of this food; however the L. salivarius spp. salivarius microbial content in the final product and the results of the in vivo pilot test confirm the potentially beneficial effects against Helicobacter pylori infection.

7. In this doctoral thesis the development of a functional food with apple and mandarin juice has been carried out covering all the necessary steps of the industrial innovation process and applying the scientific method. More specifically, definition of the final product its properties and structure in such a way that an adequate physical, chemical and functional properties have been achieved at the end of the process; development of an innovative food process low cost and not complex on the technological point of view; in vivo assessment of the product functional properties in experimental animals and in children followed in Paediatric Office in Hospital Dr. Peset in Valencia. 
6. ANEJOS 



\section{Prueba de aceptación sensorial aperitivo con zumo de mandarina.}

ANALISIS SENSORIAL: PRUEBA DE ORDENACION

Nombre y Apellidos:

1. Evalúe las muestras, según su preferencia, en cuanto a la apariencia visual.

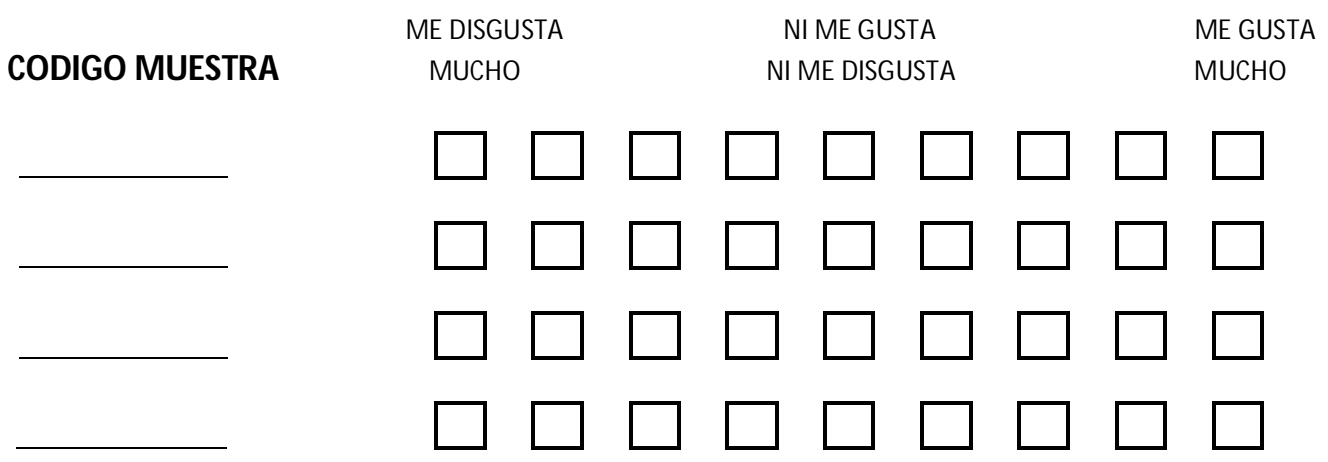

2. Evalúe las muestras, según su preferencia, en cuanto a color.

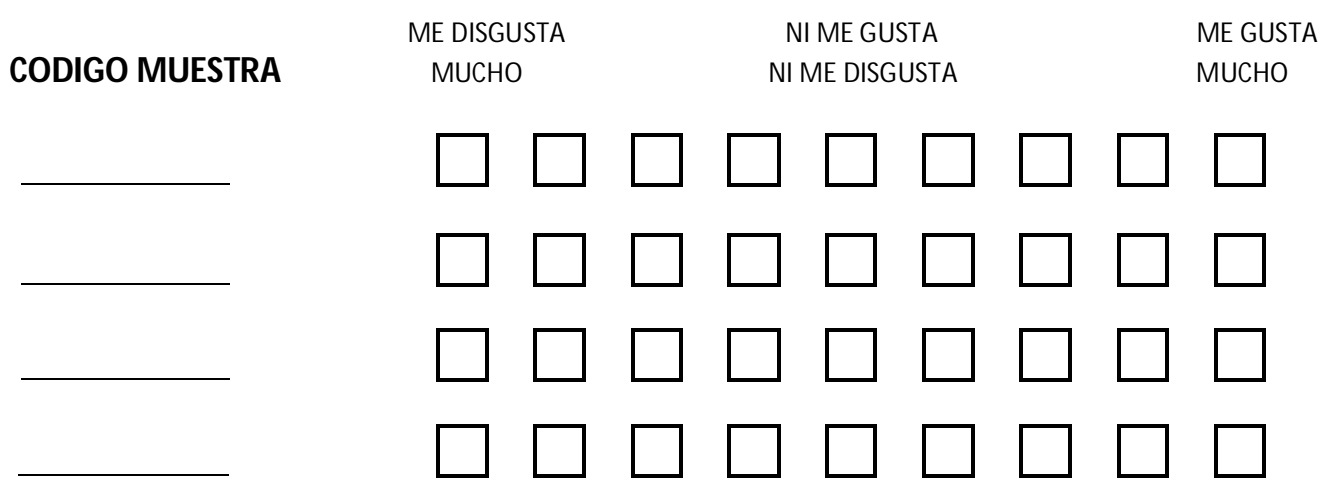

3. Evalúe las muestras, según su preferencia, en cuanto a sabor.

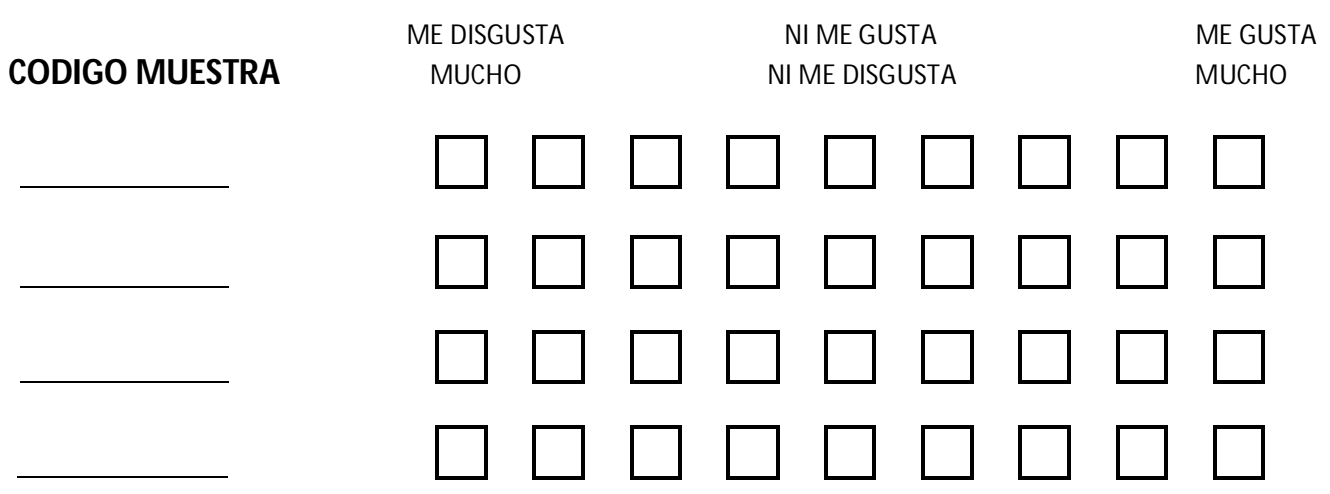


4. Evalúe las muestras, según su preferencia, en cuanto a textura.

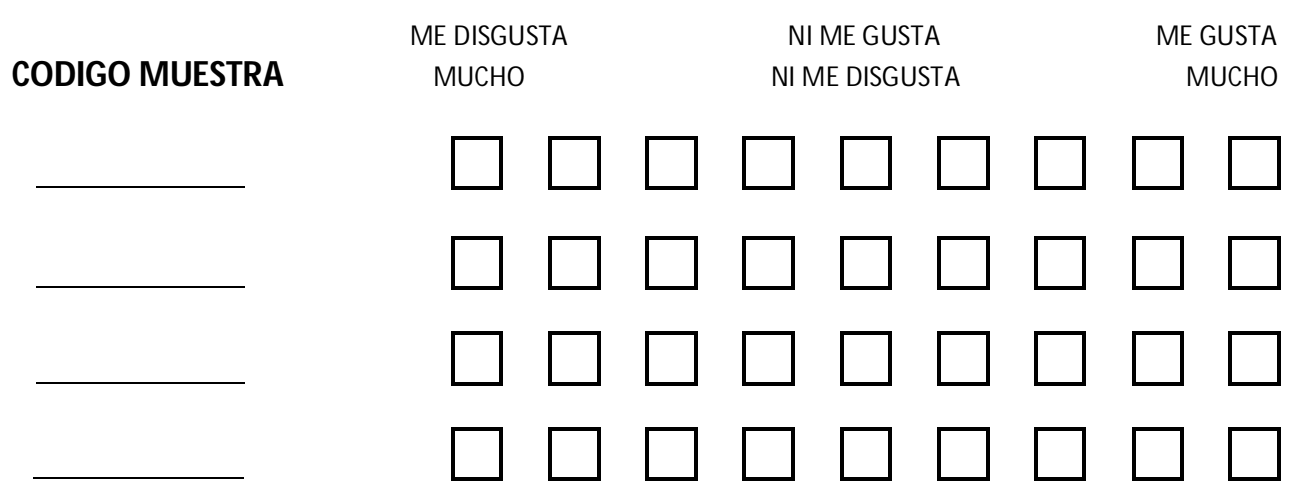

5. Indique el código de la muestra preferida de forma global:

GRACIAS POR SU COLABORACION 
Prueba de aceptación sensorial aperitivo con microorganismos probióticos.

Nombre:

Producto: Fecha:

1. a) En cuanto al aspecto del producto (forma y color), te gusta:

$\square$ Mucho $\square$ Bastante $\square$ Normal $\square$ Poco $\square$ Nada $\square$ No sabe b) Cambiarías el aspecto del producto?

\begin{tabular}{ll} 
Sí ¿Cómo? \\
\hline No
\end{tabular}

2. Con respecto al sabor, te gusta:

Mucho $\square$ Bastante $\square$ Normal $\square$ Poco $\square$ Nada $\square$ No sabe

3. a) En cuanto a la consistencia (al masticar), te gusta:

Mucho $\square$ Bastante $\square$ Normal $\square$ Poco $\square$ Nada $\square$ No sabe

b) Cambiarías la consistencia?

\begin{tabular}{ll}
\hline Sí ¿Cómo lo prefieres? \\
\hline
\end{tabular}

4. ¿Cómo te has tomado el producto?
$\square$ Sólo
Con alimentos
¿Cuáles?
$\square$ En una vez
En dos o más veces

5. ¿A qué hora te sueles tomar el producto? 

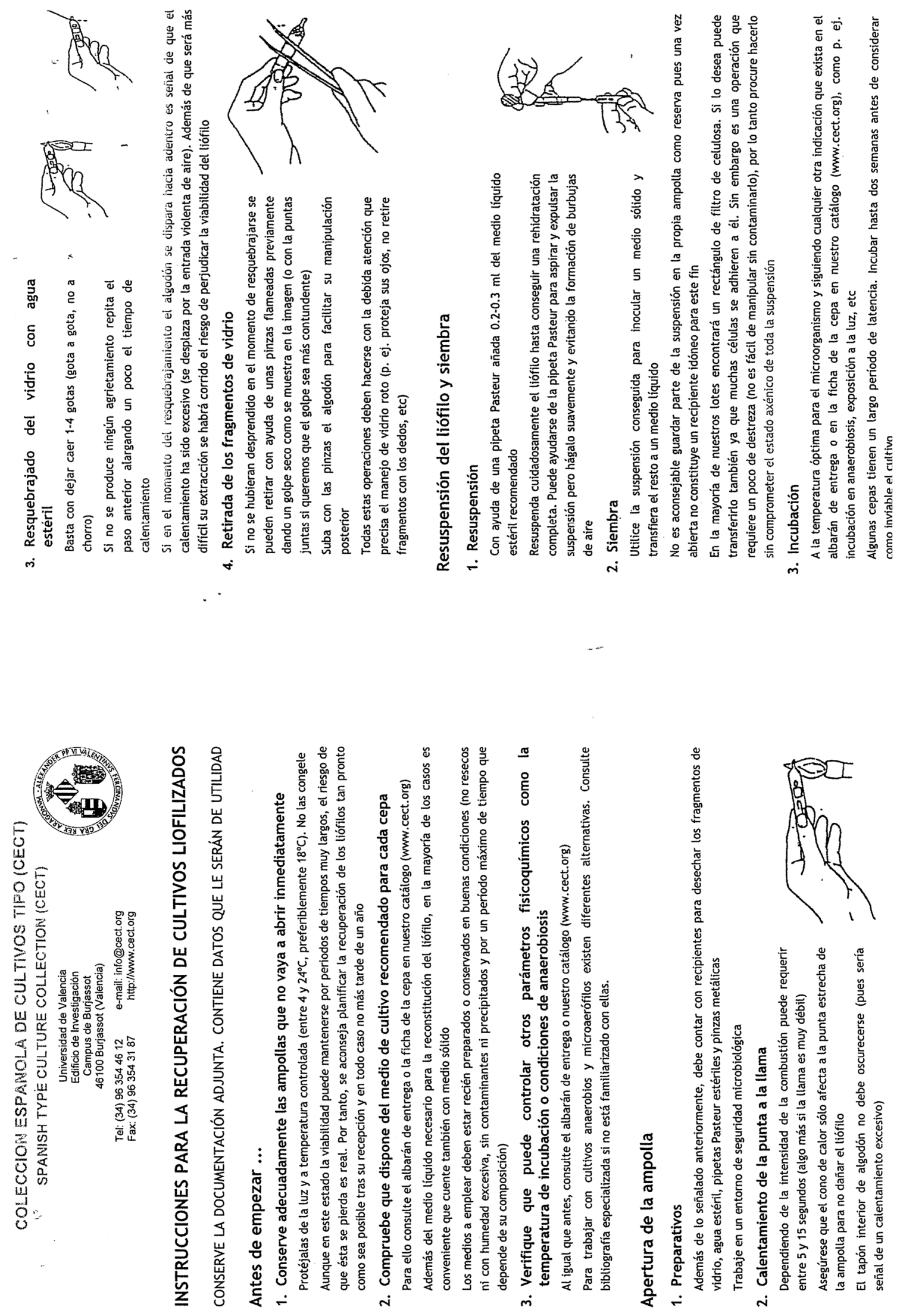


\section{Protocolo de conservación de microorganismo a -20ㅡ.}

1. Recuperación del microorganismo liofilizado (ver ANEXO 1).

2. Añadir $2 \mathrm{~mL}$ del medio específico con el microorganismo al tubo eppendorf.

3. Centrifugar durante un minuto a $3000 \mathrm{rev} / \mathrm{min}$.

4. Eliminar el sobrenadante y dejar el pelet que permanece en la parte inferior del tubo eppendorf.

5. Añadir de nuevo $2 \mathrm{~mL}$ del medio específico inoculado con el microorganismo y repetir el paso 3 y 4 . (Realizar tres repeticiones)

6. Añadir $400 \mu \mathrm{L}$ del medio específico estéril sin microorganismo.

7. Agitar hasta homogeneizar el contenido.

8. Comprobar la cantidad de volumen que contiene el tubo eppendorf con la ayuda de una pipeta.

9. Añadir glicerol $80 \%$ en una proporción de $1 / 4$ del volumen que contiene el tubo eppendorf.

10. Agitar hasta homogenizar el contenido.

11. Introducir en el congelador. El tubo eppendorf se deberá introducir en algún envase para evitar que se cubra de hielo la superficie de los mismos y además deberá estar dispuesto sobre un soporte de modo que lo mantenga recto y se evite su vuelco.

Nota:

Éste procedimiento se indica para la conservación del microorganismo en un eppendorf. Se puede repetir la operación varias veces a partir de un único medio específico que contenga el microorganismo.

\section{Recuperación de la cepa congelada.}

El procedimiento para la descongelación de los microorganismos en estudio fue el siguiente:

1. Preparar medio específico para el crecimiento del microorganismo.

2. Retirar el vial (colocado en un tubo eppendorf) del congelador que permanecía a una temperatura de $-20^{\circ} \mathrm{C}$.

3. Descongelar el vial a temperatura ambiente durante uno o dos minutos.

4. Centrifugar durante un minuto a $3000 \mathrm{rev} / \mathrm{min}$. 
5. Eliminar el sobrenadante y dejar el pelet que permanece en la parte inferior del tubo eppendorf.

6. Añadir 1-2ml del medio especifico sin microorganismo.

7. Agitar hasta homogenizar.

8. Distribuir el contenido en el medio específico sin microorganismo.

9. Colocar el medio específico inoculado en una estufa a $37^{\circ} \mathrm{C}$ durante 24 horas.

10. Realizar siembras tras el periodo de crecimiento en estufa.

11. Realizar lecturas de las placas sembradas con el microorganismo para comprobar la viabilidad del mismo. 